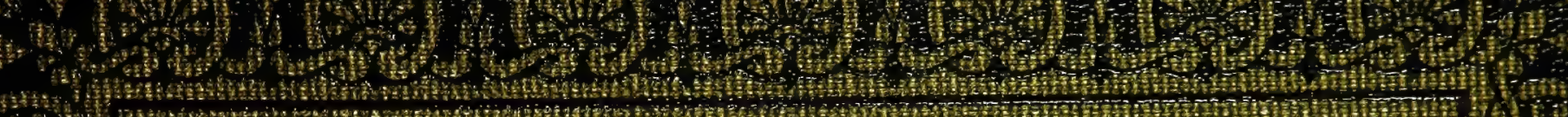

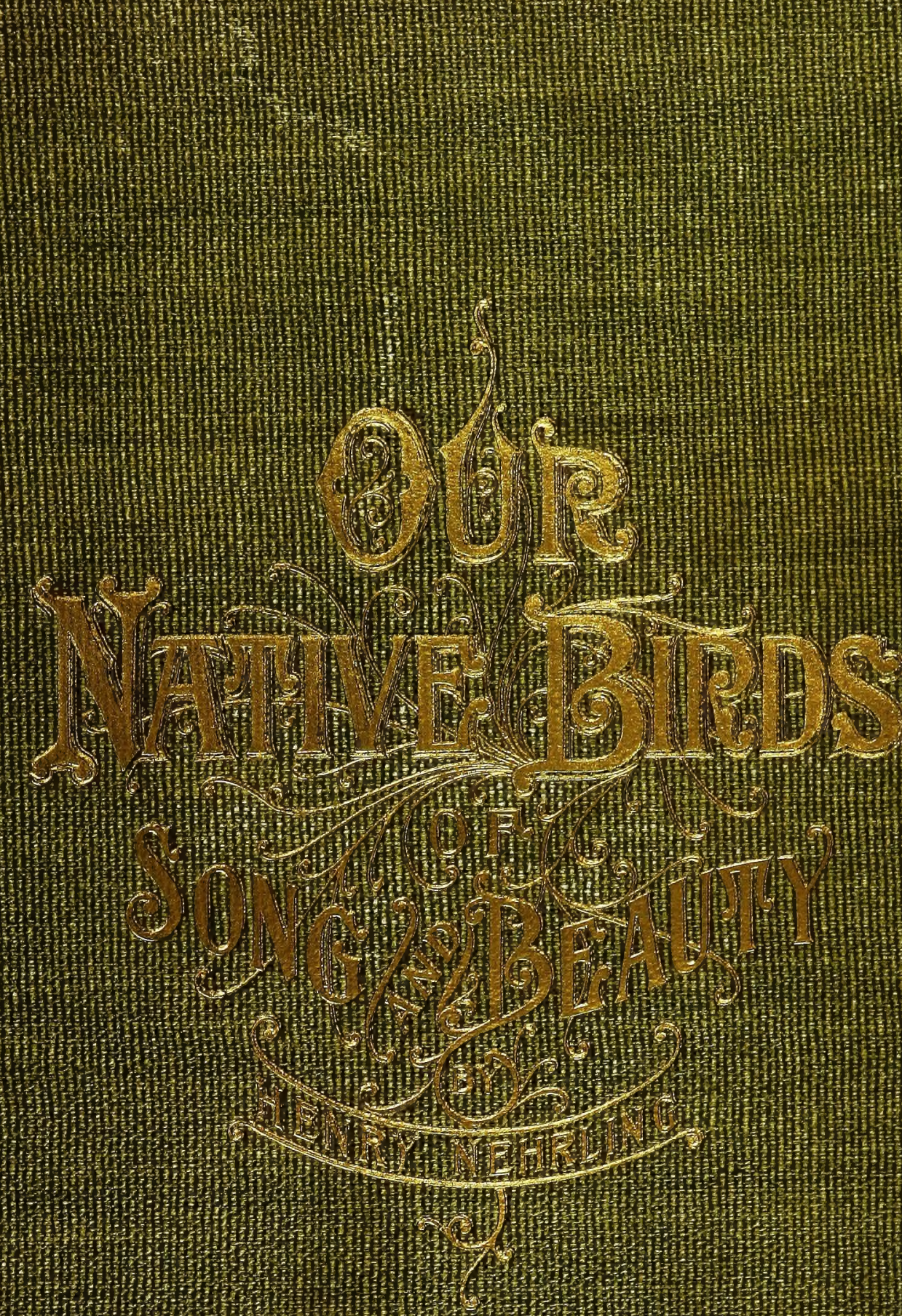

(1)

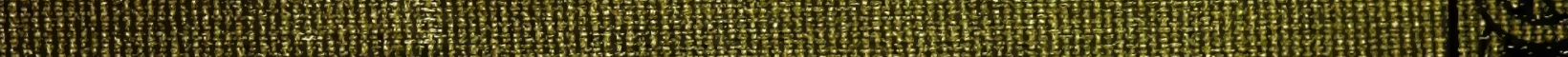

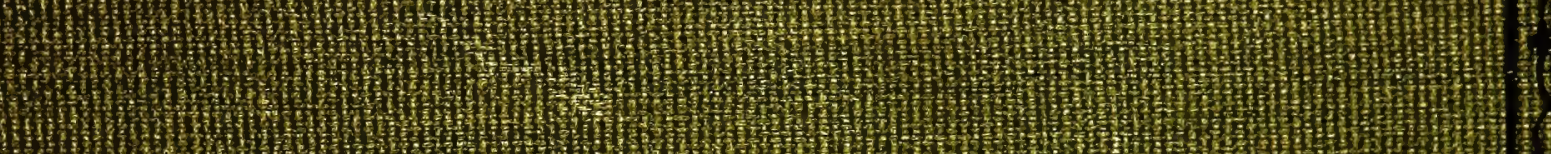
. 


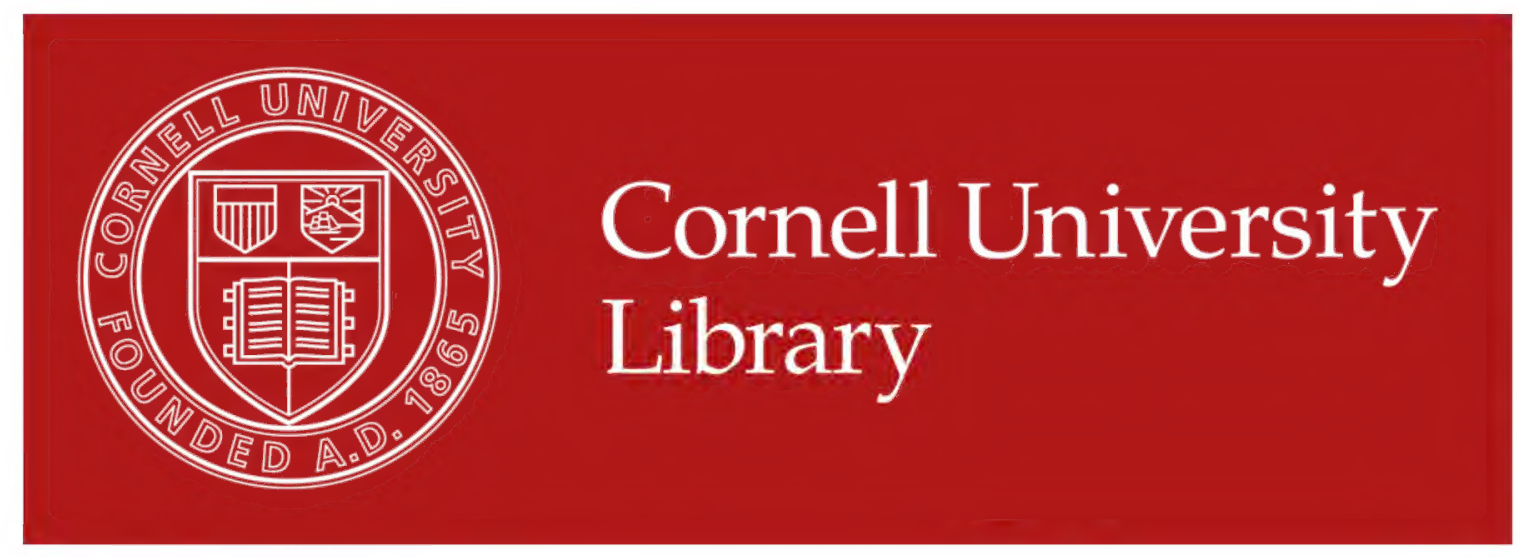

\section{The original of this book is in the Cornell University Library.}

There are no known copyright restrictions in the United States on the use of the text. 




\title{
Our Native Birds
}

\author{
- or- \\ SONG AND BEAUTY, \\ HEIN,
}

A Complete History of all the Songhird, Flychtchers, Hummingbirds, Swifts, Goatsuckers, Woodpeckers, Kingfishers, Trogons, Cuckoos, and Parrots, of North America.

\section{$\mathrm{BY}$ \\ HENRY NEHRLING,}

Custodian of the Public Museum, Milwaykee, Wis., Active Member of the American Ornithologists' Union, Corresponding Memier of the nuttalt. Ornithological Club, Member of the German Ornithological Society of Berlin, Etc., Etc.

WITH THIRTY-SIX COLORED PLATES AFTER WATER-COLOR PAINTINGS

By. Prof. RObert RIDGWAY, Smithsonian Institution and National Museud, Washington, D. C., Prof. A. GOERING, Leipzig, and GUSTAV MUETZEL, Berlin.

VOLUME I.

MILWAUKEE:

GEORGE BRUMDER.

1893. 


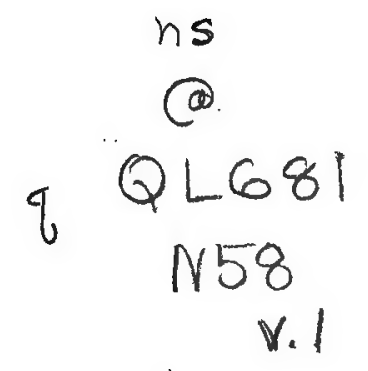

Copyright, 1893, by H. Nehrling.

Ali. Rignits Reserved.

(a.20154 


\author{
बө \\ Prof. ROBERT RIDGWAY, \\ Smithsonian Institution and National Museum, \\ WASHINGTON, D. C., \\ Dr. J. A. AL.LEN, \\ American Museum of Natural History, \\ NEW YORK, \\ Prof. WILLIAM BREWSTER, \\ Museum of Comparative Zoology, \\ CAMBRIDGE, MASS., \\ AND \\ Dr. ElLIOTT COUES, \\ President of the Amemean Ornithologists' union, \\ Smithsonian Institution, \\ WASHINGTON, D. C., \\ WHOSE SCIENTIFIC INVESTIGATIONS HAVE DONE SO MUCH FOR THE \\ ADVANCEMENT OF ORNITHOLOGY,

\section{THIS WORK} \\ IS RESPECTFULLY AND GRATEFULLY INSCRIBED.
}

THE AUTHOR. 



\section{Plea of the Birds.}

From "The Birds of Killingworth."

(5)

LATO, anticipating the reviewers,

From his republic banished without pity

The poets: in this little town of yours,

You put to death, by means of a committee,

The ballad singers and the troubadours,

The street musicians of the heavenly city,

The birds, who make sweet music for us all

In our dark hours, as David did for Saul.

The Thrush, that carols at the dawn of day

From the green steeples of the piny wood;

The Oriole in the elm; the noisy Jay,

Jargoning like a toreigner at his food;

The Bluebird belanced on some topmost spray,

Flooding with melody the neighborhood;

Linnet and Meadow Lark, and all the throng,

That dwell in nests, and have the gift of song, -

You slay them all! and wherefore? For the gain

Of a scant handful more or less of wheat,

Or rye, or barley, or some other grain,

Scratched up at random by industrious feet

Searching for worm or weevil after rain;

Or a few cherries, that are not so sweet

As are the songs these uninvited guests

sing at their feast with comfortable breasts.

Do you ne'er think what wondrous beings these?

Do you ne'er think who made them, and who taught

The dialect they speak, where melodies

Alone are the interpreters of thought?

Whose household words are songs in many keys,

Sweeter than instrument of man e'er caught!

Whose habitations in the tree-tops even

Are half-way, houses on the road to, heaven!
Think every morning when the sun peeps through

The dim, leaf-latticed windows of the grove,

How jubilant the happy birds renew

Their old melodious madrigals of love!

And when you think of this, remember, too,

'Tis always morning somewhere, and above

The awakening continents, from shore to shore, Somewhere the birds are singing evermore.

Think of your woods and orchards without birds!

Of empty nests that cling to boughs and beams,

As in an idiot's brain remembered words

Hang empty mid the colwebs of his dreams!

Will bleat of flocks or bellowing of herds

Make up for the lost music, when your teams

Drag home the stingy harvest, and no more

The feathered gleaners follow to your door?

What! would you rather see the incessant stir of insects in the windrows of the hay,

And hear the locust and the grasshopper

Their melancholy hurdy-gurdies play?

Is this more pleasant to you than the whirr

Of Meadow Lark, and its sweet roundelay,

Or twitter of little Fieldfares, as you take

Your nooning in the shade of bush and brake?

You call them thieves and pillagers; but know They are the winged wardens of your farms,

Who from the corn-fields drive the insidious foe, And from your harvests keep a hundred harms;

Even the blackest of them all, the Crow,

Renders good service as your man-at-arms,

Crushing the beetle in his coat of mail,

And crying havoc on the slug and snail.

How can I teach your clildren gentleness, And mercy to the weak, and reverence

For Life, which, in its weakness or excess,

Is still a gleam of God's omnipotence,

Or Death, which, seeming darkness, is no less

The selfsame light, although averted hence,

When by your laws, your actions, and your speech,

You contradict the very things I teach?

H. II. LONGFELLUW. 



\section{PREFACE.}

INCE MY earliest boyhood I have studied our birds in their haunts.

A small lake near my parental home in Town Hermann, Sheboygan Co., Wis., was then surrounded by a primeval forest. White pines towered high into the air. Sugar maples, beeches, birches, oaks, and other trees covered the hill-sides, while broad spreading elms, ash trees, tamaracks, and masses of dense thickets were found in the lowlands and on the peaty margins of the lake. A great number of different birds assembled here in summer. Bronzed Grackles, Red-winged Starlings, Bobolinks, and Passenger Pigeons were in these by-gone days exceedingly abundant. On the hill-side, where a clear, cool spring emerged from the stony ground, the Rose-breasted Grosbeak poured forth its rich and loud song, while the Towhee, the Scarled Tanager, different. Vireos and Warblers were frequently heard near by. When the twilight of evening fell I was saluted by the enchanting song of the Veery, which was only interrupted by the nocturnal sounds of the Whippoorwill. The flame-colored Baltimore Oriole suspended its purse-like nest from the tall elms; the Cedarbirds nested in abundance in the lowlands. Wood Ducks were common, and the Ruffed Grouse was frequently seen in the dense underwood, leading and guarding its young brood. With indescribable quickness the young chickens disappeared under the bushes on all sides when flushed. Mud Hens walked gracefully over the water-lily leaves in the lake's outlet. I was almost sure to be saluted by the loud and liquid song of the Purple Finch, whenever I entered the belt of woodland which surrounded our clearing. In spring and summer this beautiful landscape with its bird life was in reality a wonderland to me. I knew almost all the birds by their voices and colors; I was also acquainted with their nests and eggs, but knew not their names, neither did I know anything about their distribution and classification. I was anxious to learn whence the heralds of spring came, and whither they went when winter was approaching. My craving for a book, from which I 
might gather the coveted information remained unsatisfied. There was no work-and there is none at present-that could have given me the desired information in a manner adapted to my acquisitions. Audubon's unrivaled "Birds of America," Wilson's "American Ornithology," Nuttall's "Manual of the Ornithology of the United States and Canada," and the excellent work, "North American Birds," by Baird, Brewer, and Ridgway, were too expensive for my limited means. I enjoyed nature in all her dewy freshness, I was thrilled with rapture when in the beautiful month of June bird life was at its best, but I was unable to compare my observations with those of others, the standard works on ornithology being out of my reach, and the popular treatises being inaccurate and almost worthless. Thousands of our young people, true friends of nature and enthusiastic lovers of our feathered woodland minstrels, are in the same situation in which I found myself in my. boyhood. The love for nature ought to be promoted and directed in the right way in our rising generation, and there should be ways and means to accomplish this.

Our most excellent ornithological works are either too costly, or too technical for the general reader. "In the present work, which is intended to fill the gap between the very expensive and the merely technical ornithological books, I aim to "combine accuracy and reliability of biography with a minimum of technical description," and to have the work "illustrated in such a way that all figures are recognizable." Although this work is written for all lovers of natural history, I specially endeavor, to inspire our young people with a tender regard for the feathered minstrels of our woodlands, fields and meadows, groves and gardens.

The title does not give the reader a full idea of the scope and the contents of the work. It treats of all our native birds from the Thrushes to the Parrots, including all our Songbirds, Flycatchers, Hummingbirds, Swifts, Goatsuckers, Woodpeckers, Kingfishers, Trogons, and Cuckoos, from the Atlantic to the Pacific, and from Alaska and Labrador to Florida and Mexico. In a more cursory way it also treats of the climate and seasons of different localities north and south, of the utility and aesthetical value of the birds, of the woods and prairies, the more beautiful popular wild flowers of our country, and the poetry of bird life.

The life histories of many birds are chiefly based on my own observations, made from Wisconsin to Texas and Florida. For the purpose of studying the life of our birds I spent several years in Texas, five years in the Ozark region of south-western Missouri, and a number of years in different parts of Illinois. I also visited the southern Alleghanies and different localities in Louisiana, Arkansas, Mississippi, Alabama, Georgia, Florida, etc. Yet this work would be incomplete, should I have neglected to quote freely from the writings of our great American ornithologists of the present time.. Prof. Wm. Brewster's charmingly and poetically written life histories of many of our birds and his ornithological "reconnoissances" in the beautiful mountain regions of North Carolina and New England, in Florida and Georgia, and the classical and unique work on the "Birds of the Colorado Valley," by Dr. Elliott Coues, have always inspired me with enthusiasm. Prof. Robert Ridgway, Dr. J. A. Allen, and Dr. C. H. Merriam have written so attractively on many of our birds, that $I$ have quoted many an interesting passage of intrinsic value from their scientific writings. Mr. Otto Widmann, of 
St. Louis, Mo., Mr. Eugene Bicknell, and Mr. Geo. B. Sennett, of New York City, Captain Charles Bendire, of the National Museum, Prof. W. W. Cooke, Mr. B. F. Gault, of Chicago, Judge J. N. Clark, of Saybrook, Conn., and other ornithologists I have often cited. Among our best ornithological writers the name of Mr. John Burroughs will always be mentioned. His little volume, "Wake-Robin," has an enduring value, and I have freely quoted from its pages. To all these well-known ornithologists, to whom I am attached by sincere friendship, I tender herewith my sincerest thanks. The poets Mr. E. J. Loomis, of the U. S. Navy Department, and Dr. W. L. Shoemaker have contributed to the pages of this work a number of excellent poems. Miss Hilda Siller and Mr. Frank Siller, of this city, have translated several poems from the German, and Mr. and Mrs. W. Zimmermann, of Paso Robles, Cal., Mrs. Anna Sprinkmann, of this city, and General Konrad Krez have assisted me in different ways in my labor.

Special thanks I owe to Ex-Governor Francis A. Hoffmann, Jefferson, Wis., Misses Hedwig and Else Schlichting, Mr. Chr. Koerner, and Mr. Frank Siller, all of this city, for their most valuable services and many kindnesses rendered me in writing this book.

In this connection I must also mention the names of Prof. S. C. Sargent, editor of the exquisite periodical, "Garden and Forest," Dr. G. Bird Grinnell, editor of "Forest and Stream," Mrs. Olive Thorne Miller, Mrs. Mary Treat, and Prof. Geo. W. Peckham, Superintendent of Schools, Milwaukee.

Prof. Robert Ridgway's plates illustrating this work are of such beautiful and poetical execution, that they require no commendation. The plates furnished by G. Muetzel and Prof. A. Goering are also fully entitled to the highest praise.

Milwaukee, January 1, 1893. 



\section{INTRODUCTION.}

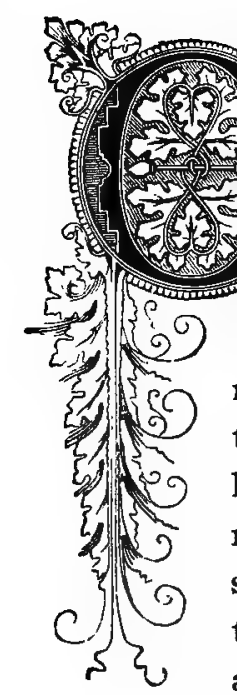

UR GREAT country is exceedingly rich in birds of song and beauty. There is no region on the globe that can boast of such a large variety of charming birds as the United States. During the most beautiful time of the year, when the soft, mild air is filled with the fragrance of numberless flowers, when in the South the magnificent magnolia, the orange tree, and the loblolly bay blossom, in the North the apple tree opens its rosy flower buds, when the shrubs on the woodland's edge are white with blossoms, we may listen to a concert of bird music that nowhere finds its rival. Without these jubilant and cheerful songsters nature would seem to us lifeless and dead. Our birds are the true poets of the landscape, imbuing joy, happiness, and song to woodland and meadow, orchard and field. Their fine form and color, their innocent and happy life, their cheerful song, their rapid and graceful flight cannot fail to create a sympathetic sentiment in the heart of every feeling man. They must attract the attention of even the most casual observer. A rich vegetation, and consequently an abundant supply of insects, is necessary to bring bird life to its greatest perfection. Every locality has its characteristic songsters. The thickets on the woodland border and the honeysuckles in the garden corner harbor one of our most beautiful and interesting songsters, the Catbird, while the Brown Thrasher sings its enchanting anthems of morn nowhere so frequently than in the osage orange hedge-rows of northern Illinois. The Indigobird and the Nonpareil are pre-eminently partial to dense thickets and brier patches near dwellings. The Bobolink, one of our most enchanting songsters, is the poet of the low flower-adorned meadow. The cheerful Red-wing Blackbird enlivens the sedge-covered sloughs and swamps, and the social Yellow-headed. Blackbird was once very common in the extensive marshes of northern Illinois and Wisconsin. The sweet $E$-o-lie of the Wood Thrush resounds in all the deciduous woodlands of the Middle States, while the indescribably sweet song of the Veery is heard more frequently in the mixed woods of the northern part of our country, usually near the babbling waters of a brook or a cool spring. The live oak and mesquit prairies of Texas are the true home of the richly 
colored and exceedingly cheerful Scissor-tailed Flycatcher. Though the gardens of the northern and eastern part of our country are the homes of a large number of fine songsters, they cannot bear comparison with those of the South Atlantic and Gulf States, where that "King of Song," the Mockingbird, from night to morn and from morn to night pours forth his sweetest reverberating music, always characteristic and beautiful, ever new and never tiring. This bird is the jewel among our Songbirds, and, according to the best judges of bird songs in Germany, it finds not its equal either in this country or in any other. In the southern gardens, if they be extensive and well stocked with trees and dense ornamental shrubbery, we may find another excellent songster, the elegant Cardinal Redbird, though it is more common in the datk evergreen thickets of the hollies, or in the entangled underwood on the edge of the forest. The pretty Blue Grosbeak, the nervous Carolina Wren, the always happy Orchard Oriole, and many others combine to make southern gardens attractive and poetical.

As there are no large mountain chains running from east to west, our birds find no check in their wanderings from south to north. This abscence of mountains is the reason why so many of our birds are distributed over such an immense territory. Some species are found during the breeding season from the Gulf region to the fur countries, and even north to Alaska. In the West the Rocky Mountains form a natural barrier to bird distribution. Many of our eastern birds occur to the foot of these mountains In the mountains farther west they are represented by nearly allied, or entirely new species. Among the birds characteristic to these mountain regions is the Clarino, or Townsend's Solitaire, who makes the mountain-sides re-echo with the sweetest music. On the wild and roaring torrents, which fall foaming and thundering over rocks, the highly interesting Dipper, or Water Ouzel, leads a happy and content life. Our familiar Eastern Bluebird is replaced by two nearly allied species in the West, and the Baltimore Oriole is represented by Bullock's Oriole and the Arizona Hooded Oriole. Almost a dozen or more species of Hummingbirds buzz from flower to flower west of the Rocky Mountains, while in the East only one species occurs.

\section{BIRDS OF SONG.}

In an article, "Song Birds in Europe and America," my esteemed friend, Prof. R. Ridgway, writes as follows: "It has been repeatedly stated by writers who have had the opportunity of making the comparison that the United States is very deficient in Song Birds as compared with Europe-the British Islands in particular. One writer even goes so far as to say that it may be safely asserted that in the midland counties of England the Sky Lark alone, even in the month of March, sings more songs within the hearing of mankind than do all the songsters of the eastern United States,'-which, of course, is an exaggeration. The same writer says: 'It is, no doubt, very patriotic to prove that the woods and fields of North America are as vocal with bird song as those of England. The attempt has been made, but it is only necessary to cross the 
Atlantic, stay a month in the British Islands, and then return, taking frequent country walks on both sides of the water, to become convinced that the other side has all the advantage in quantity of bird song. Let us grant that the quality is equal-though it is dlfficult to understand where in America the peer of the Nightingale can be found - let us grant that the United States possesses a list of Song Birds larger than that of the British Islands - all this does not prove that the quantity of bird song is greater. .... In England bird voices are everywhere. The Chaff Finch is more abundant than the Sparrow save in the centers of cities, and his cheery notes can be heard at all times; the Robin Redbreast is common in suburb and village and is not chary of his voice; and as for the Sky Lark - it is hard to go anywhere in the country without hearing him. How is it here? Does any one pretend that bird song is common in the suburbs of our cities? Do Robins and Catbirds, our most plentiful singing birds, often treat us to a song as we sit on the piazza of our semi-detached cottage, or as we walk adown the tree-lined streets?"

"It is not stated in the article from which the above is quoted where the writer's observations in this country were made, except that a 'Pennsylvania wood' is incidentally referred to. It is difficult to believe, however, that he can have had much, if any, experience with other portions of the country east of the Mississippi, for his comparisons certainly will not hold good for a large number of localities both east and west of the Alleghanies, however applicable they may be to the immediate vicinity of our larger Eastern cities. His comparison is also unfair in that, while questioning the existence in America of any 'peer of the Nightingale,' he neglected to inquire where, in England - or the rest of Europe for that matter-can be found even any approach to our Mockingbird, although since it is tacitly granted that in the two countries the quality of bird song 'is equal,' we can afford to pass this by. It may also be remarked that the comparative number of species which can. properly be ranked as songsters belonging to the United States east of the Mississippi River is about twice as great as that belonging to the entire extent of the British Islands, counting in each case every species the male of which utters notes peculiar to the breeding season, or, in other words, has a song, however rude. It is conceded by the writer to whom I have referred that the quality of their song is equal. Is there not, therefore, apparently some inconsistency in the statement that the United States is so greatly deficient in bird song as compared with England? Or, should the statement be true, is it not an anomaly which requires explanation? Although no explanation has, so far as I am aware, been attempted, the reason seems very obvious. In the first place, it would be almost impossible in most parts of thickly populated England, for a bird to sing without being heard hy human ears. In the second place-and what is by far the most important factor in the casebirds in England have for many generations been protected in numerous ways, until, in their almost absolute immunity from the perils to which they are in this country constantly exposed, a comparative large number have become accustomed to the society of man. Laws protecting all kinds of Song Birds, and their nests and eggs are there enforced with a strictness which is absolutely unknown in any portion of the United States; and, in the numerous carefully policed public parks and thoroughfares and extensive private grounds, which ample wealth and long cultivation have made a 
veritable paradise for birds, they live in full knowledge of their " security, and with nothing to check their natural increase. The extreme scarcity of predatory birds and mammals, which have been for a long time nearly exterminated throughout England, has also assisted to bring about that affluence of bird life which is so justly the pride of the English people.

"In the United States, nothwithstanding the derogatory comparisons which have been made-and which, it is true, will; for reasons stated above, apply to the vicinity of our more densely populated centers, and also to regions of extensive forests - a condition at least closely approaching that which is claimed as peculiar to the British Islands may be found in certain favored sections; that is, in those parts where bits of deciduous woodland and open country alternate, with plenty of local variety in the landscape. Such a description will apply to a very large portion of the United States situated between the Alleghanies, on the one hand, and the Great Plains on the other, although not by any means exclusively to that region. The writer was once informed by a young Canadian ornithologist-a specially observant 'field naturalist' with a remarkably fine ear for bird notes, and able to imitate many with great exactnessthat during several years' residence in England he never heard finer nor more abundant bird music than on the prairies of Manitoba, where the melodious and powerful warblings of the Western Meadow Lark were, to his ear, superior in richness and strength to the song of the famed Nightingale, while the silvery trilts of the Missouri Sky Lark also exceeded in sweetness the more powerful, but far from musical, rattling warble of the English species.

"The writer has on many occasions heard, early on mornings in May and June, grand concerts of bird music, which probably would challenge comparison, both as to quality and quantity, with any to be heard in other portions of the world, excepting, probably, the highlands of Mexico, which are said, and probably with truth, to be without a rival in number and quality of songsters. The following list is copied from my note-book, and was made during the progress of such a concert, the birds named singing simultaneously in my immediate vicinity. The locality was not a particularly favorable one, being two miles from a small village, and at least three-fourths of the vicinity either heavy woodland or wooded swamp. The date May 12, and the locality south-western Indiana:

"Four Cardinal Grosbeaks, three Indigo Buntings, numerous American Goldfinches, one White-eyed Vireo, one Maryland Yellow-throat, one Field Sparrow, one Carolina Wren, one Tufted Titmouse, one Gray-cheeked Trush, one Yellow-breasted Chat, one Louisiana. Water Thrush, one Red-eyed Vireo, and two Mourning Doves - in all thirteen species, and at least twice that number of individuals! And here is a list of birds heard singing one day in June, about the edge of a prairie in southern Illinois: Two Mockingbirds, one Brown Thrasher, three Yellow-breasted Chats, one Warbling Vireo, one Baltimore Oriole, several Meadow Larks, numerous Dickcissels and Henslow's and Grasshopper Sparrows, one Lark Sparrow, one Robin, one Towhee, one Catbird, one Wood Thrush, one Ovenbird, one Summer Tanager, several Tufted Titmice, one Redeyed Vireo, one Bell's Vireo, one White-eyed Vireo, one Cardinal Grosbeak, one Indigo Bunting, two Maryland Yellow-throats, one Field Sparrow, and one Prairie Lark - the 
latter a true Lark, singing while suspended in mid-air, exactly in the manner of a Sky Lark; in all, twenty-five species and perhaps fifty individuals. Is such a rich medley of bird music often, if ever, excelled in England? It is true that neither the Sky Lark nor the Nightingale nor the Song Thrush were included, but they were each represented, and well represented too; the first, if not by the Prairie Lark, whose manner of singing is identical, but whose song is comparatively feeble, then by his namesake the Meadow Lark, of which Wilson-himself a Scotchman-says that, although it 'cannot boast the powers of song' which distinguish the Sky Lark, 'yet in richness of plumage as well as in sweetness of voice.... stands eminently its superior'; the second by the Mockingbird, whose song is unrivaled for its combination of richness, variety, compass, volubility, and vivacity; and the third by the Brown Thrasher, whose energetic, powerful, and untiring melody is said to closely resemble in modulation that of the Song Thrush. Not less than half a dozen of the remaining species are songsters of very pronounced merit, probably equalling, in one quality or another of song, the best of European singers, excepting that celebrated trio, the Nightingale, Song Thrush, and Sky Lark....*

"Alexander Wilson, the 'Father of American Ornithology,'-a Scotchman, by the way-and Thomas Nutta11, an Englishman, both praise our Bluebird in unqualified terms, and also the House Wren, the Purple Martin, and some others.

"There is no bird in England - not even the semi-domestic Robin Redbreast-which is more easily encouraged to seek human society than the Bluebird; certainly none are so beautiful and none more lovable in every way. The modest little Chipping Sparrow is even more easily encouraged, and it is equally deserving of encouragement, for, though neither beautiful in plumage nor sweet of voice, he has a trim little form, a saucy red cap, and the most confiding manner, often, in the villages and at the farm-houses, attending the meals of the family and picking up crumbs which are thrown out the door, or, should the table be set out on the verandah or beneath the arbor, gathering them from among the feet of those sitting at the table. This trim little bird, which can so easily be made a household pet, is extremely useful in destroying injurious insects, is particularly beneficial to the garden, and is especially fond of the cabbage worm, of which one pair would keep a moderate sized garden quite free. The House Wren is, as his name implies, one of our semi-domestic birds, and, being exclusively insectivorous, is one of the most useful, while his cheerful, sprightly warble renders him excellent good company. Wilson characterizes the song of the House Wren as 'loud, sprightly, tremulous, and repeated every few seconds with great animation,' and says that 'in strength of tone and execution, it is far superior' to that of the English species. The Purple Martin, largest, handsomest, and most musical of all the Swallow tribe, is not only an agreeable companion, but is also extremely useful as a destroyer of insects, which exclusively constitute its food, and as a protection to the farmer from Hawks and Crows, against the depredations of which there can be no better safeguard, since not one of these predatory birds dares approach the vicinity of a pair, much less a colony, of Purple Martins. - The birds which are specially mentioned above are, with the Robin and Catbird (and, west of the Alleghanies, the Blue Jay), pre-eminently our most familiar species; but there are many others which are most at home in our orchards or among the

* In order to a roid repetition I refer the reader to page 80 and 81 of this work. 
shade trees along the streets of villages and towns, or even sometimes within large cities. A good example of this latter class is the Warbling Vireo, which Nuttall characterizes as a bird 'almost confined to our villages and even cities.' He says that it is 'rarely observed in the woods; but from the tall trees which decorate the streets and lanes, the almost invisible musician, secured from the enemies of the forest, is heard to cheer the house and cottage with his untiring song,' and that he has heard it singing as late as October 2. Its song, says Mr. Thomas McIlwraith (in 'Birds of Ontario'), 'is soft, subdued, and flowing, like the murmuring of a hidden brook in the leafy month of June.' The beautiful Yellow Warbler is one of our commonest orchard birds ; and if the Bluebird is the most delightful of our birds, this is the most lovely, with his plumage of mellowest gamboge-yellow, streaked with richest chestnut-red on breast and sides, and pretty, cheerful song. He is not only beautiful and tuneful, but useful as a destroyer of insects infesting fruit trees, which constitute his only food.

"This list of familiar, attractive, and useful songsters might be greatly extended; but enough have been mentioned to show that the United States is not so badly off in the matter of Song Birds as might appear. We have them in abundance, but they are treated with indifference-or, what is worse still, snubbed by the perverted sentiment which prefers the detestable House Sparrow to the Bluebird, the House Wren or the Purple Martin. When that worse than useless foreign vagabond was introduced to this country, boxes were immediately put $\mathfrak{x p}$ for his accommodation, and every means taken to protect him. Yet, none of our native birds, no matter how useful, beautiful, or melodious, was considered worth the trouble. Had the same steps been taken to encourage and protect those of our native species which are most worthy of such attention, there is no question that our towns and villages and city parks would by this time have become full of Bluebirds, Wrens, and other attractive and useful birds, whose place is now taken by that rank weed among birds, the European Sparrow. Successful as has been the introduction of the latter pest, attempts have been made to naturalize various European Song Birds, but they have all proven failures, as might have been expected had the matter been properly considered. It should be remembered, in this connection, that the climate of this country is exceedingly different from that of Europe-especially the British Islands-which is characterized by milder winters and cooler summers, while our winters are severe and with frequent changes of temperature, and our summer heat of tropical intensity. Therefore, few of the resident European species could stand the vicissitudes of our climate. Again, birds which in the mild climate of England are resident throughout the year would, if brought to this country, be forced to migrate or else perish; while migration being but an inherited instinct, followed by the predecessors of existing individuals of each species for thousands of generations, this instinct serves them to no purpose in a strange country, but, on the other hand, is apt to lead them to destruction, since, when the season for migration arrives, they are as apt to fly directly out to sea as not, and thus be destroyed.

"Let us, therefore, instead of continuing to deprecate our supposed scarcity of Song Birds and attempting the remedy by futile importations of foreign species, encourage and rigidly protect those which the bounty of nature has provided for us, and of which we have every reason to be proud." 


\section{BIRDS OF BEAUTY.}

Our North American birds vie in brilliancy and splendor of color with the birds of the tropics. The purple glory of the morning, the varied hues of the rainbow, the golden and fiery tints of the sunset light, the deep azure of the sky, the sparkling of the stars, the lustre of precious stones, the radiant tints and the gorgeous brillancy of the flowers seem to reflect from the plumage of our native birds. The southern and south-western portion of our country is richer in brilliantly colored birds than the North and East. In Arizona, the true home of numerous grotesque succulent plants (members of the cactus family), yuccas, and agaves, and, during the larger part of the year exceedingly dry and arid, we find a large variety of elegant birds, among them the Coppery-tailed Trogon, a true member of a tropical family, the Vermillion Flycatcher, the Painted Redstart, the Red-faced Warbler, and several species of Hummingbirds. The region of the lower Rio Grande, in Texas, is a veritable paradise for characteristic and beautiful birds. There we may observe four species of Orioles, the colors of which gleam among the leafage of the forest trees. The rare and exceedingly beautiful Varied Bunting, the Green Jay, the Verdin, Sennett's Warbler, and many others occur there in the prairie thickets, in chapparal, and woodland. The mesquit and live oak prairies of Texas are the true home of the Scissor-tailed Flycatcher. Its beauty and its graceful flight are so singular that it is everywhere known as the "Texan Bird of Paradise." In all the Gulf and South Atlantic States we may observe the familiar and beautiful Cardinal. Its fine scarlet color, its long and effective crest, its coral-red beak, relieved from the scarlet color of the head by a narrow, pure black band, and a black crescent on the throat; its lirely ways and manners, its loud flute-like song combine to make this one of our most valuable birds. Nothing can be more beautiful than the Nonpareil, or Painted Bunting, in a dark green hedge of blossoming Cherokee roses, or in a flowering orange tree. Dr. Carl Russ, of Berlin, the best authority on cage birds, pronounces the Nonpareil the most beautiful of all the Finches. Its shining deep purplish-blue hood, its green back, and vermilion under-parts make it a striking object. Its near relative, the deep ultramarineblue Indigo Bunting, of the brier and hazel patches of the central and northern part of our country, is a bird of the greatest elegance, and the Lazuli Bunting of the West with its turquoise-blue upper parts, its tawny breast, and white wing-patches and under-parts is also a very striking denizen of the low shrubbery. In my memory the beautiful Blue Grosbeak is always associated with the blackberry thickets, the shrubbery of the fence corners and the orchards of the South. It is an elegant bird and a fine songster, lendding a peculiar charm to its bushy haunts. In the northern and eastern parts of the United States we not only find numerous excellent songsters, but also many brilliantly colored birds. The Scarlet Tanager in its dress of rich pure scarlet and deep black on wings and tail, gleams among the foliage of the forest trees like a flame. Its gaudy and richly contrasted colors, and its loud flute-like song convert those parts of the forest where the Tanager selects its home, into an ideal spot of poetry and song. Its near relative, the Summer Tanager, belonging to a more southern fauna, is not so richly colored, its plumage showing a dull red on the upper parts, and a light vermilion on 
the lower. In the distance it resembles a Cardinal, and is often confounded by the ignorant with that bird. In Texas the boys know it only by the name of "Cardinal without a crest." Both our Tanagers have a loud Thrush-like song, resembling in volume and loudness the Robin's. Among the beauties of the northern woodlands, usually in the same places where the Scarlet Tanager chooses its home, the jaunty Towhee, or Chewink, nicely dressed in black, white, and chestnut, and the elegant Rosebreasted Grosbeak, famous for brilliancy, both in color and song, are my special favorites among the minstrels of our northern woodland scenery. The Purple Finch, the Cedarbird, the Goldfinch, the Yellow Warbler of our gardens rank among our birds of beauty, while the Catbird, the Robin, the Song Sparrow and Chippy, and the Vireos of the garden shrubbery and ornamental trees are very pretty. The meadows of the North, adorned with lilies and other pretty flowers, are the home of numerous Bobolinks. The males in their jaunty attire of black, creamy and white, bubbling over with exhileration, rivalling each other in thousand extravagancies, are always seen in the air or on fences and the tops of weeds. The Meadow Lark is often the Bobolink's neighbor. It is also a fine song bird and dressed in fine colors. The Red-winged Blackbird of the swamps and marshes may also be counted among our birds of beauty, its vermilion-red wing-patches contrasting finely with the deep shining black of the rest of the body. All our Hummingbirds are beautiful creatures. "These jewelled feathers are so precious that with all the boundless wealth of nature economy must be practiced in the use of such materials ; which is one reason why the Hummingbird is so diminutive a creature." The bird and its haunts belong always together. This is the reason why I have so frequently made the attempt in this work, to depict the surroundings of our birds. The haunts of the birds, the trees and bushes and flowers, the water, the rocks, the floweradorned meadows, and even the sky increase the beauty of their colors. A Hummingbird, skimming and darting from flower to flower, is a much more interesting object than one perched quietly on a pole. The Cardinal in the holly thickets, the Bobolink over the waving grass, the Redwing among the sedges, the Catbird in the twining honey-suckles, theSwallow in the air, the Phœbe on the top of the barn roof, the Robin in the top of a high tree, the Bluebird flying from one stump or tree to another, are all striking objects. They belong to their surroundings, imbueing them with life and happiness.

Since my early boyhood the exquisite Baltimore Oriole is associated in my mind with the high and spreading elms of my native State Wisconsin. Wherever the opportunity is favorable this bird, famous alike for its flash.of color, its assiduity in singing, and its architectural ability, selects the magnificent elms in the lowlands, on the woodland border, and even in the proximity of houses, for its home.

Our Warblers are all clad in variegated colors - always pretty and tasteful, and often strikingly brilliant. The true Wood Warblers (Dendroica) are the most attractive of our songsters to every lover of bird life for their own sakes - "to everyone" who delights in those æsthetic emotions which the interpretation of bird life never fails to excite." The Blackburnian Warbler is the most richly colored of all the members of the family. An intense orange on crown, eyelids, throat, and breast is relieved by a deep black and white on the rest of the body. The Magnolia Warbler is a dainty little bird, 
noted for richness and elegance of its attire. The Parula and Prothonotary Warbler, the Maryland Yellow-throat, the Hooded Warbler, the Redstart, the Black-throated Blue Warbler, Myrtle Warbler, Black-throated Green Warbler, Cerulean Warbler, Yellow Warbler, and almost all the other members of the family are lovely birds, not less famed for their beauty than for their confiding disposition and noble bearing.

\section{THE DAILY LIFE OF OUR BIRDS.}

No other animals understand to lead such a cheerful and poetical life as our birds. The longest day is scarcely long enough, and the shortest night scarcely short enough for them. All birds rise early in the morning. Darkness still hovers over field and forest. In the far east a light grayish hue announces the arrival of a new day. This is the time when most birds begin to sing their sweetest lays, which are now more effective and enchanting than later in the day. The Swallows chatter under their roof, and the Martins peep out of the entrance holes of their nesting-boxes, singing their sweetest notes. The Bluebird warbles its familiar and lovely strain almost incessantly, and the Robin carols its flute-like notes from the top of yonder elm. The Catbird, the humble tenant of the shrubbery, pours forth its sweetest music, praising the coming of the new day. The Thrasher we also hear. Like the Catbird, it delights to mount to some isolated perch during the nuptial season, "and there, in easy attitude, with depending tail, loosened plumage, and head thrown up, repeats again and again its delightful strains." When the farmer, shortly before the sun rises, follows his team to the field, he is greeted by an enchanting bird concert. All the birds are now in ecstacy of song, joy, and happiness. They all sing their anthem of morn before breakfast, looking for food not until the sun has risen. When building their nests they also perform their duty in the early morning hours. When the sun ascends higher and higher, the song ceases. Only now and then we hear a few notes. During the warm noontide we rarely hear a bird. The most diligent songsters are the Vireos. They sing during the warmest part of the day with the same diligence as in the early morning, and even in rainy and stormy weather their song resounds through woodlands and orchards. The Mockingbird sings with great fervor even'at night, especially during the beautiful moonlit nights of the Gulf region. Whenever the rays of the sun become oppressively hot, most of the birds seek a resting place in shady thickets, or among the dense foliage of trees. There they sleep or bring their plumage in order. The weather has a great influence on their bearing. Is the sky clear and the weather cheerful, they are also cheerful and happy; is the sky covered with clouds, they are depressed and quiet. During a number of cool and rainy days, when insects are hidden beneath the bark, in crevioes of the wood, and among the old leaves, the hunting for food takes all their time, absorbing every other interest. They look now sad and discouraged. But as soon as the bright rays of the sun fall down again, their old good humor and happiness returns, and all are spending their time in singing and looking for food.

All birds are fond of bathing, be it in the water, in sand, or dust, . After this 
performance they feel exceedingly comfortable. This cleaning seems to be a necessity for them. Near the residence of Miss Hedwig Schlichting, in immediate vicinity of the kitchen, the Catbirds, Robins, Yellow Warblers, and other birds several times each day take their baths in a wooden trough especially provided for them. The same lady, who is an enthusiastic friend of nature and especially of the birds, provides also nesting material. In early June a pair of Robins built a nest almost exclusively of Spanish moss which I had given to Miss Schlichting, and in which I had received some plants from Florida.-Toward the late afternoon most birds sing again, and many as fervently and impressively as in the morning hours. When the dawn of evening falls, the song of many, is exceedingly beautiful. As soon as darkness sets in, each bird retires to its roosting place, where it spends the night.

The young birds are attended by their parents with the utmost care. They never tire in searching for food for their always hungry offspring. In case of danger they defend the nestlings with great courage and boldness, and even after they have left the nest, they are cared for and guided by the parents until they are perfectly able to take care of themselves. Late in July and in August we see comparatively few birds, and, with the exception of the Goldfinch, a few Vireos, and some young Robins, we hear no songsters. The plumage of most birds looks untidy and shabby, and almost all are very peculiar in their manners, trying to hide when we approach them. This is the time of moulting. They are not able to fly well, and many hop and skip around without tails. They seem to feel safest in the thickets and briers, on the woodland's edge and in the tall weeds, where they lead a retired and quiet life till the moulting is over.

\section{MIGRATION.}

A charming and peculiar poetry surrounds the life of our feathered songsters. Their flight into the sun-resplendent vastness of the heavenly dome, their rocking on the undulating twig, their hiding in woodlands, thickets, and fields, their chant and carols in thousandfold variations, their searching for food among the flower-laden branches of trees and shrubs-every glance into their life and habits is attractive and indescribably pleasing to a thoughtful feeling mind, disposes it to earnestness, attunes it to. cheerfulness. The longing of the human soul as well as its hope, these two foundations, upon which much of our true poetry rests, are influenced by two of the most important occurrences in the life of our birds: their departure in autumn and their return in spring.

The short and intensely warm summer of our northern clime has passed away. The days become perceptibly shorter, the nights steadily cooler. The air is pure and invigorating, and the sky shows a deeper tint of blue. The tender spiderweb-like, silvery threads float past us, slowly and noiselessly, like a bright dream of the departed summer time. Then also comes that peculiar veil-like, exceedingly fine-spread haze, perceptible only on distant objects. It does in no way diminish or interfere with the wonderful salubrity of the atmosphere prevailing in this season of the year, which 
excels by the peculiarly beneficial warmth and softness of the calm and peaceful air. Everywhere the gentians, the asters, and golden-rods are now in bloom, farther south the blazing-stars (Liatris) and other late summer and autumn flowers. The leaves of the sumach, the maple, and the Virginia creeper are perfecting their rich red hue. We feel the full charm of Indian summer. The soul is touched by a feeling half pleasing, half sad. Secretly the low notes of birds, singing in bush and tree, seem to awaken a gentle echo within us. Toward the end of August we notice the Swallows congregating and departing. It seems as though our heart would wish to go with them far, far away. The Red-winged Blackbirds and the Grackles collect, large swarms of them also depart toward the South. This general exodus strongly and strangely touches the human heart. The gentle twittering, the low toned singing in bush and tree denote the desire for departure. We hear the gentle voices, we divine their intent and meaning, they are so cozy, they are so gentle; the voices sing what the migration means: "Farewell, we go to the far distant realm of the warming sun, and shall return to our old haunts with his enlivening rays!" Two causes may be given for these wanderings to the far South: scarcity of food and an unbounded impulse to move onward. With most birds migration is a necessity, a condition of life. But it does not originate in the experience of the bird when food and warmth are missed, it is simply what we term an instinct, belonging to the nature of the bird. Food is still plentiful at home, and yet they move away, irresistibly into the far-off land. Young and old, wild or brought up in cages, they all feel this wonderfully strong impulse. The caged birds at this time become restless and wild. They eat little and have hardly any rest by day or night, occasionally they call and sing in unsatisfied longing, and this restlessness continues till the end of the time of migration and is renewed at the time of the return. Generally our small birds migrate at night, and then we can observe in our little prisoners very frequent fluttering in the cage. As soon as the time of migration of the wild birds is over, our caged pets become quiet, easy, and happy again. I have observed this in my caged Catbirds, Thrashers, Warblers, Bluebirds, Orioles, Mockingbirds, Redwinged Blackbirds, Wood Thrushes, Veerys, Fox-colored Sparrows, Juncos, Chewinks, White-throated and White-crowned Sparrows, and many others. This plainly shows that the migratory impulse or instinct has become an inextirpable pectiarity of the bird with its birth. But not all our birds migrate. Many of them are resident. They are hardy enough to stand severe cold, and are able to find an abundant supply of food at all seasons. Jays, Titmice, several Hawks, most of the Owls, Gulls, etc. do not leave their home. The Cardinal Redbird can be found in its haunts at all seasons of the year. Many birds roam over a large portion of the country in search of food, caring little for the inclemency of the weather. To these we may count several Woodpeckers, Titmice, Sparrows, Goldfinches, Cedarbirds, etc. But most of our happy summer sojourners are true migrants. Many of them find congenial winterquarters in our Southern States, especially in the Gulf region. I found the dense thickets near water-courses, the bushy ravines, the borders of swamps, and the dense wreath of thickets on the woodland's edge in Texas, Louisiana, Florida, and other southern States fairly swarming with northern birds from October to April. Even the grasses in corn and cotton fields and the weeds had their peculiar winter visitants. Among 
these winter birds we notice especially members of the Sparrow family, Thrashers, Myrtle Warblers, Wood Thrushes, Robins, Bluebirds, etc. The more delicate insect eaters, such as the majority of the Warblers, the Baltimore Oriole, almost all the members of the Swallow family move farther south to Mexico, Guatemala, Honduras, Costa Rica, the West Indies, and even to northern South America. Most of our familiar northern birds are exceedingly wild and unapproachable in their winter-quarters. The Robin and the Catbird rarely enter gardens in the South, the latter preferring the seclusion of the dense underwood in forests, the former being more abundant in large woods. The lovely and familiar Bluebird feels very uneasy in its winter home and shuns the society of man.

A large number of the small birds have only a short stay in their northern home. They appear by the end of May, build their nests, raise their young, and by the end of August or early in September are already on their way to their winter home. As a rule, the later the birds appear in spring, the earlier they return, and the earlier they arrive, the later they migrate southward. Some birds wander singly, others in paits or families, and many in large flocks and even swarms. Most of our songsters also migrate separately as regards sex; the males first, the females several days later. The old Martins leave their haunts earlier than the young. Every friend of nature knows that the male Robins, Baltimore Orioles, Martins, Scarlet Tanagers, Bluebirds, etc. arrive a few days earlier than the females of the same species. None of our birds breed in distant lands. The land of their winter resort is to them, indeed, a foreign country. There they are timid, live in retirement, do not sing, and never build nests or hatch. But when they return to their old homes, their natural cheerfulness returns and is manifested by their delightful music. They departed sad and sorrowful, drawn by an irresistible force to the foreign country; with a new dress, cheerful, in full song they return to their old home. Their desire to return home is so strong, that frequently they appear too early, while cold weather still prevails, and nourishment is very scarce. As a rule, all larger birds migrate in day-time, the small ones at night. The latter take their flight so high as to be often invisible, while their voices are distinctly audible. When the nights are dark and sultry, the birds, which often move in immense swarms, consisting of the same and different species, are frequently misled by the electric lights on towers, light-houses, and even by street lights in cities. Half blinded they flutter in large numbers about these lights, especially on light-houses, many being killed outright in striking the glass, others fly so forcibly against the light, that they injure themselves beyond hope of recovery. One of our leading ornithologists, Prof. Wm. Brewster, of Cambridge, Mass., spent about seven weeks at the light-house of Point Lepreaux, New Brunswick, with the purpose to observe the birds during their migration: He has laid down his observations in an excellent paper, "Bird Migration." To show how the birds move, how they strike the light, and how many are killed, I quote what Mr. Brewster has observed in two nights, Sept. 1 and Sept. 4, 1885.

"My stay at Point Lepreaux lasted nearly seven weeks, from August 13 to September 26. Living at the house of the light-keeper (Mr. G. H. Thomas), within a few yards of the light-house itself, I was able to keep a close watch on the movements of the birds, and I believe that no flight of importance escaped my notice. At the time of my arrival the migration of many of the smaller land birds had hegun. Nearly every 
morning brought new comers to the Point, and at night, especially after August 20, Thrushes and Warblers were often heard passing overhead. But up to the close of the month there was no considerable movement, at least of species which migrate by night. Rather it was like the gradual setting of ocean currents immediately after the turn of the tide. During this period the weather was unfavorable for birds to be attracted to the light, and none were seen there either living or dead.

"The first real 'rush' occurred on the night of September 1, and, for the two weeks following the feathered tide flowed swiftly and more or less steadily, marking its course through the star-lit heavens by the incessant chirping of its passing legions, in thick weather surging confusedly about the light, wrecking many a bird life against the fatal shaft, and at daybreak leaving hundreds of tired little travellers stranded in the scanty covers of the Point. With this date then begin my notes on 'Birds about the Light.'

"Sept. 1. Night cloudy and dark, but not foggy. Wind south-west, light. At ten o'clock small birds appeared about the lantern in considerable numbers, and for the succeeding two hours a dozen or more were constantly in sight, skimming along or across the pathway of light. Every now and then one would fly directly against the glass, sometimes striking it with considerable force, but oftener merely fluttering against the pane. During the evening two killed themselves outright, and seven were hopelessly disabled. These nine specimens represented eight species, seven of which were Warblers (Dendroica virens, D. maculosa, D. pensylvanica, D. cærulescens, Gèothlypis philadelphia, G. trichas, and Setophaga ruticilla) and one a Vireo (V. olivaceus). A tenth (Empidonax trailli) entered the mouth of the ventilator and came down through it into the lantern, uninjured. The majority, in fact fully ninety per cent, did not strike, but after dallying with the danger passed on, marking their progress westward by incessant chirping. Others were constantly arriving, heard at first faintly in the distance, then nearer, and finally joining the throng within the circle of light.

"Sept. 4. A clear cool day; the evening perfectly clear up to ten o'clock, when a heavy curtain of clouds rolled overhead from the North-west, and it became very dark. An hour later dense fog set in, and at midnight it began to rain, heavy showers succeeding one another at frequent intervals. Wind south; puffy, at times strong.

"As soon as the sky became overcast, small birds began to come about the light. Their numbers increased steadily from ten to eleven o'clock, but during this time the majority kept at a safe distance, and only two or three struck. With the advent of the fog they multiplied tenfold in the course of a few minutes. For the next hour from fifty to a hundred were constantly in sight, and from one to cight or ten dashing at the lantern. About seventy-five per cent struck the glass with slight force, fluttered down the pane, and dropped to the platform beneath, exhausted, but uninjured. After a moment's rest these would make off with uncertain flight, usually disappearing in the darkness, sometimes returning and striking again, always harder the second time. About twenty per cent struck so forcibly as to injure themselves beyond hope of recovery, often, however, fluttering off the platform and down to the ground beneath. Not over five per cent were killed outright. None of the killed or wounded were defaced externally, but all had one eye slightly bulged out and more or less blood settled about 
it under the skin. With the beginning of the rain their numbers diminished rapidly, ${ }^{*}$ but a larger percentage struck, and they also struck harder.

"I remained on the light-house from ten o'clock until two the next morning. During this time fully two hundred birds came against the lantern. Of these at least fifty were killed or disablet; and I caught and examined probably fifty more which were too wet or exhatusted to fly after dropping on the platform. About forty per cent of the specimens identified were Maryland Yellow-throats, forty per cent more Red-eyed Vireos, with the remaining twenty per cent made up of Grey-cheeked Thrushes, Olivebacked Thrushes, Chestnut-sided, Magnolia, Bay-breasted, Blackburnian Warblers, American Redstarts and Canadian Warblers.

"At the height of the mêlee the scene was interesting and impressive beyond almost anything that $I$ ever witnessed. Above, the inky-black sky; on all sides, dense wreaths of fog scudding swiftly past and completely enveloping the sea which moaned dismally at the base of the cliffs below; about the top of the tower, a belt of light projected some thirty yards into the mist by the powerful reflectors; and in this belt swarms of birds, circling, floating, soaring, now advancing, next retreating, but never quite able, as it seemed, to throw off the spell of the fatal lantern. Their rapidly vibrating wings made a haze about their forms which in the strong light looked semitransparent. At a distance all appeared of a pale, silvery gray color, nearer, of a rich yellow. They reminded me by turns of meteors, gigantic moths, Swallows with sunlight streaming through their wings. I could not watch them for any length of time without becoming dizzy and bewildered.

"When the wind blew strongly they circled around to leeward, breasting it in a dense throng, which -drifted backward and forward, up and down, like a swarm of gnats dancing in the sunshine. Dozens were continually leaving this throng and skimming towards the lantern. As they approached they invariably soared upward, and those which started on a level with the platform usually passed above the roof. Others sheered off at the last moment, and shot by with arrow-like swiftness, while more rarely one would stop abruptly and, poising a few feet from the glass, inspect the lighted space within. Often for a minute or more not a bird would strike. Then, as if seized by a panic, they would come against the glass so rapidly, and in such numbers, that the sound of their blows resembled the pattering of hail. Many struck the tin roof above the light, others the iron railing which enclosed the platform, while still others pelted me on the back, arms, and legs, and one actually became hopelessly entangled in my beard. At times it fairly rained birds, and the platform, wet and shining, was strewn with the dead and dying."

Regarding the routes of migration Prof. Brewster writes :

"As is well known, there are certain definite routes or paths of migration along which birds pass in especially great numbers. These are usually coast lines, river valleys, or continuous mountain ranges. Towards them converge innumerable less frequented paths, each of which in turn has still smaller tributaries of its own. Thus bird streams, like brooks, flow into common channels, and each particular region may be

\footnotetext{
* They were probablv obliged to neek the nearest sheiter, for many that came to the lantern had their plumage so water-soaked that they could hardly fly.
} 
said to have its bird, as well as water, shed. An important consideration is that the tributary bird streams follow courses in no wise strictly dependent on points of compass."

All those of my readers who are especially interested in bird migration I refer to the above named pamphlet, to Dr. J. A. Allen's "Origin of the Instinct of Migration of Birds" (Bulletin of the Nuttall Ornithological Club. Vol. V, p. 151-154), and Mr. W. W. Cooke's "Report on Bird Migration in the Mississippi Valley in the years 1884 and 1885." (Washington: Government Printing Office. 1888.)

Thus it is migration which carries away the living ornaments of the forest, the songsters of the wood, and brings them back in time; it is this instinct of bird nature which depopulates the surroundings of our lakes, ponds, and brooks, our meadows and fields, our glens and forests, and again repeoples them; this impulse, whose pain and pleasure we share when we bid farewell to our winged friends and welcome them home again.

\section{UTILITY OF OUR BIRDS.}

The friend of nature, and especially the lover of rural life, of plants and woodland scenery, can find no more interesting and refined reading matter than "Garden and Forest," so ably conducted by Prof. C. S. Sargent, of Cambridge, Mass. In the interest of my readers I quote in full from its pages (Vol. II, p. 529) the following article, "The Utility of What Makes Life Interesting":

"Food, clothing, and shelter are the primeval, universal wants; but when these are supplied, new needs arise, the wish for increasing comfort and security, and then the desire to make life interesting, so that it may be something more than mere existence. The means to this end are as varied as the special qualities and dispositions of individual men, but, however it may reveal itself, this hunger for something beyond the means of physical subsistence is an ideal element in our nature. It is the origin of poetry and romance, and of all art. It is the source of progress and civilization, and is, indeed, the distinguishing endowment and crown of humanity. It is not enotigh for men to have food, clothing, and shelter in amplest supply. The physical life itself is not prosperous or secure when the mind is starved and dwarfed. Pleasant thought is a vital force. Interesting mental employment promotes health and longevity, and is a necessity for all.

"The means, conditions, and occupations which make life interesting for some persons, have no such value or result for others. The sustaining pleasures of one man would be a burden and weariness to another. Growth carries the same individual beyond the earlier ideal satisfactions, and he discerns more truly what is normal, sane, and healthful. A cultivated and developed taste rejects what was once highly esteemed. In an advanced state of society every person would be free to employ his means and opportunities for the satisfaction of his own ideal needs-to pursue the objects which would make life most interesting to him, if he did not trespass upon the rights of 
others. At the same time every individual would be influenced and aided by the general taste, judgment, and culture of the community about him.

"The growing interest in out-of-door life, and in means of recreation that can be enjoyed in the open air, is one of the most encouraging tendencies of the time. Gardening and the care of flowers and trees are becoming more and more attractive to thoughtful and cultivated people everywhere. These are sane and wholesome occupations, and they are coming to be depended upon for relief from weariness and 'nervous prostration,' as it is found that pleasant activity in the open air is often a more potent restorative than medicine. The primary benefit comes, of course, from our breathing purer air, and more of it, when out-of-doors; but every one needs a more inspiring reason for going out than the bare and depressing thought of the need of improvement to health. It is much better to think about our flowers or shrubbery, or to be interested in plans for the care of a garden or door-yard, than to think of ourselves in any more direct way. In all such activities immediate utility is associated with the more ideal aims.

"The best garden or farm is partly a work of art. Its order and beauty add to the interest of life for its possessor, especially if he cultivates it with his own hands and brain. A day laborer with a garden, or a few square yards of ground about his door, has an artist's opportunities in the application of his taste to the capabilities of the area which he plants and shapes. He may have the delight of creating something beautiful and interesting which did not exist before. It is a serene happiness to think out plans for doing the best that can be done with even the smallest piece of ground on which anything can be made to grow. He who has room for trees has it in his power to make enduring changes in the landscape, and the care of even a few trees will supply much of interest from the time they are planted till their protector can walk or rest at will under their shade. One becomes attached to them as to children and friends, and they respond in their way. The watch against their many foes often involves unpoetical activities; but struggle is the condition of all animate being, and life without it, if it were possible, would not be interesting.

"The defense of trees against their insect enemies introduces us to one of the most interesting provinces of the out-of-door world, the life of birds and their services to man. In the order of animal existence on our planet they are the natural instrument for keeping insect life down to its normal level and proportion. But we have repressed the bird population in this country to such an extent that we have produced an enormous over-development of insect life, so that the dominion is given over to them, and they have become an all-pervading curse, like that of the frogs in Egypt when they covered the land, entered the houses, and climbed into the very bread-bowls. Learned men write books and governments make large appropriations to help farmers, orchardgrowers, and vine-growers to defend their crops against injurious insects, but if we were civilized enough to protect our friends and allies instead of cherishing our enemies, the birds would soon dispose of most of these pests.

"It is often observed that birds are more particular about their food than form. erly, and that many of the worst insects are not eaten by them. But that is because their supply of food is so abundant that they can afford to be dainty and to eat only 
what they like best. It is much the same as if a banquet for a thousand men were served every day for half a dozen. They could taste here and there, and would make little impression on the whole supply. It is so with the birds because they are so few, but if they were protected till the bird population began to press upon their means of subsistence, they would not be so fastidious, and would be glad to get any kind of bug or worm, and would snap up every one that showed his head.

"Besides their utility as insect destroyers, birds are among the most interesting and companionable of all living creatures. Few people in this country have any intimate acquaintance with birds and their ways, but those who have studied them in close and pleasant relations know that they have a great deal of individual character and a wonderful and most interesting kind of intelligence. Their music, too, often peculiarly sweet and fascinating, with a mysterious and indefinable quality - a kind of divine suggestiveness-appeals strongly to the higher and gentler elements of our nature. But few persons now hear this music, because the birds that remain are so hunted, terrified, and tormented that they rarely feel like singing. If the children and young people of the country were instructed in their homes, schools, and churches regarding man's relation to the earth on which he lives, and his responsibility for the care and ordering of it and its products, not only would there be a saving every year of millions of dollars in the crops of our farms, 'gardens, orchards, and vineyards, which are now destroyed by insects, but life would soon be much more interesting to the wiser race of men and women."

That injurious insects are on the increase and are becoming more destructive to the crops of the garden, orchard, and field, than they used to be, are facts verified by gardeners, horticulturists, and farmers in all parts of our country. Not a year passes without bitter complaints being uttered of the ravages of cut-worms, wire-worms, corn-worms, tent-caterpillars, codling moths (apple-worms), the many different curculios, army-worms, borers, chinch-bugs, Hessian flies, and thousands of other injurious insects, and the loss from these pests is simply beyond calculation. It was once no trouble to raise fruits of all kinds free from knots, spots, and other defects, but now this is no longer the case. An apple without a worm is now almost an exception. The orchard is full of insects, and unless they are destroyed, fruit can not be profitably raised. The tent-caterpillar, so troublesome of late years, was never known to do serious harm to orchards half a century ago. Now the orchards must be carefully watched to keep this terrible enemy in check. The apple is also greatly injured by the curculio. Sometimes out of hundreds of barrels of apples only a few of perfection can be found, the rest being full of knots and specks, the result of the bite of the curculio. The curculio is the greatest enemy of the plum and peach orchards, and these excellent and popular fruits are no longer easily raised. To briefly describe all the worst insects and the mischief they do, would take up many pages of this book.

There is a cause why insects do more mischief now than in former years, and the fruit-growers and farmers should loose no time in hunting it up and removing it if possible. There is nothing new or unusual about insects multiplying so rapidly, for they always did when their increase was not checked in some way, but what checks existed in the early settlement of the country that are out of the way now? There can 
be but one answer to this question: when we had forests and woodlands edged with belts of shrubbery, swamps with masses of thickets, when on the road-sides and along the fences trees and bushes overgrown with vines and other climbing plants, grew in abundance, we had birds everywhere and plenty. They limited the increase of insects, but now, that the birds are gone, insects have no enemies and can increase to unlimited numbers. All small birds are insect eaters, and at certain seasons of the year they feed on nothing else. But they have been killed and driven off, and their homes have been cut down. Some of the once common birds are now rarely seen. Scarcely fifteen years ago the Bobwhite, or Quail, was common in almost every field, but to-day it is heard no more, except in the most favorable localities. Of late Mr. Gustave Pabst, of Milwaukee, Wis., attempts to re-introduce these once familiar birds into the southern part of Wisconsin. Many pairs have been set free in different localities during the last spring (1892).

The eggs from which the cut-worms are hatched, are laid by a small moth of the genus Agrotis, which many birds and especially the Bobwhite are very fond of. It can be easily understood that several flocks of Quails must materially check the increase of cut-worms. The number of cut-worms are out of all proportion to the number of moths that lay the eggs. The destruction of a few hundreds or thousands of moths at the right time, is equal to destroying an army of cut-worms numerous enough to destroy large fields of corn and other cereals. On a field where there are several old Quails and their young, not many moths succeed in laying their eggs.

During the early settlement of the country the insects were so incessantly attacked by numerous birds, that they did little or, at least, no serious harm; but now, that the birds are so greatly reduced in numbers, fruit-growing is no longer the pleasant and profitable business it was.

To the question, what must be done to lessen insects, there is only one answer: protect the birds. Make laws forbidding the killing of them at any time, and see that all such laws are enforced. Of all civilized nations we have the least regard for the birds. We suffer them to be slaughtered at all seasons of the year, as if it were a matter of no consequence whether we have any birds or not. It seems that farmers and horticulturists have suffered enough already in consequence of the merciless war against the birds, and would need no arguments to convince them of the necessity of protecting these faithful allies. One thing is quite certain. If the destruction of birds is not stopped, and that soon, crops all over the country will be annually damaged to a much greater extent than even now.

We appeal to every farmer and horticulturist, to every man who loves his country and nature, to everyone who is interested in seeing insect depredations lessened, to protect the birds. Give no one the privilege of shooting on your farm, or in your woods. Teach your children at home and have them taught in the schools, that the birds are the farmers' friends, and are not to be hurt or in any way disturbed. Encourage them to build their nests and rear their young on your farm, in your garden and yard, and in a few years you will be astonished at the result. The once familiar sound of the Bobwhite will again be heard coming from every field, the tinkling song of the Bobolink will enjoy you again, the Meadow Lark will greet you in the early morning 
when going to field, and the Vesper Sparrow's evening hymn will wish you a good night: All kinds of birds will multiply in your fields, orchards, and woods, and around your dwellings, and innumerable insects, now so injurious, will disappear.

In the preface of her valuable and excellent work, "Injurious Insects of the Farm and Garden,"* Mrs. Mary Treat writes as follows:

"I also wish to add my testimony in a few words in favor of the various birds that visit our gardens and orchards in the capacity of helpers, as they feed upon some of the most noxious insects which we have to contend with.

"First and foremost among these helpers is the Purple Martin. It is the general impression that this bird takes insects only on the wing, but it does more than this. I saw numbers of them this past summer, taking the rose bugs from the grape-vines. They swooped down and picked them off without alighting. They circled around in companies, back again to the same vine, each one snatching off a bug as he passed. And not only the rose bug falls a victim to his appetite, but he even stoops to take the Colorado potato beetle. This has been seen by others in our town as well as by myself. Put up boxes for the Martins, and see that the English Sparrow does not get possession.

"The Oriole is another great helper. He knows how to pull the bag worm from his case, and does it systematically and rapidly. The tent caterpillar and fall web worm he also has a liking for. He ruthlessly tears the tents and webs to pieces and destroys untold numbers. Allow no gunner to shoot one of these beautiful, gaily dressed birds on your premises - not even if the lady of his choice is pining for a skeleton to perch on her hat.

"For several years past, the leaves of our elm trees have been ruined by the elm beetle. Last year I noticed the Cedarbird devouring the beetles and larvæ. This year our elms are comparatively free from the pests. The leaves are scarcely injured at all, and the Cedarbirds are obliged to look close to find a beetle. They hunt over the trees in small flocks. They also destroy many other injurious creatures. This bird likes cherries. Raise enough for them, as well as for yourselves, and they will pay you back with interest.

"The Catbird and Red-eyed Vireo both eat the unsavory pear slug. But it is not necessary to mention the good services rendered by our more common birds, such as the Robin, Brown Thrush, Catbird, Bluebird, and Wrens, as all observing horticulturists are aware of the good they do. Our winter birds are also doing good work. The seed-eating ones pick up great quantities of the seeds of noxious weeds, while our Woodpeckers, Creepers, Nuthatches, and Chickadees are constantly on the lookout for hibernating insects. Spare and encourage the birds, both winter and summer, about your grounds."

The great good our birds do can be observed by everybody who has an open eye. In the fall, winter, and early spring a great variety of Finches are constantly searching on the ground and even on the snow for the seeds of harmful weeds. The Goldfinch or Thistle-bird subsists in late summer mostly on the seeds of the thistle. Robins, Thrashers, Bluebirds, Catbirds, Red-winged Blackbirds, Meadow Larks, Bobo- 
links, and a great number of other songsters take up from the ground every worm, grasshopper, bug, beetle, and caterpillar they are able to find. In April and May the orchards from the Gulf to the Northern Lakes swarm with beautifully colored Wood Warblers and Vireos. These birds are always looking for insects among the leaves and blossoms of the orchard trees, and their good service is inestimable. The Woodpeckers, Titmice, Nuthatches, and other birds are the guardians of our woods and forest lands. The farmer has no better ally in his struggle against the insect enemies in his meadows than the Bobolink, and the Red-winged and Yellow-headed Blackbird. These birds alone save incalculable sums each year and should be protected in every way. The old birds each day carry much more insects to their young than their own weight consists of.

\section{BIRD ENEMIES.}

It is exceedingly disheartening to the friend of nature to see how merciless a war is waged in all parts of our country against the living ornaments of our landscapes, the birds. This is particularly the case near towns and villages, and especially near the large cities. In the vicinity of Milwaukee, Chicago, and St. Louis I have seen numbers of boys roaming around in the fields and forests on Saturdays and Sundays, engaged in shooting birds and robbing their eggs. In the South the lazy negroes are always ready to kill birds. Near Houston, Texas, I frequently met negroes in the woods who carried large strings of birds, consisting of Cardinals, Bluebirds, Fox-colored, Whitethroated, and White-crowned Sparrows, Blue Jays and many others. Near New Orleans, negroes as well as French Creoles and Italians (Dagos), combine in waging a shameless war against our birds. The booty of these robbers is usually found in the French market of that city.

In order to give my readers a clear idea of the shameless war waged in all parts of the country against our birds, I quote from an excellent article of Dr. J. A. Allen, "The Present Wholesale Destruction of Bird-life in the United States." *

"In the bird-world, as elsewhere, the,struggle for existence, even under natural conditions, is a severe one, undue increase being held well in check. Birds, and their eggs and young, are not only the natural prey of many predaceous mammals and reptiles, but also of predaceous birds. Squirrels, spermophiles, and mice, although not in a strict sense rapacious, are among the worst natural enemies of the smaller birds, whose eggs and young they seek and devour with avidity; while many birds not usually classed as predatory, as the Jays, Crows, Grackles, Cuckoos, and some others, wage unremitted warfare upon the eggs and young of the weaker species. The elements are also far more destructive of bird-life than is commonly recognized. Late cold storms in spring destroy many of the early migrants, sometimes nearly exterminating certain species over considerable areas where they had become prematurely settled for the season. The unusual southward extension of severe cold waves and heavy snow-falls

"Supplement to "Science," Feb. 26, 1886. No. 160.

American Ornithologists' 'nion. Hulletin No. 1 of the committee on Protection of Birds, 
are destructive to the bird-life of the regions thus exceptionally visited. During the migrations, both in the fall and spring, immense numbers of birds are sometimes caught by storms, and blown far out to sea and drowned, or perish in attempts to cross the larger inland lakes. There is abundant evidence to show that the annual destruction of birds by the elements alone must prove a severe check upon their increase. But all this is a part of nature's routine, which has characterized past ages as well as the present, and which, so far as we know, may be only the natural and necessary check upon undue increase. It is only when man comes upon the scene that nature's balance is seriously disturbed.

"Man's destructive influence is to some extent unavoidable, but in far greater part selfish and wanton. The. removal of forests, the drainage of swamps and marshes, the conversion of wild lands into farms, and the countless changes incident to the settlement of a country, destroy the haunts and the means of subsistence of numerous forms of animal life, and practically result in their extermination over vast areas. The birds, particularly the larger species, suffer in common with vertebrate life in general. Electriclight towers, light-houses, and light-ships are also a fruitful and modern source of disaster to birds, particularly during their migrations, when, in thick weather, thousands upon thousands kill themselves by dashing against these alluring obstructions. Telegraph-wires contribute also largely to the destruction of bird-life. While the destruction by these agencies is greatly to be regretted, it is not directly chargeable to cupidity and heartlessness, as is the far greater slaughter of birds in obedience to the dictates of fashion.

"The history of this country, as is well known, is the record of unparalleled destruction of the larger forms of animal life. Much of this destruction, it is true, was unavoidable, sooner or later. But it is no less true that the extirpation of our larger game animals has been needlessly hastened by what may be fairly termed a disgraceful greed for slaughter, -in part by 'pot-hunting' on a grand scale, in part for the mere desire to kill something, - the so-called 'love of sport.' The fate of extermination, which, to the shame of our country, has already practically overtaken the bison, and will sooner or later prove the fate of all of our larger game-mammals and not a few of our game-birds, will, if a halt be not speedily called by enlightened public opinion, overtake scores of our song birds, and the majority of our graceful and harmless, if somewhat less 'beneficial,' sea and shore birds.

"The decrease in our song and shore birds is already attracting attention; and the protest against it, which reaches us from many and widely distant parts of the country, is not only painful evidence of this decrease, but gives hope that the wave of destruction, which of late years has moved on in ever-increasing volume, has at last reached its limit of extension, and that its recession will be rapid and permanent. But to secure this result, the friends of the birds - the public at large-must be thoroughly aroused as to the magnitude of the evil, and enlightened as to its causes and the means for its retrenchment. It is therefore the purpose of the present series of papers to throw some light upon the extent, the purposes, and the methods of the present wholesale slaughter of our native birds.

"Birds are killed for food, for 'sport,' for natural-history specimens, to stuff as 
objects of curiosity or ornament, and for personal decoration. The birds killed for food are, of course, mainly the commonly so-called game-birds,-Pigeons, Grouse of various kinds, Ducks and Geese, and the great horde of smaller Waders, known as 'Peeps,' Snipes, Plovers, Rails, etc. The slaughter of these has been so improvident, and their decrease of late so marked, that they are now more or less cared for by the numerous game-protective associations, but are still, in the main, very inadequately guarded. In addition to the birds commonly recognized as game-birds, many song-birds are hunted for food, notably the Reed-bird, or Bobolink, the Robin, The Meadow Lark, the Blackbird, and the Flicker, and, in some localities, all the larger song birds. This is particularly the case in portions of the Sotuth, where strings of small birds may be seen suspended in the game-stalls. In March of last year, a well-known ornithologist reports finding in the market at Norfolk, Va., hundreds of Woodpeckers and song birds exposed for sale as food, the list of species including not only Robins, Meadow Larks, and Blackbirds, but many kinds of Sparrows and Thrushes, and even Warblers, Vireos, and Waxwings. While some of the stalls had each from three hundred to four hundred small birds, others would have but a dozen or two. 'Nearly all the venders were colored people, and doubtless most of the birds were captured by the same class.' This 'daily exhibition in southern markets' indicates an immense destruction of northernbreeding song birds which resort to the Southern States for a winter home....

"In general, the game and quasi-game birds are killed for sport rather than for gain or for their intrinsic value as food: exception, however, is to be made of the 'professional' or 'market' gunners, by whom the ranks of the water-fowl are so fearfully thinned, and who often resort to any wholesale method of slaughter their ingenuity may be able to devise. But the slaughter of our birds in general is doubtless largely due to the mere fascination of 'shooting.' Many song birds are killed 'for sport' by the 'small boy' and the idler, whose highest ambition in life is to possess a gun, and whose 'game' may be any wild animal that can run or fly, and wears fur or feathers. Some slight depredation on the small fruits of the garden, or on field-crops, is ample pretext for a war of extermination on Robins, Catbirds, and Thrashers, Jays and Chewinks, as well as Blackbirds and Crows, and the birds so unfortunate as to fall into the category of Hawks and Owls, notwithstanding the fact that everyone of these species is in reality a friend. Yet the slaughter is winked at, if not actually encouraged, by those who are most injured by it; while the 'general public' of the districts where such practices prevail are either too ignorant of the real harm done, or too apathetic, to raise any serious protest.

"Among the important agencies in bird-destruction is the 'bad small boy'-and in the ornithological sense his name is legion - of both town and country. Bird-nest robbing is one of the besetting sins-one of the marks of 'natural depravity'-of the average small boy, who fails to appreciate the cruelty of systematically robbing every nest within reach, and of stoning those that are otherwise inaccessible. To him the birds themselves, too, are also a fair target for a stone, a sling, a catapult, or a 'pea-shooter': to the latter many a Sparrow, a Thrush, or Warbler falls a victim. Says a recent writer on the subject of bird-destruction, 'Two ten-year-old lads in that quiet and moral hamlet (Bridgehampton, Long Island) confessed this autumn, that with 
pea-shooters they had killed during the season fifty Robins and other birds which frequent the gardens, orchards, and cemetery. Such boys exist all over the United States, and war on birds as things made to be killed.... The pea-shooter* gives no sound, and can be carried in the vest-pocket; but so destructive is it in the hands of a skilful child, that the legislatures of some of the Western States were obliged to pass laws making the sale of the thing a misdemeanor, and punishing the possession or use of it.'

"Perhaps equally, possibly more destructive, and certainly more reprehensible, is the newly-arrived 'foreign-born citizen,' who, to demonstrate to himself that he has really reached the 'land of the free,' equips himself with a cheap shot-gun, some birdtraps, clap-nets, or drugged grain, one or all, and hies himself to the nearest haunt of birds for indiscriminate, often very quiet, slaughter or capture. Of course, only a few of our guests from foreign shores either possess or indulge in this propensity; but in the neighborhood of our larger cities, notably on Long Island, and elsewhere near New York, the destruction of bird-life thus effected, we are credibly informed, is startlingly large.

“'The destruction of birds by taxidermists, and for alleged 'scientific purposes,' has justly attracted attention, and has unjustly brought into disrepute the legitimate collecting of both eggs and birds for scientific use; but much of this alleged scientific collecting is illegitimate, being really done under false colors, or wrongly attributed to science. Of the birds killed or mounted by taxidermists, some, not unfrequently a large part, are for museums or private cabinets : another large share is put up for parlor or hall ornaments, either as groups or singly. All this, by a little license, may be allowed as legitimate, or at least not seriously reprehensible. But, unfortunately, the average taxidermist has too often an unsavory alliance with the milliner, and, in addition to his legitimate work, is allured into catering on a large scale to the 'hat-trade.' Although a few of them are too high-principled and too much the naturalist at heart, to thus prostitute their calling, taxidermists as a class are at present in deserved disrepute, and are to a large degree responsible for much of the public and mistaken criticism of scientific collecting. This criticism is perhaps more especially directed against the 'eggcollector,' who ranges in calibre and purpose from the schoolboy, who gathers eggs as he does postage-stamps or 'show-cards,'-for the mere purpose of 'making a collection,' - to the intelligent oölogist or ornithologist, who gathers his eggs in sets, prepares them with great care, with the strictest regard to correct identification, and in series sufficient to show the range of variation-often considerable-in eggs of the same species, and takes a few additional sets for exchange. He may have in the aggregate a large collection, numbering hundreds of species, and thousands of specimens; but in general the same species is not laid under serious requisition, and the sets are gathered at considerable intervals of time and from a large area of country. A squad of street. urchins set loose in the suburbs will often destroy as many nests in a single morning's foray as a collector gathering for strictly scientific purposes would take in a whole season, and with far more harmful results, because local and sweeping. Most of the egg-collecting by schoolboys should be stopped, and can be easily checked under proper statutory regulations, as will be explained later in an article on bird-legislation.

"The scientific collector, as already intimated, is charged, in some quarters, with

*In the South called the "nigger-shooter," and in the West the "sling or rubber-shooter." 
the 'lion's share' of the responsibillty for the decrease of our song birds; with what justice, or rather injustice, may be easily shown, for the necessary statistics are not difficult to obtain. The catalogue of the ornithological department of the National Museum numbers rather less than 110,000 bird-skins. This record covers nearly half a century, and the number of specimens is four times greater than that of any other museum in this country; while the aggregate number of all our other public museums would probably not greatly exceed this number. But to make a liberal estimate, with the chance for error on the side of exaggeration, we will allow 300,000 birds for the public museums of North America, one-half of which, or nearly one-half, are of foreign origin, or not North American. To revert to the National Museum collection, it should be stated, that, while only part of the specimens are North American, - say about twothirds, - they represent the work of many individuals, extending over a third of a century, and over the whole continent, from Alaska and Hudson Bay to Mexico and Florida, and from the Atlantic to the Pacific. Furthermore, this number-110,000, more or less - is not the number now in the national collection, which is far less than this, thousands and thousands of specimens having been distributed in past years to other museums in this country and abroad.

"So far the public museums: now in relation to private cabinets of bird-skins. Of these it is safe to say there are hundreds scattered throughout the country, containing from three hundred to five or six hundred specimens each, with a few, easily counted on the fingers of the two hands, if not on a single hand, numbering five or six thousand each, with possibly two approaching ten thousand each. Probably 150,000 would be a liberal estimate for the number of North American bird-skins in private cabinets, but, again to throw the error on the side of exaggeration, let us say $300,000,-$ not, however, taken in a single year, but the result of all the collecting up to the present tin.e, and covering all parts of the continent. Add this number to the number of birds in our public museums, less those of foreign origin, and we have, allowing our exaggerated estimates to be true, less than 500,000 as the number of North American birds thus far sacrificed for science. The few thousand that have been sent to other countries in exchange for foreign birds can safely be included under the above estimate, which is at least a third above the actual number.

"We have now passed briefly in review all the agencies and objects affecting the decrease of our birds, save one, and that the most important-many times exceeding all the others together, - the most heartless and the least defensible, namely, the sacrifice of birds to fashion, for hat ornamentation and personal decoration. Startling as this assertion may seem, its demonstration is easy.

"In this country of $50,000,000$ inhabitants, half, or $25,000,000$, may be said to belong to what some one has forcibly termed the 'dead-bird wearing gender,' of whom at least 10,000,000 are not only of the bird-wearing age, but-judging from what we see on our streets, in public assemblies, and public conveyances-also of bird-wearing proclivities. Different individuals of this class vary greatly in their ideas of style and quantity in the way of what constitutes a proper decoration for that part of the person the Indian delights to ornament with plumes of various kinds of wild fowl. Some are content with a single bird, if a large one, mounted nearly entire: others prefer several 
small ones, - a group of three or four to half a dozen; or the heads and wings of even a greater number. Others, still, will content themselves with a few wings fancifully dyed and bespangled, or a wreath of grebe 'fur,' usually dyed, and not unfrequently set off with egret-plumes. In the average, however, there must be an incongruous assemblage made up of parts of various birds, or several entire birds, representing at least a number of individuals. But let us say that these $10,000,000$ bird-wearers have but a single bird each, that these birds may be 'made over' so as to do service for more than a single season; and still what an annual sacrifice of bird-life is entailed! Can it be placed at less than 5,000,000? - ten times more than the number of specimens extant in all our scientific collections, private and public together, and probably a thousand times greater than the annual destruction of birds (including also eggs) for scientific purposes.

"Fortunately, perhaps, the supply of bird-skins for decorative purposes is not all drawn from a single country, the whole world being laid under tribute. The ornithologist recognizes in the heterogeneous groups of birds on women's hats, met with on every hand, a great preponderance of North American species; but with them are many of the common birds of Europe, and a far greater variety from South America, and many from Africa, Australia, New Guinea, and India. But, on the other hand, it is well known that our own birds are exported in immense numbers to Europe; but, whether the exportation exceeds the importation, it is impossible to determine, from lack of proper statistics.

"With the foregoing facts before us in regard to the annual destruction of our birds, it is no longer surprising that many species, and even genera, of birds, are fast disappearing from our midst. Considering that this slaughter has been waged for years, but with rapid increase year by year, is it not rather a wonder that so many birds are still left?...

"But why, some may be supposed to ask, should the slaughter be interfered with? Does it not yield profit to many an impecunious idler, who receives so much per head from the 'taxidermist' for the freshly killed bird? Do not their preparation and manufacture into the gaudy or otherwise untasteful hat-gear give employment to many a needy hand, and add materially to the milliner's gains? Why is not their use for personal decoration, à la sauvage, as legitimate and defensible as their use for food, with the added advantage of being able to utilize decoratively a great many species otherwise of no commercial value? Why should we be anxious to preserve our birds? Are they, when alive, of any practical value, or do they contribute in any way to our pleasure or well-being?

"In regard to the first of these inquiries, the men and boys really get little more - in the average for the raw material than enough to pay them for their powder and shot: it is the 'sport' that affords them their real reward. The middle-men, - the skinners and manufacturers, - and an occasional professional gunner, make most of the profit, which must be more or less considerable to induce them to run the gauntlet of public opinion and the occasional risks of prosecution in their illegal enterprises. The milliner shares, of course, in the profits of the trade in such supplies; but, if birds were not used to such an extent, other and more fitting decorations would be adopted in their place, and their business would not suffer. 
"Respecting the latter inquiries, birds may be said to have a practical value of high importance and an æsthetic value not easily overestimated. Birds in general are the friends of man, and it is doubtful whether a single species can be named which is not more beneficial than harmful. The great mass of our smaller birds, numbering hundreds of species, are the natural checks upon the undue multiplication or insect-pests. Many of them rarely make use of other than insect-food, while all, as shown by scientific investigations already made, depend largely or wholly, during considerable periods of the year, upon an insect-diet.* Even the ill-reputed Hawks and Owls prey upon fieldmice, grasshoppers, and other noxious insects or vermin, some never molesting. the farmer's poultry, and others only exceptionally. In the present general summary of the subject, it may be sufficient to say, that, while the beneficial qualities of birds vary widely with the species, none can be set down as proven to be unmitigatedly injurious. With the decrease of birds at any point is noted an increase of insects, especially of kinds injurious to agriculture. The relation of birds to agriculture has been studied as yet but imperfectly; but results could be cited which would go far to substantiate the above statement of their general utility. It is a matter for congratulation, that the investigation of the subject has now been systematically entered upon by the Department of Agriculture at Washington, under the supervision of experts especially fitted for the work.

"Birds, considered rsthetically, are among the most graceful in movement and form, and the most beautiful and attractive in coloration, of nature's many gifts to man. Add to this their vivacity, their melodious voices and unceasing activity,charms shared in only small degree by any other forms of life,-and can we well say that we are prepared to see them exterminated in behalf of fashion, or to gratify a depraved taste?* Says a recent writer, 'A garden without flowers, childhood without laughter, an orchard without blossoms, a sky without color, roses without perfume, are the analogues of a country without song birds. And the United States are going straight and swift into that desert condition.'

"Indeed, as previously noted, there is already" an encouraging recognition of that fact. Here and there bird-protective associations are being formed, and more care is taken to secure proper bird-protective legislation; but the public at large is still too apathetic, or too ignorant of the real state of the case, to insist upon, and support by proper public sentiment, the enforcement of legislative acts already on our statute-books. The American Ornithologists' Union has moved in the matter by the appointment of a large and active committee on bird-protection, which is at present bending its energies toward the diffusion of information among the people, in the hope of awakening a healthy sentiment on the subject, and is also working to secure not only more effective and intelligent legislation, but the proper enforcement of the laws enacted in behalf of birds. This, too, notwithstanding a recent writer in a popular magazine characterized ornithologists as being among the worst enemies birds have, and to whose egg-collecting and bird-stuffing propensities was principally attributed the woful decrease of our song birds?

"In England the same rage for hat decoration with dead birds has gone so far 
that anti-plumage-wearing societies have already been established by the more intelligent women of that country; and it has already been suggested, apparently independent of any similar action abroad, by ladies themselves, that the women of this country throw their influence in a similar way against the barbarous custom of using birds for personal decorations. Much could doubtless be done in behalf of the birds in this way; for, once let it come to be considered vulgar and in 'bad form' to thus decorate one's person, and the power of fashion would be a mighty weapon in defence of the birds.

"Of all the means that may be devised for checking the present wholesale birdslaughter, the awakening of a proper public sentiment cannot fail of being the most powerful. Without this, all other means would prove, to a great degree, ineffectual. Laws, however good, cannot be enforced unless backed by public opinion. To arouse this, it seems only necessary to enlighten the community respecting the nature, the enormity, and the leading cause of this great evil.

In the "American Field" I find the following article on the merciless war upon our birds from the pen of United States Senator Hon. Charles Aldrich of Iowa:

"There can be no doubt that the birds of Iowa, as of the country at large, are yearly diminishing at a rate which should excite our most serious apprehensions, though we would seem to be less merciless in some respects, in the treatment we give.them, than the people of certain other regions. Just now, December 5, we are having the most beautiful winter weather-

'When comes the calm, mild day, as still such days will come,

To call the squirrel and the bee from out their winter home.'

"But there is a wonderful dearth of birds. In the old times, say fifteen or twenty years ago, on such bright, beautiful days we would see large numbers of our winter species, the noisy Jays, troops of charming little Chickadees, the busy Horned Larks, Creepers, and Nuthatches, the lively Winter Sparrows, an occasional Shrike, and probably other species. Sometimes the Blackbirds remained for several days in December, and in frequent instances the Robins were seen even in mid-winter. But to-day the fields and woods are well nigh tenantless; so far as the birds are concerned.

"Possibly on going through a thicket one might see a pair of Jays, or a very few Chickadees, but the abundant bird-life of winter which used to impart such a charm to the landscape on days like this is gone, and the saddest idea connected with the subject is, that it has gone never to return. As it is with the winter birds, so it is, even in a more marked degree with our summer species, for many birds come here to winter which breed in wild regions in the far North.

"It would seem that the status of such species should be little changed, but it is true that their numbers are diminishing most certainly in the locality where I am writing. The unwelcome fact meets an observer at every turn, and the more he sees and reflects, the more settled will his belief become, that the alarming evil of bird destruction is utterly remediless. True, laws exist for their preservation, but they are totally dis= regarded. Writers for agricultural and general newspapers are continually sounding the alarm, showing the certainty and the dangers, and yet it would be easy to demonstrate that all such efforts fall to the ground, unheeded and unçared for. 
"The causes for this state of things are not remote or hidden. Some arise from circumstances over which there can not be in the order of nature anything like modification or control, while others in well ordered societies should be easily preventable. Rapid settlement has wrought the most marked changes in the environment of our birds. Many of those which used to nest upon our prairies have been driven away. The breaking-plow has as utterly ruined their haunts and homes as the presence of the white man has wiped out the wild Indians. True, some of the more domestic kinds may linger about the meadows we have made, but the conditions are so changed that the mass of those which build their nests upon the ground have sought newer sections of country far away, from which they will soon be driven again by the ever advancing tide of settlement.

"Several species, notably the Red-winged Blackbirds, nest in and about our prairie sloughs. Cultivation has been for years gradually reclaiming these sloughs and transforming them into dry land, while within a very short time, tile drainage has been making these changes with marvelous rapidity. The Red-wings, the Yellow-headed Blackbirds, and Marsh Wrens, build their nests in the tops of the reeds and coarse grasses, out in the water, to protect themselves and their young from foxes and other vermin. There can be no doubt that they return to the same nesting places year after year. But when the tile drain makes dry land of the old slough, which has been a miniature lake ever since the ice-plow scooped out its bed, the occupation of these poor birds is gone, and they must betake themselves to regions more remote. One of the quite visible results of our one hundred and more Iowa tile factories will be the very rapid thinning out of these beautiful birds.

"The loss which this will entail upon the farmer, the gardener, and the orchardist, we need not stop to calculate. It may be faintly imagined when it is stated that Wilson, the father of American ornithology, in his time estimated that they annually destroyed 16,000,000,000 insects in the then area of the United States. They are among the earliest birds to return from the sunny South, for many of them are singing in the tree tops in February, while the ground is still covered with snow. They are the last to leave us in autumn or winter. They do little damage, so little, indeed, in comparison with their useful work that a decent Christian should be ashamed to mention it; though it was once attempted with marvelous stupidity and monumental wickedness to pass a law in Iowa offering rewards for their destruction... That the beautiful Red-wings do a world of good, that they are most emphatically 'feathered friends,' the observations of the revered Wilson fully established almost a century ago.

"Again, our forests are rapidly disappearing, and it would not seem that the average artificial grove is accepted as a good substitute for that furnished by naturethough it is a most welcome home for many species. Especially is this true of evergreen groves. This becomes most palpable to any one who has listened to the songs of the birds, and 'the music of the wind in the pines' which surround the beautiful, princely home of 'No. 20' Whitney, at Franklin Grove, Illinois. While the artificial grove-and more especially evergreens - will arrest the emigration of some species, and shelter them from their enemies, there can be no doubt that we are not planting enough of the right kinds of timber to hold our own with the birds. A heavy balance is still against us, and it is constantly increasing. 
"But there are two modes of bird destruction in active, increasing operation, which occasion more wholesale losses than all others. They ought to be easily preventable, and would be if we had an enlightened public sentiment on the side of the birds - and humanity. The first of those is the demand for bird-skins for the purpose of decorating female 'hat-gear.' In every ordinary milliner's shop you will find bird-skins of many species, and of various qualities and prices to suit the tastes and pockets of their customers. A great majority of the ladies we meet, in town or country, have their bonnets or hats ornamented with the skins of birds. It is a strange taste on the part of the gentler sex - the best half of creation - this decorating of their heads at such a fearful cost of bird suffering and bird life! If they could but realize the economical losses, the terrible suffering which this cruel fashion visits upon the beautiful birds, together with the threatened extinction of entire species, most certainly would our women, one and all, resolve never to use another bird-skin for any decorative purpose whatever.

"Some features of this business of gathering the skins of birds are simply atrocious. In many portions of this country men make a regular business of shooting birds for their skins. The rule is to kill every bird that comes within shooting distance. If fashion does not now demand the skins of any particular species, it will before longor the feathers may be colored to suit some mysterious, inscrutable taste! An idea is said also to prevail, to the effect that the skins should be torn off as soon as possible after the bird is in hand. I have somewhere read that this is often done while the poor bird is still living and writhing in agony!-though I hope such 'cussedness' is not practiced in the United States.

"Can there be any preventive of this branch of bird murder? It is scarcely to be hoped, when we have the greed of the murderers and the demands of fashion to sustain this infamous destruction of our "feathered friends.' No argument upon such a topic is needed. The man or woman who does not revolt at the simplest statement of the facts is quite beyond the reach of argument.

"The other direction in which the birds are suffering fearful and untold destruction, is that of the stealing of their eggs by town and village boys. Within four or five years a perfect mania has sprung up in this new domain of wickedness. Boys from nine to fifteen years of age are allowed by their parents to indulge their æsthetic taste in making 'collections' of birds' eggs. So they organize in bands and go out into the fields and woods, robbing every nest they are able to find-and their eyes are very sharp for this business. The contents of the shells are blown out, and they are then arranged in 'strings.' In some places competition for the largest 'strings' of shells runs very high among the sons of village magnates. Parents who religiously insist that their children shall be regular in attendance upon the Sunday School, and learn their lessons perfectly, still allow them to indulge in the wicked and unlawful business of stealing the eggs of our birds! Occasionally a mother is oppressed by a sense of its criminality, and makes Peterkin promise that he will only take one egg from a nest! But what difference does this make when boys sweep over a tract of land in squads, carrying off every egg they find! From what I hear, the extent of loss. in this way is almost beyond belief, and quite beyond computation. A squad of these little thieves 
came to my farm one day, and in the absence of the tenant,. tried to get into a bird house, elevated upon a stout oak pole. The little house was occupied by Purple Martins, which had returned to us year after year, and had never been subjected to such rude molestation before. ...

"Every influence touching the bird seems to run in the way of destruction, and not a single one works for their preservation. Our sporting papers urge 'game clubs' to enforce the laws, not to conserve the supply of food and keep up the proper balance of nature, but to increase the delights of sportsmen; and their advertising columns fairly bristle with announcements of new and improved means of killing things.

"We all know that the average man or boy who wastes his time in carrying around a gun when he had much better be at work for wages, will shoot small birds when he can't find larger ones upon which to visit his murderous propensities. Almost every Sunday I hear the report of guns in the woods near my house. There is usually next to nothing in the way of real game, and I know that many of these scamps are blazing away at the small birds, for I have seen them doing it. Many of our great naturalists, who certainly should be as humane as they are learned and wise, speak of shooting hundreds of the small birds as indifferently as though they were considering the fate of so many gnats or flies. There is one noble exception which should be remembered, and I think it wlll be, for his is 'one of the few, the immortal names that were not born to die.' I refer to Henry David Thoreau, the poet naturalist of New England, whose ever-enduring fame is permeating every land in which our language is read or spoken. His biographers tell us that he never used a gun-never killed a bird. He made the studies of bird-life upon which his undying writings are based, with his glass, where the object was not near enough to be seen by the unaided eye. When he lived alone in the woods, at Walden Pond, where he wrote his greatest and most delightful book, the birds were his very intimate friends. Some of them became so tame, and so accustomed to his presence, that 'the legend says' they would even alight upon his hat. What a lesson of true kindness, gentleness and appreciative tenderness is taught by this simple statement! It may be necessary and very legitimate and proper for our great naturalists to slaughter vast numbers of birds, for the purpose of illustration and comparison, and to fill up the museums; but they need not tell of these exploits in a way to inspire and encourage a love of slaughter in the minds of the rising generation. Young America is 'fast' enough in that direction without the stimulus of such examples....

"Destructive insects prey upon our fruits, vegetables, and field crops, and every little while we hear of the advent or 'invention' of some new pest. And yet with a criminal indifference that will astound future generations, we are allowing our birdsthe only resource nature has provided for our protection-to be ruthlessly and most wantonly swept from the face of the earth.

"For my own part I have labored twenty-five years in defense of the birds, but with results far from satisfactory. I can and do protect them on my own farm, and I drafted and by hard work secured the passage of the provision for their protection and preservation in our code; but I do not know that I have ever accomplished a substantial thing. Public sentiment is against me-at least, people are totally indifferent on the subject." 
Regarding the so-called egg collectors, I find the following passage in Mr. John Burroughs' little volume, "Signs and Seasons":

"Among the worst enemies of our birds are the so-called 'collectors', men who plunder nests and murder their owners in the name of science. Not the gentrine ornithologist, for no one is more careful of squandering bird life than he; but the sham ornithologist, the man whose vanity or affectation happens to take an ornithological turn. He is seized with an itching for a collection of eggs and birds because it happens to be the fashion, or because it gives him the air of a man of science. But in the majority of cases the motive is a mercenary one; the collector expects to sell these spoils of the groves and orchards. Robbing nests and killing birds becomes a business with him. He goes about it systematically, and becomes an expert in circumventing and slaying our songsters. Every town of any considerable size is infested with one or more of these bird highwaymen, and every nest in the country round about that the wretches can lay hands on is harried. Their professional term for a nest of eggs is 'a clutch,' a word that well expresses the work of their grasping, murderous fingers. They clutch and destroy in the germ the life and music of the woodlands. Certain of our natural history journals are mainly organs of communication between these human weasels. They record their ex-exploits at nest-robbing and bird-slaying in their columns. One collector tells with gusto how he 'worked his way' through an orchard, ransacking every tree and leaving, as he believed, not one nest behind him. He had better not be caught working his way through my orchard. Another gloats over the number of Connecticut Warblers - a rare bird-he killed in one season in Massachusetts. Another tells how a Mockingbird appeared in southern New England and was hunted down by himself and friend, its eggs 'clutched,' and the bird killed. Who knows how much the bird lovers of New England lost by that foul deed? The progeny of the birds would probably have returned to Connecticut to breed, and their progeny, or a part of them, the same, till in time the famous southern songster would have become a regular visitant to New England. In the same journal still another collector describes minutely how he outwitted three Hummingbirds and captured their nests and eggs, - a clutch he was very proud of. A Massachusetts bird harrier boasts of his clutch of the eggs of that dainty little Warbler, the Blue Yellow-back. One season he took two sets, the next five sets, the next four sets, beside some single eggs, and the next season four sets, and says he might have found more had he had more time. One season he took, in about twenty days, three sets from one tree. I have heard of a collector who boasted of having taken one hundred sets of the eggs of the Marsh Wren in a single day; of another, who took, in the same time, thirty nests of the Yellow-breasted Chat; and of still another, who claimed to have taken one thousand sets of eggs of different birds in one season. A large business has grown up under the influence of this collecting craze. One dealer in eggs has those of over five hundred species. He says that his business in 1883 was twice that of 1882 ; in 1884 it was twice that of 1883 , and so on. Collectors vie with each other in the extent and variety of their cabinets. They not only obtain eggs in sets, but aim to have a number of sets of the same bird so as to show all possible variations. I hear of a private collection that contains twelve sets of Kingbirds' eggs, eight sets of House Wrens' eggs, four sets of Mockingbirds' eggs, etc.; sets 
of eggs taken in low trees, high trees, medium trees; spotted sets, dark sets, plain sets, and light sets of the same species of bird. Many collections are made on this latter plan.

Thus are our birds hunted and cut off, and all in the name of science; as if science had not long ago finished with these birds. She has weighed and measured and dissected and described them and their nests and eggs, and placed them in her cabinet; and the interest of science and of humanity now demands that this wholesale nestrobbing cease. These incidents I have given above, it is true, are but drops in the bucket, but the bucket would be more than full if we could get all the facts. Where one man publishes his notes, hundreds, perhaps thousands, say nothing, but go as silently about their nest-robbing as weasels.

"It is true that the student of ornithology often feels compelled to take bird-life. It is not an easy matter to 'name all the birds without a gun,' though an opera-glass will often render identification entirely certain, and leave the songster unharmed; but once having mastered the birds, the true ornithologist leaves his gun at home.

"Not the collectors alone are to blame for the diminishing numbers of our wild birds, but a large share of the responsibility rests upon quite a different class of persons, namely, the milliners. False taste in dress is as destructive to our feathered friends as are false aims in science. It is said that the traffic in the skins of our brighter plumaged birds, arising from their use by the milliners, reaches to hundreds of thousands annually. I am told of one middleman who collected from the shooters in one district, in four months, seventy thousand skins. It is a barbarous taste that craves this kind of ornamentation. Think of a woman or girl of real refinement appearing upon the street with her head gear adorned with the scalps of our songsters!"

\section{PROTECTION OF BIRDS.}

\footnotetext{
Ye gentle birds of passage,

Come hither and ye'll find

The best I have to offer,

And welcome warm and kind!

A dwelling I will give you,

Free as your own free lay,

And faithfully and truly

Protect you every way!
}

\author{
Come, enter swift the portals, \\ Aye, ye may even dart, \\ If so it be your pleasure \\ Into my inmost heart, \\ Make it resound with gladness, \\ With carols fresh and gay, \\ Charm it with tunes harmcnious, \\ As only poets may! \\ From the German, by Frank Siller.
}

The true ornithologist as well as the friend of nature, and every thinking and kind-hearted human being is and has always been ardently attached to the birds. To all such the minstrels of the grove have ever new attractions, and their songs inspire them with joy, hope, and happiness. Life in a beautiful country place is always the ideal of the true lover of nature. From the very beginning he aims to beautify such a place, and to make it as pleasant and attractive as possible. The grounds in the immediate vicinity of the house abound in evergreens, ornamental trees and shrubs. Vines in great profusion ascend on trees and trellises, piazzas and verandas. Everywhere we see and hear our native birds, and are surprised by their abundance and 
familiarity. Nesting-boxes for Bluebirds, Titmice, Wrens, and other hole-breeders are frequently seen among the branches of the orchard and ornamental trees, and Martinhouses on high posts and on the roofs of buildings. The twining woodbines on the trellises, the trees covered with wild grape-vines, the dense upright honey-suckles and mock-oranges, the evergreens and other trees and shrubs are excellent hiding and nesting places for Catbirds, Yellow Warblers, Chipping-birds, Song Sparrows, and other garden-loving species. In the gardens of the South noble magnolias, camellias, azaleas, Cherokee, Banksia, and other roses, a large number of beautiful climbing plants, orange trees, pomegranates, night-blooming jasmines, gardenias, and other shrubs and trees of a dense habit form excellent haunts for many birds. When visiting the beautiful place of the well-known entomologist and botanist, Mr. Theodore L. Mead, of Lake Charm, Fla., large numbers of grand palms ${ }^{1}$, tropical shrubs and vines attracted my attention. The veranda was transformed in a mass of allamanda ${ }^{2}$, star jasmine ${ }^{8}$, Solantum jasminoides, Bignonia Capensis, and Mexican mountain rose. ${ }^{4}$ The exquisite yellow flowers of the allamanda contrast beautifully with the scarlet flower trusses of the Cape bignonia, the rosy-red of the mountain rose, the white of the star jasmine, and the bluishwhite blossoms and deep red shining berries of the solanum. Berries and blossoms were relieved by a mass of deep green verdure. Among these vines Carolina Wrens were perfectly at home. Mr. Mead's fine orange grove is surrounded by magnificent woods, consisting mainly of splendid specimens of palmettos ${ }^{5}$, loblolly bays, live oaks, and magnolias, the last two specics being covered from bottom to top with epiphytal ferns, tillandsias ${ }^{6}$, and orchids. ${ }^{7}$ On many places in Mr. Mead's grounds the laws of the State for the protection of birds are posted, and in consequence the report of the gun is seldom heard. This example should be followed throughout the country. The lives of countless numbers of our native birds would be spared if our country people could be induced to see their own interest in protecting their best friends, the "winged wardens" of their farms and gardens. In England, Germany, Norway, Sweden, and especially in Japan birds are found everywhere, and are regarded by the people as valuable gifts of nature to man. Shrubs, trees, and vines are often planted for the sole purpose of providing nesting places for certain species. The laws for the protection of the birds are backed by a strong public sentiment, and are stringently enforced by the proper officers. In our own country we should closely follow these examples. Roving cats are always the most cruel and terrible enemies of our garden birds, and they should never be tolerated in parks and gardens.

In order to save our beautiful native birds from extermination it is not only necessary to instruct our children in the family circle to regard and love the birds, but this should also be done in all our schools. The attention of the rising generation ought to be called to the beautiful colors of the birds, to their fine forms, their flight, their delightful song, their happiness, their departure to southern climes, and their return to their natal haunts when the most beautiful time of the year, spring, with its blossoms

1 Cocos australis, C. Blumenavia, C. Bonneti, C. campestris, C. Gartneri, C. Romanzoffiana, C. Yatai; Phoenix dactylifera, Ph. Canariensis, Ph. tenuis, Ph. Leonensis, Ph. Natalensis, Ph. rupicola; Sabal Jongifolia, S. palmetto, S. umbraculifera, S. glaucescens, S. dealbata; Lantania Borbonica and many others. 2 Allamanda Hendersonii, A. Schotti. 3 Rhynchospermum jasminoides. Antigonon leptosus. 6 Sabal palmetto. G Tillandsia utriculata, T. Bartrami, T. bracteata, $T$. caspitosus, $T$, recurrata and $T$, usneoides, $T$ Epidendrum canopseum and $E$. venosum. 
and green verdure, is advancing and-last but not least-to their great usefulness in the household of nature. - The training in our schools is, as yet, very deficient in this particular. Mr. George M. Minchin, of the Royal Indian Engineering College, expresses himself as follows in regard to the same deficiency in the schools of England:

"To anyone who knows something of the habits and names of birds, the ignorance displayed by many of his friends concerning their very names, size, color, etc., is often astounding. Several of my friends, for instance-men of physical science, skilful metaphysicians, literary men-do not know the difference between a Goldfinch and a Bullfinch, or between a Grouse and a Pheasant! The same ignorance extends to the animal kingdom generally; and although it seems to be tolerated, and indeed rendered necessary by the ordinary course of education in schools, it is, in reality, a scandalous blot on our educational system. The remedy is extremely simple. Introduce among the school books a short manual of natural history, dealing rather with the interesting characteristics of animals than with the science of their structure-just those things which interest you without producing a strain on the intellect-and the result will be a far more widely spread knowledge of the inhabitants of our fields, streams, and woods than that which now prevails. Another result will be a greater sympathy with the non-human portion of life, and a diminution of that cruelty to animals which is one of the very worst characteristics of our people, a cruelty which is, sometimes at least, a result of some infinitely absurd superstition. ... Indeed, the omission of the teaching of natural history (in an easy and interesting shape) in our schools fits ill with the vast importance now attained by biology, a science of immense possibilities, and one which is 'advancing by leaps and bounds.'"

In 1886 the "American Ornithologists' Union" appointed a "Committee on Protection of Birds," consisting of the following well-known and leading ornithologists: Mr. Geo. B. Sennett, Mr. E. P. Bicknell, Mr. Wm. Dutcher, Dr. J. A. Allen, Prof. Wm. Brewster, Mr. Montague Chamberlain, Mr. L. S. Foster, Col. N. S. Goss, Dr. Geo. Bird Grinnell, and Dr. J. B. Holder. This committee did good work for our birds. Circulars for the protection of our native birds were distributed all over the country. Under its influence the law, "For the Preservation of Song and Wild Birds," was passed by the legislature of New York. Much good work was also done by the proprietors and the editorial staff of the well-known paper, "Forest and Stream." These gentlemen founded the "Audubon Society for the Protection of Birds," and issued the "Audubon Magazine," a periodical edited in an ideal and enthusiastic manner, which did good work in arousing a public sentiment in favor of our native birds. Unfortunately this periodical did not find the support it so eminently deserved, and with the close of the second volume it was discontinued. 


\section{BIRD LEGISLATION.}

"The Committee of the American Ornithologists' Union on Bird Protection" has drawn a law, which should be passed in the legislature of every State of the Union and Canada. The proposed Act reads as follows :

\section{AN ACT}

For the Protection of Birds and their Nests AND EgGs.

Sectron 1. Any person who shall, within the State of - kill any wild bird other than a game bird, or purchase, offer or expose for sale any such wild bird, after it has been killed, shall for each offense be subject to a fine of not less than ten nor more than fifty dollars, or imprisonment for not less than five nor more than thirty days, or both, at the discretion of the court. For the purpose of this act the following only shall be considered game birds: The Anatidæ, cornmonly known as Swans, Geese, Brant, and River and Sea Ducks; the Rallidæ, commonly known as Rails, Coots, Mud-hens, and Gallinules; the Limicolæ, commonly known as shore birds, Plovers, Surf-birds, Snipe, Woodcock, Sandpipers, Tatlers, and Curlews; the Gallinæ, commonly known as Wild Turkeys, Grouse, Prairie Chickens, Pheasants, Partridges, and Quails, all of which are governed by specific laws affecting each, and are not intended to be affected by this act.

SEc. 2. Any person'who shall, within the State of - take or destroy the nest or the eggs of any wild bircl, shall be subject for each offense to a fine of not less than ten nor more than fifty dollars, or imprisonment for not less than five nor more than thirty days, or both, at the discretion of the court.

SEC. 3. Sections 1 and 2 of this act shall not apply to any person holding a permit giving the right to take birds, or their nests and eggs, for scientific purposes, as provided for in Section 4 of this act.

SEc. 4. Permits may be granted by [here follow the names of the persons, if any, duly authorized by this act to grant such permits], or by any incorporated society of natural history in the State, through such persons or officers as said society may designate, to any properly accredited person, permitting the holder thereof to collect birds, their nests or eggs, for strictly scientific purposes. In order to obtain such permit, the applicant for the same must present to the person or persons having the power to grant said permit, written testimonials from two well-known scientific men, certifying to the good character and fitness of said applicant to be intrusted with such privilege; must pay to said persons or officers one dollar to defray the necessary expenses attending the granting of such permits; and must file with seid persons or officers a properly executed bond, in the sum of two hundred dollars, signed by two responsible citizens of the State as sureties. This bond shall be forfeited to the State, and the permit become void, upon proof that the holder of such permit has killed any bird, or taken the nest or eggs of any bird, for other than the purposes named in Sections 3 and 4 of this act, and shall be further subject for each such offense to the penalties provided therefor in Sections 1 and 2 of this act.
Sec. 5. The permits aluthorized by this act shall be in force for one year only from the date of their issue, and shall not be transferable.

SEc. 6. The English or European House Sparrow (Passer domesticus) is not included among the birds protected by this act.

SEc. 7. In all actions for the recovery of penalties under this act, one-half of the recovery shall belong to the plaintiff, and the remainder shall be paid to the county treasurer of the county where the offense is committed.

SEc. 8. All acts, or parts of acts, heretofore passed, inconsistent with or contrary to the provisions of this act, are hereby repealed.

SEC. 9. This act shall take effect upon its passage.

\section{COMMENT.}

It will be noticed that in Sec. 1 the different species of birds intended to be protected are not separately enumerated. Some attempt at such an enumeration is made in the New York law, as, indeed, is the case in most similar acts passed by the various States. As the birds intended to be protected by this and similar acts include about two-thirds to three-fourths of the birds of any area affected by such an act, or over two hundred species, it is impracticable to enumerate them; the brief enumerations usually attempted are so imperfect and are couched in such vague terms that in many cases conviction could be evaded on technicalities, owing to the looseness of the language usually employed in such acts. In the present draft the few groups of birds not covered by the proposed act are alone specified, and explicitly so through the use of the technical names commonly employed in ornithology for the designation of these groups. This leaves the application of the act unequivocal and exact - a most desirable point to secure.

Sec. 2 of the act requires no comment.

Sec. 3 is intended to legalize the taking of birds, their nests and eggs for strictly scientific purposes only, as for scientific museums and by persons seriously engaged in the scientific study of birds.

Sec. 4. This provision is intended to be so strict in its requirements that only a person who is properly entitled to a permit will be able to secure one. Such persons will cheerfully submit to the trouble necessary to obtain a permit, in behalf of the proper protection of our birds.

The act contemplates vesting with autbority to issue permits only such persons or agents as will be most likely to exercise due care in regard to the fitness of applicants to receive them. It is accordingly placed in the hands of incorporated societies of natural history, but authorizes its delegation to such State officers as may be especially designated for that purpose, as game commissioners or game wardens. But preferably, for obvious reasons, such authority should be delegated only to incorporated scientific societies, who, through their executive officers, or through committees specially appointed for the pur- 
pose, are naturally the lest judges of the fitness of applicants to receive permits. It is desirable that the methods of procedure under Section 4 should be as nearly uniform as possible, as regards especially the character of the bond, and the applicant's testimonials and other obligations.

The following series of blanks, prepared and already in use under the New York law, are herewith submitted as having satisfactorily stood the test of actual use. It may be premised that form " $A$ " is sent in answer to an application for a permit, with which forms " $B$ " and " $C$ " are to be inclosed. When these are returned and found to be satisfactory, form " $D$ " gives notice that the application is granted and states what other requirements are necessary to receive the permit. Form " $\mathrm{E}$ " is the permit itself. Form " $F$ " gives notice of the expiration of the permit and directions for obtaining its renewal; this, of course, is not to be sent until near the end of the term for which a permit is originally issued.

The headings of forms " $A$," " $D$," " $E$," and " $F$ " should be changed to suit the circumstances of their issue, as regards the society or officers from whom they may emanate:

\section{[A.] American Museum of Natural History, \\ (INCORPORATED MAY, 1869)}

Central Park (77th St. \& 8th Ave.),

New York City....................189

Sir :

In answer to your request for a certificate permitting you to take birds and their nests and eggs for scientific purposes under the Laws of the State of New York, I inclose an obligation, in signing which you promise to take specimens only for scientific purposes and to strictly observe the letter and spirit of the laws of this State for the preservation of birds.

This obligation must be accompanied by a properly executed bond in the sum of two hundred dollars, and by the indorsement herewith sent, signed by two responsible scientific men to whom the President of the American Museum of Natural History* can refer.

No notice will be taken of any application which does not conform to the requirements here prescribed.

If the certificate is granted, a fee of one dollar will be charged to cover the expenses attending the granting of such certificates.

President.

N. B.-The bond must be executed strict'y in accordance with Section 4 of Chapter 427 of the Laws of the State of New York, a copy of which Act is herewith inclosed.

* Here may be. substituted the name of the officer, the society or its properly appointed agent.

[H.]

Application for a permit to collect birds for scientific purposes under the provisions of Chapter 427 of the Laws of the State of New York.

.189

I, THE UNDERSIGNED, a resident of

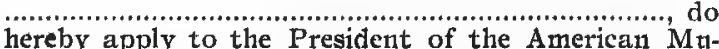
seutn of Natural History of New York City, for a pertmit granting the right to collect birds, their nests and eggs, for strictly scientific purposes only, in accordance with Chapter 427 of the Laws of the State of New York, being an Act passed May 20, 1886 entitled, "An Act for the Preservation of Song and Wild Bird." I do hereby agree and promise that in availing myself of this privilege, I will strictly comply with the spirit and letter of the Act above cited.

I herewith inclose my bond, duly executed in accordance with said Act, and the required indorsement of two scientific men, certifying to my good character and fitness to be intrusted with such a privilege.

[Signed,]

Witnessed,

FORM OF INDORSEMENT.

WE, THE UNDERSIGNED, personally" know and believe him to

be a person of good character, and fit to be intrusted with the privilege of collecting wild birds, and their nests and eggs, in accordance with the provisions of Section 4 of Chapter 427 of the Laws of the State of New York, which Act we have carefully examined and fully comprehend.

[Sign with name
and address

in full.]

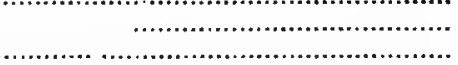

\section{(n).......}

[c.]

Know all Men hy these Presents, that we Principal, and

....................... Surety, and......................... Surety, of the............... of ................................................ unto the PRESIDENT OF THE AMERICAN MUSEUM OF NATURAL HISTORY, of the City of New York, in the just and full sum of Two HUNDRED Dollars lawful money of the United States, to be paid to the Treasurer of THE STATe of NEW York, for which payment well and truly to be made, we bind ourselves, our heirs, executors, or administrators, jointly and severally, firmly by these presentssealed with our seals, and dated the.................day of win the year one thousand eight hundred and ninety.........

Whereas, the above bounden. the ...day of...................in the year one thousand eight hundred and ninety................, by the PREsinent of THE AMERICan MUSEUM OF Natural Histors, of the City of New York, to collect birds, their nests or eggs, for strictly scientific purposes only, under the provisions of Chapter 4.27 of the Laws of the State of New York, which Chapter is "An Act for the Preservation of Song and Wild Birds," passed May 20, 1886; now the conditions of the foregoing obligations are such, that if the said. shall abstain from any infringement of said Act, then this obligation to be void, otherwise to be and remain in full force and virtue.

Sealed and delivered

in the presence of

........................................

........................................

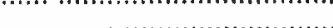

(n)

(n).................................

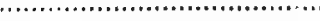

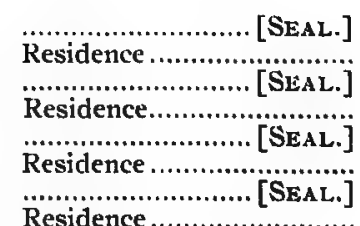


[D.] American Museum of Natural History,

(INCORPorated MAY, 1869),

Central Park (77th St. \& 8th Ave.),

New York City 189

DEAR Sir:

The President of the American Museum of Natural History* has decided to grant your application for a permit "to collect birds, their nests or eggs, for strictly scientific purposes only," in accordance with Sections 3 and 4 of Chapter 427 of the Laws of the State of New York for 1886 , entitled, "An Act for the Preservation of Song and Wild Birds.'

To cover expenses incurred for postage, printing, etc., you will be charged $\$ 1$, on receipt of which said permit will be mailed to your address.

President.

* Or whoever the proper authority may chance to be.

[E.]

[This Premit Expires July 1, 189..., and is not Transferable.)

American Museum of Natural History. (INCORPORATED MAY, 1869),

Central Park (77th St. \& 8th Ave.),

New York City 189

The President of the American Museum of Natural History * having received satisfactory evidence that $\mathrm{Mr}$.

is engaged in the scientific study of

Ornithology and in the collection of wild birds, birds' nests and eggs for scientific purposes, does hereby, in accordance with Chapter 427 of the Laws of the State of New York, grant him a permit on the condition that he will faithfully observe his written promise to the President to obey the letter and spirit of the Act for the "Preservation of Song and Wild Birds"; and in case of wanton destruction of birds or birds' eggs, or killing birds for merely ornamental purposes, or for any other breach of said promise, by the said

this certificate shall be revoled, and noticc of such revocation given in any manner the President may think best.

The holder of this permit shall not take nor kill any game bird, nor destroy their eggs, contrary to the Laws of New York, enacted for the protection or preservation of game birds.

This permit expires the first day of July, eighteen hundred and ninety-, and is not transferable. The holder thereof is not authorized to collect specimens in defiance of local laws or regulations, nor in violation of laws against trespass on private property.

\section{President.}

* Or whoever the proper authority may chance to he.

\section{[r.] American Museum of Natural History.}

(INCORPORATED MAY, 1869),

Central Park (77th St. \& 8th Ave.),

New Fork City, .189

DeAR Sir:

I beg to notify you that the permit given to you by the President of the American Museum of Natural History in accordance with Chapter 427 of the Laws of the State of New York-an Act for the "Preserva- tion of Song and Wild Birds"-expires July 1, 189... If you desire its renewal under the sane obligations, you will please return this circular witl your name and address subscribed and the sum of one dollar, on receipt of which a new permit will be sent to you: Respectfully,

President.

Sec. 5. The permits are issucd for onc year only, and are not transferable, The bond, however, may stand indefinitely, or until canceled, and the permit be annually renewed at the owner's option, in virtue of the bond continuing in force.

ENFORCEMENT OF IAWS FOR THE PROTECTION OF BIRDS.

Any constable or police officer may be called upon to make arrests under legislative acts for the protection of birds; if they fail to take proper action, through indifference or from othet causes, complaints for neglect of duty should be duly lodged against them. To secure more efficient enforcement of such laws it would be well to have officers specially appointed for the purpose, say one for each county. whose duties should be similar to those of game wardens - namely, to arrest and prosecute violators of the law. The paid agents - nearly five thousand in number- of the American Humane Association may also be called upon to assist in their enforcement.

PURPOSE AND OHJECTS OF THE PROPOSED ACT.

The primary purpose of the proposed act is the prevention of the slaughter of birds for millinery use, and by thoughtless men and boys in mere sport or to gratify a destructive propensity. As is well known, boys destroy countless numbers of the nests and eggs of birds, and even of birds themselves - the latter not only with guns, but especially by use of slings, catapults, or pea-shooters - simply for mischievous pleasure. It may not be so well known that many men thoughtlessly shoot hundreds and even thousands of Swallows, Swifts, Nighthawks, Gulls, Terns, Herons, and other birds, including even Ducks and other waterfowl, simply for the practice of shooting on the wing, or to gratify a desire to kill something. As they make no use of the birds thus killed, their only profit from such heartless destruction is the satisfaction of exercising or displaying their skill as marksmen. It is needless to say that such proceedings are wanton and barbarous, without excuse or defense, and should by summarily stopped.

The proposed act is not intended to interfere with the wearing of decorations made from the feathers of domesticated birds, or from birds lawfully killed as game, or with the use of ostrich plumes. The wings and other parts of Grouse, Partridges, Pheasants, Ptarmigans, Ducks, etc., employed so extensively for hat trimmings, are not objectionable from the point of yiew of bird protection.

GENERAL REMARKS AND SUGGESTIONS.

In any prohibitory legislation the "greatest good to the greatest number" is the first point to be considered. It is with this principle in view that the above draft of a protective bird act has been drawn. Hence if it can be shown that certain birds are included by it among those to be protected, which for any reason it is unwise to protect, as for example, the birds of prey, Crows, Jays, Blackbirds, the Robin and the Bobolink, the Committee is quite willing to see protection withheld from them. The United 
States Department of Agriculture, through its Division of Economic Ornithology, in charge of an expert naturalist, Dr. C. Hart Merriam, is at present thoroughly investigating these and similar problems, and doubtless will be able soon to throw much light upon the real economic status of these and many other species, but for the present the Committee believe, judging from the evidence already at hand, that it would be detrimental to the public interest to declare the species in question unentitled to protection. Again, while it is desirable to secure uniformity throughout the country in laws for the protection of birds, the conditions may so far vary in different portions of the country as to warrant deviations and exceptions for some parts which would be unnecessary in others. The Bobolink affords a notable case; throughout its breeding area, in the Northern States, it is unquestionably a useful insect destroyer as well as one of the most vivacious and pleasing of song birds; in the Southern States its depredations during its migratious on the rice crop are unquestionably of serious magnitude. How it had best be treated at large is not, therefore, an easily solved problem. And the same is to some extent true of the various species of Blackbirds. These are problems of the future, however, rather than of the present.

Another question of moment is the proper attitude of the law toward taxidermists, who, as a class, are valuable aids of the scientific museum and the ornithologist. The mounting of birds, single or in groups, as objects of ornament or interest, is not objectionable, since they are instructive and tend to foster a taste for natural history studies, the number so used being comparatively small.

The preparation of skins, also a legitimate part of a taxidermist's work, is, however, more open to abuse, since it is in this form that bircls find a ready sale for illegitimate uses. Many taxidermists are unquestionably upright and conscientious men, who scorn becoming accessories to the milliner's art; to such it would be proper to grant permits for collecting specimens. But many are notoriously unscrupulous, and consequently unfit to be trusted with such a privilege. Such persons, however, would doubtless be unable to furnish satisfactory testimonials of good charzeter and fitness, or the necessary bonds. But special care should be exercised both in issuing the permits and in guarding against their abuse.

\section{ACCLIMATISATION OF EXOTIC BIRDS.}

Europeans of sentiment and intelligence, when coming to our shores painfully miss their native birds, which they have known from early childhood and with whom so many happy thoughts are associated. It is, therefore, only natural that so many attempts have been made to introduce European song birds into our country. Doubtless it is due to this sentiment, that we now have the detestable House Sparrow, the most harmful of all foreign and native birds.

It is said that in the early part of this century the famous Skylark was introduced in Virginia. Twenty years ago the Society of Acclimatisation of Cincinnati and Mr. Carl Daenzer, of St. Louis, imported a large number of European song birds, which were set free in parks and other suitable places. Skylarks were set free in Delaware, New Jersey, and Long Island in great numbers at different times from 1860 to 1881 . All these song birds, turned loose, disappeared after a while, and nothing has been heard of them since. The Skylarks seemed to do well for several years both in New Jersey and Long Island, but the heavy snow storms in March 1886 destroyed them entirely. European Goldfinches, which were introduced a number of years ago in New York and Boston, increased in number considerably and are promising to do well.

The changeable climate of our Eastern, Northern, and Central States has proved very detrimental to exotic birds, and is certainly the main cause of the failure of the experiments mentioned. European birds which migrate to far southern countries, should never be imported with a view of naturalizing them. Their delicate constitution causes them to fall victim to our changeful climate, or if they migrate, they certainly lose their way and never return. For the Pacific coast States, Washington, Oregon, and California, this holds not true, as shown by actual experience. The climate of these States is exceedingly mild and equable. Oregon has a climate somewhat similar to that of Eng- 
land, and here the first experiment in the Pacific coast region was made to introduce European and native singing birds. The "Society for the Introduction of Useful Singing Birds of Portland, Oregon," imported in the year 1889 from Clausthal (Harz Mountains), Germany, the following birds: 10 pairs of Black-caps, 8 p. Song Thrushes, 15 p. Blackbirds, 22 p. Skylarks, 20 p. Starlings, 40 p. Goldfinches, 40 p. Chaffinches, 35 p. Linnets, 40 p. Siskins, 20 p. Crossbills, 1 pair of Nightingales, several pairs of Bullfinches, Yellow Hammers, Greenfinches, Hawfinches, and others. Under the direction of Mr. Frank Dekum, president of the society, and Mr. C. F. Pflueger, secretary, these birds were turned loose near Portland. With the exception of the Nightingales all did well and increased in numbers considerably. The Skylarks were set at liberty in clover fields and meadows. Writes Mr. Pflueger: "The birds have done well ever since they were introduced. We watched them all through the summer of 1889. Some nested in Portland, and some in the suburbs, while others went far off into the State. We have received quite a number of very fiavorable reports from all parts of the State. Many of the birds left in fall and returned in spring 1890. Blackbirds, Skylarks, and all the Finches did not migrate. The society has received reports from numerous places in this vicinity which show that the birds, set at liberty a year ago, have prospered, and that the experiment was a grand success."

This success induced the society to import another large lot of European and native birds, among them Mockingbirds, Cardinals, and others. These birds arrived in March 1891 and were set free in May. All did well, and Mr. Pflueger receives now reports from all parts of the State that the naturalized birds are multiplying rapidly. Skylarks, Blackbirds, Goldfinches, Siskins, Linnets, and Greenfinches are doing especially well.

Similar societies have been founded in Washington and California.

\section{NESTING BOXES.}

Convenient nesting-boxes must be provided for a number of our birds, if we desire their presence in our parks, gardens, and orchards. In many cultivated regions, and especially in the prairie districts, our beautiful and familiar Bluebird can scarcely find a hole where it can build its nest. Nesting-boxes for this highly beneficial songster ought to be found in every garden and orchard. These boxes should be firmly fastened to the branches of trees by strong wire or nailed to posts. Of the illustrations appearing on page $\mathrm{L}$ No. $1,2,3,4$, and 5 are especially designated for the Bluebird. No. 6 and 7 suit the taste of the Phobe exactly, if it is unable to find another more convenient nesting-site. No. 8 is a good box for Titmice. These boxes are easily made of boards or hollow branches and hollow tree-trunks. In the South the hollow cypress knees furnish excellent material for the construction of convenient nesting-boxes. Cigar-boxes are entirely unfit for our purpose and should never be used. 


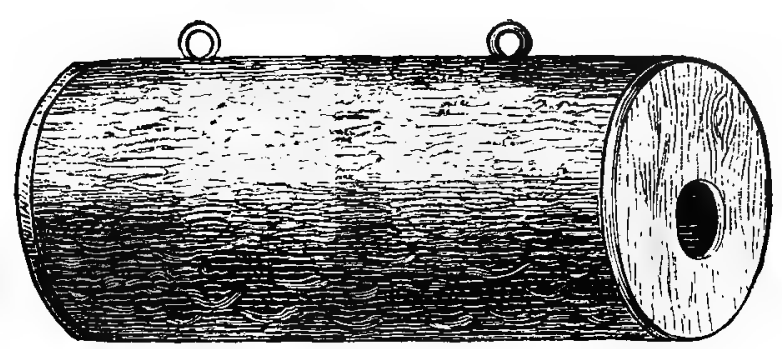

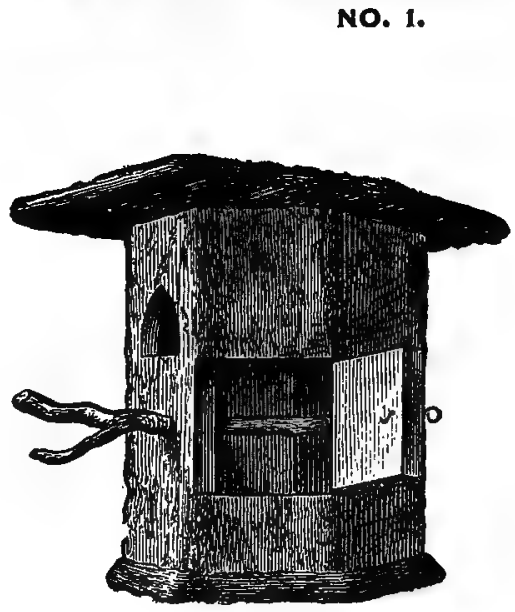

No. 3.

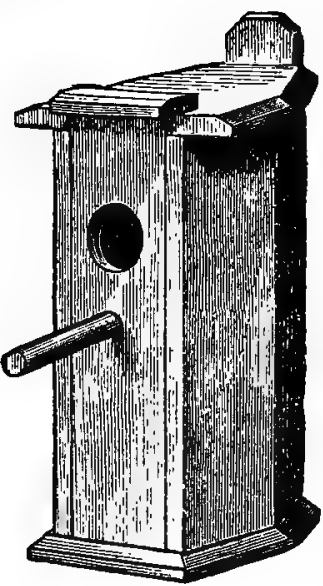

No. 4.

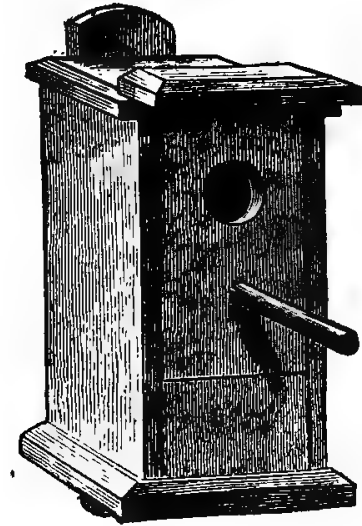

No. 2.

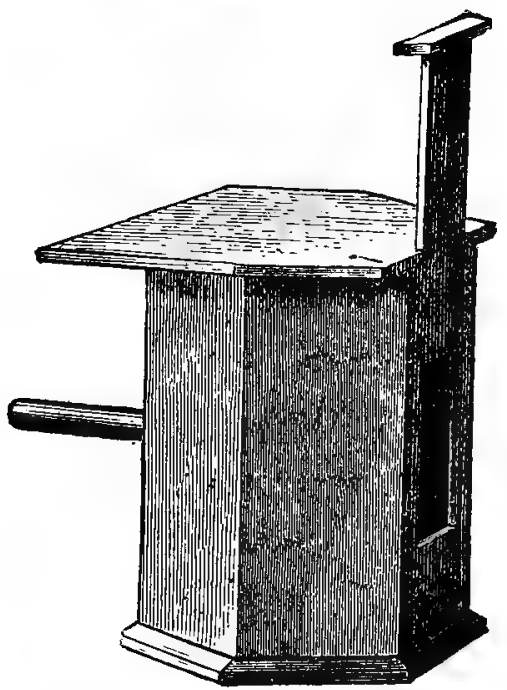

No. 5.

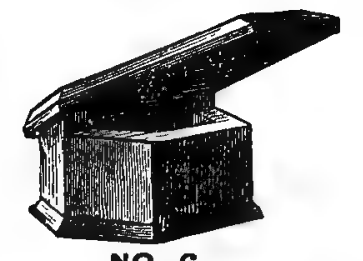

NO. 6.
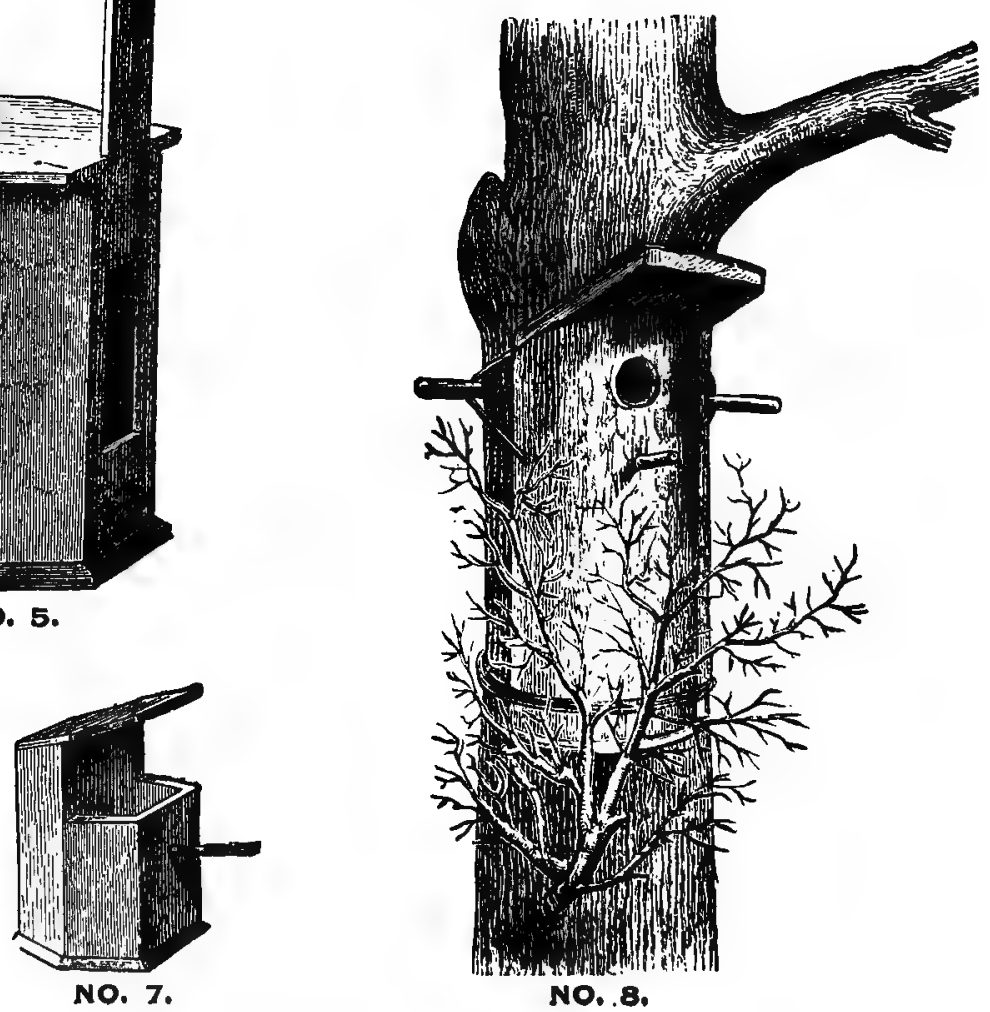


\section{THRUSHES.}

Turdidae.

ERE an artist required to paint on his canvas a bird of most harmonious proportions throughout, he would be compelled to represent more or less closely the form of a Thrush. This bird seems to me to be in every respect what a philosopher would call "the bird as such." What leads me to this conclusion is the fact that the beak of the Thrush is neither long nor short, neither thick nor thin, neither straight nor much curved. The forehead is neither retreating nor very high; the whole head, the eyes, neck, body, wings, legs, claws, and tail, all are of average proportions and uniformly developed. Hence these fine birds justly rank first in our book.

The Thrushes may be regarded as true cosmopolitans, for every part of the world has some species. The group is represented by the greatest number of forms in the northern temperate zone, but some species occur even in the tropics.

Thrushes inhabit both the depths of the forest and the haunts of man. They build both in foliage trees and in pine woods, ascend mountains, and abound in the lowlands. The true home of our native species is in the Northern States;-it is here that they pour forth their jubilant songs, here too they breed. The Robin and Wood Thrush go farthest south, occurring abundantly in the mountains of South Carolina and spreading thence to Arkansas. None of our true Thrushes extend any farther south during the breeding season.

.In color, too, the Thrushes exhibit pleasing harmony. Their modest suits, usually gray and brown, are relieved by brighter colors (chestnut-brown, black, white, or yellow). Thrush pattern has even become a technical term. Thrushes cannot be called either large or very small birds-in this respect they maintain the average. They are all, without exception, powerful and persevering in their flight, flit skilfully through the tangled branches of the trees and are not in the least awkward on the ground to which they very often descend. They hop about on the surface in long separate bounds. When anything unusual strikes their sight, they quickly jerk their tails and at the same 
time drop their wings. This is a very characteristic trait of all true Thrushes. They hop over considerable distances on trees, using their wings to aid them. Usually they only fly from bush to bush, from tree to tree; during migration, however, they rise high into the air and fly with extraordinary rapidity. Their senses are more keenly developed than those of most other birds. This is particularly true of sight and hearing. They hear the faintest sound and they perceive small insects at a considerable distance. Mentally they rank high above all other birds. They are very intelligent and even cunning, shy and careful when they have learned to know man. They quickly distinguish friend from foe, and in their native woods at the approach of danger they stand as sentinels for other birds and even for mammals. The love for their, brood is highly developed, and they often courageously attack any enemy that disturbs their household peace. Another very characteristic trait is their curiosity. They notice everything that happens around them; anything strange immediately excites their attention: They come out inquisitively, hold their heads slightly to one side in a listening attitude, stop, and then again advance a little further, always keeping at a respectable distance.

Though surpassed in song by some allied species of the subfamily of Mockingbirds, they far excel all other birds in this respect. It is merely a matter of taste, whether the song of the Mockingbird be preferred to that of the Hermit and Veery or vice versa. The powerful sonorous voice of all of our true Thrushes fills a whole woodland or orchard. It rises high above the various voices of the great mass of birds.

However great the æsthetic force with which these birds beautify out-door nature by means of their wonderful songs and charming sprightliness, their highest value still lies in the quality of their food. Though at times they eat small fruits (cherries, strawberries, raspberries, and blackberries), their principal diet is at all times insects, especially such as live on the ground and do inestimable damage to the fruit-grower and farmer.-The Thrushes and all other small insectivorous birds cannot be valued too highly. Let us do all in our power to protect and care for them in every way.

All our Thrushes are particularly adaptable to cage-life. I shall, however, have occasion to revert to this in the description of each particular species. 


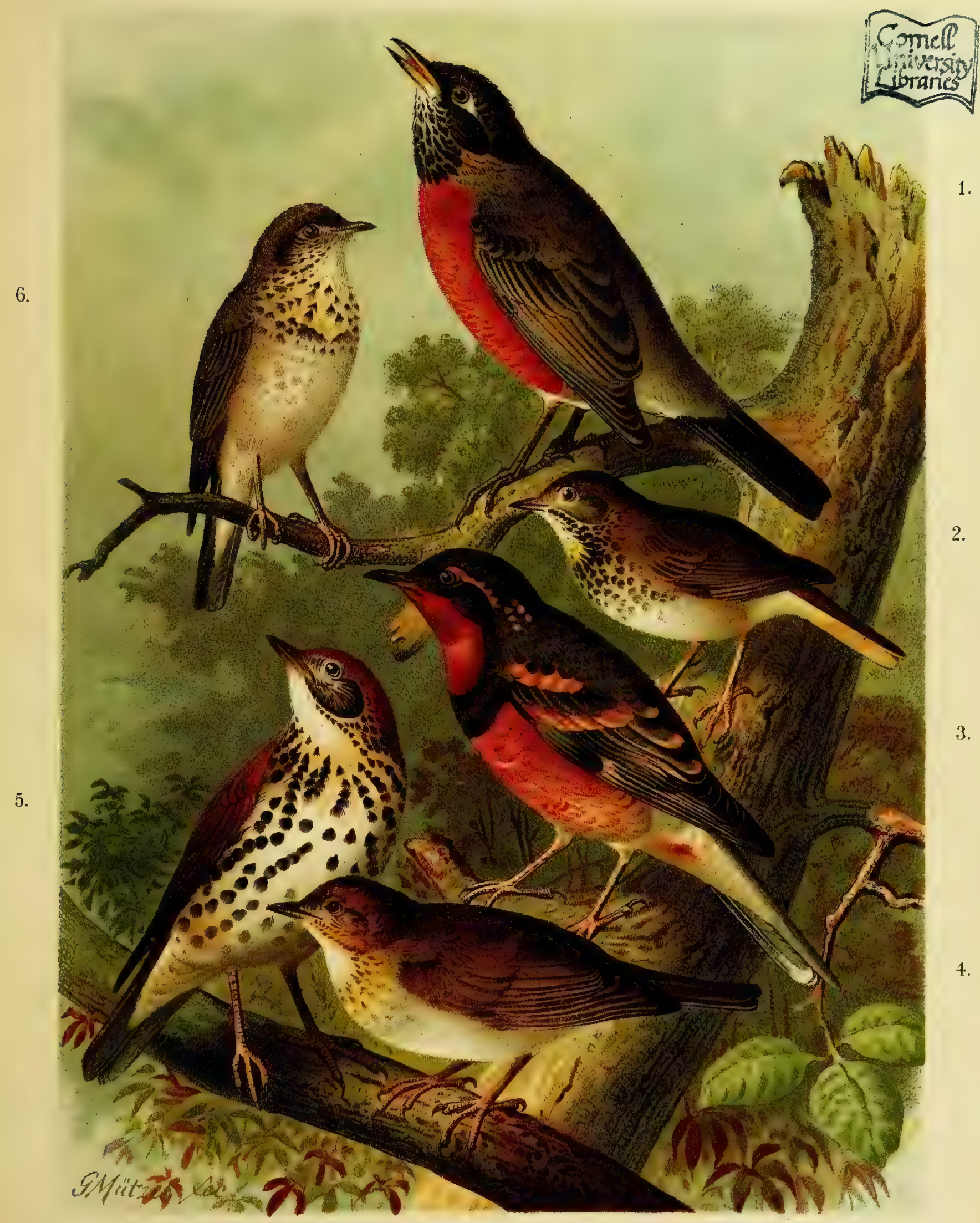

1. MERULA MIGRATORIA Swains.

- WANDERDROSSEL. - Rabin.

2. TURDUS AONALASCHKAE PALLASII Ridg̊w. - EINSIEDLERDROSSEL. - Hermit Thrush.

3. HESPEROCICHLA NAEVIA Ridgw.

4. TURDUS FUSCESCENS Steph.

5. TURDUS MUSTELINUS Gmel. BUNTDROSSEL. - Varied Thrush

6. TURDUS USTULATUS SWAINSONIl Ridgw.

- RÖTHELDROSSEL. - Wilson's Thrush,Veery

- WALDDROSSEL. - Wood Thrush.

- SÄNGERDROSSEL. - Olive-backed Thrush. 



\title{
WOOD THRUSH.
}

\author{
Turdus mustelinus GmeLin.
}

Plate I. Fig. 5.

In the Summer-time is heard"Eolie-Eolie!"

O'er and o'er, this single word, Little song of little bird-

Love song if I have not erred"Eolie!"

Lonely longs he deeply stirred,

As so clear, so soft sings he"Eolie-Eolie !"

As be sings with flute-like trill"Eolie-Eolie!"

Lists the air, grown hushed and still;

Listens in the vale the rill;

List the trees on plain and hill"Eolie!"

And his notes the wild flowers thrill,

As so clear, so soft sings he"Eolie-Eolie!"

Long he calls his sweetheart dear"Eolie-Eolie!"

Where is she?-afar or near?-

She is dead, I sometimes fear,

Nevermore his song will heat "Eolie!"

Seems it "a melodious tear,"

As so clear, so soft sings he-

$$
\text { "Eolie-Eolie!" }
$$

As I hear at close of day"Eolie-Eolie!"

Memories of a lovely may,

Loved and loving, far away,

Chiming, mingle with the lay"Eolie!"

"Where is she?" I, sighing, say,

As so clear, so soft sings he"Eolie-Eolie!"

W. L. SHOEMAKER.

May 12, 1883.

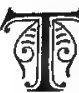

HE majestic forests of middle and northern Wisconsin, Michigan, New England and the mountain ranges of the Alleghanies are full of untold delight for the lover of nature. In the wildest confusion grow hemlocks, balsam firs, white pines, maples, elms, birches, beeches, ashes, oaks, lindens, hickories, and many other trees and shrubs. The balsamic odor of the evergreens and the fragrance of the wild flowers fills the atmosphere. On every side dense shrubbery and thickets of various conifers are seen. All the 
ground beneath the trees is covered with a soft green carpet. Here grow whole patches of club-moss ${ }^{1}$, there masses of aromatic wintergreen ${ }^{2}$, beautiful, deliciously scented trailing arbutus ${ }^{3}$ and creeping checkerberry ${ }^{4}$, to say nothing of the many different delicate ferns. Everywhere gurgle the springs and prattle the brooks of the forest. Now we tread on damper swampy soil thickly covered with many kinds of dense shrubbery, trees and ferns, and with pretty. evergreen heathworts, especially with andromeda ${ }^{5}$, blueberry, and luxuriant huckleberry bushes. The small ponds and lakes, which are met with here and there, heighten the charms of the landscape. This is an idyllic poetical world, rarely disturbed by a discordant sound. Everywhere reigns the most delightful variety and still the most perfect harmony. From early morning till late in the evening these woodlands echo with the songs of numerous birds. We hear the mournful and in these surroundings indescribably melodious song of the Rosebreasted Grosbeak, the echoing notes of the highly pleasing Towhee Bunting, or Chewink, and from the lofty foliage the lays of the different Vireos and Wood Warblers. The Robin, too, our beautiful familiar Bluebird, several Woodpeckers, the Wood Pewee and Scarlet Tanager may be heard. - In the swampy thickets resounds the incomparable song of the Hermit, and the Veery, or Wilson's Thrush, sends its voice from the distance. These two Thrushes may be justly called the "prima donnas" of our northern woods, true queens of song. They belong to the best of singing birds in general, though they are excelled in some respect by the WooD THRush, the most frequent denizen of these regions. This bird is also known in different parts of our country as the Wood Robin, Wood Nightingale and Song Thrush.

When of late years, impelled by longing, I wandered southward, hoping to find. lovelier landscapes, more beautiful woods, more interesting plants, a more tropical birdlife, I was completely disappointed, and the farther to the south I sojourned, the more did this disappointment grow upon me. In Texas, the State I had so often longed to behold, I saw nowhere what I had expected to see:-a semi-tropical flora and avifauna. True, all this is different in southern Lotisiana, and in Florida really tropical landscapes burst on one's astonished gaze. The woods of Texas and many other parts of the South cannot be compared with their counterparts in the North and East. The charm and irresistible attraction of the latter is almost wanting, though the floral world does possess interest in some places. I found and admired the beautiful Magnolia grandiflora, the spanish moss, dangling at length from the boughs of the trees, the odd forms of the yucca and numerous cacti, and many a strange bird did I find, among others that queen of songsters, the Mockingbird-but all this possesses but little attraction for the northener, who has grown up in romantic surroundings. The truly poetical, the truly idyllic is to be found only in the woods of the North and East and in the mountain ranges of the Alleghanies, where our Wood Thrush has chosen its home, where it builds its nest and sings its wonderful song.

Nowhere rare and nowhere particularly common, the Wood Thrush occurs regularly from the Atlantic Ocean to the Mississippi, and from the northern States to Arkansas and the mountain ranges of North and South Carolina. It is a bird of the

1 Lycopodium dendroideirm. 2 Gaultheria procumbens. a Epigxa repens, 1 Chiogenes hispiduta. O Andromeda polifolia and A. calyculata. 
Alleghanian fauna. It is found chiefly in low damp woodlands which are thickly covered with undergrowth, and prefers for settlement the shady interior to the noisy and busy neighborhood of man. It loves the deep half-darkness of the forest-solitude with its peace and quietness. Here one can hear the wonderful, harmonious, flute-like song from early dawn till the fall of the evening twilight. Although usually selecting low woods for its home, it seems to love equally well high mountain regions. In the mountains of North Carolina and elsewhere it loves to nest in the grand evergreen Rhododendrons $(R$. Catawbiense, $R$. punctatum).

$I$ found it most abundant in the woods bordering the streams and creeks of northern Illinois. There it prefers for its breeding-place pieces of woodland containing masses of dense thickets. In my native State-Wisconsin-the Wood Thrush is a somewhat shy bird, which regularly breeds in deep forest recesses, but in northern Illinois it departs considerably from such habits, and although not breeding in gardens near to man, I occasionally found nests in woods close to an orchard. In the East nests have been found repeatedly in gardens, and my friend $\mathrm{Mr}$. O. Widmann informs me, that this bird often nests even within the city limits of St. Louis.

The Wood Thrush rarely appears in its northern home before the middle of May - often some days later-at the time when the first flower-buds open upon the appletrees. It usually remains for the first few days after its arrival in the dense undergrowth. Were it not for hearing repeatedly the far-sounding, delightful "Eolie" or "Hallolee," one would hardly know that this famous vocalist had returned home again. Besides this common song-like call it utters a low "tuck" or "tack" and a quickly reiterated "tucktucktucktuck," which is especially frequent after its arrival and is perhaps intended as a love-call to its mate. Only when it sings does it perch on a treetop and pour forth its exquisite song. Usually it selects such a seat at a considerable distance from the nest, and returns to it very often. When disturbed it suddenly dives into the underwood.

Formerly this Thrush nested very abundantly in the woods along the Calumet and Des Plaines River near Chicago. These woods consist mostly of oaks, tall elms, lindens, black walnut and ash trees. Dense hawthorn bushes, intertwined with wild grape vines and virgin's bower (Clematis virginica), Juneberry trees, dogwood, elder, black haw, hazel-copses and beautiful wild crab-trees make up the underwood, which stands in clustered masses, forming dense thickets with sunny openings here and there. In these rather damp places our vocalist choses his regular domicile.

In their northern habitat these birds commence nestbuilding usually in the first week of June. All the nests I found were from four to six, more rarely as high as fifteen feet from the ground. The first and only nest near a human dwelling I found June 17th, 1876, at River Forest (Illinois), about a quarter of a mile from Des Plaines River. It was placed in a wild crab-tree ${ }^{1}$ growing on the edge of the woods right back of an orchard, and was about thirteen feet from the ground. All the other nests discovered by me were more in the depths of the woods. In the following year I found the nests particularly numerous in that part of the forest (then called Hase's Park) traversed by the Desplaines River. It was a beautiful piece of woodland, since con- 
verted into large cemeteries. Here I found this Thrush more common than ever before, even more abundant than the Robin. Excepting the Catbird the Wood Thrush was here the most frequent nesting bird. In a part of the woods comprising about one and a half acres, partly shaded by broad-spreading forest trees where the thickets were crowded together, $I$ found in a few hours three nests of this Thrush. Two were in the immediate neighborhood of an extensive, much tangled thicket, in which there were also two Catbird's and a Blackbilled Cuckoo's nest. One structure on the east side of the thicket was very near a Catbird's nest. It was placed in a small tree about five feet from the ground, and contained three eggs. The structure was very loosely built of grass-stems, barkstrips and dead leaves; in the inside of this was placed a cup of black mud lined with delicate rootlets and a few grass-blades. It contained three greenish-blue eggs. The second nest on the north side of the same thicket was hardly fifty steps from the first. It was placed in a small hawthorn about six feet from the ground and contained only two eggs. It differed but little from the first. The third nest I discovered on the "Indian Mound," a little elevation in the woods,--said to have been a burial place of the Indians. This nest was situated in a dense black haw ${ }^{1}$ about six feet from the ground, and contained four uniformly greenish-blue eggs. It was much more carefully constructed than the other two, though composed of the same materials. The sitting female was so tame that I almost touched her with my hand before she started from the nest. Without a cry of distress she disappeared in the shrubbery and noiselessly returned when I had stepped back. Strange to say, the male did not make his appearance in the neighborhood of the nest.

In Wisconsin the Wood Thrush prefers to build in young white pine and hemlock copses. Here the structure is usually from four to eight feet from the ground close to the trunk on a horizontal branch.

The song of our Wood Thrush, usually poured forth from a tree-top, is among the most exquisite of all bird-melodies. In this respect the bird is not only not inferior to the famed European Song Thrush (Turdus musicus), but rivals and perhaps even excels it in some respects. Words can give no idea of the song of this nightingale of the forest. To be appreciated it must be heard in the free open air of unfolding nature. Nobody, perhaps, has felt more keenly the beauty of this song than our poet Dr. W. L. Shoemaker. - All Wood Thrushes do not sing equally well, some are only of medium ability, others sing little more than the three-syllabled flute-like "E-o-lie." Wherever this Thrush abounds, the woods actually re-echo with this glorious note. Those inhabiting the deciduous woods are not such fine singers as those occurring in woods where foliage trees and conifers intermingle. In the mountain regions of Penn. sylvania, Virginia, North and South Carolina, where the gushing mountain streams are bordered with tangled thickets of rhododendrons (mountain bays), kalmias (mountain laurels), andromedas, sweet scented calycanthus, viburnums, and dogwoods, the birds are said to sing more beautifully still. No doubt the surroundings greatly affect the singing. The song of the Wood Thrush is characterized by fullness, modulation, purity of tone, and variety. The hearer is involuntarily reminded of the tone of a fine stringinstrument. Though the song of the most of these Thrushes is tinged with the gayful, 
loud, and sublime, there are many whose song flows forth softly, deliberately, almost plaintively. The bird's fine form and position, its plain but rich plumage, its aristocratic mein-all harmonize with its song. Truly, the Wood Thrush is the queen of song of our northern woods. I, for my part, prefer its lay to the day-song of the hurrying, ever gay and somewhat careless, all-imitating Mockingbird. All of our birdlovers, all our great ornithologists and students of nature speak with enthusiasm of the Wood Thrush.

"The song of the Wood Thrush," says Audubon, "although composed of but few notes, is so powerful, distinct, clear, and mellow, that it is impossible for any person to hear it without being struck by the effect which it produces on the mind. I do not know to what instrumental sounds I can compare these notes, for I really know none so melodious and harmonical. They gradually rise in strength, and then fall in gentle cadences, becoming at length so low as to be scarcely audible; like emotion of the lover, who at one moment exults in the hope of possessing the object of his affections, and the next pauses in suspense, doubtful of the result of all his efforts to please."

The lay of this exquisite songster is heard soon after its arrival. It appears during the night in its summer quarters, and in the gray of dawn announces its coming by its song. It is heard singing even after the fading of the evening twilight and in dark and gloomy weather. The effect of such singing on the fine-feeling lover of nature is described by Audubon in his lively, fascinating manner:-

"The Wood Thrush is my greatest favorite of the feathered tribes of our woods. To it I owe much. How often has it revived my drooping spirits, when I have listened to its wild notes in the forest, after passing a restless night in my slender shed, so feebly secured against the violence of the storm, as to show me the futility of my best efforts to rekindle my little fire, whose uncertain and vacillating light had gradually died away under the destructive weight of the dense torrents of rain that seemed to involve the heavens and the earth in one mass of fearful murkiness, save when the red streak of the flashing thunderbolt burst on the dazzled eye, and, glancing along the huge trunk of the stateliest and noblest trees in my immediate neighborhood, were instantly followed by an uproar of crackling, crashing, and deafening sounds, rolling their volumes in tumultuous eddies far and near, as if to silence the very breathings of the unformed thought! How often, after such a night, when far from my dear home, and deprived of the presence of those nearest to my heart, wearied, hungry, drenched, and so lonely and desolate as almost to question myself why I was thus situated, when I have seen the fruits of my labors on the eve of being destroyed, as the water, collected into a stream, rushed through my little camp, and forced me to stand erect, shivering in a cold fit like that of a severe ague, when $I$ have been obliged to wait with the patience of a martyr for the return of day, trying in vain to destroy the tormenting mosquitoes, silently counting over the years of my youth, doubting perhaps if ever again I should return to my home and embrace my family!-how often, as the first glimpses of the morning gleamed doubtfully amongst the dusky masses of the foresttrees, has here come upon my ear, thrilling along the sensitive cords which connect that organ with the heart, the delightful music of this harbinger of day! - and how fervently, on such occasions, have I blessed the Being who formed the Wood Thrush, and placed 
it in those solitary forests, as if to console me amidst my privations, to cheer my depressed mind, and to make me feel, as I did, that never ought a man to despair, whatever may be his situation, as he can never be certain that aid and deliverance are not at hand."

The Wood Thrush may be called the prototype of our Thrushes. Its character is good throughout, no inferiority mars its perfection. All its attitudes, all its movements are elegant, its bearing nobly refined. Its flight is persevering, graceful and rapid, its movements among the boughs of the trees are nimble and easy. It is intelligent and careful, much less sociable than the Robin, and consequently not open to such persecution. It always wears its simple plumage smooth. The dull-brown back, the white dark-spotted breast make it look like a little Song Thrush, and indeed, it is the most closely related of all our Thrushes to the European Songster. It is, however, smaller, its length being only eight inches, whereas the Song Thrush measures about ten inches.

Like all of the genus, the Wood Thrush is one of the most useful of birds. The bulk of its food consists of insects, especially of all kinds of worms, caterpillars, grass. hoppers, \&c., which it looks for on the ground. It eats all kinds of berries, too, especially such as grow in its bushy home. The young are fed with insects only. The male assists its mate but little in building the nest, and does not help at all in breeding. He has to participate actively, however, in bringing up the young. As there is only one brood in the North in a season, the young are under the protection of the parents long after they have left the nest. The whole family seems to keep regularly together till the time for migration. Then a few families from the neighborhood collect, and sometime between the middle and latter part of September they all start off on their journey southward.

They appear in the coast region of Texas according to my own observations, in great numbers by the beginning of October, at the time when the cones of the Magnolia grandiflora glow invitingly with their wealth of beatiful vermillion, aromatic seeds. The flesh of these Thrushes is said to acquire a peculiarly delicious flavor from this fruit, on which account many thousands are annually killed by the creoles of Louisiana, where these and other species of this family, as well as the Towhee Bunting, are commonly called "grassets."

In many protected spots numerous Wood Thrushes pass the winter even near Houston, Texas, especially where they are not molested and find shelter in the beautiful evergreen magnolias, hollies, long-leaved pines, and other evergreen trees and shrubs. In greater numbers they are found at this season in Louisiana and Florida, States which are less often visited by cold "Northers." From here their winter quarters extend to Guatemala, Honduras, Cuba and Jamaica. Some are said to spend the winter also in the Bermudas. Their breeding-range has already been sketched. It is the region from the Atlantic Ocean to the Mississippi. This species does not go far northward, being rarely seen even in northern New England. According to Dr. Brewer it breeds in Georgia but doubtlessly only in the mountain districts in the northern part of the State. In the Ozark region of southwestern Missouri I rarely found the Wood Thrush breeding. It was, however, more common near water-courses. Prof. J. A. Allen found it in Kansas and Dr. Elliott Coues mentions it as one of the birds of northern Dakota. 
The Wood Thrush is particularly adapted to cage-life. During my stay in the North I always kept a few of them in captivity, some old birds which had been caught, and some taken from the nest. Old birds which have just been captured, are very wild for a long time, but after kind treatment they grow tame and affectionate.

In order really to enjoy this princely songster, it is necessary to give it a roomy cage with an arched top, and to feed it carefully and keep it clean. Then the bird will reward all care with its exquisite song, which is often kept up uninterrupted from the latter part of February to the beginning of July. The bird is best fed with a mixture of equal parts of "Mockingbird Food" and grated carrot, to which may be added a small quantity of dried "ants eggs." Meal-worms, now and then different berries and a little fruit are absolutely essential to its welfare. It is remarkable that some caged males sing very little, others not at all. I believe the cause of this is improper, and often very unnatural and careless keeping. In company with other birds, too, it will not sing. Many caged males sing only their loud "E-o-lie."

In Germany, where bird-fanciers and enthusiastic friends of the beauties of nature are very numerous, the Wood Thrush seems to have attracted little attention as yet, perhaps because the fullness of its charming song has never yet been heard there. Brehm seems to have kept it only in the aviary, and Dr. Karl Russ merely mentions it in his "Handbook of Foreign Cage Birds." Young birds taken from the nest become exceedingly tame and affectionate, but are decidedly inferior in vocal powers to caged adult males.

NAMES: Wood Trrusf, Wood Robin, Wood Nightingale, American Song Thrush.-Germ. Walddrossel.

SCIENTIFIC NAMES: TURDUS MUSTELINUS GMELIN (1788), Hylocichla mustelina Baird, Turdus melodus Wilson (1808).

DESCRIPTION: Upper parts tawny, brightest and deepest on the head, more olive on the rump and tail; below white, marked with roundish or triangular blackish spots on the breast and sides. Female and young similar. Length 7.50 to 8 inches.

"Nest usually saddled upon a horizontal branch of a small tree, in damp woods, very compact, composed partly of mud." (Ridgway.) Eggs 3-5 plain greenish blue. 


\title{
VEERY; WILSON'S THRUSH.
}

\author{
Turdus fuscescèns STEPH.
}

Plate I. Fig. 4.

\begin{abstract}
With dreamy delight $I$ think of thee,
For thou doest swell my bosom with glee

When the gloom of evening falleth;

And even now 'mong the leafy trees,

When thy sweet inspiration doth rise on the breeze, Its beauty my being inthralleth.
\end{abstract}

FrIsch.

2UNE is really the spring month in the northern part of our Union. Only during this month do Flora's children come forth in full beauty, and it is not till then that bird-life is at its best. Every songster, even the most delicate, has returned home from the tropical winter quarters; all sing in jubilation, almost all of them breed.-During the silent evening twilight we are sitting in the woods on one of those prostrate forest monarchs that on all sides press the ground with their moss-grown flanks. A mysterious silence, a serene peace hangs over this northern forest. The sweet fragrance of many blossoming trees and shrubs fills the air. Delicate anemones ${ }^{1}$, wintergreen, various ericaceous plants, ferns, the blood-root and terrestrial orchids, arrest our attention. Through the clearings the evening chimes of the returning herds fall on the ear. From the distance comes the mournful and yet enchanting song of our beautiful Rose-breasted Grosbeak. Suddenly, unexpected, from our immediate neighborhood, sounds a beautiful melting song - at first soft, continuous - then ever louder, happier, more glowing, triumphant. Every note is bursting with entrancing euphony! No weariness falls on us as we listen to the wondrous chorister, but the quickly deepening darkness and the loud call of the Whippoorwill warn us to depart. We hear the glorious song from all sides now for the one songster has made rivals of many. This musician, often mistaken for the Wood Thrush by lovers of nature, is the VeERY, or WiLson's THrush.

In many parts of the northern States this species is much commoner than the Wood Thrush and is therefore in many places a well-known and familiar bird. This is well indicated by its popular names. It is commonly called VEERY or CHEEURY from its call-note. The reddish brown color of its upper part has given it the name TAWNY Thrush, and on account of its song it is called the Nightingale. The ornithologist calls it WiLson's Thrush after Alexander Wilson, the father of American ornithology. In Wisconsin and Michigan, of the smaller species only the Wood Thrush and Hermit are known to any extent. It seems that the Veery and Wood Thrush are confounded 
in many places. The former is by no means a rare bird in the woods of Wisconsin and is more common than the latter species, especially in extensive damp stretches of bushy woodland. I have most frequently observed it during migration in northern Illinois. It arrives from the South during the first week of May in small companies, tarries a few days and then passes northward. Only a few straggling pairs remain to breed. From the middle to the end of September they may be met with again on their way south. Though the Veery is in its breeding range a shy bird, it will enter large gardens even in towns and cities during migration. In a neighboring garden near my home at Harlem (Illinois) which contained many small and medium sized spruces and ornamental shrubs, I regularly found among the bird-visitors of the place a small number of Wilson's Thrushes. During the day they busily searched the ground under the bushes for insects, in the evening they withdrew to the pine and spruce trees where they were well protected from the real cold north and west winds not unusual even in May. They love most to congregate on the forest-covered banks of creeks and rivers. - They appear near Houston (Texas) early in October. The berry-like, very aromatic fruit of the magnolias, and later the scarlet berries of the hollies and those of many other plants, form a portion of their diet. Some, no doubt, pass the winter on those sheltered banks of the Buffalo Bayou which are bordered by evergreen shrubs and tangled thickets of smilax, wild grape, \&c., but the majority move further southward to the tropics. Many pass the winter in the dense hammock woods of Florida, but more go to Cuba, Guatemala, even to South America. According to A. von Pelzeln, Natterer met with them in December at San Vincente in the interior of Brazil. In Europe the Veery is said to have been killed as a straggler.

The breeding range is larger than that of the Wood Thrush, for it extends from the Atlantic westward across the Mississippi far into the Rocky Mountains. This bird has been observed especially in Colorado and Utah at an altitude of 8,000 feet. Mr. Henshaw found nests at almost this elevation; it is, therefore, also a true mountain inhabitant, though it usually prefers the valleys of the mountain streams. Prof. R. Ridgway regards it as one of the most characteristic birds of the valleys of the Provo, Bear and Weber Rivers in Utah. In some parts of Wisconsin it nests quite frequently, but in northern Illinois it seems to be a more rare summer sojourner. Excepting the Robin, the Veery is the commonest of the Thrushes in southern New England during the breeding season, where with the Wood Thrush it is characteristic of the Alleghanian fauna. In mach less numbers it also extends sparingly into the Canadian region, where the Hermit and Olive-back are so abundant and prominent.* It is also common in the Alleghanies and breeds as far south at least as North and probably South Carolina. Mr. W. Brewster, one of our leading ornithologists, has written a number of beautiful bird-sketches, full of poetry. Lately he published a very interesting and accurate account of the birds of the mountain region of North Carolina. $\neq \mathrm{He}$ found the bird abundant over the elevated plateau of Highlands, and scarcely less numerous on the Black Mountain, ranging in both localities from about 3,500 to 5,000 feet. Like the Wood Thrush this species haunted, by preference, rhododendron thickets along streams, and in

* See Stearns and Coues' "New England Bird Life" Vol. I, p. 60, 61.

$\ddagger$ W. Brewster, Birds of western North Carolina. "Auk" III, 1886, p. 178. 
many of these tangled retreats it was far more numerous than Mr. Brewster had ever seen it in the North. Its call-notes were louder, sharper, and more penetrating than those of the New England bird. The song, also, was clearer, more varied and altogether finer.-On the Black Mountain Wilson's Thrushes abounded in the dense evergreen forest of spruces and balsams at, and for a little distance above, 5,000 feet.

According to my experience the Veery is shy and circumspect, more retiring, and fonder of solitude than the Wood Thrush, and consequently rarer in woods often frequented by man. As a rule it is found only in the deepest seclusion. It chooses for its haunts and nesting place more swampy and damper spots than its congener, the Wood Thrush. It may be said that the last named species inhabits the high and low woods, Wilson's Thrush the damp woods, and the Hermit the swampy woods of middle and northern Wisconsin, notwithstanding all three species sometimes occur close together. The Veery's home is in one of the most delightful and beautiful parts of the woods. It is always found in the neighborhood of water, either close to a rushing rivulet wandering under thick shrubbery, near a clear gurgling spring, or a pond. In such places vegetation is always luxuriant and dense, with here and there open spots overgrown with moss, ground-pine ${ }^{1}$ and wintergreen ${ }^{2}$. The friend of the beauties in nature is struck by the wonderful forms of magnificent ferns, especially Osmunda cinnamomea, the varied orchids ${ }^{3}$ rising from the peaty ground in full splendor, the curious pitcherplant4, the numerous huckleberry bushes covered with lovely bell-shaped flowers, the many different blossoms along the edge of the stream from among which the dazzling red and later the blue lobelias ${ }^{5}$ shine forth with greatest brilliancy. The large widespreading forest-trees overshadow whole thickets of cranberry, wild goose-berry, dogwood, and other bushes. In the region of mixed woods, the pine and hemlock thickets greatly heighten the charms of the scene. In the sunlight falling through the high trees myriads of mosquitoes, gnats, and other water-loving insects hover. The whole forest ground is covered with old, completely moss-grown logs which have almost turned to soil. One sinks almost to the knees into the decomposing mass, which is the very lifespring of the rich plant growth. Except in the hummock woods of Florida, I have never seen such beautifully luxuriant vegetation. This is the true home of our Veery. Here the female finds its mate, that has arrived a few days earlier, here the beautiful song sounds through the forest, here the nest is built, and the young raised. In this silent solitude the Veery must be sought, if the friend of nature, and especially of birdlife, would make its acquaintance. Care, however, is taken by the endless swarms of blood-thirsty mosquitoes that man shall not enter this seclusion with impunity. I think it is just the haunts chosen by this Thrush that are the cause of its being considered rarer than it really is.

In Wisconsin the nest may be found during the first week of June. It is always either on or near the ground, often beneath a cluster of ferns, under an evergreen shrub or supported in the forks of some stems that spring directly from the ground, but always so that it is protected from above or from one side. When placed directly on the ground, it rests upon a bed of leaves. Among the various materials which enter into

1 Lycopodium. 2 Gaultherla procumbens. 3 Arethusa bubosa, Calapogon pulchellus, spiranthes, Cypripedium, etc. sarracenia purpurea. 5 Lobelia cardinalis and L. syphiltica. 
its composition, old dry leaves form a large part. These are intermingled with barkstrips, grass-stems and weed-stalks; moss and fine hemlock twigs are sometimes also used. The interior is lined with the same material. The nest is large as compared with the size of the bird and not so elegant and pretty as we might expect. It is not at all easily found on account of the hidden spot in which it is built. The female will not leave the eggs till almost touched with the foot. A charming picture, this bird with its large intelligent eyes, hidden by the fine branches of a huckleberry bush or the overhanging fronds of ferns, with its nest surrounded with moss and delicate forest plants! One step more and she leaves her place. Looking in the nest we see four, rarely five, eggs, like those of the Hermit, greenish-blue without markings, except in very rare instances when a few spots appear on the larger end.

The young are fed with different kinds of insects found on the ground, and these also constitute the main diet of the parents. Later in the season various kinds of woodland berries are also eaten.

The Veery is one of the most exquisite songsters of its forest solitude. It is in truth a rival of the Hermit, the Olive-back, and the Wood Thrush. One hardly knows which to award the palm. In many respects the Veery's song reminds one of the Wood Thrush, but it is not so loud and flute-like, and seems to be more modulated. All its notes are "clear, bell-like, resonant, distinct, yet soft and of indescribable sadness." The bird sings so diligently that it is often heard long after sunset. Hence in some places of New England the bird has been called the "Nightingale." The sounds "woit, woit" are often distinctly heard in the song, and these especially are uttered very powerfully and with wonderful harmony.-All our present great ornithologists praise the song of the Veery. Prof. R. Ridgway who heard it in the mountains of the West, describes it as really inspiring; their song consisting of an inexpressibly delicate metallic utterance of the syllables ta-weel'ah, ta-weel'ah, twil'ah, twil'ah, accompanied by a fine trill which renders it truly seductive.

The following interesting passage on the Veery's powers of song occurs in Dr. Elliott Cones' "Birds of the Colorado Valley": "For myself, I rate this bird as one of the sweetest of our songsters.... No one of the voices of the woodland is less quaint than the Veery's; no one is truer to its theme, more measured in its cadences, or softer and clearer in tone than that of the Veery - rival of the Olive, the Hermit, and the Wood Thrush, completing the quartette of silver-tongued cantatrices, who pledge the promises of spring-time in choral symphony."-Like all the other Thrushes the Veery perches on elevated branches when it sings, usually on a tree-top.

Its flight and mode of progression over the ground is decidedly thrush-like. In all its actions and ways, too, it does not differ from the other small Wood Thrushes. It is never particularly gregarious not even in its winter quarters. Migration takes place during night, while during the day it looks for food.

This species is quite as adaptable to cage-life as the others. When first caged, it is very wild and unruly, but it soon learns to know its keeper and finally puts aside all shyness. All that I have said about the Wood Thrush in this connection holds true of the Veery also. The small Thrushes - I refer here to the five species usually known as Wood Thrushes (Hylocichla), viz.: the Wood Thrush, Veery, Alice's Thrush, Herimit, and 
Olive-back - are very amiable and noble birds, they are also very peaceable and get along well with other birds, though they never delight us with their full song in an aviary. In order to enjoy their song fully it is necessary to give them a roomy cage and to tend them carefully. Then these little Thrushes, which belong to the finest songsters of all birds, become the most grateful companions the bird-fancier can possess.

- NAMES: Veery, Wrson's Thuush, Tawny Thrush, "Nightingale."-Germ. Röteldrossel, Fuchsdrossel, "Viry".

SCIENTIFIC NAMES: TURDUS FUSCESCENS STEPH. (1817), Turdus mustelinus Wils. (1812), T. wilsonii Bonap. (1824), Merula wilsonii Brewer (1844), Hylocichla fuscescens Baird.

DESCRIPTION: Upper parts light tawny browa with a faint olivaceous tint; below creamy white, 'marked with brownish spots and streaks. Sexes do not differ in color. Iength 7 to 7.50 inches. - Nest on or near the ground, built without mud. Eggs 4 to $5(.85 \times .66)$ plain greenish-blue.

Recently Prof. R. Ridgway described a new variety ( $T$ : fuscescens salicicolus Ridgw.) from the Rocky Mountain region. See his "Mantal of North American Birds" p. 574.

\section{Gray-Cheeked, or Alice's Thrush.}

Turdus aliciae BAIRD.

原 $I$

LTHOUGH this Thrush bears a strong resemblance to the Olive-back, it is never-

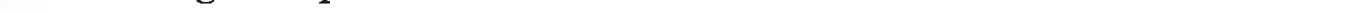
named, breeding abundantly within the Arctic Circle, especially near the mouth of the Mackenzie River, and in the woods bordering the Anderson River and Great Slave Lake. Dr. Elliott Coues found it nesting commonly in Labrador. So far our incomplete information does not enable us to state how far south it ranges during the breeding season. It is, however, not known to breed anywhere in the northern part of the Union. Here it is represented by a variety, Turdus aliciae bicknelli RIDGw., which is confined to the Alpine regions of the Eastern States.

McFarlane collected near the mouth of the Mackenzie River and the Coppermine a large number of nests and eggs and sent them to the Smithsonian Institution. Almost all the nests found by various collectors were placed in low bushes two to seven feet from the ground. A few were discovered even on the ground. The structure is usually composed of mosses, bark-strips, old leaves, grass, and the stems of some species of Equisetaceae. The eggs are greenish blue, spotted with light brown.

During migration in autumn and spring the Gray-cheeked Thrush is a common bird in our woodlands. In northern Illinois it makes its appearance late in September and passes southward without long delay. In spring it usually arrives during the last days of April and then often lingers several weeks. At this time you may hear its really beautiful, delicious song. It is unlike the song of all the other smaller Thrushes, but is nearest that of the Hermit. It differs, however, in being exactly inverse, for 
whereas the Hermit begins with its lowest notes and proceeds on an ascending scale, Alice's Thrush begins with its highest and concludes with its lowest note. So, at least, Brewer tells us. The song is softer, more distant, not so loud and ringing as that of the Olive-back. In Chicago I kept several in a cage, but not one delighted me with its full song.

I have never seen more than two of these birds together. They are shy and avoid the immediate vicinity of man. Their food consists mostly of insects, which are sought for on the ground among dead leaves. In autumn they also feed on the berries of the black-haw, holly, magnolia, Mexican mulberry ${ }^{1}$, and with preference on pokeberries ${ }^{2}$.

NAMES: Gray-Cheeked Thrush, Alice's Thrush.-Germ. Grauwangendrossel, Alice-Drossel.

SCIENTIFIC NAMES: TURDUS ALICIAE BAIRD (1858), T. swainsonii aliciae Coues (1872).

DESCRIPTION: Above grayish-olive, the cheeks uniformly grayish; chin, throat, and belly creamy white, marked with large sagittate dark spots. Sexes alike.-Length 7 to 8 inches. -Nest in low bushes, sometimes on the ground. Eggs greenish blue, spotted with light brown.

\section{BICKNELL'S GRAY-CHEEKED THRUSH.}

Turdus aliciae bicknelli Rrogw.

More interesting than the real species is the local race discovered by Mr. Eugene Bicknell on June 15, 1881, in the Catskill Mountains and subsequently named after its discoverer by Prof. R. Ridgway of the Smithsonian Institution. Mr. Bicknell gives such a beautiful description of the region and its bird-life; that I will cite it in full for the benefit of my readers.

"That there remained unrecognized at this late day a bird regularly inhabiting one of the most populous portions of our country; or, indeed, that a species of eminently boreal habitat during its breeding season, and not known to occur at all at such time within the limits of the United States, should have a representative race regularly breeding in our midst, are facts for which we were little prepared. . . On June 15, 1881, nearing the summit* of Slide Mountain in Ulster County (N. Y.), the forests of a more northern latitude were forcibly suggested. A shower had fallen during the ascent, and the sun was still obscured, while a sharp wind from the northwest piercing the wet woods and sighing among the balsams, blasted and weather-beaten, heightened an impression of remoteness and desolation. The evergreens, constituting the principal arboreal growth, extended off on all sides, clothing the rocky and moss-grown slopes, and presenting the striking contrast of a young and fragrant second growth clustering about the branchless and spiny trunks of their sires tottering in decay; or, with tangled and matted branches outlined here and there, as we approached the summit, against a gray and cheerless sky. Owing to the comparatively short life of these trees, that high portion of the mountain where their tribe had pitched was brought into grim contrast

1 Callicarpa americana. 2 Phytolacca decandra.

* The highest peak of the Catskills, -4205 feet altitude. 
with its surroundings. Old age and death, continually present invading their ranks, had everywhere left their traces; flourishing clusters had been stricken in their fellow. ship, groups and gatherings had been divided and scattered, and like a contagion the destroyer had spread among their hosts. But the younger generations are continually forming their associations, and with green and fragrant grouping filling in deserted chambers and screening the devastation that has gone before, although only to furnish material for its continuance in the future. All this, with an occasional undergrowth of greater or less luxuriance, gave a diversified and somewhat open character to the surroundings, entirely dissimilar to that of the evironing forest; conditions which, in conjunction with humidity and elevation, have brought this mountain top into some relation with the swampland of a more northern region.-Reaching a more elevated portion of the ridge where the ground was more level and the surface less rocky, that north-woods tree, the paper birch ${ }^{1}$ occasionally appeared, and more abundantly the mountain ash. Almost the only remnant of the dense mountain forests below was the yellow birch ${ }^{2}$ which, joining the undergrowth, persisted with small and stunted stature to the summit. On all sides were to be seen the white blossoms of Viburnum lantanoides which, though also found in the valley woodlands, had there long since flowered and was now bearing green fruit. Another characteristic shrub was Amelanchier canadensis oligocarpa; lower down had been found the var. botriapium, but here the northern form was well marked, seeming almost specifically distinct. In the deep, damp moss, covering and filling in the rocks beneath the balsam growth, and relieving the ruggedness of the slopes, northern plants were growing in greater or less profusion. The dwarf cornel $^{3}$ grew in such close luxuriance in congenial spots, that its snowy bracts imparted an almost uniform whiteness to whole beds. With, or near it, blossomed the wood sorrel 4 with delicately violet-veined petals, and the appropriately named gold-thread ${ }^{5}$ of evanescent bloom but shining evergreen leaves, and the little star flower ${ }^{6}$ were often also associates. Excepting the pale yellow bells of Clintonia borealis, and the purplish tinge, or veining, of the blossoms of several other species, all the plants noticed in bloom at this time upon the mountains, bore flowers of some shade of white. The more open ground about our course along the ridge supported a luxuriant and graceful growth of that lovely fern Aspidium spinulosum, and with it, in openings about the summit, grew abundantly the mountain golden-rod ${ }^{7}$ which, although yet many weeks from bloom, heralded a royal emblem to light the mountain's brow ere the white locks of winter should again possess it.

At an elevation where these plants first appeared the trees nowhere attained more than a medium stature, those which seemed best to have surmounted the difficulties of their situation, the balsam and the paper birch, never rising to a height of more than, perhaps, twenty-five feet. This growth completely encompassed the range of vision, but an occasional scantiness in the foliage permitted glimpses of surrounding mountains rolling off like huge green billows into the blue distance.

From these evergreens came the leisurely call of the Canada Nuthatch ${ }^{8}$, and on closer approach the low plaintive notes of the little Yellow-bellied Flycatcher ${ }^{9}$. The

1 Betula papyracea. 2 Betula Iutea. 8 Cornus canadensis. 1 Oxalis acetosella. "Coptis trifolia. B Trientalis americana. "Solidago tbyrsoidea. u Sitta canadensis. - Empidonax faviventris. 
brief warble of the Black-and-Yellow Warbler ${ }^{1}$ told of the presence of its unseen author in the surrounding trees, while among the undergrowth the less frequent, but louder and more sustained song of the Mourning Ground-warbler ${ }^{2}$ showed that this species, which had been left at the foot of the mountain, had here reappeared. At intervals, faintly mingling with these songs, from some hidden fastness from below, came the fantasia of the Winter Wren, a melody that seemed to pass from the spirit of unclaimed nature, voicing some mystery of the mountains. The clamor of a party of Blue Jays occasionally arose and died away in the forest, but here in this mountain solitude, their screams seemed more subdued than in less primitive regions, and lacked that suggestion of consciousness which individuals constantly within human hearing, seem to acquire. Busily roaming Chickadees" at times came about our path, and the Snowbird ${ }^{4}$ was present with its simple song. Olive-backed Thrushes ${ }^{5}$ too, were constantly to be heard, and finally, guided by its near song, one was followed up and secured. A moment later another Thrush darted across the path, and disappearing through a young balsam growth, immediately began to sing a few rods off. The song was different from that of the bird which has just been shot, so much so, in fact, as to be remarked even by my guide. It seemed to be more uniform in character, with less variation and definition of the notes: as I wrote in my note-book at the time-more suggestive of the song of the Veery. A conspicuous point of difference was that it was more subdued in tone, in fact of a somewhat ventriloquous nature. On examining the bird, in hand, although I had thought myself familiar with all our eastern Wood Thrushes ${ }^{6}$, I must confess to having been puzzled. It was obviously neither the Olive-backed nor the Hermit Thrush, the only species of our own smaller Thrushes which from the distribution of their group (as then understood) could possibly be expected to occur. I at once noted its general resemblance to the Gray-cheeked Thrush, but it seemed impossible that this Hudsonian bird could be found so far south at this season; and though a second specimen pointed more strongly toward it, it was not until I had reached home and made actual comparisons, that I could feel satisfied that its true relationship was with that species. These examples from the Catskills were stubmitted to Mr. Ridgway, the result being the recognition of a new bird, belonging to our eastern fauna.

But to return to the mountain. It would hardly be justifiable to make a positive statement about a difficult song that had been but once identified, but I feel positive that the Thrushes which were last heard that evening about our camp on the extreme summit of the mountain were of the new form. Night was rapidly falling, and the valleys were in darkness, when one sang several times near the camp, and for some time afterwards a single call-note was occasionally heard, and the varying distance of the sound showed that the birds were still active. Excepting these sounds, the last bird-notes heard were those of the Yellow-bellied Flycatcher.

The sharp northwest wind continued late, and the night became clear and cold. Shortly after midnight the bright moon showed the temperature, by a thermometer which I had hung beside the camp, to be $35^{\circ}$, and at sunrise it stood at $32^{\circ}$. Before daylight I was standing on a boulder of conglomerate on the dim mountain's brow

1 Dendroica maculosa. 2 Geothlypis philadelphia. a Parus atricapillus. 4 Junco hyemalis. o Turdus ustulatus swainsoni. G Hylocichlae. 
listening for the awakening of the birds. The first songs heard were those of the Hermit Thrush, Snowbird, and Yellow-bellied Flycatcher, which began almost simultaneously, followed a little later by those of the Olive-backed Thrush and the Mourning Warbler, but $T$. aliciae bicknelli was not heard, or at least not near enough to be distinguished among the other species.

The increasing light upon the mountain seemed to attract the birds from below, whither, perhaps, they had retired for the night, and soon many different notes were to be heard about the camp; not, however, in that boisterous chorus with which the day is often announced about our homes, in which the notes of many individuals of many species are blended in such confused medley that separate voices are almost vindistinguishable, but simply the association of a few vocalists, the very isolation of whose position endowed their voices with an additional interest and charm.

After those already mentioned the Black-poll Warbler ${ }^{1}$ began its unpretending notes, which almost to me suggest a short dotted line, and this song, with that of the Black-and-Yellow Warbler, occasionally alternated about us in agreeable contrast. Now and then a Canada Nuthatch, on its morning tour, tarried to inspect some dead trunk or thinly clothed tree, upon the projecting apex of which, or that of some companion, a solitary Purple Finch occasionally alighted, and with a few wild fugitive notes was gone, to other mountain tops or the forests of the descending slopes.

But to revert to the Thrushes. The two specimens of the new form which were obtained were both males, and were unquestionably breeding, though no nest known to belong to their species was found:" *'

In the following year, $1882, \mathrm{Mr}$. Wm. Brewster found this new race among the White Mountains, especially in the forests covering the slopes of Mt. Washington. He gives a very attractive and interesting account of the Alpine fauna and flora of that famous mountain in the January Number of the "Bulletin of the Nuttall Ornithological Club" for 1883 p. $12-17$, though the article to which I refer treats especially of Bicknell's Thrush.

Mr. Langille found the nest of this Thrush in the almost impenetrable evergreen thickets of the Mud and Seal Islands southwest of Nova Scotia. "Placed a few feet from the ground, and against the trunk of an evergreen tree, the nest was composed externally of various kinds of mosses, including a few fine sticks, weed-stems and rootlets, and was lined with fine grasses well bleached; so that, outside, the nest was as green as a bunch of fréšh moss, and the inside was light brown. The eggs, $.87 \times .63$ of an inch, are light bluish-green, speckled with brown. About the Mud and Seal Islands dense fogs prevail almost continually throughout the summer. This excessive moisture, so productive to mosses, causes the moss in the walls of the Thrushes' nests to grow; hence the nests of the previous years, well protected from the weather by dense evergreens, become elegant moss-baskets finely ornamented within and without with living cryptogams." $\ddagger$

In coloration the bird is very similar to Alice's Thrush and only to be distinguished from that form by the scientific ornithologist.

\footnotetext{
1 Dendroica striata.

* "Bulletin of the Nuttall Ornithologienl Clib." 1MM3, p. 152-159.

\$."The Aulk. A Quarterly Journal of Ornithology." 1K\$4, p. 268-270.
} 


\title{
Olive-BAcked Thrush.
}

\author{
Turdus ustulatus swainsoni RIDGw.
}

Plate I. Fig. 6.

\begin{abstract}
LL our small Thrushes are true woodland birds and are often especially abundant fore where are many conifers intermingled with deciduous trees. They also show a particular preference for coniferous trees during migration. Regularly they may be found where pines and spruces have been planted for ornament. In these trees they can find the best protection against the inclemencies of the weather and can most easily seek refuge from their many enemies. It was in the belts of evergreens in the midst of the otherwise monotonous prairies of northern Illinois that I first observed
\end{abstract} this little Thrush in great numbers.

In the greater portion of our country the Olive-backed, or Swainson's Thrush is only a transient visitor. Its real home, its breeding range, extends from $44^{\circ}$ North latitude to the Arctic regions. Hence it must be looked for where the Hermit breeds, a bird which it surpasses in northern extent. I have observed this active little Thrush almost every year in Wisconsin, Illinois, Missouri, and, during migration, though rarely, in Texas. In the last named State the bird appears about the middle of April, in Wisconsin it rarely arrives before the first week of May. It migrates in pairs or in small flocks, tarries only a short time on the route, and then hastens to its northern home. About the middle of September the first Olive-backed Thrushes appear again in northern Illinois, by the end of the same month they are still abundant in Missouri and by the beginning of October, with the exception of a few stragglers, they have all departed for more southern regions.

This Thrush fearlessly visits the gardens and orchards even in cities and thus comes within the immediate neighborhood of human dwellings. In Oak Park, a suburb of Chicago, it came daily in company with White-crowned Sparrows, White-throated Sparrows, and Snowbirds under the kitchen window of my house to look for food. If frightened by any strange noise it would fly quickly to the next group of spruces, only to descend to the ground the very next moment. During fall migration they prefer to keep to the bushy edges of woods, in the neighborhood of water, though they also occur in the interior of woods, even where there is little undergrowth. Like many other birds they are often found in great numbers along rivers and creeks flowing in a southerly direction. It is usually seen rapidly and restlessly hopping about after the manner of all the true Thrushes in search of insects, its principal food. The dead leaves beneath trees and shrubs are searched with particular care. In autumn all kinds of berries constitute no small part of its food. It will even search freshly-dug garden soil 
for insect larvae and worms and when thus engaged it acts just like its near congener the Robin, hops a little distance over the ground, suddenly comes to a stand, quickly raises its tail and drops its wings, listens attentively, leaning its intelligent head slightly to one side, picks up a worm here and a beetle there, and again repeats the same action till the whole piece of ground has been searched. Nothing escapes its attention, every strange object is curiously examined from a respectable distance. Notwithstanding its boldness, the Olive-backed Thrush is a suspicious bird that knows well how to keep out of danger. I actually know no bird that looks into the world with such pretty intelligence as this little Thrush. In spite of its plain plumage there is something aristocratic, a noble air, in all its ways.

Among the branches of trees and shrubs the Olive-backed Thrush is very agile. Its flight is easy and quick. Every one of its movements is entirely thrush-like. It appears in south-eastern Texas in the beginning of October and feeds in company with other species on the berry-like, balsamic fruit of the Magnolia grandiflora. Many thousands are annually killed by pot-hunters. This shameful slaughter is carried on notabiy near New Orleans, where this species together with the Wood Thrush and Veery is killed in large numbers during fall migration. The Hermit escapes a similar fate only by arriving much later.

Should the weather be pleasant, the Olive-backed Thrush will tarry, but as soon as the first cold "Northers" sweep across the Texan prairies it moves on southward. It wanders not only as far as southern Mexico but even to Guatemala, Costa Rica, and across the Isthmus of Panama into the interior of South America, where many seem to pass the winter in Ecuador or even in Peru and Brazil. As a straggler this Thrush has also been found on the small North Sea Island of Heligoland. No other of our Thrushes is distributed over such an immense territory as this species, for it nests northward as far as the Arctic regions and spends the winter near or even under the equator. Probably many pass the winter in the West Indies and southern Florida.

During the breeding season we find Swainson's Thrush from the Atlantic to the Yukon and Great Slave Lake. It is also a common summer resident in the Rocky Mountains as far west as the East Humboldt Mountains and the upper Columbia. In mountainous districts it occurs much further south during the breeding season than on the plains. In the Catskill Mountains in eastern New York, it is, like Bicknell's Thrush and the Hermit, a tolerably common summer resident. Probably it is found much farther south in the Alleghanies.

"My correspondent, Mr. T. M. Trippe," says Dr. Elliott Coues *, "found the bird in Colorado in May and September; and on one occasion in October, when the snow lay a foot deep on the ground, he observed it in company with various other species which had gathered about the Hot Sulphur Springs, in the Middle Park, apparently attracted by the warmth of the tepid pools." "In the vicinity of Denver," says Mr. H. W. Henshaw, "this species makes its appearance about the 10th of May; and by the 17th the thickets and partially open ground in swampy localities were fairly swarming with these birds. They were perfectly silent, and busied themselves after the usual manner of the family in scratching and seeking among the leaves for food. The males preceded 
the arrival of the females by at least a week." The most explicit accounts from the far West.are, however, those given by Mr. Ridgway, in his still unpublished Report on the birds observed during 'Clarence King's Survey of the Fortieth Parallel. I quote from proof-sheets which he kindly placed at my service: "Swainson's Thrush is a very abundant species among the Wahsatch Mountains, and is, in fact, one of the most characteristic summer birds of that region. It breeds plentifully in the cañons, where its song may be heard almost continually during the nesting season..... Numerous nests were found among the thickets bordering the streams; they were generally situated about five to six feet from the ground, in the willows or other shrubs, near the water." According to Mr. Ridgway the song resembles that of the Wood Thrush in its modulations; but the notes want the power, while they possess a finer and more silvery tone. Still the bird is a superb singer. This is corroborated by all observers who have had an opportunity of listening to its notes. According to Dr. Brewer its song has a certain resemblance to that of the Hermit, being yet quite distinct, and the differences readily recognized by a familiar ear. It is more prolonged; the notes are more equal and rise with more regularity and more gradually, are richer, and each note is more complete in itself.

In some parts of New Hampshire and Maine it is the commonest Thrush excepting the Robin, and it probably may be found in equal numbers in the mountainous regions of Vermont and New York during the breeding season. Its usual resorts are like those of the Hermit. With the exception of Alice's Thrush it differs from all other Wood Thrushes in the coloring of its eggs. These, usually four in number, are greenish blue in color, spotted all over with brown. As a rule the nest is built in a bush or small tree, five to six feet from the ground. In the Arctic regions Mr. Kennicott found nests only two feet above the ground. The materials vary with the locality, being moss, leaves, bark-strips, and fine fibres, but the layer of mud, so characteristic in the nests of the Robin and Wood Thrush, is wanting. Some nests have a very peculiar appearance from the Hypnum-mosses used in their construction.

I have kept several specimens of the Olive-backed Thrush in confinement for years. With kind treatment and proper attention these birds, notwithstanding their unruly ways at first, grew accustomed to their new home and even became very tame and affectionate. Numerous recently captured adults which I received from time to time in Chicago, soon became so docile that they would take meal-worms, grasshoppers, and flies from the hand. Their cheerful ways, their peacefulness with other birds of their own and other species, their smooth pretty plumage, and other excellent qualities, render them very agreeable cage-birds. I kept an especially fine pair in an aviary in company with Bluebirds, Baltimore Orioles, Hermits, Catbirds, and Snowbirds. They would often chase one another in play about the cage at the same time uttering their prolonged very melodious call-notes.

When these Thrushes are kept in company with other birds, they rarely sing. Only when kept alone in a roomy cage and tended carefully, may they be expected to sing their full song. For years I have had only two that uttered their wonderful notes in all their completeness. This piece of bird music is full of variety, though somewhat mournful. I cannot maintain that it bears any great resemblance to the song of other species. 
It is almost too loud for the narrowness of a room. It belongs to the silent woods where the constant whispering in the pines, the murmur of the forest brooks, and the gurgling of the springs are its proper accompaniment. Only when the song has been heard here, can it be fully appreciated.

NAMES: Olive-Backed Thrush, Swainson's Thrush, Swamp Robin, Little Thrush.-Germ. Sängerdrossel, Olivendrossel.

SCIENTIFIIC NAMES: Turdus swainsoni Cab., TURDUS USTULATUS SWAINSONI RIDGw,

DESCRIPTION: Male and female alike. Above clear olivaceous; below white, throat, breast, and sides of the head suffused with buff; most of the under parts, except the throat, marked with numerous dusky triangular spots. Length 7 to 7.50 inches. - Nest in bushes in damp woods. Eggs, usually 4 , light greenish blue spotted with brown $(.90 \times .65 \mathrm{inch})$.

The RusseT-BaCked, or Oregon Thrush (Turdus ustulatus NuTT.) is now regarded as the real species, and the preceding as only a variety. This species is an inhabitant of the Pacific Coast north to Sitka. It winters through Mexico to Guatemala, and breeds abundantly in the Sierra Nevada and in the mountains of Oregon and Washington. Mr. Ridgway speaks with enthusiasm of its song. In regard to nesting and other points it does not differ from Swainson's Thrush. The color of the back is more russetbrown, the spots on the chest smaller and of a dark brown color.

\section{HERMIT $\dot{T} H R U S H$.}

Turdus aonalaschkae pallasi RIDGw.

Plate I. Fig. 2.

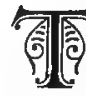

HE highly interesting HermiT Thrush might be called the "May Blossom"* of our birds. Its charms are manifold but the enthusiastic observer and lover of birds is rarely able to penetrate the solitude of its swampy northern woodland home. To obtain a clear idea of the species from the older ornithological literature he must work his way through an almost impenetrable confusion of different scientific names, incorrect accounts, and misunderstandings of all kinds. This confusion and everchanging nomenclature has lasted till the present time and only recently have our leading ornithologists introduced order into this chaos. In obedience to the law of priority the American Ornithologists' Union have adopted a scientific name which, though not pretty, must come into general use.

In the Eastern States the Hermit is one of the best known and most common of our Thrushes, at least occasionally in spring and autumn. Usually it is confounded with the similar but somewhat larger Olive-backed Thrush, from which it may be distinguished at the very first glance by its reddish brown tail. On this account the bird is sometimes called the Rufous-TaIled THRush. It further differs from the Olive-backed, 
by appearing in spring fully two weeks sooner and returning two or even three weeks later in the fall. Being restricted to the Canadian fauna it nests only in the Northern and in the high mountain woods of the Eastern States, but it is abundant in many parts of the Middle States during migration. The Southern States are its winter quarters. I have observed the Hermit every year in small companies or in pairs in Illinois from about the beginning to the middle of October and in southern Missouri towards the end of the same month. At this time they fearlessly and unsuspectingly enter gardens close to dwellings and look for insects on the ground and among the fallen leaves. I found them most common along the bushy, low and damp edges of woods, which are at this time also the favorite resort of a great number of different birds bound for the South or North. Finches, especially Fox-colored Sparrows, Whitecrowned Sparrows, White-throated Sparrows, Slate-colored Juncos, and others are the constant companions of the Hermit. In spring it is the first of all the smaller Thrushes to return from its winter quarters. Even. in the beginning of April I have seen these birds on their way to their northern breeding haunts. They often tarry from one to two weeks before deciding to continue their journey.

During its stay in spring it will return daily with great regularity to the same clump of trees or thickets, and to the same garden. In the neighborhood of Houston, Texas, and thence westward to Austin, it is one of the most common winter visitors. It keeps in the dense shrubbery that borders the bayous, rivers, creeks, and branches, along the margins of the bottom woods and in the neighborhood of fields, but always where it has as companions besides the birds above mentioned, hundreds of Cardinals, Towhees, Thrashers, Yellow-breasted Chats, Carolina Wrens, Myrtle Birds ${ }^{1}$, and many others. Here, too, the Hermit seeks the greater part of its food on the ground, though it eats many berries, especially those of the holly and Mexican mulberry ${ }^{2}$. On entering, some time between November and March, their sheltered haunts, overgrown mostly with evergreen trees and shrubs, such as the magnificent magnolias, hollies ${ }^{3}$, cherrylaurels ${ }^{4}$, wax myrtles ${ }^{5}$, red bay ${ }^{6}$, loblolly bay ${ }^{7}$, and many deciduous trees, a whole host of the most varied species of birds rises from the ground to settle on the trees and bushes. All remain perfectly silent, only the Hermit utters a soft "chuck." While residing in my simple cabin in the woods near the Yegua Creek, in Texas, I had the best of opportunities during the whole winter to observe these Thrushes in my immediate neighborhood. Though there were hundreds of them in the thickets near the creek, I never saw more than from six to ten individuals together and these were usually scattered over a considerable portion of the woods. At the warning note of one of these Thrushes not only all other Hermits but even the swarms of Finches and other birds rapidly disappeared in the nearest tangled thickets. I never heard the song during their winter stay or during migration. Towards the end of February and the beginning of March they begin to leave south-eastern Texas, and by the middle of the latter month the last stragglers seem to have departed for the North. These Thrushes pass the winter also in gleat numbers in Louisiana, Mississippi, Alabama, and especially in Florida. They have been observed even in southern Illinois and in the neighborhood of

1 Dendroica coronata. 2 Callicarpa americana. 3 Ilex opaca, I. dohoon, and I. myrtifolia. 4 Cerasus caroliniana. 5 Myrica cerifera. G Persea carolinensis, 7 Gordonia lasianthus. 
Washington, D. C., during the winter, and scattered individuals pass the cold season even farther north.

The breeding range of the Hermit extends northward from the 44th parallel. It is very common in Maine, likewise in the beautiful Adirondacs and Catskills, probably also in Canada and northward from central Michigan, Wisconsin and Minnesota. Westward it extends up into the Rocky Mountains. In Colorado it occurs at an altitude of from 1,000 to 8,000 feet. Here the bird appears toward the end of May; about the middle of June it abounds in the thicket-grown mountain valleys and forests, from which its beautiful song continually echoes. - It always chooses for a home the dense swampy woods composed of luxuriant and varied vegetation, rarely pierced by the sun's rays. On this account it is often called the Ground Swamp RoBin or Swamp RoBIN. In the many luxuriant and solitary woods of central and northern Wisconsin the Hermit seems to be a rather common summer resident. This is especially true of the large white cedar and tamarack swamps. Far removed from the bustling activity of man in the secluded forest solitude, in the half shadow cast by the trees and bushes, the Hermit Thrush pours forth its charming song, so wonderful that the people in the romantic Adirondacs call the bird the Swamp ANGEL.

In Dr. Elliott Coues' admirable work on the "Birds of the Colorado Valley" I find the following paragraph on the Hermit's song: "Great injustice would be done were the Hermit's musical powers overlooked in any sketch, however slight, of its life-history. The earlier authors were evidently unaware of its accomplishments, for its melody is lavished in the gloom of the swamp, or lost in the darkening aisles of the forest, where years past by before the ear of the patient and toiling student of nature was gladdened by the sweet refrain. Wilson denies its song; Audubon speaks of 'its single plaintive note,' though he adds, perhaps upon information received from his friend Dr. Pickering, that 'its song is sometimes agreeable.' Nuttall seems to have first recognized the power and sweetness of the lay of our Flermit: he compares it to the famous Nightingale, that sweet princess of song, and ranks it far above the Wood Thrush. Later writers agree in this high estimate of the bird's powers, though it may be questioned whether a comparison unfavorable to the Wood Thrush is a perfectly just discrimination. The weird associations of the spot where the Hermit tritumph, the mystery inseparable from the voice of an unseen musician, conspire to heighten the effect of the sweet, silvery, bell-like notes, which, beginning soft, low, and tinkling, rise higher and higher, to end abruptly with a clear, ringing intonation. It is the reverse of the lay of the Wood Thrush, which swells at once into powerful and sustained effort, then gradually dies away, as though the bird were receding from us; for the song of the Hermit first steals upon us from afar, then seems to draw nearer, as if the timid recluse were weary of solitude, and craved recognition of its conscious power to please. Yet it is but a momentary indecision - true to a vow of seclusion, the anchorite is gone again to its inviolate grotto in the fastnesses of the swamp, where a world of melody is wasted in its pathetic song of life:-

Ful1 many a gem of purest ray serene

The dark infathomed caves of ocean bear;

Full many a flower is born to blush unseen,

And waste its sweetness on the desert air." 
Mr. John Burroughs in his little book "Wake-Robin" gives a very beautiful description of the song of the Hermit Thrush. He observed this bird especially in the Adirondac Mountains. The description shows what an eye and ear he has for everything beautiful in nature:-

"Ever since I entered the woods, even while listening to" the lesser songsters, or contemplating the silent forms about me, a strain has reached my ears from out the depths of the forest that to me is the finest sound in nature, - the song of the Hermit Thrush. I often hear him thus a long way off, sometimes over a quarter of a mile away, when only the stronger and more perfect parts of his music reach me; and through the chorus of Wrens and Warblers I detect this sound rising pure and serene, as if a spirit from some remote height were slowly chanting a divine accompaniment. This song appeals to the sentiment of the beautiful-in me, and suggests a serene religious beatitude as no other sound in nature does. It is perhaps more of an evening than a morning hymn, though $I$ hear it at all hours of the day. It is very simple, and I can hardly tell the secret of its charm. 'O spheral, spheral!' he seems to say; 'O holy, holy! O clear away, clear away! O clear up, clear up!' interspersed with the finest trills and the most delicate preludes. It is not a proud, gorgeous strain, like the Tanager's or the Grosbeak's; suggests no passion or emotion,- nothing personal,- but seems to be the voice of that calm sweet solemnity one attains to in his best moments. It realizes a peace and a deep solemn joy that only the finest souls may know. A few nights ago I ascended a mountain to see the world by moonlight; and when near the summit the Hermit commenced his evening hymn a few rods from me. Listening to this strain on the lone mountain, with the full moon just rounded from the horizon, the pomp of your cities and the pride of your civilization seemed trivial and cheap."

The life sketch of the Hermit would be incomplete, should I forget to cite Dr. Elliott Coues' excellent description on the nesting of this bird. $\mathrm{He}$ writes as follows :

"How quietly and with what solicitude for privacy the nesting of the Hermit Thrush is accomplished! Such care is taken to conceal its nest in the recesses of tangled undergrowth that few are the ornithologists who have found it. If Wilson, Nuttall, or Audubon ever saw a nest, no one of them recognized its owner. The nests and eggs which they describe as those of the Hermit, were certainly the Olive-backed Thrush's, the only one which nests at any considerable distance from the ground and lays spotted eggs. And unless the Hermit has changed its choice of a summer home since Wilson and Audubon thought they had discovered its nest, it never bred in the southerly regions where they thought it did. But their mistake was not unnatural, since, singular enough, neither of these ornithologists knew the difference between the Olive-backed and the Hermit Thrush.... The manner in which the nest of the Hermit Thrush is built, its situation, and the eggs, are all so similar to the Veery's that one must detect the shy parents themselves before being sure which has been found. The nest is built on the ground or near it, generally in some low, secluded spot; no mud is used in its composition, the whole fabric being a rather rude and inartistic matting of withered leaves, weed-stalks, bark-strips, and grasses-the coarser and stiffer substances outside, the finer fibres within. The cup is small in comparison with the whole size, owing to the 
thickness of the walls and of the base. The eggs are like those of the Robin and Wood Thrush, in their uniform greenish blue color, but smaller, measuring about nine-tenths of an inch in length by five-eighths in breadth; being thus not distinguishable from those of the Veery. I have never known of an instance, to my recollection, of the eggs being spotted; but so many birds which usually lay whole-colored bluish eggs occasionally drop a set which are somewhat speckled that I should not be surprised to find at any time a Hermit Thrush's egg showing a few specks about the larger end."

We are still little acquainted with the breeding habits and the life of the Hermit in its summer haunts. Even the limits of the breeding range have not yet been established with certainty. That it is a common bird of the Canadian fauna we well know, but probably it breeds in considerable numbers also in the rhododendron and kalmiaclad Alleghany Mountains. Mr. Bicknell found it with the Olive-backed and Bicknell's Thrush during the breeding season in the Catskills of eastern New York.

Its flight and all its manners are precisely the same as those of the smaller Thrushes. Its food, usually sought on the ground, consists principally of insects. The different berries found in its swampy home vary this diet.-

Caged Hermits, though very wild during the first days of their captivity, finally become quite tame and affectionate. I have kept many, and almost all of them became so tame that they would take meal-worms, grass-hoppers, \&c., from my hand. As the sexes are colored alike, a long time elapsed before I could single out and isolate a singing male. Even when thus separated, a year may pass without once hearing the bird's real song. It commences singing about the beginning of April, at first very softly, with interrupted twittering; finally, about the beginning of May, the song becomes full and exceedingly harmonious. It sings loudest and most persistently in the morning and in the calm quiet evening twilight when almost all other birds are silent. Every sound is so pleasing, so full of euphony, so charmingly sweet, that it fills every hearer with enthusiasm. Unfortunately the bird stops singing as early as the end of June.

To make it easy for the non-scientific bird lover and friend of nature to distinguish the more or less similar small Thrushes of Eastern North America I may note how the four leading species can be readily distinguished by the color of the UPPER PARTS alone:

1, The Wood Thrush is tawny, turning to olive on the rump.

if

2 , The Veery is entirely tawny.

3 , The Hermit is olive, turning to tawny on the rump and tail.

4, The Olive-backed Thrush is entirely olive.*

NAMES: Hermit Thrush, Solitary Thrush, Rufous-tailed Thrush, Swamp Robin._Germ. Einsiedlerdrossel.

SCIENTIFIC NAMES: Turdus pallasii Cab., TURDUS AONALASCHKAE PALLASII RIDGw., Merula solitaria Sw.

DESCRIPTION: Male and female above brownish-olive, changing to tawny or recldish-brown on the rump and upper tail-coverts; under parts whitish, tinged on the neck and breast with buff, shaded with gray on the sides, and marked with numerous large dusky spots. "Throat unmarked. Round the eye a yellowish ring. Length 7 to 7.50 inches. - Nest bilky, without mud, placed on the ground in deep, bushy, and swampy woods. Eggs uniformly greenish-blue, without spots. $.88 \times .66$ inch.

"See Stearns and Coules' New İngland Bird Life." Vol, I, p. 60. 
The description of our smaller Thrushes with their varieties is no easy matter. It is especially difficult to find a way through the ornithological literature bearing on this subject, as several allied and frequently identical birds have been ranked as different species. Of late, however, our "American Ornithologists' Union" has laid a solid foundation for nomenclature. Besides the Hermit just described, former ornithological works mention two closely related birds as true species. Audubon called a somewhat smaller western form Turdus nanus (Dwarf Thrush) and later a somewhat larger variety, also found in the West, was called Turdus auduboni (Audubon's Thrush). The real eastern species was called Turdus solitarius by Wilson, a name which was accepted by many ornithological writers of by-gone days, but as Linnaeus had before named another species "solitarius," and as it is necessary to recognize the right of priority in scientific nomenclature, the name given by Dr. Jean Cabanis, Turdus pallasi, in honor of the famous traveller and naturalist Pallas-has been accepted. Prof. Robert Ridgway, the celebrated ornithologist of the Smithsonian Institution, both a learned systematist and a gifted artist-as the beautiful plates of this work, partly painted by him, showfound that the small western form had been named Turdus aonalaschkae as early as $\mathbf{1 7 8 8}$ by Gmelin, consequently prior to the naming of the eastern Hermit Thrush. He therefore selected the first named form as the real species and regarded the two forms discovered and named later as varieties of the same.

The Western Hermit Thruse, or DWarf Hermit Thrush (Turdus aonalaschkae Gmel.), the typical species, inhabits the Pacific Coast from Lower California and western Mexico to Alaska. It breeds from the mountains of California north to Kadiak. Gmelin named the bird in accordance with the description of Pennant and Latham, two well known ornithologists of the last century. Little is as yet known about this bird's habits, nesting, song, \&c. It probably closely resembles the eastern Hermit in all these points.

DESCRIPTION: It is smaller than the Hermit of the East. Length 6 to 7 inches. The tail is "deep rufous, almost chestnut" (Ridgw.).

Audubon's Hermit Thrush (Turdus aonalaschkae auduboni RidGw.).-This variety which Brehm called the "Silent Thrush" (Schweigdrossel) after Swainson's name Merula silens, inhabits the Rocky Mountains from the northern border of the United States south to the highlands of Mexico and Guatemala. According to Sumichrast it is abundant in all the mountain forests. He found the bird at all seasons in the mountains near Moyoapam and Orizaba to an altitude of 8,000 feet. The Mexican name "Solitario" is proof enough that this variety does not differ in its habits from the eastern Hermit Thrush. Though little is as yet known concerning its song, one is justified in maintaining that this bird, like its related forms, is an excellent singer. The name "Silent Thrush" is doubtless misapplied.

DESCRIPTION: Larger than the eastern Hermit. Length 7.50 to 8.25 inches. "Tail dull ochraceous-rufous, or litlvous; colors in greneral ratlier grayer." (Rirgw.) 


\title{
AMERICAN ROBIN.
}

\author{
Merula migratoria SwaINs.
}

Plate 1. Fig. 1.

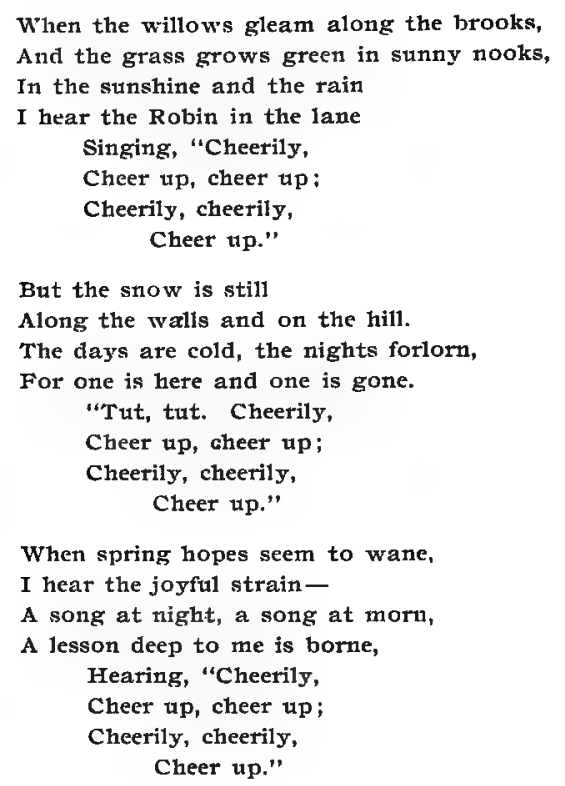

周HE early spring flowers still sleep beneath snow and ice, the cold north and west winds still wildly sweep the northern part of our country. All nature seems dead. Only a small number of feathered winter visitants have come from the far North and move about in the trees and shrubbery of the garden. Crossbills and Redpolls have already departed for their northern home. A few Kinglets, Tree Sparrows, Titmice, and Cedar Birds swing themselves on the snow-laden boughs of the pines and spruces. Suddenly and entirely tnexpected a loud song of jubilation is carolled from the top of a neighboring elm. There, in the top of yonder dark-green pine is perched another one of these singers. They are Robins just returned from their winter quarters, heralding in reverberating jubilation the approach of spring. This, our beatiful familiar Thrush, certainly merits the name "harbinger of the vernal season," for it is one of the first of our birds to arrive from the South. In the Northern States it often makes its appearance before the middle of March, though the great majority does not arrive till the end of that month. The inclement weather which often persists for several weeks, and the consequent scarcity of food sometimes force the bird to return southward again. Usually, however, it will remain in spite of the wintery garment covering nature, search- 
ing for food in spots from which the snow has melted, and enlivens its habitation with its powerful music. In the Northern States the whole of April is an inclement, changeful month. It is only in May, a month which often, too, retains traces of winter, that our birds of early arrival find favorable weather and abundance of their principal insect food.

Probably none of our birds has become so esteemed a favorite with the American people as the Robin. The pilgrim fathers of Massachusetts called this Thrush the Robin, or Robin Redbreast, because it reminded them of the affectionate and beloved Robin of their English home. The love of the latter bird together with its name passed over to the somewhat similarly colored Thrush of their new country. Hence to this very day the people of New England highly prize and in every way protect the Robin. It has, thanks to this protection, not only multiplied greatly but has taken up its home in numbers in villages and even in cities. Its familiarity, its early arrival from the South, its sonorous flute-like song, and its wide distribution have contributed not a little to this bird's favorable reception among us.

The Robin ranges from the highlands of Mexico to the Arctic regions and from the Atlantic to the Pacific.* No other Thrush of the United States has so extended a distribution and occurs so regularly and in such numbers as the Robin. A few even go to the West Indies and Central America in winter. It has been repeatedly found during migration in Europe and in summer it was observed as far north as the inhospitable regions of Greenland and on the islands of the Behring Sea. The greater number pass the winter in the Gulf States. I have observed them in large flocks in the forests of the lowlands of Texas and in the hummock-woods of Florida, where the fruit of different species of holly ${ }^{1}$ and the sparkle-berry ${ }^{2}$ furnish an abundance of food during the whole winter. Even in the middle of February $I$ have seen them in great numbers in the sugar-cane fields and in the extensive cypress-swamps of southern Louisiana. During mild winters single individuals may be found in protected spots even in New England, where they subsist on the remains of wild fruits and berries. More commonly they pass the winter in the Middle States. In Wisconsin the Robin is very common everywhere. In the beautiful, well watered forests of that State the bird is almost as numerous as in the cultivated districts. In Illinois and likewise in the southwestern part of Missouri and northern Arkansas it is also a common summer resident. In the last named localities it arrives, according to the weather, from the beginning to the end of February. In the Gulf region the Robin appears only in winter.

All our Thrushes, with few exceptions, are timid and shy, and shun the society of man. Most of them retreat to the deep woodland solitudes far from the abodes of man. All this is different with the Robin. Though originally a true forest bird, it has now everywhere attached itself to man, and though still retaining its former sagacity and vigilance has become quite confiding and fearless. You can find the Robin everywhere, in field and forest, in meadow and marsh, on hills and in valleys, in parks and gardens, and even high up in the mountains. It may be met with invariably in the woods

* Merula migratoria proper is found west to the Great Plains; thence to the Pacific it is represented by the variety M. migratoria propingua.

1 Ilex opaca, I. dahoon, I. myrtifolia. 2 Vaccinium arboreum, the tree-buckleberry. 
where the trees and undergrowth are not too dense. The Robin's favorite haunts, however, are districts where woods and fields alternate, and where there are orchards and swampy meadows. It breeds even in wooded swamps, especially where evergreens and deciduous trees grow together. In the cultivated parts of the entirely treeless western prairies, the Robin has become abundant since orchards were planted.

In Wisconsin and other Northern States the Robin will begin to build its nest as early as the middle of April, providing the weather is fair. In southwestern Missouri it commences as early as the end of March. I have found the nests at a height of from two to thirty feet from the ground, in the most various positions and situations; on trees, on high stumps, in the roots matted together with soil of trees prostrated by storms, in corners of rail fences, on rafters and under the eaves of old and uninhabited log-cabins, in sheds and old barns, on all kinds of fruit and ornamental trees, in bowers formed by the wild grape and other climbing plants, \&c. With decided preference it selects a nesting site in the dense coniferous trees now so generally used in ornamental gardening. It probably chooses such places because the nest is more protected from cats, than in other situations. It is remarkable that such an intelligent bird as the Robin does not always display the necessary precaution in selecting a spot for its nest, for the structure is sometimes built in a very exposed part of a tree, so that it may be seen from a distance, or it is located in the corners of rail fences close to a country road, or in the immediate vicinity - of a dwelling. Indeed, it is never very concealed and is one of the most easily found nests. The structure is composed externally of grassblades, plant-stems, bark-strips, moss, and fine rootlets; then follows a layer of mud which is motilded into a smooth cup-shaped cavity lined with dried grasses. The eggs, numbering five on an average, are of a uniform, rich, greenish blue color, without spots. Only the female sits on the eggs and is not fed by the male, on which account it has to leave the nest a short time each day to look for food. At such times the male stands guard near the nest, singing his finest melodies. After about thirteen days breeding the young hatch, and are faithfully cared for and defended by both parents. The first brood is usually followed by a second and further south there is often a third. During the breeding season the male is all vigilance and no enemy can easily succeed in catching him off his guard. The loud and shrill warning note, which sounds somewhat like "chips, chips," announces the stealthily approaching cat, the skunk snuffing about in the undergrowth, as well as the raccoon roaming about among the boughs, and the hawk overhead gliding in large circles through the air. But the Robin is not content with uttering its screaming call of distress. It will courageously attack every intruder as soon as he approaches the nest. At the male Robin's alarm-note all the Robins nesting in the neighborhood assemble to take part in the contest. They try to frighten and defeat the enemy by screaming loudly, flitting to and fro with great rapidity, and going through other manoeuvres. Small intruders almost always retreat quickly. - While still a small boy in my native State, Wisconsin, I remember once climbing a pine-stump about twelve feet high to examine a Robin's nest built on its top. While I was climbing up, the angry pair whizzed past my face with loud screaming. The noise at once assembled two or three other pairs, and I was soon so courageously and persistently attacked by the birds, some flying right into my face, others whirring 
past loudly snapping their beaks, that I had to jump down and run off at full speed. The Robins which nest farthest from man are, as a rule, the most pugnacious. It is remarkable but easy of explanation, that one may examine a Robin's nest in a garden without the birds acting in the least angry or uneasy. They have doubtless been convinced by experience that no one intends to molest them.

Besides the cry of alarm we frequently hear other characteristic notes during the breeding season. "Durick" and "Tuck-tuck-tuck" may often be heard.

It is during this season that the Robin's truly melodious and pleasing song is loudest. A harbinger, indeed, it is the first bird to carol from the tree tops the near arrival of the spring. The song, though simple and modest, is not without effect at such a time in the snow-covered, sadly silent landscape.-It fills desolate nature with indescribably joyous life and gives voice to man's longing for the warm, soft, and mild breezes of spring and the odor of opening flowers. The Robin's manner of singing is significant. While many of our birds choose a concealed bushy spot when they sing, and moreover accompany their song with lively movements, the Robin selects an exposed spot, usually the top of a tree, and pours forth its song for hours from this lofty perch. It sits quietly, with its bill directed to the sky. It sings most earnestly and persistently early in the morning, as soon as the dawn appears in the east, and in the evening, often long after the fading of the bright sunset. I have heard a few sing during the hot hours of June and even of July, but this is a departure from the rule. There is great difference in singers: some sing with such excellence that they satisfy even the most fastidious hearer, others again are decidedly inferior. I have observed the finest songsters in the so-called "mixed woods" of Wisconsin, where the music of the gurgling springs and gushing brooks, and the weirdly charming whisper in the pines accompanied their songs; the poorest singers I have found in the monotonous "black jack" regions of Missouri. Many students of bird-life, and even our great Audubon, compare the Robin's song to that of the European Blackbird ${ }^{1}$, and maintain that the song of both birds is very similar. Judging from my own experience, which is confined to caged Blackbirds only, I would say that this is only conditionally true, viz.: so far as the voice, the note itself, is concerned. Both birds, which are very near relatives, have a powerful and beautifully flute-like whistle, but the Blackbird's song is more continuous, more modulated, the Robin's briefer, more monotonous. The Blackbird is one of the very best and most superb of songsters, and the comparison of the two birds shows that our Robin is to be classed with the finest of singers. - What makes the song of the Robin especially valuable, is the fact that it is uttered in the immediate neighborhood of our rural and even city homes where every lover of nature can delight in it during the pleasant season of the year. The loud flute-like, highly melodious song poured forth in magnificent maestoso involuntarily reminds one of the clear, quietly flowing notes of a sacred song. Whenever the bird sits high aloft and sends its voiee to the distance, all the other male Robins of the neighborhood feel duty bound to enter into competition. Soon three, four, and even more, may be heard in loud chorus. This is usually the case during evening twilight, and then one may hear quite a number of birds all striving to outsing one another, while they make the surroundings echo with the powerful vibration 
of their jubilant, exultant melody. What is a northern garden without its joyful songsters, the Robins? Who can fail to love them? Even the farmer, if he does not lack all sense of beauty in nature, is delighted to see a pair of these fine, lively birds, so versed in melody, take up their home in his garden, for they belong to the first of living beings to hail him with the greeting of morning when he enters the open air at early dawn.

But the Robin is also a very useful bird. Its food consists during the greater part of the year of insects which are usually captured on the ground. It consumes incalculable numbers of the very destructive cut-worms, canker-worms, beetles and their larvae, grasshoppers, borers, snails, caterpillars, and many others. This usefulness increases as the young are hatched. Then the parents destroy an immense number of insects, confining their attention almost entirely to those species that do great damage to vegetation, destroying in every conceivable manner fruit trees and ornamental plants as well as vegetables, and working mischief which man is generally helpless to remedy. This is likewise true of all our other small garden birds, such as the Catbirds, Thrashers, Mockingbirds, Bluebirds, Vireos, Titmice, Warblers, Orioles, Kingbirds, and others. If the Robin does take a few ripe cherries and other small fruits, it is no more than just that it should receive this reward for its usefulness. The few berries, grapes, \&c., consumed by this bird are not to be comparcd with the great number of insects it destroys. As it does not occur in flocks, except during migration and in winter, it is evident that it can do but very little harm.

"The Robin," says Dr. Elliott Coues," “is a great eater of berries and soft fruits of every description; and these furnish, during the colder portion of the year, its chief sustenance. Some of the cultivated fruits of the orchard and garden are specially attractive, and no doubt the birds demand their tithe. But the damage done in this way is trifling at most, and wholly inconsiderable in comparison with the great benefit resulting from the destruction of noxious insects by this bird. The prejudice which some persons entertain against the Robin is unreasonable; the wholesale slaughter of the birds which annually takes place in many localities is as senseless as it is cruel. Few persons have any adequate idea of the enormous - the literally incalculable numbers of insects that Robins eat every year. It has been found, by careful and accurate observations, that a young Robin, in the nest, requires a daily supply of animal food equivalent to considerably more than its own weight! When we remember that some millions of pairs of Robins raise five or six young ones, once, twice, or even three times a year, it will be seen that the resulting destruction of insects is, as I have said, simply incalculable. I. have no doubt that the services of these birds, during the time they are engaged in rearing their young alone, would entitle them to protection, were the parents themselves to feed exclusively upon garden-fruits for the whole period. But at this time the diet of the old birds is very largely of an animal nature; nor is this the only season during which the destruction of insects goes on. Upon the first arrival of the main body of the birds early in the spring, long before any fruits are ripe, they throw themselves into newly-plowed fields, and scatter over meadows, lawns, and parks, in eager search for the worms and grubs that, later in the season, would prove invincible to 
the agriculturist, were not their ravages thus stayed in advance by the friendly army of Robins.

It is a matter of congratulation that the good services of the Robin are becoming duly appreciated - thanks to the timely and judicious interference in its behalf on the part of many of its friends; among whom no one, perhaps, deserves higher praise for his active and successful exertions than Dr. Thomas M. Brewer, of Boston. The bird is now very generally protected by legislative enactments, during a portion of the year at least; it is to be hoped that the laws may be made still more stringent, and the "close" time become co-extensive with the year itself. As an object of "sport" the Robin can possess no attractions save to idle children of larger or smaller growth; while its commercial value, as an article of food, is wholly inconsiderable. There are, therefore, weighty and cogent reasons, why the Robin should be protected.by law at all seasons; for there would rarely if ever be difficulty in gaining permission, upon proper representation, to destroy the very few that might be required for scientific purposes. ...."

Among wild fruits the Robin is particularly fond of elder and poke-berries. In winter these birds are unusually common in the beautiful hummock-woods of Florida, where the mealy sparkle-berry and the holly with its shining vermillion berries grow in abundance. - The plumage of the bird's breast is often stained with the violet juice of poke-berry.

From early in the morning to late in the afternoon these birds are busy almost without interruption. It is only during the hot part of the day that they are somewhat less active. Their flight is smooth, rapid and skilful, and does not lack grace and beauty. To one who has seen during migration flocks of several hundred individuals rapidly flying high over the forest trees it seems easy to understand how they can traverse such an immense expanse of country in so short a time. They move about nimbly among the boughs and are perfectly at home on the ground. They run about quickly, frequently stand still, raise the tail with a jerk and simultaneously lower the wings, turn the head to one side to listen, and then hop along again. This jerking of the tail and wings while running about on the ground is a common trait of all the true Thrushes.

Towards autumn the Robins unite in larger or smaller flocks and travel south. They now prefer the woods along the banks of rivers flowing southward. Especially the Mississippi, Wabash, and others, are such highways during migration. In their winter quarters they are very shy; rarely will they approach a human dwelling, prefering to stay in the depths of great forests, where they look for food among the dead leaves which cover the ground.

Like all of our smaller birds the Robin has many enemies. In gardens the cats catch many young and even old birds, in the woods squirrels, raccoons, opossums, and many birds of prey kill them. Their greatest enemy, however, is man. In the South almost incalculable numbers are killed by white and black pot-hunters, and in many localities of the North many hundreds of almost fully fledged young are taken from their nests and meet their doom in the kitchen. Such unreasonable slaughter should be stopped everywhere by the rigorous execution of the law for the protection of birds. 
The Robin is excellently adapted to cage-life. One of these fine Thrushes in a roomy cage is a delightful sight. The bird is often kept in confinement and is a really satisfactory and persevering songster. Wilson tells us that a lady of his acquaintance who was very fond of birds, reared and kept a Robin in a caige for seventeen years, and would probably have kept it longer had its days not been cut short by a cat. Caged Robins are best fed with two parts of "Mockingbird Food," mixed with one part of grated carrot and with an abundance of meal-worms. They should also have fruit and berries from time to time. Young birds taken from the nest and reared by hand, become very tame and affectionate. Next to the famous Mockingbird no insectivorous bird is such a favorite cage-pet among American people as the Robin.

NAMES: Robin, American Robin, Robin Redbreast, Migratory Thrush, Red-breasted Thrush. - Germ. Wanderdrossel, Robin, Rotbrust-Drossel.

SCIENTIFIC NAMES: Turdus migratorius Linn., MERULA MIGRATORIA Sw.

DESCRIPTION: Above plain ashy-gray, becoming blackish on the tail, and entirely black on the head; under parts including the under wing-coverts beautiful deep chestnut brown; under tail-coverts and tibiae white, more or less tinted with gray; throat white, streaked with black; eye-lids white; ends of the outer tail-feather tipped with white. Bill of a rich yellow, upper mandible tipped with black. Female usually a little paler. Young, chiefly on the under parts, spotted dusky.-Length 9.50 to 10.50 inches.

A local race of our beautiful Robin inhabits the western part of the Union. Merula migratoria propinqua RIDGWAY (Western Robin) is distributed from British Columbia south to the table-lands of Mexico, and east to and including the Rocky Mountains.

(The ST. LuCas Robin [Merula confinis BRD.] is to be found in Lower California near St. Lucas.

The Matzatlan Robin [M. flavirostris Swains.] is confirred to western and southern Mexico, north to Matzatlan.

The Tres Marias Robin [M. graysoni RIDGw.] inhabits the Tres Marias Islands, western Mexico.)

\section{VARIED THRUSH.}

Hesperocichla naevia RIDGwAY.

PI,ATE I. FIG. 3.

匐骨

HE VARIEd Thrush is the most beautiful member of its family. It inhabits the north western part of our country, especially the coast region, and breeds from Washington north to Alaska. In winter it is found in considerable numbers in California, and as a straggler it sometimes occurs in Massachusetts, New Jersey, and Long Island. The bird was discovered at Nootka Sound by the naturalists accompanying Captain Cook on his third voyage around the globe. The specimens passed into the possession of the famous director of the Kew Gardens, Sir Joseph Banks. The 
species was originally described both by Latham and by Pennant, and figured by the latter. "VAried Thrush and SpotTed Thrush were the names bestowed by these writers, upon whose accounts Gmelin, in 1788, based his Turdus naevius. In 1831, Swainson figured and accurately described the species under the name of Orpheus meruloides, given, however, in opposition to the prime rule of nomenclature, for no better reason than that such designation appeared to him to be more expressive. These two terms are the only ones to be found in current quotations; a third, however, is to be added; for Pallas received from Kadiak, through his friend Billings, specimens of the same species, to which he applied the name of Turdus auroreus. That he had no other bird in view will be evident upon consideration of the description given in the Zoographia RussoAsiatica, all the terms of that account being in strictness applicable to the female or immature male, in which the black pectoral collar is incomplete." (Dr.'E. Coues.)

None of these naturalists could give any reliable account of the bird's mode of life and its breeding habits. Nuttall and Townsend were the first to form its closer acquaint: ance. The former observed that it reached the Columbia River in October, and remained in some numbers during the winter. "At this time," he writes, "they flit through the forest in small flocks, frequenting usually low trees, on which they perch in perfect silence, and are at times very timorous and difficult to approach, having all the shy sagacity of the Robin." In May they again journeyed northward. According to Townsend the song of the Varied Thrush is different from that of the Robin, being louder, sharper, and quicker, and he alludes to a pleasant song which the bird utters in the spring, just before it sets out, and on its northern journey.

In Washington, according to Dr. Cooper, the Varied Thrush, or Western Robin, is common during winter, and he thinks that a few remain near the coast all summer, as he has seen them in the dark spruce forests in June and July. They are much more shy and retiring than the Robin, and differ very much in their song, which consists only of five or six notes in a minor key, and in a scale regularly descending; they are commonly heard in the tops of the trees, and in summer only in the densest of forests. In winter they associate with the Robins, and feed much on the ground, sometimes approaching houses in cold weather. Dr. Suckley observed this Thrush in Oregon and Washington and seems to have had excellent opportunities of studying its habits. He writes as follows: "In winter it is a shy bird, not generally becoming noticeable in the open districts until after a fall of snow, when many individuals may be seen along the sand beaches near salt water. They are at such times tame and abundant, at least sufficiently so for any ordinary shot to obtain a dozen specimens in a forenoon. I suppose that they are driven out of the woods during the heavy snows by hunger. It may then frequently be found in company with the common Robin, with which it has many similar habits..... At this time of the year it is a very silent bird, quite tame, allowing near approach; flying up when the intruder comes too near, but alighting on the ground again a short distance in front. It appears to be fond of flying by short stages in a desultory manner, sometimes alighting on the ground, at others on fences, bushes, or trees. The settlers here (at Port Townsend) call them Spotted, Painted, and Golden Robins. The most conspicuous mark on the bird which strikes the eye at first is the black crescent on the fore part of the breast." 
Several investigators have found the Varied Thrush common in Alaska. There the first nests were discovered by Dall and Minor. The former found the structure at Nulato as early as May 22nd. It was built in a willow-shrub about two feet from the ground, on a mass of débris. Lum found other nests in Washington. According to his statements the bird breeds there in June, and builds its nest on the lowlands which are covered with water during the winter but are dry during the summer months. The nest is often found in the branches of a prostrated tree or in a small shrub, usually not more than from three to six feet from the ground. It is built of delicate mosses, plantstems, and lichens, but mud seems not to be used in its construction. The eggs are greenish blue, distinctly spotted with dark umber-brown. In the dense lowland woods of Washington the Varied Thrush's beautiful song may be heard from early morning until late in the evening.

At Nulato (Alaska) this bird arrives about the middle of May and prefers for its home bushy river-banks in secluded places. Doubtless it breeds in large numbers in the northwestern parts of British America. Sir John Richardson found it near Fort Franklin on the 65th parallel, and it is probably an abundant summer resident on the shores of the Great Slave Lake and on the Mackenzie River. In winter it is common near San Francisco and also in southern California. Our fine picture of the bird was painted from a specimen which I received from Portland, Oregon.

In Germany, where many of our birds are highly prized as cage-pets, this Thrush seems to be entirely unknown.

NAMES: VARIEd Thrush, Varied Robin (Ridgway), Columbia Robin (Lewis and Clarle), Tlirush-like Mockbird (Swains.), Spotted Thrush (Lath.), Spotted Robin, Painted Robin and Golden Robin of the settlers. - Germ. Buntdrossel (Brehm), Columbia Roljin, Gold- und Alaskadrossel.

SCIENTIFIC NAMES: HESPEROCICHLA NAEVIA Ridgw. Proc. U. S. Nat. Mus. III, 1880, 166. Turdus naevius Gmel. (1788), Vieill., Aud., etc.

DESCRIP'TION: Male above dark slate-colored; "wings and tail blackish with more or less of plumbeous or olive shade; wing coverts, greater and lesser, tipped with orange-brown, forming two cross-bars"; a broad band or collar across the breast blackish. Stripe behind the eye, lower eyelid and under parts rich orange-brown; vent and crissum white, tinged more or less with ochraceous. Bill black.Female much paler, the upper parts and the collar across the breast grayish brown. - Young similar to female, but the collar much less distinct and more or less broken by dark spottings. - Length 9.50 to 10 inches. About the size and form of the Robin, but the black collar and the orange wing-markings distinguish it at a glance. (For more detailed descriptions see Dr. Elliott Coues' "Key to the North American Birds," and Prof. Robert Ridgway's "Manual of North American Bircls," both works that slould be in the hands of every one who is interested in the scientific part of American ornithology.) 


\section{MockingBirds; Thrashers.}

Miminae.

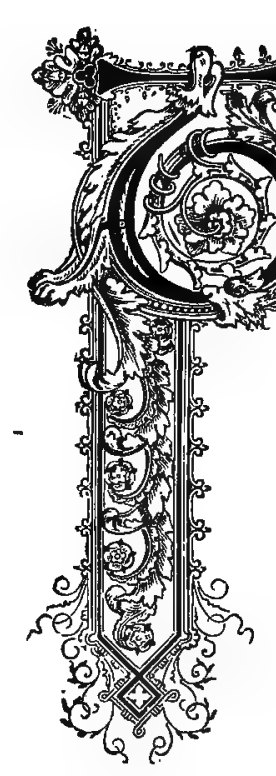

HOUGH not in accordance with the new system of our American Ornithologists' Union,-which, however, should be universally adopted-I nevertheless treat of the Mockingbirds immediately after the true Thrushes. All the members of this subfamily are birds which, in many respects, bear a strong resemblance to the Wrens both in their structure and habits. On the other hand their mode of life and their vocal powers remind one of the true Thrushes. They are all slender, long-tailed, very active birds. They usually keep near the ground, and some of them, like the Thrashers, are decidedly terrestrial, as indicated by their strong feet.* The bill is sometimes as straight as that of the typical Thrushes, but in other cases it is very strong and sickle-shaped. The wings are usually short and somewhat rounded, generally much shorter than the tail. There are hair-like bristles at the base of the bill. The fine soft plumage exhibits no loud coloring but is rich notwithstanding its dullness of tint, and differs but little in birds of different seasons, age, and sex. This subfamily of birds is represented by many species, principally in the tropics, but hardly ranges beyond the northern limits of our territory. They are all insectivorous but also feed on various soft fruits. In contradiction to the typical Thrushes, which are really forest birds, the Mocking-Thrushes inhabit the shrubbery, cactus-thickets, forests margined with thickets and woody twiners, and gardens planted with ornamental shrubbery, such as the various kinds of upright and twining honeysuckles, weigelias, gooseberry bushes, mock-oranges, evergreens, \&c. They never take to the dark interior of woods destitute of underwood. They usually pass much of their time on or near the ground. The bulky nests are generally built in bushes, never high above the ground. The eggs, five and even six in number, are commonly spotted; only two species: the Catbird and the Crissal Thrasher, lay uniformly bluish green eggs. The

* See Dr. E. Coues' "Birds of the Colorado Valley" p. 47-75. 
gift of song has been awarded to this group of birds with greatest munificence. They surpass in power, range and euphony, and variety of voice, all other birds. Many even mimic the voices of other species very successfully and weave their imitations into their own song.

We have representatives of the following four genera in the United States:

1, Oroscoptes Baird. Sage Thrashers. One species.

2, Mimus BoIE. Mockingbirds. One species.

3, Galeoscoptes Cabanis. Catbirds. One species.

4, Harporhynchus Cabanis. Thrashers. Eight species. Only one species inhabits the eastern part of North America. The others occur in the southwestern part of the United States, especially in Arizona.

\section{SAGE THRASHER.}

Oroscoptes montanus BAIRD.

Plate IV. Fig. 3.

周HE Mountain Mockingbird is peculiar to and common in the mountain districts y] of the West. It does not inhabit the Alpine regions, but rather the ravines, the greater or smaller mountain valleys and more especially the extensive plains in the Great Basin covered with sage-brush ${ }^{1}$, and ranges south into Mexico in winter. It frequents almost exclusively the sage-bushes, and the only other bird which inhabits the same locality, seems to be the Sage Grouse, or "Cock of the Plains" 2 as it has been called by Lewis and Clarke. On this account Mr. Ridgway named this bird the SAGE Thrasher. It appears to be most common in Nevada and Utah, extends northward to the Columbia, eastward as far as the Black Hills and Fort Laramie, and south-eastward as far as San Antonio and Austin, Texas, where individuals may occasionally be met with. My friend Mr. L. Woltersdorf of Chicago, who is a great bird-fancier and who visited Mexico in 1879, brought with him on his return, besides Morellet's Seedeater ${ }^{3}$, House Finches ${ }^{4}$, Green Jays ${ }^{5}$, Parrots, \&c, some specimens of the Mountain Mockingbird, which he had found to be one of the commonest cage-birds in the City of Mexico.

Like many other western birds this Thrasher was discovered in 1835 by Townsend while he was exploring the region of the Columbia with Nuttall. Townsend, an excellent collector, and Nuttall, ranking equally high as an ornithologist and botanist, were the first to give an accurate description of the bird and its traits.

On superficial observation the appearance of the Sage Thrasher reminds one strongly of the Mockingbird. The spotted underparts especially make it very closely

1 Artemisia tridentata. 2 Centrocercus ureophasianus, 3 sporophila morelleti, 1 Carpodacus mexicanus. 5 Xanthoura Iuxuosa. 
resemble the young of the latter. Still it differs widely from the Mockingbird in all its peculiarities and in all its actions.

No other ornithologist has described the habits of the Mountain Mockingbird so well as Prof. Robert Ridgway of the Smithsonian Institution. As I myself have had no good opportunity of observing this fine songster, I shall conclude its history with an extract from the author last mentioned.

"Carson City, Nevada, March 24, 1868:-To-day we saw the Sage Thrasher for the first time this spring, and heard its song. The sage-brush was full of the birds, and many were singing beautifully when the evening shades were lengthened by the sinking of the sun behind the Sierras. Owing to the earliness of the season, the song was uttered in a subdued tone, and its full merit could not be appreciated. The bird was generally seen sitting in an upright position upon a sage bush, but when approached would dive-apparently into the bush, though close examination failed to reveal its hiding place; often, however, we again heard it sweetly warbling, perhaps a hundred yards away in the direction from which we had come. This concealed, circuitous flight is characteristic of the species.

"April 2.- Rained throughout the night; this morning the air is fresh and balmy; clouds are lowering about the bases of the mountains, concealing them from view. The air is rocal with the music of the spring birds, singing with vigor and joyousness. The Meadow Larks are singing throughout the sage-brush, and with their notes are heard the sweet warblings of Oroscoptes montanus. To-day we heard this song in all its loveliness. Although weaker than that of either the Brown Thrasher or the Catbird, it is more varied and longer sustained as well as superior in sweetness and delicacy of tone. The song has, in modulation or style, a great resemblance to the soft, tender warbling of the Ruby-crowned Kinglet, although it is stronger, of course, in proportion to the size of the bird.

"April 9. - The Sage Thrasher is now one of the most common birds in this vicinity. To-day a great many were noticed among the brush-heaps of the city cemetery. Its manners during the pairing season are peculiar. The males, as they flew before us, were observed to keep up a peculiar tremor or fluttering of the wings, warbling as they flew, and upon alighting (generally upon the fence or a bush), raised the wings over the back, with elbows together, quivering with joy as they sang.

"April 23. - Although we saw these birds everywhere among the sage-brush, their nests were found only with great difficulty. In the cemetery, the sage bushes had all been pulled up and thrown in piles in different parts of the enclosure, and upon these the birds were most frequently seen. On one occasion, a female was observed to fly into one of these brush-heaps, with a bunch of building material in her mouth; but it was only by taking off bush after bush that the nest was discovered; this, though unfinished, contained one egg, and, in its construction and situation, resembled some of the nests of the Thrasher, though less bulky. The bushes were carefully replaced, and the nest left undisturbed. In walking through the sage-brush on the open commons, several more nests were found, in similar situations, being placed in the thickest portion of the bushes, generally two feet from the ground, but occasionally imbedded in the ground beneath them. They were all well concealed. At one time the parent birds came 
near us, running gracefully upon the ground in the manner of a Robin, stretching their necks, curious to see what we were doing, and watching our movements with an anxious look, but uttering no note whatever.

"The only note of this species, besides its song, is simply a weak 'tuck,' seldom uttered unless the young are disturbed; except during the pairing and nesting seasons, it is one of the most silent birds with which I am acquainted. In September I saw it feeding upon the 'service-berries,' which grew abundantly in certain localities at the foot of the mountains."-

The eggs of this bird, usually four in number, measure about .97 inch in length, and .72 inch in breadth. The ground-color is light greenish-blue, marked heavily with dark and light brown spots and some others of a neutral tint. "The pattern is generally bold and sharp, but in some cases finer and more diffuse, when the numberless speckles and dots give an effect similar to that of some styles of Mockingbird's eggs." (Coues.)

No subsequent observer agrees with Nuttall in attributing to the Sage Thrasher the power of imitating the songs of other birds. In captivity it is never heard to mimic sounds like the Mockingbird and the Catbird. It has an excellent song of its own, very beautiful, loud, and modulated. It closely resembles that of the Thrasher, but is not so loud and continued. At any rate the Mountain Mockingbird is one of the most valuable of our singing birds.

NAMES: Sage Thrasher, Mountain Mockingbird.-Germ. Salbeidrossel, Gebirgs-Spottvogel.

SCIENTIFIC NAMES: OROSCOPTES MONTANUS BAIRD, B. N. Am. 1858, 347. Orpheus montanus Towns. (1837). Turdus montanus Aud. O. B. 1838 p. 437.

DESCRIPTION: Adult male and female: Above brownish gray; two narrow white bands on the wings; outer tail-feathers broadly tipped with white. Beneath whitish, more or less tinged with buffy on the flanks and under tail-coverts: the breast and almost the entire under parts marked with triangular dusky spots, largest and most crowded across the breast, smaller and sparse and sometimes absent on the throat and lower belly. Young similar to adult, but above conspicuously streaked with dusky, and spots on lower parts less sharply defined. - Length a little over 8 inches. 



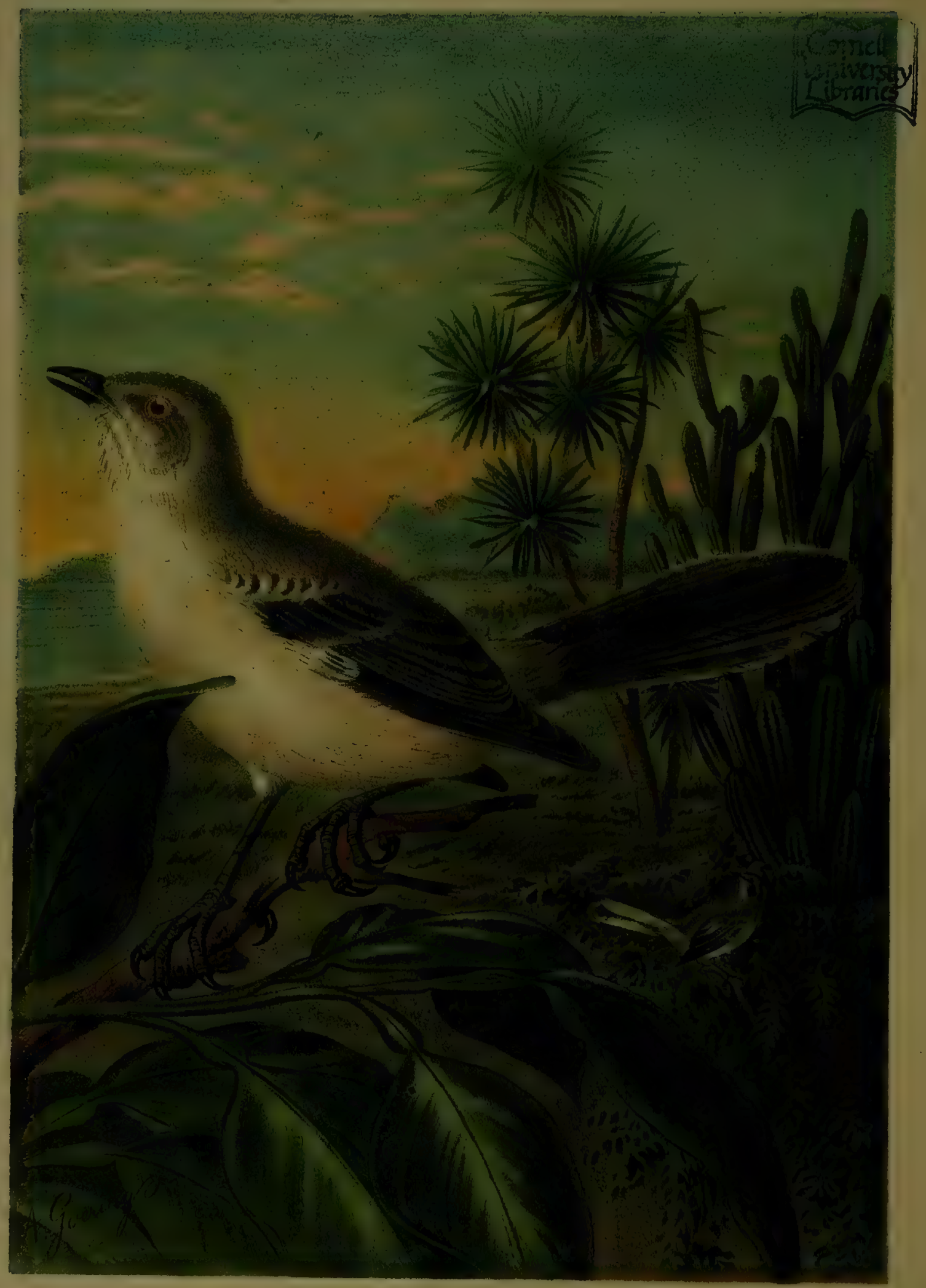

MIMUS POLYGLOTTUS BOIE. DIE SPOTTDROSSEL. Mockingbird. 


\title{
MOCKINGBIRD.
}

\author{
Minus polyglottus BoIE.
}

Plate II.

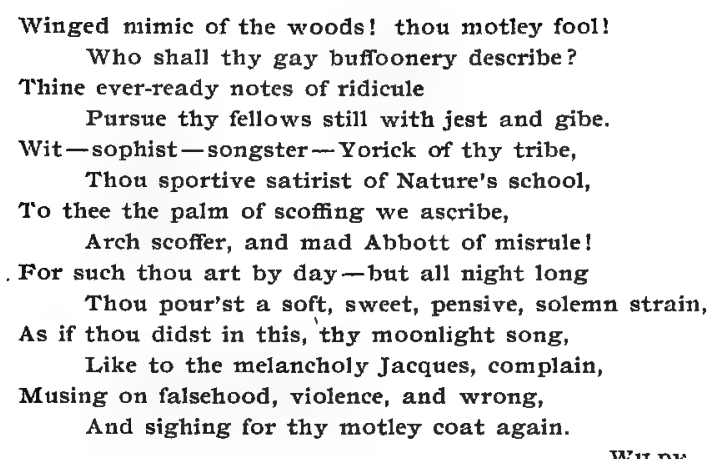

FT IS where the great magnolia shoots up its majestic trunk, crowned with evergreen 1. leaves, and decorated with a thousand beautiful flowers, that perfume the air around; where the forests and fields are adorned with blossoms of every hue; where the golden orange ornaments the gardens and groves; where bignonias of various kinds interlace their climbing stems around the white-flowered stuartia, and mounting still higher, cover the summits of the lofty trees around, accompanied with innumerable vines that here and there festoon the dense foliage of the magnificent woods, lending to the vernal breeze a slight portion of the perfume of their clustered flowers; where a genial warmth seldom forsakes the atmosphere; where berries and fruits of all descriptions are met with at every step;-in a word, kind reader, it is where Nature seems to have paused, as she passed over the earth, and opening her stores, to have strewed with unsparing hand the diversified seeds from which have sprung all the beautiful and splendid forms which I should in vain attempt to describe, that the Mockingbird has fixed its abode. There only its wondrous song can be heard.

Thus Audubon describes the woodland scenery of his native State Louisiana, and correct as it is I think that the southern woods cannot compare with the romantic beauty and idyllic loveliness of our northern and eastern forests. But the gardens and ornamental plantations of the Gulf and South Atlantic States far surpass those of the North in beauty and magnificence. There luxuriates the deliciously-scented pure white gardenia, the glorious camellia, the umbrella-shaped pittosporum, the glowing hibiscus, the brilliant Indian azalea, the aromatic myrtle, the gorgeous amaryllis and crinum, the strongly fragrant banana-shrub and night-jasmine. Trees not known in northern gardens, such as umbrella china, grape-myrtle, magnolias, palms, and many different 
evergreens adorn streets and lawns. Oleanders, lantanas, yuccas, pomegranate-shrubs, and a host of the most beautiful tea roses are met with in almost every garden. The verandas and porticos of the houses are festooned with Japanese honey-suckle, Rhynchospermum jasminoides, jasmines, clematis, and climbing roses.' And what beautiful hedges do we find around gardens! It is, indeed, impossible to penetrate a living fence of Cherokee and Macartney roses.

No wonder that the Mockingbird forsakes its native shrubbery on the borders of woods and swamps and prefers to settle in these beautiful southern gardens. Almost every cluster of trees and ornamental shrubs shelters a pair of these birds, and even near woods and in the bushes intertwined with woody climbers $I$ have never seen so many Mockingbirds as in the gardens in southern cities and villages. They are still more numerous in the orange groves of Florida. In my former field of observation, in Wisconsin and the northern part of Illinois, the Mockingbird does not occur; it is, however, one of the commoner birds in the southern portion of the latter State. I first observed this far-famed songster in the beginning of March, 1879, in and about Austin, the picturesquely situated State Capital of Texas. The bird's loud song rose from all the larger gardens in and around the city. Later in the season $I$ found it very common in Houston, where almost every large garden had its pair. In many places the Mockingbird is a constant companion of the Cardinal Redbird, as both species prefer similar localities.

In Houston the Mockingbird is the commonest of feathered songsters and is almost always in sight, everywhere attracting one's attention. A great number migrate south to pass the winter in the "terra caliente" of Mexico, while some few remain all through the cold season, retiring to the thick undergrowth near bayous and rivers when one of the cold "northers" sweeps over the entire State. The majority return from their winter quarters as early as the end of February, and again strike up their full chorus which reaches its climax in May but still continues till moulting time in August and September. Like all birds they sing most diligently some time before and during the breeding season, although $I$ heard many in September and October, and a few even about Christmas and New Year. During the spring months, particularly in April and May, many sing their most beautiful songs even at night, and not only when the silvery rays of the moon fall on the dark foliage and on the many fragrant flowers, but also during very dark nights. Most of the males commence singing between three and four o'clock in the morning. First a single individual begins its lay from a magnolia draped with gray Spanish moss, or from its hiding-place in a banksia rose, or even from the top of a chimney. Another male sleeping in the neighborhood, probably in a tree overgrown with a large wistaria, or trumpet creeper, excited to rivalry, also begins to sing. The stanza of the song, first softly uttered, gradually grows louder, intenser, more inspired and modulated. More and more singers.join in the chorus, till one can often hear five or six different voices at the same time. Thus they excite one another to greater efforts and each tries to excel every other. These are incomparable bird-concerts which produce a deep and lasting impression on the listener in the quiet night when all nature lies in deep slumber. When the gray dawn appears in the far East, and soon afterwards the sky reddens, all the Mockingbirds sing diligently, and the Cardinal Red- 
birds, the Nonpareils and others join in the chorus of jubilation to greet the day-star as he rises above the horizon. Very rarely a Mockingbird is heard during the hot hours of noon; the greater number are silent, and only towards the later afternoon does the full chorus commence again. Many sing till after dusk and far into the night. I have often listened full of rapture to these songs on the beautiful May evenings when the soft refreshing breezes blew from the Gulf, when the bright light of the moon fell on the shining evergreen leaves of the magnolia, the cape jasmine, and all the rest of the garden and lawn vegetation, when the whole air was filled with the strong odor of blooming Marechal Niel and Chromatella roses, the flowers of the China trees, gardenias, oleanders, banana-shrubs, fragrant olives, night-jasmines, and a multitude of other trees and shrubs.

Even other birds, especially Tufted Titmice and Cardinal Redbirds, are excited to exert their vocal powers to the utmost. The evening and night song of the Mockingbird is indisputably the sweetest. It is almost entirely original as it contains only a few strange notes. The day-song is entirely different. It is not so soft, sweet, and enchanting; but louder, more changeful, more eager, and noisier. Usually whole series of accurate imitations of a number of birds are heard in succession. Still the song is always exceedingly beautiful, differing in different birds. One bird sings with an exquisite charm, another with less modulation; in one case the song is wonderfully rich and euphonious, in another shriller and poorer in melody, but it always delights and fascinates. Old males sing most beautifully, while younger birds are often less accomplished and utter less melodious notes. But these last perfect themselves very rapidly. Their power of imitating many other birds, as well as various quadrupeds is, indeed, wonderful. The imitations of the Summer Redbird may be suddenly interrupted by the crowing of a cock or the barking of a young dog; the warblings of the Bluebird and the beautiful song of the Carolina Wren may be mingled with the notes of the Martin, the clamoring of the Blue Jay and Crow. Most of the Mockingbirds in and around Houston commenced their song with the sweet melancholy lay of the Bluebird; then usually followed the liquid notes of the Carolina Wren, the song of the Cardinal Redbird, and sometimes the peculiar reiterations of the Chuck-will's-widow. All of these notes are so accurately mimicked, so harmoniously mingled with the bird's own notes as to form one beautiful composition, rarely interrupted by a discord. I was particularly fond of the song when it commenced with the Bluebird's delicate warble and the bell-like notes of the Carolina Wren. The rapidly uttered lays of some Finches are not so successfully imitated. I never heard the song of the Painted Bunting, the Indigo Bird, Lark Finch, and others, imitated by a Mockingbird. As a rule this "king of song" only mimicks those voices which it hears in its immediate neighborhood. I have heard individuals sing during the warmer days throughout the winter. The song at this time consisted mostly of original notes and was very different from the performances later in the year. As soon as the first Bluebird sings, its melody is echoed by the Mockingbird, first by one, in a short time by all. Later, when the Martins return home pouring out their joyous notes upon the air, the Mockingbirds at once take them up. As soon as the Cardina1, the Phoebe, the Carolina Wren commence singing, their songs and callnotes may also be recognized in the Mockingbird's song. It seems as if the old and 
well-known.warblings and notes are called to mind only when they are heard again. The mimicry is not perfect at the first trial. Say, for instance, a hawk flies past shrieking. The Mockingbird, singing in boundless joy on the top of a chimney, has already picked up its cry and renders it with somewhat different coloring, but finally, after three or four attempts, imitates it with perfect excellence. Very soon the others likewise learn it, and in a short time all the Mockingbirds of the neighborhood have taken these notes into their songs.

While singing the male usually perches in the top of a tree, on a gable, on the top of a chimney or a lightning rod, \&c. Before descending to a definite spot he usually bounds into the air, and then alights on his perch. During the performance of his song he spreads his wings, expands his tail, and hops and flies around in an ecstasy of enthusiasm and joy. In spring the Mockingbird is the personification of unrestrained mirth and activity. It always accompanies its song with lively movements. It turns its head in a very self-conscious manner to the right and left, jerks its tail occasionally, raises its wing over its back, bounds up quickly, and descends again to the same spot, all the time singing without interruption. On the 11th of July, 1881, I happened to observe an especially fine singer in one of the prettiest gardens of Houston. It flew in joyful excitement back and forth from one side of the street to the other, now alighting on the ground, now in a tree, then on a fence, and all the time singing its truly enchanting notes. It seems as if the Mockingbird were conscious of being the "king of song"; it always perches high, and makes itself noticeable everywhere, both in populous cities and near the settler's secluded log-cabin. When not singing it usually hops around in the shrubbery and trees, or hunts for insects on the ground.

For a long time ornithologists and lovers of birds disagreed as to the value of the Mockingbird's song before coming to a definite conclusion. Of late even the most eminent European students of bird-melody have expressed the opinion that the Mockingbird, as Dr. Carl Russ says, "is to be regarded as the most excellent of all songsters among birds."

"They are not the soft sounds of the flute or of the hautboy that I hear, but the sweeter notes of Nature's own music. The mellowness of the song, the varied modulations and graduations, the extent of its compass, the great brilliancy of execution, are unrivalled. There is probably no bird in the world that possesses all the musical qualifications of this "king of song,", who has derived all from Nature's self. Yes, reader, all!... The musical powers of this bird have often been taken notice of by European naturalists, and persons who find pleasure in listening to the song of different birds whilst in confinement or at large. Some of these persons have described the notes of the Nightingale as occasionally fully equal to those of our bird, but to compare her essays to the finished talent of the Mockingbird, is, in my opinion, quite absurd."

Dr. A. E. Brehm adds the following to these words of Audubon: "In one point I agree with the distinguished naturalist: The performances of the two birds cannot be compared, as the one is a warble, the other a song. Each one has its own peculiar charms. The warble of the Nightingale has the rounded finish of the strophes, the exulting joy of tone, the Mockingbird's song possesses extraordinary variety, a really unbroken change of the separate parts, hardly recognized as articulated, and a really 
unexcelled and unequalled skill in interweaving other birds' notes, whole or in part with its own song and moreover in lending melody to these tones, in purifying them and, if you will, in perfecting them with wonderful ability. In the Nightingale's song the stanzas are heard clearly and distinctly, and the hearer is able to explain, if not to render them in syllables; in the song of the Mockingbird, though certain com. binations recur, they never appear with the same regularity as in the Nightingale's warble, nor even in the same approximately regular sequence. All the notes gurgle forth wildly intermingled, without, however, any lack of graceful sweetness. The song flows out like a rippling brook of tunes and melodies, ever new, ever irresistible and peculiarly charming, like the billow that passes, always apparently the same, but still always another."

One of the best German connoisseurs of birds' songs, Dr. Golz, Counselor of Justice at Berlin, who for a long time kept a Mockingbird which seemed to have been caught wild, was able to compare its song with the most select Nightingale's, and thus expresses his conviction: "The Mockingbird in question, eviclently old and exceedingly shy, was the admiration of all bird fanciers during its two years life in Berlin. It corroborated all that Audubon had said and which had been regarded in this city as mere exaggeration, because all Mockingbirds heretofore heard were poor songsters. Had it been possible to multiply the bird, it would at once have become the foundation for a new stock company.

"According to bird-dealer Brune who had bought it in St. Petersburg, the bird came originally from New Orleans and did not sing before the beginning of May, but continued from that time to sing loudly till September when it moulted. Its song was singularly lacking in discordant notes, was of such fullness and euphony, and uttered with such mobility of tongue and throat, that both indoors and in a large bird-gallery outdoors numerous master-songsters of other species were cast in the shade. And among these were many much admired Nightingales and Stonechats, counted among the rare 'oleur' and 'voyack' birds. This Mockingbird's performance was perfectly organized music and of really inexhaustible variety. It was easy to observe that the separate tones were fixed but not the sequences, as is the case with a Finch's song, and that the sequence was constructed during the singing in every case in accordance with the feelings of the bird at that particular time.

"No one could tell which of these melodious strophes were its own, and which were borrowed. Cabanis, who had heard many wild Mockingbirds in South Carolina, maintained that this bird had doubtless learned to imitate Skylarks, Nightingales, and Garden Warblers, with its former owner, for the gurgling, liquid, and flute-like notes of these birds could not be original with the Mockingbird. Be this as it may: the Mockingbird has certainly the ability to attain the highest perfection in singing. This was proved by this bird.

"A distinguished composer was finally requested to fix parts of this Mockingbird's song according to Beckler's note system of Australian songsters. This was found impossible, however, and after examining Beckler's notes and previously listening to several noted songsters, among them Nightingales, Song Thrushes, and others, he gave the following statement: In the performance of this Mockingbird a scale of notes as 
long and distinct as that found by Beckler in the voice of the Australian Magpie, can not be made out; but it surpasses all of Beckler's notes in variety of diatonic series. As to the Nightingales and Song Thrushes some of their notes are approximately or quite euphonious; but they all move in a limited range of melodies, they do not articulate the notes in repetition, but rather slur them over portamenta di voce, and thereby obscure the musical composition to such a degree that one can scarcely speak of the performance of real melodies. This particular Mockingbird, on the other hand, sings in pure intervals of thirds, sixths and fifths, everywhere metallic and soft, exhibiting such rapidity of change in the passages from one clause to another, from brilliant acuteness to liquid complaint, that one is really filled with wonder at such talent."

In concluding my remarks on the song of this bird I will quote the following from a letter of one of our prominent American ornithologists, Mr. Otto Widmann, of St. Louis :

"I cannot, from my personal experience, assert that all Mockingbirds are good singers. Among caged birds I have heard more poor than good songsters. Disregarding differences in individual endowment, the poor singing seemed to me to be explained by such birds having lacked the opportunity of hearing good songs. The Mockingbird is and will ever be an imitator. If it hears good singing, it mimicks good singing; if it hears little or nothing good, its song becomes poor and monotonous. Most Mockingbirds taken as nestlings and reared in the city are poor songsters. How could it be otherwise? The Berlin songster that had heard the Nightingales, Song Thrushes, \&c., attained its world-famous perfection by being in fine company, and the good singers among the wild birds have acquired their rich and varied repertoire through companionship with other birds. - There is no doubt that the Mockingbird's song cannot be compared with the glorious warble of the Nightingale. The Nightingale's melody ranks high above all bird-songs I have ever heard, and I have learned to esteem the Mockingbird's song only since I have made the acquaintance of the birds whose voices it imitates. Out of doors I love to hear it, and have often stood for five or ten minutes to listen to it attentively, but I can feel nothing but cool admiration for its really wonderful power of imitation. The voice of the Nightingale, on the other hand, thrilling as it does with a peculiar charm, has worked mightily on my deepest feelings, has so fascinated and inspired me that I shall never forget it. I confess that I owe to it a feeling of homesickness." -

The Mockingbird never chooses its home in the deep interior of the woods, but prefers the bushy margins of forests, the prairie thickets, and swamps bordered with bushes. Our beautiful plate, made from a water-color painting by Prof. A. Goering, presents a scene in south-western Texas, a region where yuccas and different species of cacti predominate, and where also the Mockingbird is abundant. It especially loves to settle in gardens and orchards, and in districts where woods are relieved by fields. I observed the greatest number of pairs nesting about a mile south of Houston, in a somewhat low-lying locality. This piece of woods and thicket-covered land bordering on a prairie, is largely covered with groups of swamp and white-oaks, watertupelos, and elms. In other spots the beautiful foliaged pyramidal sweet-gum trees combine to form large clusters. Here and there a solitary long-leaved pine raises its head high into the air. Some of the finest trees are overgrown with mustang-grapes 
or with trumpet creeper to their very tops, while many others are picturesquely draped with festoons of gray Spanish moss. Among these groups of trees we often find large spots covered with grass and small thickets-so-called "bosquets"-consisting of a few small trees, usually elms, soap-trees, prickly ash or oaks, dog-wood thickly intertwined with clematis, honey-suckle, Carolina jasmine, supple-jack, blackberry, trumpet-creeper, grape vines, and poison ivy. A wreath of dense bushes, generally viburnum, surrounds the larger trees and shrubs. Evergreen thorny smilax, honey-suckle and passion-flower vines spread out like a protecting roof and cover the outer shrubbery. It is no easy matter to penetrate such thickets as these, especially when the edge of the underwood is defended by blackberry bushes, or by the evergreen tangled Cherokee roses armed with horrible thorns. It is only with great pains and perseverance that these thickets can be traversed. Here we find hundreds of Cardinal Redbirds, many Painted Finches, Blue Grosbeaks, Chats, Orchard Orioles, Carolina Wrens, White-eyed Vireos, and Mockingbirds. There seems to be a pair of the latter in every one of these clusters of thickets during the breeding season, and this pair will not allow the intrusion of others of its own species. Other birds, however, are often found breeding in the same thicket. Several times I discovered nests of the Cardinal Redbird only a few steps from a Mockingbird's nest. As early as the first week of March the Redbirds commence nestbuilding, but when the delicate partridge-berry ${ }^{1}$ had unfolded its sweet-scented white blossoms, I knew that it was time to look for the moss and lichen-covered purse-shaped nests of the White-eyed Vireo, which were usually placed in small viburnum bushes on the borders of the thickets: At this time the Mockingbirds began to select nesting sites. They usually built in trees covered with climbing plants, in Cherokee-rose bushes, and in the bushy thickets described above. I found the first nest here on the 9th of April, but it was not until the last week of that month and the first week of May that I found a greater number of nests. The Mockingbird settles with preference in the neighborhood of man. I found it unusually common in the orange groves of Florida, and in southern Louisiana. Even in the villages and cities of the South it is a common bird. I found it common also in the orchards of south-western Missouri, where it lives on the best terms with Catbirds, Brown Thrushes, and Robins. The Mockingbird is so lively, fearless, and affectionate, that it becomes attached to man wherever it finds him a friend and protector. As soon as the settler builds his plain log-cabin in the midst of the virgin forest, the Mockingbird welcomes this first step of civilization with jubilant song. When protected the bird will build its nest often in the immediate neighborhood of a dwelling in a small tree or in climbing roses and dense shrubbery. It will nest even in the horribly spiny prickly pear $^{2}$ so common in Texas. The nest is often placed in the corners of rail fences or on a tree, in so exposed a spot as to be seen from a distance. These rather bulky structures were always built in the vicinity of houses. Still the bird knows how to conceal the nest with great care when necessary, and to protect it from unwelcome intruders. It may frequently be found in cacti, yuccas, in the interior of the most thorny and most densely foliaged bushes. I sometimes found it on large horizontal limbs of forest trees covered with Spanish moss, where it was impossible to see anything of the structure or the bird. It was only when I accidentally shook such a bough and the 
sitting bird started from the nest, that I found the structure, built almost entirely of moss and hidden in moss. Some nests which $I$ found were built exteriorly of very strong twigs, others were roofed with the same. These sagacious birds, therefore, know how to adapt themselves to existing circumstances. A pair whose exposed nest is once destroyed, will ever after build in a concealed nook. The exterior of the nest is usually composed of twigs, plant stems, grasses, pieces of paper and rags, strings, and feathers; it is lined with finer grasses and rootlets. It is never placed far from the ground, usually from three to seven feet, rarely higher. The eggs, four to five in number, are pale greenish blue, spotted with reddish brown. These spots are rather large and quite uniformly scattered over the whole egg. The male is too much taken up with singing to participate in the building of the nest or hatching of the eggs. He usually perches on the top of a tree, or on a roof or chimney, where he sings while he continually looks about in all directions. He will courageously defend the nest against every intruder. Cats, dogs, and other animals, sometimes even man, are valiantly attacked as soon as they approach the nest. In company with Kingbirds the Mockingbird will often attack birds of prey and pursue them for long distances. In the South there are usually two broods, further north only one.

The Mockingbird's flight is not particularly quick and persevering; when undertaken over large tree- and bushless places it is slow and heavy. Still it is a better flyer than the Catbird and Thrasher. On the other hand, the Mockingbird is very agile in its native haunts, when flitting from tree to tree, and from thicket to thicket. It is completely at home among the branches of trees and shrubs. It often descends to the gound, runs about like the true Thrushes but with elevated tail, and seeks here the greater portion of its insect food. At such times it carefully examines the dead leaves and all the nooks and corners under shady bushes for insects. The number of noxious species it devours, is immense. It has also a taste for small fruits, figs, grapes, cherries, \&c., and, no doubt, the birds demand their tithe. But in comparison with the great benefit resulting from the destruction of an inestimable number of noxious insects, the damage done is trifling and wholly inconsiderable.-Mockingbirds are particularly fond of the juicy poke-berries ${ }^{1}$, the beautiful purple juice of which colors the whole plumage about the bill, and on the breast and neck. They are also fond of the berries of a species of red pepper which grows wild, and which is, therefore, called bird-pepper. In the South during autumn and winter the fruits of the Mexican mulberry ${ }^{2}$, the holly, the magnolia, and mistletoe, are eaten. Mr. Albert Fries, of St. Nicholas, Florida, told me that they were especially fond of the berries of a bush which is known in that State by the name of sparkle-berry ${ }^{3}$. He has numbers of these shrubs, and also hollies growing for this special purpose of providing food for the bird, in his beautiful park on the St. John's.

The Mockingbird is such a cheery, lively bird, that it would attract general attention even if it were not a beautiful songster. Its talent of imitating other birds' and its own sonorous song, at once make it noticeable wherever it occurs. It knows better than any of our other birds how to acquire the love and good will of man. Its happy disposition, its extraordinarily developed gift of mimicry, its wonderful song,

1 Phytolacca decandra. 2 Callicarpa amcricana. "Vaccincum arborcum 
and not least their trustfulness, make them the most beloved and most cherished birds of our country. Our Southern people love this famous bird with the same affection as the people of New England love the Robin. In most gardens and orange groves it is truly at home, and every one is delighted by its exceeding happiness. A singing Mockingbird perched at early morn in the top of a flowering Magnolia grandiflora is a picture never to be forgotten. The ringing notes sounding through the air, the thousands of starry white blossoms among the beautiful evergreen foliage, exhaling a delicious fragrance, powerfully affect the observer. The grand gardens of the South would be barren and dead without this songster. It lends them life; it is their poetical soul.

The following example shows how tame and affectionate the Mockingbird may become under kind treatment: In Texas I kept in a cage a very tame female which I had reared from the nest. The next spring I set her free, but she had no desire to depart. She would often fly into my room, alight on my desk where I was writing, and was very fond of staying with the children in the garden. Several times I took her away a considerable distance, but she returned at once. When I worked among my flowers in the garden, she hopped about on the ground looking for insects. Every evening she returned to her cage. This lasted some weeks, when a male appeared upon the scene. Now she was often absent longer at a time, but always returned when I called, and perched on my shoulder or on my arm, and took worms and beetles from my hand in the most affectionate manner. She still returned to her cage in the evening. One day early in the morning I observed her carrying blades of grass into a corner of a rail fence, and here $I$ found the almost completed nest. As soon as the first egg was deposited, she failed to return to the cage at night. She was so tame while on the nest that she could be stroked without stirring. Unhappily my delight in the bird was destined to come to an end. One morning, shortly after the young were hatched, I found the nest destroyed, and my tame bird had disappeared. A chicken-snake had probably swallowed both the parent bird and its young. The forsaken male fluttered about uttering sad and disconsolate notes.

Mrs. Harriet Beecher Stowe, the famous authoress of "Uncle Tom's Cabin," tells us in her little book "Palmetto Leaves," that the wild Mockingbirds, too, may become quite tame. A young man from Massachusetts, driven to seek health in a milder climate, had bought a piece of land in the neighborhood of St. Augustine, Florida. "We visited this place, and found him and his mother in a neat little cottage, adorned only with grasses and flowers picked in the wild woods, and living in perfect familiarity with the birds, which they have learned to call in from the neighboring forests. It has become one of the fashionable amusements in the season for strangers do drive out to this cottage and see the birds fed. At a call from the inmates of the cottage, the Blue Jays and Mockingbirds will come in flocks, settle on their shoulders, eat out of their hands, or out of the hands of any one who chooses to hold food for them. When we drove out, however, the birds were mostly dispersed about their domestic affairs; this being the nesting season. Moreover the ample supply of insects and fresh wild berries in the woods makes them less anxious for such dry food as contented them in winter. Only one pet Mockingbird had established himself in a neighboring tree, and came at their call." 
In this connection I quote the following from a letter of Mr. E. K. Turner, of Providence, Florida: "I had two large old Cape jasmine trees (Gardenia) in my back yard. They were about twelve feet high and fully fifteen feet in diameter, forming a dense, almost impenetrable, mass of green. Mockingbirds had their nests in these bushes every spring for years. I think they were the same birds, for generally they used the same old nest after a few repairings. They were so tame as to fly in the kitchen and drink from the kitchen bucket. I made a habit of scattering a little food for them. They also would fly down and eat with the poultry. These tropical trees were destroyed by fire, and the birds disappeared from the yard."

Though the Mockingbird destroys innumerable noxious insects, though it possesses such a high æsthetic value, still man, heartless, unfeeling, ignorant man, who lacks all sense of beauty in nature, is one of the Mockingbird's greatest foes. Because it takes a small part of his fruits and berries, it is, regardless of the innumerable noxious insects which it consumes, killed in large numbers. - In the South, where it. was common only a few years ago, the numbers of the beautiful songster have been fearfully diminished, and farther North, where it was never very common, it is almost exterminated.

Mr. Carl Dänzer writes: "We hear complaints from Lonisiana of the disappearance of the Mockingbird. There as elsewhere the birds are shot, year in year out, by villanous boys, both old and young, and as the bird loves to settle near human dwellings, its very trustfulness leads to its own destruction. Then there is the unfortunate circumstance that the bird is adapted to cage-life and brings a high price; this is the cause of the nests being eagerly sought and robbed of their half-fledged occupants. Carloads of Mockingbirds are sent annually from the South to the North.-In St. Louis and its vicinity the Mockingbird was common only a few years ago; now it has become rare. Notwithstanding the severity of Missouri bird-laws it has disappeared almost completely from all the public parks. As far as their enforcement by the police is concerned, the laws are a dead letter. We do not know of a single case in which the police have made an arrest for the transgression of the law.-Should matters continue as heretofore, all the American birds of attractive plumage or voice will be exterminated, at least in the neighborhood of our larger cities. Only the most severe laws, enforced by the most vigilant public sentiment, can be of any service. Laws for the protection of our birds should be instituted everywhere, and the public, especially the farmers, should see that they are executed to the letter. The shipping of living native birds from one State to another as also the transportation of bird-skins, hundreds of thousands of which are sent even to foreign countries for millinery purposes, should be forbidden under penalty of heavy punishment. Only the severest laws, enforced without compunction, can effectually stop the demoralizing, shameful love of destruction, which threatens to rob our landscapes of their most charming bird-life."

Let me add to these words of a kind-hearted friend of nature, that especially the press and the schools should take hold of the laws for bird-protection and see that they are enforced. Parents and teachers, divines and newspapers can do infinite good in this matter. - Cruelty must vanish and yield to a nobler, kinder mode of thinking!

In this country the Mockingbird is caged more frequently than is any other native 
insectivorous bird. No objection could be raised against this practice, were it not that the majority of the young birds annually taken from the nests perish by careless keeping. With many people it is a mere matter of fashion to keep a Mockingbird. They take the nestlings because some one else does the same, hang the cage near the nest, and let the old birds feed them until they are able to take care of themselves. Usually they pine away, scarcely one surviving till spring. Then the whole thing is repeated again. No one ought to keep a Mockingbird, or any other bird, in a cage unless he feels an earnest desire to care for it to the very best of his ability. - In this country wild Mockingbirds are rarely caged, but they are far more valuable than reared nestlings.

Usually the bird-hunters take the young from the nest as long as they open their beaks for food. These are sold in Southern cities by Negro boys for from fifteen to twenty-five cents a piece. The experienced bird-fancier can distinguish the sex of the nestlings at once; he leaves the females and takes only the males from the nest. The young are put in small boxes containing cotton, and are covered with pieces of flannel to keep them warm. They are fed with a mixture of hard-boiled egg and potato, and this diet is also (at least in the South) continued through the remainder of their cagelife. This food has to be made fresh two, or even three, times a day. By the beginning and the middle of June great cargoes of young Mockingbirds reach Chicago and New York. Quite young birds sell at a price of five dollars each, while one year old singers run as high as fifteen, and older ones even as high as twenty-five dollars, at which price they find ready sale. In the North the birds are also fed for some time with egg and potato; later, however, they are given the well-known mixture called "Mockingbird-food," which is mixed with grated carrot. Sometimes dried ants' pupæ, and often also raisins and currants should be added. Every singer should receive his daily share of meal-worms, say fifteen to twenty-five, and different berries and fruits in season, with now and then a pod of red pepper. I often noticed in the South that caged and wild Mockingbirds ate the last apparently with great relish. The cages in general use are quite roomy, with arched tops; they are sometimes really elegant and answer their purpose perfectly. The food must be freshly prepared, at least twice daily. In winter, when it does not turn sour quickly, one preparation is perhaps sufficient. The birds must always be provided with fresh water for drinking, and frequently with water for bathing. The floor of the cage must be cleaned every day and strewn with clean dry, coarse sand.

Thousands of Mockingbirds find their way across the Atlantic to Europe. In Germany these birds are highly valued. The price of a bird there is regulated by its song, and varies exceedingly, as some Mockingbirds are most excellent singers whereas others are not in the least remarkable. In that country they have already bred very successfully in confinement.

The Mockingbird ranges from the Atlantic to the Pacific, and from central Illinois, Indiana, Pennsylvania, etc., southward to the Gulf of Mexico. The West Indies, Mexico, Central and South America, have their own species.

NAMES: Mocking bird, Mocking Thrush, Mimic Thrush.-Merle moquetr (French). Spottrogel, Spottdrossel (German). 
SCIENTIFIC NAMES: Turdus polyglottos Linn. (1758). Turdus polyglottus Gmel. (1788), Lith., Wils., Aud., Nutt. MIMUS POLYGLOTTUS Boie, Isis, 1826, 972., Brd., Coues, Ridgw., ete. Orpheus polyglottus Sw. (1827).

DESCRIPTION: Male above ashy-gray; below grayish-white; tail and wings blackish, the latter marked with large white spots on the primaries, and across the ends of the coverts; the outer tail-feathers entirely white, the next one or two tipped with white. - Female similar to the male, but the colors less clear. The male is distinguished from the female by the superior size, and greater cxtent and purity of the white markings on wings and tail. Bill and feet are black. Iris in young bircls hazelcolored, in older birds yellow. - Young Mockingbirds are above brownish-gray, and below speckled with dusky. Length 9.50 to 11 incles. -Nest bulky, usually in bushes or trees. Eggs, four to five, pale bluish-green, heavily spotted with reddish brown. $.97 \times .73$ inch.

\section{CATBIRD.}

\section{Galeoscoptes carolinensis CABAnIs.}

P'LA'TE III.

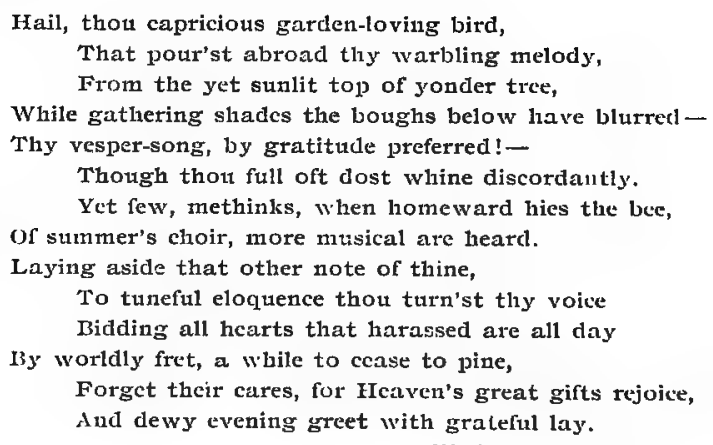

IV. 1. SHoEmaki:k.

We

HO does not love our beautiful native birds? Who does not grieve when they leave our gardens, fields, and forests in autumn with the bright days of Indian summer, and who does not welcome them back as dear friends when they return to us again from their winter quarters in the sunnier South? Who has not enjoyed the familiar song of our beautiful Bluebird or the first whistle of our Robin, when in early March they come once more to tell us that winter must go and spring is coming? Who has not learned to love the plainly colored little Hairbird, or "Chippy," the modest and yet so attractive Snowbird and the admirable Song Sparrow, as they pick up the crumbs at our feet? Or who has failed to admire the bright-colored Baltimore Oriole, as it weaves its purse-shaped hanging nest high over-head in the boughs of a beautiful wide-spreading clm, so safe from snakes and prowling cats? What can be more delightful than our shady northern woods carpeted with fragrant trailing arbutus, checkerberry, wake-robins (Trillium), twin-flowers, partridge-berry, blood-root, terrestrial orchids, bellworts, ferns and club-mosses, and enlivened by a host of Warblers, 

III.

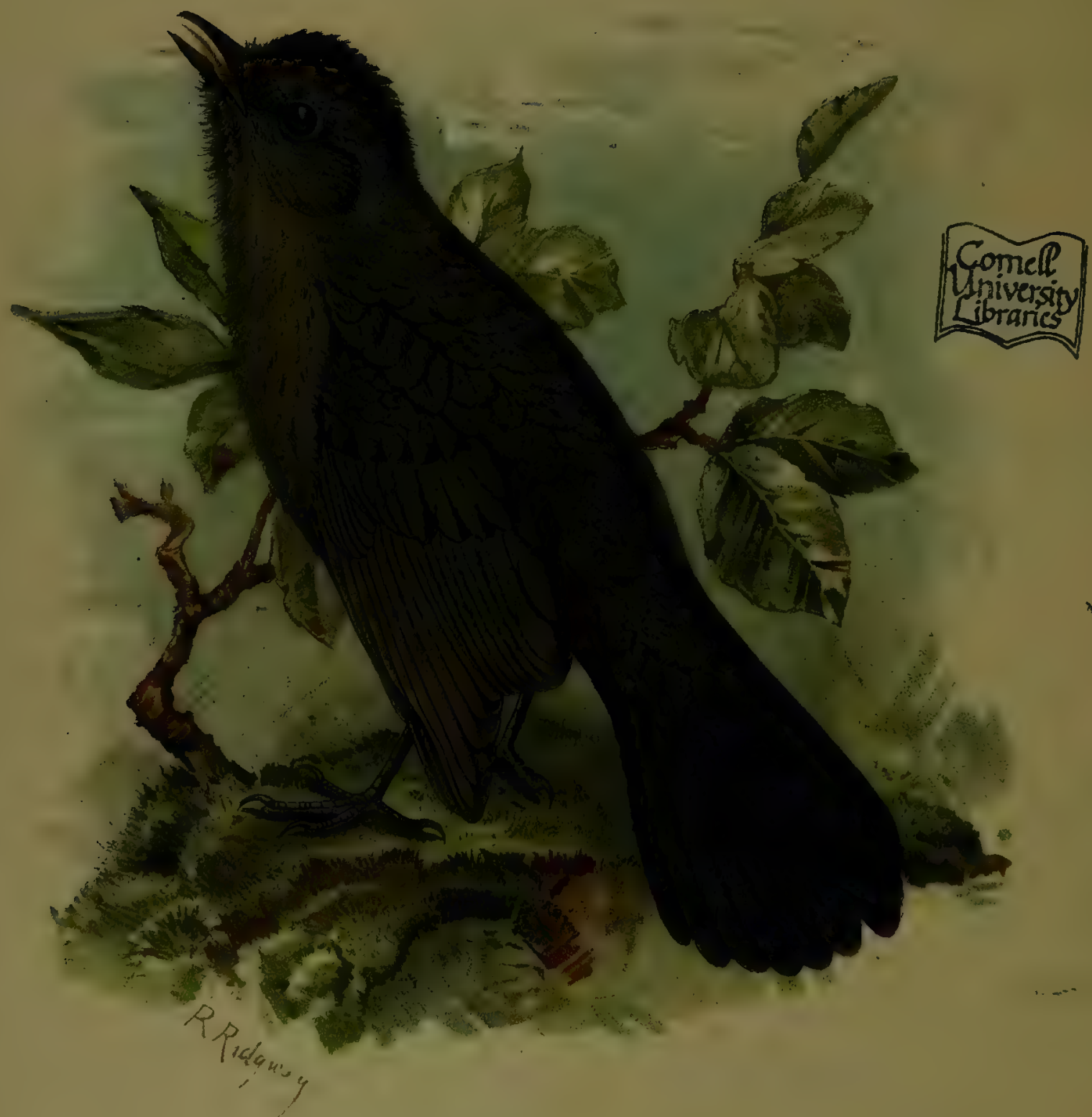

$4 / 5$

GALEOSCOPTES CAROLINENSIS Cab. KATZENVOGEL. C atbird. 
Vireos, Titmice, Rose-breasted Grosbeaks, Chewinks and showy Scarlet Tanagers! Or what can be more charming than the song of our Thrasher! Have you ever listened to the tinkling melodies of a number of Bobolinks flying over the grassy meadows adorned with bright-colored wild lilies? Have you ever enjoyed a fine June evening in the woods, when the air was filled with the fragrance of flowering shrubs, when the sounds of the Whippoorwill fall upon your ear? Who will not admit that Nature is full to overflowing with the most delightful poetry?

of all the feathered visitors who return to us in spring and make their home among our ornamental shrubbery, the CATBIRD is my especial favorite. It is an old acquaintance made in early childhood, and its reappearance with each coming spring calls up countless memories of happy days. And the Catbird deserves to be everybody's favorite. True, its plumage is plain, but, says Olive Thorne Miller, "no bird is more graceful than the Catbird, and in spite of his sober dress of slate-color and black, none is more beautiful. His plumage may be grave in hue, but it is like satin in sheen and texture, and always in the most perfect order, for he takes the daintiest care for himself." * Our bird is readily distinguished by its fine slate-color, black crown, wings and tail, and by its chestnut-colored vent. It is, too, one of our most exquisite songsters, far too little prized. It can be truly called the Mockingbird of the Northern States. In many localities it is one of the most abundant and best known birds, and it is so confiding and social that it always prefers to take up its abode in gardens close to human dwellings. It is also an exceedingly useful bird, for it destroys countless noxious insects, and the same may be said of it in this respect that $I$ have already said of the Robin. These preliminary remarks are sufficient to show that our Catbird is one of our most prominent and valuable birds.

The geographical distribution of the Catbird is confined to the Eastern States and the British Provinces, west to, and including, the Rocky Mountains. Occasionally it is met on the Pacific coast and as far south as south-eastern Texas during the breeding time. It winters in the Gulf States, Mexico, Central America to Panama, and Cuba. In the Eastern, Middle and Northern States it is especially common though rare in the far West. In Colorado, however, where it is found in the mountains as high up as 7,500 feet, it seems to be quite common. To judge from my own observations in the neighborhood of the Gulf of Mexico, it is rare throughout the Southern States. In Texas it is common only during migration, but very rare during the breeding season and in winter. It is one of the best known and most abundant birds in Wisconsin, Illinois, Missouri, and the mountain regions of Arkansas. North it is found to Lake Winnipeg.

The Catbird reaches Texas from its winter quarters in the beginning of April, south-western Missouri at the end of that month, northern Illinois about the 10th of May, Wisconsin rarely before the 15 th of the same month. Of course its arrival depends on the weather. According to Mr. Otto Widmann's statements it appears at St. Louis, Mo., rather regularly on the 24th of April or a few days earlier or later according to the weather. When the cherry trees blossom I know that it is time for the Catbird to arrive.

Our bird is a sojourner of dense thickets and shrubberies. It may be found along 
the bushy forest margins, in swampy places overgrown with thickets, in blackberrypatches, in the ornamental shrubs of the gardens and parks, in short, we may look for it in all bushy places near water. In forests wanting in undergrowth, on dry hills, and far from water it is never found. Bushes and thickets are always its haunts and breed. ing places, and the denser and more tangled they are, the more they are preferred. In northern Illinois $I$ found it most common in the woods traversed by a river or creek, where it inhabited as a rule not so much the marginal thickets as the shady intertwined undergrowth of the interior, where Wood Thrushes, Vireos, Chats, Rose-breasted Grosbeaks, Towhees, and Brown Thrashers were its near neighbors. These shady thickets are usually composed of high cranberry, arrow-wood, black-haw, elder, șeetscented crab-trees, hazel, white-thorn, cock-spur thorn, dogwood, and are overgrown with wild grape vines. In such copses the Catbird is usually very abundant. Near man it has a predilection for small dense conifers, likewise for dense ornamental shrubs, such as the different kinds of upright honeysuckles ${ }^{1}$, mock orange, sweet-scented shrub ${ }^{2}$, Mis. souri currants, twining honeysuckles, snowberry bushes, and others. In the prairie region of southwestern Missouri, where the drooping branches of the apple-trees are very dense and thickly covered with foliage, the bird occurs regularly in orchards. There it inhabits such places in company with Mockingbirds, Robins, and Thrashers. It also loves to settle in the osage-orange hedges with which the farmers surround their fields. Its trustfulness in man is so great that it will often build its nest close to a house or near a very frequented garden-path. It is almost certain to nest in thick bushes in a corner of the garden, in a shrub covered with vines, in a twining honeysuckle or in a group of small spruces. In the coast region of New England and the Eastern States where large masses of rhododendrons ${ }^{3}$, kalmias ${ }^{4}$, azaleas ${ }^{5}$, and other similar shrubs are planted, from the midst of which rise in summer noble golden-banded ${ }^{6}$ and meadowlilies $^{7}$ in wonderful profusion, where the peaty soil is carpeted with a host of the most delicate small perennials, our-humble tenant finds the fittest haunts and nesting places. The evergreen rhododendrons and kalmias are so closely covered with large leaves, the branches grow so tangled when the shrubs are planted near together, that the Catbird can hardly select a better spot for building its nest. In the mountain regions of Penn. sylvania, Virginia, North and South Carolina, the Catbird is very abundant wherever the wild rhododendrons occur. "A conspicuous feature," says Mr. Wm. Brewster in his admirable paper on the Birds of Western North Carolina, "of the plateau region at large is its extensive tracts of rhododendrons or 'laurels'. These form the principal undergrowth along streams, over damp hillsides, and throughout swampy or springy land, and, in many places, they grow in such tangled thickets, that it is impossible for a man to penetrate them without the aid of an. axe." "In this region also grows in dense thickets the mountain laurel, or Kalmia latifolia, with its beautiful rose-colored flower clusters, a recently discovered rhododendron (Rhododendron Vaseyi), and in many places in June the woods are resplendent with the gorgeous blossoms of the beautiful flamecolored azalea, or "swamp honeysuckle" 8 . In a certain place (Jocassee Valley) the very

1 Lonicera tartarica and L. xylosteum. 2 Calycanthus foridus, a Rhododcndron maximum. $\dot{R}$. Catambiense and hybrids. 4 Kalmia latifolia. 6 Azalea pontica and hybrids, A. nudiflora, A. viscosa. 6 Lilium auratum. 7 L. superbum and $L$. canadense. B Rhododendron (Azalea) calendulacea.

"See "Auk," Vol, III, p. 98. 
rare shortia ${ }^{1}$, a small herbaceous perennial is also known to flourish. In the shade of tall kalmias and rliododendrons, every little brooklet is lined with it. The mass of glossy green and white, once seen, can never be forgotten. Here we also find the beautiful Stuartia pentagyna, the tree huckle-berry, the fringe-tree, the sweet-scented calycanthus, the trailing arbutus, and a host of beautifully developed ferns. No wonder that we here find many northern and southern birds together; no wonder that our familiar Catbird is perfectly at home here.

If not molested by ignorant people, by cats and other enemies, the Catbird will return each year to the same thicket in the woods, to the same shrubbery in the garden. Some peculiarities of the song are almost always sure to tell whether the old habitation has been taken up by its former owners or by new-comers.

The nest is always situated a few feet from the ground in a shrub or small tree. It is a familiar object to every friend of nature who enjoys out-door life. Every pair of Catbirds inhabits a group of ornamental shrubs, or a small thicket in the woods, by itself, and allows no intrusion into the home it has selected. On the Desplaines, in northern Illinois, near River Forest and Maywood, I once found seven nests in a bushy spot covering an area of about two acres, besides several nests of the Wood Thrush, Thrasher, Yellow-billed Cuckoo, Rose-breasted Grosbeak, and Towhee. Though the area appropriated by each pair of birds in such places is limited, all usually live together in perfect harmony. The structure is rarely more than from two to four feet from the ground. It is always placed in the interior of a bush where it is protected above, below, and on all sides, by dense foliage, from the sun and rain, and especially from the keen eyes of all enemies. Nevertheless, the Catbird's nest is one of the most easily found and best known of all birds' nests, for its position is only too often betrayed by their peculiar mewing cries. Then one needs only to bend aside the branches of the bush, and the structure, with its glossy bluish-green eggs, lies exposed. The nest is very characteristic. Those which I found in Wisconsin, Illinois, and Texas, were alike in every particular, so that the description of one applies to all. Only those found in southwestern Missouri differed from the others in building materials. Almost all the northern nests consist of plant-stems, small twigs, bark strips, grass blades, and dead leaves; the cup is very often made of a layer of mud, lined with fine rootlets. All the material is of a gray or dark color, and I have never found a nest in the North in which the lining of fine black rootlets was lacking. In the structures found in southwestern Missouri the layer of mud is usually substituted by decayed wood, and instead of dark rootlets those of a cinnamon brown color are used. The four-rarely five-glossy greenish-blue eggs are in strong contrast with the dark back-ground of rootlets on which they rest. In the North usually one brood is reared; further south, however, two are raised under favorable circumstances. Only the female incubates, the male meanwhile singing and standing guard at no great distance. As soon as anything of a suspicious nature approaches the nest, the bird utters its loud and very peculiar mewing notes, which sound like "day-ee, day-ee," and hops about the intruder in great fear and anxiety. It flutters and skips through the bushes, in its screaming endeavoring to rid itself of the foe. These curious notes of pleading and alarm somewhat resemble the mewing of a kitten, and 
have given this familiar songster its name and are the cause of its being disliked by ignorant people who do not appreciate its good qualities. It is too often persecuted by thoughtless and rude boys and ungrateful men, who, unmindful of the good it is ever doing in the world, hate it for no good reason, are deaf to its varied song, and heed not its affectionate disposition or its many social virtues. It is true, the cries are not very pleasant, but they are so plaintive and pleading that the kind-hearted observer gives the nest and eggs a hasty glance and hurries to leave the thicket. Sometimes it is only necessary to brush the bushes which conceal the nest to move the birds to utter their mewing notes. Once, in the first part of May, while I was passing through the woods on Spring Creek (Harris County, Texas), I heard a subdued "day-ee," which convinced me that among the moss-draped branches there must be a Catbird, a bird which I had never seen in Texas during the breeding season. Advancing a few steps, I again heard the cry but could nowhere catch sight of the bird, for the woods were dense and all the branches draped with Spanish moss. While I stood peering into the foliage on all sides, I discovered in a young oak about ten feet from the ground a nest which on closer examination proved to be a Catbird's. It contained only one egg, and was in every way like the nests I have described. The birds were so shy that they did not dare approach the nest closely. Their cries, too, were more rarely uttered and more subdued than is customary with northern birds. It seems hardly credible that the Catbird, so affectionate and familiar among the shrubberies of our northern gardens, should be so suspicious, shy, and retiring as it is in the South. I saw an old nest very nearthe one just described, proving that the birds had built there during the preceding year. -I have never found a Cowbird's egg in a Catbird's nest, but Mir. Otto Widmann informs me that he once found the egg of a Yellow-billed Cuckoo in the nest of a Catbird.

As soon as the young are hatched, the male assists in their bringing up. It is astonishing what a number of worms, caterpillars, grasshoppers, moths, beetles, spiders, etc, the parents are obliged to bring to the young continually. In more southcrn localities, the old birds often commence preparing for a second brood, a few days after the first has left the nest. The old male watches, warns, feeds, and guides the young till he is called upon to attend to the second brood, by which time the young of the first are able to care for themselves. That the parents love their young exceedingly is evident on one's approaching the nest. With anxious cries, with ruffled plumage, and drooping wings they flutter about the intruder. They even courageously and selfsacrificingly defend their offspring from smaller enemies, such as snakes, cats, Blue Jays, Shrikes, and Grackles.

In Missouri, a pair of Catbirds nested every year in a dense twining yellow honeysuckle $^{1}$ and a second pair in a fine snowberry-thicket ${ }^{2}$ in the corner of my garden. Here I had an opportunity of observing with what acuteness these birds can distinguish between friends and foes. They would allow even the children to look at their eggs and young without becoming in the least uneasy and frightened. They certainly knew that they were protected and that the children, too, loved them. But as soon as a stranger approached the structure they screamed so loudly and evinced such noisy distress that

\footnotetext{
t Lonicera Aara. 2 Symphoricarpus glomeratus.
} 
the chickens in the barn-yard cackled, and old hens hurried to get their broods in safety. In the woods and thickets the Catbird thus warns other birds and even quadrupeds. Our slate-colored tenant of the shrubbery is one of the finest singers. From its arrival in the spring till the young leave the nest, it makes the air about us vocal with its quaint and charming melodies. The song is exceedingly rich, varied and euphonious. Indeed, the bird is a rival of the Thrasher and far excels in this respect the Robin and other song birds of its bushy home. Though it also possesses extraordinary ability in mimicking the songs of other birds, its performance is almost entirely original. The rule so applicable to other songsters holds true of the Catbird: not all males are masters in the art of singing. There are good singers, and such as show no great ability in this respect. In southwestern Missouri I have heard Catbirds that were able to avoid all discordant sounds, adopting only the sweetest notes of their own and other birds' songs. I was frequently unable to decide whether a particular singer was a Catbird or a Mockingbird, for both birds dwell in the same localities and each vies the other in singing. Some years ago I kept a Catbird in confinement which not only had an unusually beautiful song of its own, but could rival many Mockingbirds in imitating other birds' melodies. The call of the Whippoorwill, the song of the Wood Thrush, the metallic notes of the Towhee Bunting were imitated perfectly and fused with its own song to form a wonderful piece of melody. - When singing the Catbird almost always perches in the top of a bush or small tree. It ruffles its plumage and accompanies its notes with lively movements. The bird has been represented in such an inspired attitude by our ingenious artist Mr. R. Ridgway (see Plate III). Sometimes it flies singing to the ground, then flutters in ecstasy into the thicket, and finally appears singing again in the top of some shrub. It sings most diligently early in the morning and toward evening.

Although a very trustful and familiar bird, the Catbird knows well where to settle and where not. In gardens where many ornamental shrubs are planted, where it is protected and cherished, it lays aside all fear, comes even to the honeysuckles and grape vines of the verandah and to the bushes and trees about the windows and often peers inquisitively into the rooms. It never takes the Catbird long to ascertain where it is a welcome visitor, and it makes itself at home at once. As soon as it is satisfied that you are its friend, it will approach you with a familiarity that is quite irresistible. It seems to wish to attract your attention by its great variety of positions, attitudes, and musical efforts. "No musical young lady was ever more ambitious of entertaining an audience, however small and select, than our slate-colored songster. It will come down, in the excitement of its musical ardor, to the lowest bough, within a few feet of one's head, and devote itself to your entertainment as long as you honor it with your attention." The Catbirds are invaluable denizens of our gardens and shrubberies, of the thickets, the swamps and woods. They weave a web of quaint poetry about their native haunts and fill with joyful life surroundings which but for them would be desolate.

The flight of our songster is not very rapid or skilful. It avoids, as much as possible, traversing wide treeless spaces. Usually it flies from bush to bush, from thicket to thicket, spreading its tail as it moves forward.

Food is usually sought on the ground, but frequently also among the foliage. It 
consists chiefly of noxious insects, such as worms, grasshoppers, caterpillars, beetles, etc. The bird's usefulness as a destroyer of innumerable noxious insects cannot be estimated too highly. It is a service compared with which the small allowance of fruit which it steals is of little importance. From early morning to sunset it watches over the fruittrees and kills the insects that would destroy them or their fruit. True, it takes its share especially of cherries, but for every one it takes it eats thousands of insects. Where there are no small birds there will be little fruit.

In the last part of September the Catbirds leave the Northern States. None are to be seen in southern Missouri by the end of October. They migrate as far south as Cuba and Panama.

Unfortunately this fine singing bird has many enemies. Many nests built in gardens are destroyed by prowling cats. In swamps and woods, skunks, raccoons, opossums, and snakes rob the nests of their eggs and young. Notwithstanding its musical ability, its inoffensive disposition, and the benefit it confers upon the horticulturist and farmer, the Catbird is an object of derision and persecution, as undeserved as it is cruel.* Bad boys destroy the nests and pursue the old birds with sticks and stones. This hatred and desire to persecute probably find their explanation in the bird's mewing, somewhat cat-like notes, which might be disagreeable to ignorant people. The modest color also, which I, for my part, find exceedingly pleasing and attractive, and the by no means pleasant popular name of "Catbird" may also contribute to making it disliked. -I am sorry to say that many of our boys are so low-minded and barbarous as to stone every strange and fine-colored bird they see. Near towns and cities half grown boys roam about in the woods killing birds. No wonder that our beautiful native songsters are becoming so rare even now, that bright-colored birds, like the Scarlet Tanager, the Red-headed Woodpecker and others, are all but exterminated in some localities where they were once abundant.

The Catbird is well adapted to cage-life. It is to be treated in the same way as the Mockingbird. For an account of the "Tricks and Manners" of the Catbird in confinement I refer the reader to Mrs. Olive Thorne Miller's admirable little book "Bird Ways."

NAMES: Catbird, Cat Flycatcher (Penn.), Merle Catbird, Chat.-Merle à clerriere (D'Orb.). Zorzal Gato (Cuba). Katzenvogel and Katzendrossel (German).

SCIENTIFIC NAMES: Muscicapa carolinensis L. (1766). Turdus carolinensis Licht. (1823). Orpheus carolinensis Aud. (1839). Mimus carolinensis Gray (1856). Felivox carolinensis Bonap. (1853). Lucar lividus Bartr. (1791). Turdus lividus Wils. (1810). Turdus felivox Vieill. (1831). Mimus felivox Bonap. (1838). GALEOSCOPTES CAROLINENSIS CAB. (1850), A. O. U. "Code and Check List" (1886).

DESCRIPTION: Slate-colored, paler below. Crown of the head, tail and wings black; under tail-covert (vent) chestnut. Bill and feet black. - Young more sooty-colored, with little 1,lack, - Length 11-12 inches; wing 3.50 , tail 4 inches.

\footnotetext{
"See Stearns and Coues' "New Ėngland Bird Lite." Vol, I, p. 63, 64.
} 


\title{
BROWN THRASHER.
}

\author{
Harporhynchus rufus $\mathrm{C}_{\mathrm{AB}}$ \\ P'LATE V. FIG. A.
}

Oh, harle to the Brown Thrusin! hear how he sings: Now he pours the dear pain of his gladness!

What a gush! and from out what golden springs! What a rage of how sweet madness!

D. $\Lambda$. IVASSON.

T $T$ IS a beautiful June morning. Bathed in the brilliant sunlight, the prairie of northern Illinois lies stretched out before us. Its grassy monotony is broken only by strips of woodland, aggregated in the distance. Sometimes one must walk miles to reach one of these strips of forest, but who feels himself deterred by distance on such a morning and in such a place? Even here, in the grassy, meadowy plain, bird-life reigns supreme. Dozens of Bobolinks hover over the waves of grass uttering their tinkling notes; Meadow Larks merrily trill their matin songs; the Savanna Sparrow rocks itself on the lithe tall herbs while it smooths its plumage, and Black-throated Buntings, or "Dicksissels," making up in eagerness for all the dissonance of their voices, unceasingly emit their acute twitter. The green grass is gemmed with flowers. The Canada lily ${ }^{i}$ and the turk's cap ${ }^{2}$, although not yet in full flower, tower above their surroundings. In a few weeks the whole prairie will present an enchanting appearance, when these noble flowers shall burst into flaming bloom.

At last we have reached the margin of the woods. A Maryland Yellow-throat, perched in the undergrowth, bids us welcome. In the hazel thickets, in the blackberry, viburnums, and dogwood bushes, bordering the woods, hides many a Yellow Warbler and Indigo Bird. The Baltimore Oriole, glowing like a flame amid the foliage of some isolated elm, pours forth its song, while the wind sways its pendent nest built with exquisite art high aloft in the flexible twigs. A few steps further and we have reached the nesting place of our Brown Thrasher, or Brown Thrush, and many another forest-loving species. The margin-underwood is usually followed by dense shrubbery consisting of sweet-scented crab-trees ${ }^{3}$ and white-thorn ${ }^{4}$, overgrown with wild grape vines and virgin's bower ${ }^{5}$. Here and there isolated oaks, elms, black walnut, hickory, and ash-trees shoot upwards, their numbers and density increasing as we move on into the forest. As these woodlands almost always follow the banks of rivers and creeks, their dense undergrowth becomes a place of congregation for many different birds. They are the favorite haunts of the Wood Thrush, the Catbird, the beautiful Rose-breasted Grosbeak, the Chewink, many Vireos, of the Wood Pewee, the Redstart, etc. The Brown Thrush is one of the most abundant of the denizens of these thickets without, however, confining itself to these alone, for it is also found in bushy pastures, in the dense shrubbery along rail-fences, and in greater abundance in the dense osage-orange hedges.

Lilium canadense. 2 L. superbum, 3 Pyrus coronarius, 4 Crataegus. 5 Clematis virginica. 
Our bird loves the dense thickets near water. The more thorny and interwoven with grape-vines these are, the more they are preferred by the Thrasher. As the bird is somewhat awkward in its flight it is best protected from its many enemies in these places; and here, too, it is sure to find an abundance of food. During spring and summer its haunts are peopled with insects in great numbers, and later there is no dearth of different kinds of berries, so that the Brown Thrush never has to suffer from want of food. It is not to be found during the breeding season in the deep interior of the woods and in extensive swamps. In Wisconsin it is rarer than in Illinois. In southwestern Missouri $I$ found it to be one of the most abundant birds. In Texas, where it is common during the winter only, it was especially numerous along the Buffalo Bayou near Houston, in the dense thickets which skirt the Brazos and Colorado, and on the West Yegua Creek, where it lived in great concealment in the densest evergreen shrubs. Here, as in the Northern States, it finds plenty of food during the whole winter, for there are many insects on the ground and berries on the bushes. In its winter home it invariably avoids the neighborhood of man, and is so shy that it rarely leaves the tangled undergrowth. In its breeding haunts, too, it is rather shy and careful, building its nest in gardens only. when set with clumps of dense ornamental shrubs. It always prefers, for a nesting site, such trees and shrubs as have branches reaching down to the very ground.

The Brown Thrasher is a hardy bird. It arrives in its breeding haunts rather early, in northern Illinois and in Wisconsin, even before the beginning of May. Its arrival, however, is easily overlooked, as the bird keeps itself concealed at first. According to Mr. Otto Widmann's observations, it reaches St. Louis at a time when the landscape is still wintry, in the last part of March or the beginning of April, while the Catbird arrives considerably later.-In southwestern Missouri, near Freistatt, 1,200 feet above the sea level, some Thrashers usually make their appearance by the beginning of April, and all the individuals arrive by the middle of the same month. I have never seen them in companies even in their winter home.

The Thrasher's full song is heard a few days after its arrival, if the weather be bright and the air balmy. At first it is heard only at rare intervals; but, as soon as the spring has poured out its wealth of blossoms and warm breezes, and all the more delicate songsters have arrived, the Brown Thrushes' song reverberates from all sides. For some weeks it is the most prominent and feverishly eager of all songsters. The lay is rich in quality, being full of feeling - at first soft, whispering, delicately plaintive, then loud, powerful and sonorous, wonderful in the variety of its notes and the manner in which the strophes melt into one another. It flows along like a clear, powerful stream, occasionally sinking into soft complaint as of longing, then changing suddenly and becoming louder, fuller, livelier, till the air fairly resounds with the birds' exultant joy.This song, most eager toward the end of May and the beginning of June, is indescribably charming and beautiful. It consists entirely of original notes, those of other birds never entering into the composition. Only he who has listened to the notes of the Thrasher, when all the landscape buds and blossoms, when every living being is impassioned, and the feathered hosts of songsters hold high carnival in the labyrinth of trees and bushes, can form an adequate idea of the lofty, melting andante of the song. 
The Brown Thrush is certainly one of our very best songsters, and rivals the Wood Thrush, the Veery, the Hermit, the Catbird, and the Mockingbird. I regard the Thrasher as the finest of our American songsters. It would take the palm even from the Hermit and the Mockingbird, if only its period of singing were longer. It is, unfortunately, a prominent singer for a few weeks only; later in the season, its voice is rarely heard. When the Catbird begins to sing, the Brown Thrush has approached the end of its season of song. During this brief season, however, it sings very diligently. It usually pours forth its notes from some exposed spot, as from the top of a small tree or a telegraph post. It bears itself nobly, and its eyes speak intelligence and selfconsciousness. If disturbed while singing, it suddenly dives almost to the ground, disappearing in the neighboring bushes, or it flies along the edge of a thicket or hedge, just above the surface of the ground, till it reaches another suitable perch where it again begins its song. Usually the males of a district vie with one another from their lofty perches. Besides the song, one often hears a melodious call-note like "Yeu" or "Tsheeuh", and also a sharp smacking or hissing "Tshat", especially when the nest is approached.

About the middle of May, in the Northern States the male and female will often be seen flying about bushes and hedges. They follow each other closely as they skim over the ground. The reddish-brown color of the upper parts, the long reddish-brown tail, and the somewhat heavy flight, make them easily recognized. In the osage-orange hedges with which the prairie farmers of Illinois surround their fields, and which often extend for miles along the country roads, I have frequently found as many as five, and even six, nests in a mile's walk. In these close and very thorny hedges, the nests are built at a height of from three to five feet from the ground, and so carefully are they concealed in the dense foliage that they cannot be seen without bending the branches aside. Here they are well protected, for it is difficult to reach them without scratching one's hands. Cats, raccoons, squirrels, and other small mammals, are likewise unable to reach the structure in such a situation. In southwestern Missouri and in Wisconsin, the nests are most abundant in bushy forest margins and in pastures dotted here and there with thickets. In these places, too, the Thrasher builds its nest in the interior of some white-thorn bush, in a sweet-scented crab-tree, or in a thicket overgrown with wild grape-vines. In these latter places I found the nest from eight to ten, and even fifteen, feet from the ground. In Missouri, I occasionally discovered the nest even on the ground in brush-heaps or under low bushes. One nest was found only a few steps back of the school at Freistatt, near a foot-path along which more than fifty children passed and repassed daily. This nest, contrary to the usual habit of the bird, was built in a hollow of the ground, among some brush. The sitting female was so tame that it remained on the nest when one watched it or passed by. Although occurring sometimes in the shrubbery of gardens, Thrashers are rather shy and distrustful, avoid. ing the near neighborhood of man as much as possible. I have found the greatest number of nests in the prairie woods of Illinois alluded to in the opening sentences of this description. As soon as the pair have found a suitably secluded spot in some thicket or vine-covered crab-tree, they begin to gather materials for the foundation of their nest. They first collect small branches, thorny twigs, grasses, plant-stems, etc., 
to build the outer structure; within this they place the nest proper, which consists of leaves, fine grass-blades, and delicate rootlets. In southwestern Missouri, complete sets of eggs may be found as early as the beginning of May; in northern Illinois and Wisconsin, one need not look for them before June 1. The eggs, usually four to five, sometimes six, in number, are of a bluish or greenish-white color, thickly sprinkled with minute rusty brown dots. I have found several sets of eggs, the brown markings of which were so dense as to almost hide the light ground-color.

Both of the old birds incubate, though the male spends much time standing guard a short distance from the nest. With the approach of danger, he utters his soft warning note, which is the signal for the female to leave the nest stealthily and slip into the thicket. In the years of my youth, I was often duped by the cunning with which the Brown Thrush keeps the secret of its nest's whereabouts. Whenever I approached a nest, the male uttered his warning note and the female soon joined him hopping over the ground through the dense shrubbery. Both would repair to some thicket away from the nest and continue their plaintive notes while flying to and fro and hopping up and down, till I was convinced that the nest must be in the same thicket as the birds. I would search long and diligently, but find no nest. Meanwhile the cunning birds had suddenly disappeared. - Should the observer unexpectedly happen on a nest in the midst of a thicket, the male bird will usually not be found at hand. If there be young in the nest, however, he will come forth in great anxiety and excitement, and not infrequently courageously attack the intruder. Brown Thrashers are also exceedingly careful to keep their fledged young concealed. These hungry little "bob-tails" usually sit screaming among the dense branches of thickets, uttering their smacking "tseep, tseep" for food almost without interruption. I have very frequently heard these begging cries close beside or above me; but as soon as the young had heard the warning note of one of the old birds, they stopped their cries for food at once, and were perfectly silent till all danger was passed. The young often leave the nest before they are able to fly, while the wing and tail-feathers are still but little developed. Should the observer approach a nest of half-fledged young, he will see them skip out on all sides, jump to the ground, and vanish in the rank grass and low bushes. If he happen to visit the same spot the following day, he will at first see and hear nothing of either the young or the old birds. If he have patience enough to observe carefully and remain quiet, he will soon hear repeatedly a soft call-note, the old birds will appear with food and vanish again in the top of some small crab or white-thorn tree roofed over with wild grape vines. Under the dense canopy, the young will be found to have selected a fitting hiding place, where they can remain till they are able to use their wings to more purpose. In the Northern States, there is only one brood annually, while in southern Missouri, and southward, there are two broods.

Unobserved, silent; usually from thicket to thicket, and in bushes along streams and rivers, the Brown Thrush migrates southward, ordinarily during October. The Southern States, especially those bordering on the Gulf of Mexico, are the Brown Thrasher's winter quarters. I have found the bird in southeastern Texas from December to March. They usually remain near the water where thicket succeeds thicket. They are especially common where the magnolia, cherry-laurel, holly, dense blackberry and Mexican mul- 
berry bushes, Cherokee roses, and vines of many species, grow. The ground swarms with insects of many kinds, the old leaves cover larvæ and snails, and the bushes are rich in berries. In these thickets the Brown Thrush leads a very secluded existence, in company with the Hermit Thrush, Towhee Buntings, Cardinals, White-crowned and White-throated Sparrows, and others. It is here so shy and knows so well how to screen itself from view that it is but rarely seen. Here, its call-notes are seldom heard. In the dense hammock woods of Florida, it is one of the most abundant winter birds. These woods usually consist of large deciduous and evegreen trees, with an undergrowth of low sawpalmettos, sparkleberry bushes, hollies, smilax, Carolina jasmine, and a host of other tropical species.

The flight of the Thrasher is low, and rather heavy, on account of the shortness of its wings. It ustually flits from bush to bush, all the time opening and shutting its long tail. It is remarkable that a bird of such heavy flight should have reached Europe. Gätke obtained a specimen on the island of Heligoland during the fall of 1838 .

The bird is perfectly at home on the ground, where its strong feet enable it to move with great dexterity. It hops about rapidly, often jerking its tail. Among the old leaves it scratches like a hen. As it spends most of the time on the ground in pursuit of insects, it is less of a berry eater than the other species so far described, and does no harm in gardens, rarely taking a cherry or grape, and limits its fruit diet during the winter, when insects are scarce, to such berries as grow near, or on, the ground. I need not call attention to the fact that the Brown Thrush is one of our most useful birds. Both, its beatufifl song and its usefulness should gain for it the protection which it deserves.

The Thrasher ranges from the Atlantic to the Rocky Mountains, where it is found even at an altitude of 7,500 feet. It is said to range northward to the 54th degree of latitude, as far as the Red River of the North and Lake Winnipeg. Dr. Coures found it breeding near Pembina, on the northern border of our country. It does not seem to be common in the northern portion of its range, for $I$ have found it very rare even in northern Wisconsin, and it has nowhere been observed to be abundant in northern New England. According to Audubon, it breeds in Louisiana, but, I think, only in the northern part of that State, for I have never seen it in southern Louisiana or in southeastern Texas during the breeding season. It is not everywhere equally common, for in one place it will be found in great numbers, while in another it is almost unknown. It does not range further south, during the winter, than Texas and Florida, but is replaced along the Rio Grande and in the far West and Southwest by several closely related species.

The Brown Thrush is a good cage-bird, although little appreciated as such. Caged adult males usually remain shy, suspicious, emitting their beautiful woodland-song only when treated kindly and tenderly. Young males reared from the nest become not only very tame and docile, but also fine singers. I quote the following from a letter of an enthusiastic bird-lover, Consul General Emil Dreier, of Chicago: "I have reared many Brown Thrushes from the nest, and almost all of them have become excellent singers. Some pouref forth their melodies with as much emphasis as the Mockingbird, and, in my opinion, more beautifully." So tame do young thus reared from the nest become, that they may be taught to fly in and out of the cage. 
N.IMES: Brown Trirasher, Thrasher, Brown Thrush, Sand Mackingbird, French Mockingbird, Ferrugineus Thrush, Fox-colored Mockbird (Swains.), Ferrugineus Mockinglircl. - Braundrossel, Drescher (Germ.). Grive rousse (Le M.).

SCIENTIFIC NAMES: Turdus rufus Linn. (1758), Aud., Wils. Orpheus rufus Swains. (1831). Mimus rufus Gray (1838). Toxostoma rufum Cab. (1847). HARPORHYNCHUS RUFUS Cabanis (1850), Baird, Coures, Allen, Riclgw., Merriam, and A. O. U. Antininnus rufus Sund. (1872).

DESCRIPTION: Above, uniform rich rusty-red with a bronze tint; below, white, more or less tinged with dawny; breast marked with oval or lanceolate dark-brown spots, which run up each sicle of the throat in a chain; throat, belly, and under tail-coverts, whitish, unspotted; wings with white bars; tail, very long; bill, blackish above, yellow at base below; iris, fine yellow. - Length about 11 inches; wing about 4 , tail 5 inches, or more; bill 1 inch.

\title{
LONG-BILLED ThRASHER.
}

\author{
Harporhynchus longirostris CAB.
}

EOPO

ORNITHOLOGIST is better acquainted with the birds of the Lower Rio Grande than Mr. Geo. B. Sennett, now of the American Museum of Natural History, of New York. He has spent several seasons there, and his observations are laid down in two admirable papers: "Notes on the Ornithology of the Lower Rio Grande, of Texas," and "Further Notes on the Birds of the Lower Rio Grande, of Texas." *

"Of the Thrushes on our extreme southern border," he writes, "I found the TEXAS Thrasher next to the Mockingbird in point of numbers. Usually they keep out of the sight of man, even when their home is invaded, and the bird driven from the nest. I do not remember of their making any cry of grief at such depredation. One day in April, while concealed in a dense thicket close by some heavy timber, a pair of this species gave me pleasure for a full half hour. This, I think, was the only time J ever saw them for more than a moment or two at a time. The male was nearly as full of song as a Mockingbird, and his notes seemed much sweeter, not being so loud. They kept very near each other, the female giving frequent little chirps. I was unable to see any peculiarities distinct from the habits of its nearest relative, $H$. rufus, excepting that it was more arboreal, and built its nest much higher.... I found none without a lining, either of grasses, Spanish moss, fine roots, or bark. There was a marked depression in every nest, varying from 1 inch to 2.50 inches. Of those taken, the lowest was four feet from the ground, and the highest some eight feet, averaging, I think, $51 / 2$ feet. I found their nests in a variety of places - prickly-pear cactus, Spanish bayonets, chaparral, and most commonly in the dense undergrowth under the heavier timber. Its usual position is in the very heart of the tree or plant selected, and, like most of the nests of this region, not capable of being detached from the thorny bushes without falling to pieces. I found the birds and nests of only three Thrushes, viz: Mockinglird, Curve-billed Thrasher, and the one now under consideration; and I doubt very much

\footnotetext{
- Bulletin of the U. s. Geol. and Geogr. Surv, of the Territories. Vol, IV, V, 1878, 1x79.
} 
the ability of any one ordinarily to tell one nest from the other, either by structure or position. The usual complement of eggs is four; in fact, I found but one clutch of five. The eggs are marked very much as those of the Brown Thrush, and are hardly distinguishable from them. The typical egg has a ground-color of the faintest greenishwhite, and is finely speckled all over with brown, the dotting being thickest on the larger end...." The bird is resident throughout the whole Lower Rio Grande country, and very abundant. It feeds upon the como and other berries, as well as insects and larvæ.

NAMES: Long-Billed Thrasher, Texas Thrasher.

SCIENTIFIC NAMES: HARPORHYNCHUS LONGIROSTRIS CAB. (1850). H. rufus longirostris P. B. \& R., N. A. B. (1875). Toxostoma longirostre Cab.

DESCRIPTION: Similar to H. rufus, but rather darker brownish above. Beneath, pale whitish, strealked on the sides of the neck and body, and across the breast with dark brownish-black. - Length about 10.50 to 12 inches.

The Saint Lucas Thrasher ( $H$. cinereus Xantus) is a common bird of Lower California, especially near St. Lucas.

\section{BENDIRE'S THRASHER.}

\section{H. bendirei Coues.}

This Thrasher was discovered in 1872 by Capt. Chas. Bendire in the vicinity of Tucson, Arizona, where it seems to be not uncommon. The bird nests in trees and bushes, preferably in mesquite, sometimes thirty feet from the ground. The entire upper part of this Thrasher is uniform dull grayish-brown; beneath it is much paler grayishbrown, becoming nearly white on chin and throat and middle of belly, buffy on under tail-coverts, and more decidedly brown on flanks; the chest and breast marked with triangular spots or streaks of deeper grayish-brown.-Length about 9.50 to 10.50 in.

\section{CURVE־BILLED THRASHER.}

H. curvirostris CAB.

"This Thrush, though frequently seen, is not so common as the Long-billed Thrasher, and is readily distinguished from it. I did not meet with it until we reached Brownsville, March 20. The very first day at that place, it was seen about the brush-fences just outside of the city. The bird is very retiring in its habits, never more than one or two being seen together, and even less inclined to sing in exposed places than its near relative ( $H$. longirostris)... On May 10, while on horseback, I came upon a pricklypear cactus, wonderful to me for its size and tree-like shape. Its trunk was the size of a man's body, and some of the branches were above my head as I sat on my horse. Its general form was that of a wine-glass. While peering about and poking the stalks with my gun, I discovered in the very heart of the great cactus a nest and four eggs of this Thrasher. It was about five feet from the ground, perfectly exposed above, yet nothing could be more secure from all sides.... The shape of the egg is like that of 
the Brown Thrush's, only larger. The ground-color varies from pale to a rich pea-green. The markings are brown, evenly and finely scattered over the entire egg." (Sennett.)

In the following year, Mr. Sennett found this Thrasher more common farther up the Rio Grande, near Hidalgo. "The Curve-billed Thrush," he adds, "in color somewhat resembles the Mockingbird, and in bushes where other characteristics are not readily distinguished, 'may be taken for it at a short range. This species, like the Long-billed, is usually more fond of dense cover than the Mockingbird, and while not often found in the heaviest timber, yet will be found in the thickets common on the edges of such tracts. In open woodland, where clumps of tall, thorny bushes and cacti surround these scattered trees, it is always found, and usually in company with the Long-billed Thrush. By the 1st of April the plumage becomes faded and worn, and, by the latter part of May, moulting begins. About this time, also, the small black fruit or berry of the como-tree, upon which the bird feeds, ripens." The plumage becomes stained with the purple juice of this food. "Nests are seldom found lower than four feet from the ground. The last nest I examined, just before leaving the ranch, ... was situated on the lowest branch of a small tree near the house, entirely exposed to view and, standing upon a chair, I was able to look into it. This fearlessness is exceptional, but indicates that, were the country thickly settled, this bird might become as domestic as the Mockingbird or Robin. It is resident where found, commences to breed in March on the Rio Grande, and rears several broods in a season."

NAMES: Curve-milled Thrasher, Curve-billed Thrush.

SCIENTIFIC NAMES: HARPORHYNCHUS CURVIROSTRIS CAB. (1850). Orpheus curvirostris Swainson. Toxostoma curvirostre $\mathrm{Cab}$.

DESCRIPTLN: Above, like the Mockingbird, uniform brownish-gray; wings and tail darker brown. Below, dull whitish, shaded on the chest and along the sides with brownish-gray, marked with rounded spots of brownish, most numerous on the breast. Throat, quite white, without spots. Two white crossbars on the wings. Tail-feathers distinctly tipped with white.-Length about 11 inches.

A variety, Palmer's Thrasher ( $H$. curvirostris palmeri Ridgw.), is similar. It occurs in southern Arizona, and south into Sonora.

\section{CALIFORNIA THRASHER. Harporhynchus redivivus CAB.}

This Thrasher, one of our finest songsters, has a somewhat restricted distribution, being confined to the coast region of California, where it is, however, quite common. It resembles in every respect our familiar Brown Thrush of the Eastern States, but appears to be more shy and retired in its habits. Colonel McCall describes the song as of exquisite sweetness, "placing it almost beyond rivalry among the countless songsters that enliven the woods of America."

NAMES: California 'Thrasher, California Brown Thrush.

SCIENTIFIC NAMES: HARPORHYNCHUS REDIVIVUS CAв. (1848). Toxostoma rediviva GAMB. (1S17).

DESCRIPTION: "Bill, much decurved, longer than the head. Above, brownish-olive, without any shade of green; beneath, pale cinnamon, lightest on the throat, deepening gradually into a brownish-rufous on the under tail-coverts. The fore part of the breast and sides of the body brownish olive, lighter than the back." - Length 11.50 inches; wing 4.20 , tail 5.75 inches. 


\section{LECONTE'S THRASHER.}

Harporhynchus lecontei Bonap.

This very interesting Thrasher is an inhabitant of the dry regions of southern Arizona and California. In the Colorado Desert, it was observed by Mr. F. Stephens, and Dr. E. A. Mearns found it rather common in certain localities in southern Arizona. Like other species of the genus, it is an excellent'songster, and moreover shows no inclination to mock other birds.

"Any one," says Dr. Mearns, "who traverses the desert between Phœnix and Maricopa, will probably catch sight of at least one of these pallid Thrashers, but may consider himself fortunate if he captures a single specimen. It was in this uninviting region that I first saw Leconte's Thrasher. - The ride from the Gila River to Maricopa, on March 30, 1885, was through a desert, bordered by distant foothills, along the base of which are forests of giant cacti, some of which were found along the road. A sluice of the Gila was crossed a few miles from the river, along which were some cottonwoods and a quantity of tulè ${ }^{1}$, and cat-tails; also plenty of green grass in which Meadow Larks, and Thrashers of some species, were singing, the latter in mesquites. The rest of the country was bare of grass, sandy, and covered with scattered sage-brush and cacti $^{2}$, with occasional bare areas of white sand, where the sun's reflection was terrible. A rare squirre ${ }^{3}$ was here abundant; and all our superfluous energy was expended early in the day, which was intensely hot, in capturing some of them. As we rode along in the condition of stolid indifference to everything, which ensues after the limit of human endurance is reached, numberless lizards and horned toads of varied hues sped unheeded from our trail, until the orderly riding behind me exclaimed: 'Doctor, what are they?' and pointed with his carbine to a pair of whitish birds upon the sand, with their tails cocked up over their backs, which I saw at a glance were Leconte's Thrashers. This pair were the only ones seen that day. They ran and hid with as much agility and cunning as the Chaparral Cock. As I pursued them, some large white lizards scuttled into their holes at a side of a sandy arroyo, which, in the glare of the sun, resembled the Thrashers, than which they were scarcely more fleet, both running before me with great speed, and disappearing from view. They seldom arose from the ground, and then only skimmed over the brushwood a little way, and then ran swiftly on in zig-zags, amongst the bushes and cactuses.... On. April 1, we marched from Maricopa to Casa Grande. As before, the Thrashers were heard singing during the early morning. Their song is remarkable for its loud rich tone, and is at least as fine as that of any other of the genus.... On April 3, after passing the foot of Picacho Peak-a high castellated butte to the right, which for several days had been a prominent landmark-we rode through a grove of 'sohuaras', among which were many arborescent cacti, in which were found the nests of all three of the desert species of Thrashers. That of $H$. lecontei was built in a cholla cactus seven feet from the ground. It contained one egg, having a groundcolor of bluisin-green of a deeper hue than in Palmer's Thrasher, sparingly spotted all over with brown and lavender, the spots largest on the great end, where they tend to accumulate and form a wreath near that extremity. This is the most eastern point

\footnotetext{
1 Scirpus. 2 Opuntia, Echinocereus, Cercus, and Echinocactus. 3 Spermophilus tereticaudus. 1 Cereus giganteus.
} 
at which the species has yet been found."* Other nests were found in mesquite bushes six to eight feet from the ground. They were composed of grasses and weeds, the inner nest resting tupon a mass of large sticks loosely placed. The nest-lining was of grass and a few feathers.

NAMES: LEConte's Thrasher, Yuma-Thrasher.

SCIENTIFIC NAMES: Toxostoma lecontei Lawr. (1851). HARPORHYNCHUS LECONTEI BonAP. (1853), A. O. U. "Code and Check List" (1886). H. redivivus lecontei Coues, Key (1872).

DESCRIPTION: "General color, above pale ashy-drab; below much paler, tinged with ochraceous. Chin and upper part of throat, white, bordered by indistinct dusky submaxillary stripes. Cheeks and maxillae whitish, wilh dusky spotting." (Mearns.) - Length about 10.50 inches; wings about 4 in. "or less, tail , 5 in. or more. Bill about 1.50 in.

\title{
CRISSAL THRASHER.
}

\author{
Harporhynchus crissalis BAIRD. \\ Plate IV. Fig. t.
}

\begin{abstract}
Fe REGION of our Union is replete with so much of the unusual in nature, as 10. Arizona. The rocky, very often bald-peaked, mountains, the parched desert-like plains, and the river valleys with their meagre tree-growth, have remained almost to the present day the resorts of one of the most notorious Indian tribes, the Apaches. To keep these within due limits a number of forts have been erected. The higher officers and the army physicians there situated, have contributed to a more accurate knowledge of the natural history of this most characteristic region. Here Dr. Elliott Coues, Capt. Charles Bendire, Dr. Henry, and others, have been active. The climate of Arizona is hot and dry, and very changeable during the short winter season. During the hot months, the thermometer often rises in the valleys to 115 and $120^{\circ}$ Fahrenheit in the shade. Springs and deep rivers are rare. The vegetation of the desert-like plains consists almost exclusively of different species of cactus. Here is the real home of the giant cactus, or "sohuara," which not unfrequently grows to a height of fifty to sixty feet, and powerfully impresses the traveler who sees it for the first time. The other species (except the tree cactus ${ }^{1}$ ), especially the hedgehog cacti, the opuntias, and echinocerei, are not remarkable for height, but for their great dimensions and terrible armor of spines. Yuccas, too, agaves, and various thorny shrubs, are to be found growing here. More luxuriant and varied plant-growth is to be found in the river valleys. Notwithstanding the scarcity of water and the monotony of vegetation, bird-life is still represented by many and beautiful forms. Different Hummingbirds, Orioles, and several decidedly tropical Flycatchers and Trogons, are found here. Most numerous are the different Towhees and Thrashers, which might hence be regarded as the really characteristic birds

"See Ir. L. A. Mearns, "On the Birds of Arizona." Atk, Vol, 111, 1ssc, 1. 290-307.

I Opuntia arborescens.
\end{abstract}





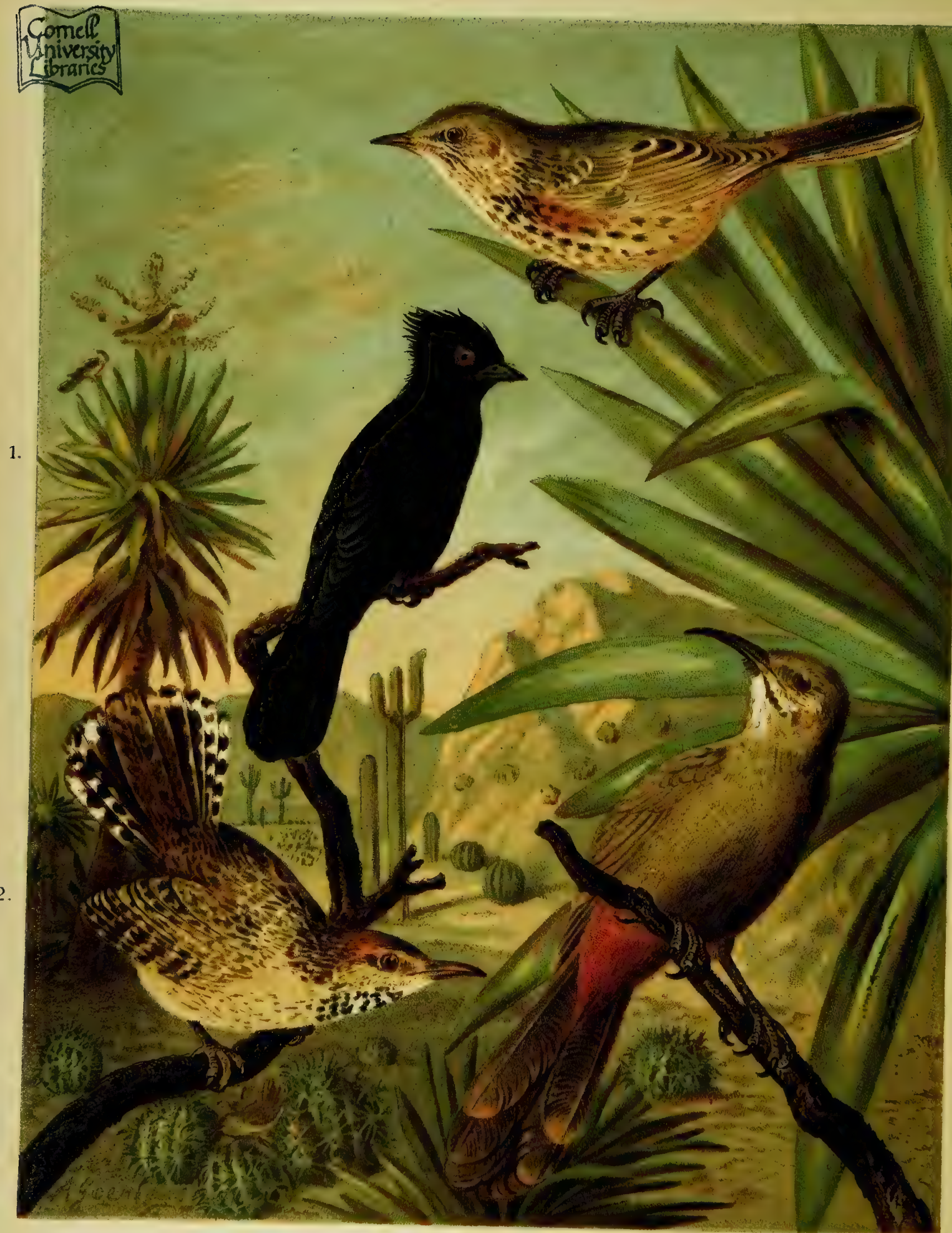

3.

4.

1. PHAINOPEPLA NITENS Sclat.

2. CAMPYLORHYNCHUS BRUNNEICAPILLUS Gray.

3. OROSCOPTES MONTANUS Baird.

4. HARPORHYNCHUS CRISSALIS Baird.
- TRAUERVOGEL. - Phainopepla.

- CACTUSSCHLÜPfer. - Cactus Wren.

- SALBEIDROSSEL. - Sage Thrasher.

- WÜSTENDROSSEL. - Crissal Thrasher. 
of Arizona. Among the Brown Thrushes one of the most interesting forms is the CRISSAL or RED-vENTED THRASHER.

As I have not had an opportunity of observing this species myself, I give here an extract of a paper written by Dr. E. A. Mearns, and published in the "Auk" III. (1886, p. 292-298). He writes: "I first met this Thrasher on March 24, 1884, about fifteen miles east of Prescott, when riding from Fort Whipple to Fort Verde, Arizona. When we left Whipple in the morning, the ground was covered with snow; but a ride of a few miles, during which we descended several hundred feet, brought us to a changed climate. A few Crissal Thrashers were then occasionally noted among the thickets of scrub oak, and their numbers increased until we reached the Verde Valley.

"The Red-vented Thrasher is abundant all over the Verde bottom land, preferring mesquite thickets and the vicinage of streams. One of the first traits that we noticed about it was that it possessed a song of very remarkable scope and sweetness, having all the power of the Mockingbird, and an evenness and perfect modulation which that bird may well envy. It is one of the few birds that truly sing; and it shares, in this Territory, this rare gift with its three congeners-Bendire's, Palmer's, and Le Conte's Thrashers. It is no warbler of pretty ditties, nor yet a medley singer like the Eastern Thrasher or the Mockingbird, but discourses pure, natural music from the top of the tallest bushes, where it perches, with its tail hanging down, in precisely the same attitude as the Brown Thrasher of the East. Its season of song is more protracted than that of any other species with which I am familiar. Its best efforts are put forth during the mating season, in February, March, and April; but, except during July and August, when the heat becomes intense and the Thrasher's plumage is bleached almost to whiteness, and worn to tattered shreds amongst the thorny chaparral in which it finds food and some shelter from the sun, it sings commonly throughout the year. The warm sunshine of a winter's day suffices to bring out its full song, which, perchance, has been hushed by a cold snap and flurry of snow. At first come a few notes of doubtful confidence, barely sufficing to remind one that it can sing; then a thoughtful, somewhat desultory song, till the power of the tropical sun asserts itself, or the genial influence of its mate is felt, when this harmonious soliloquy grows into a serene and dignified performance that challenges attention and excites admiration. The Crissal Thrasher is a shy bird, and only sings when it fancies itself secure from intrusions upon its solitude; but, about ranches, where it associates with man, it loses some of its wildness, and becomes more confident and trusting. After the autumnal moult, when berries, grapes, and other acceptable food is plentiful, there is a distinct revival of song in this species. It has no loud call-note like the other species.

"It is, like the rest of the Thrushes, highly terrestrial, and runs swiftly upon the ground from one bush to the next, often jetting its long tail upward. It mounts to the bush-tops to sing by hopping from branch to branch, and clambers through dense, spiny brush-wood with surprising agility. In general it may be set down as a shy bird, though at times becoming quite familiar. It makes but little use of its short, rounded wings as a rule, but occasionally makes long flights across a cañon or valley, setting its wings and soaring, like Gambel's Quail.

"Before the end of April, young birds were seen that were already strong on the 
wing and appeared to be taking care of themselves, showing that this species breeds early. As is the case with many birds of this warm climate, its season of reproduction. is unusually extended. I did not find its nest until the 3d'of July, when one was found in the patch of sage-brush, built in a bush, close to the ground. Its presence was betrayed by the actions of the male bird. The female was sitting upon three eggs, but skulked off upon the ground, among the bushes, and was immediately lost sight of. Another nest was discovered on June 14, in an isolated mesquite grove. It was placed upon a horizontal bough of a large mesquite bush (Prosopis [Algarobia] glandulosa), where it made a conspicuous object, owing to its bulk and exposed position. It was well built and contained two eggs, resembling those of the Robin. The proprietors of this nest divided their attention between the care of their nest and a family of young not yet capable of shifting for themselves. Two days later, the nest contained four eggs. ... Another nest, found on February 19, was saddled upon the fork of a mesquite bush $_{+}$about four feet from the ground, in part supported by the thorny branches of a neighboring bush. It rested upon a pile of sticks, and was surrounded by a bristling array of spiny 'haw' and mesquite twigs of moderate size; within this barricade the nest proper was placed; it is bowl-shaped, and, with the exception of a few feathers, composed entirely of vegetable substances, very neatly felted into a compact warm nest. The principal materials are fine withered grass, stems of plants, and shreddy inner bark. The two eggs are uniformly bluish-green, darker and greener than other specimens that have been in my cabinet nearly two years, which lave faded to a bluish tint resembling a Robin's egg.

"Crissal Thrashers inhabit by preference bushy places in the vicinity of water courses in the lower valleys, but range upward upon the oak-clad foothills to an altitude of 5,000 feet, or, in autumn, occasionally even a little higher. The Verde Valley here has an altitude of 3,500 feet, and a much warmer climate than the bordering mesas and foothills, which in winter are often deeply covered with snow. Although they may be occasionally met with in the snow belt, most of them descend into the warmer valleys in cold weather. I have seen numbers of them feeding upon the bare sand upon the edge of the Verde Valley River after a snowstorm. Making proper allowance for their being more conspicuous in winter on account of the absence of foliage, the species is undoubtedly far more plentiful in the Verde Valley during the winter season than in summer, when many of those which winter here move upward into the zone of scrub oaks, in which they breed in abundance wherever they can find water within a convenient distance. The exodus takes place about the end of February, after which the species becomes comparatively scarce; and, by the middle of March, nearly all of those remaining are settled and occupied with domestic affairs. In the surrounding highlands, it breeds late in the spring. Nests were found upon the banks of the Big Bug and Ash Creeks, at an elevation of nearly 5,000 feet, which contained fresh eggs as late as the middle of May. Some were built in oak bushes, and one conspicuously located in a swinging grape-vine six feet above the ground.

"The Red-vented Thrasher is omnivorous. It feeds largely upon berries and wild grapes. A thorny species of 'haw' is plentiful along the Rio Verde, which bears an abundance of berries, of green, red, and dark glaucous-blue colors, according to the 
degree of maturity; upon these the Thrashers delight to feed. Insects constitute an important article of their diet at all seasons.

"I found this Thrasher tolerably common in the vicinity of Fort Mojave in May, upon both the Arizona and Nevada shores of the Colorado, and also at the Needles farther down the river, in California, where the.species has been observed as far south as Fort Yuma, opposite the mouth of the Gila River. Near the Colorado River, at the mouth of Diamond Creek, it was found later in the season; but, farther east along the Colorado Cañon, I did not meet with it. Even in the deep, warm cañon of Cataract Creek, where-Mockingbirds were singing in November long after their departure from the Verde Valley, none were found. Dr. Palmer found it breeding near St. George, in southern Utah. It is very abundant in the Agua Fria Valley, west of the Rio Verde, and is found all the way to the confluence of that stream with the Gila River, from which point I have traced it as far eastward along the Gila as the mouth of San Carlos River, near which many were heard singing among the dreary sandhills of the Indian Reservation, and thence northward through Tonto Basin. Others have found it along the Gila in New Mexico; but I have only noticed it farther east, about Deming, New Mexico, in the dry course of the Mimbres River, near the point where it was first discovered by Dr. T. C. Henry of the U. S. Army. Unlike the three remaining species, it is rarely found in desert country away from streams. When crossing the hundred miles of desert between the Gila River, near Maricopa and Tucson, it was not positively identified once, although I thought I saw one near Picacho Station, when returning in May. Along the Santa Cruz and Rillito Rivers, near Tucson and Fort Lowell, the species was again found in small numbers, and was abundant thence, in suitable localities, as far east as Bowie Station, where it was found to breed, as well as in the neighboring foothills of the Chircahua Mountains, where I found a nest containing two newly-hatched young and an egg on the last day of April. The young were on wing in the dry plains of San Simon Valley below. From the abundance of the species there, I do not doubt that it ranges southward into Mexico."

NAMES: Crissal Thrasher, Red-vented Thrasher, Henty's Thrasher.

SCIENTIFIC NAMES: Toxostoma crissalis Henry (1858). HARPORHYNCHUS CRISSALIS BAIRD (1S5S), Cooper, B. Cal. I, (1870), B. B. \& R., N. A. B. I, (1874), Coues, B. Col. Va1. (187+), A. O. U. "Code and Check List"' (1886), Ridgw., Man. (1887).

DESCRIPTION: Male and female, "above nearly unilorm ashy-brown; below a paler shade of the same but clearer ashy; under tail-coverts and crissum chestnut-rufous, this color fading as it passes forward to the epigastrium into pale rusty-yellow; tibix and lining of wings washed with the same. The chin, middle of the throat, maxillary stripe and spotting upon the cheeks nearly white. There are narrow blackish stripes upon the sides of the throat, cutting off the white maxillary stripes above them. The outer rectrices have conspicuously paler, rusty tips. Under plumage lead-color. Iris brownish strawcolor." (Mearns.) Bill and feet dark. - Length, about 12 inches; wing 4, tail 6, bill 1.50 inches.

[I enumerate here a number of birds, which, in a scientific sense, belong to different families of birds, but which find their place near the Thrushes.] 


\section{AMERICAN DIPPER.}

Cinclus mexicanus SwaIns.

FN THE mountainous districts of western North America, where the mountain torrents 21 rush headlong, foaming and thundering, over the rocks, where roaring water-falls bound through the narrow cañons, lives, year in year out, the AMERICAN DIPPER, or WATER OUZEL, a bird of most romantic inclinations. It ranges from the Yukon Valley, in Alaska, south to Guatemala. Its haunts are always the clear cool mountain streams and the water-falls, always in the most beautifully romantic places, usually where the water's edge is overhung in some places by cedars, in others by the dense pines, firs or spruces of those regions; but always where the rushing and gurgling of the water mingles with its loud song. Pure, clear water, running over the stony, pebbly, or rocky bed, is one of the necessary conditions of its existence, and on this account it avoids all turbid waters and likewise the rivers and rivulets of the plains, and is not to be found on the shores of the mountain lakes. It enlivens with its presence only the clear wild streams, and of these it is as much a part as the cliffs, the mossy stones, the cascades, eddies, and swift currents. In such localities our bird is a permanent resident, rarely or never leaving its native haunts, but, at most, merely shifting up or down the torrent with the changing of the season, without ever going quite down into the plains.

The bird is usually seen on some moss-covered stone or on some larger rock protruding from the water. It will also select, as a standing ground, dead branches and drift-logs from which to sally out in search of water-insects. It lives either singly or in pairs, more than two never occurring in one place. Here these birds exhibit all day long a most persistent activity, occasionally flying through the foaming water as it bounds from the rocks, and skipping oyer the stones or walking farther and farther into the water till it closes over them. Apparently almost as much at home under the water as on the dry land, it will dive some distance beneath the surface to remain for a minute or more.

He who has watched the manœurres of the Water Ouzel in some torrent, must certainly have felt conscious of some slight feeling of envy. For he must have seen that the nimble fellow delights to tarry where the water foams and gurgles most and where the cataracts thunder and splash. There he will sit for minutes together on some damp stone overgrown with dark green moss; suddenly he will see something, and at once sallies into the water. At first he wades along, but the depth of the stream keeps increasing, rising to his neck and head. But what of that? The water may close over him-he cares not at all! He runs on under the surface with just as little concern as on the firm ground of the shore; he flies through the wildest cataract, cheerfully dives into the depth:- and when he comes out into the daylight, the water rolls off from his feathers like glittering pearls. He is at home on the ground, familiar with the water, and no stranger to the air; he calls three elements his own-he controls, he commands them. 
When disturbed, the Dipper takes to the water immediately, and even the unfledged young instantly save themselves, when in danger, by jumping like frogs into the wet element. Even in winter it is at home in the usually very cold mountain streams, at a time when the majority of true water-birds avoid such localities on account of the low temperature of the water. - The food of our bird consists almost entirely of molluscs and insects, which it obtains almost exclusively from the water.

The song of this bird of the mountain solitude is, according to Mr. Trippe, very beautiful. Although the observer usually hears its ordinary note, a rapid chatter, it has a very beautiful song "which it utters, however, very rarely. It selects the wildest, darkest ravines, and is very timid while singing. Its song is clear, sweet and varied, more wren-like than any other bird's song, yet peculiarly its own, and only to be heard amid the most romantic scenery, mingled with the music of the mountain torrents has a charm that is wanting to other and finer songsters."

The nidification is also a very interesting point of the bird's habits. The nest is always built close to the water, often so close as to be always moistened on its outside by spray and foam. At any rate it is always kept so damp that the moss of which it is built continues to grow luxuriantly. "One of the most perfect and beautiful samples of bird-architecture I ever saw," says Dr. Elliott Coues, "was a nest of this species. Dr. Hayden showed me after one of his late trips. It is an elegant ball of soft green moss, as large as a man's head, roofed over, with a small round hole on one side."

Mr. J. Stevenson, of Dr. Hayden's party, gives a very interesting and truthful account of the nesting habits of our Water Ouzel. He writes as follows: "While the camp of the United States Geological Survey of the Territories, to which I was attached, was located near Berthoud's Pass, in the Rocky Mountains, I found the nest and eggs of the Water Ouzel, which had constructed its little house near the margin of a small stream, but a little distance from our camp. Having some leisure time, I interested myself in watching and noting some of the actions of this little bird. It was not very timid, having built its nest not far from a saw-mill in which several persons were employed, and who were daily witnesses of the movements of the bird; indeed, one of these men seemed deeply grieved when he learned that I had killed the bird and taken its nest, for it had been his custom to approach the spot daily, and watch with interest the daily mancuvres of this little animal. After my attention was called to it I took pains to spend an hour or so each day for several days, watching its actions. The nest was built on a slab, about four feet from the water's edge, and was composed of green moss, the inside being lined with fine dry grass; it was oval-shaped, being about 6 in. high and about 30 in circumference at the base. The outside or walls of the nest were composed of green moss, most ingeniously interwoven, so that its growth in this manner might add to the strength of the nest and the protection of the bird, its eggs, and young. One of the first things that attracted my attention was its manner of diving down into the water and then darting back and perching itself on the summit of its mound-like dwelling, where it would shake the water from its feathers and distribute it over the nest, apparently for the purpose of keeping the moss moist and in a growing conclition, thereby increasing its strength and dimensions. The entrance of its little house was also carefully arranged; the archway was quite perfect, and the moss around 
it was so directed in its growth as not to obstruct the entrance, which was situated on one side, near the bottom of the nest. The operation of sprinkling the nest was repeated daily. An examination of the nest, which is in the museum of the Smithsonian Institution, together with the preceding facts, would induce one to believe that the performances of this little bird were for the purpose of keeping the outer lining of its nest green and growing, that it might keep its miniature dwelling in repair, while rearing its family, without the aid of a bricklayer, plasterer, or carpenter, showing that among the feathered tribe there are mechanics, as well as musicians."

Dr. C. H. Merriam's report ("United States Geological Survey of the Territories," 1872-1873) contains an account of another nest, which was discovered by Mr. W. H. Holmes about a half a mile from Mystic Lake, Montana. "The bird was observed to fly directly through the falling water, disappearing from view. Suspecting that a nest must be there, we returned the following day, when, with the assistance of Mr. Holmes, I secured the nest, containing three young. The nest was made of moss, measuring nearly a foot in diameter and six inches in depth. It was built upon the edge of a narrow shelf of rock, and so near the fall that the outside was constantly wet with spray, while the interior was dry and warm. The birds entered it by a small lateral opening in the lower half of the nest, the top being built up against a projecting rock." - The eggs, three to four in number, are pure white in color.

I will conclude the life-history of this characteristic bird of our western mountains with an interesting account from the pen of Prof. J. A. Allen, one of our leading ornithologists. He writes: "The American Ouzel is doubtless a frequent inhabitant of nearly all the mountain streams of Colorado. We met with it near Colorado City, on the Fontaine-qui-bout, even fairly out on the plains, and in the mountains up to the remotest sources of the South Platte, within a few hundred feet of the timber-line. Remarkable alike for the melody of its song and its singular habits, it is one of the most interesting members of the avian fauna of our continent. It prefers the swiftest mountain torrents, above the roar of which its melodious notes can at times be scarcely heard. At such localities, as is well known, it seeks its food at the bottom of the stream, easily withstanding the swiftest current. Along Ogden River, Utah, a powerful mountain torrent, we found it more common in September and October than we had seen it at any other point."

NAMES: American DipPer, Water Ouzel, Amcrican Otzel. - Wasseramscl, Wasserstar (German).

SĊENTIFIC NAMES: Cinclus pallasi Bp. (1826). CINCLUS MEXICANUS Sw., Philos. Mag. (1827), A. O. U. "Code and Check List" (18S6). C. americanus S. \& R., F. B. A. II, (1831), Nuttall, Audubon, elc. Hydrobata mexicana Brd., B. N. A. (1858).

DESCRIPTION: "Male and female, adult, in summer: Slaty-plumbeous, paler below, inclining on the head in sooty-hrown. Quills and tail-feathers fuscuous. Eyelids usually white. Bill black; feet yellowisli.Length 6 to 7 inches; wing 3.50 to 4 , tail about 2.25 inches." (Cot1es.) 


\title{
BLUEBIRD.
}

\author{
Sialia sialis HALdEM.
}

Plate V. Fig. $\overline{5}, 6$.

Cotrage Warbler they call thee, oh Bluebird, because thou avoidest Cities, and choosest to sing sweetly to farmers thy lay!

Twenty summers thou wert my neighbor; when melting the snow left Didst tinou ever appear, one of the heralds of spring!

Oft when I heard thee at daybreak, the frostwork I thawed at the window Eagerly with my warm breath, quickly my friend to behold!

But of late thou hast not in thy formerly favorite places

Macle thine appearance, nor have some of thy brood cone again!

Have bircl-killers waylaid thy tribe, that inordinate fancy

May with thy plumage bedeck hats upon feminine heads?

Or have the towns grown too large, has the steam engine's terrible whistle,

Smoke and the factories' din noisily driven thee off?

Manyfold changes, indeed, have occurred since first in Wiscousin-

'Twas in the years of my youth - first I had listened to thee!

Then the hilltops were crowned with the trees of the forest primeval,

Now sweet clover's white bloom spreads there, repasts for the bees,

Where in the marsles the ash as well as the fragrant white cedar

Stood, now pasture the kine, gambols the rollicking colt.

Cleared are the fields; uprooted the stumps, and smooth is the meadow;

Horses are drawing the plow, erstwhile dragged by the steer.

'Traceless, as shadows of clouds from the prairies, the Indians have vanished,

Nought, not a ring of the sod, shows where the wigwam once stoot.

Wheatfields are safe from attacks of millions of swarming wild pigeons,

Cornfields from the raccoon; bears molest not the shotes.

Forests have changed into grainfields, and villages grown to be cities, Rivulets have disappeared, streams simmered down into brooks.

All, all about me the world has changed, and $I$ recognize scarcely

Now the haunts where, when young, chasing, I followed the deer.

Can we, then, wonder why birds of migration are losing their bearings,

Or that the Bltuebird now seeks lonelier nooks for his nest,

Parts, where the air is pure, where sootflakes besmirch not his plumage,

slackles, where night is still night, yielding all creatures sweet rest.

From the German of Conkav KREL,

by Fraxk SILlik. 


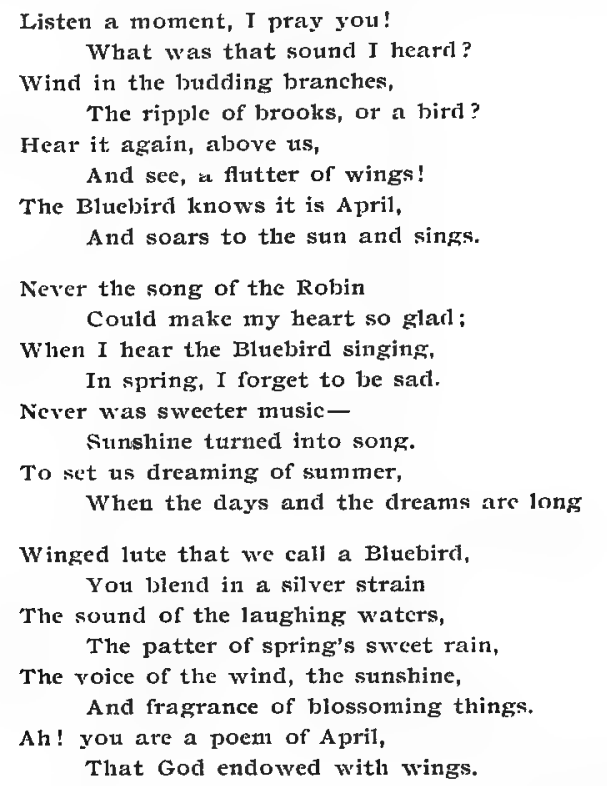

周HE WINTER yet lingers. Ice still covers the rivers and lakes, a white mantle of snow the ground: On the snow-covered branches of the Norway spruces and hemlocks, Crossbills and Cedarbirds, beautiful and attractive both in their plumage and motions, are hopping around in flocks. The berries of the mountain ash, their principal food in winter, are nearly consumed. Golden-crowned Kinglets and noisy Chickadees are busily engaged among the boughs. Many of these northern winter sojourners have made as yet no preparations to leave for their arctic breeding range.

Suddenly there appears, at the first sign of spring, the loveliest of all our plumaged garden inhabitants, the BluEBIRD, or "Cottage Warbler." This azure-backed, brownbreasted beauty is one of the first comers from southern climes, a true herald of the opening spring. In favorable weather, individuals will appear in the Northern States as early as the beginning of March, though the majority cloes not arrive till between the middle and the end of that month. Only too frequently it happens that, in the months of March and April, the weather remains cold, and heavy snow falls holding the earth in chilly embrace for weeks together. We know how long the spring often has to struggle with the cold before its warmer days can come. During the heary snowfall and continuous stormy days these beautiful birds suffer greatly. Many perish of hunger. Happily most survive their troubles, while numbers go south waiting to return with the first warm days. During the colder days when food is scarce, their songs are sad and mournful, almost supplicating, but, at the first warm sunshine, all their troubles seem to be forgotten. Sweet and gay then sounds their song. Then we hear their tender warblings, constantly they fly gaily from tree to tree, over the fences and over the roofs, and from ground to tree and tree to ground. At night they seek protection from the cold in hollow trees, nesting boxes, and many seek refuge even in chimneys.

The Bluebirds arrive invariably during the night. They ustually come in pairs. They will greet you in the early morning with their sweet welcome, where on the evening 
before they were not to be found. Soon after their arrival they paty visits of inspection to all the nesting boxes put up for them in the orchard, on the posts or shade trees near the house. While the female bird is percher on a neighboring bough, her mate flies to the perch in front of the entrance of the prospective nest, and peeps in, not for a moment interrupting his warbling song. If the spot meets his expectations he calls, in the most tencler tones, to the mate, hops about in a fluttering of excitement, with his wings quivering, and finally darts into the interior. There is hardly a more fascinating picture for man to contemplate than a pair of these beautiful, sprightly, and happy birds on and around their nesting box. The male always shows a touching solicitude and tender love toward his companion, such as I have never witnessed in any other of our bircls, excepting the Baltimore Oriole.

All the peculiarities of the Bluebird are so extraordinary and fascinating, and withal so wholly original, all its movements are so gracefully elegant; its manners so confiding and fearless; its song so melodious and soulful; its plumage of such rare brilliancy, that one can readily comprehend the love and kindly feeling the friend of nature has for it, and the eagerness with which its coming is awaited even long before the beginning of spring. We never grow weary and satiated with it, and even the hardest and most selfish human being cannot but love this attractive and affectionate little creature. - I remember well that, in my boyhood, a pair of these birds nested near my home in Wisconsin for years. They selected a hole in an old stump about twelve feet from the ground and close to the public highway, not far from the garden. I still recall the longing, with which I looked forward to their coming year by year. I became so attached to these birds afterward that, when I was obliged to live in the city, I kept them in the cage and could not be without their companionship for any length of time.

If no accident befall, the pair will return year after year to the same old home, and, as a rule, will nest in the same old tree hollow, or in the same nesting box, where it has nested previously. Their favorite haunts are orchards and groves near the habitations of man, providing they find suitable nesting places. If these be lacking, they are compelled to go to the fields and woods, especially to the borders of the latter, where there are plenty of abandoned Woodpeckers' holes. In Wisconsin, so rich in forests, I observed the bird much more frequently than in the prairie regions of Illinois where, as a rule, forest land is scanty and usually confined to the borders of rivers and brooks. Intelligent farmers who appreciate the extraordinary usefulness of these birds, lovers of the feathered tribe, and lovers of nature in general seek to gain the good will of the favorites by fixing convenient nesting boxes in fruit and ornamental trees. While I resided in the prairie near Freistatt in southwestern Missouri, nearly all the Bluebird boxes in my garden and the neighboring grove were inhabited, so that frequently broods were not more than a hundred steps from one another. In Texas, where our bird resides throughout the year, it is one of the rarer species, and is not nearly so confiding and friendly as in the North. I have seen it, however, revelling in great number in the orange groves of Florida where it makes itself perfectly at home.

We do not find the Bluebird in the interior of the forest, and since the European Sparrow was imported and fostered with such care, it also shuns cities and towns, where it was once so common. In the country, however, where the House Sparrow has 
not yet become abundant, our beatiful songster is familiar to every child.-In the North most of the birds begin building their nests by the first of May, in southwestern Missouri in the beginning of April, and in Texas and Florida as early as the last of February. In the Northern States they usually raise two broods yearly, and farther South very often three.

The Bluebird always selects for the site of its nest some ready-made hole in a tree. In uncultivated districts it chooses the abandoned holes of Woodpeckers and, in the absence of these, hollow stumps, posts, and large knot holes. In cultivated districts the birds invariably prefer the different kinds of boxes which the farmers and lovers of birds put up for them. Everywhere in our orchards, gardens, and parks these beautiful birds can be made to feel perfectly at home, if convenient boxes are fastened in trees for them.

When finally, after a long twittering consultation, the pair has found a suitable nesting site, materials, especially grasses, plant-stems, bark-strips, and, now and then, a feather, are industriously carried into it. Like all nests built in holes, the Bluebird's is a very inartistic structure. The eggs - four or five, sometimes six, in number-are pale greenish-blue, very rarely white. The male never strays far from the nest while the female is breeding. He often flies to her with a captured insect, sits on the perch before the entrance, ever and anon peeping into the interior and singing to her his most beautiful strains, accompanied by the fluttering and quivering of his wings. A pair of these birds nesting in the garden near the house, presents an idyllic, charming, and attractive family picture, one which in all its phases offers to the intelligent observer great pleasure and the best entertainment. This is the case in a still greater degree after the young are hatched. Then the real work begins for the watchful, tender, and solicitous male. The whole day is spent in the greatest activity; hardly a minute passes without his coming with insects with which to tempt the appetite of the young. It is, indeed, astonishing what an immense quantity of worms, flies, caterpillars, moths, beetles, and other insects, is necessary to satisfy the hunger of the little ones. The parents are kept continually flying to and fro, from the earliest hours of morn until the twilight falls. Right by the side of my dwelling in southwestern Missouri, in a group of young oaks, a nesting box had been put up, in which a pair of Bluebirds annually reared several broods. As it was only a few steps from my verandah, I could observe without trouble all the proceedings on the nest. Amid this same group of trees the children had their play ground and a much used hammock was swung beneath the branches, but neither the Bluebirds nor a pair of Orchard Orioles - which also had their hanging nest in the top of a thickly branched oak-allowed themselves to be in the least disturbed, either by the noise and mirth of the children or the swinging to and fro of the hammock. When they came flying with their bills full of food, they would first perch on the top of the tree, look anxiotsly around, and then fly on swiftly to the perch of the box from whence they could feed the young; then, after waiting a moment, the old birds disappeared in the interior, only to reappear in an instant with refuse matter from the nest. With peculiarly fluttering uneasy motions this disagreeable duty is performed. The refuse is dropped a short distance from the nest and the bird flies to the next fence or tree to clean its beak. 
Ustrally the birds are very silent near the nest; they approach it only in a peculiarly stealthy manner, so as not to betray its whereabouts. Should the nest be robbed of the eggs or the young by squirrels, snakes, or other enemies, it is affecting to see with what sadness, for many days to come, the parents fly around the old nesting place. All their notes are indescribably plaintive. Sometimes the same cavity is chosen again for the following brood, especially if there is a scarcity of suitable nesting places; but often, after such a disaster, the pair leaves for another district.

As soon as the young of the first brood are on the wing, then follows, even before these have become entirely independent, a second or third one. After the young are able to care for themselves, they congregate with others of the neighborhood to form flocks, sometimes to the number of fifty or more. In fields, pastures, fallow grounds, usually where the long stalks of the mullen are abundant, such companies may be observed in July, August, and September. In easy, but slow, often rather high, wavering, lingering flight, they move about, uttering constantly a sad melancholy tone which resembles the sounds "Du-ee" or "Du-way-way." These flocks are joined, generally in September and October, by the parent birds and the young of the last brood. They all remain in loosely scattered companies in the neighborhood till about the middle of October, when, at the approach of cold weather, they depart for the South, bidding "Adieu" to the old homestead in sorrowful tones. Many spend the winter in the Middle States; the majority, however, choose the South Atlantic and Gulf States for their winter quarters. Here one meets them in large flocks, usually in cotton, corn and sugar-cane fields and on the borders of woods. I observed them in great numbers from November to February in southeastern Texas. In the South they comport themselves in an entirely different manner from what is observed in the breeding range: being very timid and mistrustful, and rarely uttering a note.

The food of our charming and beautiful Bluebirds consists at all times and everywhere almost entirely of insects, for which they search the ground. Grasshoppers, crickets, all kinds of worms, caterpillars, moths, spiders, etc., are devoured in immense numbers, especially when the old birds are caring for the young. When on the ground, the Bluebird does not hop about like a Thrush, but remains on one spot till it has examined it thoroughly, when it hops to another, where the same process is repeated. When an insect happens to fly past, it runs and flutters after it.

The Bluebird possesses only good qualities. When the Pilgrim fathers came to New England, this attractive bird was one of the first that greeted them with tender and friendly warblings. Its character and movements reminded them of the beloved Robin Redbreast of their native country; therefore they named it the "Blue Robin." It is but just to say that none of our feathered summer guests, excepting perhaps the Robin, enjoys the same degree of popularity as the Bluebird, which the old German settlers of Pennsylvania and the Mohawk Valley called the "Cottage Warbler" because it preferred to make its home near the log-cabins and other habitations of man. True, the far-famed Mockingbird, the brilliant Cardinal Redbird, the glowing Baltimore Oriole, the poet of the meadows our Bobolink, the gallant Kingbird, and the brave Martin, are all favorites, but none of these seem to be so attractive as the Bluebird. This admiration is due to its harmless confidence in man, to its elegant and pretty ways, and 
to its peculiar wealth of color: on its back the tint of heaven when clearest and most beautiful, on its breast the brown of the earth!

When in the primeval forest arises the simple log cabin of the early settler, it is the Bluebird that first greets the new-comer with gentle warbling welcome as it flies from stump to stump.-Only too often the Mockingbird, the Robin, the Catbird, the Baltimore Oriole are driven from our gardens by ungrateful people, because these birds claim, as a well-deserved tribute for their work as insect destroyers, a few strawberries, cherries, and other small fruit. But it is impossible to accuse the sprightly Bluebird of the same misdemeanor. It is in no manner whatever injurious; on the contrary, the benefit resulting from the destruction of incalculable numbers of noxious insects, is beyond estimation.

The Bluebird retains with wonderful tenacity the domain which it has once chosen for its nest. Jealously every other bird of the same species is driven from the selected territory. When mating begins, two males often attack each other with such vehemence that they whirl down to the ground together and there easily fall a prey to prowling cats. The vigilant male boldly attacks every enemy that attempts to approach his nest. When, in boyhood, I examined nests, the old birds often flew into my face. By his fearless assaults the male frightens away many a small robber from his home. Nevertheless, innumerable broods are annually destroyed by Blue Jays and snakes. A still more dangerous enemy is the European Sparrow now so common in and near our cities and towns. It is a well known fact that in the same ratio as the Sparrow increases the number of our familiar native birds, especially such as breed in boxes, decreases. I have observed Sparrows, time and time again, taking possession of the boxes put up for the Bluebirds. Even when a bird box has been occupied for several weeks by its rightful owners, these foreign vagabonds try to take possession of it. First they come in pairs, but they are generally driven off by the brave male. Then they usually renew their assault in screaming crowds, and, in spite of a courageous defense, the poor Bluebirds are obliged to yield to the superior force, and leave their much-loved home. I am not alone in these observations: they are confirmed by almost all our ornithologists. It is a matter of fact that at the present time where the Sparrow is so abundant, a nesting pair of Bluebirds is rarely found in the parks and gardens of our cities and towns. Where once the soft warbling of these familiar and beautiful birds filled the air from dawn to sunset, we hear to-day only the discordant notes of the impudent foreign intruder. Prof. Robert Ridgway, in speaking of the song birds in Europe and America, denies that our beautiful country is deficient in songsters as compared with Europe. "It appears," he says, "that the apparent deficiency of singing birds in the United States is an artificial rather than a natural condition, characteristic, so far as the settled or cultivated portions are concerned, of the more densely inhabited centers, where birds have been actually driven off by the persecutions of the pot-hunter, to whom anything with feathers is game, and by the indifference of the population in general. There can be no question that the boxes put up in the parks of our larger cities for the imported European House Sparrow, which has not a single commendable quality, would have attracted Bluebirds and House Wrens, two of our most attractive and useful birds, until these would by the present time have become as common and familiar as their 
true representatives in England-Robin Redbreast and Kitty Wren. The Purple Martingrandest of the swallow tribe-could, in the same way, have been attracted in large and useful numbers to the very centers of our largest cities. - Hear, what an Englishman, Capt. Saville G. Reid, says of our Bluebird, as observed by him in Bermuda, where it is resident, and, in accordance with the English custom, rigidly protected: "This is, to my mind, the most delightful of birds, and certainly the flower of the limited flock of Bermuda residents; its brilliant plumage, vivacious manners and pleasant warble render it an object of interest to all, while its confiding and fearless nature in the breeding season, and the number of noxious insects it destroys, cause it to be strictly protected throughout the islands. The male bird in spring, when the sun's rays illumine his dazzling blue plumage, is perfectly lovely; he flashes across the road like a ray of azure light, and seems actually to blaze with intense color from among the sombre foliage of the cedars.' - There is no bird in England-not even the semi-domestic Robin Redbreast - which is more easily encouraged to seek human society than the Bluebircl; certainly none are so beautiful and none more lovable in every way.... The list of familiar, attractive, and useful songsters might be greatly extended; but enough have been mentioned to show that the United States is not so badly off in the matter of song birds as might appear. We have them in abundance, but they are treated with indifference-or, what is worse still, snubbed by the perverted sentiment which prefers the detestable House Sparrow to the Bluebird, the House Wren or the Purple Martin. When that worse than useless vagabond was introduced to this country, boxes were immediately put up for his accommodation, and every means taken to protect him. Yet, none of our native birds, no matter how useful, beautiful, or melodious, was considered worth the trouble. Had the same steps been taken to encourage and protect those of our native specics which are most worthy of such attention, there is no question that our towns and villages and city parks would by this time have become full of Bluebirds, Wrens, and other attractive and useful birds, whose place is now taken by that rank weed among birds, the European Sparrow... L Let us instead of continuing to deprecate our supposed scarcity of song birds and attempting the remedy by futile importations of foreign species, encourage and rigidly protect those which the bounty of nature has provided for us, and of which we have every reason to be proud." *

Mr. H. Baumgrertner - as great a lover of birds as of flowers - told me lately that in his garden, lying in the midst of the city of Milwaukee, a pair of Bluebirds build their nest every year in spite of the presence of countless Sparrows. After many experiments, he has found that the latter birds will not use nesting boxes where the perch, right under the entrance hole, is absent, while the Bluebird evinces a predilection for such. He uses small wooden paint kegs, bores, within four or five inches from the top, a $1 \frac{1}{2}$ inch entrance hole, and fastens them on poles or trees. If there is no perch near the entrance the Sparrow cannot support itself at all, or only with difficulty, while the Bluebird flies in and out very adroitly. Bird boxes made of boards with only an entrance hole but without a perch will also certainly prove of good service. Everyone who wishes to have Bluebirds in his garden, should profit by this cxperience.

Every friend of nature, every farmer and gardener ought to care in every way for 
our Bluebircl. Convenient nesting boxes should be put up for it in ornamental and fruit trees and on posts. Cats, Blue Jays, House Sparrows, and other enemies, should not be tolerated in gardens and orchards.

As a cage-bird our "Cottage Warbler" is well adapted, when treated in the same way as the Mockingbird. - It stands extraordinarily high in the estimation of the bird fanciers of Germany and is often reared there in cages. Dr. A. Frenzel and E. von Schlechtendal contributed to the "Monthly Magazine of the German Society for the Protection of Birds" complete accounts of their success in breeding these birds in captivity. The latter writer claims to have had a male more than seven years in his possession. Before he received it, it had belonged to Dr. Liebe, who had obtained it from the Aquarium in Berlin, which was then under Dr. Brehm's direction. He writes thus: "In the beginning of this summer, the male moved his beautiful blue wings so amorously and the female sought small grass-blades with such zeal that I, finally, placed a nesting box and some hay in the cage-for no more is needed to make a pair of Bluebirds happy. At first the female was somewhat shy, but the male urged her so constantly and pressingly that she soon began carrying hay into the box. She alone built the nest while the male looked on with quivering wings and tender warblings. The simple nest was soon finished, the female disappeared, and soon the presence of little Cottage Warblers was indicated by the joyful actions of the old ones. They are perfectly lovely, these little Bluebirds, when they, at length, leave their nest. They look at one with their large eyes in a very true-hearted manner. They are so trustful that one may assist in feeding them. When they once understand how to overcome a meal-worm themselves, they will innocently fly to their attendant's hand when he holds out to them the wriggling larvæ. The parents, however, let them be ever so tame, always remain cautious, and raise a warning note when they imagine that danger threatens. This note teaches the children greater precaution and they somewhat lose their childish ease. When the sons are grown and the spotted child's dress exchanged for the blue toga virilis of the old birds, it is the father's opinion that the man should brave the hardships of existence. He may be seen trying to make this unmistakably clear to the son by sharp blows of the bill, thereby urgently enjoining him to be off as quickly as possible."

The food which the Cottage Warblers receive in confinement consists of a mixture of dried "ants' eggs," cooked and grated ox-heart, grated "egg-bread," grated carrot, with an addition of pulverized hemp, poppy-seed flour, and "ground May-beetles" (Melolantha vulgaris), followed by meal-worms and currants. In summer, berries and fresh "ants' eggs" are also given. The parents receive for their nestlings an abundance of small meal-worms and fresh "ants' eggs" mixed with finely grated "egg-bread."

The Bluebird is distributed over a large portion of North America, ranging from the Atlantic to the Rocky Mountains, north to Manitoba and Nova Scotia, south into Mexico. In the highlands of Mexico it is represented by a similar variety, Sialia sialis azurca BRD., and in Guatemala by another variety, S. sialis guatemalae RIDGW.

NAMES: Bleebird, Bluc Robin, Blue Redbreast (Edw.), Blue Warbler, Cottage Warbler, Blue-backecl Reclbreast Warbler (Penn.), Common Bluebird, Eastern Bluebirc, Wilson's Bluebird, American Blueljird.Blauvogel, Hüttensänger (Germau). Rouge-gorge blene de la Curoline (Buff.), Fanvette blente et rousse (Le M.). El ataulejo (Mexico). 



\section{V.}

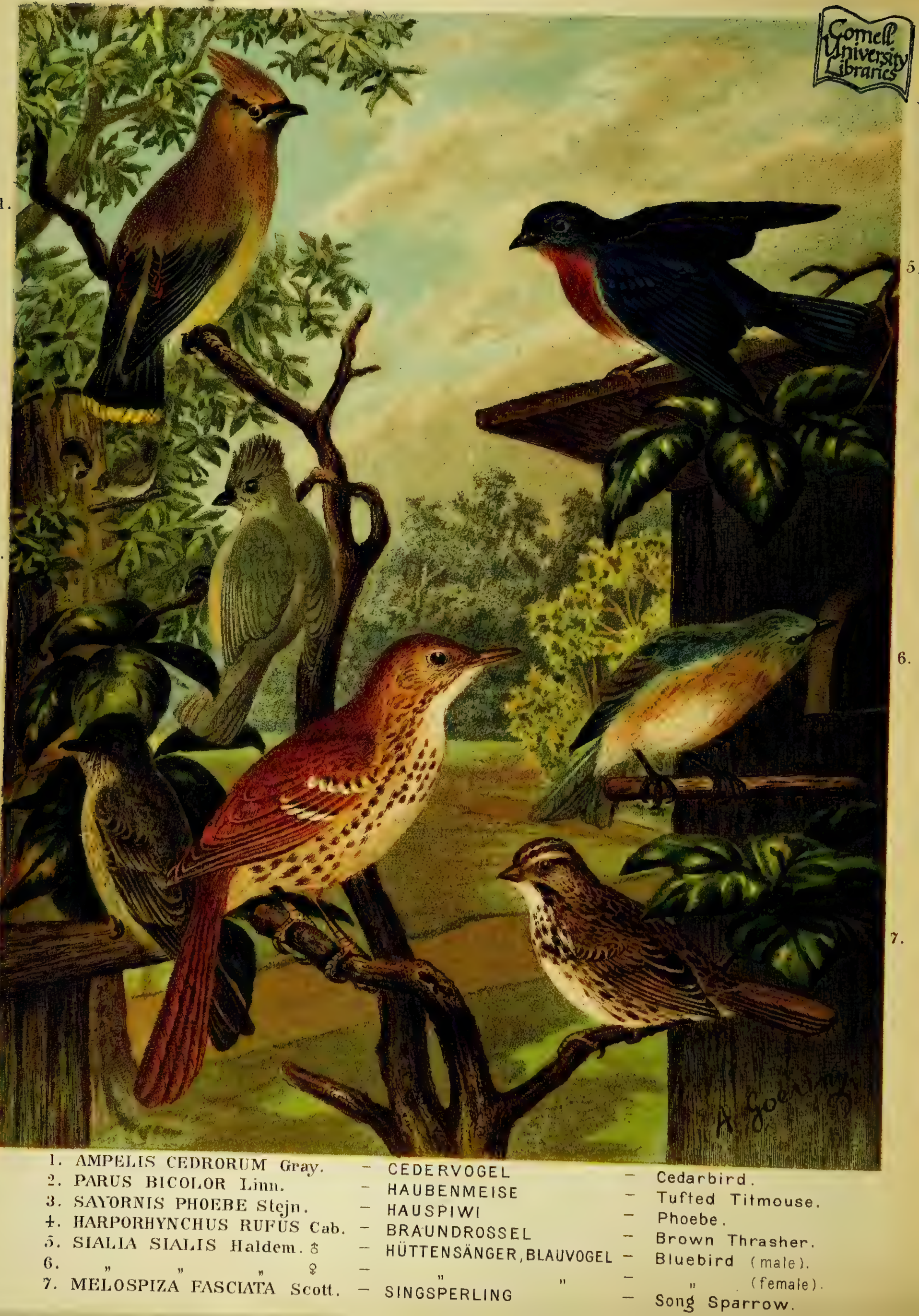


SCIENTIFIC NAMES: Motacilla sialis Linn. (1758). Sylvia sialis Lath. (1790). Saxicola sialis Bonap. (1826). Ampelis sialis Nutt. (1832). SILLIA SIALIS HALDEMAN (1843). Sialia wilsonii Swainson (1827), etc.

DESCRIPTION: Male, rich azure-blue, throat, jreast and sides chestnut-brown, belly and under tail-coverts whitish. Female and male in winter: above blue, tinged with grayish-brown; chestnut paler, white of the belly more extended. Young when leaving the nest, brownish above, becoming blue on rump and tail, back streaked whitish, nearly the whole under parts speckled with white and dark. Feet and bill black. - Length about 7 inches; wings about 4 , tail about 3 inches.

\section{CALIFORNIA. BLUEBIRD. \\ Sialia mexicana Swains. \\ Plate XX. Fig. 1.}

The Western or California Bluebird represents the common species in the western part of the United States, its proper domain being between the Rocky Mountains and the Pacific, from Mexico to Washington. It is especially common in California, but is also abundant as far east as Colorado, where both, Prof. Allen and Mr. Aiken, have observed it. These Bluebirds are as familiar as the eastern species, everywhere preferring the breeding boxes provided for them. Where these are not to be found, they build their nest in knot holes and abandoned Woodpecker's holes. Nuttall, who had a very fine ear for the song of birds, says that the notes are a little more varied, more tender and sweeter, than those of the eastern species, differing also in expression. Dr. Cooper, however, does not confirm this description by Nuttall. He regards the song as neither so loud nor so sweet. Prof. Robert Ridgway, who is an excellent connoisseur of birds' songs, corroborates Dr. Cooper's observation, stating that he did not hear, even during the pairing season, any note approaching in sweetness, or indeed similar to, the joyous spring warble which justly renders our Eastern Bluebird so universal a favorite.

The California Bluebird is in all its habits, in its familiarity and its nidification, the perfect counterpart of its eastern relative, so that a more detailed life history is superfluous.

NAMES: California Bluebird, Western Bluebird, Mexican Blutbird.-Californischer Hüttensänger, or Californischer Blauvogel (German).

SCIENTIFIC NAMES: SIALIA MEXICANA Swains., F. B. A. (1831). S. occidentalis Towns. Sylvia occidentalis Aud. (1839).

DESCRIPTION: "Head and neck all round, and upper parts generally, bright azure-blue. Interscapular region, sides and fore part of the breast, and sides of the belly, dark reddish-brown. Rest of under parts (with tail-coverts) pale bluish, tinged with gray about the anal region. Female duller above; the back brownish; the blue of the throat replaced by ashy-brown, with a shade of blue.-Length 6.50 inches; wing 4.25 ; tail 2.90 inches." (Ridgway.)

\section{MOUNTAIN BLUEBIRD. \\ Sialia arctica NutTal. \\ Plate XX. Fig. 2.}

The Mountain Bluebird is chiefly confined to the Rocky Mountain region, extending as far north as Great Bear Lake, and south into Mexico. It seems to be a true 
mountain bird, not being found in lowlands. Except in coloring, it is in all respects a true counterpart of our eastern species. Mr. Ridgway states that he found this Bluebird nesting in Virginia City, in June. Although the nests were found occasionally in the unused excavations about the mines, it preferred to build about the old buildings. At other places he found it common in similar locations, in July. On the East Humboldt Mountains it was very abundant, especially on the more elevated portions, where it nested among the rocks and, though more rarely, in the deserted excavations of Woodpeckers in the stunted piñon and cedar trees. According to his observations, it is generally very shy and difficult to obtain, seldom permitting a very near approach. In its habits it is much less arboreal than either the Common or Western Bluebird, always preferring the open mountain portions in the higher ranges of the Great Basin.Dr. Woodhouse found these Bluebirds common in the vicinity of Santa Fé, New Mexico, where they breed about the houses in boxes put up for them.

In regard to the song we are indebted to $\mathrm{Mr}$. Ridgway for the following description: "The common note of this Bluebird would, from its character, be at once recognized as that of a Bluebird. Its autumnal note, however, lacks entirely the peculiar plaintiveness so characteristic of that of our eastern species, and is much more feeble, consisting of a simple weak chirp. Like the $S$. mexicana, the $S$. arctica was also never heard to give utterance to anything resembling the lovely spring warbling of the S. sialis."

NAMES: Moun'ain Bluebird, Rocky Mountain Bluebird, Arctic Bluebird.-Gebirgs-Hiittensänger, GelbirgsBlauvogel.

SCIENTIFIC NAMES: Erythaca (Sialia) arctica Sw., F. B. A. (1831). SIALIA ARCTICA NUT'., Man. II, (1834). Sylvia arctica Aud. (1839). Sialia macroptera Brd. (1852).

DESCRIPTION: "Greenish azure-blue above and below, brightest above; the belly and under tail-covcrts white; the latter tinged with blue at the ends. Female showing blue only on the rump, wings, and tail; a white ring round the eye; the lores and sometimes a narrow front whitish; elsewhere replaced by brown.-Length 6.25 inches; wing 4.36 , tail 3 inches." (Ridgway).

\title{
TOWNSEND'S SOLITAIRE.
}

\author{
Myadestes townsendii A. O. U.
}

Plate XX. Fig. 4.

\begin{abstract}
FN ORDER that we may become acquainted with one of our most remarkable birds, - 1 one of our most prominent songsters, we must visit the far West of our country, the region of the Rocky Mountains and the Sierra Nevada. Here, on the solitary mountain sides sparsely covered with cedars, and in the valleys and cañons, far from the din and tumult of man, abounds Townsend's Solitaire, Townsend's Flycatching Thrush, or Clarino, a very peculiar and highly attractive bird.

It ranges from the eastern foothills of the Rocky Mountains to the western slope of the Sierra Nevada north to British Columbia, being everywhere a true mountain bird.
\end{abstract}


It appears to feed mostly upon the berries of the cedar, and its abundance is to be determined, in a measure, by the presence of these trees. All our ornithologists who have had an opportunity of studying the western birds, agree in the statement that the Clarino is a resident throughout the entire year in its mountain home.

As I am not able to give my own personal observations, I will gather from the published records of other observers some items of its life history. Dr. J. S. Newberry has given a very interesting account of the bird. Noticing its occurrence in the Des Chutes Basin, he continues: "It does not inhabit dense forests, or prairies entirely destitute of trees, but chooses surfaces covered with a scattered growth of pine and cedar. We first met with it in the cañon of Mptolyas River, at the base of Mt. Jefferson. As we picked our way with infinite difficulty down the side of this gorge, my attention was attracted by the delightful song of, to me, a new bird, of which a few were sitting in the pines and cedars which, by a precarious tenure, held a footing on the craggy face of the cliff. The song, so clear, full, and melodious, seemed that of a Mockingbird; of the bird I could not see enough to judge of its affinities. The next day, we followed down the river in the bottom of the cañon; all day the deep gorge was filled with a chorus of sweet sounds from hundreds and thousands of these birds, which, from their monotonous color, and their habit of sitting on a branch of a tree projecting into the void above the stream, or hanging from some beetling crag, and flying out in narrow circles after insects, precisely in the manner of Flycatchers, I was disposed to associate with them. Two days afterward, in the cañon of Psuc-see-que creek, of which the terraced banks were sparsely set with low trees of the western cedar (Juniperus occidentalis) I found these birds numerous, and had every opportunity of hearing and seeing them, watching them for hours while feeding and singing. With the first dawn of day they began their songs, and at sunrise the valley was perfectly vocal with their notes. Never, anywhere, have I heard a more delightful chorus of bird music. Their song is not greatly varied, but all the notes are particularly clear and sweet, and the strain of pure, gushing melody is as spontaneous and inspiring as that of the Song Sparrow. At this time, September 30, these birds were feeding on the berries of the cedar; they were very shy, and could only be obtained by lying concealed in the vicinity of the trees which they frequented: I could detect no difference in the plumage of the sexes."

Dr. Cooper adds his testimony to that of Dr. Newberry respecting the bird's vocal powers: "The scarcity of the juniper on the western slope of the mountains, toward the north, seems to be the reason why this bird is not more frequent there; as, according to all accounts, they are found wherever that tree grows in abundance, especially on the mountain ranges of the great interior basin, and their extensions to the north and south. Although plain in plumage and retiring in habits, this bird is one of the most interesting in the western country; for, like its not distant relative, the European Nightingale, it compensates by its delightful melody for its deficiencies in beauty. Having seen them in the Rocky Mountains, where they seemed merely plain and silent Flycatchers, my astonishment, when I first heard one sing in the Sierra Nevada, was indeed great... Their song can be compared to nothing uttered by any other bird $I$ have heard in the United States, for it excels that of the Mockingbird in sweetness, besides being entirely original. It has the melancholy slowness, but without the interruptions, 
of that of the Wood Thrush, and agrees better with the descriptions of that of the Nightingale of Europe."

When Dr. Elliott Coues prepared his valuable work "Birds of the North-West," he was favored by Mr. Trippe with the following interesting communication: "This exquisite songster is a permanent resident of the mountains of Colorado, and may be seen at all times of the year, from the lower valley of the country up to timber line, and in midsummer even beyond it, to the highest limit of the shrubby willows and junipers. It is never a familiar bird, shunning the vicinity of houses and cultivated fields, and seeking the rockiest mountain sides and darkest cañons as its favorite haunts, yet avoiding the sombre depths of dense forests, though occasionally found therein. During the winter it feeds on berries and such insects as it can find, but in the warmer months subsists almost entirely upon the latter, which it captures with the address of the most skilful Flycatcher. It is never gregarious, and usually solitary, associating together only from the time of pairing, which is in the early part of May, until the young are able to shift for themselves. It frequently alights on the top of a dead limb or tree, from which it keeps a bright lookout for passing insects, and returns several times to the same perch after capturing its prey; it also frequents the lower boughs, and at times alights upon the ground and searches among the leaves for food. In its flight it bears some resemblance to the Cedar Bird, with which, indeed, it has many common traits. In summer and fall its voice is rarely heard; but as winter comes on, and the woods are well-nigh deserted by all save a few Titmice and Nuthatches, it begins to utter occasionally a single bell-like note that can be heard distinctly at a great distance. The bird is now very shy; and the author of the clear, loud call, that I heard nearly every morning from the valley of Clear Creek, was long a mystery to me. Toward the middle and latter part of winter, as the snow begins to fall, the Flycatching Thrush delights to sing, choosing for its rostrum a pine tree in some elevated position, high up above the valleys; and not all the fields and groves, and hills and valleys of the Eastern States, can boast a more exquisite song; a song in which the notes of the Purple Finch, the Wood Thrush, and the Winter Wren, are blended into a silvery cascade of melody, that ripples and dances down the mountain side as clear and sparkling as the mountain brook, filling the woods and valleys with ringing music. At first it sings only on bright clear mornings; but once fairly in the mood, it sings at all hours and during the most inclement weather. Often while traveling over the narrow, winding mountain roads, toward the close of winter, I have been overtaken and half-blinded by sudden, furious storms of wind and snow, and compelled to seek the nearest tree and projecting rock for shelter. In such situations I have frequently listened to the song of this bird, and forgot the cold and wet in its enjoyment. Toward spring, as soon as the other birds hegin to sing, it becomes silent as though disdainful of joining the common chorus, and commences building its nest in May, earlier than almost any other bird. During this season it deserts the valleys, and confines itself to partially wooded hill-tops."

That the Clarino only sings in winter and is silent during the breeding season, as Mr. Trippe believes, is not corroborated by other observers. On the contrary, it sings in breeding time still more beautifully and persistently. Mr. Henshaw, who saw the Clarino in June, says that its habits, as far as he noticed them, are singularly like those of the 
Bluebirds. Besides a loud, liquid call-note, the male has a beautiful warbling song, which somewhat resembles that of the Purple Finch, but far excels it in power, sweetness, and modulation.

The first nest of this bird was found by Prof. Robert Ridgway in July, 1867, in a deep ravine on the western slope of the Sierra Nevada, at an altitude of about 5,000 feet. "This nest was placed in the cavity of the rocks forming the perpendicular upper bank of a sluice, constructed for mining purposes, and through which ran the water of a considerable mountain stream. The nest, which was about a foot above the water, was nearly as bulky as that of the Brown Thrasher, and similarly constructed; it contained four young. When we approached it, the female was much excited, flying before us or running upon the ground in the manner of a Thrush, a species of which she was at first thought to be, from her entirely thrush-like manners and appearance."

The first nest with eggs was found in 1876 by an eastern tourist, Mr. Lamb of Holyoke, Mass., in Summit Co., Colorado, at an altitude of 10,000 feet. Another, found by Mr. Wm. G. Smith of Buffalo Creek, Jefferson Co., Colorado, June 18, 1883, in the end of a large hollow fallen log, was constructed of a great quantity of thrash, including some bits of stick as thick as one's little finger. Upon this rested the nest proper, constructed chiefly of pine needles, grasses and disintigrated weed-stalks, the whole loose and slovenly, hardly to be handled without coming to pieces, without any well-defined brim or very regular circular disposition of the material. "The two eggs differ from each other in color as much as those of the Song Sparrow might, and not distantly resemble Song Sparrow's eggs. The ground is dull white; in one case wreathed about the butt, and elsewhere sparsely sprinkled with dull reddish-brown surface-markings and shell-spots duller still; in the other sample so heavily marked all over with a brighter and more chocolate brown that the ground-color scarcely appears. - Size about $0.95 \times 0.70$ in." (Coues.)

Mr. W. E. Bryant of Oakland, Cal,, adds the following to what is already known of the nest and eggs of the Clarino: "Of four nests of which I have notes, three were placed either on the ground or in a slight depression, giving the nest a saucer shape. In each case concealment had been attempted by the aid of weeds, a stone or a large piece of bark. One nest was built on the ground, within a semi-circular cavity of a standing tree. The nests were composed mostly of pine needles. One had a lining of soap-root fibre, and another was built of pine needles upon a slight foundation of small sticks. Three nests, found by Mr. Belding at Big Trees, Cal., June 8 and 9, 1879, and June 10, 1880, contained each four nearly fresh eggs." They correspond closely to the description of the eggs, quoted above. Dr. Elliott Coues in his incomparable work "Birds of the Colorado Valley" concludes the life history of this interesting bird with the following beautiful passage: "The sociable disposition which Townsend's Thrush manifests during the winter, contrasting with those traits it shows at other seasons so conspicuously that it has acquired the soubriquet of 'Solitaire,' is also attested by Mr. J. K. Lord, from observations made at Colville during November, when the leaves had fallen, snow covered the ground, and the cold was intense. His attention was attracted by the sound of singing, unusual at that inclement season; and he soon discovered a score of these brave little birds perched upon the sprays of some thorn-bushes, and was reminded, by their low, 
sweet notes, of the Song Thrush of Europe. Commend me to the rare bird that sings in winter, whose pipe, yet limpid when the rivers cease to flow, it tuned to sounds harmonious amid the discord of the elements, in earnest of more genial times to come!"

The genus Myiadestes consists of about ten or twelve species, only one of which occurs within our limits, the others belonging to tropical America.

N.IMES: Townsend's Solitaire, Solitaire, Clarino, Townsend's Ptilogonys, Townsend's Flycatching Thrush. - Klarino, Klarinettvogel (German).

SCIENTIFIC NAMES: Ptilogonys townsendi Aud,, O. B. (1839). Culcivora townsendi De Kay (1844). Myisdestes townsendii Cab. (1847). MYADESTES TOWNSENDII A. O. U. (1886).

DESCRIPTION: General color bluish-ash or dull brownish-ash, paler beneath. Wings blackish, the inner secondaries edged and tipped with white, nearly all the quills extensively tawny or fulvous at the base, tertials tipped with white. Tail rather deeply forked. Tail-feathers dark brown; the middle one aslyybrown; the lateral with the outer web and tip, the second with the tip only, white. A white ring round the eye. Bill and feet black. - Length about 8 inches; wings and tail about 4 to 4.50 inches.

\title{
PHAINOPEPLA.
}

Phainopepla nitens SCLAT.

Plate IV. Fig. 1.

\begin{abstract}
[0:0
STATE of our fair country presents to the naturalist and to the lover of nature so many attractions as the State of California. The geologist, the zoologist, and the botanist find here the richest treasures. The admirer of the beautiful must be enchanted by the many attractions with which all nature is here endowed. The noble mountain landscapes of the Sierras and the Coast Range, the gorgeous, romantic valleys and cañons, the beautiful mountain lakes, the numerous clear streams and torrents rushing down from the rocks, the famous groves of "big trees," the far-famed Yosemite Valley-all are majestic, grand, and yet exquisitely beautiful. The flora of California is especially rich and fine, quite different from what we see in the East and South. The mountains are covered nearly to their summits with different species of coniferous trees, beautiful as well as gigantic. In the rich valleys and on the mountain meadows, we find the gorgeous Humboldt ${ }^{1}$ and leopard lily ${ }^{2}$, the white, sweet-scented Washington lily ${ }^{3}$, and the very fragrant lemon lily ${ }^{4}$. The butterfly tulip ${ }^{6}$ flourishes here, too, in great luxuriance and in many varieties. Hill and dale are adorned with a great variety of foliage trees. Of the many evergreen shrubs one appears to be more beautiful than the other. Behold the manzanitas ${ }^{6}$ and madronas ${ }^{7}$, the California laurel ${ }^{8}$ and the photinia", and other ornamental evergreen shrubs! Near by, we may find different pretty species of California lilacs or Ceanothus. The flowers of all of these have a pleasant fragrance, and, when in bloom, give a charm to these regions peculiarly attractive to the lover of nature. They flourish most abundantly among the openings of oaks, redwoods, pines and firs, on the borders of cañons. Lovely garryas and rhododendrons,

1 Lilitum HLmboldti. 2 L. pardalinum. 3 L. Wrishingtonianum. 1 L. Parryi. B Colochortus. o Arctostaphylos glauca. 7 Arbutus Menzicsij. "Oreodaphne californica. O Photinia arbutifolia.
\end{abstract}


beautiful pickeringias, and a host of other fine shrubs and plants, different evergreen oaks, and other large forest trees, give us an idea of the variety and beauty of Californian forest scenery. These are only a few names of the most characteristic plants of California. Almost none of them thrive in eastern and northern gardens and parks, notwithstanding the care bestowed upon them. The climate of California is so peculiarly mild and fine that tropical araucarias ${ }^{\perp}$, pepper trees ${ }^{2}$, Australian acacias, eucalyptus, and many palms, grow to perfection in the open air, even near San Francisco.

The animals likewise vary widely. Particularly is this the case with the birds. Here we find a number of Hummingbirds, Finches and Warblers, which are never seen east of the Rocky Mountains. A very characteristic bird of California, and adjacent States and Territories, is the Phainopepla, or Black Flycatcher. This beautiful crested shining-black songster, with a large white spot on each wing which can be seen plainly only when the bird is flying, does not belong to the Thrush family; its closest relationship is with the Waxwings.

As already suggested, the Phainopepla is not confined to California. It is found in the arid regions of Mexico and contiguous portions of the United States, from western Texas to southern California, north to southern Nevada, and probably portions of Utah and Colorado. In the Santa Clara Valley near Santa Paula, Cal., in the Yosemite Valley, and in many parts of Arizona, it seems to be a rather common bird.

No one of our ornithologists has written so fascinatingly and in such a beautiful language about many of the western birds, as Dr. Elliott Coues. His life histories of many birds are incomparable models of beauty, full of feeling and poetry.

"While roaming aboüt in Arizona," he says, "sometimes hunting for birds and sometimes for Indians, I used at intervals to see a bird that I did not then know, and that I came to regard at last as great 'medicine,' so persistently did it elude me-now I could not get a shot at the shy thing-now a fair shot offered, but we had orders not to shoot for fear of discovery. It was a beautiful jet-black creature, showing a pair of white disks, one on each side, when it flew; generally seen amidst dense chaparral, dashing about with a nervous yet lightsome flight, reminding one of the action of a Mockingbird; now for a moment balancing with expanding wings and tail on some prominent spray, then darting into the air to secure a passing insect, or hurrying out of sight in the safe recesses of the covert. A rather harsh and querulous note, which I learned to associate with this wild and restless bird, was sometimes heard; and once I listened to a superb piece of music which I am perfectly sure came from this mysterious stranger. It was growing dusk: the scene, the camp of a scouting-party returning from unsuccessful pursuit of some Indians who had raided and run off our beef, and men busy gathering for burial the charred and dismembered body of a comrade who had been killed and burned a few days before on that very spot, where the wolves had afterward fought for the remains. The bird of omen, for good or bad, appeared in sombre cerements, and sang such a requiem as touched every heart; the camp grew more quiet than usual, and we went to bed early. - This was the last time I ever saw or heard this remarkable bird, which was a rather uncommon summer resident in the immediate vicinity of Fort Whipple, though abundant a little lower down and farther south." 
The Phainopepla is a very beautiful and highly interesting bird. It is remarkable for its slender, active form, its long tail and conspicuous crest. It is light and graceful on the wing, and very often numbers of them are actively engaged in the pursuit of flying insects. In these evolutions the bright white spot on the wing, is in fine contrast with the glossy black of the general plumage. It seems to be found only on mountain sides, in wooded cañons, or in the timbered borders of wooded mountain streams, being a true mountain bird. Many observers have seen as many as forty and fifty together, acting very much in the same way as Cedarbirds do. Like these birds, they are very fond of all kinds of berries, especially the fruit of the mistletoe, which grows in abundance in the regions where they live; it also subsists largely on cedar berries. Although an expert and successful insect hunter, it seems to prefer berries of various kinds. At all times they are wild and timid, jutting their tails and erecting their crests whenever they are alarmed.

In the "Auk," Mr. W. E. D. Scott gives a very interesting account of the habits and nesting of these birds (Vol. II, 1885 p. 242-246). This noted ornithologist found the Phainopepla in different parts of Arizona abundantly. North of Riverside, at a considerable altitude in a section known as the Mineral Creek District in the Pinal Mountains, he found the species an abundant one. From October till December he found that in certain localities - sheltered flats in broad cañons, where there was a heavy growth of a kind of juniper, then laden with fruit, - the birds were abundant, often gathering in flocks of fifty or more, and reminding one of the common Cedarbird. All the time they, adults and young birds, male and female, were calling to each other in a peculiar, bell-like, whistling note that was very musical. Mr. Scott describes six nests which he found there. They were all built rather high, in large trees. Three were built ten feet from the ground, one twenty, one twenty-five, and one even forty feet high. I will quote here only the description of the first nest he found: "June 17, 1884 . Built in an oak, twenty-five feet from the ground. Contained three fresh eggs. It was saddled on a thick limb near where it forked, and about ten feet from the main stem of the tree. It is composed mainly of the stems of a soft flowering weed abundant hereabout, and the flowers, which are worked into and form a part of the structure. Also some strips of fine bark, and various dried grasses, small twigs, and much plant down, help to make up the walls and bottom. These are thick and very soft, and the materials composing them are not woven at all, but simply laid together with some little attempt as fastening them with thread-like grasses. Externally the nest is 2 inches deep, and the external diameter is a little less than 4 inches. The greatest depth inside is 1 inch, and the diameter of the interior at the rim of the nest is 2.75 inches. It is not at all an elegant structure, though peculiar, and is very fragile, being quite as delicate and soft as that of Trochilus alexandri. The three eggs are greenish-white in ground-color, but so completely flecked all over with faint lilac spots as to seem at a very short distance of that general color. Again, all over the lilac spotting, are very strongly defined spots of deep umber brown, almost black."

Capt. Charles Bendire, who discovered more than a dozen nests with eggs and young in Arizona, never found more than two eggs in a nest. Other ornithologists and collectors found quite as frequently three. 
Mr. Evermann observed the Black Flycatcher rather common in the Santa Pat1la cañon, in Ventura County, Cal. Says he: "It was not until July, when returning from a camping-out trip to the Big Trees and that wonderful gorge, - the Yosemite Valley, that I again saw this species. We were ascending the steep grade which leads from the floor of the valley towards Inspiration Point, when a single individual was seen perched upon a top-most twig of a tall sugar-pine, now and then giving utterance to its peculiarly sad call-note. A few days later, while in camp near Fresno Flats, twenty miles east of Madera, we again met these birds. Our camp was among the foot-hills of the Sierras, where live and white oaks are about the only trees. Among these this bird was common and was undoubtedly breeding. We left this locality late in July, drove leisurely down out of the foot-hills, crossed the burning plains of the San Joaquin, and up over the Coast Ranges to Hollister, Gilroy, and San Jose, but though I was constantly on the watch, I saw no more of this species during the trip. So the evidence seems pretty conclusive that the Black-crested Flycatcher is greatly restricted in its habitat and is found only in localities the most favorable.-Upon my return to Santa Paula in August, I found it rather common in the cañon where I first saw them. They were feeding upon the berries of the choke-cherry, and remained in the locality until October, when they disappeared, going farther south.

"Early in spring of 1881, they again returned to the same cañon, where they continued to be seen throughout the summer. Their love for cañons, or narrow valleys, is shown by the fact that, although the mouth of the Santa Paula Cañon is only half a mile from where I lived, yet I seldom saw any of the species nearer my house than the mouth of the cañon,- only one pair nesting outside the cañon, as far as I could discover. During this season I made frequent excursions to various small valleys and cañons of Ventura County, and found the Black-crested Flycatcher in only two places besides Santa Paula Cañon. One of these was the beautiful Ojai (O-hi) Valley, about seven miles from Santa Paula Cañon, and connected with it by Si-Sa (See-Saw) Cañon; the other was among the moss-covered oaks on the Cocitos Pass from San Buenaventura to Santa Barbara. In each of these places it was quite common, but I was unable to find a single nest."

Later in the season, Mr. Evermann found seven nests, six containing three eggs each, and only one containing two. A correspondent of the same region informs me that he found nests near the habitations of man in pepper trees, blue gums, and elder bushes.

NAMES: Prainopepla, Black Flycatcher, Black Ptilogonys, Shining-crested Flycatcher, Crested Shining-black White-winged Flysnapper. - Trauervogel (Nlg.), Schwarzer Fliegenfänger.

SCIENTIFIC NAMES: Ptilogonys nitens Sw. (1838). Cichlopsis nitens Brd. (1858). PHAINOPEPLA NITENS Sclat., P. Z. S. (1858). Phaenopepla nitens Coues (1865).

DESCRIPTION: "Adult male: entirely lustrous black, with steel-blue or greenish reflections. Primaries with a large white space on the inner webs. Bill and feet black. Length about 7.50 inches; wing 3.50 to 3.75, tail 3.50 to 4 inches. - Adult female: crested like the male. Entirely brownish-gray, paler beneath, the wings and tail blackish, the white on the inner webs of the primaries much reduced or extinguished, and in its stead much whitish edging on the quills and coverts, tail-feathers and crissum." (Coues.) 


\title{
Gnatcatchers, Kinglets, WARBLERS.
}

Sylviidae.

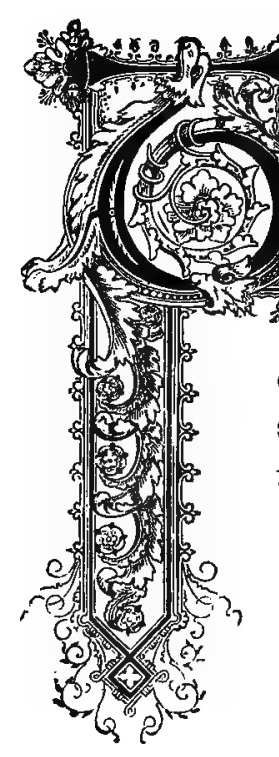

HE FAMILY Sylviidae is a large group of birds represented chiefly in the Old World and having but few representatives in this country. "The family is not well distinguished from the Turdidae and Saxicolidae, and no attempt will be made here to cover all its phases by any diagnostic phrase-it is perhaps insusceptible of exact definition. While there are several hundred species of the Eastern Hemisphere, less than a score occur in America." (Coues.) The family as represented in our country consists of the three genera:

1, Polioptila Sclater. Gnatcatchers. Three species.

2, Regulus Cuvier. Kinglets. Three species.

3, Phyllopseustes MeYer. Old World Warblers. One species.

\section{Blue-gray Gnatcatcher.}

Polioptila caerulea ScLAT.

Plate VI.

\begin{abstract}
(10in A BEAUTIFUL day in the first part of April, 1886, I found myself on the wooded shores of Lake Apopka, Fla. The air laden with fragrance, the deep blue sky, the thousands of small flowers which carpeted the sandy soil, the song of innumerable Mockingbirds, and the many strange trees and shrubs held my very soul spell-bound. The fine hammock woods on the borders of this large body of fresh water consists of a great variety of evergreen and deciduous trees and shrubs. I have nowhere
\end{abstract}


seen such gigantic live and water oaks, loblolly bays ${ }^{1}$, magnolias and cabbage palms ${ }^{2}$. Many of the huge forest monarchs were entangled to their very tops in a mass of woody vines, such as the Virginia ${ }^{3}$ and trumpet creeper ${ }^{4}$ and bignonias ${ }^{5}$, while the smaller trees and bushes were covered with fragrant Carolina jasmine ${ }^{6}$ The luxuriant ferns, orchids, and especially air plants ${ }^{7}$ growing parasitically on the branches of almost every tree, give these woods a decidedly tropical appearance, a peculiar charm. Near the water's edge we find the fragrant white lily-like crinum ${ }^{8}$, and several species of deliciously scented spider lilies ${ }^{\circ}$, and a great variety of half-aquatic plants. The brownish water of the lake swarms with fish. The greatest attraction, however, are the many cultivated and wild orange groves found on the borders of the lake. Whether the wild orange is indigenous is as yet an unsettled question, but the weight of evidence seems to be in favor of the idea that it was first introduced by the Spaniards, and that the wild orange groves now found in various localities are simply the result of that deterioration which so many cultivated plants undergo when left for long periods to run riot in a state of nature. The adjoining pine lands with their high and scattered trees and their dense undergrowth of huckle-berry bushes and saw-palmettos ${ }^{10}$ look poor against these rich hammock woods. Among birds, I saw here a great number of Yellow-throated Warblers and particularly GNATCATCHERs, which generally took their exercise high up in the tops of the huge magnolias and live oaks.

One day, April 12, I was rambling with a friend through the woods near Gotha. We had been fishing in Long Lake and were now before a low-lying apparently very shallow body of water which was covered with a mass of water-lilies, among them the fragrant yellow water-lily ${ }^{11}$, figured in Audubon's great work, afterward lost sight of, and a few years ago re-discovered by the well-known naturalist Mrs. Mary Treat of Vineland, N. J. - Gallinules were busily engaged on the floating leaves, and now and then an Anhinga or Snakebird was seen. No sound was to be heard except the song of the Mockingbird. The forest consisted almost entirely of pines, and only near the lake small oaks and a few other trees were to be found. As I stood gazing on the mass of water-lilies I perceived a pair of little, nimble birds, clinging to the trunk of an oak, and loosening lichens from the bark. I was much surprised to see them fly directly to a tree near which I stood. As I looked up I saw, scarcely nine feet from the ground, the beautiful lichen-decorated nest of my old well-known favorite, the BLUE-GRAY GNATCATCHER. The chosen haunts of this tiny bird are usually the tall tree-tops in the river bottoms of the Middle and Southern States. Hence my surprise at finding it in such a locality as the one I have described.

Its pretty, dwarfish form, its extraordinary adroitness in capturing flies and gnats, its very peculiar song, and the skill it shows in building its beautiful, decorated nestsuch skill as is attained by few other birds-excites attention and stimulates admiration. The small genus Polioptila, consisting of about a dozen species, is confined to America, and is represented by the greatest number of species in Central and South America. Only three species are found in the United States, one in the East, the other two in the West.

1 Gordonia Lasianthus. 2 Sabal Palmetto. 3 Ampclopsis quinrtuefolia. 4 Tccoma raclicans. 5 Rignonia capreolata. 6 Gclsemitum sempervirens. 7 Tillandsia (several species). 8 Crinum americanum. 9 Hymenocallis carribaca, crassifolium, etc. 10 Sabal serrulata. 11 Nymphaea Aava. 
I have observed the Blue-gray Gnatcatcher from northern Illinois to Texas and Florida. In the northern part of its breeding range it seems to be everywhere a rare bird, even in southern New England. It is evidently restricted to the Carolinian fauna, rarely occuring north of latitude $42^{\circ}$. In the dense bottom woods of Missouri and thence southward, it is everywhere a common bird. It is more numerous than is generally thought, as it takes its abode high in the tops of huge bottom-wood trees, elms, magnolias, and other forest giants. Only by him who is acquainted with the habits of this dimunitive woodland species, is it easily found. Near Houston, Texas, these birds arrive from their winter quarters in the later part of March, or early in April ; in southwestern Missouri they rarely make their appearance before April 15. By the last of that month they are all back again in their summer home. In northern Illinois, where they are very rare, they are not met before the last week of April or in May.

Although well acquainted with this sprightly little bird, I cannot but quote from Dr. Elliott Coues' admirable work on the "Birds of the Colorado Valley": "In the Colorado Basin, this Gnatcatcher is sparingly but generally distributed in summer, and resident, as far as the whole area is concerned, though partially migratory within its limits, since those individuals that repair to northerly or alpine districts to breed, retire in the fall to the lower warmer portions. At Fort Whipple, in the spring of 1865, I did not notice their presence until the last week in April; but as I was not then collecting every day, I may have missed them on their first appearance. At Washington, D. C., where they are more numerous than $I$ have found them to be anywhere in the West, I used to note their arrival each spring for several years in the early part of April. On entering the noble oak forests which still surround the city, at a time when the buds, though swollen, have not yet burst into the leafy canopy which later covers the nakedness, of the branches and gives privacy to the life of numberless sylvan species besides the Blue-gray Gnatcatchers, I seldom missed first hearing, then seeing, these wayward and capricious little creatures. Though so near the most uncertain and dangerous spot in America - Washington, 'Mecca of the unfortunate and the tomb of ambition,' the Blue-grays seem to have no fears for the success of their recent pilgrimage from the South, and indulge the aspirations of the day. Not content with the low estate of the shrubbery, which seems best suited to shelter their insignificance, they mount the tallest trees, and go the rounds with all the bluster and display of assured success. From the tree-tops come the shrill noisy notes, two or three at a time, like tzee-tzee-tzee, as the birds skip nimbly from twig to twig, with lowering half-spread wings and nervous twitching of the whole body, in eager quest of insects and larvæ, now pausing a moment to pry more closely into a suspected crevice of the bark, then darting into the air to capture a passing fly, and regaining their perch after almost a somersault. Restless and bustling as all its actions are at such times, there is something more remarkable still in the excessive eagerness betrayed, and the wonderful clan with which they dash upon their prey - as if they would crowd the business of a lifetime into its early days, and seize its prizes with the first impetuous assault. We must admire such spirit, even after we have learned it is unsafe.

"Days passed in this incessant activity, this impetuous revolt from the monotony of idleness, till other impulses are stimulated with the warmth of the advancing season, 
and the sharp accents of the voice are modulated into sweet and tender song, so low as to be inaudible at any considerable distance, yet so faultlessly executed and well sustained that the tiny musician may claim no mean rank in the feathered choir. A little later still we may, perchance, if our eyes are sharp, and we know just where to look, discover the extremely beautiful nest which the Blue-gray makes for itself-a structure which cannot fail to excite our wonder and admiration. Excepting the Hummingbird's nest, none can compare with this exquisite specimen of bird architecture, cunningly contrived to combine elegance with comfort, artfully rendered substantial without sacrifice of good taste, and ingeniously screened from observation by the same means that are employed for its onnamentation. True to its aspirations, the bird nestles high in the trees, usually àt least twenty yards from the ground, placing the fabric among slender twigs, to which it is woven, oftenest to the extremity of a bough which sways with the wind. To insure the safety of its contents during the motion to which it is oftenest subjected, it is built remarkably deep, and contracted at the orifice, so that the cavity is somewhat purse-shaped, and the general shape outside is like that of a truncated cone. It seems large for the size of the bird-it is sometimes three and a half inches in height, and nearly as much in width at the base, with a diameter of two inches at the brim. The walls are closely and warmly matted or felted with the softest vegetable material, the decomposed fibres of various plants, thistle-down, and like substances, in some cases woven with spider's webs.... The structure is artistically finished with stucco-work of lichens all over the outside, which serves the double purpose of perfecting its beauty and making it resemble a natural excrescence. In stuch an elegant cradle, eggs are laid, to the number of four, five, or even six, measuring scarcely three-fifths of an inch in length and less than half an inch in their greatest diameter-white in color speckled and dashed, generally over the whole surface, with several shades of reddish or tumber brown and lilac. In such a secure home as this, the Blue-gray Flycatcher usually rears its brood unmolested; it has little to fear except from the Cowbird and from the ornithologist, against which enemies no art avails. The parasitic bird might have its own excuse to offer, could its motives be called in question; the other may apologize, after a fashion, by averring that even this slight sketch of the Blue-gray Gnatcatcher's life could not be finished had the nest never been rifled."

A few of the Blue-grays spend the winter even in south-eastern Texas, especially in the magnolias, hollies, and other evergreens which skirt the bayous and rivers. During one of the cold "northers," which, from November to March, sway so frequently over the fields and prairies of Texas, they come in company with Titmice, Kinglets, and Myrtle Warblers into the gardens of Houston, where they rove cheerfully about among the trees and shrubs, busily engaged in hunting for insects. But it is in spring and summer, when the forest trees have donned their coats of green, that the Gnatcatcher adds pleasure to the locality in which it has chosen its home. It is then constantly employed in catching the buzzing and flying insects, and this is done with such swiftness, dexterity, and grace of motion, as is the case. with none of our other birds. Its favorite haunts are always the tops of high forest trees, from which it often descends in zig-zag lines nearly to the ground. The richest table is served to our Gnatcatcher and other small birds about the end of April and the beginning of May, when the magnificent, 
beautifully leaved and still more gorgeously flowered Magnolia grandiflora unfolds its chalice streaming with delicious fragrance. In the open white flowers the small insects revel and sip the sweet nectar. Every moment the Gnatcatcher changes its position. Now it is fluttering almost like a Hummingbird before the open flower, now it flies with astonishing rapidity from bough to bough, through the green canopy of leaves, then again into the air, and the next moment it descends in zig-zag lines almost to the ground. It is constantly in motion, granting itself hardly an instant's rest. As it is not a shy bird, one is able to watch its movements of activity and restlessness for a considerable length of time.

In September whole families of old and young birds enter the Texan orchards and ornamental groves. They are then busily engaged in capturing small insects on fences. out-houses, and trees. Still more charming is the picture when a half dozen or more of these sprightly birds are engaged about one tree. They even fly about the windows to search for spiders and concealed larvæ. Insects of many kinds, also their eggs and larvæ form their principal food. I have never seen them feed upon berries although they grow in abundance in their woodland home.

The song of the Blue-gray Gnatcatcher is as peculiar as it is attractive and beautiful. I have listened to it frequently, and I have always been struck with the enchanting beauty of the performance. On April 17, 1881, while wandering along a branch of the West Yegua, searching for nests of Vireos and Parula Warblers and observing Wood Warblers on their way to their northern breeding grounds, I heard emanating from a white-thorn bush, covered with clusters of sweet-scented flowers, a low, whispering, continued, exceedingly harmonious song, but so soft and low, that it was scarcely audible at a short distance. I was completely surprised when I noticed that the song came from a tiny Gnatcatcher nimbly hopping and fluttering through the mass of flowers. The song bears some resemblance to the Catbird's, but is of course much lower and softer, not perceptible at a distance.

A nest and a pair of these fairy-like birds are so accurately and beautifully figured in Mr. Ridgway's plate (VI) that I deem a more detailed description unnecessary.

NAMES: Blde-Gray Gnatcatcher, Bluc-gray Flycateher (And.), Little Blue-gray Flycatcher (IEdwards). Müclienlärnger (German). Figuier gris-dle-fer (Buff.).

SCIENTIFIC NAMES: Motacilla caerulca Linn. (1766). Sy.lvia cacrulca Lath. (1790). Culcivora caerulca D'Orb. (1839). Sylvania cacrulea Nutt. (1840). POLIOPTILA CAERTILEA ScLAT. (1855), etc.

DESCRIPTION: Above clcar ashy-blue, brightest on crown, hoary on rump; below whitish; lail long, black, onter feather almost wholly white, next about half whitc, third tipped with white; wings blackish; forehead and line over the cye black. Female similar, but more grayish-blue, lacking the black on the head. Bill and feet black. - Length 4.50 to 5 inches; wing 2 to 2.25 , tail a little over 2 inches.

\section{PLUMBEOUS GNATCATCHER.}

Polioptila plamber Baino.

This species of Gnalcatcher is found from western Texas to Arizona and the eastern coast of Lower California. I am not able to report anything particular on its habits, but believe that it comes very near our well known castern'specics. According to Prof. Wm. Brewster, it seems a rather common bird in many localitics in Arizona, especially 


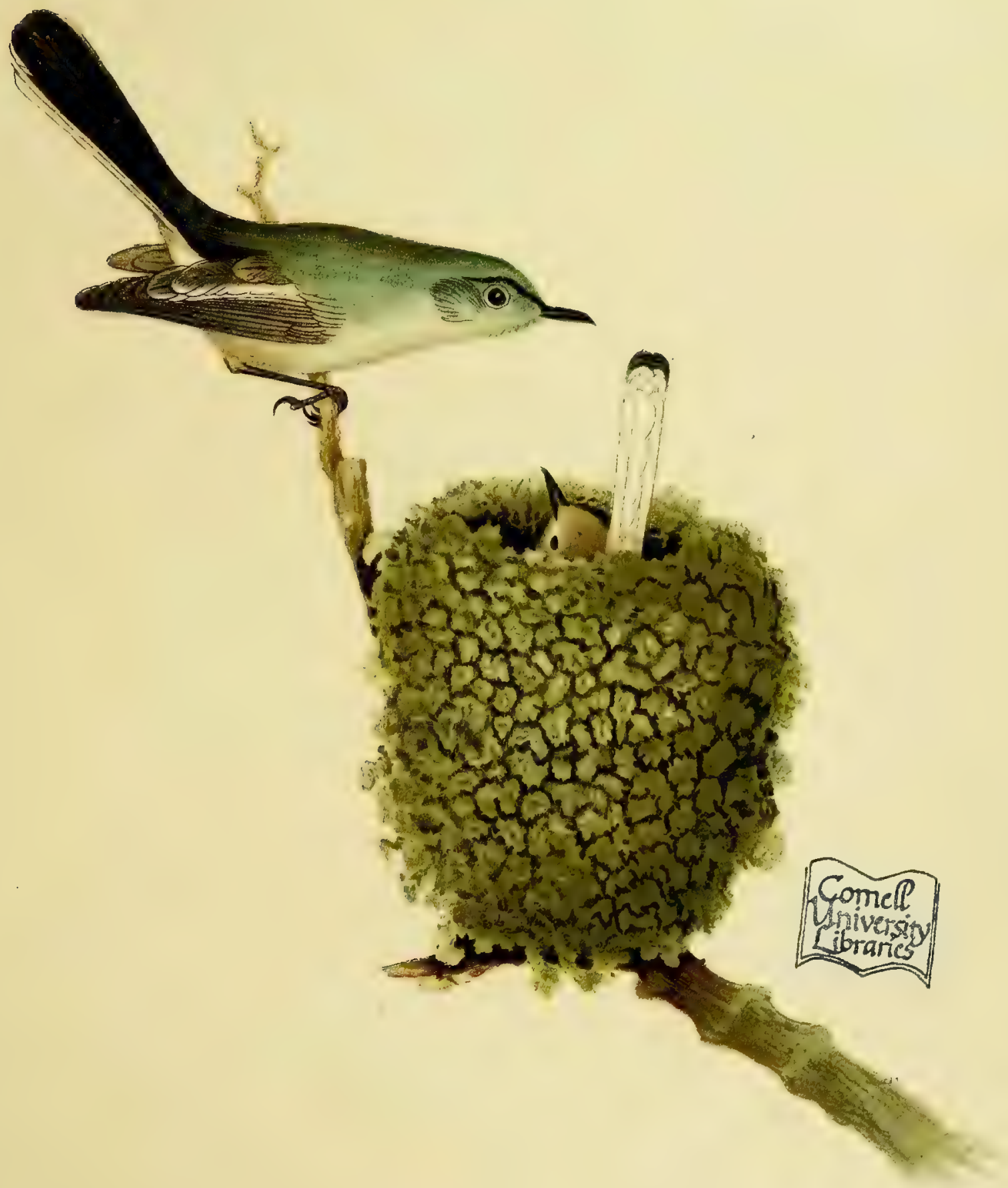

$1 / 1$

POLIOPTILA CAERULEA Sclat.

MÜCKENFÄNGER.

Blue-gray Gnatcatcher. 

at Tucson, Camp Lowell, and near Yuma. Two nests were found by Mr. Stephens, one June 27, the other July 15. This last nest taken at Yuma, "although a delicate structure, will not compare with that of $P$. caerulea. It entirely lacks the exterior coating of lichens so effectively employed by the commoner bird, and in its general appearance closely resembles the Redstart's well-known domicile, being similarly felted of soft bark-strips and henip-like vegetable fibres. It is lined with down from plants, a few feathers, and the hair of some small quadruped. Externally it measures 2.25 in. in width by 1.55 in. in depth; internally 1.45 by 1 . The egg is pale greenish-blue, coarsely and very evenly spotted with reddish-brown.... This nest was placed in a bunch of mistletoe, at the height of about eight feet from the ground."*

NAMES: Plumbeous GNatcatcher, Arizona Gnatcatcher.

SCIENTIFIC NAMES: POLIOPTILA PLUMBEA Brd. (1858). Culcivora plumbea Cass.

DESCRIPTION: "Male adult: Upper parts like those of $P$. caerulea, but duller and more grayish; no black on the forehead; a short black stripe over each eye, and below these another one of white. Outer tail-feather with the whole outer web and tip white (much like the second feather of $P$. caerulea); the next two feathers tipped with white. Size of $P$. caerulea.

"Female like the male; the upper parts still duller, and frequently with a decided brownish shade, no black over the eye. Only distinguished from the female caerulea by less white on the tail." (Coues.)

\section{BLACK-TAILED GNATCATCHER.}

\section{Polioptila californica Brewster.}

This Gnatcatcher is an inhabitant of southern California and the Pacific Coast of Lower California. Its habits are similar to those of the Eastern species. The song is noticeable for its harshness, and it is said to bear a strong resemblance to that of Bell's Vireo. Mr. Xantus found this bird in considerable number at Cape St. Lucas, Lower California, and was so fortunate to discover several nests. They were usually built among interlacing tendrils of a beautiful woody climber (Antigonon leptosus), and so closely interwoven with the smaller branches as to be inseparable. These nests, like those of all this family, are structures of great beauty and delicacy. "The external portion of the nest is composed of a composite blending of various vegetable materials, fine hempen fibres of plants, strips of delicate bark from smaller shrubs, silken fragments of cocoons and downy cotton-like substance, all very closely impacted and felted together, somewhat after the manner of the Hummingbird. The whole is very softly and warmly lined with a beautifully interwoven and silky fabric composed of the soft down of various plants." (Dr. T. M. Brewer.)

NAMES: BLACK-TAILED GNATCATChER, California Black-capped Gnatcatcher, Black-headed Gnatcatcher.

SCIENTIFIC NAMES: Culicivora atricapilla Lawr. (1852). Polioptila melanura Lawr. (1852). POLIOPTILA CALIFORNICA BREwster, Bull, Nutt. Orn. Club, VI, 1881.

DESCRIPTION: "Male, whole top of head from bill to occiput, deep, shining black. Wings dusky-brown; the primaries edged with grayish-white, the secondaries and tertials, with light brown. Rest of upper surface plumbeous-ashy. Tail glossy-black; the external half of the outer webs of the outer pair of rectrices, dull brownish-white; the white passing narrowly across the end of the feather, and at its

*Wm. Brewster, On a Collection of Arizona Birds. Bull. Nutt. Orn. Club. VIr, 1882, pp. 77, 78. 
extremity. nearly touching the shaft, but basally, diverging more and more until at the tail-coverts it is confined to a scarcely appreciable edging; no light coior on any of the outer rectrices. Throat and upper parts of the breast, with sides of head, neck, and body, dull but decided ash, with a faint wash of brownish-fulvous on the tips of the feathers. Along the central portion of the body beneath this wash becomes clear fulvous, which is deepest in tint on the abdomen, crissum, and under tail-coverts. Lining of wings very pale pearl-gray.

"Length, 4.50; extent, 6.10; wing, 1.84; tail, 1.80 in." (W. Brewster.)

\title{
Ruby $\sim$ CROWNed Kinglet.
}

\author{
Regulus calendula LicH'.
}

息

$\mathrm{N}$ AUTUMN, when the trees and shrubs of our woods don their brilliant colors, one who observes attentively the birds migrating southward, will soon discover among their numbers the lively, fairy-like RUBY-CROWNED KINGLE'T. Usually it arrives in the Northern States from its more northern breeding-habitat late in September, or early in October. During a few weeks it is a very abundant bird in woodland and garden, making itself conspictous by its fearlessness and activity. Toward the end of October, or the beginning of November, I have observed these birds in great numbers in south-eastern Texas. The majority migrated further south, but many remained during the whole winter. They kept together in small companies, preferring the pine-woods. During the cold "northers" they frequently visited the beautiful gardens of Houston, where they looked for insects among the evergreen live-oaks, the loquats, and other trees and shrubs. Though in the fall they often linger for weeks in the same locality, they do not tarry so long in spring. They arrive in northern Illinois from the South about the middle of April, and a few stragglers are even seen in early May. In southern Texas I saw none after March 10th. During their migration they abound on the bushy edges of woods, in orchards, and especially in such parks and gardens as contain coniferous trees. Here these charming, always cheerful little minstrels of the trees and shrubs, confiding and fearless in the highest degree, present a picture of beauty and attractive activity. "To observe the manners of the Ruby-crown, one need only repair, at the right season, to the nearest thicket, coppice, or piece of shrubbery, such as the Titmice, Yellow-rumps, and other Warblers love to haunt. These are its favorite resorts, especially in the fall and winter; though sometimes, in the spring more particularly, it seems to be more ambitious, and its slight form may be almost lost among the branchlets of the taller trees, where the equally diminutive Parula Warbler is most at home. We shall most likely find it not alone, but in straggling troops, which keep up a sort of companionship with each other, as well as with different birds, though each individual seems to be absorbed in its particular business. We hear the slender wiry note, and see the little creatures skipping nimbly about the smaller branches in endlessly various attitudes, peering in the crevices of the bark for their minute insect food, taking short nervous flights from one bough to another, twitching their wings as they alight, and always too busy to pay attention to what may be going on around them. They 
appear to be incessantly in motion. - I know of no birds more active than these-presenting the very picture of restless, puny energy, making much ado about nothing." (Dr. Elliott Coues.)

The Ruby-crowned Kinglet is one of our most exquisite songsters. During spring migration, in April and early May, the attentive listener can frequently hear the beautiful lay. The notes are clear, very loud and prolonged, full of variety and purity. "The Kinglets' exquisite vocalization," continues Dr. Coues, "defies description; we can only speak, in general terms, of the power, purity, and volume of the notes, their faultless modulation and long continuance. Many doubtless have listened to this music without suspecting that the author was the diminutive Ruby-crown, with whose common-place utterance, the slender wiry 'tsip,' they were already familiar. Such was once the case even with Audubon, who pays a heart-felt tribute to the accomplished little vocalist, and says further-'when I tell you, that its song is fully as sonorous as that of the Canary-bird, and much richer, I do not come up to the truth, for it is not only as powerful and clear, but much more varied and pleasing.' - This delightful rôle is chiefly executed during the mating season, and the brief period of exaltation, which precedes it, it is consequently seldom heard in regions where the bird does not rear its young, except when the little performer breaks forth in song on nearing its summer resort."

I have never heard the song in Texas or Missouri, but frequently in central Wisconsin, and several times also in northern Illinois, near Chicago.

Although found at varying periods in all the wooded parts of North America, from the Arctic regions to Guatemala, and from the Atlantic to the Pacific, its breedingrange is chiefly confined to the expanse between the extreme northern border of the United States and the Arctic seas, though it also breeds in the higher mountain regions of the United States, especially where dense coniferous woods clothe the mountain sides.

The nesting habits are imperfectly known, as yet. All the nests - only six, to my knowledge, having been found so far-have been discovered in the mountain regions of Colorado and Montana. The structure is usually semi-pensile, very bulky (about $4 \times 3$ to 4 inches outside), composed of very soft and fine materials, such as fine bark-strips, feathers, green moss, lined with hair and feathers. It is usually attached to the extremity of a spruce or pine branch, about twenty feet, or more, from the ground. A nest, found by Dr. Merrill in the Big Horn Mountains, Montana, on the 18th of June, at an elevation of 7,700. feet, was built in a fir tree, about eighteen feet from the ground, and placed directly against the trunk, supported by a single branch beneath, and by several twigs to which the sides are firmly attached. "It is a very neat, wellmade structure with thick walls. With the exception of the lining, which consists of feathers of the Richardson's Grouse, well woven into the sides and bottom, the whole nest is composed of delicate strips of bark, small pieces of green moss, and fibres of weeds, with a few feathers, spiders' webs, and fragments of a wasp's nest, the whole forming a somewhat globular mass of soft materials. The eggs were eight in number. It is not easy to give an accurate idea of the color of these eggs by any description. At first sight they appear to be of a uniform dirty cream-color, but a close examination shows that in most of the specimens this color is deeper at the larger end, and this forms a faint ring." Other eggs of this species are spotted. One set is described as 
having a creamy-white ground-color, over which are profusely scattered minute dots of brown with a reddish tinge.

The Ruby-crown, like so many of our small birds, destroys immense numbers of noxious insects, especially those small "pests" which infest our fruit and ornamental trees and shrubs.

NAMES: RUBY-crowned Kinglet, Ruby-crown, Ruby-crowned Wrell (Edw.), Ruby-crowned Warbler (Pennant). - Rubin-Goldbähnchen. (Germ.) - Roitelet rubis (Buff.).

SCIENTIFIC NAMES: Motacilla calendula Linn. (1766). Sylvia calendula Lath. (1790). REGULUS CALENDULA Lichт. (1823), Aud., Nutt., Baird, Coues, and A. O. U. Reguloides calendula Bonap. (1850). Phyllobasileus calendula Cab. (1853). Regulus rubineus Vieill. (1807).

DESCRIPTION: Sexes alike. Above, olive-green, brighter on rump; wings and tail dusky, edged with yellowish; two white cross-bars on the wings. Underparts, white, tinged with creamy-yellow or greenish-gray. Crown with a concealed patch of rich scarlet or ruby-red. White ring around the eye.

Length about 4.25 inches. Wing about 2.20 ; tail, 1.75 inch.

\section{Golden-Crowned Kinglet.}

Regulus satrapa LICHT.

Plate VII.

To $T$ IS winter. The ground is covered with a mantle of snow. Only a few of our 6 feathered friends are to be seen or heard. Most of them have migrated to the South, some even to the tropics, where they enjoy abundance of food, and a genial climate. Many even of those birds arriving from the high arctic regions suffer from lack of food, or the rigors of the season. Still the landscape is not entirely desolate. Among the dense thickets bordering the woods, in the underwood of the forest, in farm-yards and orchards, along the osage-orange hedge-rows, and near fences, we find troops of finches. Occasionally we see numbers of Titmice busily engaged among the twigs of the trees and shrubs, and now and then we hear even their familiar chickadee-dee-dee. Among the roaming flocks of these active birds, we frequently observe numerous dainty GoLDEN-CROWNED KINGLETs, cheerfully hopping through trees and shrubs, always on the look-out for insects and their eggs and larvæ. It is truly astonishing, how these delicate pigmies are able to survive a temperature of 20 to $30^{\circ}$ below zero. At times, when the branches are covered with snow and ice, so that the birds are unable to find sufficient food, they do, indeed, appear to lose their good spirit, and hop more slowly about with ruffled plumage. Mr. Ridgway's admirable plate introduces us to a bleak winter-landscape, the monotony of which is broken by the two charming little Golden-crowned Kinglets.

It appears to be of a more hardy nature than the Ruby-crown, and better enabled to endure the rigors of a northern winter. Doubtless the majority of these birds also move further south, passing the winter in great numbers in the South Atlantic and Gult States, In Texas, I found the Golden-crown to be one of the most abundant of all 



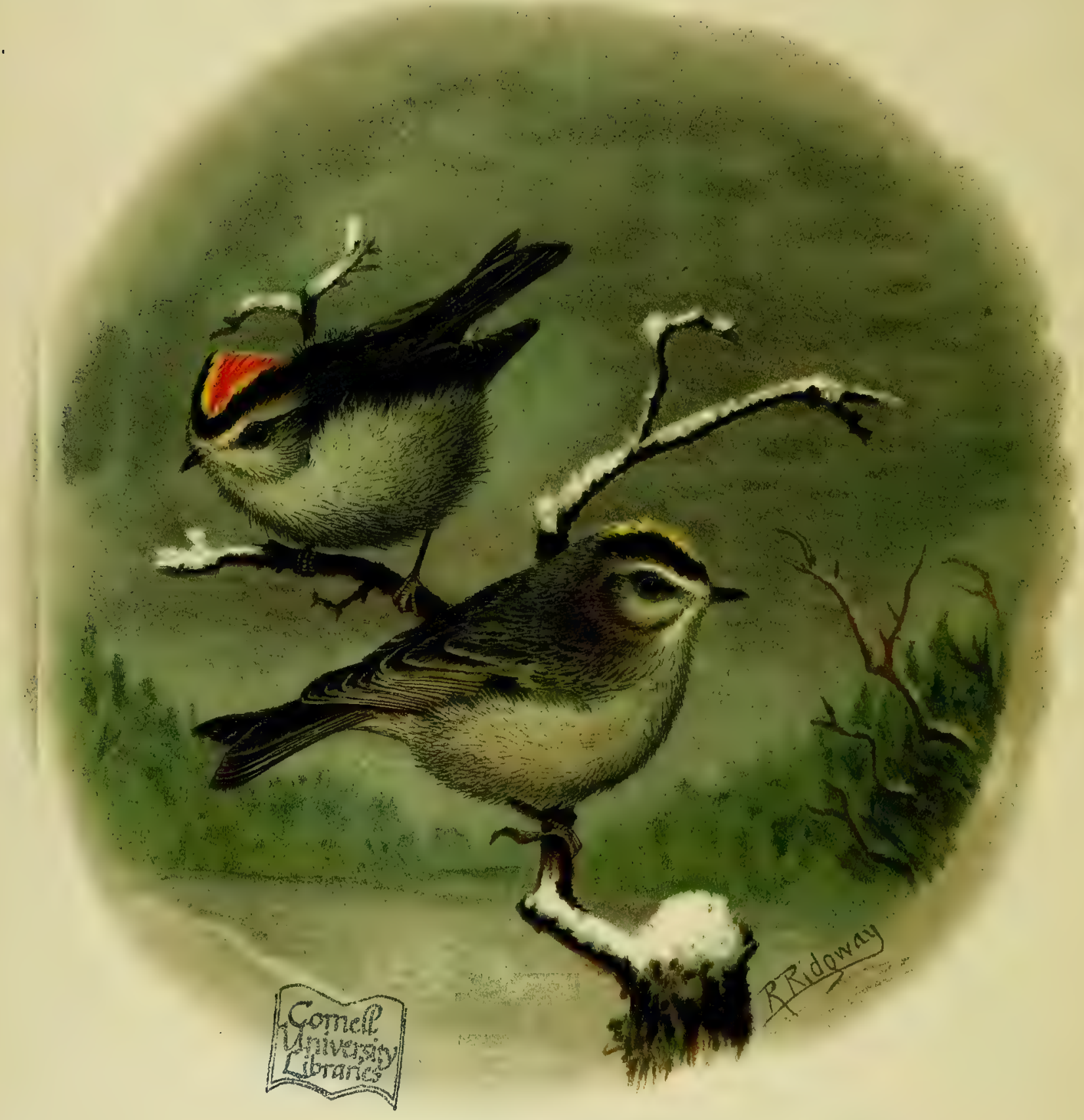

む

REGUIC'S SATRAPA Licht. SATRAP. Golden-crowned Kinglet. 
birds, from November to March. In Wisconsin and Illinois, it usually arrives from its northern breeding-range toward the beginning of October, often in company with its near relative, the Ruby-crown. - That the true home of the former species is in the fir, pine, and spruce woods of the North is proved by its predilection for coniferous trees, even during migration. In Wisconsin, it is most likely to be found wherever the white pine and hemlock grow; and in northern Illinois, it prefers to haunt those ornamental gardens and parks which are planted with different species of conifers. In south-eastern Texas, the bird is to be found, as a rule, only in the extensive woodlands of longleaved pine. Only when there is a scarcity of insects, does it search the deciduous trees and shrubs.

Its habits are so fully in accordance with those of the Ruby-crown, that a more detailed description of it seems superfluous. Its nearest relative is the common European Kinglet (Regulus cristatus).

"I have long been familiar," says Dr. Elliott Coues, "with the resorts and the sprightly ways of the Golden-crest; but these scarcely call for remark after what has been said about the Ruby-crown, since their habits and manners are closely correspondent. In peering about for insects and larvæ that lurk in the chinks of bark, it is equally tireless, and makes the same show of petty turbulence-another 'tempest in the teapot.' The song, I am not sure, I have ever recognized, and most authors have passed it over." I have often had an opportunity of hearing its notes, but they are much inferior to the loud and melodious strain of the Ruby-crown, with which it can hardly be compared. It is a low whispering, often interrupted by its wiry call-notes, sounding somewhat like sree-sree-sree.

The Golden-crest is a summer resident of the Canadian Fauna, breeding from the extreme northern and elevated portions of the United States northward. In his admirable paper on the "Birds of Western North Carolina,"* Mr. William Brewster mentions this Kinglet as one of the most abundant and characteristic birds of that region. He observed it throughout the sombre balsam forest on the upper slope and ridges of the Black Mountain. It remained well up in the tree-tops, where it was next to impossible to get a sight of it.

Up to the year 1888, the published descriptions of the nesting of this species were somewhat meagre, and more or less conflicting. In the October number of the "Auk" (Vol. V, p. 337-344, 1888), Mr. William Brewster gives a description of the breeding of the Golder-crested Kinglet in Worcester County, Massachusetts, in his own admirable manner. As the subject is treated into detail, I can give no more than an extract: $\mathrm{He}$ found the first nest June 13,1888, when the birds were at work on the lining, the exterior being apparently completed. June 29, it contained a set of nine eggs. "It was placed in a tall, slender spruce ( $A$. nigra), on the south side, within about two feet of the top of the tree, and at least sixty feet above the ground, suspended among fine pendant twigs about two inches directly below a short horizontal branch, some twelve inches out from the main stem, and an equal distance from the end of the branch. The tree stood near the upper edge of a narrow strip of dry, rather open woods bordered on one side by a road, on the other by an extensive Sphagnum swamp, the growth, both in the

$$
\text { * "Auk." Vol. III, 1880, p. } 177 .
$$


swamp and along its edges, being almost exclusively spruces ${ }^{1}$ and balsams ${ }^{2} \ldots$ Outwardly the walls are composed chiefly of green mosses * prettily diversified with grayish lichens and Usnea, the general tone of the coloring, however, matching closely that of the surrounding spruce foliage. The interior at the bottom is lined with exceedingly delicate strips of soft inner bark and fine black rootlets similar to, if not identical with, those which almost invariably form the lining of the nest of the Black-and-Yellow Warbler. Near the top are rather numerous feathers of the Ruffed Grouse, Hermit Thrush, and Ovenbird, arranged with the points of the quills down, the tips rising to, or slightly above, the rim and arching inward over the cavity, forming a screen that partially concealed the eggs.

"The second nest was found June 16, when it was nearly completed. It contained nine eggs. The locality was a lonely glen on high land between two ridges. The ridges were covered with young white pines. The prevailing growth of the glen was spruce and hemlock, the trees of large size, and standing so thickly together as to shut out nearly all sunlight from the ground beneath. The nest was on the west side of a sturdy, heavily limbed spruce, about fifty feet above the ground, twenty feet below the top of the tree, six feet out from the trunk, and two and a half feet from the end of the branch, in a dense cluster of stiff, radiating (not pendant) twigs, the top of the nest being only an inch below, but the whole structure slightly on one side of the branch, from which its supports sprang. Above and on every side it was so perfectly concealed by the dense flake-like masses of spruce foliage, that it was impossible to see it from any direction except by parting the surrounding twigs with the hand. From directly below, however, a small portion of the bottom was visible, even from the ground. The foliage immediately over the top was particularly dense, forming a canopy, which must have been quite impervious to the sun's rays, and a fairly good protection from rain also. Beneath this canopy there was barely sufficient room for the birds to enter. In general shape and construction this nest closely resembles the one above described. ....

"The third nest was also in a spruce which stood near the top of a steep, picturesque hill-side, covered with noble old hemlocks, interspersed with a few rather stunted spruces, the ground beneath rough and broken by ledges whose rugged outlines were more or less softened by a luxuriant covering of moss and rock ferns. It proved to be empty.

"The ground-color of the eggs varies from creamy-white to exceedingly deep, often somewhat muddy, cream-color. Over this light ground are sprinkled numerous markings of pale wood-brown, while at least three specimens have a few spots and blotches of faint lavender. The brown markings vary in size from the finest possible dots to rather large blotches. In most of the specimens they are distributed pretty thickly over the entire shell, but in nearly all they are most numerous about the larger ends where they form a more or less distinct wreath pattern. - Lest the detail of the above description mislead the reader as to the general appearance of these eggs, it may be well to add that while there can be no doubt that the markings are genuine pigment spots

1 Abies nigra. 2 A. balsamifera.

* These have been identified by a botanist as representing five species of Hypnum, and one of Frullania. 
and not mere superficial stains (this has been doubted by some writers), they are, as a rule, so fine and so little darker than the ground-color, that many of the eggs when viewed at a distance or in a poor light appear brownish cream-color and immaculate.

"In both nests the eggs, too numerous to find sufficient space for accommodation on the bottom of the nest, were piled in two layers, one above the other.

"All these nests were found by watching the birds while building, a task of no slight difficulty in dense spruce woods where the light was dim, even at noonday, and mosquitos were so numerous as to make it a torture to remain still for any considerable length of time. Moreover, the movements of the little architect were erratic and puzzling to the last degree. One moment fluttering at the end of a branch, her bill filled with a mass of building material, or tugging at the loose end of a shred of bark or moss, the next hidden from sight among the dense spruce foliage, now flitting rapidly from tree to tree, again dashing back and forth between two adjoining trees, the female would often appear and disappear a dozen times and at as many different places in the course of a minute or two. The chief difficulty, of course, was to make out just when and where she deposited her burden, which often vanished in the most unaccountable way. We finally found, that her almost invariable custom was to approach the nest by short flights and devious courses, and upon reaching it dash in, deposit and arrange her load in from two to four seconds, and at once dart off in search for more.

"The song begins with a succession of five or six fine, shrill, high-pitched, somewhat faltering notes, and ends with a short, rapid, rather explosive warble. The opening notes are given in a rising key, but the song falls rapidly at the end. The whole may be expressed as follows: tzee, tzee, tzee, tzee, ti, ti, ter-ti-ti-ti-ti. Besides the song both birds uttered frequently a low $t i, t i, t i$, which seemed to serve as a call to indicate one another's presence or position." *

A variety, $R$. satrapa olivacea BAIRD, occurs in the Coast Range of California. $R$. obscurus RIDGw. is to be found on Guadelupe Island, Lower California. $R$. Cuvieri Aud., described by Audubon, has never been observed by an other ornithologist.

NAMES: GoLDEN-CROWNEd KINGLET, Golden-crested Kinglet, American Golden-crested Kinglet, Fiery-crowned Wren. -Satrap (Germ.). - Roitelet huppé (Le M.)

SCIENTIFIC NAMES: Sylvia regulus Wils. A. O. I. (1808). Regulus cristatus Bartr., Trav. Fla. (1791), Bonap., Aud., Nutt. Regilus tricolor Nutt., Man. (1823). REGULUS SATRAPA Lichт. (1823).

DESCRIPTION: Above, olive-green; the dusky wings edged with yellowish; two white cross-bars on the wings. Below, yellowish-white; crown of head in the male marked with flame color, bordered in front and on the sides with black, this again with hoary-whitish. Bill and feet blackish. Female and young similar, but lacking the fiery patch in the yellow field.

A little smaller than the Ruby-crown. Length about 4 in.; wing about 2 : tail, 1.70 inches.

" See "Auk". Vo1. V, 1888, p. 337-344. 


\section{Tits AND Nuthatches.}

Paridae.

HE TRUE Titmice, about seventy species, are, "with few exceptions, confined to the northern hemisphere, and abound in most parts of Europe, Asia, and North America. A strong family likeness runs through the whole of them, and their habits and manners in most respects are much the same. The principal exception to this statement is found in the methods of nidification, which vary greatly-some species building in holes of trees, which they excavate like Woodpeckers, while others construct immense purse-like pensile nests of grasses or mosses. They are for the most part hardy birds, capable of enduring great cold with impunity; this circumstance which, with their omnivorous tastes, renders procuring of food of one kind or another easy at all seasons, causes them to be non-migratory or only imperfectly so. Their musical ability is decidedly of a low order, though they have a great variety of hearty and not displeasing notes. They are very active, restless, energetic, and industrious birds, withal turbulent, self-asserting, and in presence of man heedless to a degree. Among their own kind, they are sociable, in some cases almost gregarious, but are accused of being tyrannical and cruel, like Jays, toward weaker, or more defenseless species. They are very prolific, not only laying a large clutch of eggs, but often rearing more than one brood annually; as a consequence, they are usually abundant wherever found at all. They are chiefly confined to wooded country; the boreal species of. America, like Parus hudsonicus, haunt the coniferous forests; others, for the most part, prefer thickets, shrubbery, and undergrowth." *

The Nuthatches differ from the true Titmice in their climbing up and down the trees, which is their prime characteristic. "Our other scansorial birds, such as the Creepers and Woodpeckers, use the tail as a prop or stay to assist in maintaining position; for which purpose the feathers are specially contrived by their rigidity and strength, being 
pressed against the support by the action of strong muscles. In the case of the Nuthatches, the tail does not assist in the acts of climbing.

The family consists of the following genera:

1, Chamra Gamber. One species.

2, Patus Linnaus. Eleven species.

3, Psaltriparus Bonaparte. Three species.

4, Auriparus Barro. One species.

5, Sitta Linnaus. Four species.

\section{WREN $\sim$ TIT.}

Chamæa fasciata GAMB.

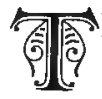

HE WREN-TIT, or GRound-Tit, is one of the most characteristic birds of California, combining traits of the Wrens, as well as the Titmice. "The Wren-Tit," says Dr. Elliott Coues, "is one of the several interesting discoveries made in California by Dr. William Gambel, of Philadelphia, whose life left an example of how much can be accomplished in a brief space of time by the wise use of natural gifts. He at first called it a Parus, but, soon perceiving its strongly distinctive characters, conferred upon it the appropriate title of Chamæa, in allusion to its terrestrial habits. According to his accounts, which remain the most accurate and pertinent of those which have thus far reached me, I gather that its habits are quite Wren-like; that it inhabits shrubby and weedy places, is restless and active, expert in eluding observation, and clamorous in resenting intrusion of its haunts, with harsh scolding notes; that it shares, furthermore, the very Wren-like way of holding the tail erect at times, and nervously twitching it. He observed its manners of searching for insect food by scrambling sideways about the weeds and bushes; and speaks of other notes it possesses, more musical than its usual scolding cries - a succession of slow monotonous, whistling notes, prolonged with a trill."

Dr. Cooper says that the bird is common everywhere west of the Sierra Nevada, on dry plains, covered with chaparral and other shrubby undergrowth. A nest which he discovered at San Diego during the last week of April, 1862, was placed in a shrub about three feet from the ground, and was composed of straws and twigs mixed with feathers, firmly interwoven, lined with grass and hair; the cavity was a little less than two inches wide, and about as deep. The eggs were $0.70 \times 0.52$ inch in size, and of a pale greenish-blue color.

The true Wren-Tit is confined to the coast region of California, while the paler variety, the PALLID Wren-TIT (C. fasciata henshawi RIDGW.), occurs more in the interior of that State. 
NAMES: WREN-TIT, Ground-Tit, Ground Wren. - Erdmeise (German).

SCIENTIFIC NAMES: Parus fasciatus Gambel (1845). CHAMAAA FASCIATA Gambel, Proc. Phila. Acad. III. (1846).

DESCRIPTION: "Above, plain brownish, the tail showing faint narrow darker bars (nearly or quite obsolete in some specimens); beneath, pale cinnamon, or buffy, middle of belly somewhat paler, throat and chest usually faintly streaked with darker.

"Length about 6.00 to 6.50 inches." (Ridgway.)

\section{TUFTED TITMOUSE.}

Parus bicolor LINN.

Plate V. Fig. 2.

N $\mathrm{N}$ THE beginning of March, 1879, when I made my first excursion through the monoto6 nous post-oak woods of Lee County, Texas, the TUFTed Titmrce were the first birds with which I struck up an acquaintance. They accompanied me in small troops through the woods, and their very loud and vehement notes reverberated from all sides. I found them common from Austin to the coast region, even in the dreariest solitudes, where only few other birds could be observed. Their activity and far sounding voices made me oblivious to the absence of the usual woodland songsters. They fearlessly entered even those gardens which are situated in close proximity to dwellings, exceeding, as they do, in familiarity and boldness' any of our other birds, with which I am acquainted.

Excepting the Blue Jay, I know of no bird that can vie with the Tufted Titmouse in persistent clamoring. All its notes are very loud and clear, and uttered with whistling reverberation. During the sunny winter-days it shouts with all its might: hee-dledee-dle-dee-dle-dee-dle, and this is particularly the case as the mating season approaches. Although these notes form a loud and melodious whistle, their ceaseless repetition soon renders them monotonous. Later in the season, when the mild influences of the southern sun make themselves felt, the song becomes more varied. In restless excitement the bird pursues its insect prey, climbing from branch to branch, and never for a moment ceasing to emit its loud and ringing notes. It is at such a time that the observer hears quite a variety of different sounds, among which the loud and querulous petopeto-peto-peto-daytee-daytee is especially pleasing. Such echoing notes enliven the tedious monotony of the post-oak woods. The birds seem to pay little attention to the observer as they hop and climb around among the branches, but in reality nothing escapes their notice. They are extraordinarily inquisitive, even daring to come close to the observer. The slightest movement, however, will drive them off, and cause them to emit a loud and creaking cry, which is well known as a signal of hasty retreat to all birds within hearing distance. They thus prove very annoying to the naturalist, and still more so to the hunter and collector.

They clamber about among the limbs with great agility and restlessness, and may often be seen hanging, head downward, on horizontal branches and trunks of trees, whilst 
exploring with great thoroughness every crevice of the bark for insects, their eggs and larvæ. They also show a liking for oily seeds, particularly those of hemp and the different species of small wild sunflowers. At times they will not despise berries, though they eat their seeds only. They also pay occasional visits to meat which has been hung out in the air to dry.

Whenever they resort to gardens, they carefully scrutinize every tree for insects, and though they do not seem to concern themselves about the actions of anyone who may happen to be working in their immediate neighborhood, perhaps directly under them, they in reality observe every movement, and hastily retreat at the slightest sign of danger.-In winter they roam about in small troops, and seem always to be busily employed in looking for food. It can not be said, however, that they live on perfectly amicable terms with one another. Only too often squabbles, and even serious battles, mar their sociability. After the beginning of April, or even. earlier, they are usually seen in pairs. At night, and at the approach of stormy and cold weather, they seek refuge in the cavities and the holes of Woodpeckers' which are to be found in almost every post-oak.

The Tufted Titmouse always chooses cavities for its nesting site. It prefers above all others abandoned Woodpeckers' holes, especially those of the Carolina, or Red-bellied Woodpecker. It has also been known to excavate a hole for itself. I always found the birds common where there was an abundance of natural cavities and Woodpeckers' holes; where these were scarce, on the other hand, the birds were ustually rare. The quantity of building materials used, varies in accordance with the depth. and circumference of the cavity. The foundation of the nest is made of grasses, Spanish moss, and bark-strips; the lining usually consists of an abundance of feathers and soft hair. Although these materials are loosely matted together, as is the case with all birds breeding in cavities, the whole structure is, nevertheless, very warm and soft. The eggs, six to eight in number, are white, thickly sprinkled with rusty-brown dots, interspersed with a few larger spots of lilac. The average size is $.74 \times .52$.

During the time of nest-building and breeding silence prevails. The old birds stealthily approach the nest in order not to betray its locality. As soon as the eggs are hatched, the parents become ceaselessly engaged in feeding their numerous offspring and in cleaning the nest. In my garden in Lee County, Texas, they nested regularly in the nesting boxes which I had put up for them in trees surrounding my house. They raised two broods annually.

In the beginning of October, 1882, I left Texas and settled in the south-western part of Missouri (Lawrence County), near woods bordering on the prairie. Here I greatly missed the Tufted Titmouse; its absence and that of other birds of like breeding habits being accounted for by the fact, that the hard and gnarled "black jacks" (Quercus nigra) did not offer the slightest trace of a cavity or Woodpecker's hole. Early in the following spring, I put up in the orchard and ornamental trees, and on the edge of the woods, near my dwelling, numerous nesting boxes, intended for my favorite, the Bluebird. They were hardly ready for occupancy, when a few Tufted Titmice made their appearance. They inspected one of the boxes from a short distance, and then cautiously peeped into it. It was remarkable how shy these birds, which I had found so con- 
fident, noisy, and curious in all parts of Texas, displayed themselves to be in my new surroundings. They did not utter a sound, their stay was only of short duration, and I supposed they would not return. But one beautiful May morning, I saw one with its bill full of food disappearing in a nesting box, to which, hitherto, I had given little attention. A few days later seven young Titmice left the nest. The parent birds were very much excited when I appeared on the scene, and uttered loud notes which sounded like hay-day-day-day-day. About twenty yards from this spot and six feet from the ground I had fastened a box which was partly open in front, and designed for Bewick's Wrens. This was used for the second brood, after the young of the first brood had become able to shift for themselves. I found this nest on June 20, 1883. When I was about to look into the box, the disturbed female flew directly into my face. Five eggs lay in the cozy little home, which was constructed entirely of human and animal hair. - Later in the season, and during the whole winter, this family of fourteen birds joyfully roamed through the woods. By this time they had grown more confiding, and frequently uttered their loud notes. Wherever the Tufted Titmouse occurs, it is resident throughout the year. In winter it frequently seeks the companionship of the Carolina Chickadees, Nuthatches, and small Woodpeckers.

The Tufted Titmouse is a common bird in all the Southern States, from Florida to Texas, north to the $40^{\circ}$ of latitude, west to the edge of the Great Plains. According to Mr. Robert Ridgway, it is perhaps the most abundant bird of southern Illinois, where it is resident, being excessively numerous in winter, when it constantly visits the dooryards and shrubberies, particularly the fruit-trees in towns, where it associates with the Carolina Chickadee and other winter birds, all of which it surpasses in familiarity and boldness.-As the bird belongs to the Carolinian Fauna, it rarely occurs in southern New England.

A variety, $P$. bicolor texensis Sennetr (Texan Tufted Titmouse), is confined to south-eastern Texas (Bee County).

NAMES: Tufted Trmouse, Crested Titmouse, Toupet Titmouse.-Haubenmeise (German). - Mésange bicolore. SCIENTIFIC NAMES: PARUS BICOLOR LrNw. (1766).-Lophanes bicolor Bonap. (1850).-Parus cristatus Bartr. (1791).

DESCRIPTION: Head, crested. Upper parts, wings and tail included, ashy. Under parts and sides of the head, dull whitish, the sides washed with chestnut-brown. A black frontlet on the base of the crest. Bill and feet, plumbeous. - Length, 6 to 6.50 ; wings, 3.25, tail, 3.20 inches.

\section{Black-Crested Titmouse.}

\section{Parus atricristatus CASSIN. .}

$\mathbb{1}^{\mathrm{N}}$ THE beginning of May, 1881, I left the city of Houston, in the south-eastern part of Texas, to take up my abode in the virgin forest, some 120 miles farther west. For nearly two years I resided with my family in a small cottage, surrounded on all sides by the forest. The days which I spent here I shall never forget. At last I was able to 
satisfy my long cherished wish to study in the quiet seclusion of the backwoods the wealth of Texan bird-life. In fact, my life, from the first day I settled, was that of a regular backwoodsman. As the house rested on posts, large numbers of the half-wild hogs inhabiting the forest, chose their night lodgings beneath its floor. The consequence was, that the blithely saltatory little insect-prosaically called the flea-came down upon us in overwhelming numbers. Scorpions of different sizes crept up the walls, and in the night, in order to vary the monotony of their existence, often made their way over our faces. Woe to him, who protested against this impudence; a painful, though not dangerous sting was the reward of such temerity. In addition to these guests there were many wasps, some of which lived in the crevices of the ceilings, while others build their mud nests in every available corner, and in the clothes hanging on the walls. The formidable centipede, too, was among our common visitors, and in small holes in the ground near my dwelling there lived many so-called tarantulas (Mygale Hentzi). These fierce spiders were more dreaded by the settlers than the venomous snakes. Most numerous and very troublesome was the rusty-red ant, known to the scientific world as Myrmica malefaciens. The children, while playing near their nests, were often bitten by them till they screamed with pain. Multitudes of these ants found their way into the bird-cages hanging in-doors and under the veranda, and in a very short time carried to their nests all the millet and canary seed intended for my birds. Kerosene, tar, and turpentine failed to exterminate them.-Being a great admirer of flowers, shrubs, and trees, I had planted cape jasmines ${ }^{1}$, myrtles, china trees, grape myrtles ${ }^{2}$, roses, pittosporums, coral-plants ${ }^{3}$, and especially magnificent amaryllis (of the genus Hippeastrum, Crinum, and Pancratium). Imagine my vexation at finding one morning all my plants stripped of their leaves. They had all been cut in small pieces and carried away by leafcutting ants to their nests which frequently were more than half a mile distant. Woodticks, and especially the almost microscopical "red-bugs," did their best to make our existence uncomfortable. The latter found their way by thousands through our clothes into the skin, causing an intolerable itching.

I have nowhere noticed so many snakes as in the neighborhood of my backwoodcabin. A very common intrepid, and poisonous species, and one, which in color closely resembles the soil or dead leaves, was the copperhead, or moccasin snake. The very first evening we spent in our new home, a large chicken snake crept through the open window into the room. Later on such intrusions became very frequent. The hideous creatures stole behind books, into closets, and often took possession of the beds. My birds, hanging in cages to the walls, were in succession choked and swallowed by the smaller individuals of the same species.

Yet, one finally becomes accustomed to the privations and hardships of life in the backwoods. Little by little many things change for the better. A fence is built, and a fine garden laid out. The half-wild hogs, centipedes, and tarantulas disappear one by one, though the ants, scorpions, snakes, and mosquitoes remain.-Highly disagreeable as is the part of the life of the backwoodsman, so far contemplated, may certainly be pronounced, it is not lacking in æsthetic qualities. Indescribably beatiful is the springtime in the months of February, March, and April. The whole ground of the post-oak woods, 
at other times so irksome, is now transformed into a pretty mosaic of flowers, gleaming with brilliant colors. Nowhere else have I happened on a field full of such rich promise for my ornithological observations. Hence I shall never forget these days, despite their many privations and hardships, the isolation, chills and fever, from which $I$ and my family suffered. Among the host of birds that dwelt in my immediate neighborhood, I had most ample opportunity to observe the beautiful Scissor-tailed Flycatchers, or "Texan Birds of Paradise," the Cardinals, the Painted Buntings (Nonpareils), the Blue Grosbeaks, the Lark Sparrows, Mockingbirds, Owls, Swallow-tailed Kites, the Summer Tanagers and Pileated Woodpeckers. Many a charming night has my sleep been interrupted by the loud call of the Chuckwillswidow, or the harsh hoot of the Great Horned Owl perched on the gable of my house.

I also became acquainted with many birds, which I, had never seen before. One of these was the Black-crested Titmouse, or Texan Tufted Titmouse, a bird which seems here to reach its eastern terminus. It bears a striking resemblance to the common Tufted Titmouse, but is easily distinguished by its black crest. In fact all its ways and actions, and likewise its ordinary notes, scarcely differ from those of the common species. Its song which resounds almost without interruption from the middle of February to May and June differs only in being louder and more melodious.

All ornithologists, who have spent some time in western Texas, have found the Black-crested Titmouse more or less common. It was discovered by $\mathrm{J}$. W. Audubon, the son of our great ornithologist. Cassin gave a very good plate of it in his fine work: "Illustrations of the Birds of California, Texas, Oregon, British and Russian America" (1856).

Mr. Geo. B. Sennett, the best and most reliable authority on Texan birds, has given us, as in the case of so many other species, some very interesting information* concerning this bird. Mr. Werner found it a rather common bird in Comal County, Texas.

But without further reference to the work of other ornithologists, I will now try to jot down my own observations of this bird.-On April 25, 1882, I found near a "branch," not far from my house, a White-eyed Vireo's nest. As the birds were nowhere to be seen, I leaned against a tree, whence I could conveniently watch the nest, waiting for the birds' return. While I stood there in perfect silence, with my gaze steadily fixed on the pretty lichen decorated domicile, a Black-crested Titmouse came very close to me. It first perched on a small bush, then it flew to the ground, and finally, growing very bold, clung fast to my trousers. When I moved, it flew back to the bush, contemplating me curiously, but finally, convinced of my good will, it returned and clambered up and down my back, pecking me, and again vigorously thrusting its bill into my clothes. It was obviously looking for insects, especially wood-ticks which in such places creep over ones clothes in great numbers. Whenever I made a noticeable movement, it fled a little distance, but invariably returned. Finally when I went and seated myself on a prostrate tree, it followed me again. It became so bold, that it not only climbed up and down my back, but fearlessly crept over to my shoulders and arms, and even on to the

* See his papers: "Notes on the Ornithology of the Lower Rio Grande" and "Further Notes on the Ornithology of the Lower Rio Grande," in Bulletin of the U. S. Geological and Geographical survey. Vol. IV and V. 
hat. This Titmouse stayed near me as long as I remained in that part of the woods, and pursued me a short distance, screaming loudly Wait-wait-wait-wait, while I continued my way through the forest. Never before have I seen such boldness and confidence exhibited by a wild bird.

A pair of these Titmice took up their abode near my house where I could observe their ways without any difficulty. Usually they were seen hammering on branches and trunks of the trees, in order to gain access to hidden insects, their eggs and larvæ. This hammering or pecking is a peculiarity of all Titmice.

In its breeding habits it is exactly like the common Tufted Titmouse. It usually nests in holes abandoned by Woodpeckers, but one pair. built their nest in a bird box, which I had put up in a post-oak near my house. In spite of the attacks of a pair of Bewick's Wrens they succeeded in rearing a brood. The eggs, five to seven in number, are white, marked with reddish-brown spots, which are most numerous on the large end. It is a rare bird in Lee County, Texas, but much more common farther west.

NAMES: Black-Crested Timmouse, Texas Titmouse.-Texanische Haubenmeise (German).

SCIENTIFIC NAMES: PARUS ATRICRISTATUS CASSIN (1850). Lophophanes atricristatus Cassin (1853). Lophophanes atroctistatus Coues (1878).

DESCRIPTION: Sexes alike. "Plumbeous, with a shade of olive, the wings and tail rather darker and purer, edged with the color of the back, or a more hoary shade of the same. Beneath, dull ashywhitish, especially on the breast; the abdomen, whiter; the sides, chestnut-brown as in $P$. bicolor. Extreme forehead and lores, whitish; entire crest, glossy black; feet, plumbeous." (Coues.)

Length, a little over 5 inches; wings, 2.95 ; tail, 2.95 inches.

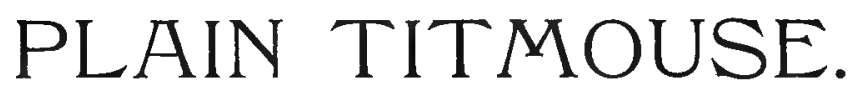

Parus inornatus GAmB.

TN REgard to the Plain Titmouse, I beg leave to quote the words of my learned A friend, Dr. Elliott Cones. Whatever he has written about our birds is incomparable. "Throughout the Colorado Basin," he writes, "the familiar Tufted Titmouse of the Eastern States is replaced by the 'plain' species, well named 'inornatus'-a peculiar sordid bird, the dull monotony of whose plumage is unrelieved by a single touch of color. It inhabits not only a portion of western Texas, the whole of New Mexico, Arizona, and corresponding latitudes of California, but also portions of Colorado, Utah, and Nevada. How far north it extends is not precisely ascertained; but we may suppose it to be distributed at least half-way across the three last named Territories, which lie in a tier together. Its southern extreme, similarly is uncertain; but, wherever the 'ragged edge' of its habitat may run, the watershed of the great Colorado of the West is its home, and there it resides continually.

"It is another discovery which the lamented Gambel made in California, where he first found it, in November, near Monterey, among the evergreen oaks of that vicinity. Since his time, nearly all the explorers of the South-west have also met with the bird, 
and recorded the impression it left upon them-among whom may be mentioned Woodhouse, Heermann, Xantus, Cooper, Aiken, Ridgway, and Henshaw, all well known in connection with the ornithology of this very interesting region. Whilst living in Fort Whipple, I frequently came upon little troops of these Titmice, especially in the wintertime-my note-book is silent for the summer months - but I never doubted their permanence in that vicinity. Nearly all of us who have had anything to say about the birds speak of their fondness for the tracts of country which are covered with scrubby evergreen oaks; in my 'Prodome,' I called it emphatically an evergreen oak species, eschewing the pines, and frequently the open hill-sides - a correct statement, though not a model of literary handicraft. There was, and for aught I know to the contrary there still may be, a large patch of oaks just back of the fort, where I was almost sure to find these Titmice at any time during a portion of the year. This scrubby hill-side, by the way, was a favorite resort of mine, not so much for what I expected to find there in the ornithological line, as for what. I very sincerely hoped not to find in the way of the aborigines-for it was in full view of the fort, and much safer than the ravines on either side, where I have gone more than once to bring in the naked and still bleeding bodies of men killed by the Apaches. This was in 1864 to 1865 , when the worst passions of both the Red and White men were inflamed by atrocities exchanged in kind, and when practical ornithology in Arizona was a very precarious matter, always liable to sudden interruption, and altogether too spicy for comfort... The recollections of a decade ago make a crowded and strangely jumbled picture, in which the high lights rest on many an interesting bird, while the swarthy savage crouches in the shadow of the back-ground. They tell me things are better now - that the trails are seldom bloodstained: in some states of the social atmosphere, a thunder-shower, with leaden rain, clears up the sky; and so it proved to be in this case.

"In studying the habits of Gambel's Titmouse, surnamed 'the unadorned,' I often desired to seize upon some salient point in its character, to contrast it with its eastern relative; but I was as often disappointed. It has character enough, I wot-few birds are of more positive, self-asserting, aggressive personality than the whole family of the Titmice; but, by the same token, there is little to distinguish them from each other. In a word, the inornatus is the counterpart of the bicolor; in that statement, the whole story of its life is summed."*

The true species inhabits California and western Oregon, the Grax Tímouse, $P$. inornatus griseus RIDGw., occurs in New Mexico and Colorado, to Arizona and Nevada, and another variety of this species, the Ashy TITMouse, $P$. inornatus cineraceus RIDGw., inhabits Lower California.

NAMES: Plain TrTmouse, Gray-tufted Titmouse, Gambel's Titmouse, Californian Titmouse-Einfarbige Hathenmeise (German).

SCIENTIFIC NAMES: PARUS INORNATUS GAMB. (1843), A. O. U. Code and Check-List (1862). Lophophanes inornatus Brd. (1852).

DESCRIPTION: "Entire upper parts dull leaden-gray, with a slight olive shade; the wings and tail rather purer and darker. Below, dull ashy-whitish, without any rusty wash on the sides. No black on the head. Extreme fore-head and sides of the head obscurely speckled with whitish. No decided markings anywhere. In size rather smaller than $P$. bicolor.

"Length usually under 6 inclies, \&c." (Coues.)

" "Birds of the Colorado Valley." By Dr. Elliott Coues, Washington: Government Printing Office. 1878, $114-116$. 


\section{BRIDLED, OR WOLLWEBER'S TITMOUSE.}

Patus wollweberi HENRY.

The BRIDled Titmouse, or Wollweber's Titmouse, is another western species. It ranges from western Texas, southern New Mexico, and southern Arizona southward. Says Dr. Coues: "This elegant little species is better known stuffed than alive; the Stubengelehrten and some of the 'Balgkrämer' (among whom it is whispered the namer of Parus galeatus is ranked by some) have had it pretty much their own way. Yet the remark, made by Dr. Brewer in 1874, that 'Dr. Kennerly is the only one of our naturalists who has mentioned meeting the species in its living form,' was not strictly correct. For one, I had become familiar with the bird at Fort Whipple, Arizona, and had summed my observations in a brief phrase:- Permanent resident; common, more so at least than the preceding ( $P$. inornatus). Usually semi-gregarious except when breeding. Found in all situations; but chiefly affects the oak thickets, and the chaparral of open hillsides. Generally distributed through the Territory, and extending southward into Sonora." The eggs, five to seven in number, are plain white.

SCIENTIFIC NAMES: Lophophanes wollweberi Bonap. (1850). PARUS WOLLWEBERI HENRY (1855). $P$. annexus Cass. (1850). P. galeatus Licht. Lophophanes galeatus Cah. (1850).

UESCRIPTION: “Adult, top of head, including crest, black, the crown, gray; a streak behind cyc, connecting posteriorly with a vertical bar or crescent behind ear-coverts, collar round hind-neck, and patch covering chin, and throat black; rest of head, grayish-whitish; upper parts plain grayish. Lower parts white medially, grayish laterally.

"Length, 4.50 to 5.00 ; wing, 2.60 to 2.80 ; tail, 2.40 to $2.65 . "$ (Ridgway, Manual, p. 562.)

\section{MOUNTAIN CHICKADEE, OR WHITE-BROWED TITMOUSE. \\ Parus gambeli Ridgway.}

The Mountain-Chickadee, or White-Browed Titmouse, is a common inhabitant of the Rocky Mountains and the Sierras, up to the timber line. "The vast tracts of coniferous forests, that clothe these alpine regions with perennial verdure, seem best suited to its requirements. Yet it is not confined to the pine-belts; it often descends to the low country, even in the southern portions of its habitat, and is then to be found among the fringes of willows and cottonwoods along the streams." (Coues.) "Eggs usually (?) plain white, sometimes spotted with reddish-brown." (Ridgway.)

SCIENTIFIC NAMES: Parus montanus Gamb. (1843). Pœeile montanus Cotres (1866). PARUS GAMBELI RIDGWAY.

DESCRIPTION: "Head without crest; top of head and throat black; a white superciliary stripe; bill very slender. Above, gray, the wings without distinct lighter edgings. Beneath, grayish-white medially, brownish-gray laterally.

"Length, 5.00 to 5.45 ; wing, 2.70 to 3.00 ; tail, 2.40 to 2.60 inches." (Ridgw., Manual, p. 562.) 


\section{CHICKADEE.}

Parus atricapillus LinN.

Plate XXI. Fig. 2.

(2) $N$

NLY a few species of Titmice inhabit our Northern States. Of them, the common

ChickadeE, or Black-CApped Titmouse, is the most abundant and best known. In New England, and almost in all the Northern States, it is a familiar bird during the breeding season, and still more common in winter, when they arrive in considerable numbers from northern regions. The range of this species extends west to the edge of the Great Plains, and south to the Potomac and Ohio Valleys. Its southern limit, however, cannot be exactly defined, as many observers have confounded it with the Carolina Chickadee, to which it bears great similarity. Prof. Wm. Brewster found it a few years ago as far south as the mountains of western North Carolina.

In central Wisconsin where coniferous trees abound, I found the Chickadee in considerable numbers the whole year around. There $I$ observed it on the edges of woods in the vicinity of thickets of raspberries and blackberries, hazel copses, and in swampy places covered with a variety of trees and shrubs, especially where many old stumps and trees with natural cavities or Woodpeckers' holes were found. In summer these Titmice shun the proximity of human dwellings, but in fall and winter they often visit the orchards and gardens in larger or smaller flocks. In northern Illinois, the Chickadee very rarely breeds, and even in fall and winter it is not regularly met. In the Eastern States and New England, it seems to be everywhere common and familiar.

"It is a resident species," says Dr. T. M. Brewer, "nesting early in May, and having full-fledged nestlings early in June. While it seems to prefer the edges of woods as best affording the means of food and shelter, it by no means confines itself to these localities, not only appearing familiarly around the dwellings in the winter season, but also occasionally breeding in open and exposed places. A hollow post of a fence in the midst of open cultivated fields, a decayed stump near the side of a public highway, a hollow $\log$ in a frequented farm-yard, and even the side of an inhabited dwelling, are localities these birds have been known to select in which to rear their young. In the winter they not unfrequently extend their visits, in search of food, into the very heart of large and crowded cities, where they seem as much at home and as free from alarm as in the seclusion of the forest, searching every crack, where insect larvæ or eggs can be hid. On one occasion a pair had built its nest over a covered well which connects with the dwelling by a side door, through which water was drawn at all hours of the day by means of buckets and a rope, the wheel for which was in close proximity to their nest. They manifested, however, no uneasiness, and even after the young were ready to fly, the whole family would return to the place for shelter at night and during inclement weather.-Their courage and devotion to their young is a remarkable trait with the whole race, and with none more than with the present species. On one occasion a 
Black-cap was seen to fly into a rotten stump near the roadside in Brookline, Mass. The stump was so much decayed that its top was readily broken off and the nest exposed. The mother refused to leave until forcibly taken off by the hand, and twice returned to the nest when thus removed, and it was only by holding her in the hand that an opportunity was given to ascertain there were seven young in her nest. She made no complaints, uttered no outcries, but resolutely and devotedly thrust herself between her nestlings and the seeming danger. When released she immediately flew back to them, covered them under her sheltering wings, and looked up in the face of her tormentors with a quiet and resolute courage that could not be surpassed."

During winter, when they roam about in flocks, they are very confiding. In orchards they often seem not to notice the presence of man, as their entire attention is absorbed in their favorite pursuit. But they actually see everything that is going on in their neighborhood. Their usual call-note is a very characteristic chick-a-dee-dee-dee, which is familiar to every friend of nature accustomed to out-door life. At other times cries like day, day, day, or "dee, dee, day," may be heard. In spring the notes exhibit a great variety of sounds and combinations, which are often blended to form a delightful twittering song. Thus we may hear, for instance, two extremely loud and euphonious notes, one high, the other low in pitch sounding like $z \bar{e}-h e ́, z \bar{e}-h e$.

The nest is always placed in cavities, especially in old Woodpeckers' holes. Sometimes the pair will take great pains to excavate an opening for themselves, and not only in decaying wood, but even in limbs and trunks that are apparently hard and sound. The site of the nest is never high from the ground. The structure is always a soft felted mass of hair, pieces of fur, downy feathers, moss, and dry grass. Although of loose texture, it is very warm; so that the eggs and nestlings are very secure against the changes of our spring weather. The eggs, from six to eight in number, are white, sprinkled more or less with reddish-brown markings, which in some specimens form a ring around the larger end, while in others they are distributed more regularly over the entire surface.

This Titmouse is one of our most useful birds. In winter the roaming flocks rid our fruit and ornamental trees from innumerable lurking.insects, their eggs and larvæ. Says Dr. Brewer: "Though nearly omnivorous in the matter of food, they prefer insects to everything else, and the amount of good conferred by them on the farmers and the owners of woodlands in the destruction of insects in all their forms-egg, caterpillar, larva, imago-must be very great. No chrysalis is too large to resist their penetrating bill, and no eggs so well hidden that they cannot find them out. I have known one to attack and fly off with the chrysalis of a 'Woolly-bear,' or salt-marsh caterpillar (Leucarctia acræa)."

NAMES: ChickadeE, Black-capped Chickadee, Eastern Chickadee, Black-capped Titmouse, Black-cap.Schwarzkopfmeise (German).

SCIENTIFIC NAMES: PARUS ATRICAPILLUS Linin. (1766). Poecile atricapilla Bonap. (1850). Parus palustris Nutt. (1832).

DESCRIPTION: Sexes alike. Above, brownish-ashy. Top of the head and throat, deep black; sides of the head, white, wings and tail, like the upper parts, but more or less edged with hoary. Beneath, whitss ; brownish-white on the sides. Bill and feet, plumbeous.

Length, 5.00 to 5.25 inches, wing, 2.50 ; tail, 2.45 inches. 
VARIETIES: The Long-TAILED ChICKADEE, $P$. atricapillus septentrionalis AlleN, inhabits the Rocky Mountain Plateau Region, east to Manitoba and the Plains; the Oregon Chickadee, $P$. atricapillus occidentalls Coues, occurs in the Pacific Coast Region, from northern California northward.

\section{CAROLINA CHICKADEE.}

Parus carolinensis Aud.

TN ALMOST all the wooded regions of the Southern States, the Carolina ChickadeE, 6 or Carolina Titmouse, is a common bird. I have become better acquainted with it than with the Black-capped Chickadee, as it appeared at all seasons in close proximity to my house in Texas, as well as in south-western Missouri. In winter the Carolina Chickadees chiefly haunt in larger or smaller flocks all such localities as are covered with shrubs and trees, no matter whether these are aggregated to form extensive forests, or bushy swamps, or whether they are only clumps of live-oak on the prairies, or orchards and gardens. Moreover, it visits villages, and even comes into the gardens of larger cities, searching every bush, every tree, every nook and corner for insects and their larvæ. In the larger gardens of Austin and Houston, Texas, it is an almost permanent resident.

It is most common in winter, when it roams about in flocks, frequently accompanied in its pleasant rambles by Tufted Titmice, Creepers, Nuthatches, Kinglets, and small Woodpeckers. They are so merry and jovial, that their happy chicka-dee-dee-dee on these beautiful southern winter days ripples through the woods continually. This species seems to be even more sociable than its near relative, the Black-cap. It has a special fondness for young groves of pines and other evergreens, which grow so luxuriantly in the rich and sheltered lowlands. Towards spring these flocks dissolve, and every pair return to their old quarters, or, if a young couple, decide upon a new home. While they are roaming about during winter, one frequently hears the familiar chickadee-dee-dee, but as soon as the first vernal breezes blow from the Gulf, and the first delicate blossoms in the woods and on the prairies open their buds, the Carolina Chickadee changes its song. A great variety of different more or less euphonious notes are now blended together into a very agreeable medley. The refrain is constantly heard while they roam through the woods and orchards in quest of food. Although some harsh notes will at times be intermingled, the quaint chant loses nothing of its pleasing originality. Two notes sounding like he-de, he-de, similar to those mentioned in the life-sketch of the Black-cap, are usually heard when the plum-trees are in flower, but after that time $I$ have never heard them. The first tone is high and prolonged, the second low and short. These sounds are so delightful and penetrating, so distinct and captivating, they overflow with such wonderful melancholy and entrancing 
harmony, that one never wearies of hearing them. When our Chickadee is excited or frightened, it utters a succession of very quick, shrill notes, sounding like hä, dä, dä, dä, dä.

The Carolina Chickadee is a true woodland bird, inhabiting chiefly such tracts as abound in old trees with natural cavities and abandoned Woodpeckers' holes. In Texas, it has a decided preference for the post-oak woods. A spot, to be a fit nesting place for a pair of Carolina Chickadees, must fulfill two conditions : it must contain plenty of old trees and stumps, and an abundance of insects. When first I saw them in the black-jack woods, just behind my dwelling in south-western Missouri, but could nowhere detect Woodpeckers' holes. or other cavities in the knotty trees, I constructed small nesting boxes which I placed near my house. I was soon rewarded for my pains by seeing several pairs take possession of them.

They are so fearless or rather daring, that they will often breed in the immediate vicinity of a dwelling where they fearlessly clamber about the orchard-trees and the ornamental shrubbery to rid them of insects. They exhibit great dexterity in extracting their hidden prey from cracks and crevices.

In Texas, I always discovered the nests in hollow fence-posts, stumps, abandoned Woodpeckers' holes, and similar cavities. In Houston, they nested quite frequently in knot-holes of cedars and catalpas in the streets and gardens. The birds seem to prefer hollow horizontal boughs, with the orifice on one side or beneath; but, if these cannot be found, the bird is satisfied with any cavity, provided its opening is not too large. The nest always consists of a mass of very soft substances, such as moss, fine barkstrips, cotton, and especially hair and pieces of rabbits' fur. The eggs, usually six to eight, but sometimes more, in number, are small and spheroidal; they have a pure white ground-color, and are uniformly and profusely spotted with reddish-brown. The parent birds exhibit great affection for their brood, and the female has very often to be removed with the hand, before the eggs and young can be inspected. Snakes can therefore easily prey upon them. Blue Jays, squirrels, opossums, and raccoons cannot harm their nests, as the entrance hole is generally very small, and the cavity from six to eight inches deep.

It is very interesting to observe a pair feeding their young. Without interruption from early morning till late in the afternoon, the parents keep bringing minute insects, worms, larvæ, and insect eggs, which they collect from the boughs, bark, and leaves of the trees and shrubs. Very rarely they descend to the ground in search of food, as the trees and shrubs offer all they need for their support. Like all our Titmice, and the rest of our small birds, the Carolina Chickadee is a very useful creature, and should enjoy to its fullest extent man's friendship and protection. In winter, it will eat at times the seeds of hemp and sun-flowers, which it skilfully opens with its strong bill.

This species, like all other members of the family, flies with apparent difficulty. They seldom leave the sheltering woods and shrubs to cross extensive treeless districts. Generally they may be seen skipping from tree to tree and from bush to bush. Whenever they are obliged to cross a treeless tract, they show signs of fear and timidity. At such times the apparent feeling of hesitation is productive of excitement in the whole 
flock, and the assemblage hops about in the branches of the last tree. At last some few ascend into the air to begin the journey, but perceiving that their comrades do not follow, they return. Then again some will make a trial until, finally, they all start in earnest, the most tardy making haste to join the crowd. By producing a sharp and buzzing sound and simultaneously throwing a hat into the air, the departure of the flock may be delayed. The birds will return to the tree which they had just left. Very soon they will repeat the same manoeuver, their reluctance being probably due to the fear of birds of prey. They are terrified by the rapid passage of a pigeon or any large bird, which may be mistaken for a Hawk; for they know only too well, that their powers of flight are sadly deficient, and that escape from an enemy in the open air is almost impossible.

The Carolina Chickadee ranges from the Atlantic to Kansas and eastern Texas. South of the once famous line of Mason and Dixon it seems to be common, but occasionally it occurs further north, as Mr. Robert Ridgway observed it frequently in southern Illinois. Its range is presumed to extend to all the States south of the Ohio and the Potomac. In Florida, I observed it as a common bird near Pensacola, in the woods of the Suwanee and St. Johns.

NaMes: Carolina Cuickadee, Southern Chickadee, Carolina Titmouse.-Carolina-Meise. (Germ.)

SCIENTIFIC NAMES: PARUS CAROLINENSIS AUd. (1834). Poecile carolinensis Bonap. (1850).

DESCRIPTION: Sexes alike. Upper parts, brownish-ash. Crown and throat, black, and the sides of the head, white. Beneath, white, with a brownish wash on the sides. Primaries, Secondaries, and outer tail-feathers not edged with white.

Length, 4.50 inches; wings, 2.50 ; tail, 2.40 inches.

The Hudsonian Chickadee, Patus hudsonicus Forster, also known as the Hudson Bay Chickadee, and Brown-capped Chickadee, is a bird of the Canadian Fauna. It is resident in northern New England, and of casual occurrence in northern Michigan and New York. It is the very counterpart of the two last described species. Above it is pale olive-brown; below, whitish, shading into light rusty-brown on the sides and behind; its crown and throat are brown.

The Chestnut-backed Chickadee, $P$. rufescens Towns., is a resident throughout the year in the forests of the coast districts of Oregon, Washington, British Columbia, and southern Alaska. Back, deep rusty-chestnut; top of head and throat, more sootybrown. Sides of head and neck, and upper parts of breast, white; sides and flanks, bright rusty. A similar variety, the Califormia Chickadee, $P$. rufescens neglectus RIDGw., inhabits the coast region of California.

The Mexican Chickadee, $P$. meridionalis Sclat., a bird of the highlands of Mexico, is of rare occurrence in southern Arizona.

The Siberian ChickadeE, $P$. cinctus obtectus RidGw., has been known to occur in northern Alaska. 



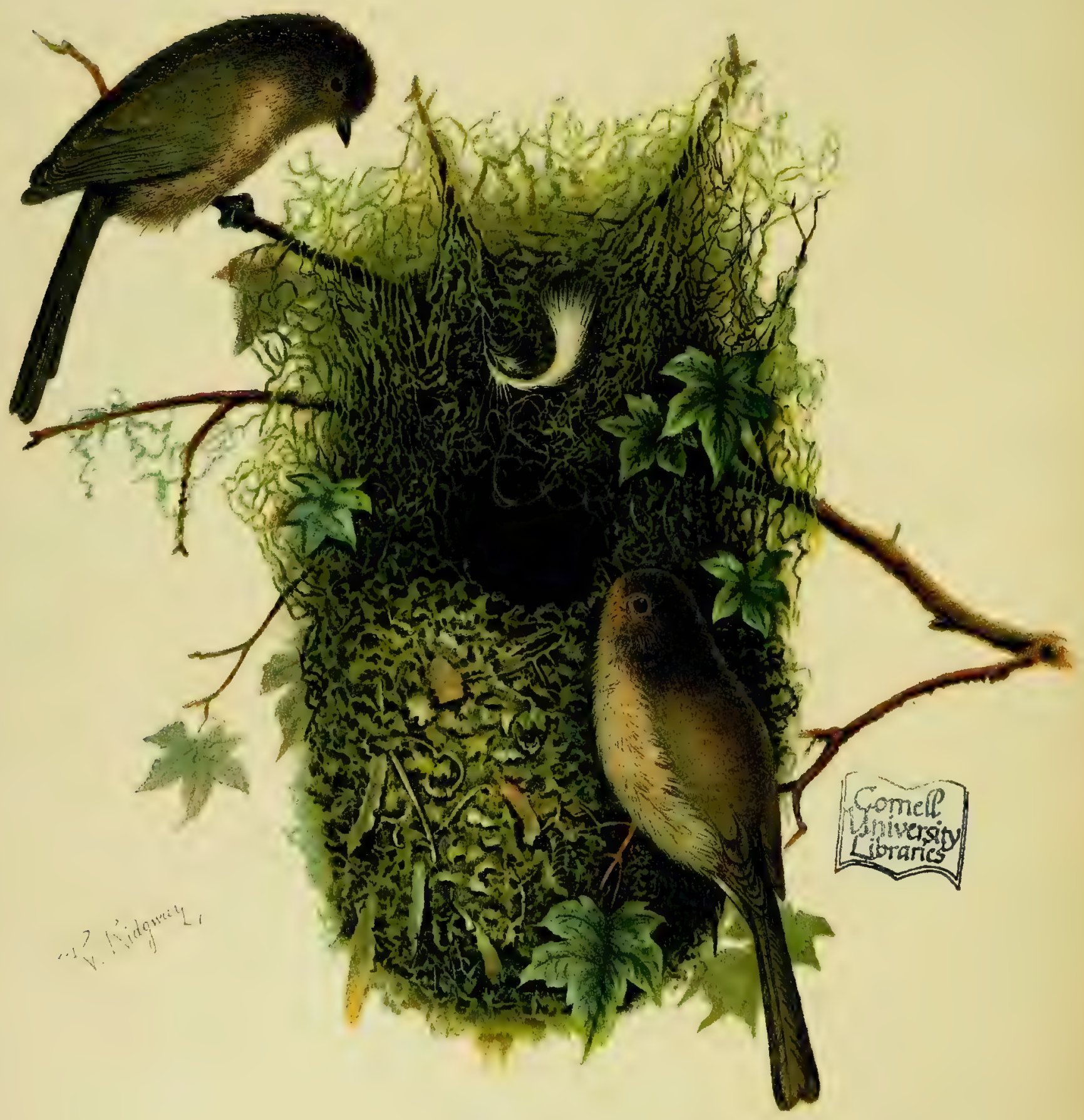

PSALTRIPARUS MINIMUS BP.

BUSCHMEISE.

Bush - Tit. 


\section{BUSH-TIT.}

Psaltriparus minimus BonaP.

Plate VIII.

ALIFORNIA abounds in natural wonders, a fact well known to the old Spanish (2. missionaries, when, more than a century ago, they.settled among the Indians. Even to-day, although the gold-fever has long subsided, the "Golden State" possesses an irresistible attraction. Every year thousands of tourists from both hemispheres pour into the famous El Dorado to revel in the grand and majestic scenery, and thousands more go there to take up their abode to enjoy one of the most delightful climates on earth. There is, probably, no place on the globe, of equal area, that contains so many attractions. In wild beaty the majestic Sierras rival the Alps, and in grandeur surpass them. Above the snow-line glaciers accumulate, while below are spread vast and noble forests. Evergreens screen the mountain slopes, while deciduous trees prevail in the valleys and cañons. Murmuring and roaring, foaming and thundering, the mountain torrents plunge from the precipitous rocks, incessantly rushing towards the Pacific. Crystal mountain lakes, in whose waters charming forests reflect their tufted foliage, burst on the view, entrancing the beholder. And above all the delightful climate, the unsullied air, the sky, ever blue, ever virginal! Who has not heard of the wonderful Yosemite Valley with its magnificent scenery and its waterfalls, surpassing all description; or of the gigantic trees ${ }^{1}$, some of which measure three hundred feet in height, with a diameter of twenty feet or more! Descending in the valleys of the mountain streams and cañons, we are at once confronted with almost tropical beauty and variety of vegetation.

The gardens abound in eucalypti and acacias, pepper-trees ${ }^{2}$, palms and araucarias, luxuriant pampas-grass and bamboos, while roses, fuchsias, and heliotropes clamber about the piazzas and verandas in dense festoons. So vigorous is the growth of all these, and many other semi-tropical plants, that they fill with admiration all who have seen them previously in green-houses. It would lead me too far from my subject, should I attempt to give only a superficial deliniation of the many plants and animals of that wonderful region. There exists a marked difference between the flora of California and the flora of the East. We note a similar disparity between the eastern and the western fauna. The dissimilarity in both cases is, indeed, very singular. Both, in the animal and the vegetable kingdom, the giant and the dwarf live in close proximity to each other. The grizzly-bear, the king of his family, even to this day inhabits the inaccessible heights, and the lordly elk ${ }^{3}$, all but exterminated, except among the northern Sierras, still proudly bears the weight of his branching coronet. The many species of small rodents, peculiar to the region, form a world of pygmies. On the summits of the mountains reigns the California "Condor," or Vulture", one of the largest of known

1 Sequoia gigantea and S. sempervirens. 2 Schinus molle. 3 Cervus americanus. 4 Pseudogryphus californianus. 
birds, while different species of Hummingbirds scintillate among the fragrant mountain lilies, the California lilacs (Ceanothus), fremontias, garryas, manzanitas and madroñas, and among the honeysuckles, roses, and fuchsias of the gardens.

But little larger than the brilliant-throated Liliputians of the bird-world, is the subject of our life-sketch, the BusH-TIT, or LEAST-TiT. In different varieties * it ranges from Washington to Lower California. The bird was first added to our avifauna by Mr. Townsend in 1837, and a few years later a plate of the species, and also of the nest, was given in Audubon's famous "Birds of America." Dr. Gambel found the species very abundant in California, during the winter. The woods were alive with busy and noisy troops, searching for food in company with Kinglets. While thus engaged, they assume all possible attitudes, of which these mobile little bodies are capable. Although constantly twittering, they are so intent on their employment that they appear to lose sight of all danger. At times Dr. Gambel was completely surrounded by a whole flock so that he could almost touch them with his hand. In habits and actions this species is so very similar to other Titmice that it is difficult to detect any difference. Like all the other species, it is a very hardy bird. According to Townsend, it is a constant resident along the Columbia River, where it hops about among the bushes, hangs from the twigs in the manner of other Titmice, and keeps up a constant twittering which is characterized by a rapid enunciation, resembling the sounds thshish-tshisttsee-twee.

But while all the other Titmice, excepting the Verdin, breed in holes, the members of this genus are known to be expert nest-builders. They all construct fine, durable purse-shaped, hanging nests, with a round orifice on the side near the top. In this respect they resemble the European Aegithalus pendulinus, but the nest of our Bush-Tit is still more beautiful and built of softer materials, which are woven together to form a remarkably complicate texture. The achievement of such a marvelous piece of workmanship not only requires unusual dexterity and skill, but also assiduous toil. A lady in California informs me that she watched the construction of a Bush-Tit's nest from the beginning till the deposition of the first egg. She observed that the wee creatures had to toil two full weeks, before their beautiful domicile was completed. Generally this artificial structure is found on some horizontal branch of a shrub or a tree, often only a few feet from the ground. It is never basket-like-i. e. with the opening on the top, as are the similarly elaborate structures of the Vireos or Orioles, but it is comparatively long, closed above, and with the entrance hole on one side. Dr. Cooper says, the nest is so large, compared with the size of the birds, as to suggest the idea that the flock unite to build it. He gives the measurements as 8 inches in length and 3 inches in diameter, outside; the cavity being 5 inches deep and 1.50 inches in diameter. He found the birds the year around near San Francisco, and discovered one nest as early as the 1st of March at San Diego.

As a rule, the nest is composed of soft materials, such as moss, lichens, rootlets, fine grasses, bast, cottony substances, etc., the interior being also lined with soft plant matter and numerous feathers, of which some can frequently be discerned in and through the opening. The felting is generally so perfect that the outsicle appears quite smooth 
and firm, and the walls are usually so thick that the cavity is quite narrow. The mosses and lichens with which the outside is decorated give the nest a very peculiar and beautiful appearance.

Mr. Robert Ridgway with the great ingenuity, peculiar to him, has givein us a portraiture, at once so clear and vivid, of a pair of birds and their domicile (Plate VIII), that any further description seems quite superfluous.

According to Mr. B. Evermann, the Least-Tit is very numerous in Ventura County, Cal. There it prefers to nest in dense clumps of California live-oaks (Quercus agrifolia), about eight feet from the ground. He found a nest twenty-one inches long. The entrance was a little more than five inches from the top.

NAMES: Bush-TrT, Least-Tit, Least Titmouse, Chestnut-crowned Titmouse.-Buschmeise (German).

SCIENTIFIC NAMES: Parus minimus Towns. (1837). Poecile minimus Bonap. (1850). Psaltria minima Cass. (1853). PSALTRIPARUS MINIMUS BoNAP. (1854).

DESCRIPTION: Adult, "Dull lead-color, frequently with a brownish or olivaceous shade, the top of the head abruptly darker-clove-brown or hair-brown. Below, sordid whitish or brownish-white. Wings and tail, dusky, with slight hoary edgings. Bill and feet, black.

"Length, 4 inches or rather less; wing, scarcely or not 2 inches; tail, 2 inches or a little more." Coues, B. C. V., 12. 124.

\section{LEAD-COLORED BUSH-TIT.}

Psaltriparus plumbeus BAIRD.

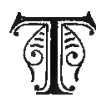

HE Plumbeous or Lead-colored Bush-Tit, ranges from New Mexico and Arizona northward to eastern Oregon and western Wyoming. Dr. Elliott Coues found it common in Arizona.

"These queer little elfs," he writes, "were very numerous about Fort Whipple, where I saw them all the year round, and learned as much about them as any one seems to know. Though living in a coniferous region, they avoided the pine forests, keeping in oak scrub of the hill-sides, and the undergrowth along the creek bottoms and through the numerous ravines that make down the mountain sides. They endured, without apparent inconvenience, an extreme of cold which sometimes proved fatal to birds of much more seeming hardihood, like Ravens for instance; and were as active and sprightly in the depth of winter as at any other time. I used to wonder how they managed, in such tiny animal furnaces, to generate heat enough to stand such a climate, and speculated whether their incessant activity might not have something to do with it. They always seemed to me model store-houses of energy - conserved to a degree in cold weather, with consumption of no more than was needed to keep them a-going, and thus accumulated for the heavier draft required when, in the spring, the arduous duties of nest-building and rearing a numerous family devolve upon them. Their food at this season consists of various seeds that persist through the winter; during the rest of the year, different insects contribite to their subsistence, and foraging for the minute 
bugs, larvæe and eggs that lurk in the crevices of bark seems to be their principal business. They are very industrious in this pursuit, and too much absorbed in the exciting chances of the chase to pay attention to what may be going on around them. They are extremely sociable - the gregarious instinct common to the Titmice reaches its highest developement in their case, and flocks of forty or fifty-some say even of a hundred-may be seen after the breeding season has passed, made up of numerous families, which, soon after leaving the nest, meet kindred spirits, and enter into intimate friendly relations. Often, in rambling through the shrubbery, I have been suddenly surrounded by a troop of the busy birds, perhaps unnoticed till the curious chirping they keep up attracted my attention; they seemed to pervade the bushes. If I stood still, they came close around me, as fearless as if I were a stump, ignoring me altogether. At such times, it was pleasant to see the earnestness with which they conducted affairs, and the energy they displayed in their own curious fashion, as if it were the easiest thing in the world to work hard, and quite proper to attend to serious matters with a thousand antics. They are droll folk, quite innocent of dignity, superior to the trammels of decorum, secure in the consciousness that their wit will carry off any extravagance. I used to call them my merry little philosophers-for they took the weather as it came, and evidently knew how much better it is to laugh at the world than to cry with it. When fretted with the friction of garrison-life, I have often sought their society, and amused myself like another Gulliver among the Liliputians."

NAMES: Lead-colered Buse-Tit, Plumbeous Bush-Tit, Leaden Titmouse, Plumbeous Titmouse.-Bleigraue Buschmeise (German).

SCIENTIFIC NAMES: Psaltria plumbea Brd. (1854). PSALTRIPARUS PLUMBEUS BAIRd (1858).

DESCRIPTION: Adult, "clear plumbeous, with little or no olive or brownish shade, the top of the head not different from the back. Sides of the head pale brownish. Underparts as in $P$. minimus, but rather clearer. Tail considerably longer than the wings. Eyes indifferently yellow or dark brown. - Length about 4.50 inches; wings, 2 in. or rather less; tail, 2.25 to 2.50 in." Coues, B. C. V., p. 125.

The Black-eared Bush-Tit, Psaltriparus melanotis Bonap., occurs from eastern Mexico south to Guatemala, north to the Rio Grande Valley.

\section{VERDIN.}

\section{Auriparus flaviceps BaIRD.}

Plate XXXII. Fig, 4.

IKE THE last species noticed, the VERDIN is an architect of extraordinary ability, IS and the history of its nidification should be as conspicuous an item in its biography as the nests themselves are in those localities where the birds are abundant. At Cape Saint Lucas, according to Mr. Xantus, Verdins are the most numerous of all the birds which nest there. The nest is described as a large globular mass of twigs, lined with down and feathers, having the entrance on one side, near the bottom. This 
singular structure is suspended from the extremity of a branch of some algarobia, acacia, or mimosa, at a varying height-sometimes only two to three feet from the ground, sometimes much higher. In the Colorado and Mojave River Valleys, Dr. Cooper observed many nests, one of which he describes with particularity:-On the 10th of March, I found a pair building, first forming a wall nearly spherical in outline, out of the thorny twigs of the Algarobia (or mesquite, in which tree the nest is usually built), then lining it with softer twigs, down, leaves of plants, and feathers, covering the outside with thorns, till it becomes a mass as large as a man's head, or $9.00 \times 5.50$ inches outside, the cavity $4.50 \times 2.70$, with an opening on one side, just large enough for the bird to enter. On the 27th of March, I found the first nest containing eggs, and afterwards many more. There were in all cases four eggs (others say four to six), pale blue, with numerous small brown spots, chiefly near the larger end, though some had very few spots and were much paler." (Coues.)

All along our southern border from California to the Rio Grande Valley of Texas, the Verdin seems to be a very common bird.' In the last named locality, Mr. Geo. B. Sennett found it in large numbers. To volume IV and V of the "Bulletin of the United States Geological and Geographical Survey of the Territories" (1878 and 1879), this excellent naturalist has contributed highly interesting papers on the birds of the lower Rio Grande of Texas. Of the Verdin he writes as follows:

"My first knowledge of the existence of this bird in the vicinity was the finding of a new nest on April 28; but it contained no eggs, and was not recognized at the time. The next day I went to the nest, found one egg in it, and saw both parents. While the female was darting in and out of the thicket, evidently alarmed at my close proximity to her treasure, the male was flitting from tree to tree, on the topmost branches, singing as hard as he could. I watched them both for at least half an hour, when they disappeared. Allowing five days to complete their complement of eggs, I again visited the nest. I cautiously approached and shook the bush, but no bird flew out of the nest. Thereupon I inserted my finger in the small opening on the side of the nest, and I could feel three eggs, and what I thought were some loose feathers. Imagine my surprise and fright upon withdrawing my finger at something flying out of the nest, directly into my face. It was the female. A few cries of alarm, and responses from her mate, and they were out of sight. Again carefully examining the nest, I very plainly felt four eggs. I decided to leave them tintil another day. Fatal mistake! for when it was next visited the female flew out of the nest before we reached it. I then went for the nest, but, lo! it.was empty - not the least vestige of an egg! Nothing, in my opinion, could have removed the eggs but the bird itself. It was owing, in all probability, to the disturbance and fright of the previous visit. But why was she back in the nest? About this time three eggs were discovered in another nest, and when visited the day after they were also gone. We were very careful in examining lest we should disturb the eggs. Can it be possible that with the least touch the parent bird abandons her eggs? Two nests that we found had been torn open from above, evidently by some Jay or other robber: Out of six new nests found between April 28 and May 10 we were only able to obtain one egg, and that was probably an infertile one, as the balance of the clutch had hatched and taken their departure. Their nests are simply wonderful, 
far excelling, to my mind, all other bird architecture of our fauna. Think of the size, varying from four to ten inches in diameter; then think of the size of the bird, but little larger than a Hummingbird! The shape is like a bottle, or, better still, a retort, with the mouth at one side and inclining downward. I found the nests built on and around one (in one instance two) horizontal branch. The body is composed of thorny twigs interwoven with wood-moss, grass, and bark. The lining is of the softest down and feathers, not loosely thrown in, but woven into a sort of matting, covering not only the whole of the interior body of the retort, or nest proper, but also the neck to the very mouth. The distance from the mouth to the eggs is sometimes six inches. The place selected is usually the extremity of a branch of an exposed bush, and easily approached. The highest nest was six feet, the lowest less than three feet from the ground. There they swing, free to every 'norther,' until they fall to pieces from decay. The only locality in which we found their nests was open chaparral, on that high ground where the cactus and a thorny, leafless bush, the junco, abound, and where are scattered at intervals clumps of trees of respectable growth, among which is the dark green ebony."

In the fifth volume of the above mentioned work, Mr. Sennett supplements his previous statements on the birds of the lower Rio Grande Valley, and, after having called special attention to the fact that his collected specimens of the Verdin are much more beautifully colored than those from Cape St. Lucas or the Colorado Valley, he proceeds as follows :

"About half of my adult specimens were caught on the nest, which may seem strange to those not familiar with the nest; but one who has seen it can readily understand why the bird feels so secure within it. A little fellow brought me a bird alive, and when asked how he obtained it, replied, 'I caught it asleep.'-As regards the habits of the bird, aside from its breeding habits, I can add almost nothing to the meagre knowledge we already have. They are so diminutive and timid, upon approach always darting into the dense cover near at hand, that a mere glance at them only can generally be had, as of a leaf falling into a thicket. I have never seen them feeding, nor this season even singing, as upon one occasion the season before. It is exceedingly difficult, if at all possible, to learn the habits of a bird no larger than a man's thumb, which affects such inaccessible places as it does. It makes its home upon ridges, drier and less fertile than the alluvial bottoms, and where chaparral and grasses will not grow, but where numerous varieties of cactus and thorny bushes flourish, with occasional stunted, thorny trees, all together forming immense labyrinths, wherein occur occasionally tempting bare places, which seem to be paths, but yet on trial lead nowhere except to confusion, and spread over, too, with trailing cactuses, whose thorns will pierce an army boot. The greatest caution is necessary in leaving the roadways or trails through these thickets, for fear of loosing the way; and a broiling, vertical sun, and a clear view above the lower growth of at very most a few yards, add still more to the difficulty of studying the bird. The nest is not so difficult of sight, but access to it is often exceedingly tedious.... In similar localities are also found Blackthroated Finches, White-eyed Vireos, and occasionally a Warbler.

"The nest is a marvel of bird-architecture, and consists of a hollow ball composed 
of a triple wall of three distinct styles of structure. The outside one is made of thorny twigs, and a few flower-stems, openly but securely intertwined among the twigs of the living branch; the middle one is a firm plaiting half an inch thick, made of flowers, flower-stems and mosses; the inner one is of a lining of feathers, matted together, sufficiently secured to the middle wall so as to line the hollow ball throughout... The shape of the nests varies from perfectly round to retort-shape, the neck of the nest being at one side and below. The size varies from four to eight or ten inches in outside diameter; the inside diameter is about three inches, and the opening of the neck about one inch.

"The eggs are rich pea-green of various shades, covered with irregular small spots and splashes of brown, sparsely at the small end, but at the other sometimes covering the entire end, though generally massed into a confluent ring. The shape is round at one end and tending to a point at the other."

NAMES: VERDIN, Yellow-headed Verdin.-Goldmeise (German).

SCIENTIFIC NAMES: Aegithalus flaviceps Sund. (1850).-Psaltria flaviceps Sclat. (1856).-Paroides faviceps Brd. (1858).-Psaltriparus faviceps Sclat. (1861).-AURIPARUS FLAVICEPS BrD. (1864).Canirostrum ornatum Lawr. (1852).

DESCRIPTION: Adult, "upper parts, ashy; under parts, dull whitish; wings and tail, fuscous, with hoary edgings. Whole head yellow. Lesser wing-coverts, rich chestnut-red. Bill, blackish-plumbeous; feet, plumbeous.

"Length, 4 inches or rather more; wing, 2 or rather less; tail, 1.75 to 2.25." (Coues.)

\section{White-Breasted Nuthatch.}

\section{Sitta carolinensis LATH.}

Plate XXI. Fig. 5.

Ane White-Breasted Nuthatch is one of the gayest birds of the woodlands. (9) Wherever it occurs it is, as a rule, stationary, being migratory only in its most northern range, where it moves but short distances during the spring and fall. In Wisconsin where there are extensive coniferous, foliage, or mixed forests, it is a common breeding-bird. In northern Illinois, it is not so frequently met with in summer, but is very numerous in winter, when it seeks the company of small Woodpeckers or more generally that of the Black-capped Titmouse. Nuthatches seem to have special fondness for mixed woods, where they may be found all the year around. Frequently they leave their homes in winter, visiting the surrounding districts, especially the orchards in which with greatest care they search every tree for insects. I have found them also very common in woodlands with low shrubbery and hazel-copses, especially where many old, decaying stumps and trees, full of natural cavities and Woodpeckers' holes, were to be found. When resting, the Nuthatch assumes a rather compressed and clumsy attitude, but its appearance changes materially, when it gracefully and nimbly moves up and down the tree-trunks. It merrily flits from tree to tree, often repeating its 
simple quenk, quenk, or kenk, kenk, the enunciation lacking neither force nor a peculiar metallic ring.

Its food consists chiefly of the eggs, larvæ, and imagos of insects, which lie hidden in the crevices of the bark. To obtain these dainty morsels, the bird assumes all possible attitudes, at times reminding the observer of the Woodpeckers, then again of the Titmice. The Woodpeckers never climb head downward; "while the Nuthatches scramble about in every imaginable attitude, running down the trunks of trees, or along the under side of branches, with the same ease with which they climb upward. When reversed in position, they are still unlike the Titmice and other small birds which momentarily hang suspended by their claws; for they appear to 'hug' the tree as closely as they do in any other posture. They are among the most nimble as well as adroit of creepers, matching any of our birds in activity and restless energy - a Woodpecker, for instance, is almost a sedate bird in comparison. Though not properly gregarious, they are sociable birds, and often gather in troops, with which Titmice, Kinglets and various Warblers may also mix. They are confined to woodland, and will be found oftener in high forests, on the larger trees, than in the undergrowth. In their relations to man, these birds are heedless and familiar, as if they trusted to his good will in return for their valuable services they render him in destroying incalculable numbers of noxious insects - a confidence too often abused by the vulgar and ignorant, who harbor against them the same prejudice that exists against the Sapsucker (Sphyrapicus), the innocent and industrious Nuthatches being supposed to injure trees, when the fact is, they spend the whole of their laborious lives in man's service. Instances are known of some Nuthatches becoming so tame, when they are appreciated and properly treated, as to almost take food from the hand." (Dr. Elliott Coues.)

Besides insects, they feed upon various hard fruits, such as beech-nuts, the seeds of conifers, \&c. The nidification is not different from that of the typical Titmice. They always nest in holes of trees and stumps, preferring abandoned Woodpeckers' holes, though very often digging holes for themselves. The nest is a warm and soft structure, consisting of a mixture of fine rootlets, feathers, hair, pieces of fur and moss. The eggs, five to six in number, are pearly-white, speckled and blotched with different shades of brown and lavender. Often the markings are distributed evenly over the surface, but generally they form a wreath-like band around the larger end.

The White-bellied Nuthatch ranges from the Eastern States to the Rocky Mountains. Mr. W. W. Cooke in his admirable book "Bird Migration of the Mississippi Valley" says, "that the 97 th Meridian very nearly bounds its western range, and beyond this line it is only met with as a straggler." I have seen it only sparingly in southwestern Missouri. It is not precisely known how far it breeds southward. Prof. Wm. Brewster, of Harvard University, found it rarely near Highlands, N. C.

In the West, from the Plains to the Pacific, and south into Mexico, it is represented by a distinct variety, the SLENDER-BILLED NUTHATCH, Sitta carolinensis aculeata AlLEN. In the mountains, this bird has been observed up to the limits of arboreal vegetation. "They seem to descend from the more elevated regions in the autumn, but there is no regular migration. We know, that the birds endure extreme cold with impunity, since they remain all winter about Colville, sometimes braving a temperature of $-30^{\circ} \mathrm{F}$." (Coues.) 
NAMES: White-breasted Nuthatch, Carolina Nuthatch, White-bellied Nuthatch.-Spechtmeise. (Germ.) SCIENTIFIC NAMES: SITTA CAROLINENSIS LATH. (1790). Sitta melanocephala Vieill. (1834). Sitta aculeata Cass. (1856). S. carolinensis aculeata Allen (1872).

DESCRIPTION: "Above, ashy-blue. Top of head and neck black. Underparts and sides of head, to a short distance above the eye, white. Under tail-coverts and tibial feathers brown; concealed primaries white. Bill, stout. Female, with black of head glossed with ashy.

"Length about 6 inches; wing, 3.75; tail, 2 inches." (B. B. \& R.)

\section{Red-Breasted Nuthatch.}

\section{Sitta canadensis LiNN.}

司凰

HE TRUE home of the pretty RED-BREASTED NUTHatch is north of the United States, although a number may breed in our northernmost states. It is also found during the breeding season in the high elevations among the mountains of the West, and probably also of the East, where the altitude is equivalent to a high latitude. Unlike the White-breasted Nuthatch, it migrates to a considerable extent in spring and fall, frequently visiting the Middle, and even the Gulf States in winter. I have seen it every spring and fall in Lawrence Co., Mo., and also in Wisconsin and Illinois, but have not found it in Texas.

A good account of the birds' nidification in Maine has been given by Mr. Manly Hardy in the "Bulletin of the Nuttall Ornithological Club" (III, 1878, p. 176). June 2, he found a nest on Little Deer Isle, Penobscot Bay. It was in a white-birch stub, some ten feet from the ground; the entrance was 1.50 inches wide. The hole ran slanting for three inches, and then straight down for four inches more. It contained six eggs, which were white, with small specks of reddish-brown on the small end, and heavily spotted with the same on the larger end. For two inches below the centre of the hole and for half an inch on either side, the birch bark was coated with fir balsam. Another nest, found June 20, in Holden, Me., was in a poplar stub some twelve feet from the ground. This hole had fir balsam one fourth of an inch thick for two inches below the hole, and then thinner, and running down in large drops for twenty-one inches below the hole. The pitch extended one inch on either side, and more than three inches above the hole, in all more than could be heaped upon a large tablespoon. This nest had been occupied two years. Near both the nests were other holes not so deep, probably used for one of the birds to occupy while the other is sitting, as is the case with most Woodpeckers. Both nests were composed of fine short grasses and roots. Mr. Hardy noticed that in making the hole, the bird makes a circle of holes around a piece about as large as a dime, and then takes out the piece of bark entire. Another nest, found by Mr. Merrill of Bangor, was also surrounded by pitch. "It seems certain," concludes Mr. Hardy, "that in most cases they do this, though for what purpose, I am unable to determine. The pitch certainly was placed there by the birds, as neither birch nor poplar contains 
pitch, and there were no overhanging trees from which a drop could come. I think it would take the bird several days of steady work to obtain what was around the nest in the poplar."

During migration they will frequently visit gardens, where they quietly and fearlessly search the trees from the ground to almost their very tops for insects. Even in the coldest days they forage without a moment's rest and move about the trees with undiminished ease and grace. The cracked and crannied bark is hunted in the most systematic manner. That the fruit trees afford an abundance of food is proved by their long stay in orchards, for they will spend half an hour or more in searching a single tree.

NAMES: Red-Breasted Nuthatch, Red-bellied Nuthatch, Canada Nuthatch.-Sitelle de Canada (Buff.).Canada-Spechtmeise (Germain).

SCIENTIFIC NAMES: SITTA CANADENSIS LINN. (1766).-Sitta varia Wils. (1808).

DESCRIPTION: Male, above, ashy-blue. Top of the head black; a white line above and a black one through the eye. Chin, white. Entire under-parts, rusty-brown. Female similar, but the back of the head mixed with ashy. Under-parts usually paler.

Length, 4.50 to 4.75 ; wing, 2.66 ; tail, 1.50 inches.

\section{BROWN-HEADED NUTHATCH.}

\section{Sitta pusilla LATH}

This Nuthatch is very common in the South Atlantic and Gulf States, where I observed it from Texas to Florida. It always prefers the pine-woods but by no means confines itself to them. Near my house in the post-oak woods in Lee County, Tex., the bird was very common. In early March, April and May, when the great bird-waves push on to the North, one might readily suppose that these active birds were absent, as their voices are lost in the great volume of bird-music that resounds through the woods from early morn to the dawn of evening: But the birds are present, nevertheless, and search for insects with the same assiduity and repeating their solemn yank, yank, with the same regularity as in June and other months. They breed in holes like the other Nuthatches.

NAMES: BROWN-HEADED NUTHATCH.

SCIENTIFIC NAMES: SITTA PUSILLA LATH. (1790).

DESCRIPTION: "Above, ashy-blue; top of head and upper part of neck rather light hair-brown, divided on the nape by white. Eye involved in the brown, which is deeper on the lower border. Beneath, muddywhitish; sides and behind paler than the back. Middle tail-feathers almost entirely like the back." (B. B. \& R.) - Length about 4 inches. 


\title{
PÿGMy Nuthatch.
}

\author{
Sitta pygmæa Vigors.
}

今)

HIS LITTLE bird seems to have been a special favorite with our gifted naturalist,

Dr. Elliott Coues, when stationed among the motuntains of Arizona. What he has written about the PyGmy NUTHatch is so beautifully expressed, and, moreover, so unlikely to reach the general reader, that I cannot refrain from quoting at least a part of it.

"I found it at all seasons about Fort Whipple; but in the pine-forests of that elevated locality it is most abundant in summer. It seems to prefer the pines, especially during the breeding season, and ranges up the mountains to an altitude of 8 or 10,000 feet, or to the timber-line; at other times it is more generally distributed through the deciduous woods of lower levels. During my residence at Fort Whipple, the habits of these birds were to me a study which never failed to please. If I loitered in listless mood among the magnificent pines, 'the world forgetting, by the world forgot,' absorbed in the sensuous undercurrent of merely animal existence, the vivacity of these ubiquitous little creatures seldom failed to break the spell of my dream, and bring me back to the realities that surrounded me. If I hurried breathless through the woods, in eager pursuit of some feathered prize that seemed likely to escape me, how did my haste in quest of a coveted thing differ from the bustling activity and restless energy they displayed in their search for what seemed good to them! The naturalist is never alone; solitude is not for him; he can call nothing his own-not even his thoughts, which he must be content to share with all the forms of life about him, and suffer to be carried beyond his control. 'How singularly,' I have said to myself, 'how perfectly, do these busy troops of birds illustrate the waste of nervous force! Will they never learn to make haste slowly? Are they so full of energy that such incessant motion becomes a pleasure-a necessity? And after all, what does this eager scrambling amount to? They make a living by it, to be sure, and that is something; but so do some of the laziest people. Perhaps they like it; perhaps they cannot help it. That may be a flock of young birds, relishing their work with the zest of enthusiasts who have yet to learn - the lesson that hard work teaches; this may be a lot of old ones, no longer buoyant, yet equally eager, for to them work has become a painful necessity, since habit has rendered idleness intolerable.'

"With such incessant activity as this do the Pygmy Nuthatches go about their daily avocations. With the appearance of the earlier broods the different families unite, and the busy throng roams through the woods, straggling from tree to tree with desultory flight, calling incessantly to each other as if to make sure that all the company keep together. They show some little preference in the matter of their hunting grounds, more rarely scrambling about the trunks than among the smaller branches of the trees, like the Brown-headed Nuthatches, which they resemble so closely in appearance, and they habitually resort to the terminal branchlets and foliage of the tree-tops. Their diet is a mixed one, consisting in part of minute insects which lurk in the cracks 
of the bark, in part of the seeds of conifers, and doubtless other small hard fruits. Their sociability is a prominent trait; indeed, they may almost be called gregarious at all times excepting during the breeding season. Flocks of a dozen or twenty, and even up to fifty or a hundred, are not seldom seen; and in the same company Titmice and Warblers may often be found. They are extremely noisy at such times-not clamorous in fretfulness or irritation, but with the jovial abandon of good fellowship."

The nidification agrees with that of its congeners.

NAMES: Prgmy Nuthatch, California Nuthatch.

SCIENTIFIC NAMES: SITTA PYGMAEA VIGORS (1839). - S. pusilla pygmæa Allen (1872).

DESCRIPTION: Sexes alike. "Above, ashy-blue; bead and upper part of neck greenish ashy-brown, its lower border passing a little below the eye, where it is darker; nape with an obscure whitish spot." Chin and throat, whitish; rest of lower parts brownish-white; the sides and behind like the back, but paler. Middle tail-feather like the back; its basal half with a long white spot; its outer web edged with black at the base.-Length about 4 inches; wing, 2.40 inches." B. B. \& R., I, p. 120.

[The family Certhiidae, or CREEPERs, is a small well-defined group of birds confined to the Old World, with the exception of a single species, the Brown Creeper, which occurs in the New World also.

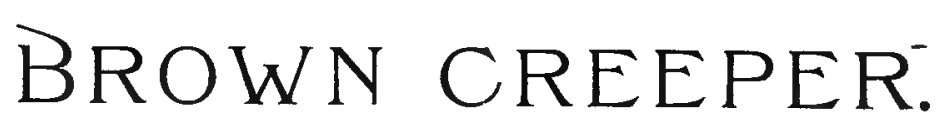

Certhia familiaris americana RIDGW.

(20,1)

UR Brown CReEper is closely allied to the European Creeper. Although nowhere abundant, it is, nevertheless, not an uncommon bird in all favorable localities, on the plains, in the wooded valleys, in the mountain forests, from the Atlantic to the Pacific. In summer it is found northward of our Northern States, breeding chiefly in the Canadian Fauna. I have found it sparingly in summer in central Wisconsin, in woods consisting partly of conifers, partly of deciduous trees. In the Middle and Gulf States, it is very numerous during the migration, being observed always singly or in pairs, sometimes in company with Chickadees and Nuthatches. In spring and fall, it frequently is seen in our orchards and parks, and even on the trees in the streets and door-yards of our larger cities, winding its spiral way up the trunks. It is always seen alighting on the foot of a tree and climbing indefatigably up the trunk hunting for minute insects which lurk in the crevices of the bark. When the first limbs are reached it flies to the foot of another tree where the same performance is repeated. It destroys in this way an immense number of noxious insects, and is thus of great service to man. I think it has rather a fondness for conifers and other trees with rough bark, as its delicate bill can more easily penetrate into the larger cracks; moreover, it is more difficult for its enemies to detect it on these trees, because of the similarity of its color to that of the bark on which it creeps. 
During the breeding season, our Creeper is a resident of the extensive northern or mountain forests. Here, in sylvan solitude remote from the noise and tumult of man, we find the nest, which, however, is not easily discovered. One of our leading ornithologists, Prof. Wm. Brewster, of Cambridge, Mass., has given $u$ s in his fascinating manner, the best description of the Creeper and its nidification we possess.* In May and June, 1879, this distinguished naturalist and writer spent his time on Lake Umbagog, in western Maine, paying especial attention to the Creeper's breeding habits.

"Throughout the heavily timbered region," he writes, "bordering on Lake Umbagog the Brown Creeper is of regular occurrence during the breeding season. It is never an abundant species there, but each square mile of suitable woodland is pretty sure to harbor a pair or two, and in places along the lake shores, where numerous decaying stubs form an outer fringe to sombre forests of spruce and fir, the combination of favorable conditions attracts them in somewhat greater numbers. Any considerable collection of these stubs is nearly certain to afford one or more trees in just the right stage of decay essential for nesting purposes, while the adjoining woodlands offer the shade and seclusion so congenial to their solitary habits during this season. It was in a locality of this character that the first nest taken during the past season was found. Let me briefly sketch the picture ere it fades.

"I had crossed the lake to a sheltered cove which opened an inviting way into the tangled forest. On either hand, heavily wooded ridges sloped steeply down to the water's edge, cutting off the high north-wind that was blowing over the lake outside, and the warm sunshine lay upon a smooth basin that was seldom dimpled by even a passing breeze. At its farther extremity, where a mossy bank rose abruptly from the shore, graceful hemlocks laved the tips of their drooping branches in the water, and tall firs and spruces looked down upon the perfect reflection of their stiff, soldierly forms in the mirror-like surface beneath. Here and there, where the land was more level and the water flowed back among the trees, grim stubs, many of them hung with streamers of the yellowish-gray Usnea 'moss,' stood grouped about, adding to the picturesqueness of the scene. These quiet little nooks abound about most of the Maine lakes, and they are almost invariably well stocked with birds. The retirement that they offer, coupled with the increased abundance of insect life, forms an attraction too powerful to be overlooked. The place just described proved to be no exception to this rule. The spruce tops were filled with busy flitting Warblers of various species, some of them migratory individuals resting for a few hours before resuming their northward journey; others already mated, and established for the brief season of reproduction so near at hand. Among the stubs, Woodpeckers were swinging from trunk to trunk, or entering their neatly rounded holes with food for their mates or young. From a dead branch that overhung the thicket beneath, a Water Thrush (Siurus nævius) uttered its gushing warble, while at intervals, in the cool depths of the forest on the mountain side, arose the exquisite liquid notes of a Winter Wren. Such were a few of the more prominent actors in the varied scene.

"Among the other voices I shortly detected the sweet wild song of the Brown Creeper, and, looking more carefully, spied a pair of these industrious little gleaners 
winding their way up the trunk of a neighboring tree. Although I watched them closely, the female soon after in some way eluded my sight and mysteriously disappeared, but the male remained in the immediate vicinity, singing at frequent intervals. Being convinced that they must have a nest somewhere near, I instituted a careful search among the dead trees that stood around, and at length detected a scale of loose bark, within which was crammed a suspicious-looking mass of twigs and other rubbish. A vigorous rapping upon the base of the trunk producing no effect, I climbed to the spot and was about to tear off the bark, when the frightened Creeper darted out within a few inches of my face, and the next moment $I$ looked in upon the eggs.

"The tree selected was a tall dead fir, that stood in the shallow water just outside the edge of the living forest, but surrounded by numbers of its equally unfortunate companions. Originally killed by inundation, its branches had long ago yielded to the fury of the winter storms, and the various destroying agents of time had stripped off the greater part of the bark until only a few persistent scales remained to chequer the otherwise smooth, mast-like stem. One of these, in process of detachment, had started away from the trunk below, while its upper edges still retained a comparatively firm hold, and within the space thus formed the cunning little architect had constructed her nest. The whole width of the opening had first been filled with a mass of tough but slender twigs (many of them at least six inches in length), and upon this foundation the nest proper had been constructed. It was mainly composed of the fine inner bark of various trees, with an admixture of a little Usnea moss and a number of spiders' cocoons. The whole mass was firmly but rather loosely put together, the different particles retaining their proper position more from the adhesion of their rough surfaces than by reason of any special arrangement or interweaving. The general shape of the structure necessarily conformed nearly with that of the space within which it was placed, but a remarkable feature was presented by the disposition of the lateral extremities. These were carried upward to a height of several inches above the middle of the nest, ending in long narrow points or horns, which gave to the whole somewhat the shape of a well-filled crescent. In the centre or lowest part of the sag thus formed was the depression for the reception of the eggs, - an exceedingly neat, cup-shaped hollow, bordered by strips of soft, flesh-colored bark and lined with feathers from Ducks and other wild birds. The whole was fastened to the concave inner surface of the barkscale rather than to the tree itself, so that when the former was detached it readily came off with it. I afterwards found two old nests which were perhaps originally built by this same pair of birds, as they were placed on a tree that stood close at hand. They were under a single enormous piece of bark, but at its opposite lateral extremities. One of them, a nearly shapeless mass of rubbish, was scarcely recognizable, but the other still retained its original shape and finish, and contained an unhatched egg, the contents of which had long since dried away. Probably they represented the homes successively occupied during the two preceding seasons, and it is hence likely that this species, like so many others, returns year after year to breed in nearly the same spot.

"If the above description conveys the desired impression to the reader's mind, he can scarcely fail to be struck by the manifold advantages of such a nesting-site. A perfect shelter from the sun and rain is afforded by the roof of bark, which, from the 
loose attachment of its lower edges, allows a sufficiently free circulation of air to insure good ventilation. And as for concealment, excepting of course the positions chosen by some of the ground-building species, who must necessarily sacrifice nearly every other consideration of safety in favor of this one, it would be difficult to imagine a more perfectly hidden nest. The very simplicity and naturalness of the situation is well calculated to deceive all enemies, and the imperfections of our past records well attest how closely the secret has been kept from man, nor is it probable that the predatory birds or mammals are often more successful. Even should a Jay or squirrel succeed in discovering the presence of such a nest, they would be unable to enter through the narrow crevice used by the Creeper, and it is not likely that either their patience or strength would endure to tear out the sticks and other materials of the sub-structure from below, and thus obtain possession of the coveted eggs or young. Yet, now that the secret is out, the very peculiarity of its position renders this nest a singularly easy one to find. After taking my first specimen I experienced little difficulty in recognizing a 'Creeper tree' - as my guide got to, calling them-almost at a glance.

"The Creeper is a frequent but scarcely a persistent singer, and his voice, though one of the sweetest that ever rises in the depths of the northern forests, is never a very conspicuous sound in the woodlands where he makes his home. This is due to the fact that his song is short and by no means powerful, but its tones are so exquisitely pure and tender that $I$ have never heard it without a desire to linger in the vicinity until it had been many times repeated. It consists of a bar of four notes, the first of moderate pitch, the second lower and less emphatic, the third rising again, and the last abruptly falling, but dying away in an indescribably plaintive cadence, like the soft sigh of the wind among pine boughs. I can compare it to no other bird voice that I have ever heard. In the pitch and succession of the notes it somewhat resembles the song of the Carolina Titmouse, but the tone is infinitely purer and sweeter. Like the wonderful melody of the Winter Wren, it is in perfect keeping with the mysterious gloom of the woods; a wild, clear voice that one feels would lose its greatest.charm if exposed to cheerful light and common-place surroundings.-On sunny April mornings I have heard the Creeper singing from the elms along the noisy streets of Massachusetts towns and cities; but the strain at such times was broken and incomplete, and gave but little idea of the author's real power of song."

The eggs, four to six in number, are nearly oval in shape, and of a creamy-white ground-color, speckled and spotted, chiefly on or around the larger end, with reddishbrown.

NAMES: Brown Creerer, American Creeper.-Baumläufer (German).-Grimpereau commun (Le Moine). SCIENTIFIC NAMES: Certhia familiaris Lath. (1758). Certhia americana Bonap. (1838). Certhia familiaris rufá Ridgw. (1873). CERTHIA FAMILIARIS AMERICANA RIDGw. (1873).

DESCRIPTION: Above, including sides of head and neck, dark brown, with rusty shade, especially on the rump, everywhere streaked with whitish. Beneath, dull white, under tail-coverts with a faint rusty tinge. A white streak over the eye; wings with two whitish cross-bars. Sexes alike.

Length, 5.50 inches; wings, 2.50 ; tail ranging from 2.50 to 2.90 inches.

A variety, the Mexican Creeper, Certhia familiatis mexicana B. B. \& R., occurs from southern Arizona and Mexico to Guatemala. 


\section{WRENS.}

Troglodytidae.

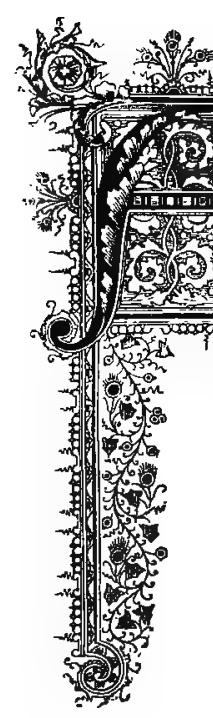

c5

CCORDING to the new system adopted by our AMERICAN ORNITHOLOGISTS' UNION, the family of WrENS includes also the Mockingbirds, Catbirds and Thrashers. It consists of a large number of species, nearly all of them American. The great majority of these inhabit the warmer parts of the western hemisphere, especially the tropical parts of South America. They are "incessantly rustling about in the intricate recesses of their chosen resorts, gliding with short flights or leaping impetuously. Such humility, and the evident desire for a means of ready concealment, even though not always taken advantage of, contrast curiously with some other traits, the Wrens exhibit in an exaggerated degree, and result in a singular compound. For the Wrens possess a high rate of irritability - they are bold, self-asserting and aggressive, petulent to the verge of fretfulness, with a certain pertness of demeanor, and a singularly prying, inquisitive disposition. They are the irrepressible busy-bodies of feathered society, and not seldom make trouble among some of the milder-mannered and better-behaved members of the sylvan circle. They are noisy birds; when alarmed or displeased, they have a loud, harsh, chattering or scolding note; but they are also fine songsters. Every one is familiar with the bright hearty carol which the House Wren trills so persistently in the spring, and the song of other species is often of wonderful timbre.... The Wrens are all plainly colored birds, the browns and grays being the prevailing shades; none of our species, at least, and perhaps none of the family, show red, blue, yellow, or green. The dietetic regimen is insectivorous." (Coues.)

The true Wrens consist of the following genera:

1, Campylorhynchus Spix. Two species.

2, Salpinctes Cabanis. Two species.

3, Catherpes BaIRd. One species.

- 4, Thryothorus Vieill. Three species.

5, Troglodytes Vieill. Three species.

6, Cistothorus Cabanis. Two species. 


\section{Cactus Wren.}

Campylorhynchus brunneicapillus Gray.

Plate IV. Fig. 2.

䨖 HE DRY south-western part of our country, from the lower Rio Grande to the Pacific, may justly be called the cactus region. This district is very arid and desolate as rain does not moisten the hard ground for many months. No luxurious and varied vegetation adds to the beauty of the landscape. Thorny mesquite shrubs, but chiefly many species of cactus, mostly armed with large spines and bunches of fine sharp bristles, agaves and yuccas, are abundant and give the landscape a very peculiar appearance. The opuntias with their thick thorny leaves attain here the height of small trees, while the hedgehog cacti ${ }^{1}$, usually provided with an array of horrid spines, appear at a distance like large casks. They are surpassed in size by the yuccas and saguarros ${ }^{2}$ of Arizona, the latter of which grows to a height of forty to fifty feet. It is often impossible to penetrate the cactus thickets as the sharp spines even pierce thick leather and the smaller ones find their way by the hundred into the skin, whence they are only to be removed with great difficulty. This region is, however, not destitute of bird-life: on the contrary, for many species it seems to be a real El Dorado. Of the great number of peculiar birds inhabiting the cactus region the CACTUS WREN is especially abundant. All its traits are thorotighly Wren-like. It is a sprightly bird, always in motion, now skulking in the shelter of the impenetrable cactus patches, now mounting the tops of a cactus or bush to scold in a loud, harsh tone, or to utter its beautiful clear and ringing song. It shows the same self-assertion, petulance, inquisitiveness, and temerity as our well-known House Wren.

“The English name," says Dr. Elliott Coues, "which the 'Cactus' Wren has acquired indicates the nature of its customary resorts, and affords a hint of its 'peculiar nidification. As we have already seen, several of the Arizona birds are architects of singular skill and taste; the Cactus Wren is one of them. In the most arid and desolate regions of the South-west, where the cacti flourish with wonderful luxuriance, covering the impoverished tracts of volcanic débris with a kind of vegetation only less surly and forbidding than the very scoria, this Wren makes its home, and places its nests, on every hand, in the thorny embrace of the repulsive vegetation. True to the instincts and traditions of the Wren family, it builds a bulky and conspicuous domicile; and when many are breeding together, the structure becomes as noticeable as the nests which a colony of Marsh Wrens build in the heart of the swaying reeds. But it is not a globular mass of material, nor yet a cup; it is like a purse or pouch, and also peculiar in its position; for such nests are usually pensile. In the present case, the nest resembles a flattened flask-more exactly, it is like the nursing-bottle, with which all mothers (and I suspect some fathers) are familiar, and this is laid horizontally; on its flat side, in the crotch of a cactus. It is constructed of grasses and small twigs woven

1 Echinocactus Orcutti, E. Wislizenii, E. Whipplei, E. Visnaga, etc. 2 Cereus giganteus. 
or matted together, and lined with feathers. Including the covered way or neck of the bottle leading to the nest proper, the structure is some ten or twelve inches long, and rather more than half as much in breadth."

Mr. Geo. B. Sennett found the Cactus. Wren a common bird of the lower Rio Grande Valley. "On my former trip," he says, "I did not find a single one of this species between the mouth of the river and Hidalgo. On this trip, about seven miles above Hidalgo, where the foot-hills begin, I found it not uncommon in certain localities. The limit of this bird's habitat in the United States is, on the east, very strictly defined. At a point from the Gulf about one hundred miles by road or three hundred by river occurs its eastern limit. Here I came upon a ridge densely covered with cactuses of large size and a few scattering trees, where I found this bird in such numbers that at times a dozen could be seen at once; and in an hour or two three of us examined as many as fifty nests in different stages of completion, from those just begun to those containing young ready to fly. The nest is large and usually confined to the pricklypear cactus, so that it is easily found... It is eminently a bird of the cactus, still not altogether confined to it for nesting purposes. I have discovered its nests in junco, ebony, and mesquite trees. On May 21, I found two new but empty nests, some ten feet from the ground, one on each side of an ebony standing alone, and on the same day a fine nest. in the lower part of a large mistletoe, at least sixteen feet from the ground, in a mesquite tree. Several times I examined nests in the junco, which is oftener seen in bush-form than in proportions entitling it to the name of a tree. It consists of a mass of green thorns, without leaves, and so full of pitch that it readily burns when green and full of sap. The nests in cacti were never found lower than three feet from the ground, and usually four or more... . One nest contained five eggs, the others four or less. The eggs are unmistakable in color and shape. They appear rich buff without a magnifying-glass, so fine and closely laid are the spots upon the white ground. They are quite slender, and more pointed at one end than the other. In size they average $.94 \times .65$; the largest one is $1.00 \times .66$, and the smallest $.88 \times .63$."

All observers agree in the statement that the Cactus Wren is a fine songster. Its notes are loud, sometimes rather harsh, clear, and ringing.

The bird ranges from the lower Rio Grande Valley to the Pacific, and is common all along our southern border, but seems not to go far into our territory; south it ranges into northern Mexico.

The St. Lucas Cactus Wren, Campylorhynchus affinis Xantus, is confined to the southern portion of Lower California.

NAMES: Cactus Wręn, California Cactus Wren, Brown-headed Creeper Wren, - Cactuszaunkönig (German). SCIENTIFIC NAMES: Picolaptes brunneicapillus LAFr. (1835). CAMPYLORHYNCHUS BRUNNEICAPILLIJS GRAY (1847).

DESCRIPTION : Above, grayish-brown, darkest on head which is unspotted. On back every feather strcaked centrally with white. Beneath, whitish, with a rusty tinge on the belly. Throat, fore-part of breast, and under tail-coverts marked with numerous large rounded black spots. Chin and line over the eye, white. Iris yellowish.

Length, 8 inches; wing, 3.40 ; tail, 3.55. 


\section{ROCK WREN.}

Salpinctes obsoletus CABAnis.

周HE ROCKY MOUNTAINS surpass in grandeur the Sierra Nevada and the Alleghanies, but they are often destitute of the beautifully romantic and delightful scenery of the former. The Sierras are covered with the most stately evergreens bearing needle-like foliage, and the Alleghanies are adorned with a luxurious growth of various deciduous and evergreen trees and shrubs, but mainly with the broad-leaved rhododendrons and kalmias or mountain laurels. In the southern Alleghanies especially the mountain sides are aglow with the flowers of Azalea calendulacea in June, and the odor of the pink Azalea nudiflora-both plants are usually called "mountain honeysuckles" by the people of that region-is sometimes overpowering. The Rocky Mountains are in many parts barren and desolate, and, to some extent, waterless. In such places our eyes behold no shrub: only a few species of grass and cacti representing the vegetable kingdom. We can hardly imagine why living beings should make the ravines and cracks in the rocks their abode. Suddenly a sweet melodious song strikes our ear, unexpectedly changing our melancholy into good humor. We endeavor to spy the songster among the lonely rocks and behold at a distance, perched on a boulder, a little bird, the Rock WREN. In Wren-like fashion, with elevated beak and tail it carols forth its loud and exceedingly melodious wild mountain song, and then disappears with mouse-like rapidity among the rocks. Very few birds are found in such arid localities. The majority of the feathered songsters are found near water fringed with shrubs and trees. But the Rock Wren prefers a wider range. We find it in great abundance in all localities, where a luxurious growth of trees and shrubs abound-and such places are also found in the Rocky Mountains. It ranges north to the $49^{\circ}$ and south into Mexico, and from the foot-hills of the mountains to the Pacific, always preferring mountainous districts for its home. According to Mr. Trippe it appears at Idaho Springs, Colorado, about May 20, and extends its range up to, and a little above, the timber-line. "It breeds most abundantly between 6,500 and 9,500 feet, rarely nesting higher than the latter elevation, though found during summer from 12,000 feet down to the plains. It is a constant resident of the piles of loose rock which lie scattered on the mountain sides, in which it finds its food and rears its young, and to which it retreats for safety on being alarmed. On its first arrival it is rather shy, but soon becomes tame and even familiar, haunting piles of boulders and small stones in the placer diggings, close to the miners' cabins. It rarely ventures far from its favorite rocky retreats; but occasionally visits the road sides to pick up flies and other insects, and sometimes hops over the roofs of cabins and mills, and not infrequently chooses the ridge of a convenient place from which to serenade its note. It has a curious, rapidly repeated note, that sounds like the whirring of wings; its song is very beautiful, louder and sweeter than that of the House Wren, though not so varied. While singing, the bird usually perches on the top of a heap of stones, and stands erect, with head thrown up, like the Carolina Wren. At such times it is quite timid and, if alarmed, instantly ceases the song and looks anxiously around, 
bobbing itself up and down every little while, like the Dipper, and presently creeps down into the stone-heap. Late in autumn its feathers become much worn from constant creeping among the rocks. In September it disappears."

Dr. Merriam found this Wren in Utah and Mr. Lloyd reports it a common winter resident in western Texas from Oct. 7 to May 1. Mr. R. Ridgway found it universally distributed from the summit of the Sierra Nevada eastward, as far as the party explored. In the middle provinces of the Rocky Mountains it was the most abundant species of the family; in the Wahsatch Mountains it was not so common. At Carson City he found it in the rubbish of the decaying pine-logs. Dr. Elliott Coues observed the Rock Wren throughout the Colorado Basin, where its' "vivacious behavior and loud notes render it conspicuous among the other smaller plainly clad species. It is found in most situations, whether wooded or open, but evidently prefers rocky places, full of chinks and crannies, where it creeps furtively about like a mouse, only with greater agility, or skips and flutters from stone to stone. The greater portion of its habitat being still unsettled, the bird thus frequenting wild and desolate places has acquired a reputation for shyness and love of seclusion; but there is every reason to suppose that in the course of time, should the country ever grow populous, it will become as familiar as the House Wren. In the West, Parkman's Wren, which is nothing but a variety of the sociable little $T$. aëdon, continues to be quite as retiring and solitary a bird as the Rock Wren. In the case of the latter, we already have the premonitory signs of the semidomestication of which the bird is susceptible; it often comes about the miner's or squatter's cabin, even building its nest in the chinks of the logs; and with equal readiness haunts the shrubbery of gardens in many of the western towns.. It would make a very disirable addition to our 'household birds.'"

Like the nests of all our species of this family, the Rock Wren's is also composed of very miscellaneous materials. It uses such substances as happen to be readily available. Sticks, weed-stems, grass, moss, bark-strips, hair, wool, feathers, etc., enter into the composition. The sites selected are quite as various; usually the nest is built in crannies of rocks, but it has also been found on the ground beneath rocks, in the natural cavity of a clay bank, etc. According to the observations of Mr. W. E. D. Scott, it raises two broods annually, at least in its southern habitat. Six to eight eggs or young were usually found in one nest. - The eggs, from four to eight or even nine in number, are "noticeable for their rotundity, and the crystalline purity and smoothness of the shell. The white ground is rather sparingly sprinkled with distinct reddish-brown dots, usually massed at the large end or wreathed around it." (Coues.) They measure from .72 to .77 inches in length by .66 to .66 in breadth.

NAMES: Rock WreN, Rocky Mountain Wren.-Felsenzaunkönig (German).

SCIENTIFIC NAMES: Troglodytes obsoletus Say (1823). Myiothera obsoleta Bonap. (1825). Thryothorus obsoletus Bonap. (1838). SALPINCTES OBSOLETUS CAB. (1847).

DESCRIPTION: Adult: Above, pale brownish-gray, minutely dotted everywhere with blackish and whitish points together, and usually showing obsolete wavy bars of dusky. Rump, sides of the body, and posterior part of the belly and under tail-coverts cinnamon-brown. Rest of under parts dirty white; throat and breast obsoletely streaked, and the under tail-coverts barred, with dusky. Middle tailfeathers brownish, with many dark bars; the other with cinnamon tips, then with a broad black bar; the outer one alternately barred with brownish and black.

Length, 5.50 to 6 inches; wing, 2.82 ; tail, 2.40 inches. 



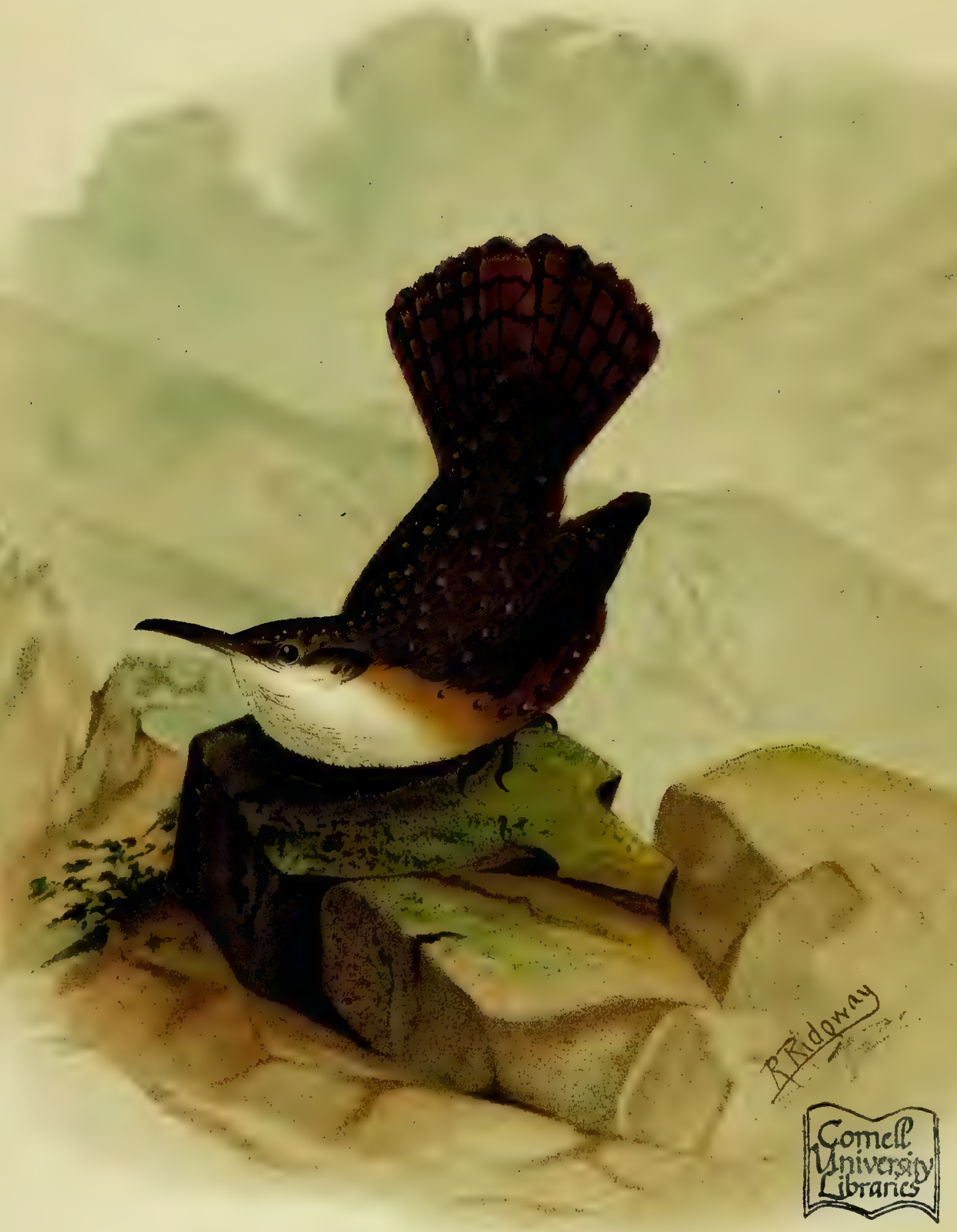

CATIIERPES MLXICANUS CONSPERSUS RideW.

FELSENZAUNKÖNIG.

Cañón Wren. 


\section{CAÑON WREN.}

\section{Catherpes mexicanus conspersus RIDGWAy.}

Plate IX.

7ิ HE AUTHOR of this work esteems himself especially happy in having obtained the assistance of Prof. Robert Ridgway, of the Smithsonian Institution, who is equally prominent as a scientific ornithologist and an artist. He accomplished the task of bringing a number of our birds before the readers eyes perfectly true to nature, both in form and colors, and all his pictures showing, moreover, an ideal apprehensive perception. A most excellent representation is the one of our CAÑon WrEN, which he had sufficient opportunity to observe in the Sierra Nevada and the Rocky Mountains.

As I never had an opportunity of observing our western birds, I beg leave, in the interest of my readers, to quote from a classical sketch of Dr. Elliott Coues. He writes as follows: "The fact that I had never seen it at Fort Whipple, Arizona, supported this notion of its limited distribution, and in my 'Prodome' of $1886 \mathrm{I}$ gave the bird as one generally distributed over the southern and western portions of Arizona, up to Fort Mojave at least. I now see that its absence from that locality-at any rate, its rarity, so great that it never came under my observation-was due to the typographical features of the place, not its geographical position. There were plenty of rocks about the fort (rocks, like reptiles and cactuses, are natural products of Arizona), just suiting the wants of Salpinctes; but this immediate vicinity lacked the singular walled chasms with which many portions of the Territory are scored and seamedthose reproductions on a smaller scale of the Grand Cañon of the Colorado itself, most wonderful crack of the ground in America-and such rifts of solid rock alone are entirely to the liking of the Cañon Wren. So it fell out that it was left for the latest ornithologists of the South-west - for Allen, Aiken, Ridgway, and Henshaw - to show that the range of the bird extends from Arizona and New Mexico, and portions of Texas and southern California, into Colorado, Utah, and Nevada. How much further it may actually reach we do not know; but there is nothing in the analogies of the case to forbid the supposition that the Cañon Wren may push northward wherever its favorite resorts can be found. For it is by no means the tender, semi-tropical bird we may have somewhat unconsciously supposed; it is resident in all the Territories just named; it winters in Colorado, Utah, and Nevada; and if it is ever subjected to the migratory impulses which most of the Wrens feel at times, there is nothing but the lack of suitable haunts to restrain its movements.

"We remember the 'rift within the lute;' in the Cañon Wren we have the lute within the rift-a curious little animated music-box, utterly insignificant in size and appearance, yet fit to make the welkin ring with glee. This bird-note is one of the most characteristic sounds in nature; nothing matches it exactly; and its power to impress the hearer increases when, as usually happens, the volume of the sound is strenghtened by reverberation through the deep and sinuous cañon, echoed from side to 
side of the massive perpendicular walls till it gradually dies away in the distance. No technical description would be likely to express the character of these notes, nor explain the indelible impression they make upon one who hears them for the first time amid the wild and desolate scenes to which they are a fit accompaniment. The song is perfectly simple; it is merely a succession of single whistling notes, each separate and distinct, beginning as-high in the scale as the bird can reach, and regularly descending the gamut as long as the bird's breath holds out, or until it reaches the lowest note the bird is capable of striking. These notes are loud, clear, and of a peculiarly resonant quality; they are uttered with startling emphasis, and I sometimes fancied I detected a shade of derision, as if, secure in its own rocky fastnesses, the bird were disposed to mock the discomforts and anxieties of a journey through hostile deserts."

According to Mr. Ridgway, the song is soft, rich, and silvery, resembling somewhat the whistling of the Cardinal Grosbeak. - In its general habits its behavior is always Wren-like. With wonderful agility it threads the mazes of the rocks, and in a sly and furtive way it delights to baffle observation and to re-appear unexpectedly in another place, to laugh heartily at the perplexity it has occasioned. Although an inhabitant of the wild rocky mountain cañons, it sometimes displays familiar traits, "coming in friendly spirit about man's abode, to nest in crevices of walls and buildings, or even occupy boxes put up for its accommodation, like Martin, Bluebird, or House Wren." At Dr. Heermann's rancho on the Medina, in western Texas, this bird, as well as the Carolina and Bewick's Wren, nested in cigar boxes put up for its convenience.

June 8,1880, Mr. H. D. Minot found a nest of this Wren at Manitou, Colorado. It was in the roof of a cave, about ten feet from the ground, in a niche or pocket, with an opening so narrow, vertically, that he could neither look in, nor introduce his hand. Fortunately, however, the rock was so soft that he easily removed the bottom slab on which the nest rested. This, on looking down upon it, suggested the eastern Wood Pewee's. It was composed of twigs, stalks, and bits of leaves, surrónded by a few loose sticks, and thickly felted with down, silk, and a few feathers. The eggs, five in number, measured $.70 \times .50$ of an inch, and were crystal-white (rosy, when fresh), sparsely speckled and spotted, chiefly about the crown, with medium dull brown.

The true species, known as the White-throated Wren, Catherpes mexicanus BAIRD, is found in Mexico, and according to Giraud, also in Texas.

NAMES: CAÑ̃N WREN, White-throated Wren, White-throated Rock Wren. - Weisskehliger Zaunkönig. (Germ.)

SCIENTIFIC NAMES: Troglodytes mexicanus "Heerm. (1852).-Catherpes mexicanus Brd. (1858).CATHERPES MEXICANUS CONSPERSUS RIDGWAY (1873).

DESCRIPTION: Upper parts, brownish, everywhere dotted with small dusky and whitish spots. Tail, brownish or cinnamon-brown, crossed with usually five narrow, mostly zigzag-like bars. Chin, throat, and fore-breast, with the lower half of the side of the head and neck, white, shading behind into deep ferrugineous. Sexes alike.

Length, 5.02 inches; wing, 2.32 ; tail, 2.14 inches. 


\title{
CAROLINA WREN.
}

\author{
Thryothorus ludovicianus BonaP.
}

Plate XXVI. Fig. 6.

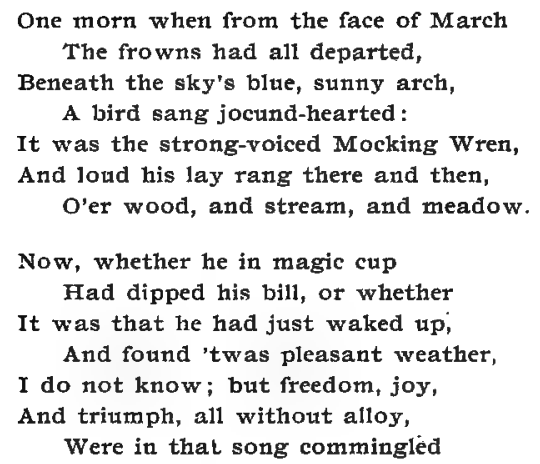

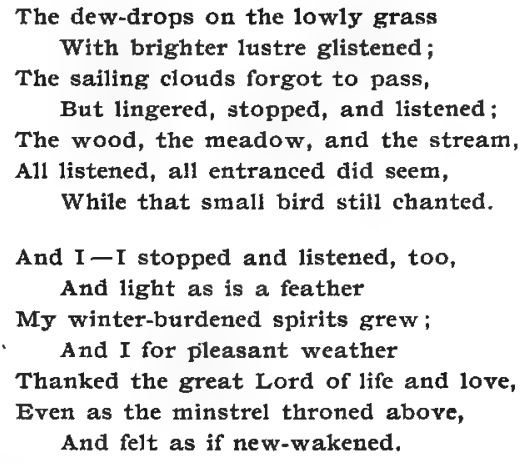
And felt as if new-wakened.

\footnotetext{
Would I might from some magic cup, Some fount of inspiration, Quaff deep, or wake more truly up To this most fair creation; To beauty, duty, love, and good; Then would I sing in loftier mood, And all the world would listen!
}

W. L. SHOEMAKER.

ERHAPS no portion of our country can boast of so luxuriant a growth of charm[O- ingly beautiful plants as the mountain region of South Carolina and adjacent states. At the same time, the gardens of this region, especially near the coast, far surpass those of other parts of the United States in beauty and variety. The flora of the southern Alleghanies is very rich. The most beautiful plants of our country seem to congregate there. Of late years, the railroads have penetrated the seemingly boundless fastnesses of luxuriant vegetation, their lines of steel winding through deep gorges and over wide chasms, unveiling to the entranced gaze of the beholder the most wonderful riches of floral beauty- and variety. The hills are clothed in green, to their very summits, and bewildering forms of beauty appear on every side. Ferns, too, grow here in unlimited profusion, and vines climb to the tops of the tallest trees. The greatest floral treasures of these marvelous mountain landscapes are the ericaceous plants. Foremost among these are the azaleas or the "mountain honeysuckles," which are massed together in dense profusion and luxuriance. The flame-colored azalea ${ }^{1}$ is a magnificent shrub, covered in May and June with thick, heavy clusters of yellowish, fiery-red, or orange-colored blossoms. Imagine whole mountain-sides crowned with dense masses of this and other varieties, from two to eight feet in height, as far as the eye can reach, mingled with spruces, rhododendrons, mountain laurels, ferns, and other plants of enchanting beauty! The pinxter flower ${ }^{2}$ and the swamp honeysuckle ${ }^{3}$ with

\footnotetext{
I Azalea calendulacea. 2 Azalea nudifora. 3 Azalea viscosa.
} 
its clusters of clammy, deliciously fragrant flowers, white or deep rose-colored, grow side by side with the flame-colored species. Higher up in the mountains we find the tree azalea ${ }^{1}$, attaining a height of fifteen to twenty feet. The fragrant flowers are white, with a rusty tinge. Among these, but more luxuriant in the shady ravines and on the borders of the mountain streams, we find the broad-leaved evergreen thododendrons. No description can convey an idea of the clear, cool streams, rushing down to the Atlantic or the Gulf, fringed with fragrant clethras"2, different species of andromedas, rhododendrons, and kalmias. The gorgeous rhododendrons, particularly, appear in such a revel of luxuriance in the mild, moist atmosphere and in the fruitful soil of this region that such famous botanists as Bartram and Michaux speak in the highest terms of the same. The swamps, the shady mountain-sides, and the deep ravines are covered, likewise, with impenetrable thickets or jungles. The plants attain unusual size, the boughs bending to the ground and rooting by natural layers, producing the nearest approach our flora makes to a tropical jungle. The purple mountain bay $^{3}$, the rose bay ${ }^{4}$, and the smaller growing laurel ${ }^{5}$, all find here a congenial home, forming thick masses of solid green. The recently discovered deciduous Rhododendron Vaseyi, a plant of great beauty, the rare sorrel-tree ${ }^{6}$, and the mountain laurel or Kalmia latifolia, a plant of resplendent beauty, mingle in charming confusion with sweet calycanthus, whose chocolate-colored flowers fill the air, nay, the "senses to repletion with a delicious languor," as Mrs. J. S. R. Thompson, who writes so beautifully of the flowers of her native Southland, remarks. The white or silver fringe ${ }^{7}$, sometimes called by the people of the mountain regions "old man's beard," has pure white, long, pendant, fringe-like flowers, often forming clusters six to twelve inches long. The snow-drop, or silver bell-tree, ${ }^{8}$ and the rare Stuartia pentagyna grow here with the same vigor as the sassafras, the flowering dogwood and the bead-bush or mountain holly.

Among the gorgeous azaleas and rhododendrons, we find the only place in America where the lily of the valley is indigenous. Our country's most famous flower, the trailing arbutus, flourishes here, side by side with wintergreen ${ }^{9}$, wake-robins, or trilliums, Parnassia asarifolia, the beautiful and rare shortia, bellworts and terrestrial orchids. If we examine closely we find, in some shady nook, the interesting pipsissiwa ${ }^{10}$ and the still more attractive galax ${ }^{11}$, with its round, heart-shaped bright green leaves, being in fall and winter often variegated and mottled with bright crimson. -

Farther down, among the foot-hills and in the lower districts, in rich soil, our attention is attracted by different species of deciduous magnolias, such as the cucumber ${ }^{12}$ and the umbrella tree ${ }^{13}$ Here we may also look for the beautiful American holly ${ }^{14}$ and the Cocculus carolinianus, which climbs over bushes and small trees, often for a distance of twenty to thirty feet festooning them with indescribable grace. In winter, when the innumerable vermillion-colored berries gleam out among the dark-green spiny leaves of the holly, the pale pink, deep glowing scarlet, or, later in winter, the transparent berries of the cocculus are most attractive. Another, still more charming, climber is the Carolina jasmine ${ }^{15}$ As soon as the genial February sun begins to warm mother earth, it

1 Azalea arborescens. 2 Clethra acuminata, etc. 3 Rhododendron Catawbiense. 1 Rh. maxinum. E Rh. punctatum. 6 Oxydendrum arboreum. 7 Chiononthus Virginica. 8 Halesia tetraptera. $\bullet$ Gaultheria procumbens. 10 Chinaphila maculata. 11 Galax aphylla, 12 Magnolia acuminata, 13 M. umbrella. 11 Ilex Opaca. 15 Gelsemium semperviretis, 
developes its graceful branches of golden, trumpet-like, deliciously fragrant flowers. Often, we may cull clusters ten to twelve inches long. Another interesting small tree or shrub of this region is the white bay, or Magnolia glauca, with its cup-shaped, exceedingly fragrant flowers.

We must not turn to our original subject, without having visited the gardens of the coast region. The friend of nature is overwhelmed with the beauty before him. The chief attractions are the strongly-scented tea and Noisette roses, the camellias and Indian azaleas. The gardens of Aiken and Charleston, S. C., Augusta, Ga., Tallehassee and Pensacola, Fla., are stocked with these beautiful flowering shrubs. Dr. Drayton's famous garden, on the Ashley, near Charleston, is an ideal plantation, a model of beauty not surpassed in the United States. The ground is shaded by huge magnolias and live oaks, whose roots find the best nourishment in the phosphate beds which underlie the whole region. In 1848 , Dr. Drayton planted the first camellias and azaleas of his remarkable collection. Of camellias there are some 300 varieties, and all are remarkably large, strong and floriferous. Many specimens are now trees over twentyfive feet high, with trunks thirty inches or more in circumference, and bearing, in March, thousands of flowers among the thick, leathery foliage. Of Indian azaleas there are about 150 kinds, with individual specimens from ten to fifteen feet high and fifteen to twenty feet in diameter. There are many other famous trees and shrubs in the garden. "But after all," says Prof. Sargent in "Garden and Forest," (Vol. II, p. 129. 1889), "to northern eyes, the camellias and azaleas are the glory of the garden in early spring. From this part of the coast region all, who can, escape in summer to the highlands of the interior. Dr. Drayton leaves for his summer home in North Carolina as early as the first of May, but the azaleas are in bloom a month before, and the wealth of glowing color along the avenues and on the borders of the lawn, where these shrubs are massed, can hardly be imagined, while the Cherokee roses are flinging out their white banners from the very tops of the forest trees on the lake shore and covering them all over with flowers, and the magnolias fill the air with fragrance.

"While the azaleas are in flower there seems no room for anything else, but a month or six weeks earlier the camellias appear to fill the garden. Last year they were at their best a fortnight before the great snowstorm fell upon New York, and certainly they can never be more beautiful than they are to-day (March 2), and have been for a week past. Numbers and measurements give no idea of the dazzling abundance of flowers among the bright green leaves and the long lines of camellias that stretch away in every direction, flowers single and double, and showing every tint from snowy-white to almost crimson. Glimpses of the shining river are caught through vistas of flowers, and under the moss-draped branches of oaks. The bright colors are all heightened by the dark masses of magnolia that rise behind them. And all this just at the close of February. No wonder the place is so attractive to visitors from the cold North, and no wonder so many of them feel a debt of gratitude to Dr. Drayton for throwing open all this beauty to be enjoyed by strangers."

This region of tea roses, magnolias, camellias, and Indian azaleas abounds in interesting birds. Even in January, the observer may hear from the thickets of evergreen camellias and azaleas the loud and cheering song of the beautiful red Cardinal. 
When the air is filled with the strong fragrance of flowering banana shrubs (Magnolia fuscata), and the great magnolias and innumerable tea roses, the Mockingbirds' enchanting song sounds from far and near, lending poetry to these charming gardens and landscapes. But the most poetic bird of this region seems to be the Carolina or Mocking WREN, whose sweet, silvery, ringing notes sound from almost every thicket in garden and woodland from the coast region to the mountains. Mr. William Brewster found it in the mountains of North Carolina up to an altitude of 4000 feet. But it is not confined to the Carolinas and other South Atlantic States. I found it a common bird in southern Louisiana and in Texas. North, it ranges to the Indian Territory and Arkansas, Virginia, Pennsylvania, and New Jersey, being, however, in its northernmost habitat, a rare bird. It prefers to settle in bushy places, particularly on the edges of woods bordered by shrubbery; in the tangled undergrowth near water courses, in palmetto-thickets, in the groups of yuccas (Yucca gloriosa) which grow in such luxuriance near the coast, and in gardens planted with climbing roses, ornamental shrubs and vines. Although not a shy bird, it is very cautious, not trusting man too much. Where it feels itself safe, it is very pert and sings its ringing song often in close proximity to a human dwelling. Its favorite nesting-places are thickets of different shrubs, such as calycanthus, white fringe, dogwood and viburnum, hollies, and others, overgrown with cocculus, smilax, or Carolina jasmine. Higher up in the foothills and mountains, it seems to prefer the tangled growth of rhododendrons and mountain laurels. In this underwood is moves about with wonderful adroitness. At one moment it may be seen perching in a high bush merrily caroling. If approached it suddenly dives into the shrubbery and disappears. The next moment, however, its song is heard from another point. The birds usually hop about rapidly with upraised tails, which they often jerk in an energetic manner. They do not like to be watched, and it is often very difficult to find them. They are in sight one moment and disappear the next, passing in at one place and out at another with exceeding rapidity. Upon the approach of man they suddenly hide themselves in the thick undergrowth, cautiously peering out from among the leaves. It is only when they feel themselves perfectly safe, that their habits and manners can be fully noticed. In bushy localities, they are very common, but will not venture into open view, preferring to live in the tangled vegetation on or near the ground. When the male is singing, it sits on the top of a bush or post in full view, instantly, however, plunging down into the thicket upon the slightest movement indicative of danger. When disturbed, it utters a smacking, querulous cry, which is heard as long as the supposed enemy remains near.

The food of this Wren, as of all others of the family, consists almost entirely of a great variety of insects, which it usually captures on the ground and in the bushes, from leaves and blossoms. Small caterpillars, worms, borers, insects' eggs and larvæ lurking in the crevices of the bark, seem to form its principal diet.

The Carolina Wren is a hole-breeder, always preferring for its nesting-site natural cavities, Woodpeckers' holes, and nesting boxes. In the backwoods of Lee County, Texas, where I once took up my abode for several years, it usually built its nest in boxes which I had, put up for it in the trees near my dwelling. Although not so confiding or so common as 'the Bewick's Wren, or the Tufted and Black-crested Titmice, 
it usually raised two broods in one of the nesting boxes. It also nested in barns, stables, and outhouses, but more commonly in natural cavities and Woodpeckers' holes of the rich bottom woods. Also in dense bushes and thickets I occasionally found the nest. This is usually a very bulky structure, consisting of coarse plant-stems, grasses, bark-strips, and mosses, the interior being lined with feathers, hair, and fine grasses and rootlets. The nest is arched over, with the entrance on one side. The eggs, from four to seven in number, are white or pinkish-white, thickly speckled with reddishbrown, measuring $.75 \times .58$ inches. Although a true woodland bird, the Carolina Wren will settle anywhere, if protected, and if the gardens contain thickets of ornamental shrubs and climbers and suitable nesting boxes. In Florida, where the gardens often show a luxuriant growth of pampas grass and bamboos, it often builds in the clumps of these dense plants. It also frequently nests in hedges of Cherokee and Macartney roses and climbing tea and Banksia roses.

Its song far surpasses that of any other Wren. The notes are so charmingly melodious, so powerful and voiced, so sweet and clear, so metallic, and yet so soft that we stop to listen, wherever they are uttered. The beautiful surroundings, as mentioned in the introduction, conspire to heighten the effect of this enchanting song. In the larger gardens, the song may be heard occasionally throughout the winter, particularly on those bright and balmy winter days, so common in the South Atlantic and Gulf region. When the first buds of the camellias or the "japonicas," as they are often called, unfold their waxy petals, the song may be heard from all sides, being at its best when the azaleas, magnolias, and tea roses bloom. As the bird is an untiring songster, it may be heard from early morn till the twilight of the evening. Even at night, when the Mockingbird and Cardinal vie with each other in pouring forth enchanting nocturnal songs, I have frequently listened to the notes of this bird. Sometimes it mimics other birds, though not nearly to the extent assumed by some writers. At times the lively notes of the Tufted Titmouse, the simple refrain of the Chewink and others intermingle, but they are so much altered as to be hardly recognized. Because of its power of mimicking, it is often called the Mocking Wren. Many times, and in many places, I have heard the song of the Carolina Wren in Texas, at Vermillionville and New Orleans, La., at Pensacola, and in the rich woods near the Chattahoochee, the Suwanee, the St. Johns, and in the dense hummock woods on the borders of Lake Apopka in Florida, but I have never heard it intermingle harsh notes like that of the Grackles or Jays. Nor have I ever heard two Carolina Wrens sing exactly alike, though the characteristic Wrenmelody is never wholly lost. An observer accustomed to the songs of birds, at once recognizes the lay of this Wren. As the notes are very loud, clear, and whistling, they can be heard at a great distance. When singing, the bird mounts the top of a bush or post, or perches on the roof of a building caroling with raised head and hanging tail its finest strains. The late Mr. C. W. Beckham says that at Bayou Sara, La., the Carolina Wren probably exceeds in numbers any other summer resident. It finds itself at home everywhere, nesting indifferently in the stable, under the piazza, or in an old stump down in the swamp. But wherever it may be, it makes no secret of its whereabouts, for hill and dale, and swamp and garden, all resound "from dawn to twilight with the full-toned, tireless songs of this orphean prodigy. I say songs, for the Carolina 
Wren is no one-tuned musical bore, but possesses much of the vocal versatility of his more favored rival the Mockingbird." The effect this beautiful melody has on a poetical and refined mind has been charmingly expressed by Dr. W. L. Shoemaker in his "Sweetheart Bird-song".

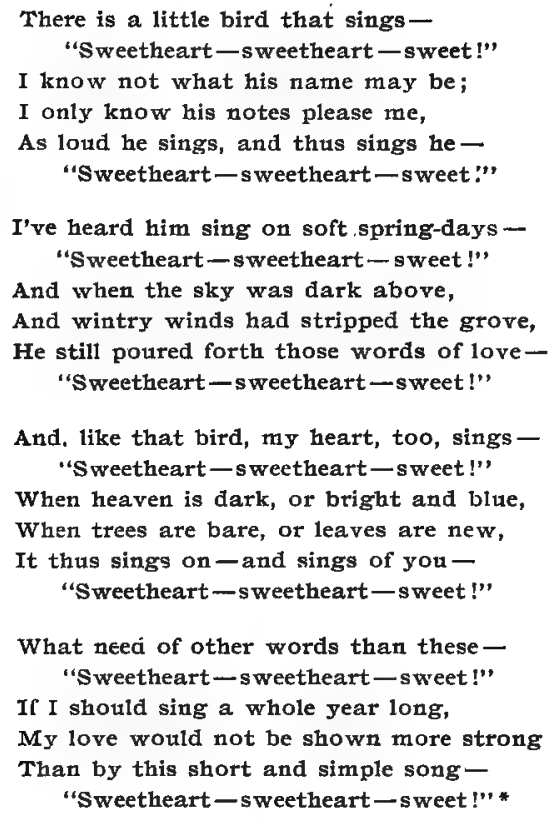

The Mocking Wren of South Florida, now known as the Florida Wren, Thryothorus ludovicianus miamensis RIDGWAY, is a variety of the species just described. If I am not mistaken, it was discovered by Mr. C. J. Maynard near Miami, Fla. "I know of no birds," says Mr. Maynard, "which are more variable in selecting places in which to build their nests. The usual situations chosen by the Wrens on Indian River, Fla., were at the bottoms of the 'boots' of the palmettos. The 'boot' is the base of the dead leaf-stalks which adhere to the tree after the top has decayed and fallen off, they are quite broad, slightly concave, and extend upward in an oblique direction, leaving a space between them and the trunk; the fronds in falling often cover the top with a fibrous débris which is impervious to water, and the cavities beneath form a snug nesting place for this variety of the Carolina Wren. Many more nests will be found in these situations than elsewhere, especially in the wilderness; but I once found one built between two palmetto leaves which had dropped over in such a position that their surfaces were horizontal and only three or four inches apart, forming a floor as well as a roof for the home of the Wrens. They had conveyed a large amount of suitable material into this place and formed a cozy domicile. The fronds were swayed by every passing breeze, yet in such a manner as not to injure the structure which was between them... They will also breed in holes of trees; one nest which came under my notice was placed in the fork of an orange tree, but a few rods from an inhabited

* When, many years ago, this song was written, I really did not know the name of the sweetly singing bird that suggested it Long afterwards, I was informed of it by my friend, Mr. E. J. Loomis, of the Nautical Almanac Office, Washington, D. C. He also pointed out to me the interesting remarks of Nuttall concerning the various songs of the Mocking Wren, and especially his "Sweetheart" song, the words of which $I$ have used as a refrain to mine. W. $L$. $\mathbf{S}$. 
dwelling; they will also take up an abode in buildings, and Capt. Durnmett assured me that two or three pairs inhabited his boat-house, which was placed over the water, every season. Mr. Henshaw called my attention to a deserted structure formed by this species which was placed in a niche of a wall in the old stone barracks at Miami. I have also known a nest in the interior of a barn, the birds having found entrance through a knot hole.

"This Wren begins to breed about the 1st of April and continues until June, rearing two or three broods. They are exceedingly sensitive about being disturbed at this season, and $I$ have frequently found nests that were being completed, but upon visiting them again, would invariably find that the birds had abandoned them. It will be seen by the examples given that these Wrens possess sufficient reason to avail themselves of surrounding circumstances when they wish to build, even turning the habitations of man to account. But what particularly distinguishes these birds from many others is their loud and cheery song; perched on some slightly elevated position they will pour forth such clear and thrilling lays that the most careless observer will pause to listen and admire their power. There are no birds which excel them in the frequency in which this melody is given; from early morning until late at night they may be heard singing. Seasons as well as time are utterly disregarded by them, for their harmonious strains are given with as much earnestness in December as during the breeding time. The remembrance of the melodies ever brings to my mind pleasant visions of dark green foliage and the rustling palm leaves which grow so luxuriantly in this land; for we were always greeted by these birds whenever we pitched our tents by the side of a hummock or thicket, and I think no one, who has heard them as often as I have, will hesitate to place this variety of the Great Carolina Wren among the finest songbirds of Florida."

NAMES: Carolina Wren, Great Carolina Wren, Mocking Wren, Louisiana Wren, Hammock or Hummock Wren, and Palmetto Wren (in Florida).-Carolina-Zaunkönig (German).-Troglodyte de la Lonisiane, Roitelet de la Louisiane (Buff.), Troglodyte de Roseaux (Vieill.).

SCIENTIFIC NAMES: Sylvia ludoviciana Lath. (1790). Troglodytes ludovicianus Licht. (1823), Aud., Nutt. THRYOTHORUS LUDOVICIANUS Bonap. (1838). Motacilla caroliniana Bart., Trav. Fla. (1791): Certhia caroliniana Wilson, A. O. II. (1800).

DESCRIPTION: Male and female alike. Above, reddish-brown, lightest on the rump. Exposed parts of wings and tail barred with brown, the outer edges of the tail-feathers and quills showing series of alternating whitish and dusky spots. A streak above the eye whitish, bordered with dark brown. Throat, whitish; rest of the under-parts, pale rusty, darkest on the under tail-coverts, which are conspicuously barred with black.

Length, 6.00 inches; wings, 2.60 ; tail, 2.45 inches. 


\title{
BEWICK'S WREN.
}

\author{
Thryothorus bewickii BAIRD.
}

(2)ing

UR FAMILIAR House Wren of the Northern and Eastern States is not found in the South during the breeding season. It is replaced by the everywhere common BEwick's WrEN, often called the SoutherN House WREN. In the beautiful sub-tropical gardens of Louisiana and Texas, this is one of the first birds to be met. So soon as the Carolina jasmine opens its yellow trumpet-shaped flowers, filling the air with sweet perfume, and the gorgeous amaryllis ${ }^{1}-$ which thrive in the open air throughout the year in this part of the country-have expanded their large, conspicuous, lily-like blossoms, the song of this confiding Wren is heard from almost every barn-yard and garden. In Houston, Texas, where in the ornamental plantations the Cape jasmine, pittosporum, Banksia rose, laurel, oleander, arbor vitae, Japanese spindle-tree ${ }^{2}$, myrtle, Indian hawthorn ${ }^{3}$, evergreen Japanese honeysuckle and other evergreen shrubs and climbers abound, this lively bird is a familiar denizen. If we add to the above named plants the Chinese wistarias, which here attain a gigantic size and climb the tallest trees, the cedars, the pomegranate bushes, crape-myrtles, and various native and Asiatic magnolias, the tea, Noisette and Bourbon roses, some slight idea is conveyed of the charming beauty of these gardens. It is no wonder that the silver-throated Bewick's Wren takes up its abode in such a region. It moves boldly about among the dense shrubs, in the outhouses, and in the piles of wood, but at the approach of danger disappears with indescribable rapidity. It assumes a bearing of familiarity more marked than that of almost any other bird with which I am acquainted, always preferring gardens and yards in close proximity to man, even in large towns, to the shrubbery of the borders of woods, where the Carolina Wren selects its home. It surpasses in familiarity even the northern House Wren. It is, however, not confined to the above described localities, but is found also in places where man has no appreciation of the beautiful, where he plants no flowers and no ornamental shrubbery, simply cultivating the soil to obtain pecuniary returns. In such places, this Wren is satisfied with stables and neglected barns, with log-houses and wood-sheds, with brush-heaps and wood-piles. Bewick's Wren was one of the first birds I observed in Texas. It soon attracts our attention by its boldness, curiosity, and lively manners. When, in the early autumn of 1882, I moved to the south-western part of Missouri, this Wren was again one of the first birds I met. - It may be approached within a few steps, when it merrily carols its lay from the top of a bush or a post. If we approach too near, it swiftly descends to the ground, disappearing in the bushes or among the rubbish; but immediately after, its song may be heard from some other direction. One not acquainted with the songster, eagerly stops to listen to the loud and melodious notes. These are liquid, sweet, finely modulated, and uttered usually as the bird is perched upon a post, or the roof of a building. It assumes the same attitude when singing as does the Carolina Wren.

1 Hippeastrum equestre, H. Johnsoni, etc, 2 Euonymus japonica. \& Rhaphiolepis indica, R. japonica. 
The song is not so full of voice or metal, nor so echoing as that of the latter bird, and it never intermingles other birds' notes in its brief chant. When I listened to the song the first time, it strangely reminded me of that of the Song Sparrow. The same impression was experienced by Mr. Robert Ridgway, who says, that it resembles "nearly, both in modulation and power, that of the Song Sparrow, though far superior to it." Bewick's Wren is not so ceaseless a songster as the Mocking Wren, singing only during the breeding season with more or less energy. Early in the morning, and again toward evening it sings most frequently and loudest.

Like the subject of the preceding sketch, this Wren is also an accomplished holebreeder, though not always selecting cavities as nesting-sites. Above all it loves the presence of man, and therefore frequents the log-cabin of the poor settler as much as the suburban villa of the rich merchant. It has become a perfect house bird-more so even than the northern House Wren. Wherever found it is a welcome visitor, especially in the southern ornamental gardens which it helps to beautify and to enliven by its exhilarating song and its confiding ways. In dense bushes of pittosporum, on the top of an arbor embowered with Japan honeysuckles and Banksia roses, in shade trees and on posts are often found convenient nesting boxes, which are almost always inhabited by these Wrens. In localities where farmers do not care for their best friends, the birds, they are very variable in selecting places in which to build their nests. If natural cavities and nesting boxes are not to be found, they build on beams in log-houses and stables, in smoke-houses and wood-sheds. I have found nests also in stove-pipes, which lay on the ground, in the pockets of an over-coat hanging on the veranda, in tool boxes, on flat boards over doors, and on cup-boards and book-cases, even in inhabited rooms.

If the nest is constructed in boxes or tree-holes, it consists of bark-strips, fine grasses, Spanish moss, feathers, bristles, and hair, all loosely put together; but, if it is built on a flat surface, it is not only a bulky structure but is exteriorly composed of rough materials, such as plant-stems, twigs, coarse grasses, leaves, small pieces of bark, etc., fastened together with mosses and spiders' webs. In such cases it is always arched over with the entrance hole on one side, being lined with feathers, pieces of fur, cotton, bristles, and the soft stems of a species of Gnaphalium. In unsettled districts, the birds usually nest in holes of stumps or in old Woodpeckers' holes.

The eggs, five to seven in number, show a rosy-white ground-color and are rather densely but regularly spotted with reddish-brown and dull slate-colored markings. They measure about $.67 \times .50$ of an inch.

Early in spring of 1883 a pair of these birds nested in the straw-roof of an old stable near my house in Lawrence County, Missouri. The seven eggs were hatched in thirteen days; and in about thirteen days more, the young left the nest. When I tried to examine the nest, the little ones hopped out in all directions, hiding themselves with mouse-like rapidity in the surrounding weeds. The parent birds always uttered harsh and angry notes when I came too near their domicile. If a cat, or a Blue Jay, or any unwelcome visitor approached the nest, they uttered their harsh notes and usually swooped in rapid flights around the intruder. In the South three broods are often raised yearly; in Missouri, I observed that they raised two broods annually. The food is exclusively insectivorous, the birds devouring innumerable destructive insects, thus 
becoming great benefactors to the gardener, horticulturist, and farmer. The greatest portion of their insect food is captured on or near the ground.

Like the Carolina Wren the subject of the present sketch is not strictly migratory. In the Southern States it is stationary; but in its northern habitat it migrates southward as soon as the first cold waves sweep over the country. Even in southwestern Texas, I observed that in most cases it moved farther south, not returning before the 1st of March. Probably all the summer residents migrated southward, while their places were taken by birds coming from the North. In southern Missouri I have never seen one of these birds between November 15 and March 15.

During the summer Bewick's Wren ranges from the Gulf of Mexico to southern Illinois, Indiana, Ohio, and Pennsylvania. Mr. Ridgway says that in southern Illinois as far north as latitude $38^{\circ} 20^{\prime} 20^{\prime \prime}$, this Wren is the most abundant of its family. Mr. William Brewster, in his excellent paper on the birds of Western North Carolina (The Auk. Vol. III, 1886, p. 176), states that the Carolina Wren inhabits the valleys of the mountains, and the Winter Wren the lonely forests of balsams from 5000 to 6000 feet, while Bewick's Wren makes the intermediate space its home. In Asheville it was breeding in such numbers that nearly every shed or other out-building harbored a pair. Dr. Gerhardt met with this species among the mountainous portions of northern Georgia. Near the Atlantic, and in Florida, it is evidently absent. Prof. W. W. Cooke says, in his valuable book, "Bird Migration in the Mississippi Valley" (Washington: Government Printing Office. 1888): "The distribution of this species over the Mississippi valley is very singular. Abundant in some places and rarely or never seen in contiguous territory, it seems to be governed by fancy in the choice of a dwelling place."

In western Kansas and Texas to Arizona, north to southern Utah and Colorado, south to the table lands of. Mexico, the true species is replaced by a variety known to the ornithologists as BaIRD's WREN, Thryothorus bewickii bairdii SALVIN \& GoDM.

Another variety, VIGor's WREN, T. bewickii spilurus BAIRD, inhabits the Pacific coast, north to British Columbia, south to Lower California and western Mexico. In color it is similiar to the species, but the bill is considerably larger. In California it inhabits, according to Dr. Cooper, the dense forests as well as the open groves. In Washington this variety and the Winter Wren are among the few birds that enliven the long rainy season with their songs which are constantly heard in the dullest weather as in the sunny spring. In those mild coast regions it seems to be resident throughout the year.

NAMES: BEWrck's WREN, Southern House Wren, Long-tailed House Wren, Song Wren. - Sänger-Schlüpfer (German).

SCIENTIFIC NAMES: Troglodytes bewickii Aud. (1831), Nutt. THRYOTHORUS BEWICKII BAIRD (1858). Telmatodytes bewickii Cab. (1850).

DESCRIPTION: Sexes alike. Above, uniform dark rufous-brown. Below, ashy-white. Quills, obsoletely waved with dusky; two middle tail-feathers, closely and regularly barred with ashy-brown and black, A whitish superciliary stripe.

Length, 5.50 inches; wings, 2.25 ; tail, 2.50 inches. 


\section{HOUSE WREN.}

Troglodytes aëdon VIEILLOT.

1)

HO OF MY readers is not acquainted with the House WREN, the active little bird, whose movements of mouse-like rapidity around door yards and gardens are so familiar? The Germans call it Zaunkönig (Hedge Kinglet), and the French know it by the similar name of Troglodyte or Roitelet (Kinglet). Its favorite resorts are fences, old block-houses and barns, brush and wood-piles, stables, and particularly the low shrubbery in gardens, etc. Fearlessly the bird hops and creeps about-every now and then stopping and elevating its body-appears on a post or on a wood-pile; overlooking its small domain, twitters its song with a powerful voice, and with an incredible celerity vanishes among the shrubs or fence rails or in an old building. The House Wren is one of our best known birds, prevailing, during the breeding season, in the North and frequenting as a winter sojourner the South.

It ranges from the Atlantic west to the Mississippi valley, being a common summer resident of the Northern and Eastern States and southern Canada. Authorities as to how far south it breeds seem to differ*, though there can be no doubt that it breeds abundantly in and near St. Louis. In the famous Botanical Gardens of that city (better known as Shaw's Garden), I have heard its song in June from all sides. Mr. Ridgway, on the contrary, has not found it in summer in southern Illinois, where Bewick's Wren takes its place. From the Mississippi valley west to the Pacific, it is replaced by Parkman's House Wren, a scarcely distinct variety. Not everywhere within their breeding range are the House Wrens equally abundant. In some parts we may find them in considerable numbers every year, while in others they are never seen. The local distribution is thus fortuitous.

These sprightly, vivacious tenants of the outbuildings and the shrubbery, wherever found, are true companions of man. Formerly the underwood and fallen logs, the cracks of rocks, the roots of prostrated trees, the tangled vines in woods and forests were their natural resorts. These localities they readily relinquished for the facilities offered in the society of man. As soon as the pioneer of civilization settles in the backwoods, this Wren is one of the first birds to seek his friendship. In Wisconsin, where in many places it is one of the boldest and most sociable and confiding birds, I have never found it in woods uninhabited by man.

Though very confiding in the surroundings of friendly people, it is, nevertheless, always very cautious. At a reasonable distance, it exhibits great courage, but when real danger threatens it becomes easily frightened, concealing itself with wonderful quickness in some secluded spot. Almost every country child knows this always happy pigmy, and every farmer who is in sympathy with the attractions of nature loves this sprightly little creature.-Restlessly it searches every nook, every corner for spiders and

* Prof. J. A. Allen, in his work on the "Mammals and Winter Birds of East Florida," says that this Wren is known to be an resident there throughout the year. 
other insects, entering even stables and outhouses for this purpose. Its movements and manners are so attractive, its song is so melodious and heartily trilled that it cannot fail to be an object of affection. It always keeps near the ground and flies only short distances, its movements being so rapid that one might mistake it for a mouse. It is like all other Wrens very inquisitive, all strange objects attract its attention. Cautiously it approaches, stretches its neck, raises its head, utters its harsh chattering notes so characteristic to the family, skips to one side and then to the other, hops around the object of its curiosity, and finally approaches it closely; or, in case the object should move, it rapidly darts into the bushes or some other hiding place. It is a cunning little bird, well enabled to distinguish between friend and foe. It readily distinguishes the people where it has taken up its abode from strangers, and if the former are friendly, it shows no timidity.

In winter $I$ have observed this Wren in great numbers in Texas. One can scarcely pass a thicket in the south-eastern part of that state without seeing one or more of these now very timid little birds. The more dense and tangled the thickets, the more welcome they are as hiding places. Often these thickets are overgrown with a thorny species of smilax, or with Cherokee roses, thus presenting formidable barriers against the invasion of man or larger animals. I rarely succeeded in driving the Wrens away from a certain thicket, for if they skipped out on one side they entered again on another. So confident, bold, and noisy is this bird in its breeding habitat, and so timid and quiet in its winter quarters, that one might regard it at different times as a different species. It is usually seen in pairs or single specimens during winter. It winters in great numbers in Texas and other Gulf States and also in the South Atlantic region.

As early as the beginning of March it leaves south-eastern Texas. The tardiness of its movements may be judged from its late arrival in the North. In northern Illinois and central Wisconsin I have never noticed it before the last days in April or the beginning of May.

Our Wren does not feel at home until it arrives at its summer quarters. As soon as these are reached, it exhibits its old boldness, activity, and confidence. It announces its return by jubilant songs, and furiously attacks the House Sparrows which may have claimed its old nesting box. Frequently we hear two or more male.Wrens from different directions trying to rival each other in song. They produce their notes so powerfully and in such a charming way that the attention of even indifferent listeners is attracted. Although the song is far less beautiful than that of Bewick's Wren, it is, nevertheless, very sprightly, consisting of a few loud notes, followed by an exceedingly melodious trill. From the time of its arrival until the hot days of August, it sings, with few interruptions, very diligently. To sing, it mounts some high object, ustually a pole or fence-post, and carols from that vantage point its mirthful notes with extreme vivacity; then it darts down again into the shrubbery. Besides its song, we hear frequently its harsh chattering notes, particularly when a cat, a Blue Jay, or some other enemy appears in its nesting grounds.

In the Northern States nest building begins in the latter part of May. As a hole-breeder, it always chooses, for a nesting-site, some cavity. It prefers nesting boxes put up for its accommodation on the walls of buildings, on trees and posts. By means 
of such boxes it is readily induced to take up its abode in gardens and door yards, not only in the country but even in towns and larger cities. Frequently a pair of Wrens engage in regular combat with Bluebirds and Martins, in which the latter are often defeated by the vigilance and courage of the former. Its worst enemy is the European Sparrow, which not only expels the famous Bluebirds but which usually intrudes in flocks on the House Wren's domicile and drives the Wren away. If nesting boxes be not.furnished, it is satisfied with any crevice or hole in a wall, with eaves of stables and barns, with window-sills and knot-holes in trees. It even breeds under the roofs of piazzas and on beams of unfinished rooms in the upper stories of dwellings. Sometimes it nests in empty jars, in discarded stove-pipes, in pockets and sleeves of old garments hanging in outbuildings, and in old hats. An enthusiastic lover of the beautiful in nature, Miss Hedwig Schlichting, informs me that a pair of House Wrens nested in an old wooden shoe which was kept as a curiosity in an arbor of her garden and in which the gardener used to put his strings and cordage for fastening up flowers. These strings the birds utilized in forming the foundation of their nest, regarding them as providentially provided for their special benefit. If the nest is built in a large cavity the birds carry in such a mass of various materials that the whole space is soon filled. Sticks, plant-stalks, coarse grasses, bark-strips, etc., form the exterior barricade, leaving only a small entrance. The interior of this mass of material holds the nest proper, composed of fine bark-strips, rootlets, and grasses lined with feathers, cotton-like substances, pieces of fur, bristles, etc. In small cavities soft materials enter almost exclusively into the composition of the structure. The eggs, of which there are often two sets in a season, are from six to nine in number; they are of a pinkish-white groundcolor, very closely sprinkled all over with reddish or rusty brown dots. They measure about $.65 \times .55$ and are in form nearly spherical or oblong-oval.

The food consists invariably of insects, especially of small caterpillars, plant-lice, and the like, which render the birds great benefactors to the farmer and gardener. The young require an immense amount of food daily. After they have left the nest they keep together for some time, "moving about, an interesting, sociable, and active group" under the charge of their parents.

The Wood Wren which the famous Audubon described and figured as a distinct species, our scientific ornithologists of to-day regard as only somewhat darker colored specimens of the House Wren, hardly sufficiently distinct to be treated even as a variety.

Parkman's Wren, also known as the Western House Wren, Troglodytes aëdon parkmani Coves, represents the common species in western North America, from Texas, the Mississippi valley, and Manitoba westward to the Pacific; north it is found in the region of the Great Slave Lake, south to Jalapa, Mexico, and in Lower California. It is merely a pale variety of the House Wren, "while certain supposed peculiarities of habit are shared by $T$. aëdon in those unfrequented districts where its ways have not been modified by contact with civilization. In its nidification it agrees so closely with its eastern congener that one account would do for both. We have only to remember that it does not yet generally avail itself of the artificial accommodations that its relative usually selects, for the simple reason that there are comparatively few 
such resorts to be found where it lives. Nevertheless, it shows the same readiness to do so whenever opportunity offers, and is rapidly growing semi-domesticated in settled parts of the West. The nests of both birds are remarkable for the endless variety of the materials of which they are composed, the dimensions which they sometimes attain, and the diversity of the sites selected for them. The birds seem to be afflicted with an insanabile construendi cacoëthes (to borrow a simile from Juvenal), which impels them to keep on building after they have built enough for any practicable purpose. Their notion seems to be, that whatever place they select, be it large or small, must be completely filled with a lot of rubbish before they can feel comfortable about it. When they nest in a knot-hole, or any cavity of inconsiderable dimensions, the structure is a mass of sticks and other thrash of reasonable bulk; but the case is otherwise when they get behind a loose weather-board, for instance where there is room enough for a dozen nests; then they never know when to stop. I witnessed a curious illustration of their 'insane' propensities in one case where a pair found their way through a knot-hole into one of those small sheds which stand in the back-yard, with a well-worn path leading to the house, showing its daily use. Having entered through a nice little hole, into a dark place, the birds evidently supposed it was allright inside, and began to build in a corner under the roof, where the joists come together. Though annoyed by frequent interruption, the indefatigable little creatures, with almost painful diligence, lugged in their sticks till they had made a pile that would fill a bushel, and I cannot say they would not have filled the whole shed had they not been compelled to desist; for they were voted a nuisance, and the hole was stopped up. The size of the sticks they carried in, was enormous in comparison with their own stature; it seemed as if they could not lift them, much less drag the crooked pieces through such a narrow orifice." (Dr. Elliott Coues.)

NAMES: House WrEN, Wood Wren. - Hauszaunkönig (German). -Troglodyte aëdon (Vieill.), Roitelet.

SCIENTIFIC NAMES: TROGLODYTES AËDON VIELL. (1807). Motacilla domestica Bartr. (1791). Hyle mathrous aëdon Cab. (1860). Sylvia domestica Wils. (1808). Troglodytes domesticus Coues (1875). Troglodytes fulvus Nutt. (1832). Troglodytes americanus Aud. (1834). Hylemathrous americanus Cab. (1860).

DESCRIPTION: Sexes alike. Above, brown, darker on the head, brighter on the rump; nearly everywhere waved dusky, strongest on the wings and tail. Beneath, pale fulvous-white, tinged with light brownish across the breast. Under tail-coverts, whitish. An obscure whitish line over the eye.

Length, 4.90 inches; wings, 2.08 ; tail, 2.00 inches.

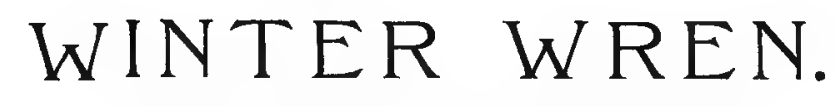

Troglodytes hiemalis VIEILLOT.

(aili.)

UR WINTER WREN differs but little from the common Wren of Europe. Although reported as a breeding bird from several localities in Illinois and Iowa, its real home begins with the mixed woods of central and northern Wisconsin and Michigan. It is a species of the Canadian Fauna, which fact prescribes the southern limits of the 
region in which it is found in the breeding season; it is, therefore, a summer resident in the northern parts of the Northern States and New England. In mountainous districts, where altitude answers for latitude, it is found south to the Blue Ridge Mountains of South Carolina. Prof. Wm. Brewster met with the species on the Black Mountain in western North Carolina where it was abundant in the balsam firs from 5,000 to 6,000 feet above the sea, filling the lonely forests with its exquisite melody at all times of the day. The song seemed to him even finer than in the North.

I have found the bird in such woods in Wisconsin, where a dense and beautiful vegetation fringes the rippling and dashing brooks, where beautiful ferns grow among the shrubbery and where the humble trailing arbutus, and the spicy wintergreen and the dark green ground pine ${ }^{1}$ carpet whole acres of the shady forest. When the beautiful snowy-white flowers of the moosewood" shine through the still leafless woods the melody of the Wood Wren is one of the most conspicuous of all bird-songs. This Wren is a shy bird, avoiding during the breeding season the neighborhood of man. In fall and winter, however, I have observed it frequently in door yards, usually among wood-piles. In localities alluded to above, it is more numerous than is generally believed, as it is easily overlooked on account of its living on or near the ground where it hops along with surprising rapidity. It always seems to be a very happy bird. The night scarcely has passed, the morning scarcely dawns, and our little Wren loudly carols its matin song, sending its cheerful greeting to its feathered neighbors, still enjoying the repose of their sheltered nooks. It admonishes them to share its enjoyment of the early morning, ere the clouds of floating mist vanish before the rising sun. After it has awakened all the songsters of its woodland solitude, and having joined them in greeting the new morn, our lively bird begins its daily work. At first, however, it must take a refreshing drink, which it obtains from the clear and murmuring brook. Perched upon a stone or upon an exposed root it swallows the precious drink, than it utters a harsh trrrrrr and flies to the shore, where it soon disappears among a network of small roots or in a dense thicket searching for food.

In the shady forests of central Wisconsin, where large stumps or prostrated trees, more or less decayed, are overgrown with moss, where luxurious ferns emerge from the rich leaf-mould, our pretty Winter Wren is a regular breeding bird. More common it seems to be in the Adirondacks and Alleghany Mountains, particularly in localities where mountain streams and bubbling springs abound. In the Alleghanies where our most magnificent shrubs, rhododendrons, mountain laurels or kalmias and different azaleas fringe the streams and brooks and often cover whole mountain sides, lending to them an indescribable charm, this bird appears to take up its abode everywhere.

Not having met with the nest myself, I will quote from an excellent account: "The song of the Winter Wren excels that of any other bird of its size with which I am acquainted. It is truly musical, full of cadence, energetic and melodious; its very continuance is surprising, and dull, indeed, must be the ear that thrills not on hearing it. When emitted, as it often is, from the dark depths of the unwholesome swamps, it operates so powerfully on the mind, that it by contrast inspires a feeling of wonder 
and delight, and on such occasions has impressed me with a sense of the goodness of the Almighty Creator, who has rendered every spot of earth in some way subservient to the welfare of his creatures.

"Once when traveling through a portion of the most gloomy part of a thick and tangled wood in the great pine forest, near Mauch Chunk in Pennsylvania, at a time when I was intent on guarding myself against the venomous reptiles I expected to encounter, the sweet song of this Wren came suddenly on my ear, and with so cheery an effect that I suddenly lost all apprehension of danger, and pressed forward through the rank briers and stiff laurels in pursuit of the bird which I hoped was not far from its nest. But he, as if bent on puzzling me, rambled here and there among the thickest bushes with uncommon cunning, now singing in one spot not far distant, and presently in another in a different direction. After much exertion and considerable fatigue, I at last saw it alight on the side of a large tree, close to the roots, and heard it warble a few notes, which I thought exceeded any it had previously uttered. Suddenly another Wren appeared by its side, but darted off in a moment, and the bird itself, which I had followed, disappeared. I soon reached the spot, without having for an instant removed my eyes from it, and observed a protuberance covered with moss and lichens, resembling the excrescences which are often seen on our forest trees, with this difference, that the aperture was perfectly rounded, clean, and quite smooth. I put a finger into it and felt the pecking of a bird's bill, while a querulous cry was emitted. In a word, I had, the first time in my life, found the nest of a Winter Wren. .... Externally it measured 7 inches in length and 4.50 in breadth; the thickness of its walls, composed of moss and lichens, was nearly 2 inches; and thus it presented internally the appearance of a narrow bag, the wall, however, being reduced to a few lines where it was in contact with the bark of the tree. The lower half of the cavity was compactly lined with the fur of the American hare, and in the bottom or bed of the nest there lay over this about half a dozen of the large downy abdominal feathers of our common Grouse (Bonasa umbellus)."

Audubon found six eggs in this nest, and the same number in a second one discovered by him. Another nest which Mr. H. D. Minot found in the White Mountains, was thickly lined with feathers of the Ruffed Grouse; it was built in a low moss-covered stump, in a dark, swampy forest, filled with tangled piles of fallen trees and branches. The eggs, from four to six in number, have a clear white ground-color, spotted with reddish-brown and lavender, chiefly at the larger end. The average size is $.69 \times .49$. Mr. Ruthren Deane describes* three nests which were found in Houlton, Maine. One found Aug. 8, with four eggs, was a beautiful piece of bird-architecture. It was composed mainly of compact green moss, with which a few hemlock twigs were interwoven, and lined thickly with feathers of the Canada Grouse, Blue Jay, and other birds. All three were found in similar situations, in the débris about fallen trees.

The Western Winter Wren, Troglodytes hiemalis pacificus BAIRD, inhabits the Pacific coast region from Sitka to southern California. Its habits and nidification are in conformity with those of the true species. 
NAMES: Winter Wren. - Winterzaunkönig (German). - Troglodyte d'hiver (Le M.).

SCIENTIFIC NAMES: TROGLODYTES HIEMALIS VIEILL. (1819). Anorthura hyemalis Coues (1861). Sylvia troglodytes Wilson (1808). Troglodytes europæus Bp. (1824). Anorthura troglodytes var. hyemalis Coues, Key. (1872). Troglodytes parvulus var. hyemalis Ridgw. (1873).

DESCRIPTION: Sexes alike. Above, deep brown, darkest on head, brightest on rump and tail, waved obscure dusky, except on head; several of the primaries barred with white; an indistinct whitish line over the eye. Under parts pale reddish-brown; belly, flanks, and under tail-feathers, barred with dusky and whitish.

Length, 4 inches; wing, 1.66 ; tail, 1.26 inches.

\title{
Long-Billed Marsh Wren.
}

\author{
Cistothorus palustris BAIRD.
}

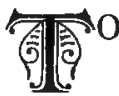

SEE NATURE in all her real glory the observer should rise early in the morning. This may appear to be a platitude, but only in the early hours of the day is nature animated with the highest degree of beauty, perfume, song, and happiness. In years gone by, I knew of no greater delight than to ramble about on the level grassy prairies of northern Illinois. Often, long before morning dawned, I strolled about in the woods, on the grassy, flower-adorned plain, or near one of those large marshes-or "sloughs," as they are locally called - which are fringed by luxurious growths of sedges, reeds, bullrushes, and flags. Farther away from the shore, the fragrant water-lily ${ }^{1}$ and the yellow spatter-dock ${ }^{2}$ flourish. Near the water's edge we look for a hiding place to discover what is going on amidst the luxuriant vegetation. Dense clouds of mist still lie over the water and the adjoining prairie, imparting to the scene a desolate and dreary appearance. But the grayness of dawn soon disappears, the mist vanishes before the rising sun. The sweet-scented, white blossoms of the waterlilies raise their heads above the water's surface. Shy Gallinules nimbly run over the broad lily leaves, and a few Red-winged Blackbirds are seen in the rank bullrushes, smoothening their plumage. The constant, tremulous motions of the reeds make it evident that some other living being is moving among them. Attentively we gaze at those places where the reeds tremble most, but in vain do we look for a bird to take wing. But as the sun rises above the horizon we notice a plain little bird darting rapidly about among the reeds. As we draw nearer, we find that quite a number of these birds move about among the reeds and sedges, and by their peculiar motions we feel convinced that a colony of LONG-BILLED MARSH WRENS has taken up its abode here.

Like many other of our feathered inhabitants of swamps and low-lands, the Marsh Wren is but little known. The peaty shores of lakes and rivers, the swamps and marshes overgrown with wild rice ${ }^{3}$, bullrushes or tulè ${ }^{4}$, and a host of other water plants possess little attraction for most people, in consequence of. which the birds inhabiting such places are but little known, except to the naturalist.

1 Nymphaa tuberosa. 2 Nuphar advena. 3 Zizania aquatica. 4 Scirpus lacustris. 
The range of the Long-billed Marsh Wren appears to extend nearly over the entire country, from the Gulf of Mexico to southern British America, and from the Atlantic to the Rocky Mountains. Its habitation is exclusively in swamps and marshes, destitute of trees and shrubs but filled with reeds and sedges; for this reason the bird is of very local distribution, being met with in the most favorable places only. Where its requirements are satisfied, it is extremely abundant. In northern Illinois and southern Wisconsin, I never noticed its arrival before May 10, usually some days later. It always migrates singly or in pairs. In Texas, I have seen this Wren but seldom during migration time. In Dr. Elliott Cones' "Birds of the North-West," I find the following interesting passage:

"On entering a patch of rushes where the Wrens are breeding, we almost instantly hear the harsh screeping notes with which those nearest scold us, in vehement and angry resentment at the intrusion. From further away in the maze of reeds we hear a merry little song from those still undisturbed, and presently we see numbers flitting on feeble wing from one clump of sedge to another, or poised in any imaginable attitude on the swaying stems. Their postures are sometimes very comical; a favorite attitude is with the tail thrown up till it almost covers the back, and the head lowered. In this position they have a peculiar swaying motion, back and forward, as if they were on a pivot, and in this position they sing most frequently. Others may be seen scrambling like little mice up and down the reed-stems or all over their globular nests. They appear among themselves to be excitable to the verge of irascibility, and not seldom quite beyond such moderate limit; but on the whole they form a harmonious little colony which minds its own business, and doubtless makes pleasant company for the Blackbirds and other larger species which built among them."

The nidification of the Marsh Wren is a very interesting part of its life-history. In the sloughs of northern Illinois, and in the extensive, more or less inaccessible marshes of southern Wisconsin, the birds begin nest-building in the last days of May. I have found invariably that the outer walls of the structure are built of long, coarse grasses, which are thoroughly wet and consequently very pliable, and which are always collected from the water. The bulky domicile is fastened in the top of the swaying reeds, the upright stems of which run through the walls. The form of the nest is globular, about the size and shape of a large cocoanut, with a little hole on the side. This hollow ball is lined with finer grasses. Although constructed of coarse materials, it is, nevertheless, a very pretty and compact home. The large number of nests I often found in favorable localities, in some small tract of marshland was really astonishing. In one case I counted about thirty, many of which were within a few feet of each other. The water was from two to three feet deep and the ground not very muddy, so that I could examine each one without much difficulty. A large number were old nests, serving, evidently, for the old males as lodging places for the night; ten contained eggs, while the rest were in all states of incompleteness. The materials recently gathered were invariably saturated with water, and every nest was built from one to two feet above the water's surface. Most of them were plastered inside with mud and lined with fine grasses. The small entrance hole, sometimes not plainly visible, was usually a little above the centre of the globe; but, in some cases, it was nearer the 
bottom than the top. The eggs, usually five to six in number, are very heavily colored, which gives them a peculiar appearance. They are so thickly spotted with brown that they seem to be of a rich uniform chocolate color. The average size is $.64 \times .45$.

A variety, the TULE WREN, C. palustris paludicola BRD., replaces the common species west of the Rocky Mountains.

NAMES: Long-billed Marsh Wren, Marsh Wren, Salt-water Marsh Wren.-Sumpfzaunkönig (German).

SCIENTIFIC NAMES: Motacilla palustris Bartram (1790). Certhia palustris Wils. (1810). Troglodytes palustris Bonap. (1824), Aud., Nutt. CISTOTHORUS PALUSTRIS BaIRD (1858). Telmatodytes palustris Henry (1857). Telmatodytes arundinaceus Cab. (1850).

DESCRIPTION: Sexes alike. Above, clear brown, unbarred, the middle of the back with a blackish patch, sharply streaked with white; crown of head usually darker than the back; a dull whitish line over the eye. Under parts white, shaded on sides, flanks and crissum with brown. Tail evenly barred with fuscous and blackish; wings fuscous.

Length about 5 inches; wings, 1.75 to 2.00 ; tail 1.80 inches.

\section{Short-Billed Marsh Wren.}

\section{Cistothorus stellaris CABANIS.}

解

HE Short-BILled MARsh Wren is found in great numbers in some localities in

Wisconsin and Illinois, and thence eastward to the Atlantic coast. Westward, it ranges to the Great Plains, and north to Manitoba, wintering in great numbers in the Gulf States and southward. In the Koshkonong and Horicon marshes and on the swampy borders of the Menomonee and Rock River, in Wisconsin, this Wren is very common; but, as it is a shy bird and difficult to approach, comparatively few persons are acquainted with it. It always loves to take up its abode in the seclusion of the swamps and marshes, where it is found usually in pairs and not in colonies like the long-billed species. In marshy places partly covered with a growth of scrubby willows, in swamps, where the beautiful Red-winged Blackbird and Gallinules are its neighbors, and in low grassy meadows, adorned with gorgeous Canada ${ }^{1}$ and meadow lilies ${ }^{2}$, where the tinkling mellow strains of the Bobolink float down from above, I have met with this nimble little Wren frequently. Here also, in the balmy month of June, its song-if song it can be called-may be heard. The notes are very lively and quaint, consisting of a number of soft and melodious sounds, blended frequently with harsh, wiry tones. Being very assiduous, the little songster makes up in quantity of song what it lacks in quality. But could we expect anything different from a bird which inhabits localities where the bull-frog incessantly sends forth its discordant croaks throughout the entire spring time, where the cricket's croon is the farewell of summer, as the trill of the toad is the prelude to spring? The strain is very similar to that of the long-billed species, but not so loud, and more varied. Both birds are very diligent

1 Lilium canadense. 2 L. superbum. 
songsters, delivering their medleys usually from the top of a tuft of reeds or bullrushes. When the bird is approached too near the song closes with a harsh and scolding utterance; then the singer glides down in the tangled masses of reeds where it disappears with celerity, and considerable exertion is required to drive him from the dense regetation.

Evidently our bird is far more numerous than is generally assumed, but its living in secluded localities and its modest color cause it to be overlooked by most people. Only the true friend of nature, who is accustomed to ramble about through forest and meadow, through marshes and swamps, knows where to find it. $-I$ observed this Wren during the entire year in marshy places near the Gulf coast of Texas, and Mr. Maynard found it all along the eastern side of Indian River, Fla., especially in savannas covered with short grass which grows so thickly that it becomes matted together.

The nest is always placed in a tussock of reeds or coarse grass, the tops of which - are "ingeniously interwoven into a coarse and strong covering, spherical in shape and closed on every side, except one small aperture left for an entrance. The strong wiry grass of the tussock is also interwoven with finer materials, making the whole impervious to the weather." This globe-like structure is lined with finer grasses and sometimes with soft regetable down; but no mud is used in the construction. Occasionally we may find the nest in a grassy meadow where it is usually placed low down in a tussock of grass instead of hanging in the tops of swaying sedges. The eggs are entirely different from those of the long-billed species, being pure white, unmarked. They number from six to eight, measuring about $.64 \times .50$ inch.

As early as October 24, 1881, I observed this Wren making its appearance from the North in south-eastern Texas. A cold norther swept over the State, and, at the same time, thousands of migrating birds arrived. The high grass and the weeds of the cotton and corn fields swarmed with different Sparrows, but Short-billed Marsh Wrens appeared to be especially abundant; they were such awkward fliers - being ex- . hausted perhaps from the long journey-that one could catch them with his hand. One of these birds which I caught in this way I placed in a cage to observe it for some days. It was very lively, jerked its tail frequently, and without fear consumed the "ant's eggs," which I put into the cage.

NAMES: Short-billed Marsh Wren, Fresh Water Marsh Wren, Meadow Wren.-Rohrzaunkönig (German). SCIENTIFIC NAMES: Troglodytes stellaris Licht. (1823). CISTOTHORUS STELLARIS Cab. (1850). Tryothorus stellaris Turnb. (1869). Troglodytes brevirostris Nutt. (1832), Aud.

DESCRIPTION: Sexes alike. Above, brown, back and crown blackish, sharply streaked with white throughout. A whitish line over the eye. Below, whitish, shaded with clear brown across the breast and on the sides. Tail evenly barred with fuscous and blackish.

Length about 4.50 inclies; wings and tail about 1.75 inches. 


\title{
WAGTAILS.
}

\author{
Motacillidae.
}

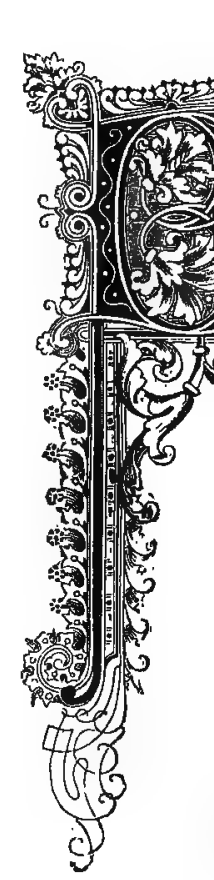

IRDS LIKE the WAGTAILs and PIPITs belong to a family which is largely represented on the Eastern Hemisphere, while of about one hundred species, known to science, only eight or ten make the New World their abode. And even these are of little interest to us as they mainly inhabit high northern regions. Dr. Coues says, that these birds may be considered Sylvians modified for terrestrial habits.

The family consists of three genera:
1, Motacilla Linnaus.
2, Budytes Cuvier. $\}$ Wagtails.
3, Anthus Bechstein. Pipits. Four species.

The White WagtaIL, Motacilla alba LinN., of northern Europe and northern Asia, is an accidental bird in Greenland, while SwINHoE's WaGTAIL, Motacilla ocularis SwINH., of eastern Asia, is accidentally found in Lower California and on the Aleutian Islands (?). The Siberian Yellow WAGTaIL, Budytes flavus leucostriatus STEjN., is found in Alaska and northern Siberia to China, wintering in the Moluccas.

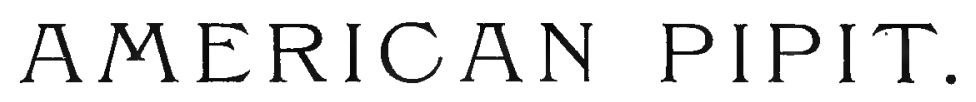

Anthus pensilvanicus THIEnEmann.

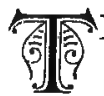

HE American Pipit, or Titlark, breeds abundantly along the coast of Labrador and other regions of the Hudsonian Fauna to the Arctic coast, and also in the higher regions of the Rocky Mountains. During the migration, in September, and again in April and May, it is a common bird in the Mississippi valley. On the prairies near Houston, Texas, I have found it throughout the winter singly as well as in pairs and small flocks. Even on vacant places and on the streets of the city they moved about, 
much in the manner of Horned Larks. Some of them came regularly every day into my door yard searching for food. They rarely leave the ground and hardly ever alight on trees, fences, or posts. In Texas, I never saw them before November, but from that time they were abundant throughout the winter, returning to the North early in March. Audubon and Coues found nests in Labrador. "Although $I$ have myself seen Titlarks wherever I have been," says the last-named ornithologist, "I never found any breeding except in Labrador. It was there the most numerous of the land birds, excepting perhaps the White-crowned Sparrow, frequenting open, bare, and exposed localities, often on the rocky and barren islands, almost untenanted by other species. Here, as elsewhere in maritime localities, the birds are fond of resorting to the sea-shore at low tide, there to ramble in quest of food on the mud and sea-wrack in company with Sandpipers, and not distantly resembling these birds in their manners. Two nests I obtained in July were both placed in a cavity in the ground, about as large as a child's head, on the side of a steep rocky chasm. A flooring of dried grass had been introduced to keep the nest from the wet; the nests were built upon this, of coarse dried grass loosely arranged, and without lining." One nest contained five, the other four eggs, of a dark chocolate color, indistinctly marked with numerous small spots and blackish streaks.

The Meadow Pipit, Anthus pratensis Bechstein, a bird of Europe, occurs sometimes in Greenland, and the Red-Throated Pipit, Anthus cervinus Keys. \& Blas., is occasionally met with in St. Michaels and on the Aleutian Islands.

NAMEs: American Prpit, Titlark, Prairie Titlark, Reddish-brown Titlark, Louisiana Lark, Hudsonian Wagtail.-Pieper (German), Polarpieper (Thienem.). $\rightarrow$ Farlouzanne (Buff.), Alouette aux joues brunes de Pensilvanie (Buff.), Hochequetue de la baie d'Hudson (Vieill.).

SCIENTIFIC NAMES: Alauda pensilvanica Briss. (1760). ANTHUS PENSILVANICUS ThIENEM. (1849). Alauda ludoviciana Gmel. (1788). Anthus ludovicianus Licht. (1823). Alauda migratoria Bartr. (1791). Alauda rufa Wils. (1812). Anthus spinoletta Bp. (1826). Anthus aquaticus S. \& R. (1831). Anthus pipiens Aud. (1832).

DESCRIPTION: Sexes alike. Above, olive-brown, most of the feathers with dusky centres. Wings and tail dusky, with lighter edgings; line over the eye brownish-white or buffy-brown; chin, breast, sides of the body, streaked with dusky.

Length, 6 to 7 inches; wings, 3.20 to 3.50 ; tail, 2.65 to 2.85 inches.

\section{Sprague's Pipit; Missouri Skylark.}

\section{Anthus spragueii BaIRD.}

7F WE WISH to become acquainted with SpRAGuE's PIPIT we must visit the extensive 9 prairies of North Dakota and the Saskatchewan. Where but a few years ago the Sioux Indians chased the buffalo and where, even to-day, large districts are unexplored, there is the home of Sprague's Titlark. At the present day settlers from other States and Europe constantly and irresistibly immigrate into this prairie country, for the deep 
fertile soil possesses great attraction to the farmer. But the winters of Dakota are long and extremely cold, and the blizzards during that season are dangerous to all who have to be out of doors. Furthermore, these prairies are almost entirely destitute of trees and shrubs. We can look around for miles without espying a single tree to serve us as a land mark. Nevertheless, we find on these prairies which are covered during summer with tall and dense grasses, many interesting birds. The most valuable among song birds and the most characteristic is SpRague's PipIT, or Sprague's TITLARK, known by the people of that region under the name of Missouri Skylark and Prairie Skylark.

The breeding range of this singular bird extends perhaps from Nebraska northward to Manitoba. In his elaborately prepared "Report on Bird-Migration in the Mississippi Valley in the years 1884 and 1885" (Washington: Government Printing Office. 1888.) Prof. W. W. Cooke says: "Sprague's Titlark breeds abundantly in the Assinaboine region, and in Dakota and western Minnesota. Since Dr. Coues, in his 'Birds of the North-West,' queried, whether Sprague's Lark left Dakota for the winter, much has been learned of its movements. We now know that its winter haunts lie far from Dakota, and that it penetrates even to the south of south-western Texas. Just where it winters seems not yet determined, but as the record now stands it appears to winter below the United States. Mr. Nehrling found it in small flocks near Houston, Tex., in early November, but it soon disappeared. Mr. N. C. Brown did not find it at Boerne, near San Antonio, Tex., until March 16, so that its winter home must be south of these points. At Gainesville, Texas, it was seen as late as May 7. While North Dakota and western Manitoba constitute its special breeding grounds, where it nests in great numbers, yet it can be found in summer in western Minnesota, in Nebraska (where it arrives about the middle of May), and probably also in western Kansas."

The Missouri Skylark was discovered by Audubon at Fort Union, June 19, 1843, but it remained long unique, until Dr. Elliott Coues, during his connection with the Northern Boundary Commission, became perfectly familiar with the bird. This plaincolored inhabitant of the prairies may be termed the American representative of the famous European Skylark, both in regard to its manners and its exquisite song, although it belongs to an entirely different family of birds. Whether its song equals that of the European Skylark, future observations will have to decide. The few ornithologists that have heard it, speak with enthusiasm of its admirable strain. "On several occasions," writes Audubon, "my friend, Mr. Edward Harris, sought for these birds on the ground, deceived by the sound of their music, appearing as if issuing from the prairies, which they constantly inhabit; and, after having traveled to many distant places on the prairie, we at last looked upward, and there saw several of these beautiful creatures singing in a continuous manner, and soaring at such an elevation as to render them more or less difficult to discover with the eye, and at times some of them actually disappearing from our sight in the clear, thin air of that country."

Dr. Coues found the Missouri Skylark, one of the most common and characteristic birds of all the region, along the 49th parallel of latitude. "The ordinary straightforward flight of the bird," he says, "is performed with a regular rising and falling, like that of the Titlark; but its course, when startled from the ground, is exceedingly 
rapid and wayward; at such times, after the first alarm, they are wont to hover around in a desultory manner for a considerable time, and then pitch suddenly down to the ground, often near where they rose. Under these circumstances they have a lisping, querulous note. But these common traits have nothing to do with the wonderful soaring action, and the inimitable, matchless song of the birds during the breeding season-it is no wonder Audubon grew enthusiastic in describing it. Rising from the nest, or from its grassy bed, this plain-looking little bird, clad in the simplest colors, and making but a speck in the boundless expanse, mounts straight up, on tremulous wings, till lost to view in the blue ether, and then sends back to earth a song of gladness that seems to come from the sky itself, to cheer the weary, give hope to the disheartened, and turn the most indifferent, for the moment at least, from sordid thoughts. No other bird-music heard in our land compares with the wonderful -strains of this songster; there is something not of earth in the melody, coming from above, yet from no visible source. The notes are simply indescribable; but once heard they can never be forgotten. Their volume and penetration are truly wonderful; they are neither loud nor strong, yet the whole air seems filled with the tender strains, and the delightful melody continues long unbroken. The song is only heard for a brief period in the summer, ceasing when the inspiration of the love season is over, and it is only uttered when the birds are soaring."

Prof. J. A. Allen, while connected with the Yellowstone Expedition, was so fortunate as to find the nest of this interesting prairie bird. "The only nest we found," he says, "was placed on the ground, and neatly formed of dry, fine grass. It was thinly arched over with the same material, and being built in a tuft of rank grass, was most thoroughly concealed. The bird would seem to be a close setter, as in this case the female remained on the nest till I actually stepped over it, she brushing against my feet as she went off. The eggs were five in number, rather long and pointed, measuring about $.90 \times .60$ inch, of a grayish-white color, thickly and minutely flecked with darker, giving them a decidedly purplish tint."

At times, these Titlarks are associated with numbers of Chestnut-collared Longspurs and Baird's Buntings.

NAMES: Sprague's PrPIT, Missouri Pipit, Sprague's Skylark, Missouri Skylark, Prairie Skylark. - Missouri-, Prärielerche (German).

SCIENTIFIC NAMES: Alauda spragueii Aud. (1844). Agrodoma spraguei Brd. (1852). Neocorys spraguei Brd. (1858). ANTHUS SPRAGUEI Brd. (1864).

DESCRIPTION: Sexes alike. Above, dark brown or wood-brown, all the feathers edged with lighter, especially on the neck, where a brownish-yellow tinge predominates. A line over the eye and lores whitish. Under parts dull white, with a collar of sharply defined narrow brown streaks across the forepart and along the sides of the breast. Two whitish bands on the wings. Tail dark brown; the outer tail-feather white, the second one white, with the inner margin brown. Bill and feet yellow.

Length about 6 inches; wings, 3.50 ; tail, 2.60 inches. 


\title{
WOOD WARBLERS.
}

\author{
Mniotiltidae.
}

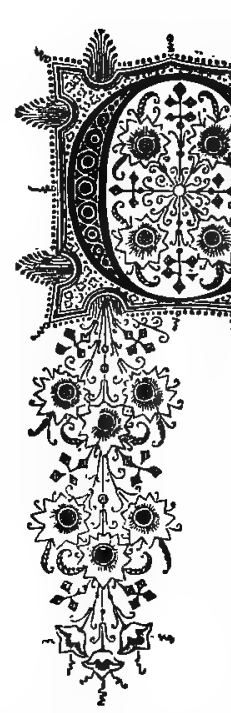

RAND AND FULL of poetry is nature when in spring the trees and shrubs of our forests and gardens don their varied garments of leaves and blossoms. Numerous fairy-like birds, beautiful both in color and form, are now busily engaged among the new leaves and the flowers in the pursuit of insects, which are nowhere else found in such immense numbers. These beautiful woodland minstrels are known to the ornithologist and lover of nature as Wood WARBLERs. In no other name lies such an exhilerating sensation as in the term Warbler, and none other is so dear to the hcart of every lover of birds as this. It always reminds me of my early rambles through that region of central and northern Wisconsin, which abounds in beautiful lakes, prattling brooks, and cool forests, where the white pine and hemlock raise their sombre-colored tops high into the air, where the ground beneath is enamelled with a rich mosaic of trailing arbutus, tiarella, uvularia, rue-anemone ${ }^{1}$, goldthread, claytonia, spicy wintergreen or checker-berry, partridge-vine, twin-leaf, and club-moss, where the blood-root, the wake-robin or wood-lily ${ }^{2}$, and a host of other spring flowers grow out of the rich mold. I enjoy to remember also the gorgeous masses of azaleas, kalmias, and rhododendrons fringing the banks of the cool mountain streams and frequently clothing whole mountain-sides of the southern Alleghanies with dazzling hues and green verdure. I often call to mind the magnificent Magnolia grandiflora with its broad evergreen leaves and large white blossoms exhaling a powerful fragrance, and amid which our Wood Warblers on their way to the North seem to revel. The tea-olive, the gardenia, the orange, the palms, the glorious tea roses, the banana-shrub ${ }^{3}$, which for six weeks in spring is covered with thousands of brown miniature magnolia blooms, whose deliciously pungent odor is the very harmony of perfume, and other semi-tropical plants of the Gulf region; - the sweet-scented rosy-white clusters of the wild crab-tree, the flowering white-thorns of the woods, which in a distance remind the observer of a cloud of mist, the blooming fruit-trees of the northern gardens; the Cherokee rose hedges of southern Louisiana and Georgia, the azalea and camellia gardens of South Carolina, all these crowd into my mind, when I hear the name Wood Warbler. 
This is the second largest family of native birds, the Finches alone surpassing it in number of species. They replace the true Warblers (Sylviidae) of the Old World in America, "having much the same rôle in bird-economy: both families abound in species and individuals." All are small, insectivorous, migratory birds, which everywhere take a prominent part in the make-up of the bird-fauna. There are about a hundred different species of Wood Warblers distributed over the whole of North America, Central and South America. The Flycatching Warblers, of which our beautiful Red-start is the type, belong mostly to the warmer parts of America, while the Wood Warblers properly are more particularly birds of North America; comparatively few of the species are confined to tropical America. Says Dr. Elliott Coues: "Dendroica, the leading type of this group is the largest, most beautiful, and most attractive genus of North American birds, preeminently characteristic of this country.

"... I wish to bring into this sketch of the Warblers at large some touches to show their family traits. I said that Dendroica was a 'beautiful' genus; and I am sure that the Warblers, taken altogether, are the most attractive of our birds to every lover of birds for their own sakes - to every one who delights in those rsthetic emotions which the interpretation of bird-life never fails to excite. We have just seen what a problem they offer to the strict scientist; the most determined utilitarian will find them not beneath his notice, for their good services in the interests of agriculture are immeasurable; the naturalist derives from them never-failing gratifications of his sense of the beautiful, whether he regards their forms, their colors, or their habits. They are prominent among the birds that awaken and stimulate the enthusiasm of the young ornithologist, nor do they cease to feed the ardor of maturer years; they challenge interest perpetually, and engage attention in their. endlessly varied aspects. They are the universal favorites of the amateur; every collector is keen on the scent of the 'rare Warbler'; emulation quickens the quest of its nest and eggs; the rivalry is to discover some unrecorded trait, some unrecognized plumage, some note unheard before; and the specimen itself is among the treasures of every cabinet. Has any one stopped to think what our ornithology would be with this life of the woodland left out?

"With few exceptions, the Wood Warblers are clad in variegated colors-always pretty and tasteful, often brilliant and strikingly effective; even when the tints are subdued, as in the olivaceous species, there is a pleasurable harmony of color, in keeping with shy and modest demeanor; while some of the Warblers may boast of the most exquisite and delicate of hues, next after those that glitter in the sheen of iridescence. Most Warblers, moreover, have several suits of color; the sexes are seldom alike, the young are different again, and so many are the changes, that here is a study by itself, to recognize the same bird under its color-variations. The plumage of the Warblers may be used to illustrate a very broad and important truth that bears upon the question of species itself.....

"Musical proficiency might be reasonably presupposed in a group of birds known by the delightful suggestive name of 'Warblers.' It is quite our own fault, however, that they are misnamed; we have simply perpetuated an early blunder in classification, by which these birds were referred to the Old World genus Sylvia. We have corrected the technical misnomer of 'Sylvia,' but have been less precise in our vernacular. Nothing 
less like warbling than the songs of our 'Warblers' can well be imagined. Bluebirds and Wrens warble or trill their lays; Warblers, as a rule, do not. There are few great singers among them all. Their voice usually is thin, sharp, 'unsympathetic'; the pitch is too high; the notes are abrupt and jerky; movement is uneven and never long-sustained. The song indeed has musical quality, and may effect us rather pleasantly; but our attention is more likely to be arrested by its oddity than attracted by its melody. I cannot but criticise here; yet I am ready to bear witness to the endless variety of the songs of the Warblers, - probably every species has its own, distinctly recognizable by the practised ear; and much of the pleasurable excitement which the study of these birds affords, comes from the effort of discriminating between their wonderfully varied performances. Probably no single ornithologist has learned them all-even all those to be heard in his own vicinity; so subtile, so fugitive, so incomprehensible are these quaint snatches of song, which arouse attention only to disappoint expectation, and make us feel that we can never interpret the language in which these sylvan sprites tell the story of their lives. But the Warblers are such a multitude, so composite, that no indiscriminate comment, however guarded, can fail to do injustice. There are singers among them. The voice of the Summer Yellowbird is sweetly modulated. The species of the genus Seiurus are splendid performers: the Golden-crown is a musician of extraordinary yet long-unsuspected ability, so seduously does he hide his real accomplishments - one who continually obtrudes upon us his loud shrill chant, in accelerated monotone, as if this were all that lay in his power; yet in rare moments of triumph delighting to transport us with the exquisite vocalization which his nuptial ecstasies inspire.

"More anon of the general habits of the Warblers, when I come to speak of the genera and species individually; here I can do little more than witness the 'various language' which they speak 'to him who in the love of nature holds communion with her visible forms.' The Warblers have we always with us, all in their own good time; they come out of the South, pass on, return, and are avay again, their appearance and withdrawal scarcely less than a mystery; many stay with us all summer long, and some brave the winters in our midst. Some of these slight creatures, guided by unerring instinct, travel through to the meridian in the hours of darkness, slipping past 'like a thief in the night,' stooping at day-break from their lofty flights to rest and recruit for the next stage of the journey. Others pass more leisurely from tree to tree, in a ceaseless tide of migration, gleaning as they go; the hardier males, in full song and plumage, lead the way for the weaker females and the yearlings. With tireless industry do the Warblers befriend the human race; their unconscious zeal plays due part in the nice adjustment of nature's forces, helping to bring about the balance of vegetable and insect life, without which agriculture would be in vain. They visit the orchard when the apple and pear, the peach, plum, and cherry, are in bloom, seeming to revel carelessly amid the sweet-scented and delicately tinted blossoms, but never faltering in their good work. They peer into the crevices of the bark, scrutinize each leaf, and explore the very heart of the buds, to detect, drag forth, and destroy those tiny creatures, singly insignificant, collectively a scourge, which prey upon the hopes of the fruit-grower, and which, if undisturbed, would bring his care to nought. Some Warblers flit incessantly in the terminal foliage of the tallest trees; others hug close to the scored trunks 
and gnarled boughs of the forest lkings; some peep from the thicket, the coppice, the impenetrable mantle of shrubbery that decks tiny water-courses, playing at hide-and-seek with all comers; others more humble still descend to the ground, where they glide with pretty mincing steps and affected turning of the head this way and that, their delicate flesh-tinted feet just stirring the layer of withered leaves with which a past season carpeted the ground. We may seek Warblers everywhere in their season; we shall find them a continual surprise ; all mood and circumstance is theirs."

This beautiful family is divided into the following genera:

1, Mniotilta Vieirlot. One species.

2, Protonotaria BaIRd. One species.

3, Helinaia Audubon. One species.

4, Helmitherus Rafinesoue. One species.

5, Helmintophila Rrdgway. Eight to ten species.

6, Compsothlypis CaBanis. Two species.

7, Dendroica Grax. Twenty-four species.

8, Seiurus Swainson. Three species.

9, Geothlypis Cabanis. Six species.

10, Icteria VieILLot. One species.

11, Sylvania Nuttall. Three species.

12, Setophaga Swarnson. Three species.

13, Cardellina Dubors. One species.

14, Ergaticus Barrd. One species.

15, Basileuterus Cabanis. One species.

\title{
BLACK AND WHITE WARBLER.
}

\section{Mniotilta varia VIEILLO'T.}

Plate XI. Fig. 3.

\begin{abstract}
TN THE DENSE and shady woodland regions of the Northern States and New 6. England, this pretty Warbler appears to be more numerous than elsewhere. Where the Wood Thrush and the Veery sing their jubilant anthems, where the Towhee utters its metallic notes, where Ovenbirds and Winter Wrens skip over the soft ground adorned with trailing arbutus, checker-berry, wake-robins, bellworts, smilacina, blood-root, and ferns, where the beautiful hepatica flowers soon after the snow leaves the ground, where not far away a murmuring brook or a bubbling spring winds its way through the forest, there we most likely may find the BLACK AND WHITE WARBLER, or the CREEPING WARBLER, as our earlier ornithologists called it, a bird that has no end of pretty ways, and which often is surprisingly unsuspecting.
\end{abstract}





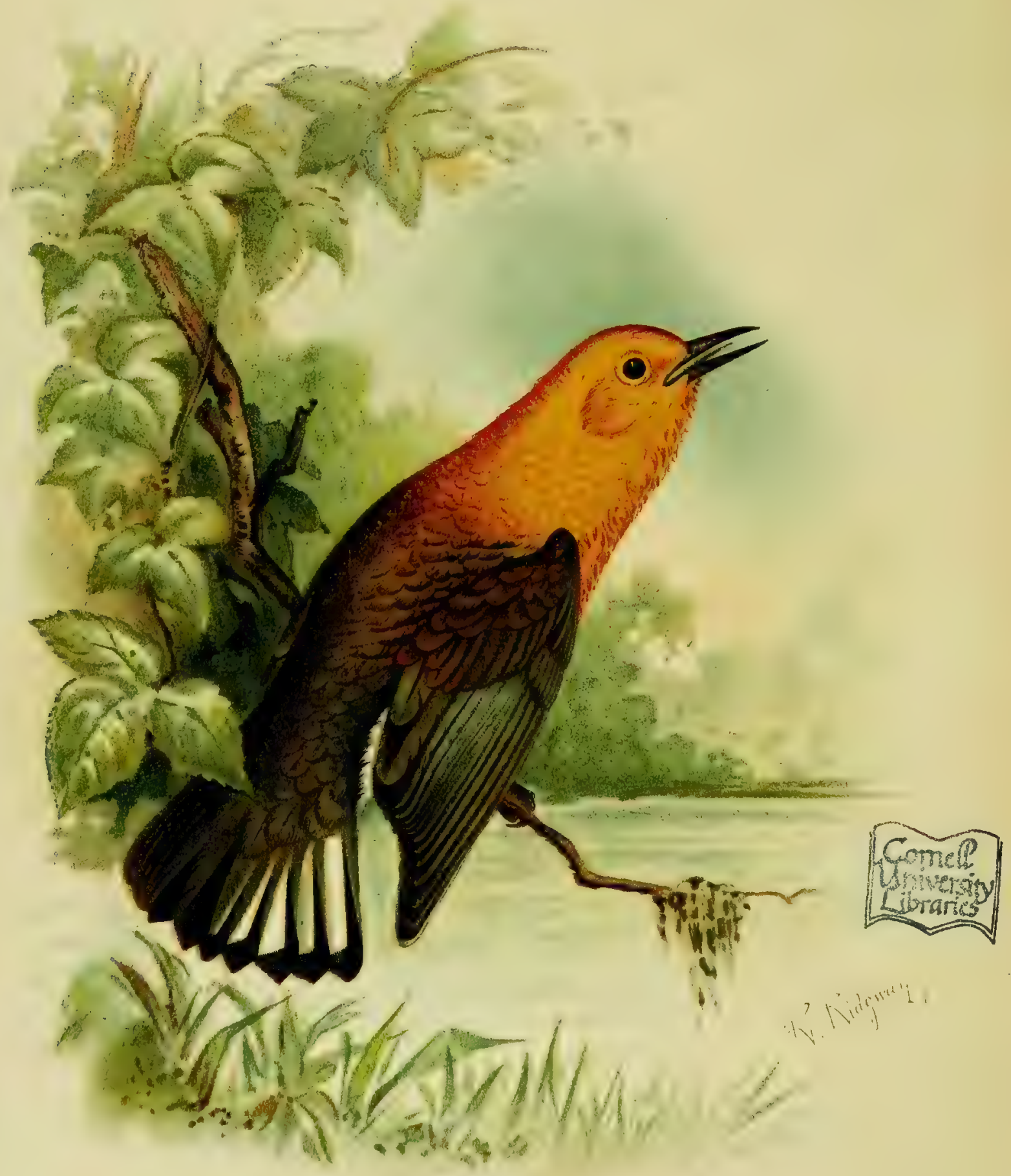

PROTONOTARIA CITREA BAIRD

GOLDSÄNGER.

Prothonotary Warbler. 
During the breeding season this bird is found from Texas and Louisiana to Wisconsin and New England, and even as far north as Fort Simpson, British America, and from the Atlantic to the Plains. It winters south to Central America and the West Indies.

In south-western Missouri the Black and White Creepers arrive usually late in April, and in central Wisconsin $I$ have never seen them before May 10; usually they become abundant when the orchard trees are in full bloom. They are, at least in spring, always seen singly or in pairs; during their fall migration small family groups may be seen occasionally. Although found frequently in the same flowering trees with other Warblers they never mingle with them. In their method of securing food they differ from all our other Warblers. They scramble actively about the trunks and branches of the trees, much in the manner of the true Creepers (Certhia), originating their classification with that family by our older ornithologists. Even to-day this error is manifested by its generally prevailing name Black and White Creeper and Creeping Warbler.

During migration this Warbler usually enters orchards and gardens, and like resorts of man, toward whom it shows no shyness; it creeps fearlessly up the trunks of trees and along the fences, looking diligently for insects and their larvæ that may be hidden in the crevices of the bark and underneath the foliage. Subsisting entirely upon a great variety of noxious insects, it is eminently useful, as all Warblers are. The good services it renders in this way to man cannot be overestimated. As it creeps around the trunks and stumps it often utters its rather weak call-notes sounding like tsip or chip. The chant which almost incessantly is poured forth on mild and sunny June days is decidedly Warbler-like. It is not very musical, being a rather feeble refrain of chi-chichi-che-che-chee, or we-we-we-we-we-see. As the bird is a very diligent songster, it fills its place well in the choir of our forest musicians.

The nest is usually placed on the ground-rarely in holes of stumps and trees built of grasses, leaves, bark-strips, and moss, lined with fine, soft rootlets, hairs, and fern-down. It is usually imbedded in a depression and placed on a foundation of old leaves near a fallen $\mathrm{log}$, an old stump, or among the roots of a tree. Frequently it is hidden under the shelter of dense fern-fronds or bushes. The nest is, as a rule, so artfully concealed as to be discovered only by accident. The eggs, four to five in number, are of a creamy-white ground-color, more or less evenly sprinkled with brown dots, generally in the form of a wreath around the larger end.

I have seen these Warblers during the breeding season in Texas and Louisiana, but I was never fortunate enough to find a nest. Mr. C. W. Beckham found the Creeping Warbler breeding at Bayou Sara, La. On April 23 he found a nest, containing four eggs. It was placed on the ground in a densely wooded hillside, loosely constructed of dead leaves, etc., and was roofed over so as to be completely sheltered from the rain. The female did not leave the nest until he was two to three feet of her, when she flew on the ground, feigning lameness, but this old and pathetic subterfuge proved unfortunate. It led to the discovery of the nest which was admirably concealed and would never have been found, had not the bird itself betrayed its location.

NAMES: BLACK aNo White Warblek, Black and White Creeper, Creeping Warbler. - Klettersänger (German). 
SCIENTIFIC NAMES: Motacilla varia Linn. (1766). Certhia varia Vieill. (1807). MNIOTILTA VARIA VIEILL. (1816). Certhia maculata Wils. (1811).

DESCRIPTION: General color, black, the feathers broadly edged with white; the head black, with a median stripe in the crown, a superciliary and maxillary one of white. Middle of belly, two broad bands on the wings, inner edge of all wing and tail feathers, white; rump and upper tail-coverts black, edged externally with white; the sides of body broadly streaked with black; the chin and throat more or less black. Female similar, but colors duller.

Length, 5.25 inches; wing, 2.80 ; tail, 2.10 inclues.

\title{
PROTHONOTARY WARBLER.
}

\author{
Protonotaria citrea BAIRD.
}

Plate X.

(2)

OUTHERN INDIANA and Illinois and adjacent districts in Missouri have a very rich avifauna. The magnificent bottom woods, the numerous swamps and ponds, and the extensive thickets which skirt every water-course afford excellent haunts for numerous birds. The flora is entirely different from that of our Northern States. The southern cypress reaches here its northern limit. Tall sycamores, sweet gums, water oaks, white elms, coffee-trees, black gums, tulip trees, honey-locusts, black walnuts, hackberries, and hickories predominate. Now and then we see a beautiful specimen of Catalpa speciosa. "These woods," says Mr. R. Ridgway, "are very open, it being comparatively easy, in many places, to drive through them with a light wagon. There is almost no shrubby undergrowth, the usual underwoods consisting of red-bud ${ }^{1}, \mathrm{dog}^{-}$ wood $^{2}$, pawpaw ${ }^{3}$, and mulberry ${ }^{4}$, here attaining the stature of good-sized trees. The unobstructed sunlight, which, directly, or by reflection and diffusion, freely permeates all portions of these beautiful forests, promotes the development of a luxuriant and varied herbaceous growth-grasses, sedges, ferns, flags, balsam-plants ${ }^{5}$, cardinal flowers ${ }^{6}$, etc., according to locality, and others far too numerous to mention; even the decaying logs are covered with weeds, thus presenting the appearance of miniature gardens. Other characteristic features are the abundance and luxuriance of climbing plants, embracing no less than four (probably five) species of wild grape, the Virginia creeper, cross-vine?, trumpet-flower ${ }^{8}$, pipe-vine, and others, not forgetting the far too abundant poison vine $^{10}$. The switch-cane ${ }^{11}$, occasionally, chiefly monopolizes the soil, and the scouring rush $^{12}$ sometimes constitutes the exclusive growth, but only in a few places of limited extent.

"It is because of this abundance of sunlight and exuberance of vegetation, that these woods surpass all others in abundance of bird-life, and, therefore, afford the richest

1 Cercis canadensis. '2 Cornus florida. 3 Asimia triloba. 1 Morus rubra. I Impatiens fulva and pallida. B Lobelia cardinalis. T Bignonia capreolata. a Tecoma radicans. S Aristolochia tomentosa. 10 Rhus toxicodendron. 11 Arundinaria tecta. 12 Equisetum hyemale. 
field for the ornothologist. The willows are the chosen home of the Prothonotary Warbler; the undergrowth of the Hooded and Blue-winged Yellow Warblers; Ducks and other aquatic species have a secure home in the shelter of the water-lilies; Herons build their nests in the lofty tops, and Turkey Buzzards hide their young in the hollow bases of the gigantic sycamores. Thirty years or more ago, Parakeets (Conorus caroli. nensis) disturbed the solitude or drowned the voices of the songsters by their piercingly shrill screeching notes, but they have long since vanished, never to return. The Turkey still lingers, however, but must surely disappear when its shelter shall have passed away.

Everywhere in these southern bottom lands the ponds are characteristic features. Some of them are open, but others are "filled with willow-trees", averaging perhaps fifty feet, but occasionally growring more than seventy feet, in height, but of slender form, while even the open ponds have a bordering fringe of these trees, occasionally mixed with swamp cotton-wood ${ }^{2}$. In the swampy tracts between the ponds grow dense and tangled thickets of button-bush ${ }^{3}$, clumps of black alder or water holly ${ }^{4}$, tall stems of Amorpha fruticosa, and occasionally crooked, thorny trees of the water locust ${ }^{5}$. The open portions of the ponds are in summer choked with a rank growth of various aquatic plants, the 'spatter-dock', prevailing, but giving way in deeper water to the beautiful western pond lily?."

The most beautiful and characteristic denizen of these ponds fringed with willows is the Prothonotary Warbler. I have observed this beautiful bird in south-eastern Texas, in south-western Missouri, and near St. Louis, when roaming through the woods with Mr. Otto Widmann, but it seems to be nowhere so abundant as in southern Indiana and Illinois. There it was observed by Mr. Robert Ridgway, the great ornithologist and artist of the Smithsonian Institution, and by ${ }^{\circ} \mathrm{Mr}$. Wm. Brewster of Cambridge, Mass., the ingenious naturalist and admirable writer. The bird under consideration is so beautiful and $\mathrm{Mr}$. Brewster's life-sketch of the same is so classical and fascinating that it can be only in the interest of my readers, when I quote from him. Mr. Brewster writes:

"The middle of April, 1878, found me at Mount Carmel, Ill,, in the pleasant company of Mr. Robert Ridgway, with the delightful anticipation of a prospective four weeks among the birds of a, to me, new region. What ornithologist but has felt the sensations arising at such times, - the pleasing certainty of meeting many species that are known to occur; the stimulating hope of detecting others that may, nay, probably will, be found; and the vague dream of securing some rare prize that shall excite the interest of the whole ornithological world? But most potent of all to encourage and sustain are the possibilities, without which the toils and hardships of field collecting would be but sad drudgery. A person of prosaic temperament can rarely if ever make a good field-worker. Enthusiasm must be the spur to success. At the time of our arrival there was a temporary lull in the development of the season. March and early April had been unusually warm and pleasant, and vegetation had far advanced. Many of the forest trees were already green with young foliage, and the leaves of others were

1 Salix nigra. 2 Populus heterophylla. 3 Cephalanthus occidentalis. 4 Ilex verticillata. 5 Gleditschia monosperma. 6 Nuphar advena. 7 Nymphæa tuberosa. 
beginning to unfold. But a period of cold rainy weather succeeded, and everything for a time was at a stand-still. On April 19 the first Prothonotary Warblers were seen. They seemed to be new arrivals, forerunners of the general migration; shy, comparatively silent, and with that peculiar restraint of manner observable in the first comers of most migratory birds, - a restraint not so much to be wondered at, for a subtile chill and gloom still brooded over the budding forest. Nature seemed to hold her breath in expectancy, and the birds, as well as all wild creatures, are her children, and sympathize in all her varying moods. What lover of the woods has not observed the effect produced upon them by a sudden undefinable something that comes at times over the face of everything,- a slight imperceptible chill, perhaps, or a brief period of cloudiness; where a moment before all was life, bustle, and joyous activity, there is now brooding depression and almost death-like silence. Oftentimes the effect is transient, and the former state of things soon resumes.

"With a few warm days the change came, and Nature entered upon her gala-day. The tree-tops became canopies of dense foliage; from the starlit heavens at night came the mysterious lisping voices of numberless little feathered wanderers pushing their way northward amid the darkness, guided by some faculty which must ever remain hidden from mortals. Each succeeding morning found new-comers taking their places in the woodland choir, and every thicket was enlivened by glancing wings and merry bird voices. The spell was broken, and among all the gay revellers none were more conspicuous than the beautiful Prothonotaries. Day by day their numbers rapidly increased, until by April 27 all had apparently arrived. We now found the Prothonotary Warbler to be, in all suitable localities, one of the most abundant and characteristic species. Along the shores of the rivers and creeks generally, wherever the black willow $^{1}$ grew, a few pairs were sure to be found. Among the button-bushes ${ }^{2}$ that fringed the margin of the peculiar long narrow ponds scattered at frequent intervals over the heavily timbered bottoms of the Wabash and White Rivers, they also occurred more or less numerously. Potoka Creek, a winding, sluggish stream, thickly fringed with willows, was also a favorite resort; but the grand rendezvous of the species seemed to be about the shores of certain secluded ponds lying in what is known as the Little Cypress Swamp. Here they congregated in astonishing numbers, and early in May were breeding almost in colonies. In the region above indicated two things were found to be essential to their presence, namely, an abundance of willows and the immediate proximity of water. Thickets of button-bushes did, indeed, satisfy a few scattered and perhaps not over particular individuals and pairs, but away from water they were almost never seen. So marked was this preference, that the song of the male heard from the woods indicated to us as surely the proximity of some river, pond, or flooded swamp, as did the croaking of frogs or the peep of the hylas. In rare instances, it is true, nests were found several hundred yards away from any water; but such apparent exceptions were in nearly every case explained by unmistakable indications that the place, or its immediate vicinity, had been flooded earlier in the season, probably at the time when the site was selected and the nest built. Owing to the exceeding variability of the waterlevel in the western rivers, it is not at all improbable that 
whole tracts of country where these birds breed may be sometimes left high and dry by the receding element before the eggs are hatched.

"Everywhere now, from the willow thickets along the streams and the buttonbushes on the pond edges came the songs of numerous males, and, occasionally, one would appear among the foliage or glance across the open water like a ray of golden light. Little idea can be had from preserved specimens of the wonderful beauty and brilliancy of this bird's plumage when alive. Although at times somewhat hard to discover among the yellowish-green of their favorite willows, at others, when clinging against the side of an old log or tree-trunk, the yellow head and breast, turned outward to the light, seemed fairly to glow with color, in contrast with the green moss or dusky wood. On cloudy, lowering days I have been surprised at the effect produced by a male flying across an open space close to the dark water. It was as if a sumbeam had glanced athwart the spot, lighting up everything for a moment, and leaving greater gloom from the contrast after it had disappeared....

"Mating began almost immediately after the arrival of the females, and the 'old, old story' was told in many a willow thicket by little golden-breasted lovers. The scene enacted upon such occasions was not strikingly different from that usual among the smaller birds : retiring and somewhat indifferent coyness on the part of the female; violent protestations and demonstrations from the male, who swelled his plumage, spread his wings and tail, and fairly danced round the object of his affections. Sometimes at this juncture another male appeared, and then a fierce conflict was sure to ensue. The combatants would struggle together most furiously until the weaker was forced to give way and take to flight. On several occasions I have seen two males, after fighting among the branches for a long time, clinch and come fluttering together to the water beneath, where for several minutes the contest continued upon the surface until both were fairly drenched. The males rarely meet in the mating season without fighting, even though no female may be near. Sometimes one of them turns tail at the outset; and the other at once giving chase, the pursuer and pursued, separated by a few inches only, go darting through the woods, winding, doubling, now careering away up among the tree-tops, now down over the water, sweeping close to the surface until the eye becomes weary with following the mad flight. During all this time the female usually busies herself with feeding, apparently entirely unconcerned as to the issue. Upon the return of the conquerer her indifference, real or assumed, vanishes, he receives a warm welcome, and matters are soon arranged between them.

"The usual song of the Prothonotary Warbler sounds at a distance like the call of the Solitary Sandpiper, with a syllable or two added,-a simple peet, tweet, tweet, tweet, given on the same key throughout. Often when the notes came from the farther shore of a river or pond we were completely deceived. On more than one occasion, when a good opportunity for comparison is offered by the actual presence of both birds at the same time, we found that at a distance of several hundred yards their notes were absolutely undistinguishable; nearer at hand, however, the resemblance is lost, and in ringing, penetrating quality becomes apparent in the Warbler's song. It now sounds like peet, tsweet, tsweet, tsweet, or sometimes tweet, tr-sweet, tr-sweet, tr-sweet. When the birds sing within a few yards the sound is almost startling in its intensity, 
and the listener feels inclined to stop his ears. The male is a fitful singer, and is quite as apt to be heard in the hot noontide or on cloudy days, when other birds are silent, as during the cool morning and evening hours. The ordinary note of alarm or distress is a sharp one, so nearly like that of the Large-billed Water Thrush (Seiurus motacilla) that the slight difference can only be detected by a critical ear. When the sexes meet a soft tchip of recognition common to nearly all the Warblers is used. In addition to the song above described the male has a different and far sweeter one, which is reserved for select occasions, - an outpouring of the bird's most tender feelings, intended for the ears of his mate alone, like the rare evening warble of the Ovenbird (Seiurus auricapillus). It is apparently uttered only while on the wing. Although so low and feeble as to be inaudible many rods away, it is very sweet, resembling somewhat the song of the Canary, given in an undertone, with trills or 'water-notes' interspersed. The flight during its delivery is very different from that at all other times. The bird progresses slowly, with a trembling, fluttering motion, its head raised and tail expanded. This song was heard most frequently after incubation had begun.

"In general activity and restlessness few birds equal the species under consideration. Not a nook or corner of his domain but is repeatedly visited through the day. Now he sings a few times from the top of some tall willow that leans out over the stream, sitting motionless among the yellowish foliage, fully aware, perhaps, of the protection afforded by its harmonizing tints. The next moment he descends to the cool shades beneath, where dark, coffee-colored water, the overflow of the pond or river, stretches back among the trees. Here he loves to hop about on floating drift-wood, wet by the lapping of pulsating wavelets; now following up some long, inclining, half-submerged $\log$, peeping into every crevice and occasionally dragging forth from its concealment a spider or small beetle, turning alternately his bright yellow breast and olive back towards the light; now jetting his beautiful tail or quivering his wings tremulously, he darts off into some thicket in response to a call from his mate; or, flying to a neighboring tree-trunk, clings for a moment against the mossy bole to pipe his little strain or look up the exact whereabouts of some suspected insect prize.

"This Warbler usually seeks its food low down among thickets, moss-grown logs, or floating débris, and always about water. Sometimes it ascends tree-trunks for a little way like the Black and White Creeper, winding about with the same peculiar motion. When seen among the upper branches, where it often goes to plume its feathers and sing in the warm sunshine, it almost invariably sits nearly.motionless. Its flight is much like that of the Water Thrush (either species), and is remarkably swift, firm, and decided. When crossing a broad stream it is slightly undulating, though always direct. Its food consists of insects, generally of sucl spiders and beetles as are found about water. Audubon positively asserts that he has discovercd minute molluscous animals and small land-snails in their stomachs.

"The nesting of the Prothonotary Warbler affords the most interesting phase of its life history. Audubon's account of its nest, 'fixed in the fork of a small twig bending over the water,' seems in the light of our present knowledge open to serious doubts. At least, it is not the mode of nidification used in the places where it is best known at the present day. Mr. B. F. Goss of Neosho Falls, Kansas, first brought to light the 
fact that in that locality the bird invariably nested in holes of trees or buildings. Since his discovery of the first nest in 1863, others similarly situated have been found by Dr. Palmer and Mr. Robert Ridgway, at the Kiowa Agency, Indian Territory, and at Mount Carmel, Ill. The first nest collected the past season was found by Mr. Ridgway on April 27. It contained four fresh eggs. This was probably an exceptionally early date, as nearly a week elapsed before any other eggs were taken; and, indeed, the greater proportion of a large number collected between May 8 and 12 were freshly laid. At least forty nests were examined altogether, about one half of which contained eggs. To give an account of all the various situations in which these nestswere placed, would entail a description of nearly every conceivable kind of hole or cavity that can be found in tree-trunks. The typical nesting-site, however, was the deserted hole of the Downy Woodpecker or Carolina Chickadee. The height varied from two to fifteen feet, though the usual elevation was about four. If the cavity was old and broken out, or otherwise enlarged, it was far more apt to be chosen than a neater and newer one close at hand. The stump selected almost invariably stood in or projected over water, although, as above stated, it was oftentimes left high and dry after the eggs were laid.

"Of the many exceptions to the above described typical site, I will here notice only two of the most marked. A nest discovered May 8 was built in a sort of pocketshaped cavity in the side of a large cypress stump. The hole descended vertically in the inside of a shell-like wall, the central heart of which had crumbled away. Another, found by Mr. Ridgway, was built in an extremely rotten snag which stood on the edge of a road; the eggs or sitting parent could easily be seen by any one riding by. This nest was several hundred yards away from water.

"In the construction of the nest the female labors somewhat desultorily. Fresh green moss enters largely into its composition, and although this substance is readily obtained, a week is sometimes consumed in building the simple little affair. Most of the materials are gathered in the immediate vicinity from half-submerged logs or the nearest dry ground. The male almost always accompanies his partner on her trips to and from the nest, making a great show of hunting up choice bits of material, but apparently never succeeding in finding any to his mind. He usually precedes her on her return, enters the hole to investigate the condition of affairs, pops out his golden head to assure her with a soft chirp that all is well within, and then gives way to allow her to enter, clinging against the bark outside to cheer her labors with his song and await her reappearance. Sometimes, however, both birds remain inside together, although how much assistance the male renders in house furnishing I cannot say. Probably his presence is only tolerated, and he is perhaps often accused of being a nuisance.

"The shape and size of the nest vary with that of the cavity in which it is placed. When the hole is deep, it is usually filled up to within four or five inches of the entrance. Thus the nest when removed presents the appearance of a compact mass of moss five or six inches in height by three or four in diameter. When the cavity is shallow, it is often only scantily lined with moss and a few fine roots. The deeper nests are of course the more elaborate ones. One of the finest specimens before me is composed of moss, dry leaves, and cypress-twigs. The cavity for the eggs is a neatly 
rounded, cup-shaped hollow, two inches in diameter by one and a half in depth, smoothly lined with fine roots and a few wing-feathers of some small bird.

"The number of eggs constituting a full set varies to an unusual degree; two nests were found, each of which contained seven eggs, while in another instance a nest, which from its position could not possibly have been molested, had only one, nearly ready to be hatched. Out of fifteen nests found, two included seven eggs; three, six; three, five; four, four; two, three; and one, one egg. The average number is probably five or six. The ground-color is clear, lustrous white, with a high polish. Eggs from different sets vary considerably in markings, but two types of coloration seem to prevail. In one, spots and dottings of dull brown with faint submarkings of pale lavender are generally and evenly distributed over the entire surface. In the other, bold blotches of bright reddish-brown are so thickly laid on, especially about the larger ends, that the ground-color is in some instances almost entirely obscured.

"In the hope of presenting to the reader's mind some slight idea of the general character and surroundings of the locality where the Prothonotary Warblers were found breeding in the greatest abundance, I close with a brief description of a visit, on May 11, to the Cypress Swamp. Towárds the middle of the afternoon we reached Beaver Dam Pond, and embarked in an old weather-beaten dugout. Our guide, a half-breed Indian and a most accomplished woodsman, took his station in the stern, and with a vigorous shove upon his long push-pole sent the frail craft well out into the pond. Before us stretched a long, narrow sheet of water hemmed in on every. side by an unbroken wall of forest trees. Around the margin grew a fringe of button-bushes, with a sprinkling of tall slender willows, while behind and above them towered the lightgreen feathery crests of numerous cypresses. The low shores were in many places flooded with water for a considerable distance back into the woods, to where the land rose in broken ridges and the cypresses gave way to a growth of oaks, black-walnuts, lindens, and numerous other forest trees. The depth of the water, even in the centre of the pond, did not exceed five feet, and over the greater part of its extent rank grasses, yellow water-lilies, and other aquatic plants reared their tall stalks or broad leaves in such profusion, that everywhere, except immediately around the canoe, the eye rested upon what seemed a meadow of waving green. The few acres of comparatively open water were sprinkled with water-lilies ${ }^{1}$ or thickly studded with the delicate, star-shaped blossoms of the Cabomba caroliniana; the moss-like stems of which extended in a perfect labyrinth beneath the surface. As we pushed our way through the denser growths, the stems yielded before the bow with a slight rustling sound. Wood Ducks and Hooded Mergansers rose on every side, while their broods of downy ducklings scuttled off among the water-plants, sometimes huddling close together, a dusky mass of bobbing little forms, at others, when closely pressed, separating and diving like water-sprites. Overhead, Buzzards were wheeling in graceful, interminable circlings, while in their nests upon the tops of some gigantic sycamores, a little back from the shore, stood a number of Great Blue Herons, their tall graceful forms boldly outlined against the sky. From the lower depths of the forest came innumerable bird voices, the slow, solemn chant of the Wood Thrush, the clear, whistled challenge of the 
Cardinal, the sweet wild notes of the Louisiana Water Thrush, the measured pter-dle, pter-dle, pter-dle of the Kentucky Warbler, and the emphatic song of the Hooded Flycatcher. Higher up among the trees Woodpeckers rattled upon dead limbs, a Tanager sang at intervals, the Tufted Titmouse reiterated its monotonous peto, peto, and numerous Blue Warblers added their guttural little trills to the general chorus. From all along the pond edges came the Sandpiper-like song of the Prothonotary Warblers. As we advanced, the button-bushes gave way to stretches of black willows, which at the head of the pond formed the exclusive growth over an area of perhaps six acres. This tract had at one time evidently formed part of the pond, for as we pushed our canoe in among the trees we found the water scarcely shallower than in the open portions.

"Although the willows grew rather thinly, the spaces between the living stems were filled with stubs in every stage of decay, and perforated with countless Woodpecker-holes, most of them old, and long since given up by their original tenants. That a locality so favorable in every way had not been overlooked by the Prothonotary Warblers was soon evinced by the presence of the birds on all sides in numbers that far exceeded anything which we had previously seen, and careful search soon revealed a number of nests. Probably not less than twenty pairs were here breeding in close proximity. In the larger holes and among the branches were the nests of a colony of Grackles, and a few Woodpeckers and Carolina Titmice were also nesting somewhere in the vicinity. As we returned down the pond late in the afternoon the sun was sinking behind the tree-tops. The dying breeze still agitated the crest of the forest, but not a breath rippled the still water beneath. The lonely pool rested in deep shadow, save at its upper end, where the slanting sunbeams still lighted up the group of willows, bringing out their yellowish foliage in strong relief against the darker mass behind. The arches of the grand old woods were filled with a softened, mysterious light, and a solemn hush and silence prevailed, broken only by the occasional hooting of a Barred Owl or the song of some small bird among the upper branches, where the rays of the setting sun still lingered. High in air, over the open space the Buzzards still wheeled and soared on easy wing. Ducks were scurrying about in all directions or plashing down among the lily leaves, and a heavy plunge in shore told where a startled otter had risen and disappeared. As the last rays of sunlight touched the top of a mighty sycamore that raised its towering head above its fellows, the Herons left their rookery and laboriously winged their way overhead to some distant feeding-ground. Long in the writer's memory will linger that last glimpse of beautiful Beaver Dam Pond."

NAMES: Prothonotary Warbler, Willow Warbler, Golden Warbler, Golden Swamp Warbler.-Goldsänger, Weidensänger (German).

SCIENTIFIC NAMES: Motacilla citrea Budd. (1783). PROTONOTARLA CITREA BalRd (1858). Sylvia protonotarius Wils. (1811), Nutt., Aud.

DESCRIPTION: "Back, olive-green; 'wings, rump, and tail, plain bluish-gray, or" plumbeous; head and lower parts yellow, the latter white posteriorly; inner webs of tail feathers (except middle pair) white, tipped with dusky. Adult male in spring: Entire head and neck, and lower parts, except crissum, rich mellow gamboge-yellow, varying to cadmium-yellow; top of head sometimes touched or tinted 
with cadmium-orange, occasionally tinged or washed with olive-green, but often pure yellow. Bill, uniform deep black; iris, brown; legs and feet, dark plumbeous. Adult female: Similar to the duller colored male (in winter), but yellow appreciably less pure, the pileum always olive-greenish, and gray of wings, \&c., less bluish.

"Total length, about 5.40; wing, 2.90; tail, 2.25 inches." (Ridgway, in "The Ornithology of Illinois," Vol. I, p. 119.)

\section{SW AINSON'S WARBLER.}

\section{Helinaia swainsonii Audubon.}

氛图 HIS VERY interesting Warbler was discovered by Rev. John Bachman in 1832, near Charleston, S. C., but for upwards of forty years succeeding its discovery, our bird was so nearly lost sight of that only three specimens seem to have been taken, -one in Georgia, one in.Florida, and one in Cuba. The year 1873 brought an important contribution to our knowledge of this mysterious bird from Mr. N. C. Brown, who met this Warbler at Coosada, Elmore Co., Ala. Later on it was found also in Texas, Louisiana, southern Illinois, and Indiana. In May 1883, and again in spring 1884, Mr. Wm. Brewster of Cambridge, Mass., visited South Carolina, expressly for the purpose to search for Swainson's Warbler. The result of his investigation he describes in his inimitable way in "The Auk" (Vol. II, 1885. p. p. 65-80). The paper is very long, but I cannot refrain from quoting the most interesting part of it. He writes as follows :

"While... the present species may occur at times in dry scrubby woods, or even in such open situations as orange groves, it certainly haunts by preference the ranker growth of the swamps, to which, indeed, it appears to be confined during the breeding season. In South Carolina, as elsewhere, the term swamp is somewhat general in application. As our Warbler is by no means equally general in his tastes but, on the contrary, exceptionably fastidious in the choice of a summer home, it is necessary to be more explicit. The particular kind of swamp to which he is most partial is known in local parlance as a 'pine-land gall.' It is usually a depression in the otherwise level surface, down which winds a brook, in places flowing swiftly between well-defined banks, in others divided into several sluggish channels or spreading about in stagnant pools, margined by a dense growth of cane, and covered with lily leaves or other aquatic vegetation. Its course through the open pine-lands is sharply marked by a belt of hardwood trees nourished to grand proportions by the rich soil and abundant moisture. Beneath, crumbling logs cumber the ground, while an undergrowth of dogwood ${ }^{1}$, sassafras, viburnum, etc., is interlaced and made well-nigh impenetrable by a net-work of grapevines and greenbriar. These belts-river bottoms they are in miniature-rarely exceed a few rods in width; they may extend miles in a nearly straight line, but ordinarily the brooks which they conceal form short tributaries of streams of larger size,

$$
\text { - Cornus forida. }
$$


which in turn soon mingle their waters with those of neighboring rivers. More extensive swamps, especially those bordering the larger streams, are subject to inundations which, bringing down deposits of alluvial soil, bury up or sweep away the humbler plants, leaving a floor of unsightly mud, interspersed with pools of stagnant water. Such places answer well enough for the Prothonotary and Hooded Warblers, which, although essentially swamp-lovers, are not to any extent terrestrial; but you are not likely to find SwaInson's WARBLER in them, unless about the outskirts, or on islands elevated above the reach of the floods. Briefly, four things seem indispensable to his existence, viz., water, tangled thickets, patches of cane, and a rank growth of semi-aquatic plants.

"All four conditions are fulfilled by the 'pine-land galls.' These belts, with their cool shade, running water, and luxuriant vegetation, attract many thicket-haunting birds. They invariably swarm with Cardinals, White-eyed Vireos, Carolina Wrens, and Hooded Warblers, while there are occasional pairs of Maryland Yellow-throats, and now and then a Wood Thrush, sounding his flute-like notes, or a Painted Finch, warbling softly among the bushes. From the pines outside come the sweet refrain of the Yellow-throated Warbler, the petulant cry of the Great-crested Flycatcher, and, from somewhere in the distance, the matchless reverie of Bachman's Finch.

"In the early morning, before the sun's rays have evaporated the delicate frosting of dew-drops from the fronds of the ground palmetto, or invaded the swamp, still cool and fragrant after the night, one may hear fifty birds singing in such a spot. The effect is confusing at first, but the practised ear soon identifies the various performers, and a few minutes spent in this way will often give the listener a fairly accurate idea of the bird life by which he is surrounded. Amid the general din, if he be fortunate, may be heard the song of Swainson's Warbler, a performance so remarkable that it can scarcely fail to attract the dullest ear, while it is not likely to be soon forgotten. It consists of a series of clear, ringing whistles, the first four uttered rather slowly and in the same key, the remaining five or six given more rapidly, and in an evenly descending scale, like those of the Cañon Wren. In general effect it recalls the song of the Water Thrush. It is very loud, very rich, very beautiful, while it has an indescribably tender quality that thrills the senses after the sound has ceased.

"It is ventriloquial to such a degree that there is often great difficulty in tracing it to its source. You advance confidently enough at first, when suddenly the sound comes from behind you. . Retracing your steps, the direction is again changed. Now it is to the right, shortly after to the left; one moment in the tree tops overhead, the next among the bushes almost at your feet. Hurrying hither and thither with rapidly diminishing caution you finally lose all patience and dash through the tangle, tripping over hidden obstructions or perhaps floundering in morasses at imminent risk of being bitten by some venomous moccasin. When at length you pause near the starting point, tired of the fruitless pursuit, and convinced that your will-o'-the-wisp has been momentarily changing his position, you may perchance discover him sitting quietly near the end of some low branch, where he has probably been all the while, calmly curious perhaps with respect to the strange two-legged creature rushing about beneath, but more likely lost to everything except his own ecstatic music. At times, however, he actually will flit from perch to perch as you advance, keeping more or less concealed among the foliage. 
"In addition to its song this Warbler utters a soft tchip indistinguishable from that of the Parula Warbler, but wholly unlike the cry of any Ground Warbler of my acquaintance. I heard this note on only one occasion; when the bird was excited over some disturbance in the shrubbery, perhaps the presence of a snake.

"Although a rarely fervent and ecstatic songster, our little friend is also a fitful and uncertain one. You may wait for hours near his retreat, even in early morning, or late afternoon, without hearing a note. But when the inspiration comes he floods the woods with music, one song often following another so quickly that there is scarce a pause for breath between. In this manner I have known him sing for fully twenty minutes, although ordinarily the entire performance occupies less than half that time. Such outbursts may occur at almost any. hour, even at noontide, and I have heard them in the gloomiest weather, when the woods were shrouded in mist and rain.

"When not singing Swainson's Warbler is a silent, retiring bird, spending nearly his entire time on the ground in the darkest recesses of his favorite swamps, rambling about over the decaying leaves or among the rank water-plants in search of the small beetles which constitute his principal food.* His gait is distinctly a walk, his motions gliding and graceful. Upon alighting in the branches, after being flushed from the ground, he assumes a statuesque attitude, like that of a startled Thrush. While singing he takes an easier posture, but rarely moves on his perch. If desirous of changing his position he flies from branch to branch instead of hopping through the twigs in the manner of most Warblers. Under the influence of excitement or jealousy he sometimes jets his tail, droops his wings, and raises the feathers of the crown in a loose crest, but the tail is never jerked like that of a Geothlypis, or wagged like that of a Seiurus. On the contrary, his movements are all deliberate and composed, his disposition sedentary and phlegmatic. At the height of the mating season the males do occasionally show some spirit, chasing one another among the trees, or even attacking larger birds; but these lapses, like their song periods, seem to form comparatively rare breaks in a life which, for the most part, is passed in profound quiet and seclusion.

"In these, as well as other characteristics, he is the very counterpart of the Connecticut Warbler, as I have observed the latter in the swamps about Cambridge. In none of them does he bear the least resemblance to the Worm-eating Warbler, with which he has been so closely associated by ornithologists. The Worm-eater is an active, restless bird, spending much of its time winding about the trunks and branches of trees in the manner of the Black and White Warbler. Moreover, it breeds by preference, if not invariably, in dry situations, such as tracts of oak scrub, on the steep sides of elevated ravines or mountain slopes-precisely such ground, in short, as is resorted to by the Ovenbird ....

"Judging by my personal experience, Swainson's Warbler is at all times a singularly unsuspicious bird. If singing he may be usually approached within a few yards, even though the crashing that inevitably marks your every movement among the thickly-growing canes has long ago alarmed and silenced the other songsters of the swamp. When flushed from the ground he flies in silence to the nearest low branch, whence he regards you with a half timid, half-wondering expression, precisely like that

* The stomachs of all the specimens that I have examined contained exclusively small Coleoptera. 
of the Connecticut Warbler under similar conditions. The chief difficulty is to find him, for if on the ground his coloring harmonizes so well with that of the general surface that the keenest eye may overlook him, while he is not apt to start unless almost trodden on. Like most thicket-haunting birds, however, he is intensely curious, and by concealing yourself and producing a shrill screeping or chirping you may often call him directly to you. More than once has this plan been successful when I had no idea that the bird was near. On one such occasion the victim proved a female, which had unmistakably just laid her full set of eggs. I had barely begun to 'screep' on the edge of a small cane-brake bordering a brook, and surrounded by comparatively open ground swept clear of undergrowth, and the usual débris, by a recent fire, when there was a glimmer of wings and the Warbler appeared, alighting on the stem of a cane. Upon shooting and examining her I discovered that she was incubating. As it was near noon of a very sultry day, and birds of all kinds closely hidden, I felt sure that she had come directly from the nest. This conviction became almost a certainty when, a few paces further on, I flushed and secured her mate. Needless to say, the remainder of the day was devoted to searching that thicket. But although it covered only a few square rods of surface, the nest could not be found."

Several nests were found by Mr. Wayne in the last week of June, 1885, near Charleston. He writes: "The first was built in a cane over a pool of stagnant water, at a height of about five feet; the second, also in cane, was at a height of at least eight feet, and over clear, running water. It was found when the birds had just begun work, and I watched them repeatedly at their labors. They would fly up from the ground, and, hovering like a Hawk or Kingfisher, fix the leaves in place with their bills." The first nest contained two eggs "dead white without spots"; the second three eggs of a dull white ground-color with a faint bluish tinge. One of these eggs was perfectly plain, the second one had two or three minute spots, while the third was unmistakably spotted and blotched with pale-lilac, forming a well-defined ring on the larger end. One of the nests was neat and compact, while the other one was rather bulky. The structure is usually composed of bleached straw-colored cane leaves, leaves of the sweet gum, wateroak and holly, Spanish moss, with an interior lining of pine needles and thread-like strands of black moss (Tillandsia).

NAMES: Swanson's WARBLER, Swainson's Swamp Warbler.

SCIENTIFIC NAMES: Sylvia swainsoni Aud. (1834). HELINAIA SWAINSONI Aud. (1839). Helmitherus swainsoni Brd. (1858).

DESCRIPTION: "Crown and nape, reddish-brown; remainder of upper parts, including the sides of neck, clear olive, the wings, tail, and upper tail-coverts, tinged with reddish-brown; under parts creamy white with a lemon-yellow tinge, most pronounced on the breast and abdomen, faintest on the throat and crissum; sides of body, brownish-olive; sides of breast, olivaceous-ashy, extending completely across the breast in a broad but rather indistinct band of pale, nebulous spots; throat, abdomen, and crissum, immaculate; a dusky stripe starting at the lores (which are nearly black) passes backward along the side of the head intersecting the eye and separating a conspictuous, brownish-white, superciliary stripe from the region below the eye, which is dappled with a reddish-brown on a creamy-white ground. There is also a short, yellowish, concealed median stripe on the forehead. Iris hazel; legs and feet fiesh-color. Sexes undistinguishable." (Brewster.)

Length, 5.65 inches; wing, 2.82 ; tail 2.03 inches. 


\title{
WORM-EATING WARBLER.
}

\author{
Helmitherus vermivorus BAIRD.
}

Plate XI. Fig. 5.

司高

HE WORM-Eating WARBLER is very retiring in its habits, unusually shy, plainly colored, and has no distinctive song. For these reasons it is not known to the general friend of nature, although it is not uncommon in many parts of our country. It is chiefly found south of $40^{\circ}$, being especially common in the Middle States and, perhaps, also in many parts of the South. According to my own experience, it is a rather common bird near St. Louis, and in south-western Missouri, where it frequents the wooded bluffs and steep sides of ravines. It is also found in suitable localities in southern Illinois. In southern Pennsylvania and New Jersey, in Kentucky and Tennessee, it has been observed as a more or less abundant bird.

Despite its dull color and retiring habits, the Worm-eater is a very interesting bird. It is an active, restless creature, spending much of its time on the ground, but often winding its way up the trunks and branches of trees in the manner of the Creeping Warbler. It is always in pursuit of insects. Its color harmonizes so well with the dry leaves that it is no easy task to observe it for any length of time. It searches for its food among the green foliage and blossoms as well as among the decayed leaves on the ground. Although its haunts are on dry ground, water will always be found in close proximity. Not far away we may find a cool brook, a lakelet, a spring, a river, or a pond. In Pennsylvania and elsewhere it chooses for its haunts the mountain-sides, which are densely covered with spice-bushes ${ }^{1}$, white-fringe ${ }^{2}$, witch hazel, kalmias, and azaleas. Vigorous columbines ${ }^{3}$ grow in phenomenal luxuriance, and their masses of red and yellow flowers relieve the occasional monotony of the green or glaring white colors. Ovenbirds, Chewinks, Wood Thrushes, Rose-breasted Grosbeaks, and many other songsters literally throng this beautiful idle-wild. The Worm-eating Warbler is not conspicuous among them, and we may easily mistake its song for that of the Chipping Sparrow, which it so closely resembles "that it is sometimes difficult for the most critical listener to distinguish it" (Ridgway).

The nest of this species is built on the ground, imbedded in dry leaves, and hidden by herbaceous plants, fern-fronds, or other similar objects. Nests found in West Chester, Pa., by Mr. T. H. Jackson, were composed of dead leaves, mostly those of the beech, while the interior was prettily lined with fine, thread-like stalls of hair-moss ${ }^{4}$. The eggs, four to six, but ustually five, in number, have a clear crystal-white ground, some being faintly marked with light reddish spots, while others are more heavily blotched with lavender and rich chestnut, chiefly on the larger end.

1 Calycanthus floridus and C. levigatus. 2 Chlonanthus virginica. 3 Aqtilegia canadensis. 4 Polytrichium. 
NAMES: WoRM-EATING WARBLER, Worm-eater, Worm-eating Swamp Warbler.-Wurmsänger (German).

SCIENTIFIC NAMES: Motacilla vermivora Gmel. (1788). Sylvia vermivora Lath. (1811), Wils., Nutt., Aud. Helinaia vermivora Aud. (1839). HELMITHERUS VERMIVORUS BaIRD (1858).

DESCRIPTION: Sexes alike. Head, buff or yellowish, with a broad black stripe on each side of the crown, and a narrow black stripe behind the eye. Upper parts, plain olive-green. Lower parts, buff.

Length, 5.50 inches; wing, 3.00 ; tail, 2.35 inches.

\title{
Blue-winged Yellow Warbler.
}

\author{
Helmintophila pintus RIDGWAy.
}

Plate XI. Fig. 2.

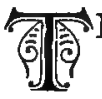
HIS BEAUTIFUL Warbler inhabits, during the breeding season, the central and, probably, also the southern portion of our country, moving north as far as the Connecticut valley; in some exceptional cases it has been found even in southern Wisconsin and Minnesota. Westward it has been noticed in Kansas and the Indian Territory. It arrives in the southern parts of its breeding range late in April, and in the more northern localities early in May. It is particularly common in southern Illinois, in many parts of Missouri, in southern Indiana and, according to the observations of Mr. J. N. Clark, in the lower Connecticut valley. We may look for this bird where the brilliant Hooded Warbler has taken up its abode. Thickets of flaming azaleas, andromedas, kalmias in woods and on woodland edges, half-cleared fields which have grown up to sprouts, rich open bottom-woods, where the "switch-cane forms a considerable proportion of the indergrowth," the BLUE-WINGed YeLLOW WARBLER seems to prefer for its haunts, being one of the characteristic birds of such localities. This bird searches for insects in the same way as do the true Wood Warblers (Dendroica). Bushes and low trees are diligently explored for food, and orchards are frequently visited, especially when the apple trees are, in full bloom. At such times it mounts the tops of bushes and fruit trees, uttering its sharp, wiry notes, which sound like $\ddot{a} r-$ ree-är-ree, and have a rising and falling inflection. The song is very similar to that of the Grashopper Sparrow. During the time when in southern Missouri the orchard trees are in full bloom, I had frequent opportunities to listen to the notes of this Warbler. They rarely pursue insects on the wing, seizing only such which live on the leaves, in crevices of the bark, and in the blossoms. The bird, as shown on Plate XI, rests on a beautiful flower truss of Kalmia latifolia.

The nest is usually built on the ground, among upright stalks, resting on a thick foundation of old leaves. Mr. J. N. Clark of Saybrook, Conn., informs me that he found nests on the ground, in sprouts, four inches from the surface, one in a small shrub, twelve inches high, and still another one in a wild rose-bush, four feet above the ground. Mr. Ridgway, who is better acquainted with the nesting habits of this bird than any other ornithologist, found the nests invariably on or near the ground. He described 
them as loose, open structures, composed chiefly of broad, thin, and flexible strips of the inner bark of deciduous trees, chiefly bass-wood. Others were built of a quantity of oakleaves, sparingly mixed with rather coarse grass and lined with finer grass. Mr. Edwin H. Eames, who observed this bird in southern Connecticut, writes about the nidification: "When the nest of this Warbler contains eggs, it is difficult to find, as the male ranges over quite an area. The nest is as conspicuous and bulky as the Maryland Yellow-throat's. It is variously situated-in the edge of a thicket, at the foot of a brier, etc., or quite as often in a clump of golden-rod (Solidago). I have seen one nest, with young, placed on a bog in the edge of swampy woods. This bog was surrounded by eight inches of water. Normally the nest rests but lightly on the ground, and measures about 4.50 inches deep externally, depends largely on surrounding grasses for concealment, fallen leaves being inconspicuously about it."

The eggs, four or five in number, have a white ground-color and are sprinkled with a few reddish-brown dots.

NAMES: Blue-winged Yellow Warbler, Blue-winged Swamp Warbler, Blue-winged Warbler. - Blauflügeliger Buschsänger (German).

SCIENTIFIC NAMES: Certhia pinus Linn. (1766). Helmintophaga pinus Baird (1858). HELMINTOPHILA PINUS RIDG Way (1881). Sylvia solitaria Wils. (1810). Helinaia solitaria Aud. (1839).

DESCRIPTION: Above, yellowish-olive, becoming ashy-blue on the wings and the tail; underparts and crown show a rich yellow; a blackish stripe through the eye; wings with two white cross-bars; tail with several white large spots. Sexes alike.

Length, 5.00 inches; wings, 2.50 ; tail; 2.25 inches.

\section{GOLDEN-WINGED WARBLER.}

\section{Helmintophila chrysoptera RIDGWAy.}

Plate XI. Fig. 4.

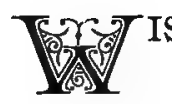

ISCONSIN and other Northern States abound, even in cultivated districts, in swamps and boggy places with a rich peaty soil. Very frequently these swamps are found surrounded by fields and meadows or on the borders of woods. Not many years ago a heavy growth of white cedars, tamaracks, and ash-trees covered these swampy tracts. Most of the trees were cut down, only small specimens being left undisturbed. There is, during the entire summer, something fascinating about these swamps - their exceedingly beautiful flora, their gloom in daylight, their freshness in the dry days of July and August, their rich bird-life, their ever-present mystery. The places once occupied by large forest trees are now taken up by elders, willows, exceedingly beautiful specimens of the red osier ${ }^{1}$, the kinnikinnik ${ }^{2}$, the panicled dogwood ${ }^{3}$, the sheep-berry ${ }^{4}$, the black-haw ${ }^{5}$, and other shrubs. The leather-wood ${ }^{6}$, huckle-berries of various species,

1 Cornus stolonifera. 2 Cornus sericea. a Cornus paniculata. \& Viburnum lentago. i Viburnum prunifolium. a Dirca palustris. 


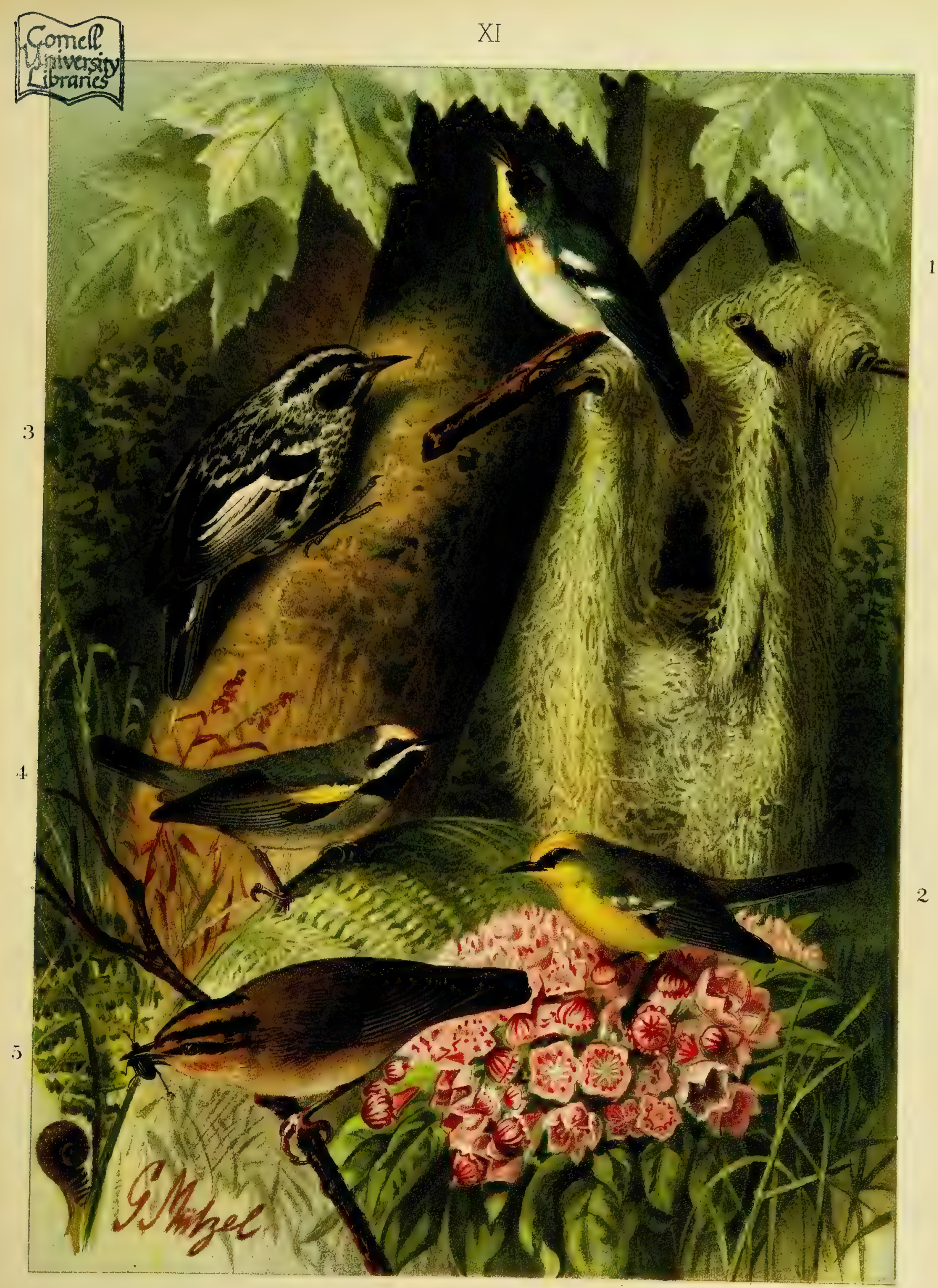

1. COMPSOTHLYPIS AMERICANA CAb 2. HELMINTHOPHILA PINUS RICSW 3. MNIO'TILTA VARJA Vieill.

4. HELAINTHOPHILA CHRYSOPTERA Ridgiw 5. HELMITHERUS VERMIVORTS BP.
MEISENSÄNGER. -. BLAUfLÜgELSÄNGER. - KLETTERSÄNGER. GOLDFLÜGELSÄNGER. WURMSÄNGER.
Parula Warbler Blue-winged Warbler. Black and white Warbler. Golden-winged Warbler. Worm-eating Warbler. 

the aromatic black currant ${ }^{1}$, the cranberry, the wild goose-berry ${ }^{2}$, and the winter berry $^{3}$, are also more or less common. Ferns revel in this black spongy soil, and so does the common meadow sweet ${ }^{4}$, the scouring rush ${ }^{5}$, and a large number of swamp grasses. The wild balsam ${ }^{6}$, the swamp butterfly weed ${ }^{7}$, and the poke milk weed ${ }^{8}$, grow in rank luxuriance. The gorgeous cardinal-flower ${ }^{9}$ shows in midsummer the most vivid red of the year- "a red that seems endowed with conscious life, so glowing is its fire," says Mr. George H. Ellwanger in his classical book "The Garden's Story." Growing near it we find the blue lobelia ${ }^{10}$, also a very conspicuous flower, and, occasionally, a plant of the fragrant snake-head ${ }^{11}$. In these localities the elegant vase-like blossoms of the fringed gentian ${ }^{12}$, and in September those of the closed gentian ${ }^{13}$ may be found. I always admired the white wax-like, bell-shaped blossoms of the leather-leaf ${ }^{14}$ and the common andromeda ${ }^{15}$, both being at home only in this spongy cool soil. There are also Turk's caps and Canada lilies, purple eupatoriums, evening primroses, pink epilobiums, all jostling and striving for supremacy. In early spring the bush and treeless edges of these swamps are covered with a broad cloth of gold by the sheet of flowers of the marsh-marigold ${ }^{16}$, indeed a sight ever to be remembered. Near by we may see the immense leaves of an interesting aroid, the skunk-cabbage ${ }^{17}$. The blue flag ${ }^{18}$ grows always in great luxuriance where water stands. Jack-in-the-pulpit ${ }^{19}$ is also very common, but "it looks more like a snake than a flower." Its dazzling red but poisonous heads of berries arrest our attention late in summer.-Few realize the richness of our native flora, and comparatively few are acquainted with the charming plants of these cool, moist swamps. The most beautiful of Flora's children are the lovely terrestrial orchids, many of which are still found common in such peaty tracts. The showy lady's slipper ${ }^{20}$ grows here often two feet high, the white flowers with their globular lips embellished with pink-purple being exceedingly charming. The yellow lady's slipper ${ }^{21}$ is also very magnificent, growing in great abundance in the shade and opening its uniform yellow flowers early in June. The purple-fringed orchis ${ }^{22}$, a plant of marked beauty, was once common, but of late years I rarely had an opportunity to cull its brilliant purple-violet, fragrant flowers. Habenaria leucophæa and $H$. lacera, with greenish flowers, are more common. Arethusa bulbosa, also a lover of wet, cool places, is a charming orchid. At the top of the stem it bears a single, large, fragrant flower of a rich rosy purple color. The Calopogon pulchellus, or grass pink, with its beauteous pink flowers ranks next to the lady's slipper. Pogonia ophioglossoides grows frequently side by side with the grass pink, opening its pale rose, sweet-scented flowers at the same time. The two ladies'-tresses (Spiranthes latifolia and S. cernua) are also very interesting and fragrant. These are only a few, the most beautiful, plants of our northern swamps. In the East such localities are much more ornamental, as there the ericaceous plants flourish in great abundance. Side by side with the fragrant rhodora ${ }^{23}$, the broad-leaved labrador tea ${ }^{24}$ is often to be found. The sweet-scented white alder ${ }^{25}$ often grows in the same swamps where the magnificent great rhododendron ${ }^{26}$ abounds. The swamp honey-suckle or

1 Ribes foridum. 2 Ribes roduntifolium. 3 Ilex verticillata. 4 Spiraa salicifolia. 5 Equisetum. 6 Impatiens pallida. 7 Asclepias incarnata. 8 Asclepias phytolaccoides. 9 Lobelia cardinalis. 10 L. syphilitica. 11 Chelone glabra. 12 Gentiana crinita. $13 \mathrm{G}$. Andrewsit. 14 Cassandra calyculata. 15 Andromeda polifolia. 16 Caltha palustris. 17 Symplocarpus foditus. 18 Iris versicolor. 19 Arisama triphylium. 20 Cypripedium spectabile. 21 Cypripedium pubescens. 22 Habenaria psycodes. 23 Rhodora canadensis. 24 Ledum latifolium. 25 Clethra alnifolia. 26 Rhododendron maximum. 
clammy azalea ${ }^{1}$, the fragrant pinxter flower ${ }^{2}$, and the flame-colored azalea ${ }^{3}$, the dazzling flowers of which vie with the glories of aurora and the hues of the setting sun, are in many places the predominating shrubs of the eastern swamps.

I mentioned the ever-present mystery of these swamps, and this is not only true in regard to the plants but even more so in regard to the animal life. If surrounded by fields and meadows, or if situated on the borders of woods, these swamps harbor a large number of birds. The inimitable song of the Veery, and the enchanting notes of the Golden-crowned Thrush, we nowhere else hear so frequently. The clamoring sounds of the Blue Jay, the busy mallet beating of the Downy and Red-headed Woodpecker on hollow trees, the fine call-note of the Brown Creeper running up and down and around the limbs of tree-trunks in quest of food, the caressing chicka-dee-dee of the Blackcapped Titmouse, the solemn yank, yank of the Nuthatch, are common sounds during the fine days of June. One of our most admirable writers on nature, Mr. Geo. B. Ellwanger, says :

"The swamp is nature's sanctuary - the great game-keeper and game-protector. It is the rampart of the landscape. Within its sheltering arms is matured the most beautiful of sylvan utterances, the roll-call of the Ruffed Grouse. Without its helping hand both furred and feathered game must in many localities become virtually exterminated, and a wood without game is a wood devoid of one of the most individual attributes."*

In these swamps the Swamp Sparrow, our familiar Catbird, one of the best songsters we have, the White-eyed Vireo and many others find a congenial home. Near the edges we may look for the bright Maryland Yellow-throat and the pretty Mourning Warbler, while the Black-throated Blue Warbler leads a more solitary life amidst the dense shrubs.

In the foregoing introduction I have delineated the true home of the GOLDENWINGED WARBLER, the subject of this sketch. In such localities our beautiful little bird is by no means uncommon, but we have to keep a sharp lookout, in order to discover it in the dense vegetation. It generally appears in the middle of May, when the orchard trees and white-thorns are in full bloom. When it hops around among the new leaves or snowy white blossoms in quest of insect food, it is not shy, being easily observed. Even at a distance it may be readily distinguished by its rich yellow crown and broad wing-bars of yellow, its black throat, the black stripe through the eye, and the slatyblue back. In its summer-haunts it usually searches for insects in shrubs, but during migration it visits in company with other species of the same family the flowering orchard trees, procuring its food precisely in the same manner as the true Wood Warblers (Dendroica). In Texas I found it common in spring, usually at the time when the great magnolia blooms exhaled their delicious perfume. In south-western Missouri it was a rare migrant in April. In Wisconsin I have never noticed its arrival before May 15. It is a bird of eastern North America, its dispersion being limited in the West. Mr. N. S. Goss, in his model "Catalogue of the Birds of Kansas," does not enumerate it. Its breeding range extends from the mountainous regions of northern Georgia northward.

1 Azalea riscosa. 2 A, nudifora. 9 A calendulacea.

"G. B. Ellwanger, "A Garden's Story," p. 253 
Mr. R. Ridgway found it breeding along the southern edge of Calhoun Prairie, Richland Co., Ill. I cannot find any authoritative record as to its most northern breeding place, but I think it migrates not farther north than southern Canada. Since my boyhood this beautiful bird is one of my favorites. I always found it in the localities described. I never saw it during the breeding season in open woods or on high ground. After the young were able to shift for themselves they frequently entered, in company with the old birds, the orchards and ornamental shrubberies, leaving late in August or early in September for the South.

The males arrive first from their winter quarters in Cuba, Costa Rica, Guatemala, and even from Bogota, usually singly, frequently in company of other Warblers, the females following five to six days later. I have never heard a note during their stay in south-eastern Texas, save a sharp wiry call-note sounding like tseep. Only in their breeding grounds the full original song may be heard. Their notes are not very loud, but sweet and thrilling, resembling much the joyous lay of the Maryland Yellow-throat. While the bird hops around in the branches of low shrubs in quest of food, it sings almost incessantly, particularly on the bright balmy days of June. Its food, consisting almost entirely of small insects infesting the leaves and blossoms of shrubs and trees, is collected from the bark, the leaves, and flowers. I have never noticed it catching flying insects, and it very rarely searches the ground for food. We may usually see it near old moss-covered logs, where ferns, huckle-berries, black currants, terrestrial orchids cover the rich soil. Male and female are always close together, but it is exceedingly difficult to find the nest in this dense vegetation. I have observed the birds many a season closely, searched almost every inch of the ground where they hopped around in distress, but only accidentally I discovered several nests. They were found 1875 and 1876, in Sheboygan Co., Wis., in swamps on the ground. One was placed under the fronds of a fern, another near an old moss-covered $\log$, and a third one under a dense huckle-berry bush. All resembled closely the nests of the Maryland Yellow-throat. Externally they were composed of strips of bark and grasses, lined with finer grasses and pine-needles. They rested on a thick layer of old dry leaves. One nest contained five, the other two four eggs each, of a white ground-color, speckled more or less thickly with reddish-brown, chiefly at the larger end. As the old birds were observed almost daily until the young were able to leave the nest, there can be no question as to their correct identification. When breeding the birds were rather shy and retired, but as soon as the nests contained young, they always hopped around in great excitement when I approached their hidden domiciles.

Nests found by other ornithologists in eastern Massachusetts were built in the same manner. The late Dr. Gerhardt found this Warbler breeding in Whitfield Co., Ga.

NAMES: GoLdEN-WINGED WARBLER, Blue Golden-winged Warbler; Golden-winged Swamp Warbler.-Goldflügelsänger (German).-Fauvette chrysoptère (Vieill.); Figuier aux ailes dorées (Buff.).

SCIENTIFIC NAMES: Motacilla chrysoptera Linn. (1766). Sylvia chrysoptera Lath. (1810), Wils., Nutt., Aud. Helinaia chrysoptera Aud. (1839). Helmintophaga chrysoptera Cab. (1850). HELMINTOPHILA CHRYSOPTERA RIDGw. (1882).

DESCRIPTION: "Above, slaty-blue; below, whitish, frequently tinged with yellow; crown of head and two bars on the wing, rich yellow: side of head, whitish, with a broad bar of black from bill through eye; 
a large black throat-patch; white blotches on several tail-feathers; bill, black. Female and immature specimens have the back and wings glossed with yellowish-olive, and the peculiar markings of the head and throat obscure.

"Length, 5.00 to $\mathbf{5 . 2 5}$ inches; wing, 2.50 to $\mathbf{2 . 7 5}$, tail, 2.25 inches." (Stearns and Coues, "New England Bird Life," I, p. 115.)

\section{LUCY'S WARBLER.}

Helmintophila luciz RıdWay.

LuCy's WARBLER inhabits the valleys of the Colorado and Gila Rivers in Arizona and occurs south into Mexico. According to Dr. Elliott Coues this Warbler reaches the vicinity of Fort Whipple, Arizona, which is pretty high among the mountains, about the middle of April and remains until the latter part of September, if not longer. These Warblers certainly breed there, for Dr. Coues observed newly fledged young in May. Captain Bendire discovered a nest with eggs of this species near Tucson, Arizona, May 19, 1872. The structure was placed between the loose bark and the trunk of a dead tree, a few feet from the ground, similar to that of our Brown Creeper. In the same locality, Mr. F. Stephens found the birds abundant in 1882. They frequented the willows along the banks of streams, and spent much time in searching for insects on the outer branches. Many nests and eggs were examined after May 8 . The situation of the nests varied considerably, the characteristic place being like that found by the well-known ornithologist and oologist, Captain Bendire, but nests were also built in deserted Woodpecker's holes, knot-holes, and other crevices, and a brood of young was found in the deserted domicile of the Verdin. The eggs, usually four in number, are white, sparsely spotted with brown and black, chiefly at the larger end.

NAMES: LuCY's WARBLER.

SCIENTIFIC NAMES: Helmintophaga lucia Cooper (1862). Mniotilta luciz Giebel (1875). HELMINTOPHILA LUCIAE RIDG WAY (1882).

DESCRIPTION: "Clear ashy-gray. Beneath white, with a faint tinge of buff on the breast. A rich chestnut patch on the crown, and upper tail-coverts of the same color. A white eye-ring. Quills and tailfeathers edged with the color of the back, or whitish. Lateral tail-feather with an obscure whitish patch. Lining of wing white. Feet dull lavender-olive. Iris dark brown or black.

"Length, 4.33 inches; wings, 2.25; tail, 1.75 inches." (Coues).

\section{VIRGINIA'S WARBLER.}

Helmintophila virginiz RIDG Way.

This Warbler inhabits the Rocky Mountain region, from Colorado, Utah, and Nevada southward. In some portions of that region Virginia's Warbler is quite abundant. Prof. Ridgway found it common in the East Humboldt and Wahsatch Mountains, where it was breeding in thickets of scrub-oak. A nest with eggs, discovered by him, was imbedded in a thick layer of old decaying leaves, which covered the ground. Its rim was even with the surface. It was built under dense oak-bushes, on the side of a narrow ravine, at the bottom of which was a small stream. The material consisted 
of loosely interwoven strips of bark of the "mountain mahogony," fine grasses, mosses, and slender rootlets, and was lined with the fur of some small quadruped. The eggs were four in number, the ground-color of the same being white, with a slight roseate tinge; they were profusely spotted with numerous small blotches and dots of purplishbrown and lilac; especially at the larger end.

Mr. Aiken found Virginia's Warbler in various parts of Colorado, especially along the eastern base of the mountains, where, in its favorite haunts, it sometimes outnumbers all the other Warblers put together. It is a shy and timid species, generally darting, with its sharp notes of alarm, into its place of concealment when approached. In summer, it frequents the scrub of the hill-sides, at an elevation up to about 7,500 feet, but during the migrations it is found alternately in the pine forests and among the cotton-woods and willows along the streams. "The male is very musical during the nesting season, uttering his sweet ditty continually as he skips through the bushes in search of his morning repast; or having satisfied his appetite, he mounts to the top of some tree in the neighborhood of his nest, and repeats at regular intervals a song of remarkable fullness for a bird of such minute proportions. . . No bird with which I am acquainted conceals its nest more effectually than this Warbler. This is placed at a tussock of grass among oak-bushes, being sunk in a hollow scratched in the earth, so that the rim of the nest is on a level with the surface. The overhanging grass of the tussock hides all so completely that the nest is only to be discovered by the most careful and persistent search. About the 1 of June, five white eggs, delicately speckled with reddish-brown are laid."

NAMES: VIRGINIA's WARBLER, Rocky Mountain Warbler.

SCIENTIFIC NAMES: Helmintophaga virginize BAIRD (1680). HELMINTOPHILA VIRGINIAE RIDGWAX (1882).

DESCRIPTION: Ashy-plumbeous on back, top and sides of head. Below dull whitish, the sides shaded with asly. Lining and edge of wings white. Upper and under tail-coverts, and isolated spot on the breast, yèllow, in strong contrast with all surroundings. A white ring around the eye. Crown with a chestnut-brown patch.

Length, 4.75 inches; wings, 2.25 ; tail, 2.25 inches.

\section{NASHVILLE WARBLER.}

\section{Helmintophila ruficapilla RIDGWAY.}

क雨 HE NASHVILLE WARBLER is a common bird in many parts of our country during the migration, especially in the East, from the Atlantic to the Mississippi and the Plains. It breeds from northern Illinois northward. In New England it is chiefly limited southward in the breeding season by the Alleghanian Fauna, though it also nests sparingly in the Carolinian, as far as the mountain regions are concerned. In Texas I observed these birds always in the first and second week of April, and in 
south-western Missouri never before April 28. In central Wisconsin they are seen about May 10, and by the 26 of that month the last have migrated northward or retreated to the coniferous woods, where they breed. During migration they habitually frequent the bushy borders of woods, openings, shrubbery, and orchards about houses, often even visiting city gardens and parks. As their color is not bright, they are easily overlooked, even when quite abundant. They are very active and industrious, being almost continually in motion. According to my experience they are more sociable than other members of the genus, often as many as a dozen searching one tree for insects, especially in fall. In spring rarely more than two are seen together.

Their summer haunts are preferably high dry pine-woods with a more or less dense growth of small shrubs, ferns, and herbaceous plants. Here they lead a quiet and retired life, and, like their allies, place their nest upon the ground. I have never been able to discover their domicile, although the birds are not uncommon during the breeding season in Wisconsin, my native state. The best account on the nesting habits of the Nashville Warbler has been given by Prof. J. A. Allen, the President of the American Ornithologist's Union. Referring to Springfield, Mass., he says: “Abundant in May and in early part of autumn. Arrives May $\mathbf{1}$ to 5, and for two or three weeks is a common inhabitant of the orchards and gardens, actively cleaning insects among the unfolding leaves and blossoms of the fruit-trees. Nearly all go north, but a few retire to the woods and breed. During June, 1863, I frequently saw them in my excursions in the woods, often three or four males in an hours walk. Its song so much resembles that of the Chestnut-sided Warbler, that it might readily be mistaken. To this cause, and to the difficulty of seeing such small birds in the dense summer foliage, is doubtless owing to the fact of its being so commonly overlooked by naturalists during the summer months, rather than to its [supposed] extreme rarity in this latitude at that season. I have found the nest of this species for two successive seasons, as follows: May 31, 1862, containing four freshly laid eggs. The nest was placed on the ground, and protected completely, concealed above by the dead grass and weeds of the previous year. It was composed of fine rootlets and dry grasses, lined with fine dried grass and a few horsehairs, and covered exteriorly with a species of fine green moss. The eggs were white, sprinkled with light reddish-brown specks, most thickly near the larger end.... The following year, June 5, 1863, I found another nest of this species within three or four feet of where the one was discovered the previous year, containing three eggs of this species and one of the Cow-bunting; in all of which the embryos were far advanced. The nest, in every particular, was built and arranged like the one above described, and the eggs must have been laid at just about the same time... The locality of the nests was a mossy bank at the edge of a young woods, sloping southward, and covered with bushes and coarse grass."

Wilson discovered this Warbler near Nashville, Tenn., from which fact it was named by him NaShVILLE WARBLER.

A variety, the Calaveras Warbler, Helmintophila ruficapilla gutturalis RidGWAY, occurs in the western part of our country, from the Rocky Mountains to the Pacific. 
NAMES: NAShvir.e WarbeEr, Nashville Swamp Warbler, Naslville Worm-eater.

SCIENTIFIC NAMES: Sylvia ruficapilla Wils. (1811). Helmintophaga ruficapilla Brd. (1858). HELMINTOPHILA RUFICAPILLA RIDGw. (1882). Helinaia ruficapilla Aud. (1839).

DESCRIPTION: Above, dull olive. Back of head, slate; crown with a concealed chestnut-brown patch. Below, bright yellow. No superciliary stripe and no white wing-bars. In female, head markings indistinct, and chestnut-brown crown patch often wanting.

Length, 4.60 inches; wing, 2.40 ; tail, 1.85 inches.

\section{ORANGE-CROWNED WARBLER.}

Helmintophila celata Ridoway.

"During the seasons of migration," says Prof. R. Ridgway in his "Ornithology of Illinois," "this species is occasionally common, but some years appears to be very rare if not wanting altogether. It possesses no special characteristic of habits or song, in which respects it resembles the other members of the genus," especially the Nashville Warbler. In the Eastern States and New England it is rare. I found it rather common in south-western Missouri, in northern Illinois, and in Wisconsin during the spring migration. In Lee Co., Texas, it was from April 6 to April 15 an abundant bird. In the mountainous regions of the West it seems to be more abundant than anywhere else. Mr. Ridgway found it very abundant during autumn in the mountains of Nevada and Utah, and a rather common bird in the higher woods of the Wahsatch Mountains, where it was breeding. "Its summer home extends far to the northward, even to the shores of the Arctic seas, and it breeds abundantly throughout the Yukon valley in Alaska, quite to the shores of Norton Sound, and thence eastward to the McKenzie River district, from which region numerous nests have been received at the National Museum." The domicile does not differ from those of others of this group, being placed on the ground under low bushes. The eggs are white, marked with spots and blotches of reddish-brown and purplish slate.

A variety, the Lutescent WARBLER, $H$. celata lutescens Brewster, occurs on the Pacific coast, eastward, during the migration, to the Rocky Mountains, and northward to Kadiak, Alaska.

NAMES: Orange-crowned Warbler, Otange Crown.

SCIENTIFIC NAMES: Sylvia celata Say (1823). Vermivora celata Nutt. (1810). Helmintophaga celata Brd. (1858). HELMINTOPHILA CELATA RInGW. (1882).

DESCRIPTION: Above, olive-green, lightest on the rump. Below, greenish-yellow; a concealed orange-browı patch on the crown. Female, similar, but with little or no orange-brown on the crown.

Length, 4.70 inches; wing, 2.25 ; tail, 2.00 inches.

TENNESSEE WARBLER.

Helmintophila peregrina RınGwy.

The Tennessee WARBLer is not uncommon during the migration in the Mississippi valley, but in the Eastern States and New England it appears to be nowhere very numerous. I have observed it in south-eastern Texas early in April, and in south-western 
Missouri it was very abundant in the last week of April. The last was observed in Texas about April 20, and the first was seen in Milwaukee, Wis., May 8. Its breeding range is from northern Wisconsin and Minnesota northward. Westward it occurs to Colorado, a state which is the western limit of many eastern species, such as the Parula Warbler, the Baltimore Oriole, the common Bluebird, the Indigobird, and others.

Occasionally our bird breeds in the northern part of the United States. Barnston found a nest at Michipicoton, Lake Superior, and Prof. Horsford another one at Springfield, Mass. Both nests were built on the ground and the eggs were similar to those of other species, being white and marked on the larger end with brown spots.

During their wanderings to the North and back they are very quiet birds, uttering at long intervals feeble cricket-like sounds. They arrive very quietly and depart in the same unostentatious manner. The Tennessee Warbler belongs to the less bright-colored species of its family. It resembles, especially late in the season, the two preceding Warblers, not only in its ways and manners, but more so in color. For this reason it is not known except to the ornithologist.

It winters in Costa Rica, Guatemala, Panama, and the northern part of South America.

NAMES: Tennessee Warbler, Tennessee Swamp Warblet.-Fauvette du tẹnnessée (Vieillot).

SCIENTIFIC NAMES: Sylvia peregrina Wils. (1811). Vermivora peregrina Bp. (1838), Nutt. Helmintophaga peregrina Cab. (1850). HELMINTOPHILA PEREGRINA RIDGw. (1882).

DESCRIPTION: Above, yellowish-olive; no crown patch; lores, eye-ring, whitish. Underparts, dull whitish or yellowish. Female, similar but duller.

Length, 4.60 inches; wing, 2.75 ; tail, 2.00 inches.

Bachman's Warbler, Helmintophila bachmani RIDGw., is a but little known species. It was discovered in July, 1873, by Rev. Dr. John Bachman, near Charleston, S. C., and in the same vicinity he afterwards discovered a few more. He describes this Warbler as a lively, active bird, gliding among the branches of the thick bushes, occasionally mounting on the wing and seizing insects in the air, in the manner of a Flycatcher. Its nest and eggs remain unknown.

Brewster's WARBLER, Helmintophila leucobronchialis Brewsted, has been supposed a hybrid between $H$. pinus and $H$. chrysoptera, but Prof. Robert Ridgway feels convinced that Mr. Brewster expressed the exact truth when he stated (Nuttall Bulletin, III, p. 99) that "the validity of this distinctly characterized species must now be regarded as established." This beautiful bird is known to occur in Virginia, New Jersey, New York, Connecticut, Massachusetts, Michigan, etc. Nest and eggs still remain unknown.

Lawrence's Warbler, $H$. lawtencei Herrick, and the Cincinnati Warbler, $H$. cincinnatiensis RIDGw., seem to be hybrids, probably between $H$. pinus and $H$. chry. soptera. 


\section{PARULA WARBLER.}

Compsothlypis americana CABANIS.

Plate XI. Fig. 1.

TN SOUTH-EASTERN TEXAS, April is the month of fragrance and beaty: At this 6 time not only the gardens abound in deliciously scented tea roses and gardenias, in gorgeous amaryllis and fragrant daffodils, but the woods are made especially attractive by the colors and forms of many indigenous flowers. It affords great pleasure to ramble about; even the monotonous post-oak woods in Lee County unfold charms which our gazing eyes did not expect to behold. The trees, mostly post-oaks, do not stand close together. Here and there we find sunny spots where beautiful cacti, especially Echinocereus cæspitosus, Echinocactus Texensis, Mammillaria applanata and others, open their somewhat fugitive but exquisite blossoms. Underneath the trees the ground is carpeted with masses of brilliant phlox, fragrant nemastylis, and commelynas, together with cooperias, coreopsis, and bunches of soft white wool-plants ${ }^{1}$. Indeed, the flowers are so manifold that lack of room makes it impossible to enumerate them. Many of the forest trees are overgrown with grape vines, especially with the winter or frost grape, the greenish flowers of which exhale a strong fragrance which the gentle breezes carry far through the woods. In many places the irregular forms of the post-oaks are densely draped with soft greenish-gray lichens ${ }^{2}$ which hang down in graceful festoons, imparting to the landscape a very singular appearance. April is also the time when many of our more delicate birds are on their way to their northern habitat. Some trees literally swarm with Warblers of different species, and peculiar notes and strange forms we may perceive in each walk which leads us through stretches of woodland. Thousands of flowers, and great numbers of merry birds, the flute-like notes of the Cardinal Grosbeaks, the enchanting song of the Mockingbird and the Carolina Wren, lead us to the conclusion that nature can hardly be arrayed with more beauty and poetry than is here displayed to our rapturous delight.

During my four yearș' stay in 'Texas, rarely a day in April and May passed by on which I did not ramble through field and forest. The air at this time of the year is exceedingly soft and bracing. On my way to the West Yegua Creek, I had to pass a piece of woodland, where the Usnea lichens grew in great luxuriance on almost every branch of the post-oaks. Not many birds take up their abode in these lichencovered trees. Blue-gray Gnatcatchers, Tufted Titmice, Red-eyed Vireos, Wood Pewees, Great-crested Flycatchers, and Mourning Doves form the majority, but the most characteristic are the Acadian Flycatcher and the tiny PARULA WARBLER, also called the Blue Yellow-BACKed Warbler, a very attractive and beautiful species. From April 20 to Sept. 10, this bird was found to be rather common. - About May 5, I noticed its arrival in south-western Missouri, in Wisconsin never before May 10. 
According to the state of the weather it arrives now earlier, now later. As a rule, it makes its appearance when the apple trees are in full bloom.

Wherever the Usnea lichens grow abundantly the Parula Warbler is a common bird, nesting invariably in the dense tufts which hang down from the branches, in the high woods as well as in the dense forests of the lowlands. From Maine and Canada to Texas, it seems to make itself at home wherever it can find a suitable nesting place. If we watch closely its actions and manners in such localities, we may readily notice that it prefers such trees and bushes which are draped with festoons of long, light green, beardlike moss. With the agility of a Titmouse it climbs about among the lichen-covered branches, and with the dexterity of a true Warbler it hunts among the leaves and flowers for insects. My small cabin near the West Yegua Creek, in Texas, was surrounded by forest trees, many of which were draped with lichens. Here I had an excellent opportunity to observe these beautiful Warblers. My attention was first called to the bird by its wiry, rather shrill notes, sounding like chirr-rirr-irr-reeh which came from all sides. I can hardly imagine a more lively and charming bird than the Parula Warbler in its habitat of lichens and mosses. Incessantly it hops from branch to branch. Now it rests a moment, and, holding its bill erect, chirps its short lay; the next moment it creeps through the pendulous lichens, or is in pursuit of an escaping insect; then it returns to the tree, and again sings its brief notes, which are very savory to the ear. By its lively ways, its song and beauty it contributes much to the charms of these woods.

During the first week of May, in the North early in June, we may find the nest. This is as peculiar as it is beautiful. It is always built in one of the many beard-like tufts of lichens. The building of the nest is easily accomplished. The bird simply enters the matted pendulous tuft, shapes in the center a small cavity, lining it with the same material, and the nest is finished. The entrance is usually on one side of thetruss and scarcely visible. Occasionally we find nests which are open above. The dimensions of these beautiful nests vary considerably, differing according to the size of the tufts of lichens in which they are.placed. One nest which I found was 8 inches long and 5.50 inches in diameter. The entrance was 3 inches from the top and hardly visible. (See plate XI, fig. 1, and the nest below.) .

- The slightest breeze swings these hanging structures to and fro.-Some nests are very long. Mr. J. M. Wade informs me that he saw one which was 21.50 inches long. He also states that in some places the Parula Warblers are so common as to form almost a regular colony. In 1881 he found near Norwich, Conn., in a small group of trees from five to six new nests and several old ones.

As the bunches of lichens containing nests are not in the least different from other tufts on the same or neighboring branches, the difficulty of finding a nest becomes evident. The only way to success is the most patient vigilance. Where you see a bird enter'abunch in a timid and stealthy manner you may expect to find a nest. Assuredly, these lichen or moss nests afford to our beautiful birds the best of protection against their many enemies. According to my observations in Texas, snakes, squirrels, Blue Jays, and other marauders rarely, if ever, destroy these nests, and the obnoxious Cowbird is prevented from laying its eggs in the domiciles of the Parula Warbler. This 
may be an explanation why this bird is common in so many different localities. Its occurrence in regions where no lichens and mosses are to be found on the trees was for many years inexplicable to me, being unable to imagine how the bird could nest in such localities. One of our most prominent ornithologists, Mr. Otto Widmann, of St. Louis, Mo., presents the following explanation: "This year (1885) I have found a nest of the Parula Warbler in a place where I did not look for it. You doubtlessly have seen bunches of straw, grass, dry leaves, etc., attached to branches of trees, being touched by the water during freshets. In such a bunch, attached to the end of a birch tree branch hanging over the water, I found the nest of the Parula Warbler. In structure this nest is similar to other nests of this bird with the exception that the straw and leaves take the place of the lichens and mosses."

The usual number of eggs laid by this Warbler is four, sometimes five. The groundcolor is pearly-white, glossy, speckled with rusty-brown and chestnut. In many cases the spots form a wreath near the larger end.

The Parula Warbler ranges from the Atlantic to the Plains, north to Canada. In Connecticut, Wisconsin, Illinois, Michigan, New Jersey, and most of the States bordering the Atlantic it seems to be common. It winters in the West Indies and Central America, in Florida and eastern Mexico.

NAMES: Parula Warbler, Blue Yellow-backed Warbler.-Flechten-, Moossänger (Getman).

SCIENTIFIC NAMES: Parus americanus Linn. (1758). Parula americana Bonap. (1838). Sylvicola americana Aud. (1839). COMPSOTHLYPIS AMERICANA CABANIs (1850). Sylvia pusilla Wils.

DESCRIPTION: Above, ashy-blue, back with a golden-brown patch; beneath, yellow; belly, white; a reddishbrown patch accross the breast; a small white spot on either eyelid; two conspicuous white bands across the wings; outer two tail-feathers with a white spot. Bill, black above, yellowish below. Female, similar, with less brown on the breast and back; blue, not so light.

Length, 4.75 inches; wing, 2.30 ; tail, 1.80 inches.

\section{SENNETT'S WARBLER.}

Compsothlypis nigrilora STEJNEGER.

SENNETT's WARBLER is a bird of the Rio Grande region of Texas, where it was discovered by Mr. Geo. B. Sennett, in 1877.* It is truly a bird of the forest and delights to be in the upper branches of the tallest trees. After reaching Lomita, April 8, 1878, Mr. Sennett met this pretty little Warbler frequently. The song of the male is at this time almost continuous as it flits about, its notes are so clear that they can be heard at a long distance, and may be readily distinguished from those of all other birds. In feeding habits, Mr. Sennett saw nothing different from our familiar Parula Warbler. On May 17, a nest containing one egg was found. It was an exceedingly beautiful and interesting structure and was built in a gray mistletoe-like orchid, an air-plant very common on the Rio Grande, which establishes itself on the small branches of trees, and varies in size from 8 to 10 inches in diameter. "This one was 6 inches long by 4.50 inches wide, quite firm in texture, and was fastened some ten feet from the ground,

- See "Bulletin of the United States Geological and Geographical Survey of the Territories," Vol. IV, p. 11, 12, and vol. V, pp. 384-386. 
to the end of a drooping branch of a brazil-tree in open woodland. The nest was constructed very simply, being formed by parting the gray leaves of the orchid and digging into its centre from the side, a cavity some 2 inches in diameter being made, with an opening of 1.50 inches. The bottom and sides were lined pretty well up with short cottony wood-fibres, forming a fine matting for the eggs to rest upon. A firmer and more secure nest is seldom seen, although so easily made. I imagine a day would complete one, and certainly but little time need be wasted in selecting a site, for thousands of orchids stand out on the partially dead branches or on trees with little foliage. That they build also in the hanging trusses of Spanish moss, so abundant everywhere, is true, as young were found in a nest in one." (Sennett.) The eggs are very similar to those of the Parula Warbler.

NAMES: SENNETT'S WARBLER.

SCIENTIFIC NAMES: Parula nigrilora Coues (1878). COMPSOTHLYPIS NIGRILORA STEJN. (1884).

DESCRIPTION: Male, "above bluish-gray, or plumbeous, relieved by olive-green patch on back and two broad white wing-bands; lores, deep black; chin, throat, chest, breast, and sides, gamboge-yellow, deepening into a more saffron tinge on chest; rest of lower parts white, the flanks usually tinged with brown. Adult female: Much duller than male, the upper parts tinged with olive-green, lores dull grayish-dusky, yellow of lower parts paler and duller." (Ridgway.)

Length, 4.50 inches; wing, 2.10 ; tail, 1.66 inches.

\section{CAPE MAY WARBLER.}

\section{Dendroica tigrina BARD.}

The pretty but rare CAPE MAY WARBLER occasionally visits with other species the blooming orchard trees in the Northern and Middle States. I never observed it in Texas, but in Lawrence Co., Mo., I found it rather common from April 20 to May 3. In northern Illinois and central Wisconsin, it arrives about May 15, when the orchards swarm with many species of migrating Warblers. Like other species, it darts and hops about among the branches dexterously catching insects on the wing. I never saw it on the ground. This is about all I can say from my own experience regarding this Warbler.

Its breeding grounds are the coniferous woods of eastern North America, north to the Hudson's Bay Territory, west to the Plains. It breeds in northern New England and, probably, also in northern Michigan and Minnesota. As yet little is known about its nesting habits. During the summer of $1871, \mathrm{Mr}$. H. B. Bailey found a nest on the Richardson Lakes, in north-western Maine. It was built in a low spruce, less than five feet from the ground, and contained one egg. Near Calais, Me., it is a common summer resident and breeds. According to the authority of Mr. Montague Chamberlain, a nest was found by James W. Banks, near St. John, N. B. It was hidden among a cluster of low cedars growing in an exposed position, on a rather open hill-side, near a dwelling, and within a stone's throw of a much frequented lane. The nest was placed less than three feet from the ground and within six inches of the tips of the branches, amid the densest part of the foliage, by which it was well screened from observation. The walls of the nest were composed of minute twigs of dried spruce, grasses, and strawberry vines, with spider's webbing interwoven. The lining, composed entirely of horsehair, is laid with precision, and shaped into a prettily formed cup, the brim being 
turned with exquisite grace. It contained four eggs of a dull white ground-color, of a slightly ashen hue; the markings are of a light and dark lilac, and yellowish and reddish tints of brown. As a rule the spots are circular and very small, and are irregularly distributed.

It is very singular that this northern bird breeds in the West Indies. Turnbull received nests, eggs, and skins from San Domingo, and March states that he found nests and eggs in Jamaica.

NAMES: CAPE MAY WARBLER.

SCIENTIFIC NAMES: Motacilla tigrina Gmelin (1788). DENDROICA TIGRINA BaIRD (1858). Sylvia maritima Wilson (1812).

DESCRIPTION: Male, back yellowish-olive, with dark markings; crown, black; abdomen and tail-coverts, yellow; rump, rich yellow; an orange-brown ear-patch; a black loral line; under-parts, yellow, streaked with black on breast and sides; large white patch on the wings; three pairs of large white tail-blotches. Female, similar, but lacking distinctive head-markings; small wing-patch and tailblotches; under-parts, paler. Bill and feet, black.

Length, 5.25 inches; wing, 2.75; tail, 2.00 inches.

\section{OLIVE WARBLER.}

Dendroica olivacea BAIRD.

The OLIVE WARBLER is one of the "sixteen species" described and figured as new in 1841, by J. P. Giraud, and by him attributed to Texas. "Doubt has been often expressed with reference to the ascribed habitat of these birds, the presumption being that some, if not all of them, actually came from contiguous Mexican territory. But it is well to bear in mind that their describer's declaration of their origin was unwavering to the last, and that his statement is gradually being borne out by the rediscovery of his species within our limits; while the Texan side of the valley of the lower Rio Grande has afforded various species, the existence of which in this region long remained unsuspected." (Coues.)

In 1885 Cassin redescribed and figured the Olive Warbler, without giving, however, any information as to its occurrence in the United States. The Smithsonian Institution received specimens through Mr. Sumichrast from the Popocatapetl and the alpine region of Orizaba. Others were taken in Cordova, Oaxaca, Xalapa, and Vera Paz. The first unequivocal testimony of the presence of this rare Warbler over our border has been afforded by Mr. H. W. Henshaw, who found it in 1875 in Arizona. Mr. Henshaw's narrative of his experience with the bird is as follows :-

'During a three days' visit to Mount Graham, August 1 to 4 , the species was not detected; ... Returning here Sept. 19, many of the species found in August in abundance had migrated south, and were either entirely wanting or represented by individuals from farther north, while the woods, the silence of which was often unbroken for long intervals by the note of a single bird, would now and then, as if by magic, be filled with hundreds of feathered migrants, who in noisy companies were proceeding on their way south. The day after establishing our camp here, Mr. Rutter, of the party, brought in a fine specimen of this Warbler, which he stated he had shot from among a flock of Audubon's Warblers and Snowbirds, which he had started from the ground 
while walking in the pine woods. With the rest, it had apparently been fceding apon the ground, and had flown up to a low branch of a pine, where it sat and began to give forth a very beautiful song, which he described as consisting of detached, melodious whistling notes. During the next few days, I confined my trips to the spruce woods, and though I watched eagerly for this to me strange Warbler, I did not see it until the last day of my stay in the locality, when I heard a few strange Vireo-like notes coming from some thick pines, and, hurrying to the spot, soon had the satisfaction of seeing one of these Warblers on the low limbs of a huge pine, where it was moving quickly over the large branches, its manner and whole appearance reminding me instantly of the Pine Creeper (Dendroica vigorsii). A few moments later, a second specimen was seen .... As all the Warblers present here at this time were migrants, we may reasonably infer that, with the others, this species was en route from.some locality to the north, and perhaps it may be found to be a rare inhabitant of the high pine region throughout Arizona and New Mexico."

NAMES: OLIVE WARBLER, Orange-breasted Warbler.

SCIENTIFIC NAMES: Sylvia olivacea Giraud (1841). DENDROICA OLIVACEA BaIRD (185s). Peuce dramus olivaceus Coues (1875).

DESCRIPTION: Upper parts, ashy; head and neck all around orange-brown or intense saffron yellow, with a broad black stripe on the sides of the head through the eyes; wings, blackish but much white on the inner webs of the quills. Belly and sides, whitish, tinged with olive. Female, duller; lacking the black bar, which is replaced by whitish.

Length about 4.75 inches; wing, 3.00 ; tail, 2.25 inches.

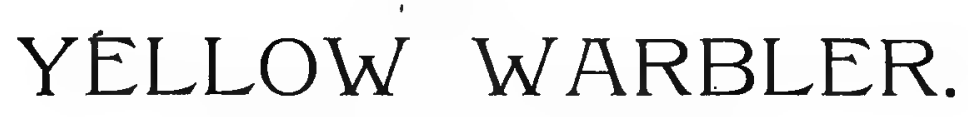

Dendroica rstiva B.tIRD.

Plate XV. Fig. 1 .

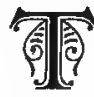

HE SPRING in our Northern and Eastern States does not awake when the first

Robin and Bluebird, just returned from the sunny South, carol forth their enchanting spring melodies. It lingers along for more than two months from its commencement, and, although a season of hopes and promises, it is frequently interrupted by short periods of wintry gloom. Till the last days of May we notice a constant struggle between winter and spring. The more hardy birds return from their winter quarters in April, but we do not find many flowers and bright colors during that month. In early May, the ever-changing aspects of the fields, the meadows and woods, are sources of continual pleasure to the friend of nature. The colt's foot, the modest liverwort, the delicate wood-anemone, and a multitude of violets, more numerous than the stars of heaven, afford us the agreeable sentiment of spring beauty. Every morning's sun is greeted by new flowers, until every nook sparkles with them, and every pathway is embroidered with them. Gradually countless numbers of dandelions, anemones, buttercups, saxifrages, columbines, solomon's seals follow, draping every place with the universal wreath of spring. Though we do not find the glowing colors and rich perfumes 
as in June, we must, nevertheless, pronounce the flowering of the orchard trees exceedingly charming. Pear trees, clothed in snowy whiteness; apple trees, with flowers of every shade between white and rosy crimson, enlivened by hosts of brilliant Wood Warblers; cherry trees, with their clusters of white blossoms, occupied by the gorgeous Oriole, - all gladden our heart late in May. Although lacking the powerful fragrance of southern spring, the air at this time is scented with various perfumes. This is most agreeable and sweetest when the weather is rather sultry, and "while the sunbeams are tinged with a purple and ruddy glow by shining through an almost invisible haze."

All the birds have returned now. The concert which they perform from early dawn to the fall of the evening twilight arouses our sentiment. Wherever our way may lead us, we admire the feathered poets of upland and meadow, orchard and garden, field and forest. Among all our smaller birds none arrest our attention in such a degree as the beautiful Wood Warblers when the orchard trees bloom. They are always busily engaged searching for insects among the new leaves and the dense flower clusters. They disappear as quietly as they have arrived. The majority moves further northward, only comparatively few remaining to breed in the Northern and Eastern States.

The most common and the most well-known of all our Warblers is the Summer YELLOW-BIRD, or more properly the YELLOW WARBLER, also named the GoLDEN WARBLER, YELLOW-POLL WARBLER, and "Wild Canary." It is a brilliant bird of a rich gamboge-yellow color. The breast and sides are broadly streaked with rich chestnutrufous, while the back shows a yellowish olive-green tinge. I found it a common summer sojourner from Wisconsin to southern Texas. During the breeding season it occurs from the Atlantic to the Pacific and from Mexico and Florida to the high Arctic regions. In Wisconsin I noticed its arrival from the 10 th to the 15 th of May; in southeastern Texas it usually arrives in the second week of April. It prefers to settle in woodland and orchards, parks and gardens, always being found most common near the habitations of man. On the borders of woods it prefers to take up its abode in hazel copses, dogwood, and viburnum bushes and wild crab trees. In gardens it shows a special fondness for apple trees, upright honey-suckles and mock-oranges. The sugar maple is also selected as a favorite nesting-site. Being one of our most familiar and attractive birds, and breeding frequently in close proximity to human dwellings, it must appear strange how persistently it is confounded with our Goldfinch by many people. Others even mistake it for a "Wild Canary."

We may usually see it searching and pursuing insects among the flowering orchard trees, in forest trees of moderate height, and in shrubberies, where its gay colors make a pretty spot as the bird flits through the green foliage, or plays amid the rose-tinted flowers of the apple trees. Its sprightly song is heard from all sides, being one of the most characteristic and familiar sounds of rural bird-life in the pleasant days of May and June. While searching for insects it constantly skips about in the dense foliage and in the wealth of blossoms, securing its food from the flowers and leaves and even from the bark, occasionally pursuing an escaping insect on the wing. Frequently it descends to the low bushes, but it rarely comes down to the ground. Its song, though short, is exceedingly pleasant and by it and its pleasant-tempered and affectionate disposition it contributes much to the beauty of its habitat. In localities where the gardens abound 
in mock-oranges and upright honey-suckles ${ }^{1}$, a more beautiful picture can hardly be imagined, than these shrubs in full blow and fragrance, amidst which one of these beautifully attired Warblers hops and skips about, frequently uttering its sprightly notes. It gladdens the heart of every one who has a sense for beauty, refinement, and poetry. In the Gulf region I frequently observed it in the flowering magnolias and banana shrubs, cape jasmines and China trees, all of which exhale a delicious perfume, and in the gorgeous flowering hibiscus, oleanders and pomegranate shrubs. Together with Mockingbirds, Cardinal Redbirds, Nonpareils, Blue Grosbeaks, Carolina Wrens, and Orchard Orioles it is a common bird of the southern gardens.

Early in June, in Texas fully a month earlier, we may look for the nest and eggs. In Wisconsin and Illinois, I found it most frequently in upright honey-suckles and in mock-oranges, where usually the uppermost branches were selected for a nesting-site. Pear and apple trees, and the sugar maple are likewise chosen for nesting places. Hedgerows, dogwood, viburnum shrubs, wild currant bushes, the hazel thickets fringing the border of woods, pomegranate, rose bushes, and orange trees in southern gardens are favorite nesting-sites. Sometimes the nest is built at heights ranging from twelve to thirty feet, but usually it is not more than five to eight feet above the ground. It is always more or less concealed among the dense leaves and is always fastened very skillfully to several small upright twigs, which run also through the walls. The structure is very neat, symmetrical, compactly felted, and durable. It is built of soft vegetable matter, such as asclepias and hemp fibres, fine bark-strips, hair and cottony substances, lined with soft plant down, feathers, and very frequently with the chestnut-colored down of ferns. Near buildings wool, feathers, and thread enter into the composition. Some nests are constructed almost entirely of the down of willows, the nankeen wool of the Virginia cotton-grass, and the down of fern-stalks. In such cases the nest is very light and fluffy. Although frequently built in the uppermost branches of shrubs, the thunder storms which so often occur in early June and which are so destructive to many a bird nest, do not harm the domicile of the Yellow Warbler. The cavity of the nest is deep and the structure so compactly felted that the eggs do not roll out, when the winds swing the branches to and fro. In northern Illinois and south-western Missouri, I discovered many nests in dense hazel thickets. When thus situated they were protected from above by dense leaves, so that neither sun nor rain could do much harm to them. In orchards and gardens, even in villages and towns, the Yellow Warblers are exceedingly lovely and dauntless birds, and, if treated kindly, their breeding habits may be readily observed. Near the window of my room and close to a much used garden path, two large shrubs, an upright honey-suckle and a mock-orange, unfolded all their beauty during the season when the year renewed its youth. Both shrubs were dense, about eight feet high and as much through, the side branches bending down gracefully to the ground. During four successive years, a pair of Yellow Warblers built their nest in one or the other of these shrubs, always selecting the uppermost branches for a nesting-site. They worked early in the morning and constructed their nest chiefly of silvery asclepias fibres which were provided by the male, while the female was engaged in forming the nest.

The eggs, three to five in number, show a greenish-white ground-color and are

1 Lonicera fragrantissima, L. Standishii, L. tartarica. 
dotted and spotted with different shades of brown and lilac, chiefly about the larger end. This Warbler is one of our birds most persistently victimized by the "reprobate tramp of a Molothrus (Cowbird), and one which sometimes displays great ingenuity in avoiding the disagreeable task of incubating the alien egg, by adding a second story to its nest, thus leaving the hateful object in the basement below, out of the hatching way forever." (Stearns.)

The young are fed with minute insects; such as infest our orchard and ornamental trees and shrubs. The food of the old birds also consists of insects, especially small caterpillars, canker-worms, moths, small beetles, etc. Like all our small birds, they are of invaluable benefit to man.

Early in September, before the first storms of autumn sweep over the Northern States, they depart for the South. In Texas they leave late in September and early in October. They spend the winter in south-eastern Mexico, Central America, and northern South America.

The Yellow Warbler west of the Rocky Mountains is said to be paler, with chestnut streaks on breast and sides averaging much narrower and paler. This form is now called the Western YelLow WARBLER, Dendroica zstiva morcomi CoAle.

NAMES: Yellow Warbler, Summer Yellow-bird, Summer Warbler, Yellow-poll Warbler, Golden Warbler, "Wild Canary."-Gartensänger (German).

SCIENTIFIC NAMES: Motacilla æstiva Gmel. (1788). Sylvia æstiva Lath. DENDROICA AESTIVA BAIRD (1858). Sylvia citrinella Wils. (1810). Sylvia childreni Aud. (1831). S. rathboni Aud. (1831).

DESCRIPTION: Adult male: Entire lower parts and head, pure rich gamboge-yellow; breast and sides, boldly striped with rich chestnut or orange-brown; wings and tail, dusky, every feather edged with yellow; upper parts, olive-green, sometimes streaked dusky; bill, dark horn-blue; feet, brownish. Female: Paler yellow, the chestnut-rufous stripes dull, few, or wanting entirely.

Length, 5.25 inches; wing, 2.66 ; tail, 2.25 inches.

\section{Black-throated Blue Warbler.}

\section{Dendroica cærulescens BAIRD.}

Plate XIV. Fig. 2.

周HE WARBLERS are the most attractive and lovely of all our birds. Their. 5] delicate forms and brilliant plumage, their spritely and showy bearing, their interesting migration when the trees are flowering and the air is filled with fragrance, their pretty and often exquisitely artificial nests and the rarity of many, contribute to make them the special favorites of the ornithologist. They all are small and very active, but their song is often feeble, and, to be seen, they must be sought for. Most persons are not acquainted with them, a fact which was clearly shown in the spring of 1888 . The season alluded to was extremely cold, rainy weather prevailed throughout the month of May. Hundreds and thousands of delicate migrants, mostly Warblers in full spring dress, were killed by the cold weather and many hundreds came to the windows even in Chicago and Milwaikee, to seek protection from the cold and rain. The daily 
papers brought long reports of "unknown, and never described, but beautiful tropical birds having missed their way and having been driven by heavy winds to the far North." Now, almost all of these birds were Warblers, and all were known for many years to every ornithologist of the country. The majority of Warblers found near Milwaukee on the shore of Lake Michigan were Magnolia, Blackburnian, Black-throated Green, Summer, Cape May, and Black-Throated Blue Warblers.

Among the Warblers of the Dendroica-group the last named species is my special favorite, not because it is more beautiful and interesting than others, but because I made its acquaintance many years ago, when rambling about in the swampy thickets of central Wisconsin when only a boy. In the Northern States this pretty bird arrives with many other species about the middle of May, when the apple trees of the orchards and the white thorns and wild crab trees on the woodland borders are in full bloom. It tarries usually until the last days of May, when it studdenly disappears. Unlike the most of its allies, it is more sociable, being frequently observed in companies from four to six. Its breeding range we may look for in Canada, north nearly to the Arctic regions, but it sparingly breeds south to central Wisconsin, Michigan, northern New York, and Connecticut. In the beautiful Alleghanies it breeds from northern Georgia northward. Mr. William Brewster enumerates it in his model list "On the Birds of Western North Carolina." * Speaking of its occurrence there, he says :

"I heard the first Black-throated Blue Warbler on the crest of the Cowee Mountains, but at the time supposed it to be a belated migrant." On the following day, however, others were met with at Cullasaja Falls, and along the road between that point and Highlands many were seen or heard. In the neighborhood of Highlands they were everywhere numerous, and in the extensive rhododendron swamps, literally swarming and evidently settled for the season, if not actually breeding. Mr. Boynton tells me that he regularly hears them singing in these swamps through June and July, but he has never found the nest. On the Black Mountains they were scarcely less numerous in belts of rhododendrons bordering streams at between 3,200 and 4,500 feet, but, curiously enough, none were seen above the latter elevation, although the balsam forests on the upper slopes of these mountains would seem to furnish congenial haunts."

In other localities, especially in Connecticut, this Warbler finds a congenial home in the exceedingly charming laurel or kalmia thickets, consisting almost entirely of Kalmia latifolia, one of our most beautiful shrubs. In Wisconsin I found it during the breeding season always on the borders of swampy woods, where dogwood, viburnum, and the leather or moose wood ${ }^{1}$ grew in great luxuriance. When in June $1872 \mathrm{I}$ was rambling about in the swampy woods of Plymouth, Sheboygan County, Wis., I found a nest of this Warbler in a low but rather dense shrub of the leather wood. Dogwood, wild goose-berry and huckle-berry bushes grew near it. As the locality was shaded by spreading elms and ash trees, the rays of the sun could not strike. It was built in upright branches about twelve inches above the ground, consisting chiefly of silvery fibres of the milkweed ${ }^{2}$, spider's nests and plant down. The interior was lined with fine bark-strips, a few hairs, and the rusty down of the cinnamon fern, which usually

"See The "Auk," Vol. III, 1886, p. 94-112, 173-179.

1 Dirca palustris. 2 Asclepias. 
grows in great luxuriance in such localities. The nest contained four eggs of a greenishwhite ground-color, more or less heavily spotted with different shades of brown and purple. - This was the only nest I found, although the birds were seen in other places, but always in the thick underwood shaded by high timber. Rev. C. M. Jones found this Warbler breeding at Eastford, Conn. One nest, found June 8, 1874, was located in deep woods, near the base of a hill which sloped down to a swampy run. It was built in a small laurel ${ }^{1}$. About five inches from the ground the bush separated into three branches, and in this triple fork the nest was situated. It had a firm and compact appearance, being composed outwardly of what appeared to be dry bark of grape-vine, with a few twigs and roots. This was covered in many places with a reddish wooly substance, apparently the outer covering of some species of cocoon. The inside was composed of small black roots and hairs. The nest contained four eggs. A second nest was also found in a laurel about eleven inches from the ground.

Wherever found, the Black-throated Blue Warbler prefers to settle in dense swampy woods with a heavy undergrowth. It has a particular fondness for the beautiful kalmia and the rhododendron, both of which sometimes cover extensive areas in southern New England and the Alleghany Mountains.

I observed the bird in the flowering magnolias and loblolly bays of Florida, in the apple trees of Missouri, Illinois, and Wisconsin, together with Magnolia, Black-throated Green, Blackburnian, Black-poll Warblers, and others, but $I$ have rarely heard its song. Without producing a single sound the whole company is busily searching for insects among the new leaves and the blossoms. Only on rare occasions we may hear a low plaintive $z$-ing or $z$-ip, or a few notes sounding like chee-chee-chee-cheep in the upward slide. The song in the breeding range is quite different. According to Mr. W. L. Kells, this little wildwood wanderer warbles its song with clearness and animation, especially for some weeks after its arrival from the South, yet it must be admitted that its music is not remarkable for its melody, for in its refrain there seems a melancholy plaintiveness, as though the little performer was complaining that it was seeking in vain for something that it had loved and lost. But, as adding a varying strain to the great orchestra of the wilderness, it must ever be interesting to the lover of bird music, and the student of animated nature.

During the middle of September it is on its way to the South. Even in greater numbers than in spring we may see it on the borders of woods, not frequenting at this time orchards and gardens. Its winter-quarters are the Bahamas, Greater Antilles, and Florida.

NAMES: Black-throated Blue Warbler, Canadian Warbler, Pine Swamp Warbler.

SCIENTIFIC NAMES: Motacilla cærulescens Gmel. (1788). DENDROICA CARULESCENS BATD (1865). Sylvia canadensis Wils. (1810). Dendroica canadensis Baird (1858).

DESCRIPTION: Adult male: Above, uniform slaty-blue, sometimes with a few black streaks on the back; below, pure white; the sides of the head to above the eyes, sides of the body, chin, throat, jet-black; a white spot at the base of the primaries; wings, dark; tail, dark, with a white patch near end of inner web of each feather except middle two. Female: Entirely different; above, dull olive-green, with bluish shade, below, pale dull yellowish; easily recognized by the triangular white spot near base of primaries.

Length, 5 inches; wings, 2.50 ; tail, 2.00 inches. 


\title{
MYRTLE WARBLER.
}

\author{
Dendroica coronata Gray.
}

Plate XIII. Fig. 5.

The autumn time is with us! Its approach

Was heralded, not many days ago,

By hazy skies that veiled the brazen sun,

And sea-like murmurs from the rustling corn,

And low-roiced brooks that wandered drowsily

By purpling clusters of the juicy grape,

Swinging upon the rine. And now, ' $t$ is here,

And what a change hath passed upon the face

of Nature, where thy waving forests spread,

Then roped in deepest green! All through the night

The subtle frost hath plied its mystic art,

And in the day the golden sun hath wrought

True wonders; and the wings of morn and even

Have touched with magic breath the changing leaves

And now, as wanders the dilating eye

Athwart the raried landscape circling far,

What gorgeousness, what blazonry, what pomp

of colors, bursts upon the ravished sight!

Here, where the maple rears its yellow crest,

A golden glory; yonder, where the oak

Stands monarch of the forest, and the ash

Is girt with flame-like parasite, and broad

The dogwood spreads beneath the rolling field

Of deepest crimson; and afar, where looms

The gnarled gum, a cloud of bloodiest red!

WM. D. Gallagher.

(a)

UR COUNTRY is famous for the beautiful tints of its autumn foliage. October seems to me the most brilliant of all the months of the year, being unsurpassed in the clearness of its skies and in the wonderful variety of colors that are sprinkled over the leaves of trees, shrubs, and herbs. The mixture of green, rosy, purple, scarlet, vermillion, orange, yellow, and brown is indeed wonderful, and admired by everyone who has a sense for beauty. The early autumn frosts are usually considered an important factor in the production of vivid effects, but much more depends upon the moisture or dryness of the atmosphere and the temperature of the season. Soil, exposure, and situation also play an important part. Long before the first frost sets in the foliage of the sumach and the Virginia creeper assumes its crimson and scarlet tints. The flowering dogwood, the tupelo, the sweet gum and the sassafras are striking objects in their brilliant autumn livery, the leaves assuming their beauty almost at the same time. The sugar maple sometimes differs in this respect, as only one single twig or a small number of branches change their color, while all the rest remains green or greenish-yellow. Oaks, ashes, azaleas, andromedas, etc., are also beautifully arrayed, but the colors are not so gorgeous as in the first named species. As the month advances one tree after the other partakes of this beautiful transformation. The tupelo, the staghorn and smooth sumach, the flowering dogwood, and the Virginia creeper are the most beautiful, always calling forth admiration. All the shades of red, yellow, and purple are resplendent from 
different species, the colors becoming intensified as the season advances. It seems as if the departed flowers of summer had revisited the earth, and were wreathing their garlands around the brows of the forest and the mountains. While the woods and thickets are glowing, we forget in our ravishment that fairy-like flowers of beautiful form and striking colors are still opening their chalices. They do not grow in exposed places and, to be admired, must be sought for. Not in fence corners and on road sides, where the weedy golden-rod still predominates, not in the thickets and wild pastures, where asters and gerardias bloom in great luxuriance, but in yonder glen, near water courses and rich meadows, we may cull the beauties of autumn, the gentians. The most charming species is the fringed gentian ${ }^{1}$ with its enchanting beattifully fringed flowers. The smaller fringed gentian ${ }^{2}$ and, further south, the prairie gentian ${ }^{3}$ are also exceedingly beautiful. What can equal these flowers in the intensity of their rich deep blue chalices? One might imagine that the autumnal sky borrowed its deep azure from the reflection of theseblossoms. The more common closed gentian ${ }^{4}$ with its dense flower heads does not show such a striking color, being more light purple. In waste places the wild tobacco, introduced centuries ago by the Indians, still opens its yellowish flowers. - Despite the sunshine and the interminable beauty of the landscape, we are ever reminded that melancholy rules supreme. The merry song of the birds does not gladden our hearts as in May and June, most of our happy summer sojourners have already sought a warmer and more congenial clime. The crimsoning woods are but the presage of nature's approaching death, "when the snow shall be a burial shroud and winter's winds shall chant the funeral dirge." During the night we hear the strange voices of innumerable birds, which are migrating southward high through the air. New arrivals from high northern latitudes are almost daily noticed. Juncos, White-throated, White-crowned, and Fox Sparrows, Palm Warblers and many others are swarming among the glowing bushes and thickets on the borders of the woods.

Among Warblers the Myrtle Bird, Myrtle Warbler, or Yellow-Rump is the most noticeable of all during autumn. It comes about the houses, even in towns and cities, darting spitefully about among trees and ornamental shrubs, uttering now and then a sharp chirping sound. This active bird is especially attractive among the gorgeous autumn foliage. We see them usually in companies of from five to ten and more, searching the trunk, the leaves, and branches for insects, their eggs, and larvæ, thus rendering invaluable service to the farmer and fruit-grower. It is a common bird in the northern gardens and woods in May, when the "leaves are as big as a chipmunk's ear"-as Mr. John Burroughs correctly remarks-; but still more numerous it is in the fine days of Indian summer.

In Wisconsin, Illinois, Missouri, and Texas the Myrtle Warblers are among the most common of all the feathered migrants. I found them wintering in great numbers in southeastern Texas, near and in Houston, where the evergreens, such as live-oaks, magnolias, loblolly bays, hollies, cedars, and long-leaved pines, afforded them excellent resting places for the nights. In gardens they frequently roosted in the beautiful evergreen Banksia and Cherokee roses, in laurel cherry ${ }^{6}$ and loquat trees ${ }^{6}$, and in the dense Chinese honey-

1 Gentiana crinita. 2 G. detonsa. 3 G. puberula. 1 G. Andrewsit. 5 Cerasus Caroliniana. 6 Eriobotrya Japonica. 
suckle $^{1}$ which drapes in dark green festoons piazzas and verandas. Even in the thick masses of English ivy, which cover the walls of churches and houses, many find protection during the inclement season of the year. In the orange groves and the incomparable semi-tropical gardens of Florida these birds, in company with Palm Warblers, winter in great numbers. Every hammock seems to swarm with them from November to March. In the romantic region of southern Louisiana, described so classically in Longfellow's "Evangeline," I observed them in great numbers during the month of February. There they seemed to prefer the dense thickets of evergreen wax-myrtles (hence the name Myrtle Warbler or Myrtle Bird). These shrubs grow vigorously in the South Atlantic and Gulf Region, and the berries which the bushes yield in abundance are coated with a waxy substance; they form not a small part of their food in winter. - In south-western Missouri the first arrivals were noticed about April 10, but the bulk did not appear before the last days of the same month. According to Mr. W. W. Cooke, this species winters over an immense area. While it is abundant in southern Texas, and great numbers pass on through Mexico on their way to Central America, as far even as Panama, still it is the hardiest of our Warblers, and unnumbered thousands regularly pass the winter in the lower half of the Mississippi valley. With plenty of poison ivy and wax-myrtle berries it seems not to care how the mercury stands. In the coast region of Connecticut, New Jersey, Delaware, etc., it also winters in more or less abundance. In Wisconsin I noticed the Myrtle Warblers in the last days of April. There they usually remain in full force for two to three weeks, when they suddenly disappear.

They reappear during the bright and glowing days of Indian summer late in September, loitering in undiminished numbers all through October. While migrating in spring they are found usually amongst the ornamental shrubbery of gardens, in orchards, in hedgerows, on the edges of swamps, and on the borders of woods. Moving about in small flocks, they are always eagerly on the lookout for insects, which they capture from the leaves and blossoms as well as from the air, where they dart about. with great dexterity. Especially in fall they may be generally distinguished at a distance by their habit of being much in the air, and taking comparatively long circling flights. If the weather be fair, which is usually the case when the orchard trees flower, we often may hear the song, which is loud, clear, and sprightly, bearing much resemblance to the lay of others of the family, especially that of the Maryland Yellow-throat.

The Myrtle Warbler breeds from northern Wisconsin, Minnesota, and New England northward, being especially common from our northern border to high Arctic regions. Its favorite haunts during the breeding season are thickets of spruces, hemlocks, and white pines. It is now a true forest bird, spending much of its time in the higher branches of trees, but building its nest low down in some thicket of spruces, hemlocks, etc., usually four to five feet, sometimes eight to ten feet from the ground. Mr. McFarlane found nests on the Anderson River, British America, and Mr. H. B. Baily discovered several at Upton, Me. There the bird was traced to its home in old clearings in the forest, where the second growth had begun to obliterate the work of axe and plough. Among such thickets of young spruces nests of this Warbler could gener- 
ally be discovered within easy access. All the nests were built about four feet from the ground and were rather neat structures, composed externally of hemlock twigs and lined with a few feathers. The eggs, four to five in number, are of a creamy-white ground-color, speckled and spotted, and sometimes blotched, generally in a wreath-like manner around the larger end, with reddish-brown and purple. - This Warbler has also been known to nest in Jamaica.

NAMES: Myrtie WARRLER, Myrtle Bird, Yellow-rumped Warbler, Yellow-rump, Yellow-rumped Wood Warbler.

SCIENTIFIC NAMES: Motacilla coronata Linn. (1766). Sylvia coronata Lath. (1790). 'Sylvicola coronata S. \& R. (1831). DENDROICA CORONATA Gray (1842).

DESCRIPTION: Old male: Above, slaty-blue, streaked with black; under-parts, white; breast and sides, heavily streaked with b'ack; throat, pure white; eyelids and superciliary line, white. Wing with two white cross-bars; tail with large white spots. Crown, rump, and sides of breast, bright yellow. Female: Slaty color almost ent:rely replaced by plain dull brown; streaks on under-parts few, or not so pure black. Rump always yellow; traces of yellow on crown and sides of breast.

Length, 5.50 to 5.75 inches; wing, 3.00 ; tail, 2.50 inches.

\section{AUDUBON'S WARBLER.}

Dendroica auduboni BAIRD.

Audubon's WARBLER is very similar to the species just described, being equally common and no less conspicuous among the small insectivorous birds which throng the forests and thickets of the entire West. It almost entirely replaces the Myrtle Warbler in this region, and in fact forms its exact western representative. According to Dr. Elliott Coues, Audubon's Warbler, one case excepted, has never been known to come eastward beyond the line of arboreal vegetation which marks the easternmost foot-hills and outlying elevations of the Rocky Mountains. As soon as we fairly enter the wooded tracts, as distinguished from those slight fringes of trees that straggle along the water-courses, we are pretty sure to find Audubon's Warbler, and we may find it anywhere, so we be in the woods at the right season, thence to the Pacific. The bird is known to occur in British Columbia and on the head-waters of the Saskatchewan. It is not a less hardy bird than its eastern congener. During the winter it may be found southward to Central America. In Colorado it breeds from an altitude of 9,000 or 9,500 feet up to the timber line, preferring for its haunts the dense spruce forest of the mountain-sides. A nest found by Mr. Henshaw in southern Colorado, June 1, in the top of a spruce, some thirty feet high, was composed of bark-strips, firmly and neatly woven, with a lining of fine grasses. The same naturalist ascertained that they also breed in the White Mountains of Arizona. In a private letter to the author, Capt. Charles Bendire, now of the Smithsonian Institution, says that he found Audubon's Warbler to be a summer resident at Fort Klamath, Oregon. There, as elsewhere, they built their nests in pine and spruce trees. A pair nested in a clump of pines on the parade grounds of the fort. The eggs, usually four to five in number, show a greenish-white groundcolor, and are marked, chiefly about the larger end, with dark brown spots.

In coloration this Warbler is very similar to the Myrtle Bird, but it may at once be recognized by its yellow throat. 


\title{
MAGNOLIA WARBLER.
}

\author{
Dendroica maculosa BAIRD.
}

Plate XII. Fig. 2.

Trif ERY DIFFERENT from the April of the North is the April of the Gulf region. There, Nature employs its utmost efforts to disengage itself from the still lingering and still resisting shackles of winter's rigid dominion, while here already reign in undisputed sway the mildest weather, the perfume of enchanting flowers, the songs of happy birds. In the gardens myrtles, oleanders, China and orange trees, banana shrubs, deliciously scented Cape jasmine (gardenias) and a wealth of tea and Noisette roses are flowering in unrivalled luxuriance and glory, their blossoms filling the mild and invigorating air with delightful fragrance. One of my favorite haunts is a tract of woodland on the Buffalo Bayou, near Houston,-Tex., where live oaks, hollies, laurel cherries, and especially magnificent magnolias grow in great abundance. This place is sure to be alive with birds, and I rarely enter it in April or May without making new and pleasing discoveries. Before reaching these woods, I have to force my way through half-wild openings and thickets over which are trailing Cherokee roses, trumpet vines, smilax, grape-vines, and other luxuriant creepers. Here the sonorous whistle of the Cardinal Redbird, the peto, peto of the Tufted Titmouse, and the mellow notes of the Lark Finch are almost constantly heard. The clear song of the Carolina Wren enlivens the depths of the woods, while from the densest thickets one hears the emphatic and peculiar strain of the White-eyed Vireo. Here this bird is the most conspicuous inhabitant of the thickets, especially on the borders of the woods. Mockingbirds are exceedingly commun, particularly in orchards, where they are treasured by the native Southerners as personal property, any interference with them is sure to be promptly resented. The natural result of this sentiment-a sentiment which ought to exist everywhere-is that this famous songster is universally abundant and familiar.-Although these woods swarm the entire month with birds, they are most abundant during the last week of April when the magnolia opens its creamy-white flower-buds. I am not able to describe this enchanting picture: only a poet can do it appropriate justice. I can only point to the large white blossoms, which exhale a wonderful fragrance, to the beautiful evergreen leathery leaves and to the stately form of the tree. All nature seems to be imbued with happiness and joy. Among the leaves and flowers of these trees of worldwide fame thousands and thousands of small birds are busily engaged in the search for insects. Warblers, breeding in high northern latitudes, seem to congregate in the magnolias. Interesting companies of these tired migrants, resting after the fatigues of their last night's journey, and preparing for that still before them, may be here observed among green verdure and enchanting flowers. The blossoms attract great numbers of insects for which these little birds eagerly search. In one large flowering magnolia I observed at one time-that is during a few hours-besides Blue-gray Gnatcatchers, Red-eyed Vireos, and Hummingbirds, the following Warblers: Parula, Prothonotary, 


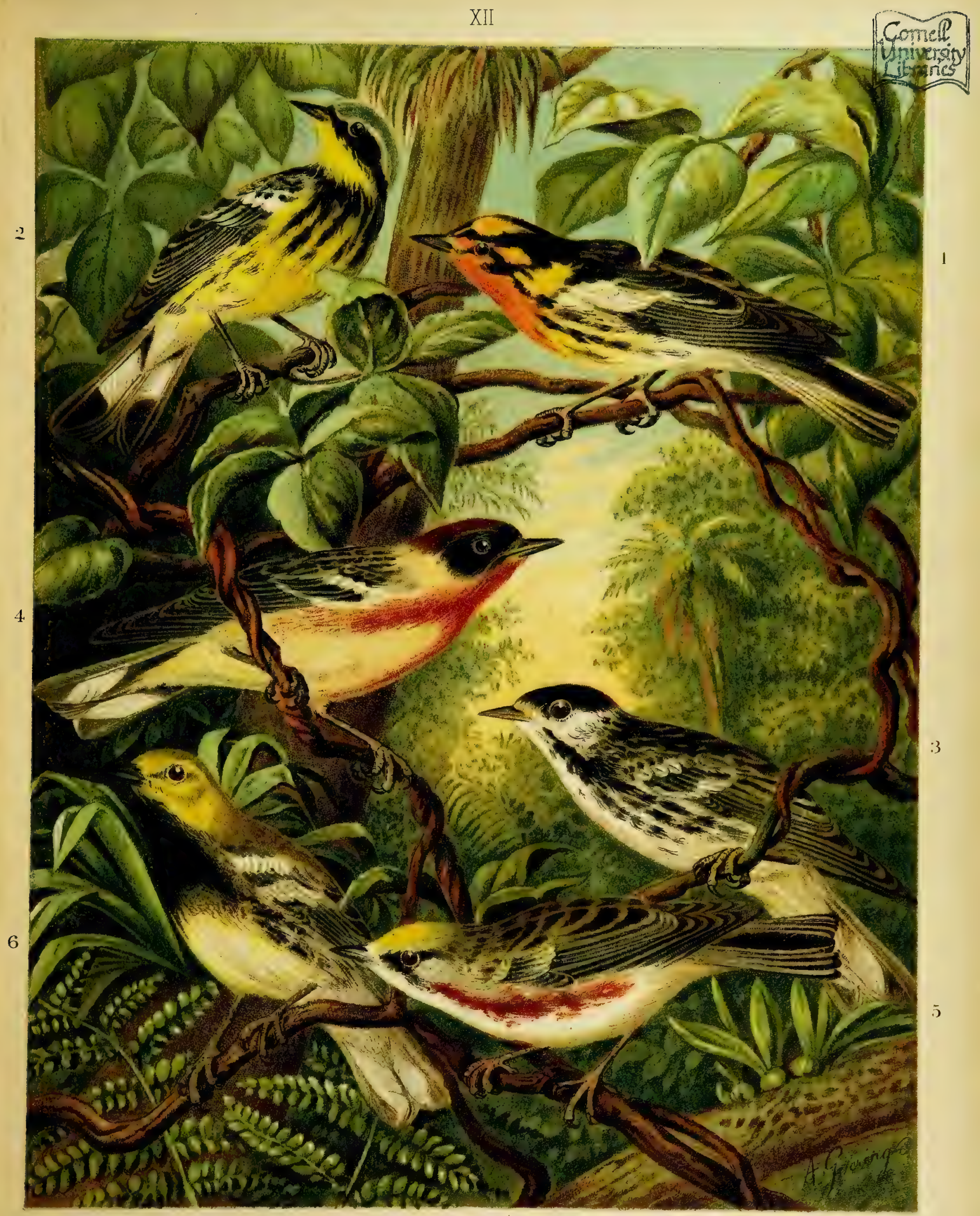

WALDSÄNGER IN DER WINTERHERBERGE WARBLERS IN THLIR WINTEROCARTERS.

1. Dendroica Blackburniae. 2. Dendroica maculosa. 3. Dendroica striata 4. D. castanea. 5. D. pennsylvanica. 6.D. virens. 

Creeping, Golden-winged, Black-throated Blue, Blackburnian, Chestnut-sided, Bay-breasted, Black-poll, Sycamore, Black-throated Green, Prairie, Mourning, Canadian, Hooded Warbler, and the American Redstart, but no species was more common and none more elegant than the Magnolia Warbler. Wilson, who found the bird during the first decennial of this century among the magnolias on the lower Mississippi, called it Sylvia magnolia; indeed, a beautiful name for a "dainty little bird, one of the most dressy of a family noted for the richness and elegance of their attire." It usually searches among the leaves and flowers for insects, rarely seizing them in the air. Although very active and joyous, I rarely heard its song in this region of the country. They were observed from April 20 to May 10, when the last stragglers suddenly disappeared. This woodland tract I never left without reluctance in the charming days of April and May when I was, perhaps, "the only invader of its secret recesses; and now, in recalling these rambles, the feeling is scarcely less strong."

In the extensive hammock woods, near Lake Apopka, Fla., which abound in magnolias, loblolly bays, palms and other semi-tropical trees, I observed the Magnolia Warblers April 15. In south-western Missouri the first were seen among the flowering apple trees May 2. In the second week of May they enter Wisconsin, lingering almost throughout the month. Here they frequent the orchard trees, ornamental shrubbery, and the various kinds of coniferous trees as well as the forest. In their habits they closely resemble the Yellow Warbler. Being now so near their breeding range, they may be frequently heard singing. The song is a simple but pleasing chant, vividly recalling the lay of the Myrtle Bird and at other times that of the Yellow Warbler. According to Mr. Minot, unfortunately of all these numerous sounds not one is distinctively characteristic of these Warblers, who are somewhat shy; but, fortunately, on the other hand, bright colors cannot always be concealed.-Doubtless the Magnolia Warbler breeds in northern Michigan and Minnesota but the bulk crosses our line. From my own experience I know nothing of its breeding habits, but it gives me pleasure to quote from a classical sketch, written by our distinguished naturalist, Prof. William Brewster, of Cambridge, Mass. Mr. Brewster writes feelingly and poetically as follows:

"The Black-and-yellow Warbler arrives in Massachusetts from the South about the 15th of May. During the next two or three weeks they are abundant everywhere in congenial localities. Willow thickets near streams, ponds, and other damp places, suit them best, but it is not unusual to find many in the upland woods, especially where young pines or other evergreens grow thickly. Their food at this season is exclusively insects, the larger part consisting of the numerous species of diptera. The males sing freely, especially on warm, bright mornings. They associate indifferently with all the migrating Warblers, but not unfrequently I have found large flocks composed entirely of members of their own species, and in this way have seen at least fifty individuals collected in one small tract of woodland. By the first of June all excepting a few stragglers have left. If we follow them northward, we find a few pairs passing the summer on the mountains of southern Maine and New Hampshire. In July, 1875, I found them breeding, in company with the Blackburnian Warbler, the Snowbird, the Golden-crested Kinglet, and several other birds of the Canadian fauna, on Mt. Monadnock, New Hampshire, within fifteen miles of the Massachusetts'State line. Throughout 
the White Mountains of New Hampshire they are everywhere common during the summer, but it is not tuntil we reach the latitude of the Umbagog lakes, in western Maine, that we find them evenly distributed over high and low country alike. In this region summer succeeds winter so quickly that there is almost no spring. Thus when I reached Upton on the 25th of May, 1876, I found that the lakes had broken up but four days previously; not a leaf had unfolded, even in the most sheltered places, and snow lay in large masses everywhere in the hollows and on northern exposures. Yet many species of Warblers had already arrived, and among them the subject of the present sketch was well represented. They kept closely about the buildings, and although the day was warm, maintained an almost perfect silence. Dozens at a time were hopping about the manure heap behind the stables and around the sink-spout, while all showed a certain apprehensiveness of manner, as if they feared the issue of their temerity in penetrating into so bleak and dreary a region. Taking a short walk into the woods, I found them untenanted, save by a few Titmice, Woodpeckers, and some of the earlier Sparrows. But in the course of the next week wonderful changes took place. The birches first, afterwards the maples, beech trees, and poplars, put on a feathery drapery of the most delicate green. The shad-bush ${ }^{1}$ and the moosewood ${ }^{2}$ became white with blossoms, and looked at a distance like fleecy summer clouds entangled among the trees. Underfoot, beautiful trilliums of both the purple ${ }^{3}$ and white ${ }^{4}$ species, were conspicuous among a host of other wild flowers. Bees hummed among the blossoms, and butterflies flitted airily through the forest glades. Everything was fresh, lovely, and suggestive of the calm, changes that, farther south, are often extended through nearly thrice the time. All this while the birds had kept ample pace with the advance of the season. Hundreds were daily arriving, passing on, or settling into their accustomed summer haunts, and the woods fairly rang with the first burst' of their melody. During the next week all the Warblers, and most of the smaller birds generally were occupied in pairing and constructing their nests. Then came the harvest time for the oölogist, and rarities were in order. But how brief it all was! A dozen or so days only, and the young were hatched out: the woods swarmed with mosquitoes, black flies, and other blood-thirsty insects, and 'the season' was at an end. Nothing remained but to pack up the accumulated treasures, and get them safely home for future comparison and investigation. Before taking out our cabinet specimens, however, and diving into the dry details of description, let us return to the woods, and contemplate for a few moments the undisturbed nest. We shall be most likely to find one along this old wood road, for the removal of the taller trees has let in the sunlight a little, and birds love such places. You will rarely find the interior of a forest so well peopled as the edges and little openings, and the birds are not singular in this respect. Men always choose the shores of rivers, ponds, or the sea, for their first settlements in a new country, I fancy it is not entirely from consiclerations of utility, but partly because they crave an adjacent breathing space, where the sun and wind may have fair sweep. There are some exceptions to the rule among the birds, of course, there being some morbidly disposed individuals that can find no place too dark or too secluded. As we follow the old wood path, you shall take one side when I make good the other. These little 
clumps of fir and spruce shrubs are the likely places, and, judging from the numbers of Black-and-yellow Warblers that I hear singing, our chances are good, but you must remember that not above one male in three or four of this species is blessed with a mate, so do not let your hopes rise too high. They are a gay lot of bachelors, though, are they not? chasing one another through the branches, more in sport than anger apparently, and uttering their queer, emphatic little songs on all sides.... 'She knew she was right; yes, she knew she was right,' they seem to say; but what all this means I never could imagine. Some idle gossip of theirs, probably, which it will not profit us to inquire into. Ha! I have it, even so soon. I thought yon fellow singing so gayly in the fallen tree top had more the air of a Benedict than any we have previously seen, and here, almost under my hand, sits his modest little wife on her nest. Be careful how you shake that branch, for I would have you take a good long look ere we disturb her. See how her dark little eye glistens, and note the rapid pulsating motion of the back. Underneath those puffed-up feathers a poor little heart is beating wildly with fear and apprehension, but still she sits bravely on her trust. She would say, if she could, with the Roman mother, 'These are my jewels,' and would entreat us to spare them. Now I will advance my hand cautiously. See! I almost touch her tail with my finger tips: but the next instant she is gone. How quietly at the last moment she slid over the edge of the nest, barely eluding my grasp! A faint cry or two, and there comes the male; but he, gaudy little braggart! is far better at singing brave deeds than preforming them, and will not trust himself very near, though he keeps up a constant chirping. His mate, however, is bold enough for both, and in her anxiety almost comes within reach of our hands. Now look into the nest! Beauties, are they not? Four of them; rosy-white, spotted prettily with umber, lilac, and a few scattered dashes of black. Observe how cunningly the whole affair is concealed,- built close to the stem of the little fir, resting on the flat horizontally disposed rows of 'needles,' and arched over by the flake-like layer of twigs above. One long rootlet alone hangs down in full view, and had it not caught my eye I might have passed without discovering the nest. It seems, indeed, a pity to disturb it, but we shall regret it next winter if we leave it behind. Naturalists are probably not hard-hearted by inclination, but of necessity. I dare say the female will commence another nest before we pass here on our way back, and the male will be singing as joyously as ever in an hour or two. Bird's grief, like their average lives, is short, though apparently intense for the time. It is only the end, however, that can ever justify the destruction of a nest, and unthinking persons might, in many cases, be benefited by contemplating a little more closely the suffering which they inflict. In eastern Massachusetts this species occurs as a fall migrant from Sept. 21 to Oct. 30, but it is never seen at this season in anything like the numbers which pass through the same section in spring, and the bulk of the migration must follow a more westerly route. Its haunts while with us in the autumn are somewhat different from those which it affects during its northward journey. We now find it most commonly on hill-sides, among scrub-oaks, and scattered birches, and in company with such birds as the Yellow-rump and the Black-poll. A dull, listless troop they are, comparatively sombre of plumage, totally devoid of song, and apparently intent only upon the gratification of their appetites. It seems, at first thought, strange 
that the birds, at a season when all the rest of nature puts on its most gorgeous coloring, should array themselves in their dullest; but it must be borne in mind that many of them played their part before these brilliant leaves had burst their buds, and now, like ushers and orchestra, whose duty has been proformed, they stand aside among the audience, and watch the shifting glories of the final transformation scene. So let us leave them until, attired in fullest costume, they come again to herald, with overtures of joyous songs, the rising of the curtain on a new year."

NAMES: MAGNolia WARBLER, Black-and-yellow Warbler.

SCIENTIFIC NAMES: Motacilla maculosa Gmel. (1788). Sylvia maculosa Lath. (1790). Sylvia maculosa Wilson (1811). Sylvicola maculosa S. \& R. (1831), Aud. DENDROICA MACULOSA BAIRD (1858).

DESCRIPTION: A very beautiful bird. Male, above, dark; rump, bright yellow; "crown, clear ash, bordered on the sides by white, framed in black, there being a black band across forehead and along sides of head, joining that of back, enclosing the white under eyelid." Entire underparts bright rich yellow, heavily streaked across breast and along sides of body with black; under tail-coverts, white. Wingpatch, white; tail-spots, white, of small size. Female, similar, with head-marks and streaks less distinct.

Length, 5.00 inches; wing, 2.50; tail, 2.00 inches.

\section{CERULEAN WARBLER.}

Dendroica cærulea BAIRD.

Plate XiII. Fig. 6.

The beautiful little Cerulean Warbler is a common bird in the rich bottom woods of southern Indiana, Illinois and adjacent parts of Missouri. Near St. Louis, and especially in the woods bordering the lower Missouri, the Mississippi, the Kaskaskia, the Wabash and Ohio, it is by far the most abundant member of the Warbler family. When rambling about with Mr. Otto Widmann in the woods near Creve Coeur Lake, we frequently observed this Warbler in the tall trees. In the willows close by numerous Prothonotary Warblers, and near the banks of the lake Large-billed Water Thrushes trilled their wild woodland melodies. The woods consist here entirely of deciduous trees, many of which are of gigantic size. Water-oaks, sweet gum, hack-berries, tulip trees, elms, black walnut and pecan trees, coffee-bean, honey locust, and hickories being the most common. The Cerulean Warbler almost exclusively frequents these woods, keeping much among the tree tops, rarely descending to the low bushes, and then perhaps only to search for nesting material. On warm days in June one may almost constantly hear the song, which sounds like the syllables dee-dee-dee-teree-teeh.

This Warbler occurs east to the Alleghanies and north to southern Canada. In western and central New York it seems to be no rare bird. Rev. J. H. Langille gives the following account: "It is a bird of the woods, everywhere associated with the tall forests of the more northern counties of western New York, sometimes found in the open woods of pasture-lands, and quite partial to hardwood trees. In its flitting motions in search of insect-prey, and in the jerking curves of its more prolonged flight, as also 'in structure, it is a genuine Wood Warbler, and keeps, for the most part, to what Thoreau calls 'the upper story' of its sylvan domain. Its song, which is frequent, 
and may be heard for some distance, may be imitated by the syllables rheet, theet, rheet, rheet, ridi, idi, e-e-e-e-e-e-e; beginning with several soft, warbling notes, and ending in a rather prolonged but quite musical squeak. The latter and more rapid part of the strain, which is given in the upward slide, approaches an insect-quality of tone which is more or less peculiar to all true Warblers. This song is so common here as to be a universal characteristic of our tall forests. The bird is shy when started from the nest, and has the sharp chipping alarm-note common to the family. The nest is saddled on a horizontal limb of considerable size, some distance from the tree, and some forty or fifty feet from the ground. Small, and very neatly and compactly built."

According to Prof. J. A. Allen, a nest, found at East Penfield, Monroe Co., N. Y., June 7,1878 , was placed in the fork of a small ash tree, about twenty-five feet from the ground. It was neatly and compactly built, consisting externally of fine dry grasses of an ashen tint, bound firmly together with spider's silk, to which were affixed a few bits of whitish lichen; it was lined with strips of bark and fine grasses, of a reddish-brown color. The nest was thus gray externally and brown within. Another nest, found at Mount Carmel, Ill., May 16, 1878, differed from the one described in having thicker walls, thus giving to the structure greater bulk and firmness. It was partly covered externally with lichens, and was also placed about twenty-five feet from the ground.

The eggs are bluish or greenish-white, spotted with reddisn-brown or lilac, chiefly on the larger end.

NAMES: Cerutean Warbler, Azure Warbler, Blue Warbler.

SCIENTIFIC NAMES: Sylvia cærulea Wilson (1810). DENDROICA CAERULEA BAIRD (1858).

DESCRIPTION: Small, and very beautiful. Male, above, azure-blue, with black streaks; beneath, pure white, with dusky-blue streaks on the breast and sides; wings, with two white bars; bill, black. Female, with the blue imptre tinged with greenish; beneath, white, tinged with greenish-yellow.

Length, 4.25 inches; wing, 2.65 ; tail, 1.90 inches.

\title{
Chestnut-Sided W ARBLER.
}

\section{Dendroica pensylvanica PARKER.}

Platé XII. Fig. 5.

\begin{abstract}
F WISCONSIN this elegant species is not uncommon. Its favorite haunts are f the bushes on the woodland border and the swampy thickets in pastures and meadows, where Catbirds, Thrashers, Towhee Buntings, White-eyed Vireos, Ovenbirds, Maryland Yellow-throats, the Veery and the Rose-breasted Grosbeak are its near neighbors. Despite the swarms of mosquitoes, these low and bushy localities are very interesting to the friend of nature. Beautiful shrubs and flowers grow on all sides with
\end{abstract}


luxuriance. Ferns flourish side by side with Cardinal flowers ${ }^{1}$ and spotted balsams ${ }^{2}$. The Indian hemp ${ }^{3}$ together with nettles and other rank herbs, struggle for existence with dogwood, viburnum, goose-berry and huckle-berry bushes. In cool damp places the aristocrats among our wild flowers, the terrestrial orchids, grow out of the rich black soil. Not only the exceedingly beautiful mocassin flower $^{4}$ and the yellow lady's slipper $^{5}$, but also the more modest coral-root ${ }^{6}$, the arethusa $^{7}$, the calopogon ${ }^{8}$ and others, are to be frequently met with. They are not so gorgeously colored as the cardinal flower, and to appreciate their beauty and delicate tints, they must be sought for. The very peculiar pitcher-plant ${ }^{9}$ always attracts our attention when rambling about in these low and rich localities. High and broad elms and ash trees overshadow these thickets and copses in many places, while in others not one of the original forest trees escaped the axe of the woodsman. Foxes and skunks are still present in the more extensive swamps, but the once common Canada porcupine seems to be exterminated. The Ruffed Grouse, an exceedingly common bird in the days of my boyhood, rarely attracts our attention now by its drumming sounds. The Pileated Woodpecker or Logcock was frequently observed in pioneer times, its scarlet crest flashing like fire among the leaves. Now one may travel many days before seeing a single specimen. Small birds seem to be at home here, for all the thickets on the woodland border and the canopies of green in swampy places, the fern-clumps, the huckle-berry patches, have their peculiar feathered inhabitants.

In central and southern Wisconsin the CHESTNOT-SIDED WARBLER always chooses for its summer haunts the seclusion of swampy tracts, persistently shunning the society of man. It is a rather timid bird, but in spring when the orchard trees bloom it may be regularly observed among the flowers, eagerly searching for insects. Like many other Warblers, it is not gregarious, but is often found with other species in the same tree. Its habits remind one of those of the Myrtle Warbler, for it is much in the air capturing flying insects with great dexterity. Most of the time it gleans quietly among the new leaves and blossoms, generally among the lower branches. It rarely utters its song during migration, except when it approaches its breeding range. Like the song of other species it lacks peculiarity, consisting only of a few simple notes, not unlike the song of the Summer and Myrtle Warbler. In Wisconsin the Chestnut-sided Warblers usually arrive about May 10, and remain in the orchards and gardens to the end of the month. In south-western Missouri I never saw them before April 25; it is about two weeks later when the last stragglers have left. Late in September and early in Oçtober I saw a few at Freistatt, Mo., on their way to the South.

In Wisconsin the nest is finished early in June. It is placed from two to ten feet above the ground in a low shrub or small bushy tree. All the nests I have found were built in upright forks of dogwood or viburnum bushes, and none was more than five feet above the ground. They were found in a woody pasture, where cows passed and browsed daily. The structure is not so soft and fine as that of the Summer Yellow-bird, being built of coarser material. It is composed outwardly of narrow strips of bark, plant-down, and grasses, lined with fine bark-strips and a few hairs. The eggs, four to

1 Lobelia cardinalis. 2 Impatiens fulva. asclepias. 4 Cypripedium spectabile. C Cypripedium pubescens. B Corallorhizo. odonthorhiza. 7 Arethusa bulbosa. 8 Calopogon pulchellus. 8 Sarracenia purpurea. 
five in number, are white with purplish or reddish-brown spots, which are frequently grouped in a ring around the larger end.

Although almost as common in its favorite haunts as the Yellow Warbler in orchards and gardens, it is nowhere a familiar bird. Its retired habits are the cause that it is only known to the ornithologist and collector. According to Mr. Winfred A. Stearns and Dr. Elliott Coues, it breeds rather more numerously in the Alleghanian than in the Canadian Fauna, frequenting in New England open mixed woods, thickets, orchards, and gardens. In northern Illinois it is found during the breeding season only in low, swampy places, apart from cultivated grounds. During the breeding season this elegant Warbler occurs from the Atlantic to the Plains, and from southern Canada to central Illinois and in the Appalachian highlands, probably, to northern Georgia. It winters in the Bahamas and Central America.

NAMES: ChestNut-Sided Warbler, Quebec Warbler, Yellow-crowned Warbler.

SCIENTIFIC NAMES: Motacilla pensylvanica Linn. (1766). Sylvia pensylvanica Wils. (1810). DENDROICA PENSYLVANICA BAIRD (1858). Sylvia icterocephala Linn. (1766). Sylvicola icterocephala Lath., Aud., Nutt.

DESCRIPTION: Male: Upper parts, greenish-yellow, streaked with black; crown, yellow, borđered by white, then enclosed in black; sides of head and under-parts, pure white; lores, with a line through the eye and one below it, black; a conspicuous chestnut-brown stripe on the sides, starting in a line with the black mustache; wing and tail-feathers, dark brown, edged with bluish-gray; wing-bars, white, generally fused in one large patch. Female: similar, but less highly colored; black on head, obscure, and chestnut streaks thinner and fewer.

Length, 5.00 to 5.25 inches; wing, 2.50 ; tail, 2.00 inches.

\title{
BAY-BREASTED WARBLER.
}

\section{Dendroica castanea BAIRD.}

Plate XII. Fig. 4.

\begin{abstract}
N SOUTH-WESTERN MISSOURI May is really the "poet's month of May," the month of flowers and birds. For several years I occupied a small cottage on the edge of the woods and on the north side of an orchard, the trees of which were very dense, their lower limbs touching the ground. By the end of April and early in May the forest trees, the ornamental shrubbery, and the fruit trees of the orchard literally swarmed with many species of Warblers. They explored every branch from the tallest oaks and hickories to the lilacs, the upright honey-suckles, mock-oranges, and spicebushes, so urgent is the demand of food during their long northern journeys. Usually they are seen early in the morning and all day long. At night they are all up and away. Their beautiful.colors and delicate forms can frequently be seen among the dense flower-clusters of the apple and pear trees, and in the wealth of highly scented flowers of the fragrant and Standish'shoney-suckles. All the Warblers are exceedingly interest-
\end{abstract}


ing, many are showy, and some remind one of the gorgeously colored birds of tropical countries. One of the most richly attired species is the BAY-BREASTED Warbler. Together with other species I observed it in the apple trees of my garden. It was not an abundant bird, being seen always in few specimens. I usually observed it about May 7 , and by the 20th of that month the. last stragglers left for their northern home. In south-eastern Texas $I$ found it one of the most common species of the family during the spring migration. They arrived from their winter-quarters about the 25th of April, when the magnificent magnolias opened their first flowers, and May 5 they were still numer. ous. In a large garden .where a beautiful specimen of the laurel magnolia ${ }^{1}$ was in full bloom, filling the air with its delicious perfume, I saw at one time seven Bay-breasted Warblers besides several other species. They searched every leave and every flower-cup for prey, darting about with great activity and frequently catching insects on the wing. Wherever I have observed them they kept more on the lower branches, rarely ascending to the tops of tall trees. They always prefer to hunt in small trees and the underwood, being especially common on the edges of the woods, where the larger shrubs hang over the woodland's border in wild grace. In Wisconsin they seldom arrive before May 15, and extend their stay to the first days of June, when they suddenly disappear. Probably some breed in the beautiful coniferous lake and mineral region of northern Wisconsin and Michigan.

"The New England record of the Bay-breast coincides closely with that established for the Black-poll; but the former is not quite so late a migrant in spring or fall, and is more irregular, both in local distribution and apparent abundance. The two species are alike strictly limited in their southern extension in the breeding season by the Canadian Fauna; the difference in breeding range being, that the Bay-breasts are limited by the same Fauna in their northward dispersion in summer, while the Blackpolls pass on in the Hudsonian. The consequence is, that the Bay-breasts are abundant summer residents of certain portions of northern New England, while the Black-polls are comparatively rare in the same districts at such period. The more southerly summer range of the Bay-breast is also evident by the fact, stated by Mr. Minot, that the bird has been seen in Massachusetts in June and July." *

Mr. C. J. Maynard and Mr. Wm. Brewster found this species one of the most abundant of the Warblers at Umbagog, Me. The nest is usually placed on a horizontal branch of a hemlock or spruce, from fifteen to twenty feet from the ground. One nest was found on the side of a thickly wooded hill, another one along a cart-path in the woods. The nests were large in comparison with the size of the bird. They were composed of small larch-twigs, mixed with a little tree-moss, very neatly and smoothly lined with black fibrous rootlets, seed-stalks of ground-moss, a little rabbit fur, a bit of green sphagnum moss, and sometimes the materials include a few grass-stalks.

The ustual number of eggs is four. They are white, with a bluish tinge, more or less thickly spotted and speckled with brown, especially near the larger end.

In September the Bay-breasts are again on their way to the South. They winter abundantly in Central America and perhaps also in the West Indies. This Warbler is 
an eastern species, which reaches only to the edge of the Plains. In his excellent "Revised Catalogue of the Birds of Kansas," Mr. N. S. Goss does not enumerate this Warbler, but it strikes western Missouri and Iowa.

NAMES: BAY-BREASTED WARBLER, Bay-breast.

SCIENTIFIC NAMES: Sylvia castanea Wilson (1810). DENDROICA CASTANEA BATRD (1858).

DESCRIPTION: Male, back, ashy-olive, thickly streaked with black; wing-bars, white; white spots on outer tail-feathers; fore-head and sides of head black; crown, throat, and breast, deep chestnut-red; rest of under-parts, whitish. Fimale, similar but chestnut paler and more restricted.

Length, 5.50 inches; wings, 2.80 ; tail, 2.25.

BL_ACK-POLL WARBLER.

Dendroica striata BAIRD.

Plate XII. Fig. 3.

In Wisconsin and Illinois the BLAck-POLL WARBLER is very common during the latter part of May, and again early in September. With many other species I found it common in the latter part of April and in the beginning of May in south-eastern Texas. The last stragglers there were seen May 11. In the tropical hammock-woods, near Lake Apopka, Fla., I observed it in great abundance in April among palmettos, liveoaks, magnolias, and loblolly-bay trees (Gordonia). Like other species, it seems to follow the warm spring as it proceeds northward, for in the North we find it when all the apple and pear orchards are snowy with blossoms. These birds always linger a week or even a few weeks, before they depart for the high northern latitudes, arriving there when nature has assumed her most festive garb. "Thus, in all their long passage from the far South to their summer home, they revel amid bursting buds and the fragrance of a continuous spring." Although more robust than other species of the genus, the Black-polls are the last to appear from their winter-quarters. Like other Warblers they vary greatly in numbers from year to year, being exceedingly common in one spring and very rare in another. They indifferently search for insects among both the higher and lower branches of trees, and occasionally seize their prey in the air. Evergreens are always preferred, even during their migration. They are usually seen in pairs or in small companies of from four to five. It is possible that some of the Black-polls may be found breeding in northern Wisconsin and Michigan, but the majority passes farther to the North. The Arctic regions around Fort Anderson, Fort Yukon, and Fort Good Hope, the Hudson Bay country, Labrador, are the true summer home of this species. They affect exclusively the heavy timbered forests and woods which consist entirely of a great many evergreens. Their winter-quarters are almost under the tropics in Central and northern South America. During the migration they are found from the Atlantic to the Rocky Mountains. In September they are very common in our northern woods, being now on their way to the South. According to Mr. Maynard, it is difficult to believe that the little green birds, which come drooping in by thousands, are the same which passed us in the bright spring time; then the low lisping songs of the males were constantly heard; now they flit silently and hurriedly through the changing foliage which too shortly precedes the season of desolation. 
According to Dr. T. M. Brewer, who found the Black-polls breeding around Eastport, Me., and Grand Menan, N. B., they confine themselves to the thick swampy groves of evergreens, where they breed on the edges of woods. All of the several nests he met with in these localities were built in thick spruce trees, about eight feet from the ground, and in the midst of foliage so dense as hardly to be noticeable. The nests were large and bulky for the size of the bird. They were constructed chiefly of a collection of slender young ends of branches of pines, firs, and spruces, interwoven with and tied together by long branches of Caladonia lichens, slender herbaceous roots, and finer sedges. The nests were strongly built, compact and homogeneous, and were elaborately lined with fine panicles of grasses and fine straw. In all the nests found, the number of eggs was five. The ground-color is a beautiful white, with a slight tinge of pink when fresh. They are blotched and dotted over the entire surface with profuse markings of a subdued lavender, and deeper markings of a dark purple intermixed with lighter spots of reddish-brown.

NAMES: BLACK-POLL WARBLER, Black-poll.

SCIENTIFIC NAMES: Muscicapa striata Foster (1772). Sylvia striata Lath. (1790). DENDROICA STRIATA BALRD (1858).

DESCRIPTION: Male, above, slaty, with an olivaceous tinge, streaked with black; Crown down to the eyes, glossy black. Sides of head, white; under-parts, white, with a chain of black streaks from chin to tail; wings, dusky, with two white cross-bars; tail, dusky, with small white spots on the onter feathers. Female, similar, but crown like the back; under-parts, tinged with greenish-yellow.

Length, 5.25 to 5.50 ; wings, 2.80 ; tail, 2.25 .

\section{BLACKBURNIAN WARBLER.}

\section{Dendroica blackburnize BAIR̉D.}

Plate XII. Fig. 1.

Te OKING BACK on my ten years' residence in different parts of the South, I can 0 recall no pleasanter time than my first winter in south-eastern Texas. In my daily rambles over prairies, through woods, over swamps, and cultivated lands, I was sure to make some new and interesting discoveries. Many a locality still retained a primitive quiet and simplicity that was all the more inviting from its contrast with the enervating and bustling life of Chicago, my former place of residence. During the latter part of February and the beginning of March, many flowers commenced to bloom. March was an exceedingly pleasant month with now and then a cold "Norther" and a frosty night. Above all I missed the distinguishing line between winter and spring. The vegetation, indeed, takes a partial rest during the winter months, "but it is checked rather than suppressed, and the reign of summer begins without that interval of preparation which we call spring." The holly with its beautiful evergreen foliage and shining red berries, the magnolia and live-oak, and many other trees and shrubs are broad-leaved evergreens, but some of them, curious enough, assume bright autumn tints in spring, when 
they shed their leaves. This is especially the case with the live-oak and magnolia. They cast their old leaves in April, before the flowers and the new leaves appear. Some of these magnificent trees are then nearly denuded, while the ground underneath is bestrewn with yellow, orange-tinted, and scarlet foliage. Orchards are in full bloom usually in March, but I saw peach trees opening their flower-buds as early as February 20. Warblers, as a rule, do not appear from their winter-quarters before the forest trees are clad in green verdure and beautious masses of flowers. Only then these delicate birds are able to find a sufficient supply of insect food, a congenial resting place and safe protection from their enemies. Unseen and unheard by ordinary people they pass by on their way to high northern latitudes. They must be sought for, and only the friend of nature knows where to look for them. In the Northern States the apple and pear trees of the orchards, and the wild plum and crab trees on the woodland border are their favorite haunts during the middle of May. In Texas and Florida I used to search for them in the flowering magnolias, or on such trees as were overgrown with trumpet-vines, the dazzling orange-scarlet flower clusters of which hanging down in graceful festoons. Besides many other species of the family, the most richly attired BLACKBURNIAN WARBLER was always among them. When I first saw this brilliant bird in the flowering magnolias, I thought that nothing could rival the beauty of this picture. The delicacy and brilliancy in the orange of the throat, together with the chaste whiteness of the flowers, and the dark shining green of the leaves made a combination of unsurpassed beauty. Sometimes I observed two or three males together in one tree, but more often they migrate singly. Usually they are seen together with Magnolia and other Warblers, always frequenting the same localities. In Texas I never noticed them before April 20; in south-western Missouri about May 7, in northern Illinois May 15, and in Wisconsin one or two days later. They are rather rare in all these localities, and their stay among the northern woods and orchards is short. In the coniferous region of Wisconsin they always show a fondness for pines and hemlocks. According to my friend Prof. W. W. Cook, "few lovers of forests and birds could fail to notice this brilliantly colored Warbler, should they pass near its favorite haunts." The Blackburnian Warbler breeds from the heavy forests of northern Minnesota and Michigan, and probably also Wisconsin, northward. It is a summer resident in New England, breeding in suitable localities, but more sparingly in the Alleghanian and Carolinian than in the Canadian Fauna, which latter must be regarded as its true summer home. Langdon found it the most abundant species of the family in the Chilhowee Mountains of eastern Tennessee, "ranging from 2,000 to 4,000 feet and keeping mostly in the higher tree tops." Both adults and young were seen together. Dr. W. C. Rives Jr. observed it in the mountains of Virginia, and Prof. W. Brewster in the beautiful mountain region of western North Carolina, where it seems to be abundant. On the crest of the Cowee Range, and about Highlands, they were among the most numerous and most conspicuous woodland birds, frequenting old oak timber interspersed with hemlocks, or bordering on hemlock swamps. In these evergreens they were evidently breeding, or about to breed, for the males were in full song and paired, and Mr. Brewster noticed that each had its particular hemlock which it guarded with jealous care, driving away all other small birds which came near it. 
It is only since the beginning of the last quarter of this century that reliable information on the nesting habits of the Blackburnian Warbler was given. Mr. H. D. Minot found a nest in northern New Hampshire and another in a thick hemlock wood near Boston. Dr. C. Hart Merriam, now Curator of the Division of Ornithology and Mammalogy of the Department of Agriculture, Washington, D. C., gives the following excellent description of the nest and eggs of this beautiful bird:*

"On the 23rd of May, 1879, my lamented friend, the late A. Jenings Doyan, pointed out to me, high in a lofty pine, the yet unfinished nest of the Blackburnian Warbler. The exact locality was a grove of large white pines ${ }^{1}$ on a dry hill just east of Black River, at Lyon's Falls, Lewis County, N. Y. Some days previously Mr. Doyan had observed the female bird carrying in her bill a downy substance which afterwards proved to be the tufted seeds of the cat-tail. By the aid of a field-glass, after many hours of patient watching, he finally discovered the nest. On the 3rd of June he ascended the tree and secured the prize. It was saddled on a horizontal limb twenty-five and a half metres (about 84 feet) from the ground, and three metres (about 10 feet) from the trunk. The limb measured $15 \mathrm{~mm}$. in diameter where the nest was attached. The nest contained four fresh eggs of the Blackburnian Warbler and one of the Cowbird. Authentic published descriptions of the nest and eggs of this Warbler are so few in number, and so meagre in exact details, that I make apology for presenting the following: .... The ground-color is pale bluish-green, spotted all over with umber-brown of varying intensity, the spots tending as usual to form a ring at the large end. One differs from the rest in being well sprinkled with blotches of rich, dark umber, which coalesce into a broad zone around the large end. The nest is large, substantial, and very compact. It consists almost entirely of a thick and densely woven mat of the soft down of the cat-tail ${ }^{2}$, with seeds attached, and is lined with fine lichens, horse hair, and a piece of white thread. On the outside is an irregular covering of small twigs and rootlets, with here and there a stem of moss or a bit of lichen ..."

Prof. Wm. Brewster found the Blackburnian Warbler breeding at Winchendon, Mass., about sixteen miles south of Mt. Monadnock. As usual, Mr. Brewster gives an inimitable description of the locality.* According to his notes, the surface of the country is everywhere broken and hilly, very wild and picturesque, and mainly wooded. On the hills and drier portions of the lowlands, the forests are composed chiefly of white pine, hemlock and various deciduous trees. The swamps are covered with a dense, almost impenetrable and rather stunted growth of black spruces, balsams, and larches, with a very few white spruces. The hardwood timber on the uplands is composed chiefly of beech, red and sugar maple, yellow and paper birch, with a sprinkling of red oaks and basswoods, a very few chestnuts and, more or less scattering, old-growth spruces. The underwood is chiefly of hobble bush ${ }^{3}$ and striped and mountain maples. In places yew is also found. About swamp edges the beautiful pink azalea ${ }^{4}$ is everywhere common. Ferns of various species flourish in great luxuriance wherever the soil is damp enough for them, and a deep, suggy carpet of sphagnum covers the ground in the swamps. On the hill-sides, especially under white pines, the exquisite little Linnæa borealis is

"See "The Auk," Vol. II, 1885, p. 103. -"* "The Auk," Vol. V, 1888, p. 386-393.

1 Pinus strobus. 2 Typha latifolla. \& Viburnum lantanoides. Aralea nudifora. 
frequently met with, and Clintonia borealis abounds everywhere. No wonder that in a locality so beautiful such birds as Magnolia, Myrtle, Black-throated Blue, Canada, Black-throated Green, and Blackburnian Warblers find a congenial home. On the nesting habits of the last named species Mr. Brewster writes as follows:

"On both high and low ground, wherever there were spruces in any numbers, whether by themselves or mixed with other trees, and also to some extent where the growth was entirely of hemlocks, the Blackburnian Warbler was one of the most abundant and characteristic summer birds, in places even outnumbering the Black-throated Green Warbler, although it shunned strictly the extensive tracts of white pines which Dendroica virens seemed to find quite as congenial as any of the other evergreens. A set of four fresh eggs was found June 26, 1887. The nest, which was found by watching the female, was built at a height of about thirty feet above the ground, on the horizontal branch of a black spruce, some six feet out from the main stem. Its bottom rested securely near the base of a short, stout twig. Above and on every side masses of dark spruce foliage, rendered still denser by a draping of Usnea (which covered the entire tree profusely), hid the nest so perfectly that not a vestige of it could be seen from any direction. This nest is composed outwardly of fine twigs, among which some of the surrounding Usnea is entangled and interwoven. The lining is of horse hair, fine, dry grasses, and a few of the black rootlets used by the Magnolia Warbler. The whole structure is light and airy in appearance, and resembles rather closely the nest of the Chipping Sparrow. The eggs are marked with pale lavender, vandyke-brown, mars-brown, and black. Over most of the shell the markings are fine and sparsely distributed, but about the larger end they become broad and more or less confluent; tending to form a wreath pattern. Some of the markings are linear, resembling penscratches. The ground-color of these eggs, before blowing, would have been passed for dull white, but with the removal of their contents a delicate, yet faint, greenish tinge appeared and has since persisted."

The Blackburnian Warbler is a bird of eastern North America, west to Missouri, Iowa, Minnesota, and, casually, to Utah and New Mexico. In September they are on their way to their winter-quarters in the Bahamas, eastern Mexico, Central America, South America (Venezuela, Colombia, Peru, etc.).

NAMES: BlackBURNIAN WARBLER, Hemlock Warbler, Orange-throated Warbler.

SCIENTIFIC NAMES: Motacilla blackburnix Gmelin (1788), Wilson, Audubon, Nuttall. DENDROICA BLACKBURNIAE BAIRD (1858).

DESCRIPTION: Male: Above, including wings and tail, black; wing-patch, white; back, variegated with white; several lateral tail-feathers mostly white. Crown-spot, eyelids, line over the eye, throat and breast, brilliant orange or flame-color, contrasting beautifully with the black surroundings; sides, streaked with black. Female: Black of upper parts replaced by brownish-olive, with black streaks; flame-color replaced by yellow; two white wing-bars.

Length, 5.40 inches; wings, 2.75; tail, 2.00 inches. 


\title{
YELLOW THROATED W ARBLER.
}

\author{
Dendroica dominica BAIRD.
}

Plate XIII. Fig. 1.

\section{1} OBSERVED the beautiful YELLOW-THROATED WARBLER frequently in Alabama, Georgia, and Florida in the fine days of April, and can fully corroborate what $\mathrm{Mr}$. Wm. Brewster says in regard to it. This most distinguished and admirable writer published the following account of the bird in the "Bulletin of the Nuttall Ornithological Club" (Vo1. II, 1877, pp. 102-106).

"Although I cannot myself claim an acquaintance of very long standing with this beautiful little species, still for five or six weeks during the past spring scarcely a day passed that I did not see one or more individuals. I first met with them at Mellonville, Florida, where, on March 14, I shot two specimens, both females, in the pine woods near the town. They were associated with Pine Warblers, Nuthatches, and Woodpeckers. During a trip up the Wekiva River, March 19 to 23 inclusive, I heard at frequent intervals a Warbler that I did not recognize, singing in the cypresses, but from the impenetrable nature of the swamps, and the great height of the trees, I was unable to get even a glimpse of the bird. A week later, while descending the St. John's River by steamer, I again constantly heard, both from the cypress swamps and the open piny woods, the notes of this, to me, unknown species, and although I felt almost certain of its identity, it was not until I reached St. Mary's, Georgia, that I proved to my satisfaction that my suspicions were correct. There, from the 6th of April to the 4th of May, I enjoyed abundant opportunities of studying its habits, for it was everywhere, in suitable localities, if not one of the most abundant, at least a generally distributed species. At the time of my arrival the males were in full song and mating. A few individuals haunted the moss-hung live-oaks that shaded the village streets, but the open piny woods were their favorite abode. There, with the Summer Redbird, the Pine Warbler, the Brown-headed Nuthatch, and a variety of Woodpeckers, they frequented the beautiful southern pines. Indeed, so great was their attachment to this tree, that, with the exception of those heard in the cypress swamps of the upper St. John's and the few that inhabited the oaks in the town, I do not remember to have seen one in any other tree. So marked and unvarying was this preference, that on more than one occasion I made use of the notes of this bird to guide me out of some bewildering thicket; feeling sure that beyond where it was singing I should find the more open pineclad country. Nearly all the authors who have written on the Yellow-throated Warbler from personal observation compare his movements along the branches to those of the Black and White Creeper. At first I was inclined to the same opinion, but after having spent many hours in carefully studying their habits, I became convinced of the error of my earlier impressions. Their movements are much slower than those of the Mniotilta, and there is less of that crouching, creeping motion. They do, indeed, spend 
much of their time searching the larger branches for food, but it is much more in the manner of the Pine Warbler, and their motion is rather a hopping than a creeping one. I have never seen them ascend the trees from the roots to the topmost branches, as Audubon relates, but I occasionally observed one clinging against the main trunk for a moment, to seize an insect, as will the Bluebird and many of the Warblers. Their hunting ground is for the most part, however, among the higher branches, and a considerable part of their time is spent at the extremities of the limbs, searching for food among the pine needles. Their bright yellow throats, brought out by contrast with the dark evergreen foliage, give them a certain resemblance to the Blackburnian Warbler. The males are not very persistent singers. I rarely heard them during warm hours of the day, even when pairing was almost their sole occupation. Their song is very pretty; it may be nearly imitated by the syllables $t w s e e-t w s e e-t w s e e, t w s e e-s e e$, the last two notes rising and terminating abruptly. It most nearly resembles that of the Nashville Warbler, beginning in almost the same way, but ending differently, and, indeed, throughout the notes are much sweeter. Both sexes utter a chirp similar to that of other Warblers, but sweeter. By the middle of April there was a marked decrease in the number of Yellow-throated Warblers about St. Mary's."

I observed this bird first near Mobile and Pensacola in the pine woods and a few days later more abundantly on the St. John's River and in the tall pines near my little orange grove and ornamental plantation at Gotha, Fla. It sang almost incessantly in the tops of the tall pines, but it frequently entered the grove and visited the oleanders, magnolias, and oaks covered with masses of air-plants. A nest I could never find. Mr. Wm. Brewster discovered one at St. Mary's, Ga., which was placed "at the height of about thirty-five feet from the ground, on the stout horizontal branch of a southern pine, one of a thinly scattered grove or belt that stretched along the edge of a densely wooded hammock. It was set flatly on the $\operatorname{limb},-$ not saddled to it, - nearly midway between the juncture with the main trunk and the extremity of the twigs, and was attached to the rough bark by silky fibres. It was composed externally of a few short twigs and strips of bark, bound together by Spanish moss and a silky down from plants. The lining consists of a few hair-like filaments of moss and soft cottony vegetable fibres. The whole structure is neatly and firmly compacted, though essentially simple in appearance, and, from the nature of the component materials, of a grayish color. In size, shape, and general formation, it very nearly resembles nests of the Black-throated Green Warbler in my collection... The eggs, four in number, measure $.69 \times .53$ of an inch. They are quite regularly ovate, with fine dottings of pale lilac scattered thinly and evenly over a grayish-white ground-color. A few spots or blotches of burnt sienna occur about the large ends, while occasionally irregular, pen-like lines of dark brown diversify the remaining surface." Near Raleigh, N. C., the nest is from twenty to ninety feet or more above the ground, and the distance from the trunk about three to twelve feet. The nest there is usually much like the Pine Warbler's in general character, but lacks the black grape-vine bark, which gives the latter such a dark appearance. The materials of which it is composed are plant-stems, strips of trumpet-vine bark, fine grass, and caterpillar's silk; the lining consists of horse hair or feathers, or both. The bird commences nesting there early in April, frequenting for its haunts the pine woods. Mr. 
A. T. Wayne found nests of this Warbler in mixed woods near Charleston, S. C., which were built in tufts of Spanish moss, and lined with feathers.

The Sycamore WARBLER, Dendroica dominica albilora BaIRD, is only a variety of the foregoing. In the Mississippi valley, at least as far north as central Illinois, in the bottom woods of the lower Arkansas and Missouri, in Mississippi, Louisiana, and south-eastern Texas, it is a summer resident. Most common it seems to be in southern Illinois and southern Indiana. According to Prof. Robert Ridgway, the Sycamore Warbler is a common summer resident in the bottom lands, where, according to the writer's experience, it lives chiefly in the large sycamore trees along or near watercourses. On this account it is a difficult bird to observe during the breeding season, ,the male usually keeping in the topmost branches of the tallest trees, out of gunshot and often, practically, out of sight, although his presence is betrayed by his loud, very unwarbler-like song. The song of this species is so much like that of the Indigo Bird that it requires a practical ear to distinguish them; the tone is remarkably similar, but there is a difference in the modulation which, after one becomes thoroughly acquainted with it, renders it distinguishable. In its motions, this Warbler partakes much of the character of a Creeper, often ascending or descending trunks of trees or following their branches, much in the manner of Mniotilta."

The distribution of this variety is not yet well made out. I never saw it in northern Illinois, but Mr. Nelson records it as a rare summer visitant, and Dr. Gibbs found it at Kalamazoo, Mich. - It is also called WHITE-CHEEKED WARBLER, and WHITEBROWED YelLow-THRoATEd WARBLER. This variety is smaller with a shorter bill; superciliary stripe usually entirely white.

NAMES: Yellow-throated Wakbler, Pensile Warbler (Lath.), Yellow-throated Gray Warbler, Yellowthroated Wood Warbler.

SCIENTIFIC NAMES: Motacilla dominica Linn. (1766). Sylvia dominica Lath. (1790). DENDROICA DOMINICA BaIRD (1865). Dendroica superciliata Baird (1858). Motacilla pensilis Gmel. (1788). Sylvia pensilis Lath. (1790). Sylvicola pensilis Rich. (1837), Aud. Motacilla flavicollis Gmel. (1788). Sylvia flavicollis Lath. (1790). Sylvicola flavicollis Hoy (1853), Wisconsin.

DESCRIPTION: Male, adult: "Upper parts, uniform grayish-blue. Chin and throat, bright yellow; underparts, white. Forehead, and sometimes most of crown, lores, and cheeks, sides of throat, and numerous streaks on the sides of the breast, black. A stripe from the nostrils over and behind the eye, a crescent on the lower eyelid, the sides of the neck behind the black cheek-patch, and two conspicuous bands on the wings, white. Terminal half of the outer two, and terminal third of the third tailfeathers, white. Female, almost precisely similar.

"Length, 5.10 inches; wing, 2.60; tail, 2.30 inches." (Baird.)

\section{GRACE'S WARBLER.}

Dendroica gracia Couss.

GraCE'S WARBLER was discovered by our distinguished naturalist, Dr. Elliott Coues, in Arizona, and named after his sister Grace. In the mountain region of Arizona it always frequents the pine belt. "They keep not only among tall pines, but even in the upper portions of these magnificent trees, some of which grow to such a height that it is a fair gunshot range to their lower limbs, let alone the canopy of foliage that 
stretches to the sunlight out of the lower shade it casts itself, affording the happiest hunting-ground to these nimble and industrious birds. They are seen coursing among the branchlets, skipping at apparent random through the endless intricacies of the foliage, hovering momentarily about the terminal branches of needles, and then dashing far out into clear space, to capture the passing insect with a dexterous twist and turn." (Coues.) Doubtless the birds breed high up in the pine trees. Their song is similar to that of other members of the family.

DESCRIPTION: Male: The color above is ashy-gray, with a slaty-blue tinge; middle of back, streaked with black; the crown with crowded black arrow-heads, the tendency of these markings being to form a line along the side of the crown, meeting its fellow on the forehead. Over the eye a broad line of yellow, changing to white behind the eye; sides of the head like the back, enclosing a yellow crescentic spot below the eye. Chin, throat, and fore-breast, bright yellow, bordered with blackish streaks. Two white wing-bars. Female, similar; yellow not quite so strong.

Length about 5 inches.

\section{BLACK-THROATED GRAY WARBLER.}

Dendroica nigrescens BAIRD.

This species occurs in the western United States, north to Colorado and Oregon, south, in winter, to Orizaba, Mexico. Dr. Coues found it during the migrations and also in summer at Fort Whipple, Arizona. Nuttall and Townsend, Dr. Cooper, Prof R. Ridgway, Mr. Henshaw, Mr. Aiken, and other ornithologists observed these rather rare birds in the mountain regions of the West, especially in coniferous trees.

DESCRIPTION: Male: "Above, bluish-ash, interscapular region, and usually also the upper tail-coverts, streaked with black. Below, from the breast, pure white, the sides streaked with black. Entire head, with chin and throat, black; a sharply defined yellow spot before the eye, a broad white stripe behind the eye; and a long white maxillary stripe widening behind from the corner of the bill to the side of the neck. Wings, fuscous, with much whitish edgings, and crossed with two broad white bars on the ends of the greater and median coverts. Tail, like the wings, the three lateral feathers mostly white, except on the outer webs, the fourth with a white blotch." (Coues.) Female: Similar.

Length about 5 inches.

\section{GOLDEN CHEEKED WARBLER.}

\section{Dendroica chrysoparia SCLATER \& SALvin.}

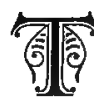

HE MOUNTAIN REGION of south-western Texas is not covered with such a magnificent forest growth as the Alleghanies in western North and South Carolina and northern Georgia. Prattling brooks and gushing mountain streams, so common. in the region last mentioned, are rarely met with in western Texas. The Comal near New Braunfels is exceedingly picturesque, imbuing the surrounding landscape with a charm peculiarly its own. Owing to the great dryness of this region the hill-tops and mountain-sides are often quite destitute of trees, but more frequently they are covered 
with a dense growth of mountain cedar $^{1}$ and stunted evergreen oaks. Elms, mesquit, hack-berry, and pecan trees, various oaks and cotton woods are the prevailing trees in the river and creek valleys. In company of my friend, Mr. P. H. Oberwetter, of Austin, we start some fine day early in May in a north-western direction. About four miles from Austin we reach Mount Bonnell, lifting its head several hundred feet above the Colorado River, which here leaves the mountains and enters the undulating prairie and post oak country. It is only half of a mountain, half of it being torn away by the Colorado in past ages. Arriving at the summit we have a splendid view in all directions. Cedar thickets abound almost everywhere. No large forest trees are noticed, but a beautiful evergreen shrub, Sophora speciosa, arrests our attention near where we stand. The spikes of violet-blue flowers are powerfully fragrant. But what plant is yonder gray-leaved bush, which selected its abode on and between the clefts of rocks overhanging the steep precipice? It is Leucophyllum Texanum, a shrub from five to ten feet high, with evergreen, wooly, bluish-green leaves. It is very beautiful, flowering from May to October. A bush, loaded with thimble-shaped rosy-purple flowers is a beautiful object to behold. Close by, in clefts of rocks, we notice a maurandia, hanging down in graceful festoons, loaded all summer with light blue flowers. The shooting star ${ }^{2}$ seems to find its southern limit in this region. In the shade of the cedars we find a beautiful terrestrial orchid, indeed, the most beautiful orchid of Texas, Bletia aphylla. The flower stalk grows about twelve inches high, half of its length being densely covered with beatiful flowers of the peculiar shape of all orchids. The color is deep purple with yellow or bronze lines. Members of the cactus family are very common. On ledges of rock and in moist shady places we find another beautiful orchid, Epipactis gigantea. It grows about one to two feet high and has a leafy stem which terminates in a spike of about twelve flowers of a yellow color streaked with purple. On the foot of the mountain we notice a shrub ${ }^{3}$ six to ten feet high, with white sweetscented flowers in summer. One of the most gorgeous plants, Lisianthus Russellianus, is sometimes found here, too, but more abundantly in the prairies in wet places, where it lifts up its panicle of splendid violet flowers from June to September. Pentstemons ${ }^{4}$ open their exquisite, large bluish flowers later in the season. A small, tuberous rooted commelyna, growing in sandy places, has rosy-purple flowers with the fragrance of heliotrope. An evening primrose ${ }^{5}$ is very showy, having large golden yellow flowers. In many places we meet with Lantana camara and the Mexican mulberry ${ }^{6}$. The bird pepper $^{7}$, relished by birds, grows on the mountain-side. The popinac ${ }^{8}$ produces its globular yellow flowers in March, which perfume the whole neighborhood. The cardinal flower $^{9}$ is abundant where it is sufficiently moist. On this mountain we also find a species of dasylirion, and in the cañon in the vicinity the pretty Clematis coccinea. Clematis Viorna is also present, but not in the same places with the last. On our way home we notice the bluish, two-ranked leaves of a spider lily ${ }^{10}$. Cooperias ${ }^{11}$ are also very common. In the sandy post oak soil around Austin a pretty little flower, bright yellow inside and purplish-brown outside, attracts our attention. It is the yellow fairylily ${ }^{12}$. All these bulbous plants belong to the royal order of Amaryllidacex.

1 Juniperus montana. 2 Dodecatheon Meadia. a Lippia lycioides. 1 Pentstemon Cobea, digitalis, Murryanum. - Enonthera macrocarpa. G Callicarpa Americana, 7 Capsicum fruticosum. a Acacia Farnesiana. o Lobelia Mexicana. 10 Hymenocallis Jacera. 11 Cooperia Drummondil and $C$. pedunculata. 12 zephyranthes Texana. 
Further to the south-west the flora is still more peculiar. There we find a fine spotted agave ${ }^{1}$. The leaves are spotted with brown, and the greenish flowers are very fragrant. Here we also find one of the most magnificent yuccas ${ }^{2}$ in existence. It attains a height of fifteen to twenty feet, and produces every year an immense spike of pure white, lily-like blossoms. Growing between the rocks we find an elegant shrub, about nine feet high, with bright green leaves, and the entire summer covered with racemes of tubular orange-scarlet flowers. This is Anisacanthus Wrightii. In dry river beds grows everywhere the beautiful willow catalpa ${ }^{3}$, a tall tree with spikes of purple and white large flowers during summer.-This is only a very small list of remarkable plants of western Texas, but in my opinion those enumerated are the most characteristic of the region.

This part of Texas is the home of the GoLDEN-CHEEkED WARBLER, one of our most interesting and beautiful Wood Warblers. Wherever cedar brakes are found, this elegant bird seems to be more or less common. In appearance and habits this species is very similar to the Black-throated Green Warbler of the North. Mr. W. H. Werner found several nests in Comal County, Texas. According to his observations the birds are very active, always on the alert for insects, examining almost every limb, and now and then darting after them when on the wing. The male utters soft notes at intervals, which sound somewhat like tserr weasy-weasy tweah. He found them invariably in cedar timber, or "cedar brakes," as the ranch men call them. On the 13th of May he succeeded in finding his first nest in a dense cedar thicket. It contained three eggs, and also one of the Cow Bunting. In the immediate neighborhood he found a second nest, but it was abandoned. On May 14, 1878, he discovered two more vacant nests, and on examining them he found that young ones had been hatched, and had already left the nest. - All four nests were similar in construction, and were built in forks of perpendicular limbs of the mountain cedar, from.ten to eighteen feet from the ground. The outside is composed of the inner bark of the cedar, interspersed with spider webs, well fastened to the limb, and in color resembling the bark of the tree on which it is built, so that, even at a short distance, it is difficult to detect the nest. In April, May, and June of the following years I had frequent opportunities of observing these beautiful birds in the cedar brakes in Travis, Hays, Comal, Lee, arrd Bastrop Counties. In the first and second weeks of May I saw them carry nesting materials into the interior of large and dense cedar thickets where it was almost impossible to follow them. Suffice it to say that I did not succeed in finding a single nest.

Mr. Brewster describes a nest, presented to him by Mr. Werner, more minutely: "The original position of this nest is well shown, as it is well preserved with a section of the limb upon which it was found. It is placed in a nearly upright fork of a red cedar, between two stout branches, to which it is firmly attached. Although a large, deep sitructure, it by no means belongs to either the bulky, or loosely woven class of bird domiciles, but is, on the contrary, very closely and compactly felted. In general character and appearance it closely resembles the average nest of the Black-throated Green Warbler. It is, however, of nearly double the size, in fact, larger than any Wood Warbler's nest (excepting, perhaps, that of the Myrtle Warbler) with which I am acquainted. It measures as follows: external diameter, 3.50; external depth, 3.45; 
internal diameter, 1.60; internal depth, 2.00. The exterior is mainly composed of strips of cedar bark, with a slight admixture of fine grass-stems, rootlets, and hemp-like fibres, the whole being kept in place by an occasional wrapping of spider webs. The interior is beautifully lined with the hair of different quadrupeds and numerous feathers; among the latter, several conspicuous scarlet ones from the Cardinal Grosbeak. The outer surface of the whole presents a grayish, inconspicuous appearance, and from the nature of the component materials is well calculated to escape observation. Indeed, it must depend for concealment upon this protective coloring, as it is in no way sheltered by any surrounding foliage."*

The eggs, four to five in number, are creamy-white, glossy, speckled and spotted with shades of reddish-brown and umber.

The Golden-cheeked Warbler occurs from south-western Texas to Guatemala.

NAMES: GoldeN-ChEEKEd WARBLER, Cedar Warbler, Texas Warbler.

SCIENTIFIC NAMES: DENDROICA CHRYSOPARIA Sclater \& SALviN.

DESCRIPTION: Head and body, above black, the feathers with olive-green edges, especially on the back; rump, clear black; entire side of head, yellow, with a narrow black line through the eye. Beneath, white; a large black patch covering the chin and throat, and occupying the entire space between the yellow patches of the two sides of the head and neck, and extended along the sides in a series of streaks. Wings, above ashy, with two white bands across the coverts.

Length about $5 \cdot$ inches; wing, 2.50 ; tail, 2.15 inches.

\section{Blackmthroated Green Warbler.}

\section{Dendroica virens BAIRD.}

Plate XII. Fig. 6.

氛 HE CONIFEROUS region of central and northern Wisconsin, with its many lakes, romantic scenery, gushing streams, and prattling brooks, cool springs and extensive forests, is very attractive to every lover of nature during the short summer. Tourists and pleasure seekers from all parts of the country, especially from the South, make this region their favorite summer home. The ground underneath the white pines, hemlocks, and spruces is always covered with a dense underwood, consisting of moosewood $^{1}$, June-berry bushes, white thorns, and other shrubs. A dense dark green carpet of wintergreen, trailing arbutus, ground pine, wood lilies, bellworts, bloodroots, terrestrial orchids, ferns, bunch-berries ${ }^{2}$, clintonias ${ }^{3}$, solomon's seals, and many other delicate and beautiful plants, cover the ground in these woods. The remoteness and surrounding wildness render many a scene doubly impressive. The lakes are usually very irregular in their outline but always picturesque and surrounded by dark evergreen forests. Near such a sheet of water I spent the most poetical part of my life, my boyhood. The

* Bulletir Nuttall Ornithological Club, IV, pp. 77-79.

1 Cornus circinata. 2 Cornus Canadensis. I Clintonia borealis. 
hill-sides and the lowlands were then still covered with primeval forests. White pines, interspersed promiscuously with paper birches, sugar maples, beeches, and lindens prevailed in the upland woods. During the short summer time almost every morning found me on the south side of the lake, on a densely forest clad hill, at the foot of which a very clear and cool spring originated. A well-worn foot-path leading to this fountain from the house had been there for many years and very probably was formerly an Indian trail. It is true what our genial writer, Mr. John Burroughs, says: "Indeed, of all foot-paths, the spring-path is the most suggestive." * I never left this place without reluctance during the beautiful summer months, and even now the impression on my mind of the pleasure there enjoyed is very vivid. Near this pretty spot trees and shrubs and birds seemed to congregate. Here the Veery sang its anthem of morn, and the call notes of the Whippoorwill sounded through the calmness of the night. The exquisite song of the Rose-breasted Grossbeak, the enchanting eo-lie of the Wood Thrush, and the metallic che-wink of the Towhee was always heard. Among Warblers, the Maryland Yellow-throat, the Mourning and Golden-winged Warbler, as well as the Blackthroated Blue, were common in the low thickets on the border of the lake, while the Black-throated GreEN WARBLER, the subject of this sketch, was a tenant of the pines, wherever they were found. Although not common, a few pairs might always be found near the lake, and its varied and harmonious strain sounded from the tops of the pines from early morning throughout the day. They arrived usually during the second week of May, when the shad-bush and the wild crab tree were in full bloom. I have never found a nest, but I am sure that their home finds its limit in the southern border of the coniferous region of central Wisconsin. They breed from that line north to Hudson's Bay, and during the migration they are found from the Atlantic to the Plains. In south-eastern Texas I noticed their arrival from their winter-quarters in Central America about April 20, and they prolonged their stay always to about May 5, when the last stragglers disappeared. In south-western Missouri they were common when the apple trees bloomed, about May 5 to May 10. Near Lake Apopka, in Florida, they were seen first April 14. In all the pine and spruce regions of the North the Black-throated Green Warbler is, next to the Ovenbird, the most abundant species of the family. Like many other Warblers, they subsist almost entirely on insects which they collect from the blossoms and leaves of the trees, but in spring they also catch many insects in the air. "They generally remain in one spot for several minutes, and then fly to another at quite a distance, seldom staying long in one group of trees. Though active, they are not restless, as many of their kindred are, but rather are comparatively deliberate in their motions. There is to me a fascination in watching these birds, as they move among the tree tops, and a charm in listening to their drowsy notes, which (without poetical exaggeration) seem to invite one, on a warm day, to lie down and slumber on the pine needles that are strewn over the ground. The Black-throated Greens are, to me, with perhaps the exception of the Pine Warblers, the most attractive members of their family, on account, I think, of their pleasing, familiar, and oft-repeated songs, which are heard from the time of their arrival nearly throughout the summer, which form so fitting an accompaniment to the whisperings of 
the pines, and to which I am never weary of listening. Another reason, however, is that they show a fondness for the pines as great as my own, though, no doubt, from very different motives. The majesty of those trees, their gracefulness, their freshness throughout the year, their beauty in summer, when, after a hard shower, the light of the setting sun breaks upon them, their beauty in winter, when their branches are loaded, many to the ground, with snow, or when they are covered with glittering ice, their whisperings in the breezes of spring and summer, their sighing and whistling in the southern gales, and finally their odor, combine to render them the finest, I think, of all our forest trees." (Minot.)

In New England nests of this Warbler have been frequently found by Nuttall, Welch, Minot, and other ornithologists. Mr. Brewster found it a common bird in the mountains of North Carolina, where it was confined to the balsam forests, above 5,000 feet.

Mr. Minot, who has offered us a fresh and feeling description of the bird, a part of which I have quoted already, says in regard to the nesting habits of the Blackthroated Green Warbler: "The nest is usually placed in a pine, in a horizontal fork near the end of a bough, from twenty to fifty feet above the ground (but sometimes lower). It is finished in June, sometimes in the first week, sometimes not until the last. It is composed outwardly of narrow strips of thin bark, bits of twigs from vines, dried grasses, and such odds and ends as the birds have found convenient to employ; and inwardly of bits of wool, feathers, and plant-down, but it is generally lined with hairs and fine shreds of vegetable substances. It is usually small, neat, and very pretty. The eggs of each set are three or four. They are commonly (creamy) white, with reddish or amber-brown and purplish markings, grouped principally about the crown. These markings are, for the most part, either clear and delicate or a little coarse and rather obscure...."

In September they depart for their winter home in the West Indies and Central America.

NAMES: BLACK-Throated GrẹE WarkLer, Black-throated Green.

SCIENTIFIC NAMES: Motacilla virens Gmelin (1788). Sylvia virens Latham (1790). Sylvicola virens Richardson (1836), Audubon. DENDROICA VIRENS BAIRD (1859).

DESCRIPTION: Male: Above, olive-green; wings and tail, darker, the former with two white cross-bars and much white edging, the latter with the three outer feathers nearly all white. Whole side of head and forehead, rich yellow, contrasting beautifully with the jet-black chin, throat, and breast; the black color is prolonged in streaks on the sides of the body; rest of under-parts, white. Female, not so highly colored, the black restricted, veiled with yellow, or wanting entirely.

Length, 5.00 inches; wings, 2.50 ; tail, 2.00 inches.

\section{TOWNSEND'S WARBI_ER.}

Dendroica townsendi BAIRD.

TOWNSEND'S WARBLER is another western species respecting which our knowledge is limited: It occurs in the pine belts of the mountains, as far north as Sitka, Alaska, 
but the full extent of its breeding range is not yet ascertained. Almost all of our ornithologists have found it in the pine regions. Its habits do not differ from those of the other, species.

DESCRIPTION: Upper parts, yellowish-olive, streaked with black; sides of head, bright yellow, enclosing a large black patch which runs through the eye; two white bands on the wing; two outer tail-feathers, white, with a brown streak near the end; third, white streak on the end. Under-parts, yellow; chin, throat, with streaks on the sides of the breast, flanks, and under tail-coverts, black; belly, white.

Length, 5 inches.

\section{HERMIT WARBLER.}

\section{Dendroica occidentalis BAIRD.}

This species is widely spread over the western part of our country, from the Rocky Mountains to the Pacific and from Washington southward, wintering in Guatemala. Mr. Henshaw says, that it is so similar in habits and general appearance to Townsend's Warbler, that it is impossible to distinguish the two species at the distance at which they are usually seen. Like other species it always shows an attachment to high pine-clad regions. The song which is frequently heard from the tops of the pine trees at very regular intervals is, according to its discoverer, Mr. Nuttall, a soft, moody, faint, and monotonous note.-Mr. C. A.: Allen found the nest in Blue Cañon, Cal., in 1886. It was composed of the fibrous stalks of herbaceous plants, fine dead twigs, lichens ${ }^{1}$, and a cotton twine, lined with the soft inner bark of some coniferous tree and fine long hairs, apparently from the tail of a squirrel. The bright, yellow Evernia, sprinkled rather plentifully around the rim, gave a touch of color to the otherwise cold, gray tone of the exterior and contrasted agreeably with the warm reddishbrown lining. Although the materials were coarse and wadded, rather than woven, together, the general effect of this nest was neat and tasteful. The three nests Mr. Allen found were placed in "pitch-pines," from twenty-five to forty feet above the ground, on thick, scraggy limbs, where they were so well concealed that it was almost impossible to find them. The eggs resembled those of the Summer Yellowbird.

DESCRIPTION: Male: Above, ashy-gray, tinged with olive, closely streaked with black; below, white. Top and sides of the head, rich yellow, the former with black markings; central line of chin, throat, and jugulum, black, ending on the breast with a sharp convex outline, contrasted with the adjoining white. Female: Described as similar, with the yellow on the head less extended.

Length, 5 inches.

\section{KIRTLAND'S WARBLER.}

\section{Dendroica kirtlandi BaIRD.}

This species which is closely allied to the Myrtle Bird and Audubon's Warbler was discovered by Dr. J. P. Kirtland, of Cleveland, O., in May 1851. It was also found in Michigan and in the Bahamas in winter. Dr. Hoy, the veteran naturalist of Racine, Wis., told me a few weeks ago that he was confident of having seen it near that city, and Mr. Otto Widmann captured a specimen at St. Louis, Mo., May 8, 1885. It is exceedingly rare, and nothing is known about its haunts and nesting habits 


\title{
PINE WARBLER.
}

\author{
Dendroica vigorsii STEJNEGER.
}

AHE PrNe WARBLER is a common bird of the coniferous woods of the Eastern States, west to the Plains and north to Manitoba, Ontario, and New Brunswick, wintering in the Southern and Gulf States and in the Bahamas. It seems to be especially abundant in the pine barrens of the South Atlantic and Middle States. Although devoid of bold, romantic scenery, these pine woods are exceedingly attractive to the friend of birds and flowers. Here the holly, the fragrant swamp magnolia and pepper bush, the delicate andromeda and the gorgeous kaimia or mountain laurel, the charming sand myrtle and the flowering dogwood find a most congenial home. The fringe trees in full bloom look at a little distance like snowbanks. The pyxie ${ }^{1}$, the trailing arbutus, the partridge berry ${ }^{2}$, and the wintergreen ${ }^{3}$ cover the ground in charming masses underneath the pines. In low places the stat ly helonias ${ }^{4}$ is throwing up its spikes of purplish flowers by the side of the golden club". I cannot refrain from quoting here a passage from a charmingly written article "April in the Pine Barrens" by Mrs. Mary Treat. She writes: "The aroma of these low woodlands in spring is delicious. The fragrance of the swaying pines overhead, intermingled with the spicy breath of the wax myrtle and sweet fern, already waving its plumy catki is, together with odors of sassafras and the more subtle fragrance of other shrubs, all combine to make a perfume that can only be produced in nature's laboratory. The deciduous trees are still leafless, and comparatively few of our plants are in bloom-April 20-, yet there is an atmosphere of delicate color all about-on every twig aud swelling bud, and on the lowly growth that carpets the earth. The barrens will be almost vivid with bright flowers by and by, but the place will be hardly more attractive than at this spring opening with its freshness, its modest beauty, and its promise."

The Pine Warbler arrives here by the middle of April, when the woods begin to put on their spring garment and when the flowers of the far-famed trailing arbutus perfume the air. Many individuals return even much earlier, leading the van of the Warbler hosts in spring. I have observed several as early as April 20 in Wisconsin and northern Illinois. In the pine woods near Houston, Texas, they winter in great numbers. During very cold weather they visit, in company of Myrtle Birds and Palm Warblers, the rose-embowered city gardens, where they hunt for food in the pittosporum, loquat and tea olive bushes, and among the magnolias and live oaks. They even visit the rubbish piles of the door yards to look for food and search the corners of the windows for hidden insects. - The Pine Warbler is a robust and plain bird, "for a member of the Warbler family, with little of the delicacy and ornament for which most of its relatives are so justly famed."

Their habits do not differ very much from those of other Wood Warblers. During winter they search the tops of tall trees as well as the low shrubbery, but in spring and summer they look for food among the ligher branches of coniferous trees, rarely 1 Pyxidanthera Larbulata. 2 Mitchella repens. a Gawlheria procumbens. 1 Helonias bullata. "Orontium aquaticum. 


\section{XIII.}

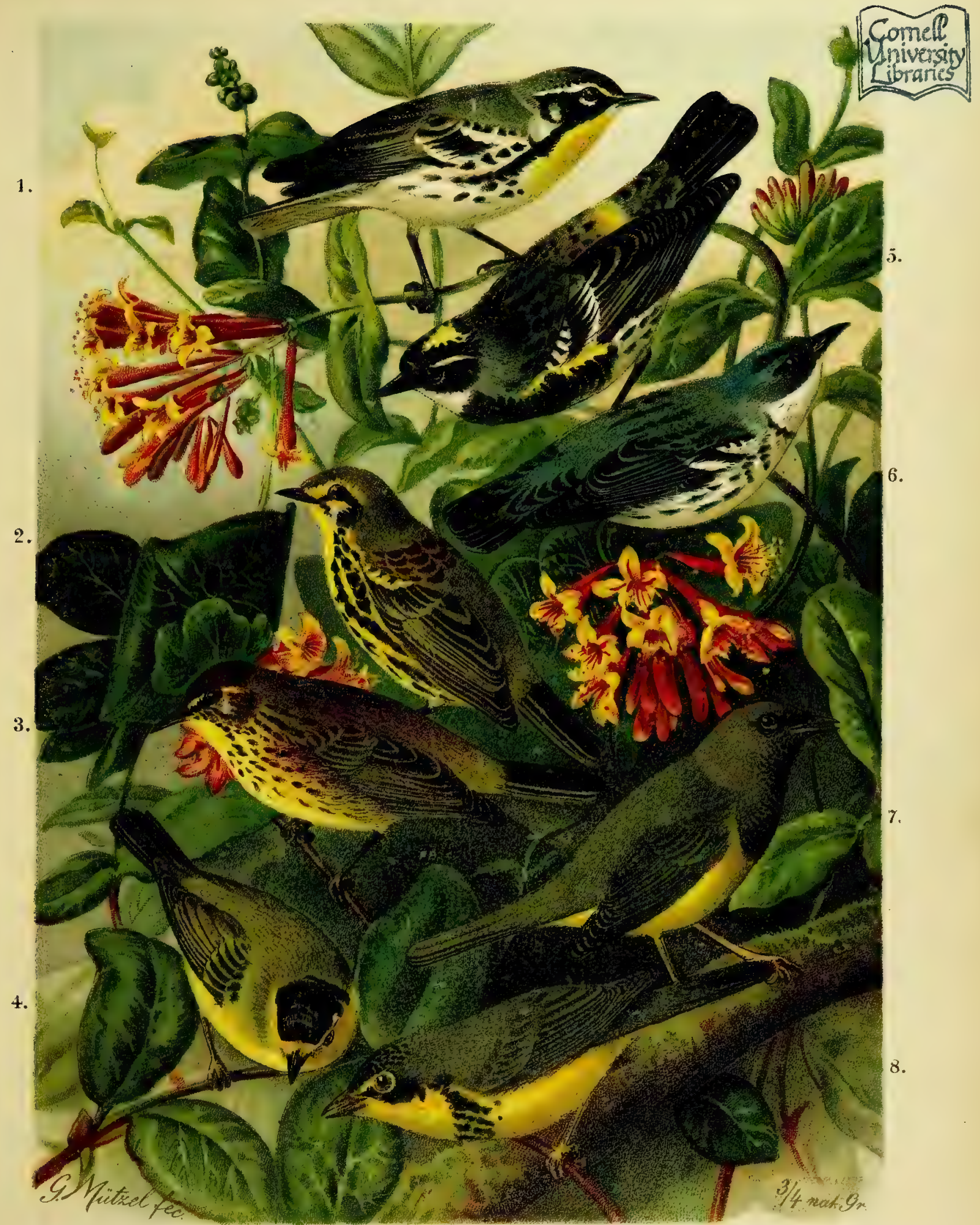

1. DENDROICA DOMINICA Baird

2. DENDROICA DISCOLOR Baird.

3. DENDROICA PALMARUM Baird.

4. SYLVANIA PUSILLA Nutt.

כ. DENDROICA CORONATA Gray.

6. DENDROICA CERULEA Bail'd.

7. GEOTHLYPIS PHILADELPHIA Baird.

8. SYLVANIA CANADENSIS Ridgiw.
- GELBKEHLIGER SÄNGER - Yellow-throated Warbler.

- PRAIRIESÄNGER

- PALMENSÄNGER

- ZWERGSÄNGER

- KRONSÄNGER

- BLAUSÄNGER

- TRAUERSÄNGER

- GÜRTELSÄNGER
- Prairie Warbler.

- Palm Warbler.

- Wilson's Warbler.

- Myrtle Warbler.

- Cerulean Warbler.

- Mourning Warbler.

- Canadian Warbler. 

catching flying insects. At the time of their migration they may be found in all kinds of mixed woods, but their haunts in spring and summer are always the tall pines, where it is often difficult to discover their whereabouts-the more so as their song is misleading, being very ventriloquial. Their song reminded me always of that of the Black. throated Green Warbler. It is very melodious, clear, and "deliciously drowsy." According to Mr. H. D. Minot, it is apparently a delicatcly trilled whistle, but really a series of fine notes, as is proved by the fact that the birds open and shut their bills, whilst emitting the sound. It closely resembles one of the Snowbirds' whistles, and also the trill of the Swamp Sparrow.

This Warbler breeds in all our Atlantic States, at least as far south as South Carolina, where the eggs are laid in the latter part of March. In the pine barrens of New Jersey they usually breed in early May and in New England in the last week of the same month. The nests are always placed in pines, cedars, and spruces, being lodged in forks at the tops of the trees, where they are well concealed. The materials the structures consist of are soft and durable, being an admixture of wiry plant-stems, a few feathers, fibres of asclepias, caterpillar's webs, and fern-down, lined with hairs, feathers, soft roots, and fern-down. Other nests are built exteriorly mainly of fine black roots, wooly bark-strips of the red cedar and hempen fibres. The nest is about twentyfive to forty feet above the ground. The eggs, usually four in number, have a dull white ground-color, with purplish and brown markings, sprinkled chiefly around the large end.

In September old and young leave the Northern States and New England, seldom lingering into October, "and never, like the Palm Warblers and Myttle Birds, taking their chances of November weather." In its winter migrations the Pine Warbler does not appear to leave our country, and has not been recorded as a winter visitor from any of the West Indies, from Mexico or Central America. In Florida as well as in Texas it is a common winter sojourner.

NAMES: Pine Warrier, Pine-creeping Warbler, "Vigor's Vireo" (Nuttall).

SCIENTIFIC NAMES: Sylvia vigorsii Audubon (1832). Vireo vigorsii Nuttall (1832). DENDROICA VIGORSII STEJNEGER (1885). Sylvia pinus Wilson. Dendroica pinus Baird (1858).

DESCRIPTION: Above, yellowish-olive; belly and two wing-bars, white; superciliary line, throat, and breast, yellow. Female, similar, but duller.

Length, 5.50 inches; wing, 3.00; tail, 2.40 inches.

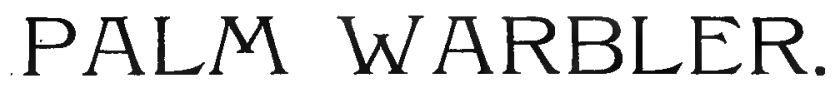

Dendroica palmarum BAIRD.

Plate XIII. Fig. 3.

周HE PALM WARBLER or Red-poll is a conspicuous bird during the autumn migration in the Northern, New England, and Middle States. It arrives in Wisconsin and central Illinois from high northern latitudes in the latter part of September or early in October, when our woods and shrubberies are ablaze with glowing autumn 
tints. Asters and golden-rods are still flowering in profusion, but the crowning glory among the last flowers of the year is the deep blue fringed gentian, which is abundant everywhere in rich deep soil. The days are clear and brilliant. Every friend of nature who has an eye for beautiful colors must ever admire the scenery of this last month of foliage and flowers. Birds of many species on their way to their winter home skip through the branches of trees and shrubs or hurry over the ground. At this time I always expect in our Northern States the Myrtle Warblers, Juncos, White-throated and White-crowned Sparrows, and especially the Red-poll, or Palm Warblers. In their habits they differ decidedly from other members of the tree-loving Dendroica-group, being always seen in loose flocks of from five to fifty and more, and spending much of their time on the ground and among low shrubs. Their most noticeable habit, one which distinguishes them from other Warblers, is their Phoebe-like flirting of their tails, which is displayed usually when on their perches. During the bright days of Indian summer they are exceedingly happy, darting gracefully and with great dexterity from one tree or bush to another, often catching insects in the air. Their favorite haunts are orchards and gardens, where groups of ornamental shrubs, such as snow-balls, weigelias, upright honey-suckles, mock-oranges, kerrias, golden bells (Forsythia), exochordas, and trees abound. The bushy woodland border, swamps and hedgerows, are also favorite resorts, where they frequently congregate with Myrtle Warblers, White-throated and White-crowned Sparrows, and Juncos. They linger leisurely through October and part of November, before taking final departure to their winter home, the South Atlantic and Gulf States. Like the Pine Warbler and Myrtle Bird, it may be associated with frozen ground and snow storms. Dr. C. H. Merriam says, that it may be seen in Connecticut in spring with the species just named "long before the hosts of other Warblers make their appearance. It is also one of the last to depart in the fall, at which time it is found along fences, and among low bushes, by the roadside and in open fields. In early spring, before the snow has quite all disappeared, large numbers of them may sometimes be seen, in company with the English Sparrows, running about on the plots of bare ground, and the roots of the elm trees, on the City Green, in the heart of New Haven. In fact, they seem to pay but little attention to the weather, as may be seen from the circumstances that they were really numerous on the 18th of April, 1875, at a time when the ground was covered with snow nearly a foot deep, with only here and there a bare spot; while none were seen this season (1877) till April 13, notwithstanding the fact that the ground had been bare since the latter part of March, and the weather unusually mild."

The Palm Warbler winters abundantly from the Carolinas southward to Texas, and even many spend the winter in the Bahamas, Cuba, Jamaica, and San Domingo. In the Gulf States they are exceedingly abundant in suitable localities from the latter part of November to the beginning of April. Evergreen trees and thickets, consisting of hollies, wax myrtles, youpons, magnolias, loblolly bays, cedars, and palms, are preferably their abiding places. An abundance of insect food and an excellent protection against the inclemency of the cold winds are afforded them by such localities. During fine weather they frequently, in company with Myrtle Birds, Pine Warblers, Nuthatches, and Brown Creepers, visit the beautiful rose-embowered gardens, gleaning among the 
exquisite semi-tropical trees and shrubs, in which these ornamental plantations abound. Like all the members of this highly interesting family they are, wherever they occur, of the greatest importance to the gardener, the farmer and fruit grower. They subsist exclusively on injurious insects which infest the bark, leaves, blossoms, and the fruit of trees and shrubs. The question of protection of these and all other small native birds should, therefore, be a matter of the maturest deliberation at all meetings of our agricultural, horticultural, and humane societies. At our common and high schools children ought to be taught not to disturb our birds and their nests, but to protect them, and to view these charming songters, which contribute so much to our happiness, with love and tenderness.

The Red-poll Warbler is not known to breed south of latitude $44^{\circ}$. It has been found in summer in the Red River Settlement, at Fort Resolution, Fort Simpson, Fort George, and in the Hudson Bay Territory. Mr. G. A. Boardman, of St. Stephens, N. B., says that in his locality the Yellow Red-poll is one of the "most common Warblers, and, unlike most other Warblers, spends much of its time feeding upon the ground. It is not an uncommon thing to see a dozen or two on the ground in my garden at a time, early in spring. Later in the season they have more the habits of other Warblers, and are in summer expert flycatchers. ... They breed in old brushy pastures, and very early, nesting alongside some little knoll, and always upon the ground. The nest is very warmly lined with feathers." In other localities the Palm Warbler usually selects for the site of its nest the edge of a swampy thicket, more or less open, placing it invariably on the ground. Mr. Kennicott met with a nest June 18. It wais on the ground, on a hummock, at the foot of a small spruce, in a swamp. The materials consist chiefly of fine dry grasses, slender bark-strips, hypnum and other mosses, with a warm and soft lining of down and feathers. The ground-color of the eggs is creamy-white, spotted chiefly about the larger end with purple, lilac, and reddish-brown.-The song is said to be grasshopper or cricket-like and very feeble.

NAMES: Palm Warbler, Red-poll Warbler, Yellow Red-poll Warblet, Red-poll.

SCIENTIFIC NAMES: Motacilla palmarum Gmel. (1788). Sylvicola palmarum Rich. (1836). DENDROICA PALMARUM BAIRD (1858). [This is the western form. The eastern form of the Atlantic States is known as the Yellow PALM WaRbler, D. PALMARUM HYPOCHRYSEA Ridgway (1876).] Sylvia petechia Wils. (1812). Sylvicola petechia S. \& R. (1831), Aud.

DESCRIPTION: "Head above, chestnut-red; rest of upper parts, brownish olive-gray; the feathers with darker centres, the color brightening on the rump, upper tail-coverts, and outer margins of wing and tail-feathers, to greenish-yellow. A streak from nostrils over the eye, and undez-parts generally, including the tail-coverts, bright yellow; paler on the body. A maxillary line; breast and sides, finely, but rather obsoletely streaked with reddish-brown. Cheeks, brownish (in highest spring, plumage chestnut like the head); the eyelids and a spot under the eye, brown. Lores, dusky. A white spot on the inner web of the outer two tail-feathers, at the end. Sexes, nearly alike.

"Length, 5 inches; wing, 2.42 ; tail, 2.25 inches." (Ridgway.) 


\title{
PRAIRIE WARBLER.
}

\author{
Dendroica discolor BAIRD.
}

Plate XIII. Fig. 2.

周HE Prairie WARbler, a very richly attired bird, one of the smallest and most active of the Dendroica-group, is distributed over the eastern portion of the United States, north to southern New England and sparingly to southern Wisconsin and Michigan, west to Kansas and Nebraska. It winters in Florida and more numerously in the West Indies. Most abundant it appears to be in the Atlantic States from Georgia to New Jersey, preferring for its haunts wild and rocky localities. Mr. E. B. Coues found it very numerous along the Potomac near Washington; Dr. Gerhardt reports it a common bird in the mountain regions of northern Georgia, and I observed it in the Ozark region of south-western Missouri in rocky places, old neglected clearings, pastures and the wildwoods, where large trees were very scarce, but where thickets of hazel, blackberry and goose-berry shrubs, white thorns, wild plums, patches of cedar and snow-berry bushes predominated. Cardinal Redbirds, Chats, Indigobirds, and Blue Grosbeaks, but particularly Woọ Sparrows (Spizella pusilla) were always found abundantly in the same localities. Being one of the most shy and retiring of Warblers, it is not easy to observe it. I was familiar with its very quaint and characteristic song long before I had seen the bird. These notes it usually utters while snugly concealed among the vine-embowered small trees or in the tangled thickets. The bird would pass unnoticed were it not for this sprightly strain, and for its habits of incessantly darting into the air to capture passing insects. Near Freistatt, Mo., it arrived always during the last days of April. It never entered, like its congeners, the blooming orchards and the gardens.

The name Prairie Warbler, given to this bird by Wilson in the early part of the present century, is very inappropriate, as it rarely or never is seen on prairies. Pasture Warbler or Wildwood Warbler would be more to the point. The wildwood is its real home. Here its song is heard from the time of its arrival throughout the month of June. Its lay is not remarkable for mellowness and beauty, but rather for sharpness and peculiarity, beginning low and gradually growing louder, resembling the syllables wee-wee-chee-chee-chee-chee. The song cannot fail to attract the attention of every friend of nature wherever he happens to hear it. Mr. Elliott Baird Coues gives an excellent description of the nesting of the Prairie Warbler in the vicinity of Washington, D. C., in "The Auk" (Vo1. V, 1888, pp. 405-408).

Although common throughout the District of Columbia, this beautiful little bird nests more abundantly in certain suitable localities than in others. Mr. Coues found it breeding within a small area, along the Potomac on the Virginia side, about seven miles from the city, in great numbers, perhaps more than fifty pairs. This was among some 
small hills, from which all the large trees had been cut away, and which are now grown up to a thick scrub of hickory, dogwood, and laurel or Kalmia latifolia, with here and there a few pines and cedars. Here the birds were found in astonishing numbers, and they could be heard singing on all sides. Yellow-breasted Chats were also common. On May 22, Mr. Coues found one nest, and on subsequent visits many more. The nests, which were easily discovered, were only a few feet from the ground, placed preferably in the hickory and dogwood bushes. Only three nests were found in young pines and one in a cedar bush. During the heat of the day the birds - the males at any rate-seemed to seek the shade of the larger pines bordering the clearing where the nests were placed, as he heard many singing from the neighboring woods while rambling through the scrub. Of the many nests he describes five very minutely. One was evenly placed upright in the triple prong of a low laurel bush, about two and one-half feet from the ground. "From among twelve nests, it is the only one symmetrically placed in a crotch, the others being all irregularly supported by twigs either branching at varying angles from a main stem, or, as in some cases, coming to the support of the nest from a different part of the bush. It is composed chiefly of dandelion-down, in which are woven a few thin straws and dry leaves. It is lined with very fine bits of straw and a little horsehair." The brim is firm and smooth, as is the rule with the nests of the Prairie Warbler." Another nest, placed about five feet from the ground, was copiously lined with red cowhair, making a marked color contrast with the other materials. A third structure was placed in a mass of grape-vine twigs, about three feet from the ground, being composed of silky plant-fibres (perhaps of a species of Asclepias), thin shreds of inner cedar bark, and fine grass straws, lined with still finer straws and a little horsehair.-Nests in my collection from Massachusetts and Connecticut are built exteriorly of fine bark-strips of grape-vines and cedars, feathers and much fern-down, lined with fern-down, bristles, and a few feathers. The eggs, usually four, rarely five, in number, have a white ground-color, with a very faint tinge of green. The markings consist of specks of chestnut and umber, usually in the form of a wreath around the larger end.

NAMES: PRAIRIE WARBLER, Red-backed Warbler, Parti-colored Warbler, "Pasture Warbler," "Wildwood Warbler."-Fauvette discolore (Fr.).

SCIENTIFIC NAMES: Sylvia discolor Wils. (1807). Sylvicola discolor Jard. (1832), Aud., etc. DENDROICA DISCOLOR BAIRD (1858).

DESCRIPTION: "Above, yellow-olive, the back with a patch of brick-red spots; forehead, line over the eye, two wing-bars, and entire under-parts, rich yellow; side of head with a V-shaped black mark, connecting with a chain of black streaks along the whole side of the neck and body; very large white tail-blotches occupying, most of the inner web of the outer feathers. Sexes almost exactly alike.

"Small: Length, 4.75 to 5.00 inches; extent, 7.00 ; wing, 2.25 ; tail, 2.00 inches.". (Stearns and Coues.) 


\section{OVENBIRD.}

\section{Seiurus aurocapillus SwaInson.}

Plate XIV. Fig. 6.

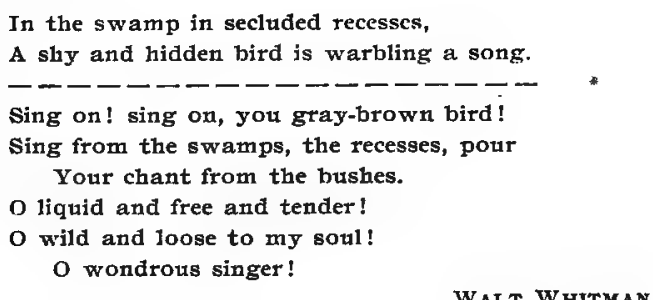

周HE HEMLOCK, white pine, and spruce woods of central and northern Wisconsin were in pioneer days much more interesting than they are now. The giants of the forest vanished with the Indian and the larger mammals. The change which took place within the last thirty-five years is very great. Extensive forests, through which the Indian chased the deer and the bear, are now grainfields and meadows. Brooks have disappeared, smaller rivers simmered down into brooks. Little has been left of the once charming forest flora, and even where the woods were not touched by the axe the famous trailing arbutus, winter-green, and ground pine are almost entirely destroyed. In many localities of the state where these plants are still common, large quantities are collected every year for the market. In my native county where I culled these and many other delicate flowers in the days of my boyhood, they are rarely met with to-day. Ferns grew almost waist high, and the beautiful ground pine ${ }^{1}$ covered the rich mould in dense masses. With what ravishment did I follow in those by-gone days the cow path or the overgrown wood road in search for the cattle! The bell of the leader I could hear plainly not far away, but other things, birds and flowers, always attracted my attention more. What a new interest the woods always had and how I longed for the months of May and June! Secrets lurked on all sides, mysteries in every bush. Expectation was ever on "tip toe." And this interest for the woods never left me. One must taste it to understand its fascination. - I often clamber over soft and decayed logs overgrown with ferns and mosses. I force my way through a net-work of huckleberry bushes and briers. Leaving the higher coniferous woods I enter a perfect bower of June-berry, shad bush, wild crab trees, moosewood, beech, and maple. The search for birds, instead for cows, is now my main object. Every new sound is a revelation to me. Hark! there, on yonder spring, the liquid song of the Veery sounds through the woods. The notes of the Rose-breasted Grosbeak, Towhee, Wood Thrush, Red-eyed Vireo, and the characteristic drumming of the Ruffed Grouse also fall on my ear. What an exquisite concert these woodland minstrels offer to the invader of their secret recesses! I penetrate a locality where dense masses of underwood and ferns grow. 
Churr! churr! churr! and a brood of young Ruffed Grouses start a few steps before me in all directions like an explosion, disappearing in the dense underwood with astonishing rapidity. Everything is quiet. If we wait silently behind a screen of ferns and bushes we may hear the wild hen call together her brood with a soft persuasive cooing, "a sound so subtle and wild and unobtrusive that it requires the most alert and watchful ear to hear it. How gentle and solicitous and full of yearning love! Presently a faint timid 'yeap!' which almost eludes the ear, is heard in various directions, - the young responding. As no longer danger seems near, the cooing of the parent bird is soon a very audible clucking call, and the young move cautiously in its direction. Let me step never so carefully from my hiding place, and all sounds instantly cease, and I search in vain for either parent or young." (Burroughs.) How frequently did I disturb in this way a brood of partridges, and how often have I heard, especially in warm gloomy days, the drumming sounds of the male bird! How must every friend of nature regret that at present these sounds fall so rarely on our ear! The drumming of the Ruffed Grouse is one of the most welcome and beautiful sounds of spring. The woods where I do not find this bird, seem to want something; they seem to suffer from some neglect of nature. I must refer the reader to Mr. John Burroughs' exquisite little volume "Wake-Robin" (pp. 74-77), where an excellent description of the partridge and its ways is given. All of Burroughs' books enshrine so many jewels that every household and school library is incomplete without then.

Though the Indian has gone forever, though the larger mammals and birds vanished from these woods, though the once extensive forests were cut down by the axe of the woodsman, only small remnants being left, many of the smaller birds are still common. In all the woodlands of Wisconsin, whether dry or moist, we find the Otentird, or Golden-CRowned Thrush. Most common it is in the woods referred te above, especially near water-courses where the underwood is dense, and pines and hemlocks predominate. Ruffed Grouses, Rose-breasted Grosbeaks, Redstarts, Red-eyed Vireos, and Blue Jays are its nearest neighbors. It is a true forest bird, rarely being detected near the woodland border. We usually see it ramble daintily over the ground among old leaves, wood-lilies, ferns, ground pines, trailing arbutus, and other plants. The Ovenbirds walk and run over the ground very prettily, "with a certain nonchalance, as if only sauntering for their amusement; now furtively examining the pathway in search of food, now turning a curious but quiet eye upon the intruder; and when alarmed they fly directly to some low perch in a tree, where they sit in silent but watchful purpose." The ways of the Ovenbird, especially its running over the ground, and its color, remind one of the smaller Thrushes. This is the reason why it was formerly classed with that family, and called Golden-crowned Thrush. The popular name of Ovenbird was given to it because of the usual oven-shape of the nest, and Wagtail, because of the habit of flirting its tail. For the same reason its name in Jamaica is Land Kickup.

The Ovenbird's breeding range extends over eastern North America, north to Hudson's Bay and Alaska, west to Kansas, south to the Ohio valley and Virginia. It winters in southern Florida, the West Indies, and Central America. During the spring migration $I$ found it a very numerous bird from Texas and Florida to Wisconsin. In south-western Texas it arrives early in April. On the 19th of the same month, the 
woods just behind my house at Freistatt, Mo., swarmed with Ovenbirds, searching in loose flocks for food among the old leaves. Only a few pairs remained to breed. During these beautiful April days the orchards were white and rosy with blossoms, and their "loud accelerated chant with which the birds proclaim the nuptial season" echoed through all the thickets and woods. These notes, sounding like $I$ see, $I$ see, $I$ see, $I$ see, commence low, grow gradually louder and louder and end very shrill. They even entered my garden and searched among flowering lilies of the valley, polyanthus narzissus, pæonies, yuccas, and underneath pretty specimens of mock-orange bushes, Chinese fragrant and Standish's honey-suckles, for all kinds of insects. In their summer haunts in central Wisconsin I never saw them before May 10. During migration they even come into the city gardens where they run about on the ground like small Thrushes. In Chicago an Ovenbird came through the open window into the interior of my room in search for flies. This was on a very fine September day. In south-eastern Texas I saw the first migrants about Sept. 20, and the last stragglers left about Oct. 25.

The food of the Ovenbird consists almost entirely of insects living on or near the ground. Very frequently it is searching for food among the almost decayed leaves and underneath ferns and other low growing plants. It is a very conspicuous bird in its haunts, being very inquisitive, easy to 'observe, and one of the most emphatic songsters of the woods. Its notes are always associated with charming tracts of woodland and beautiful summer days. Even in the silence of the noon its notes echo through the woods, and, bursting upon the ear, they disperse all melancholy thoughts as if by enchantment. The bird sings all day long, but most diligently when the twilight of the evening falls. Its common chant is heard while the bird walks over the ground in search of insects, but its rare and beautiful song is poured forth from the tops of tall forest trees, usually after sundown. Our older ornithologists had no knowledge of this song, and only very lately the discovery of its wonderful vocal powers were made independently by Mr. John Burroughs and by Mr. George Boardman.

"Coming to a drier and less mossy place in the woods," says Mr. Burroughs, "I am amused with a Golden-crowned Thrush, - which, however, is no Thrush at all, but a Warbler, the Ovenbird. He walks on the ground ahead of me with such an easy gliding motion, and with such an unconscious, preoccupied air, jerking his head like a hen or a partridge, now hurrying, now slackening his pace, that I pause to observe him. If I sit down, he pauses to observe me, and extends his pretty ramblings on all sides, apparently very much engrossed with his own affairs, but never losing sight of me. But few of the birds are walkers, most being hoppers, like the Robin.

"Satisfied that I have no hostile intentions, the pretty pedestrian mounts a limb a few feet from the ground, and gives me the benefit of one of his musical performances, a sort of accelerating chant. Commencing in a very low key, which makes him seem at a very uncertain distance, he grows louder and louder, till his body quakes and his chant runs into shriek, ringing in my ear with a peculiar sharpness. This lay may be represented thus: 'Teacher, teacher, TEACHER, TEACHER, TEACHER!'- the accent of the first syllable and each word uttered with increased force and shrillness. No writer with whom I am acquainted gives him credit for more musical ability than is displayed in this strain. Yet in this the half is not told. He has a far rarer song, which he 
reserves for some nymph whom he meets in the air. Mounting by easy flights to the top of the tallest tree, he launches into the air with a sort of suspended, hovering flight, like certain of the finches, and bursts into a perfect ecstasy of song, - clear, ringing, copious, rivaling the Goldfinch's in vivacity, and the Linnet's in melody. This strain is one of the rarest bits of bird-melody to be heard, and is oftenest indulged in late in the afternoon or after sundown. Over the woods, hid from view, the ecstatic singet warbles his finest strain. In this song you instantly detect his relationship to the Water Wagtail (Seiurus noveboracensis) - erroneously called Water Thrush, - whose song is likewise a sudden burst, full and ringing, and with a tone of youthful joyousness in it, as if the bird had just had some unexpected good fortune. For nearly two years this strain of the pretty walker was little more than a disembodied voice to me, and I was puzzled by it as Thoreau by. his mysterious night-warbler, which, by the way, I stuspect was no new bird at all, but one he was otherwise familiar with. The little bird himself seems disposed to keep the matter a secret, and improves every opportunity to repeat before you his shrill, accelerating lay, as if this were quite enough and all he laid claim to. Still, I trust I am betraying no confidence in making the matter public here. I think this is pre-eminently his love-song, as I hear it oftenest about the mating season. I have caught half-suppressed bursts of it from two males chasing each other with fearful speed through the forest."

Mr. Eugene P. Bicknell, in his very able paper: "A Study of the Singing of our Birds" ("Auk," 1884, p. 214), gives the following description of the song: "The ordinary song of the Ovenbird, but for its inseparable association with the quiet recesses of summer woods, would certainly seem to us monotonous and commonplace; and the bird's persistent reiteration of this plain song might well lead us to believe that it had no higher vocal capability. But it is now well known that, on occasions, as if sudden emotion carried it beyond the restrictions that ordinarily beset its expression, it bursts forth with a wild outpouring of intricate and melodious song, proving itself the superior vocalist of the trio of Pseudo-thrushes of which it is so unassuming a member. This song is produced on the wing, oftenest when the spell of evening is coming over the woods. Sometimes it may be heard as an outburst of vesper melody carried abore the foliage of the shadowy forest and descending and dying away with the waning twilight."

The nest is not easily found. It is usually built on the ground, underneath ferns and other plants, near stumps, roots, and fallen logs. All the nests I found were built on a thick layer of leares, constructed of pine-needles, hemlock twigs, mosses, and lichens, lined with pine-needles, fine grasses, and rootlets, and, in one case, also with cotton thread. Most of these structures had arched or domed roofs, with the entrance on one side, but when under the shelter of dense plants the oven-shaped form is sometimes not noticeable.-Dr. T. M. Brewer describes a nest found near Racine, Wis., by Dr. R. P. Hoy, our veteran naturalist, whose congenial company the author of this work had frequently the pleasure to enjoy. This nest is not different, except in regard to the materials, from those found by me further north.

In this connection I cannot refrain from quoting the following from Dr. T. M. Brewer: "On the 7 th of June, 1858, I came accidentally upon a nest of this bird of a very different style of structure. It was in a thick wood in Hingham, Mass. The 
nest was built in a depression in the ground at the foot of some low bushes, and its top was completely covered by surrounding vines and wild flowers. It would probably have escaped notice had not my daughter, then a child of four years, attempted to gather some wild flowers growing directly over its entrance. This flushed the mother, who until then had remained quiet, although we were standing with our feet almost upon the nest, and the bird fluttered and tumbled about at our feet with well-feigned manœuvres to distract our attention. The child in great glee sought to catch it, but it eluded her grasp, and, running off like a mouse, disappeared. The nest contained six eggs, was entirely open, and with no other cover than the wild plants that clustered above it. ... This nest was somewhat losely constructed of skeleton leaves, dey slender stalks, grasses, pine-needles, and was lined with a few slender grasses and leaves. It had a diameter of 6.00 inches, and was 2.50 inches deep. The cup had a diameter of 3.50 inches and a depth of 2.00, being very large for the size of the bird, probably owing to the shape of the cavity in which it was sunk."*

Mr. Lynds Jones, one of our promising young ornithologists; found the Ovenbird a common summer sojourner at Grinnell, Iowa. The nests he discovered were built "rather independent of tree or bush on a wooded hill-side, but always where the natural surroundings are most favorable for concealment." This bird, like all our small songsters, is much victimized by the notorious Cowbird. Mr. Lynds Jones always found Cowbird's eggs in the Ovenbird's nest. In two nests he found three, in another four and in a fourth just five Cowbird's eggs without any of the Ovenbird.

The eggs, four to five in number, are white or creamy-white, glossy, speckled and spotted with reddish-brown, darker brown, and lilac markings. Usually the larger end is heavily spotted and frequently wreathed.

NAMES: Ovenbird, Golden-crowned Thrush, Golden-crowned Accentor, Golden-crowned Wagtail, Wagtail, Wagtail Warbler, Accentor, Land Kickup.-Ofenvogel (German).

SCIENTIFIC NAMES: Motacilla aurocapillus Lin1. (1766). Turdus aurocapillus Lath., Wils., Aud. SEIURUS AUROCAPILLUS Swans. (1827). Henicocichla aurocapillus Sclat. (1861). Turdus coroinatus Vieill. (1807).

DESCRIPTION: "Above, uniform olive-green, with a dinge of yellow. Crown with two narrow streaks of black from the bill, enclosing a median and much broader one of brownish-orange. Beneath, white; the breast, sides of the body, and a maxillary line, streaked with black. The female and the young of the year are not appreciably different.

"Length, 6.00 inches; wing, 3.00 ; tail, 2.40 inches." (B. B. \& R.)

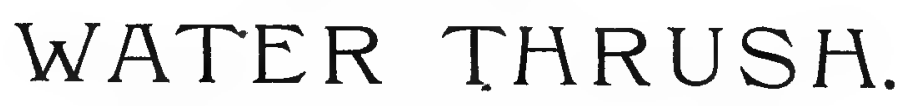

Seiurus noveboracensis BONAPARTE.

9N CLOSE proximity to the haunts of the Ovenbird is often found the home of its -1 nearest relative, the WATER Thrush, also known as the Small-billed Water Thrush, New York Accentor, or Wagtail Warbler. In the northern parts of the United States, principally in New England, Michigan, Wisconsin, Minnesota, and thence northward

- North American Birds. By Baird, Brewer, and Ridgway. Vol. I, p. 283. 
this bird is in particular localities a not uncommon summer resident. Its haunts and their surroundings are seldom touched by human feet, and only the enthusiastic plant and bird lover finds any satisfaction in penetrating, often under great difficulties, the masses of underwood and the dense tamarack and white cedar swamps. Yet it is with pleasure to recall to my mind the excursions of long past years through these swampy wildernesses. Will the reader's mind follow me through one of them? We need not search long, for these tamarack and cedar swamps exist in large numbers in northern and central Wisconsin. They are generally thickly overgrown with andromedas, dogwood, huckleberry, goose-berry, white cedar, and many other shrubs. Wintergreen, droseras, pitcher-plants, terrestrial orchids, ferns, lobelias, and many other herbaceous plants, annuals and perennials, cover the ground in dense masses. A glance at many of these peculiarly beautiful treasures of Flora's temple fully repays one for all the exertion, yet the plants here named are only a tithe of those really found in such places. There we also find charming feathered inhabitants. The Black-throated Blue Warbler darts hastily through the low bushes, while the Yellow-bellied Flycatcher flits through the aromatic and balmy air in quest of insects. The Hermit Thrush sings its most enchanting anthems in this solitude. One of the most excellent songsters of these swampy localities is the WATER ThRUSH, a bird resembling the Ovenbird in size and appearance. - Behold! there it walks over the ground, fan-like twitching and wagging its tail, suddenly disappearing under the dense huckleberry bushes. Anon it reappears. You notice that its name is well chosen, for it struts to and fro in the water, takes wing, alights on the nearest tree and begins its truly exquisite song. Its presence is, however, not confined to the swamps; I have found it frequently on the borders of brooks, ponds, and small inland lakes.

In central and northern Wisconsin the Water Thrushes make their appearance early in May, the majority passing farther to the North, only a few remaining to breed. During the migration they too, are, as a rule, found near water. They spend the winter in southern Mexico and in Central America. Some even migrate as far south as Colombia. The West Indies, the Bahamas, and the Gulf region are also the winter home of many of them. According to Mr. Robert Ridgway, a few pass the winter in the extreme southern portion of Illinois, especially if the season be mild.

Although the Water Thrush breeds as far south as latitude $43^{\circ}$, it is most abundant in the Arctic regions. Sir John Richardson met with it at Carlton House, where it was found on moist and thickly wooded banks of the river. The late Mr. Kennicott informs us that it breeds on the Yukon River.

The nest is usually built in the roots of upturned trees, mostly in shady swamps or near the banks of creeks, lakes, and rivers, where it is often concealed by the overhanging small rootlets. Now and then we may also find a nest on the ground. The structure is composed of moss, fine grass, leaves, and rootlets. The eggs, four to five in number, are creamy-white, speckled and spotted with cinnamon-brown and lilac, most heavily at the larger end.

This life history would be incomplete if I should neglect to quote Dr. Elliott Coues' charming and poetical description of the Water Thrush. This celebrated naturalist writes as follows: 
"The singing of birds is inseparably associated with the power and the desire to bring forth, as the involuntary and uncontrollable expression of emotions that are never stayed except through gratification. Surcease of passion is the fountain brimming over, when the stream of life flows downward like the loosened brook forever, and the babbling of the waters makes unconscious melody. I never heard the singing of this Water Thrush, nor do I find it carefully described; but it is likened, with good reason, to the song of the Louisiana, and this is so melodious, so loud and yet so mellow, as when once heard to slowly be forgotten. Both Audubon and Nuttall have expressed their admiration of this Philomel's performance, which the latter says is even heard at night, when the sweet incessant warbling greets the ear 'like the dulcet lay of some fairy vision.' It was long before we found out that the Golden-crown sings also, for the harsh crescendo ditty of this bird is scarcely to be called a song; and when the vocal powers of the humbler Water Thrush receive full recognition, we shall doubtless know the three birds for a trio scarcely rivaled by the Wood Thrush and the Hermit and the Veery. Mr. Boardman calls the Water Thrush one of our liveliest singers, beginning with a sudden, almost startling burst of melody, that rings as clear as if the joyous bird had found a long-lost mate, and then keeps falling till the slightest breath of air may blow the rest away. Its secrecy in singing lends a charm to the performance, for though the notes are sounded loud and fearlessly, the bird dislikes intrusion; and it sings best far away from prying eyes, amidst the dark recesses of the swamp.

"Should you force your way,- perhaps by paddling in a light canoe beneath the overhanging mysteries of the dank morass, - perhaps by clambering among the fallen logs that jut from treacherous black depths of ooze and slime-you may even catch a glimpse of this coy songster as he dashes onward into yet more secret fastness of his watery and seldom sun-lit home. His song is still now; silence broods, or else a sharp short note of anger and anxiety betrays the presence of the timid bird, too restless and too nervous in his vague alarm to hide in safety, but rather dallying with danger as he leaps and balances on log, moss-heap, or branchlet. But this is only when he feels the cares and full responsibilities of home and family. Later in the season, when these things are off his mind, he is quite another fellow, who will meet you more than half-way should you chance to find him then, with a wondering, perhaps, yet with a confident and quite familiar, air of easy unconcern. Anywhere by the water's edge-in the débris of the wide-stretched river-bottom, in the flowery tangle of the brook, around the margins of the little pools that dot the surface where tall oaks and hickories make pleasant shade-there rambles the Water Thrush. Watch him now, and see how prettily he walks, rustling among the fallen leaves where he threads his way like a mouse, or wading even up to his knees in the shallow miniature lakes, like a Sandpiper by the sea-shore, all intent in quest of the aquatic insects, worms, and tiny molluscs and crustaceans that form his varied food. But as he rambles on in this gliding course, the mincing steps are constantly arrested, and the dainty stroller poises in a curious way to see-saw on his legs, quite like a Titlark or a Spotted Sandpiper. All of his gentus share this gait, quite different from the hopping movement with which the Sylvicolidix in general progress - but see! he catches sight of us, and quite breaks off the thread of such reflections as he casts his bright brown eye upon us with a coquettish 
turning sideways of the head. Let the pretty picture be-we leave him to resume in peace his morning's walk, bidding good-speed."

The true Water Thrush inhabits eastern North America west to Illinois. From Wisconsin and Illinois westward and northward we find GRINNELI's WATER Thrush, Seiurus noveboracensis notabilis RIDGw.

NAMES: WATER Thrush, Small-billed Water Thrush, Water Wagtail, Water Kick-up, Bessy Kick-up, and River Pink (Jamaica), Aquatic Accentor, New York Aquatic Thrush.

SCIENTIFIC NAMES: Motacilla noveboracensis Gmel. (1788). Turdus noveboracensis Nutt. (1832). SEIURUS NOVEBORACENSIS BONAP. (1838). Turdis aquaticus Wils. (1811). Seiurus naevius Coues (1877).

DESCRIPTION: "Above, olive-brown, with a shade of green; beneath, pale sulphur-yellow, brightest on the abdomen. Region about the base of the lower mandible, and a superciliary line from the base of the bill to the nape, brownish yellow. A dusky line from the bill through the eye; chin and throat finely spotted. All the remaining under-parts and sides of the body, except the abdomen and including the under tail-coverts, conspicuously and thickly streaked with olivaceous brown, almost black on the breast.

"Length, 6.15 inches; wing, 3.12; tail, 2.40 inches. .. Sexès, similar." (Ridgway.)

\section{LOUISIANA WATER THRUSH.}

Seiurus motacilla BONAPARTE.

Plate XV. Fig. 6.

息

NDELIBLE in my recollection will be the days which I spent with one of our most efficient ornithologists, closest observers, and ablest judges of the singing of birds, Mr. Otto Widmann, of St. Louis. We made excursions in all directions from the city. They extended, across the "father of waters," to Illinois, down to the charming landscape of Montesano Springs, to the woodlands traversed by the Merrimac and Rock Creeks, into the grand Tower Grove Park and the celebrated, in America unrivaled, Botanical Gardens, popularly known as Shaw's Garden. On June 25, 1886, we made an excursion to the Creve Coeur Lakes, a region very rich in bird-life. The day, though rather warm, was favorable. Even before entering the woods, which border these lakes, many different bird-songs met our ears. High up in the gigantic tulip and sycamore trees Azure and Yellow-throated Warblers, Red-eyed and Yellow-throated Vireos poured forth their joyous notes. From the distance sounded the melodious song of the Rosebreasted Grosbeak, the sweet e-o-lie of the Wood Thrush and the metallic call of the Towhee. In the underwood Catbirds, White-eyed Vireos, Chats, Maryland Yellowthroats, Kentucky and Hooded Warblers were singing, while from the willows on the shore of the Little Creve Coeur Lake came the sweet lays of numerous Prothonotary Warblers. In an old willow stump, covered with poison ivy, a nest with young of this beautiful Warbler was found. On one side of the Large Creve Coeur Lake is a beautiful forest-crowned bluff, from which can be seen in the distance the broad and turbulent 
Missouri River, speeding on to meet the Mississippi. At the foot of this bluff, close to the water of the lake, the Worm-eating Warbler twittered its simple notes. Mr. Widmann remarked that the Chippy-like song in the hilly woods is always that of this Warbler. My particular attention, however, was called to a LouisianA WATER Thrush, a bird which I had previously observed in Texas, Louisiana, and south-western Missouri, but whose nest I had never found. As we were resting in the shade of high sycamores, broad elms, and pecan trees, listening to the various songsters about us and observing their manners and ways, a Water Thrush came flying across the lake and alighted with a worm in its beak on the shore near us. Noticing. our presence the bird became uneasy, ran up and down on the water's edge, jerking its tail and uttering a few warning notes. Mr. Widmann remarked that the Water Thrush in this locality; and probably elsewhere, builds its nest generally on the side of an embankment and that we very likely might find a nest here. The bank, not directly on the water's edge, was about eight feet high, and when I let myself down the bird took wing, uttering a few loud plaintive notes. I did not have to search long. Almost before me, near the top of the embankment, I noticed in a small niche of the soil, among the mass of small roots of an elm, a bunch of leaves. Into these leaves the nest was daintily built of grass, fine rootlets, moss, and plant stems. No one, not acquainted with the manner of nidification of this bird, would have suspected it in such a spot. It contained four young birds nearly old enough to fly.

Like the Worm-eating, Hooded, Prothonotary, and Blue Warblers, the Louisiana Water Thrush seems to be a common bird near St. Louis and in all suitable localities in southern Illinois and Indiana. Prof. Wm. Brewster found the bird quite common in Knox County, Ind. In the "Bulletin of the Nuttall Ornithological Club" (1878, p. 133-135), he gives the following excellent description on the nesting habits of the Large-billed Water Thrush :

"The writer had the good fortune to find two fully identified nests of this species in Knox County, Indiana, during the past spring (1878). The first, taken with the female parent, May 6, contained six eggs, which had been incubated a few days. The locality was the edge of a lonely forest pool in the depths of a cypress swamp near White River. A large tree had fallen into the shallow water, and the earth adhering to the roots formed a nearly vertical but somewhat irregular wall about six feet in height and ten or twelve in breadth. Near the upper edge of this, in a cavity among the finer roots, was placed the nest, which, but for the situation and the peculiar character of its composition, would have been exceedingly conspicuous. Its presence was first betrayed by the female, which darted off as one of our party brushed by within a few feet. She alighted on a low branch a few rods distant, uttering her sharp note of alarm, and vibrating her tail in the usual characteristic manner, but otherwise evincing no particular anxiety or concern. The nest, which is before me, is exceedingly large and bulky, measuring externally 3.50 inches in diameter, by 8.00 inches in length, and 3.50 inches in depth. Its outer wall, a solid mass of soggy dead leaves plastered tightly together by the mud adhering to their surfaces, rises in the form of a rounded parapet, the outer edge of which was nicely graduated to conform to the edge of the earthy bank in which it was placed. In one corner of this mass, and well back, is the nest proper, a neatly 
rounded, cup-shaped hollow, measuring 2.50 inches in diameter by 2.50 inches in depth. This inner nest is composed of small twigs and green mosses, with a lining of dry grasses and a few hairs of squirrels or other mammals arranged circularly. The eggs found in this nest are of a rounded-oval shape and possess a high polish. Their groundcolor is white with a fleshy tint. About the greater ends are numerous large but exceedingly regular blotches of dark umber with fainter sub-markings of pale lavender, while over the remainder of their surface are thickly sprinkled dottings of reddish-brown. But slight variation of marking occurs, and that mainly with regard to the relative size of the blotches upon the greater ends.

"The second nest was found May 8, on the opposite side of the same pond, in a precisely similar situation. Attention was first called to its proximity by the presence of the old birds, which were sitting on a mossy log a few yards off, the male pouring forth an almost uninterrupted strain of gushing melody to his mate. Enlightened by previous experience, the writer went directly to the only fallen tree in the vicinity, and almost at the first glance among the earth-laden roots looked in upon the eggs. This nest was very prettily sheltered from the rains, and concealed from prying eyes above, by a large white fungus, about the size and very nearly the shape of a shingle, which projected directly over it from the wall of earth behind, barely leaving sufficient space beneath to admit the passage of the bird. In general character this nest is nearly identical in every respect with the one alreadydescribed. It has the same rounded outer wall of closely impacted dead leaves, with, however, an admixture of dry mosses, cypress twigs, and strips of bark. In shape it is nearly square, measuring externally 6.50 inches in diameter by 3.54 inches in depth. The inner nest measures 2.73 inches in diameter by 2.50 inches in depth, and is lined with dry grasses, leaf-stems, and a few white hairs. The eggs were four in number and perfectly fresh; probably more would have been laid had the nest been left undisturbed. They agree closely in shape with those of the first set, and have an equally high polish, but are somewhat more heavily and handsomely marked. The color is creamy-white with heavy blotches of umber-brown generally distributed, but occurring most thickly at the greater ends; fine dottings of lighter brown, and a few spots of pale lavender, fill in the intermediate spaces.

"On May 12, a third nest, containing five young birds, well feathered and nearly able to fly, was found by my friend Mr. R. Ridgway, on the shore of an isolated little woodland pond. The site, in this instance, was at the foot of a huge stump, the nest being placed in a cavity in the rotten wood. Still another nest was found by the writer, April 29, under the bank of White River, among the earth and roots, and well sheltered by the projection of the bank above. In general construction, as well as situation, this nest was so nearly identical with those already spoken of that any further description would be superfluous."

Near creeks and rivers in south-western Missouri this bird is quite a common summer sojourner, though I never succeeded in finding its nest. During the early morning hours in May and June I often heard the exquisite song of this bird. As if to delight the early rambler the Cardinal Grosbeak sounds its cheery notes near by, while Maryland Yellow-throats, Kentucky Warblers, and other small songsters combine in a chorus of exceeding charm. In such localities the Water Thrush sets its music-box going 
"which fairly runs over with fine, gushing, lyrical sounds." The bird is not a diligent singer but one of the finest in such localities.

I have never observed the Louisiana Water Thrush in Wisconsin or northern Illinois. It is essentially a southern bird and is rarely found north of latitude $42^{\circ}$. It arrives at Freistatt, Lawrence County, Mo., usually about April 20, in Lee County, Tex., about April 10. It winters in the West Indies, southern Mexico, Honduras, Guatemala, south to Panama. In summer it occurs in the United States from the Atlantic west to the Plains.

NAMES: Louistana WATER Thrush, Large-billed Water Thrush, Large-billed Accentor, Water Wagtail, Wagtail.

SCIENTIFIC NAMES: Turdus motacilla Vieillot (1807). SEIURUS MOTACILLA Bonap. (1850). Tutdus ludovicianus Aud. (1832). Seiurus ludovicianus Bonap. (1838).

DESCRIPTION: "Upper parts, olive-brown, with a shade of greenish. A conspicuous white superciliary line from the bill to the nape, involving the upper lid, with a brown one from the bill through the eye, widening behind. Under-parts, white, with a very faint shade of pale buff behind, especially on the tail-coverts. A dusky maxillary line; the forepart of the breast and sides of body with arrow-shaped streaks of same color. Chin, throat, belly, and under tail-coverts, usually immaculate.

"Length, 6.33 inches; wing, 3.25; tail, 2.40 inches.... Sexes, similar." (Ridgway.)

\section{KENTUCKY WARBLER.}

Geothlypis formosa RIDGWAy.

Plate XIV. Fig. 3.

THE RIVERS, bayous, and swamps of southern Louisiana and south-eastern Texas are fringed with an almost impenetrable jungle of low bushes, trailing vines, and robust growing perennials. The branches of the trees are festooned with long pendant masses of Spanish moss. In the shallow water grow cypress trees, water tupelos, button-bushes ${ }^{1}$, and willows, while on the border several varieties of oaks, the beautiful sweet gum $^{2}$ and black birches thrive luxuriantly. Magnolias, loblolly bays, wax myrtles, hollies, and other evergreen trees and shrubs, numerously interspersed with elms and ashes, are also found in such localities. Mexican mulberry, dogwood, and other berry-bearing shrubs are encountered in great numbers. The entire forest, especially the larger trees and bushes near the water, are in many places so densely covered and interlaced with trailing and creeping vines as to form an almost solid barrier to the explorer. Garland-like the laurel smilax ${ }^{3}$ climbs over bushes and trees, and the trumpet vine $^{4}$ and the Virginia creeper ${ }^{5}$ cling to the bark of the forest monarchs even at their very tops. The beautiful clusters of orange-colored blossoms of the trumpet creeper

1 Cephalanthus occidentalis. 2 Liquidambar, styracifua. 3 Smilax laurifolia. ITecoma radicans. " Ampelopsis
quefolia. quinquefolia. 


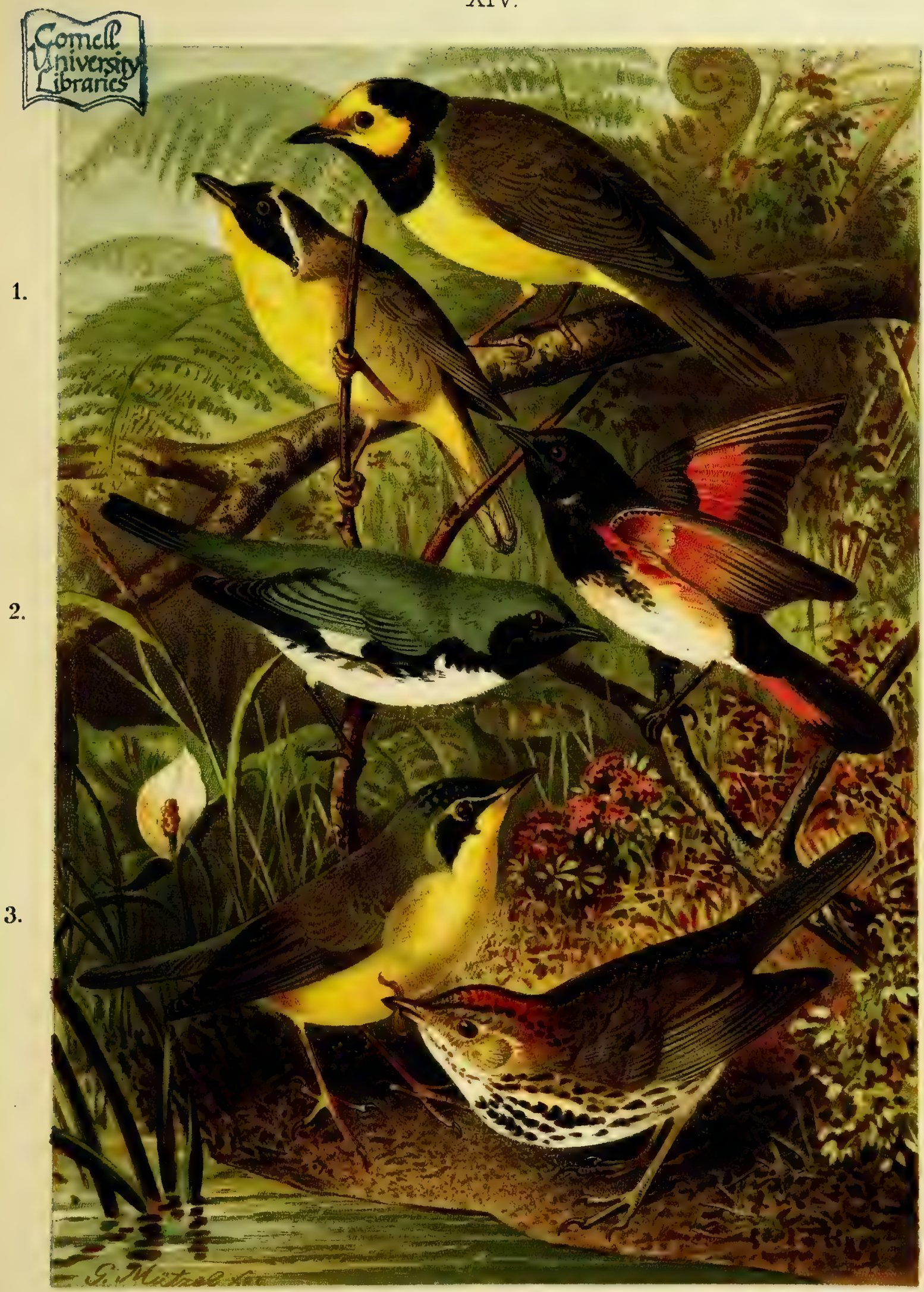

1. GEOTHLYPIS TRICHAS Cab.

2. DENDROICA CAERULESCENS Brd.

3. GEOTHLYPIS FORMOSA Ridgw.
4. SYLVANIA MITRATA Nuttall.

5. SETOPHAGA RUTICILLA Swains.

6. SEIURUS AUROCAPILLUS Swains. 

hang down from the branches in gorgeous abundance. The most remarkable plant to the novice is the strangely interwoven and twisted supple Jack ${ }^{1}$. This extremely pliable vine can be seen here in all possible shapes. In one spot numerous smooth green stems sprout up from one rooted knob, growing up vertically, and, after obtaining considerable height, begin to intertwine with each other, or reach out for the nearest tree and twist themselves tightly around its trunk and branches; in another place, two, three, or more of these stems are twisted together into one cord- or cable-like mass, directly after sprouting from the ground, or they are wound so tightly around a tree that they grow into its bark, finally killing it. The wild grape, especially the delicious scuppernong or muscadine, flourishes here abundantly, while honey-suckle, poison ivy, Carolina jasmine, Cherokee roses, and trailing thorny black-berry bushes form a dense jungle near the edge of these woods. Here it is, where birds most congregate. Such thickets are the paradise of beautiful Cardinals, Blue Grosbeaks, Nonpareils, Carolina Wrens, White-eyed Vireos, Chats, and Mockingbirds. Although this idyllic existence is frequently disturbed by furious tree-climbing snakes and the water mocassin, it nevertheless seems to the birds an ideal life of happiness. In the openings and such localities where the palmetto, the yucca, and rank weeds grow, but always near the water and the woodlands just described, abounds a bird, which I here found for the first time, the pretty little KENTUCKY WARBLER.

This bird, which, in its habits as well as in its appearance, reminds the observer of its near relative the Maryland Yellow-throat, is very common in south-eastern Texas. Its favorite haunts are among the broom grass, the spider lilies ${ }^{2}$, the palmettos, yuccas, and dense dew-berry bushes. It is more robust than its congener, the Maryland Yellowthroat, and not quite so lively and quick in its movements. The song is stronger, sweeter, and more prolonged than that of the Maryland Yellow-throat. In the early morning hours and again late in the afternoon it sings almost incessantly, and often as many as four or five males may be heard in close proximity. I noticed its arrival in southeastern Texas about April 20, and at Freistatt, Lawrence County, Mo., it was common by May 3. In the last named locality, which we might term the Ozark region, it frequents the borders of woods, where snow-berry ${ }^{3}$ and hazel bushes, persimmons and rank herbs grow. Near St. Louis, in southern Illinois, and Indiana it is also a very common bird. I have never seen the Kentucky Warbler in Wisconsin or in northern Illinois, but it is said to occur there occasionally. In his excellent work, "The Ornithology of Illinois," Prof. R. Ridgway gives the following interesting account:

"The beautiful Kentucky Warbler is one of the most abundant of birds in the rich woods of southern Illinois. As far north as Wabash, Lawrence, and Richland counties, it is even more abundant than the Golden-crowned Thrush, though the two usually inhabit different locations, the latter preferring, as a rule, the dryer upland woods, while the present species is most abundant in the rich woods of the bottom-lands. In its manners it is almost a counterpart of the Golden-crowned Thrush, but is altogether a more conspicuous bird, both on account of its brilliant plumage and the fact that it is more active, the males being, during the breeding season, very pugnacious, and continually chasing one another about the woods. It lives altogether near the

1 Berchemia volubilis, 2 Hymenocallis galvestonensis and H. rotatum. a Symphoricarpus glomeratus. 
ground, making its artfully concealed nest among the low herbage and feeding in the undergrowth, the male uttering his pretty song from some old log or low bush. His song recalls that of the Cardinal, but is much weaker; and the ordinary note is a soft pchip, somewhat like the common call of the Pewee (Sayornis Phobe). Considering its great abundance, the nest of this species is extraordinarily difficult to find; at least this has been the writer's experience, and he has come to the conclusion that the female must slyly leave the nest at the approach of the intruder and run beneath the herbage until a considerable distance from the nest, when joined by her mate, the pair by their evident anxiety mislead the collector as to its location. However this may be, the writer has never found a nest of this species except by accident, although he has repeatedly searched every square foot of ground within a radius of many yards of the spot where a pair showed most uneasiness of his presence."

The nest is similar to that of the Maryland Yellow-throat and very bulky. It is - invariably placed under a shrub, a luxuriant perennial, a fern, or a weed stalk, and is built of leaves in which it is also imbedded, and of old grasses, being lined with fine rootlets and horse hair. The eggs, four to five in number, are clear white, often creamy-white, speckled, chiefly at the larger end, with umber and dark brown.

The summer home of the Kentucky Warbler are the Eastern States, chiefly west of the Alleghanies and thence to the Plains, north occasionally to the Great Lakes and southern New England. It winters in Cuba and probably also in other West Indian islands, in south-eastern Mexico and Central America to Panama.

NAMES: KeNTUCKY WARBLER, Kentucky Yellow-throat.

SCIENTIFIC NAMES: Sylvia formosa Wils. (1811). Myiodioctes formosus Aud. (1858). Oporornis formosus Baird (1858). GEOTHLYPIS FORMOSA Ridgw. (1885).

DESCRIPTION: "Adult male. Upper parts and sides, dark olive-green. Crown and sides of the head, including a triangular patch from behind the eye down the side of the neck, black; the feathers of the crown narrowly lunulated at tips with dark ash. A line from nostrils over the eye and encircling it (except anteriorly), with the entire under-parts, bright yellow. No white on tail. Female, similar, with less black on head.

"Length, 5.00 inches; wing, 2.95; tail, 2.25 inches. - The adults in autumn are exactly the same as in spring." (Ridgway.)

CONNECTICUT WARBLER.

Geothlypis agilis GregG.

The ConNecticut WARBLER is one of the rarest of the family. I have seen it during the migrations only, especially in the fall. In the latter season it is sometimes quite abundant in Wisconsin and Illinois. Mr. Ernest E. Thompson gives the following description of the home and breeding of this Warbler in the "Auk" (Vol. I, p. 192-193): "A few miles south of Carberry, Manitoba, is a large spruce bush, and in the middle of it is a wide tamarack swamp. This latter is a gray, mossy bog, luxuriant only with pitcher plants and Droseræ. At regular distances, as though planted by the hand of man, grow the slim, straight tamaracks, grizzled with moss, but not dense, nor at all crowded; their light leafage casts no shade. They always look as though they were just about to end, though the swamp really continues for miles - the same dank, gray waste. 
"At times the Great-crested Flycatcher was heard uttering his whistling croak. Besides this the only noticeable sound was the clear song of a Warbler. It may be suggested by the syllables beecher-beecher-beecher-beecher-beecher-beecher. It is like the song of the Golden-crowned Thrush, but differs in being in the same pitch throughout, instead of beginning in a whisper and increasing the emphasis and strength with each pair of notes to the last. Guided by the sound, I found the bird high in the tamaracks. It was not shy like the Wood Warblers, so it was easily secured. It proved to be a male Connecticut Warbler. As I went on, a small bird suddenly sprung from one of the grave-like moss-mounds. It seemed distressed, and ran along with its wings held up, like a-Plover just alighting. On seeing that $I$ would not be decoyed away, it ran around me in the same attitude. Recognizing that it was the Connecticut Warbler.... I sought out the nest in the moss. It was entirely composed of dry grass, and sunken level with the surface. The eggs, four in number, measured $.75 \times .56$ inch." They were of a delicate creamy-white color, with a few spots of lilac-purple, brown, and black, inclined to form a ring around the larger end.

This Warbler inhabits eastern North America, breeding north of the United States.

DESCRIPTION: "Olive-green, becoming ashy on the head; below, from the breast, yellow, olive-shaded on the sides; chin, throat, and breast, brownish ash; a whitish ring round eye; wings and tail, unmarked, glossed with olive; under mandible and feet, pale; no decided markings anywhere.

"Length, 5.50 inches; wing, 2.75; tail, 2.00 inches. In spring birds the ash of the head, throat, and breast is quite pure, and then the resemblance to Geothlypis philadelphia is close." (Coues.)

\title{
MOURNING WARBLER.
}

\section{Geothlypis philadelphia BAIRD.}

\author{
Plate XIII. FIG. 7.
}

(d.)

N MAY 16, 1882, early in the morning, I was rambling about, as I often did, in the forest lands near West Yegua Creek, Texas, observing the ways and lays of the woodland songsters. The birds of passage had left for their northern breeding grounds, and the summer residents were busily engaged in nest-building or taking care of their young. The woods resounded with the thousand-voiced choir of happy songsters. The ground underneath the trees appeared as though a many colored carpet had been spread over it. Phlox, coreopsis, gaillardias, and many other beautiful flowers gave the landscape a charming aspect. The trees, garlanded with wild grape vines, trumpet creepers, and occasionally festooned with grayish-green lichens ${ }^{1}$, had put forth, almost eight weeks ago, their richest hue of green. Among the lichens Parula Warblers were seen in numbers, while Hummingbirds were whirring and hovering about the clusters of orange-tinted trumpet flowers. Entirely absorbed in contemplating all this rich forest life, the many beautiful plants, the choir of jubilant songsters, among whom the 
Mockingbird and Cardinal were particularly noticeable, I had hardly noticed a little bird singing in close proximity to me. Anon it approached very closely and sang with all its power. Quite surprised by the audacity of the little songster, I now observed it closely and recognized it as a splendid male of the Mourning WARBLER. The bird preferred the lower limbs of the trees and occasionally fluttered down into the low bushes, from which it emerged with large smooth, green caterpillars, which interfered but little with its exceedingly charming singing. It was so fearless that I was able to observe it closely for nearly half an hour. Although the nearest relative to the ever restless, suspicious Maryland Yellow-throat, this bird is not as rapid in its movements and far less timid. It had doubtless been belated in its northward journey. When I visited the same lecality the next day I did not find the bird again. The little straggler had evidently taken flight, continuing its journey to its northern home.

Although nowhere particularly abundant, the Mourning Warbler seems to be more common in the upper Mississippi valley than elsewhere. In the East it is a rare bird, being met with only during the migration. In the large white cedar and tamarack swamps of Wisconsin and Minnesota it finds a congenial home. The very extensive Sheboygan marsh, near the beautiful Elkhart Lake, an uninterrupted swamp consisting of thousands of acres of tamarack and white cedar lands, is the only place in Wisconsin, where I found this gay and agreeable bird rather common. "It does not hug the shrubbery so closely" as the Maryland Yellow-throat, but the male may be observed "in the tops of trees in the mixed woodland, where the undergrowth is convenient for hiding, singing a bright, hearty song."

According to Dr. Elliott Coues, the Mourning Warbler is perhaps more abundant in the breeding season along the Red River, between Dakota and Minnesota than anywhere else. There it frequents the dense shrubbery along the banks of the river, and is rather difficult to observe, the female especially.-The song of this bird is much superior to that of the Maryland Yellow-throat. It consists of a very bright and cheerful strain and is very frequently uttered, usually from the tops of trees or high bushes.

The nest I have never found. Mr. John Burroughs found this Warbler a not uncommon bird in the Catskill Mountains. In regard to its nidification he writes as follows: "The nest was in the edge of an old bark-peeling, in a hemlock wood, and was placed in some ferns about one foot from the ground. The nest was quite massive, its outer portion being composed of small dry stalks and leaves. The cavity was very deep, and was lined with fine black roots. I have frequently observed this Warbler in that section. About the head of the Neversink and Esopus, in the north-west part of Ulster County, New York, they are the prevailing Warbler, and their song may be heard all day long. Their song suggests that of the Kentucky Ground Warbler, but is not so loud and fine." The eggs are described as creamy-white, speckled all over with lilac and dark brown spots. Mr. Walter Faxon, in his paper "On the Summer Birds of Berkshire County, Massachusetts," gives the following account of the ways and nesting habits of the Mourning Warbler:

"Common. Noted at altitudes from 1000 to 3500 feet, one pair at least being established in the edge of the clearing on the summit of Graylock. Especially abundant where the forest has been cut on the south side of the 'Bellows-pipe' in Adams. Where- 
ever the land has been recently cleared, but not appropriated for pasturage or tillage, the Mourning Warbler is found, the most characteristic tenant of the dense 'sprout growth' that forms the vanguard of the succeeding forest. By widening the domain of this lovely bird the wood-cutter atones, in a measure, for the destruction he causes. The song that I most often heard resembles the syllables thuir-ree, thír-ree, thuir-ree (sometimes the repetition was four times instead of three). A refrain consisting of three notes, with the accent upon the last, or of two notes with a strong accent on the first, the voice falling on the second, was sometimes appended. At other times the form of the song was quite different, consisting of but five notes, the penultimate note strongly accented, the last pitched on a lower key. The last two notes together are equal in time to one of the first three. Something in the mode of delivery of the latter song suggests the song of the Water Thrush, as Mr. Maynard has observed. As far as I could determine, the same bird always followed one score. The Mourning Warbler, like the Golden-crowned Thrush, or its nearer relative, the Maryland Yellow-throat, is much given to an ecstatic aërial song that defies description."

The bird is distributed over the Eastern States, west to Dakota, and breeds from the Northern States northward. In Manitoba it seems to be ábundant. In winter it is found south to Central and northern South America.

NAMES: MOURNING WARBLER, Black-throated Ground Warbler.

SCIENTIFIC NAMES: Sylvia philadelphia Wils. (1810). Trichas philadelphia Aud. (1839). GEOTHLYPIS PHILADELPHIA BAIRD (1858).

DESCRIPTION: "Adult male: Head and neck all round, with throat and forepart of breast, ash-gray, paler beneath. The feathers of the chin, throat, and fore-breast in reality black, but with narrow ashy margins, more or less concealing the black, except on the breast. Lores and region round the eye, dusky, without any trace of a pale ring. Upper parts and sides of the body, clear olive-green; the under-parts, bright yellow. Tail-feathers, uniform olive; first primary, with the outer half of the outer web, nearly white. Female: With the gray of the crown, glossed with olive; the chin and throat, paler centrally, and tinged with fulvous; a dull whitish ring round the eye.

"Length, 5.50 inches; wing, 2.45; tail, 2.25 inches." (Ridgway.)

\section{MACGILLIVRAY'S WARBLER.}

Geothlypis macgillivrayi BAIRD.

In the Western States the Mourning Warbler is replaced by the beautiful and closely allied MACGILIIVRAY's WARBLER. It seems to be a rather common bird from the eastern foot-hills of the Rocky Mountains to the Pacific coast, and occurs north into British Columbia. Its winter home extends from southern Mexico to Central America, where it frequents the borders of woods. Near the Columbia in Washington and Oregon this Warbler is an abundant summer resident, being there as common as the Maryland Yellow-throat is in the East. Nuttall informs us that it keeps near the ground, and gleans its subsistence among the low bushes. It is shy, and when surprised or closely watched, it immediately skulks off, often uttering a loud click. A nest which this naturalist examined was chiefly made of strips of the inner bark of Thuja occidentalis, lined with slender wiry stalks. It was built near the ground, in the dead, moss-covered limbs of a fallen oak, and was partly hidden by long tufts of Usnea. 
Nests discovered by Dr. Kennerly about Puget Sound were all built on the ground, almost exclusively consisting of beautifully delicate mosses, peculiar to that country. They are lined with finer mosses, and a few slender stems and fibres. Mr. Ridgway found these Warblers breeding in great numbers at Parley's Park, Utah, among the Wahsatch Mountains. "This species," he writes, "inhabits exclusively the brush-wood along the streams of the mountain cañons and ravines. Among the weeds in such localities numerous nests were found. In no case were they on the ground, though they were always near it; being fixed between upright stalks of herbs, occasionally, perhaps, in a brier, from about one to two feet from the ground. The note of the parent bird, when a nest was disturbed, was a strong chip, much like that of the Lazuli, or Indigo Bunting. The eggs, usually four in number, are 'pinkish-white, marbled and spotted with purple, lilac, reddish-brown, and dark brown, approaching black.'"

Nuttall, who had a fine ear for the woodland melodies, speaks of this Warbler's song as a "loud snapping clink," which is uttered when the bird is skulking off, shy, and jealous; he likens another note to the hurried, rattling sound of the Ovenbird; another male "called out at intervals vish vishtyu, changing to vit vit vit vityu;" another still "had a call of visht visht, visht e visht t'shew." Another writer speaks of the song as "almost unrivaled in sweetness by that of any other of the forest songsters."

NAMES: MAcGILLIVRAY's WARBLER, Macgillivray's Ground Warbler, Tolmie's Ground Warbler.

SCIENTIFIC NAMES: Sylvia macgillivrayi Aud. (1839). Trichas macgillivrayi Aud. (1839). GEOTHLY. PIS MACGILLIVRAYI BRD. (1858). Geothlypis philadelphia var. macgillivrayi Allen (1872).

DESCRIPTION: 'Sexes, 'nearly alike. Upper parts, including exposed surfaces of the wings and tail, clear olive-green; below, bright yellow, shaded with olive on the sides. Head and neck all around, and throat and fore-breast, clear ashy; the eyelids, white, and the loral region usually dusky; the throat with blackish centres to the feathers, veiled by their gray skirting.

"Length, 5.25 inches; wing and tail each about 2.25 inches." (Coues.)

\title{
MARYLAND YELLOW THROAT.
}

\author{
Geothlypis trichas CABANIs. \\ Plate XIV. Fig. 1.
}

\author{
"A woodland walk, \\ A quest of river-grapes, a Mocking Thrush, \\ A wild rose, a rock-loving columbine. \\ Salve my worst wounds."
}

EMERSON.

$7 \mathrm{~T}$ IS June, the most beautiful month of the year in our Northern States, the real A spring month, the month of flowers and bird-song, of balmy air and fragrance. We forget the cold winter and the very changeable climate of April and May. The woodland walks are fringed with delicate ferns, wake-robins, and other pretty flowers. In the lowlands near water life is most abundant. The rank vegetation nurtures hosts 
of insects, and insects draw numerous birds, especially Warblers. The thickets on the water's edge, consisting of red-osier ${ }^{1}$, round-leaved dogwood ${ }^{2}$, arrow-wood ${ }^{3}$, wahoo ${ }^{4}$, and a number of different white thorns ${ }^{5}$ are now in their full glory. Near by in the meadow the ground is carpeted with innumerable flowers, and over them, in the air, the Bobolinks sing their rollicking and jubilant strains. In the high elms above us the gorgeous Baltimore Oriole utters its flute-like notes, while not far away the Veery's enchanting anthems fill the woodland's edge with the sweetest music. The Meadow Lark, the Swamp Sparrow, the Redwing, the Red-eyed Vireo, the Indigo Bunting, etc., sing their merry notes on all sides. All nature seems to be imbued with joy, happiness, and song. The sorrow and grief of the friend of nature is soon forgotten in this salubrious air, in this beauty and joy of nature. Rapture and happiness are gradually filling his heart also.

While we are resting on the grass near a mass of bushes and rank herbs, we see a very beautiful little bird, yellow on the under-side, olive-green above, and the forehead. and sides of the head marked with pure black. It is the MARYLAND YELIOW-THROAT, one of our familiar birds, and, perhaps, the most abundant of all our Warblers, not even excepting our garden and park-loving Summer Yellowbird. In almost any shrubbery near water, from the Atlantic to the Pacific coast, and from the Gulf States to British America, may be found a pair of these happy and sprightly little creatures. Being one of the terrestrial Warblers, it lives much on or near the ground, hence its popular name "Ground Warbler." It differs notably in its haunts and habits from the beatiful arboreal Warblers of the Dendroica-group, although its song reminds one frequently of the lays of other members of its family. If we observe closely, we see the grass and herbs move, and not long after a beautiful little bird appears at the top of one stout stem, first surveying its surroundings and then uttering its sprightly notes. In scrambling about in bush and brier, the undergrowth of the woodland's edge, the cool brook, the tangle in the swamp border, and the shrubbery of the meadow, it resembles much the Carolina Wren. "Like many other birds of the bush, whose hidden haunts inspire a feeling of safe seclusion, but do not afford a very good view of what is going on, the Yellow-throat shows in its actions toward man that very engaging combination of shyness, assurance, and curiosity which are betrayed by a timid child in meeting the advances of a stranger. On approaching the cover, one is sure to be saluted with the sprightly whit'-ti-ti, whit'-ti-ti of the vivacious bird, and will probably see the performer, absorbed in his ditty; upon the outer wall of his leafy retreat; curiosity or preoccupation may detain the singer for a few moments, but he is likely to duck out of sight and reappear at some safer distance, or send his greeting with a mocking accent from some hidden recess of the shrubbery. The female keeps more closely in seclusion, threading her furtive way close to the ground, and is much more rarely observed than her sprightly mate."*

From its winter home in Central America, the West Indies, and the South Atlantic and Gulf States it arrives in south-western Missouri about April 20. In the first days of May we see it in northern Illinois, and in Sheboygan County, Wis., it is rarely common before May 15. Late in August and early in September the majority leave

1 Cornus stolonifera. 2 C. circinata, \& Viburnum dentatum. 4 Euonjmus atropurpureus. 5 Crataegus.

* New England Bird Life. By W. A. Stearns and Dr. Elliott Coues. Vol. I, p. 164. 
their summer home. In New England it seems to depart later than in the Mississippi valley. According to $\mathrm{Mr}$. Stearns, it lingers late amid the rustling of dry and brittle underwood and the rasping of withered reeds; it is generally November before its final departure for the South, though a few remain after September, except in favored southern localities.

Though common in all low and bushy localities, the Maryland Yellow-throat is not so well known and appreciated as it deserves to be. It always keeps among the low vegetation, never mounting high shrubs or trees. Wild lands, where the large trees were cut down and which are now overgrown with briers, vines, low bushes, and rank weeds and grasses, it prefers to open or cultivated grounds. It also shuns the gloomy interior of woods and swamps. On high lands I have rarely met with this pretty and lively little creature, but on low lands near a rivulet, a brook, a spring, or a small lake I always found it in more or less abundance. Its food consists exclusively of insects which live on or near the ground. All the Warblers are of great service to man, but the mode of life of the terrestrial species exposes them, especially near houses, to destruction by prowling cats.

During the winter time I have frequently observed this bird in and near Houston, Texas. In the dense shrubs of the gardens, such as gardenias or Cape jasmines, roses, myrtles, bottle-brush shrubs ${ }^{1}$, and ivy they find food and shelter. They were especially common near the Buffalo and White Oak Bayous among the hollies, smilax, and other evergreens. In Florida I observed them among the dense saw ${ }^{2}$, dwarf ${ }^{8}$, and blue palmettos ${ }^{4}$ huckleberry bushes, and other low shrubs in great abundance during the winter months. In their winter home they are exceedingly quiet and shy, not allowing the observer to advance too near. I observed the Yellow-throat also during the summer in south-eastern Texas in grassy localities with thickets interspersed. On a farm near Houston, in a wet piece of land containing about two acres, I found three pairs breeding. A ditch runs through this place, and the whole ground was covered with high broomgrass $^{5}$, brier patches, thickets of water oak, overgrown with trumpet creeper, poison ivy, grape vines, Carolina jasmine, and smilax. The field was surrounded by an almost impenetrable hedge of Cherokee roses. Here the Yellow-throats sojourned with Kentucky Warblers, White-eyed Vireos, Yellow-throated Vireos, Nonpareils, Chats, Mockingbirds, Cardinals, and Blue Grosbeaks, all living in harmony and peace. Two broods were raised annually in this latitude. In almost every nest of this species, and also in almost all the nests of other birds, eggs of the Cowbird were found.

In Wisconsin nest-building begins about June 1 . The structure is snugly hidden under a dense fern, a small bush, or a tussock of grass, and is exceedingly difficult to find. Sometimes it is roofed over like the nest of the Ovenbird, but usually it is open like that of the Kentucky Warbler. It is built of dry grasses, leaves, bark-strips, and is lined with finer bark-strips and sometimes with hair. Like almost all ground-nests, it is not remarkable for elegance. The male sings in the vicinity of the nest and even collects food for the female during incubation. When the young are hatched it assists the female in collecting insects for them. The structure is always hidden in a secluded spot. The birds "rely upon concealment for the protection of their nest and rarely show any open 1 Melaleuca and Metrosideros. 2 Sabal serrulata. I S. Adansonil. Chamaerops Hystrix. 6 Andropogon macrurus. 
solicitude until it is discovered. Then they will make the most vehement demonstrations of alarm and distress, flying about the intruder and fearlessly approaching him to within a few feet." (Brewer.) In the North they rarely, if ever, have more than one brood in the season. The eggs, four to five in number, are white or creamy-white, speckled, chiefly at the larger end, with reddish-brown, lilac, and black. The family, after the young have left the nest, and even after they are able to take care of themselves, keep together. In July I frequently observed large numbers of old and young Yellow-throats on the borders of woods and swamps, in secluded thickets, and other retired places, where they were quietly searching for food on the ground. Late in August they leave Wisconsin and northern Illinois for their winter-quarters.

The song of the Yellow-throat, which is heard most frequently from the time of its arrival till the young are hatched, consists of a few very mellow notes, sounding like witchity,-witchity,-witchity. 'This lively and agreeable refrain is uttered from the top of a small shrub, or among the brambles, and is heard throughout the day, but most frequently early in the morning and again when the twilight of the evening falls. At times the song displays a marked difference, and occasionally closely resembles the strain of the Chestnut-sided and Summer Yellowbird.

Of this species there are two distinct varieties. The true species, the common Maryland Yellow-throat, is mainly found east of the Alleghanies, north to Ontario and Nova Scotia, breeding from Georgia northward. This bird winters in the South Atlantic and Gulf States, and the West Indies. The variety, known as the Western YellowTHROAT, Geothlypis trichas occidentalis BREwSTER, is distributed over the Western States, from the Mississippi valley to the Pacific, and during summer from south-eastern Texas to the Northern States and probably to Manitoba. In their habits both birds show no difference. The Western Yellow-throat is the variety I have observed since my childhood and which $I$ have described in the foregoing pages. Dr. J. C. Merrill, who found this bird very common in the region of Fort Klamath, Oregon, states that its favorite haunt there is among the tules in company with Marsh Wrens and Yellow-headed Blackbirds. I have also found the bird in marshy localities on the Rock River in Wisconsin, where rank grasses, sedges, lobelias, ferns, turtle-heads, and such shrubs as the red-osier, willows, and others grow in great luxuriance.

Belding's Yellow-THRoat, Geothlypis beldingi Ridgway, inhabits Lower California.

NAMES: Mariland Yellow-Throat, Yellow-throat, Western Yellow-throat, Ground Warbler, Black-masked Ground Warbler, Black-cheeked Yellow-throat, Brier Wren, Yellow Brier Wren.

SCIENTIFIC NAMES: Turdus trichas Linn. (1766). Sylvia trichas Lath. (1790). GEOTHLYPIS TRICHAS Cabanis (1850). Sylvia marilandica Wils. (1808). Trichas marilandica Nutt. (1840). Sylvia roscoe Aud. (1840).

DESCRIPTION: "Male, Adult: Above, olive-green; rather grayer anteriorly and brighter on rump; forehead and broad band on side of head, pure black; bordered above by hoary-ash; under-parts, including under wing-coverts and edge of wing, rich yellow, fading to whitish on the belly; wings and tail, dusky, unmarked, glossed with olive-green; bill, black; feet, flesh-color. Female: Without the black and ash on the head; the crown, quite brownish; an obscure supraciliary line, and the yellow of the under-parts, pale and restricted; smaller than the male.

"Length, 4.75 to 5.00 inches; wing and tail, each, 1.90 to 2.10 inches." (Coues.) 


\title{
YELLLOW-BREASTED CHAT.
}

Icteria virens BAIRD.

Plate XV. Fig. 3.

\begin{abstract}
夙
LL PARTS of our grand country are exceedingly rich in beautiful and attractive birds and excellent songsters, even the dry and hot cactus regions of Arizona and south-western Texas. The Warblers, with few exceptions, are beautifully colored and highly interesting birds. They are associated in my mind with the flowering and perfume of the magnolias, tea roses, and Cape jasmines of the South, with the gorgeous flowers of the odontoglossums, lælias, oncidiums, lycastes, and other epiphytal orchids of Mexico and Central America, with the rosy-white flower masses of our northern apple trees and the genial air of the, too rare, spring days of May. Many of our birds vie in brilliant colors with the birds of the tropics. What a refined and striking bird is the Scarlet Tanager, clad in the most intense vermilion-scarlet and deep black. The Baltimore Oriole in its orange and black colors among the high and pendulous branches of our magnificent American elms, or among the flowering apple trees of the orchard, is a picture which can be fully appreciated by a poetical and noble mind only! In the South we frequently find thickets of hollies covered with dense masses of elegant leaves and glowing red berries, inhabited by numbers of beautiful red Cardinal Grosbeaks. On sunny February days we may hear in these localities the far sounding and charming songs of these birds on all sides, suggesting the words what cheer! what cheer, what cheer! If our way leads us through one of the orange groves, rose and ornamental gardens of southern Louisiana, we will be surprised by the beauty and lively strain of the Nonpareil, a bird with violet-blue head, green back, and vermilion throat, breast, and under-side. The name, which is of French origin, means the incomparable, and, indeed, the bird has no peer among all our feathered songsters. Its nearest relative is the fine Lazuli Bunting of California, and the deep blue Indigobird of our Middle and Northern States. This last named songster is, like the Blue Grosbeak, of the South, one of our most beautiful birds, but being shy and retired, it is not so well known and so highly appreciated as it deserves. The Rose-breasted Grosbeak of our woodland borders is a magnificent songster, whose strain in the dusk of evening is especially enchanting and full of poetry. But all of these are far surpassed by the modestly attired Mockingbird, the "king of song," the bird which does not find its rival among the feathered tribe. If you have one or more of these or other songsters in your garden and orchard, dear reader, do not disturb them. Give them your protection and care. Keep the egg hunters and collectors away from your premises, and these birds will pay you thousandfold by their charming music, lively manners, merry gambols, and unequalled happiness.

Among the birds of the woodland shrubbery, the small trees and bushes entangled with grape vines and other creepers, the Cardinal Redbird, the White-eyed Vireo, the Catbird, and the YelLOW-BREASTED Chat, the subject of this sketch, are in south-
\end{abstract}


western Missouri especially common. The basket-vines ${ }^{1}$, black haws, blackberry bushes, white-thorns, etc., on the woodland border are the favorite haunts of this exquisite and peculiar songster. It is a bird uniting beauty, song, and some very strange peculiarities. It is truly a comical creature, a pronounced odd fellow among the feathered inhabitants of bush and brier. In certain localities the Chat is an abundant bird and well known to every admirer of nature's realms. It is prized for its beauty, the variability and peculiarity of its notes, and its extremely odd manners and habits.

Instead of jotting down my own observations of this bird, I prefer to quote from several excellent authorities. Dr. J. M. Wheaton gives the following interesting account:*

"Very common summer resident; abundant in the southern, not very common in the northern portions of the State. Arrives in middle Ohio about May 1, and remains until the last of August.

"When migrating no bird is more shy and retiring than the Chat. They skulk along silently in thickets along the banks of streams, or on the edges of upland woods. But no sooner has pairing been effected, than their whole nature seems changed, and the silent bird becomes the noisiest of the woods. His shyness gives way to an audacity which is surprising. If he discovers the approach of a human being, even at a considerable distance, he prepares to resent the intrusion; and giving three short, loud whistles, very low in tone, as a warning, he advances toward him, all the while careful that he should be heard and not seen. Then follows a medley of sputtering, cackling, whispering, and scolding notes, frequently interspersed with loud whistles, and continued as the bird runs, hops, or flies in the deepest thicket, with a pertinacity which knows no fatigue. He tells you that your gun won't shoot, that it is a flint-lock, that your ram-rod is broken, that you shot it at a buzzard, that you haven't got a gun; that you are a bald-headed cripple; that there is a horrid suicide in the bushes, and a big snake and a nasty skunk; that your baby is crying, your house is afire and the bridge broken down; that you have missed the road to the reform farm, and that the poor house is over the creek, and he calls the dogs; says that you have gone to seed; go west and grow up with the country; that you are taking up too much of his valuable time, that you must excuse him for a moment. During all this time he remains invisible; or at most, his black eye and mask, or golden breast, appear for a moment as he peers at you from the tangled branches of the brambles, or flashes from branch to branch, dancing an accompaniment to his fantastic notes. At the last, he suddenly appears on the top of a bush not ten feet from you, makes a profound bow, and with a derisive whisk of his long tail, exposes his immaculate white crissum and dives again into the deepest thicket. You take a long breath and wipe your face, and he returns to the assault from the rear. Should you move on, he follows, and if you approach, he retires, and, keeping at a respectful distance, he laughs defiance, shouts mockery and tantalizing sarcasm. He is a fearful scold, and it is no wonder the inside of his mouth is black. But this is when he knows he has the advantage. Sometimes he may be surprised as he sings in the upper branches of a tree. He then sits motionless, continuing his song

1 Symphoricarpus glomeratus.

* Geological Survey of Ohiọ. Vol. IV, Part I. Zoology, p. 277-278, 
as if unaware of any intrusion upon his privacy, and so resonant and varying are his notes, that they confuse the ear as to the spot from which they come, while his yellow breast so completely harmonizes with the green leaves and sunlight, that he is with difficulty discovered. It is to his rapid and sonorous notes, quick motions or perfect quiet, with harmonious surroundings, that he owes the reputation for ventriloquism which he has obtained; and it may be said of his reputation for mimicry, that he has no need to borrow notes from any other bird, and does not knowingly do so.

"Before the breeding season is over it becomes as silent as during the spring migration, and leaves for the South as stealthily as it came."

In Dr. Elliott Coues' "Birds of the Colorado Valley" I find the following charmingly written classical sketch of this singular bird:

"The common Chat is a migratory bird of general diffusion during the movement and in the breeding season throughout the Eastern United States, as far north at least as Massachusetts and Dakota, though it is not abundant north of the Middle States. Wherever Chats may be found, they are of this species, excepting in the Middle and Western Provinces. No Chats are known in the West Indies; but the birds migrate in the fall beyond our limits, through Mexico and into Central America. Their manner of migration is somewhat uncertain; we do not know that they ever make long-continued flights overhead, and rather presume that they come skulking through the bushes. But the fact that their ordinary flight is wayward, desultory, and never long-continued, is no proof that the emergency of the migration does not develop different and much better sustained powers of the wing.

"However this may be, no sooner is the ardor of occasion stimulated by the presence of the females than the gay and gaudy Chats develop those eccentricities that make them famous. They grow too restless to abide the covert they have chosen for their home, and are seen incessantly in motion, flitting with jerky movement from one bush and brier patch to another, giving vent to long-pent emotions in the oddest notes imaginable. Such a medley of whistling, chuckling, barking, and mewing sounds proceeds from no other bird, unless it be the Mockingbird itself, to whom all possibilities of song are open. During such performances the Chats seem sedulous to keep concealed, displaying ingenuity and perversity in thwarting our best efforts to catch them at their tricks. The notes, in all their infinite variety, come now from this and now from that spot in the bushes, shifting from point to point as we peer eagerly into the tangled underbrush to catch a glimpse of the tantalizing musician. Such restlessness, and all this variation in the rendering, have much the effect of ventriloquism, and we have not seldom to acknowledge that the Chat has fairly beaten us. But his coloring is brilliant; he has, moreover, a fancy to return again to some particular spot already chosen as his stage; so that if we discover it, and keep so still as not to cause the bird anxiety, nor yet to rouse his ire, we shall most likely see him take his stand again to swell his golden throat afresh with the fantasy of song.

"His nuptial song, I should observe, is something very different from the medley of sounds, not all of which are pleasing, that are heard when each Chat, as one performer in the orchestra, first tunes his curious pipe. Such prelude, after several days' essay, is changed into the rich, voluminous ode with which the bird inaugurates a new 
order of events, in bursts of almost startling eloquence and fervor. For the nestingplace is fixed upon, the fabric hastens to completion; and the exultant bird, no longer constrained to the lowliness of the coverts, mounts buoyantly from bough to bough of some tall sentinel that guards the leafy undergrowth, to sound his exultation from the very tree-top. Yet once more: the nest now bears its precious burden; the brooding bird assumes her patient place, and presses down her golden breast upon her hopes. Then this strange bird goes fairly wild with joy; he spurns the ground, the favorite singing-post no longer bids him welcome, he rises on the wing, and in mid-air above the nest, with fluttering pinions, down-stretched legs, and open beak, he poises, hovers, and performs a thousand antics in the sheer abandon of his eccentricity."

Mr. John Burroughs frequently observed the Chat on Rock Creek, near Washington. In his excellent little book "Wake Robin" he writes as follows in regard to this bird:

"I seldom go the Rock Creek route without being amused and sometimes annoyed by the Yellow-breasted Chat. This bird also has something of the manners and build of the Catbird, yet he is truly an original. The Catbird is mild and feminine compared with this rollicking polyglot. His voice is very loud and strong and quite uncanny. No sooner have you penetrated his retreat, which is usually a thick undergrowth in low, wet localities, near the woods or in old fields, then he begins his serenade, which for the variety, grotesqueness, and uncouthness of the notes, is not unlike a country skimmerton. If one passes directly along, the bird may scarcely break the silence. But pause a while or loiter quietly about, and your presence stimulates him to do his best. He peeps quizzically at you from beneath the branches, and gives a sharp feline mew. In a moment more he says very distinctly, who, who. Then in rapid succession follow notes the most discordant that ever broke the sylvan silence. Now he barks like a puppy, then quacks like a Duck, then rattles like a Kingfisher, then squalls like a fox, then caws like a Crow, then mews like a cat. Now he calls as if to be heard a long way off, then changes his $\mathrm{key}$, as if addressing the spectator. Though very shy, and carefully keeping himself screened when you show any disposition to get a better view, he will presently, if you remain quiet, ascend a twig, or hop out on a branch in plain sight, lop his tail, droop his wings, cock his head, and become very melodramatic. In less than half a minute he darts into the bushes again, and again tunes up, no Frenchman rolling his $r$ 's so fluently. C-r-r-r-r-r,-whrr,-that's it, - chee, - quack, cluck,yit-yit-yit, - now hit it, - tr-r-r-r, - when, - caw, - caw, - cut, cut, - tea-boy, - who, who,-mew, mew, - and so on till you are tired of listening. Observing one very closely one day, I discovered that he was limited to six notes or changes, which he went through in regular order, scarcely varying a note in a dozen repetitions, Sometimes, when a considerable distance off, he will fly down to have a nearer view of you. And such a curious, expressive flight,-legs extended, head lowered, wings rapidly vibrating, the whole action piquant and droll! The Chat is an elegant bird both in form and color. Its plumage is remarkably firm and compact. Color above, light olive-green; beneath, bright yellow; beak, black and strong."

In Wisconsin I never have observed the Chat. In northern Illinois it is an exceedingly rare bird, having met with it only a few times in the hazel thickets near the Des Plaines River, in the vicinity of Waldheim cemetery. In south-western Missouri and 
southern Illinois the bird is an abundant summer resident. It is somewhat particular in its choice of a place of residence, showing a decided preference for woodland borders, old neglected fields, and clearings overgrown with thickets and brier patches. It is never found in damp and shady, moist places near water, but prefers upland thickets and sunny localities. In Missouri I saw a few sometimes by the end of April, but the majority arrived about May 9 , when everything was in full spring beauty. The nests I found were usually built in tangled basket-vines, or in blackberry bushes, and not more than two or three feet from the ground. They are large and compact, consisting of old dry leaves, grasses, plant-stems, rootlets, and are lined with brown wiry stems, thin strips of bark of the wild grape, and fibrous roots. The eggs, usually four in number, are white, marked with reddish-brown and a few fainter lavender spots.

In south-eastern Texas I noticed their arrival about April 15. Many spent the winter in the dense myrtle-holly thickets overgrown with tangled Smilax laurifolia, in sheltered places on Buffalo Bayou. They even came, on cold days, into the larger gardens, where they found shelter against the furious "northers" in myrtle, Banksia and Cherokee rose, laurel, Cape jasmine, arbor-vitæ, cedar, and other thickets. They even visited the door-yards to search for food. During such days the birds seemed to suffer very much.

The Chat is a good cage bird if carefully attended to. My friend Mr. Emil Dreier, Consul of Denmark, at Chicago, kept one, captured near that city, in a cage. It seemed to feel perfectly happy, was in fine plumage, and delighted its keeper by its odd and beautiful song.

The LoNG-TAILED CHAT, Icteria virens longicauda CouEs, replaces the common Chat in the Western States, from the Plains to the Pacific, south into Mexico. It does not differ in its habits from the true species, but it has a decidedly longer tail.

NAMES: Yellow-breasted Chat, Chat, Yellow Mocỉingbird.-Schwätzer (German).

SCIENTIFIC NAMES: Turdus virens Linn. (1758). ICTERIA VIRENS BAIRD (1865). Muscicapa viridis Gmel. (1788). Icteria viridis Bonap. (1825). Pipra polyglotta Wils. (1808).

DESCRIPTION: "Tail, graduated. Upper parts, uniform olive-green; under-parts, including the inside of wing, gamboge-yellow as far as nearly half-way from the point of the bill to the tip of the tail; rest of under-parts, white, tinged with brown on the sides; the outer side of the tibiz, plumbeous; a slight tinge of orange across the breast. Forehead and sides of the head, ash, the lores and region below the eye, blackish. A white stripe from the nostrils over the eye and involving the upper eyelid; a patch on the lower lid, and a short stripe from the side of the lower mandible, and running to a point opposite the hinder border of the eye, white: Bill, black; feet, brown. Female, like the male, but smaller; the markings indistinct; the lower mandible not pure black.

"Length, 7.40 inches; wing, 3.25 ; tail, 3.30 inclies." (Ridgway.) 


\title{
HOODED WARBLER.
}

\author{
Sylvania mitrata NUTTALI.
}

\author{
Plate XIV. Fig. 4 .
}

7.
southern New England are in the months of May and June incomparably beautiful. The great variety of trees and shrubs, the many species of ferns, among them the delicate form of the ebony-stemmed maiden-hair fern, the remarkable diversity of tender flowers, which cover the ground in great luxuriance, are such as to engender enthusiasm in any lover of nature. Early in April the trailing arbutus, often hidden among the old forest leaves, opens its deliciously sweet-scented rosy flower clusters. This floral beauty, dear to every American heart, should be carefully preserved wherever it yet grows. There are many other charming shrubs and flowers found in this region.

The sweet-scented shrub ${ }^{1}$, the purple flowers of which exhale a very delicious fragrance, grows in many places in great luxuriance. The rich foliage and the bark of this shrub is also very aromatic. The fringe-tree ${ }^{2}$, the stuartia ${ }^{3}$, the snow-drop tree ${ }^{4}$, and many pretty shrubs and vines arrest our attention. The swamp magnolia ${ }^{5}$ which grows in profusion wherever the soil consists of a moist and rich black mould, emits from its waxy-white flower cups such a delicious fragrance that we can perceive it from a considerable distance. Especially charming are the places where azaleas and kalmias abound, as is often the case in eastern Kentucky and Tennessee, in Virginia, Maryland, Pennsylvania, North and South Carolina, and in Connecticut. The soil in which these beautiful members of the family of Ericacez grow is usually sandy, mixed with peat and vegetable mud. They grow in moist localities where the roots will never suffer from drouth. The orange-colored flowers of the flamy pinxter or flame-colored azalea $^{6}$, a shrub attaining the height of about ten feet, convert entire mountain-sides and swamps into a mass of gorgeous color. This is rather a southern species, occurring from Pennsylvania southward. The clammy azalea or white swamp honey-stuckle ${ }^{7}$ and the purple azalea or pinxter-flower ${ }^{8}$, which make up in rich fragrance what they may lack in bright hues, are common in swampy localities from Massachusetts southward. The beautiful great laurel ${ }^{9}$ also abounds in such places. Andromedas, clethras, and, in some places, rhodoras and other members of the heath families grow in the same localities. Large areas of the dark ground of the forest are covered with thickets of the exceedingly charming kalmia or mountain laurel, popularly known as calico-bush, the profuse, large, and very showy flowers of which vary from deep rose-color to nearly white and are beautifully frilled. These broad-leaved evergreens are by their foliage alone very ornamental, but when they open their rosy flower-bells, the effect is truly enchanting. Several other azaleas, jungles of rhododendrons and kalmias, different andromedas and many other highly interesting shrubs are found from the mountain forests of

1 Calycanthus floridus. 2 Chionanthus Virginica. 2 Stuartia Virginica. 4 Halesia tetraptera. 5 Magnolia glauca. 6 Azalea calendulacea. 7 A. viscosa. 8 A. nudilora. ORhododendron inaximutu. 
Georgia to Pennsylvania and some even north to Connecticut. In these mountain woods azaleas, mountain laurels, and the fine broad leaves and rich blossoms of the rhododendrons add much more to the beauty of the forest than any other tree or shrub.

In the mountain forests and in the peaty swamps and moist woods, where these gorgeous plants grow in luxuriance, we find a large number of highly interesting and richly colored birds, imparting to such localities a truly poetical tone. In the mountain laurels of southern Connecticut and in the rhododendron swamps of western North Carolina the beautiful Black-throated Blue Warbler finds a very congenial home. Different Vireos and Flycatchers, Towhees, Summer and Kentucky Warblers, Redstarts, Cardinals, Catbirds, Wood Thrushes, and many other birds enliven these localities from early morn till the sun fades away in the western sky. Parula Warblers are abundant among the trees covered with $U$ snea lichens. All these songsters fill the beautiful woods with their charming music.

On close observation we notice in the mountain laurel thickets a bird, which seems to glow among the dark green foliage. Only a moment we notice it. As it flits to and fro, up and down, around and through the bushes in the most rapid and graceful zigzag lines, it is difficult to catch a glimpse of it. Anon it alights for a moment. The black color of the hood, chin, and breast, the bright yellow of the forehead, the eye-region, and the tunder-parts, the olive-green of the back at once make it cognizable as the HoOded WARBLER. As it preferably selects the kalmias and azaleas for its haunts, it might properly be called the Mountain Laurel, or Azalea Warbler. Our poet-ornithologist, Mr. John Burroughs, of south-eastern New York, says : "In only one locality, full of azalea and swamp honey-suckle, I am always sure of finding the Hooded Warbler;" and Prof. Wm. Brewster writes, that he found it sparingly but very generally in the rhododendron thickets along streams, ranging to an altitude of at least 3,800 feet in the mountains of North Carolina. Dr. Langdon observed the bird on Defeat Mountain, in the Chilhowee Mountains of eastern Tennessee, in August. There is no question that it there also breeds in the mountain laurel and azalea shrubs. It was found at an altitude of 4,000 feet, in the heart of a giant spruce and poplar forest. "Here, on a gentle slope covered with a velvety carpet of moss, partridge-berry vine, and spruce needles, we were lulled to rest by the babbling of the waters near the rocky bed of a neighboring trout brook (middle fork of Little River); this, with the hoot-to-toot of the Great Horned Owl and the notes of a full orchestra of katydids, furnished a symphony eminently appropriate to its surroundings." As the birds foraged for insects, the dark, green carpet of moss and partridge-berry vine formed an effective contrast with their light yellow plumage.

The Hooded Warbler is usually a bird of the swampy thickets overshadowed by large trees, and of the shrubbery of the woodland border. Here it inhabits the jungled bushes, while its near relative, the American Redstart, prefers the high trees overhead. Where its favorite shrubs of the heath family (Ericacex) are missing, it is satisfied with snow-berry bushes, viburnum, dogwood, white-thorns, and other shrubs that are apt to form thickets. In most localities it does not occur in large numbers, and therefore it is much sought for by egg and skin collectors. The summer home of this beautiful bird extends from southern Wisconsin and southern New England to Texas and probably to Georgia and Alabama. In south-western Missouri I observed a few pairs among the 
dense snow-berry bushes in the woods, and Mr. Otto Widmann says that it is a rather common bird in certain localities near St. Louis. Mr. Ridgway observed it frequently in southern Illinois and Indiana. "In all rich damp woods," he says, "both in Illinois and Indiana, I have found the beautiful Hooded Warbler a more or less common species. In the woods of Knox and Gibson Counties, Indiana, immediately opposite Mount Carmel, it is particularly abundant, so much so, in fact, as to be one of the most characteristic species." In this region the woods consist chiefly of ash trees, red maple, cotton-wood, elms, swamp, white and water oaks, sweet gums, and on higher land of hickories, oaks, tulip trees ${ }^{1}$, catalpas ${ }^{2}$, elms, beech, and other trees in great variety, coniferous species being wholly absent. The bird is "only noticed in those localities, where the switch cane $\mathrm{e}^{3}$ forms more or less of the undergrowth, over which trails the rough, bright green stems of a species of Galium, and, but less frequently, a low-growing or trailing smilax (probably S. Walteri). The nest is built with scarcely any attempt at concealment, in a low bush, from one to two feet from the ground." (Ridgway.) In Wisconsin and northern Illinois I have never seen the bird, but Mr. C. E. Akeley collected a fine male at Elm Grove, near Milwaukee, on May 16, 1890.

The Hooded Warbler is distributed over the Eastern States west to the Plains. It is, however, more an inhabitant of the central and southern regions of the country, arriving in Georgia and South Carolina in the latter part of April. About April 30 to May 3 the first males arrive from their winter home in the West Indies, eastern Mexico, and Central America in south-western Missouri and other localities under the same latitude. May 9 they are usually at St. Louis the noisiest birds of the woods. They never make their appearance where spring has not fairly entered. Trees and shrubs must be in full leaf and bloom ere they deign to arrive. This Warbler rivets the attention of the observer by its peculiarly restless flitting through thickets, its dazzling hues, and its strange ventriloquial song. Few other birds, excepting the Chat, the Cardinal Redbird, and the White-eyed Vireo, make as much ado in their abodes. Where the above described woodland thickets are found, be it near a pond, river, rushing brook, or clear spring, this bird need not long be sought, though it is no easy task to discover it among the evergreen kalmias, the dense azaleas, or swamp honey-suckles, the jungles of rhododendrons, or among the thorny bushes entangled with vines, where swarms of mosquitoes buss about the ears of the observer. This bird is a very alert insect catcher, securing the main part of its food in the air. Its haunts abound in mosquitoes, gnats, bugs, and other insects. Here it leads a truly gay life, flitting after insects, often making the sharpest turns and most wonderful zigzag lines. Then it flies over, through, and around the bushes, over the ground, even turning summersaults in the air, sometimes singing and occasionally uttering its peculiar call-note, a sharp tship. It-is not really a shy bird, but, owing to the rapidity of its motions, it is difficult to observe, except during short intervals. The chance of hearing its cheerful strain occurs much oftener than the opportunity of seeing it. In its manners, especially in the way of obtaining its food, it resembles much the Flycatchers, but in form and in its song it is a genuine Warbler. Passing flowers and leaves, it often snatches insects from them. This I frequently noticed in the South, when the magnificent magnolias were in full bloom, perfuming the air with their delightful 
fragrance. Flies, mosquitoes, moths, butterflies, bugs of all kinds, spiders, small caterpillars, etc., are its main food. When flying in pursuit of insects, it has a peculiarly graceful manner of closing and spreading its broad tail like the Redstart.

The nesting of this Warbler is highly interesting. In south-western Missouri the nest is usually placed in a snow-berry bush, only one or two feet above the ground. It is well hidden among the dense foliage and branches of these peculiar bushes and is built of fine bark-strips, skeleton leaves, catkins from hickory and oak trees, fine grasses, all compactly woven together with spider webs. The lining consists of grapevine bark; occasionally it is lined with horse or cattle hair throughout. These nests are not so beautiful as those found in the kalmia and swamp honey-suckle thickets of the East. Mr. J. N. Clark, of Saybrook, Conn., gives the following description of the nesting of the Hooded Warblers in the kalmia thickets in south-eastern Connecticut:

"It was back a mile from the public road in the deep old woods, chestnuts, beeches, and birches of seventy-five years' standing, with a short undergrowth of kalmia averaging some two and a half feet in height. This shrub is abundant here and is frequently found in patches of considerable extent. I was passing quietly along in such a place when something flitted across my path almost from under my feet. It passed so swiftly from sight I could not distinguish it, disappearing instantly in the adjacent shrubbery, but I knew what it was, for I had been through the same experience before. Scrutinizing every shrub ever so carefully, I failed to fix my eyes on the nest that I knew was there, for I could soon hear the sharp, clear note of the female Hooded Warbler a few paces away in the thickets, and catch an occasional glimpse of her as she flitted from shrub to shrub, and from one thicket to another, and I could see the white patches of the tail open and shut with every movement.

"Taught by past experience, I presently abandoned searching and retired a short distance, carefully marking the spot, to watch the bird and wait developments. As I moved away from the spot, I could perceive that the bird approached it again by the continually repeated chip nearer and nearer at each repetition, till in five minutes it was silent or with only an occasional note, and I knew she was on the nest. I listened keenly for every note as I again approached the spot, for this bird will occasionally repeat her note when on the nest, as $I$ have often proved, and when she went fluttering off, I saw the little shrub tremble and knew that there was the nest closely hidden among the dark green kalmia leaves, but very easy to see now that I knew just where to look. Pieces of yellow birch bark, beech and chestnut leaves carefully matted and bound together and to the triangular crotch, formed the base of the structure, rounded and neatly finished at the top with the inner bark of chestnut and cedar, with fine grass and scales from beech buds and a little fern down mixed in, and all secured compactly together with spider webs. I speak advisedly having seen the bird diligently gather the webs. Inside the nest was neatly and smoothly lined with mixed horse hair and very fine grass. Largest outer diameter 3.50 inches, inner diameter 2.00 inches, and depth 2.00 inches, and built in a little kalmia bush about fifteen inches from the ground. This description will answer for most of the many nests $I$ have found of the species, with varying quantities of birch bark and fern down, invariably in a kalmia bush. This was the 26th of May, 1879, and within this nest were four beautiful 
little eggs, pearly and rosy, being marked with very minute dots, a few scattered over the surface but mostly in a ring around the larger end. Eleven days after this event I found another nest and set of three eggs in the same spot, scarcely a foot from where I found the other; these eggs were quite unlike the former set in markings, though of similar size, the spots being larger and more distinct, of a dark reddish brown color and chiefly collected about the large end though not in a ring. I did not look again in 1879 , but the 25 th of May, 1880 , I repeated the same experience in the same place, finding another set of four fresh rosy eggs, prettily and neatly marked in the usual manner; and again on the 3rd of June, only nine days later, I found another nest and four more eggs in the same spot. All these four sets were discovered within a radius of four feet, and I fancy were all of the same pair of birds, though very differently. marked, for I have observed that Hooded Warblers are very unsocial, having never seen two pairs of them occupying the same locality, or nearer than thirty rods of each other. If it was the same pair it would imply that the robbing of nest and eggs was no great loss to them, if they can be so promptly and completely replaced. A few notes from my observations of the bird as found here and I will close. The male bird is seldom seen near the nest except when it is building, or after the young are hatched, but he can usually be heard some twenty-five rods away, constantly repeating his clear musical che-we-e-o. I have seen him in the mating season, hovering after the manner of the Chats, and warbling so sweetly and continuously that the song seemed more like a chorus than a solo; but this performance is rarely seen. The female is usually only a little plain "Yellow Bird," with the bright yellow face contrasting sharply with the greenish-yellow of the back, but I hare. ccasionally seen females with the black hood distinctly developed.

"The bird may usually be heard by the first week of May (May 2 my earliest record) in their usual haunts from some dense thicket, and the female arrives, I think, a few days later, though she is so quiet and inconspicuous that she might be there and yet unobserved. Some of the birds tarry till September. Despite the assertions of several writers of note to the contrary, I pronounce the species a very common one here, in evidence of which I found in the season of 1880 , eleven nests, with four eggs each in every instance but one, which had a Cowbird's and three Hooded Warbler's. I believe that when the bird and its habits become better known, its breeding range will be found to be more extensive in Connecticut, than the little town of Saybrook, if not, it would seem a very remarkable circumstance."

Mr. Clark had the kindness to send me two of these nests. They are much more beautiful and compact than the nests found in Missouri. The gorgeous kalmia is usually in full flower when the Hooded Warbler breeds. Underneath these shrubs the partridgeberry, wintergreen, lycopodiums, ferns, and the trailing arbutus grow in abundance. Both nests are exteriorly finely decorated with curly bark-strips of the yellow birch, fern down, bleached leaves, and spider's webs. The rim is constructed of fine grape-vine bark, and the interior is lined with deep black rootlets. They are neatly and beautifully built in an upright crotch and are usually perfectly protected by a roof of broad evergreen. leaves.

The song of the Hooded Warbler is very distinct and striking. During the beautiful 
days of May, when all nature is imbued with happiness, song, fragrance, and balmy air, this beautiful bird sings almost incessantly. In the "Bulletin of the Nuttall Ornithological Club" (1882, p. 119-120) Rev. J. H. Langille gives the following correct description of the Hooded Warbler's song:

"From various points in the dense forest, on the balmy days of May, comes the common and familiar song of the Hooded Warbler,-che-reek, che-reek, che-reek, chi-dì-eê, the first three notes with a loud bell-like ring, and the rest in very much accelerated time, and with the falling inflection. Arriving early in May, this is one of our common summer residents throughout the dense upland forests, occupying the lower story of the woodland home, while the Corulean Warbler occupies the upper. Here let me say that in addition to its alarm note, a sharp whistling or metallic chip which is very clearly characterized, the Hooded Warbler has two distinct songs, as different as if coming from different species. Never shall I forget how I was once puzzled by this trick. I was strolling in a thick forest, near the corner of a slashing, in an evening twilight in June, when I was surprised by a strange whistling melody,-whee-reeh, whee-ree-eehwith a marked emphasis on the second syllable, and a still more marked one on the last. Part of the time this utterance was somewhat varied, a few notes being sometimes added, and again a few being dropped. My curiosity was greatly excited, for I had supposed myself familiar with the voices of all the birds in the neighborhood; but it became too dark to identify the bird. For nearly a week I went to that spot every day, always hearing the song, but never being able to get a clear sight of the bird. It seemed exceedingly shy. In vain did I crawl on hands and knees among the undergrowth to get near to it; for just as I would seem about to gain a good view of it the song would cease at. the point under observation and come from one more distant. Just as I was about to give the matter up one evening, down came the singer, stage by stage through the thick foliage, and alighting within a few feet of me and in clear sight, gave the full effect of his whistling song. I have since heard the same song a number of times and in different places from the Hooded Warbler. So I conclude that in the case of this species there are, occasionally at least, two distinct and altogether different songs.

"The Hooded Warbler is one of those which make their home on or near the ground. Here it keeps itself for the most part well concealed among the foliage of the thick undergrowth, having a rather slow and dignified movement for a bird of its kind."

NAMES: Hooded WarbLER, Mitred Warbler, Black-headed Warbler, Hooded Flycatching Warbler, Selby's Warbler.-Mitrasänger (German).

SCIENTIFIC NAMES: Motacilla mitrata Gmel. (1788). Sylvia mitrata Lath. Wilsonia mitrata Bonap. (1838). SYLVANIA MITRATA NuTT. (1840). Myiodioctes mitratus Aud. (1839). Sylvia cucullata Wils. (1811). Muscicapa selbyii Aud. (1831).

DESCRIPTION: "Male: Bill, black; feet, pale yellow. Head and neck all round and forepart of the breast, black. A broad patch on the forehead extending round on the entire cheeks and ear-coverts, with the under-parts, bright yellow. Upper parts and sides of the body, olive-green. Greater portion of inner web of outer three tail-feathers, white." (Ridgway.)

"Female: Like the male, but it is several years-at least three-in attaining its full plumage; and that the two sexes, when fully adult, can only be distinguished by the fact that, in the female, the throat, though strongly tinged with black, is never pure black as in the male." (Merriam.)

Length, 5.25 inches; wing, 2.75 ; tail, 2.25 inches. 


\section{CANADIAN WARBLER.}

\section{Sylvania canadensis RIDGWAy.}

Plate XiII. Fig. 8.

1 ${ }^{\mathrm{E}}$ ARE sometimes told "that nature hides her choicest treasures from all but those who are willing to search for them in the more secret recesses of her great laboratory of beauty - that she spreads the indifferent things before the indifferent world-and reserves her loveliest for her true lovers." With many things this is true, but generally speaking, the most beautiful plants and birds are not the rarest. It is truer to say that to many eyes the rarest will always seem most beautiful, simply because of its rarity. Greater charm than in the single bird and flower lies in the arrangements, the compositions, the pictures into which nature weaves them. I do not know a bird unless I am acquainted with its haunts, with the flowers, trees, and shrubs that grow in the same locality. If we add to this the beauty of a May or June day, the mild, balmy air, the fragrance of the flowers, and the song of the many birds, we have at once a picture full of enchanting beauty and poetry. There is no greater pleasure for the friend of nature than to ramble about in field and forest during the greater part of the year. If on a fine June day we pass through masses of gigantic ferns, almost coming to our shoulders with their feathery tufts, through patches of swamp honey-suckles ${ }^{1}$ red with blossoms, if we listen to the golden e-olie of the Wood Thrush, the metallic che-wink of the Towhee, the mellow strain of the Hooded Warbler, and the songs of many other birds, we feel at once nature's powers and her poetry. No one understands this poetry who is not familiar with the meadow enlivened by rollicking Bobolinks; with the clover fields and pastures from which sounds the joyful lay of the Vesper Sparrow; with the secluded corners of the old rail fence, well-nigh hidden by poison ivy, blackberry briers, and straggling grape-vines; with the trodden paths of the woods, crossed by the Ruffed Grouse, the Towhee, and Ovenbird. In the heart of the forest, or the depth of the swamp, or by the tangled margin of the lowly rivulet, we also must search amid nature's little things to find the truly beautiful. This is especially true in regard to plants, but many of our most charming birds must be searched for in the same way.

Many years ago, when rambling about on a bright June morning on our little lake near Howard's Grove, Sheboygan County, Wis., I found in the low woods bordering a tamarack and Sphagnum swamp, flowers which I had seldom seen before. My eyes met the beautiful and bright forms of the smaller and the larger yellow lady's slipper ${ }^{2}$. Ferns and other plants, especially huckle and cranberry bushes, grew here in great profusion. The peaty soil was everywhere adorned with flowers and ferns, and bird-life was abundant. The Swamp Sparrow's lay was frequently heard, and thunder-like the

" Compare "Garden and Forest." Vol. I, p. 303.

1 Azalea. 2 Sypripedium parviforum and C. pubescens. 
drum of the Ruffed Grouse sounded through the woods. Nature was quietly at home here, and the foot of man came seldom. Here the hand of the flower gatherer seldom disturbed the plants, and the skin and egg collector never trespassed, and this was the reason, why such a lovely picture could be seen in its dewy, fresh completeness. While culling some of the fragrant yellow lady's slippers, yellow violets, and wood sorrel, a small bird fluttered away, almost from under my hand. I knew that there was a nest, but I could see nothing except a bunch of dry Sphagnum moss under a dense fern. Examining this more closely I noticed a small hole, and on entering my finger I felt four warm eggs. A few sharp notes brought the male near the nest, and I was surprised to see such a beautiful bird before me in this little wilderness. The nest, composed exteriorlyof swamp moss, fine grasses, and dry leaves, lined with pine needles and a few cattle hairs, was in such harmony with its surroundings and the highly colored bird, that I only could stand and admire. The bluish-ash color of the back and the bright yellow of the under-parts, the breast spotted with black, made it certain that I had the beautiful CaNADIAN WARBLER before me.

This bird is distributed over eastern North America, westward to the Plains. It breeds from northern Illinois and Connecticut northward to New Foundland, Labrador, and Lake Winnipeg. In the mountain regions of New York and Pennsylvania it also breeds. Prof. Brewster found it abundant in the mountains of North Carolina, "from about 3,000 feet nearly, or quite, to the tops of the highest mountains. Over the lower portions of its range it frequented rhododendron thickets bordering streams, above 5,000 feet, the balsam forests. As its vertical distribution extends downward below the upper limits of that of the Hooded Warbler, the two species probably come together in places, although I saw no instances of this. At Highlands, June 1, 1885, Mr. Boynton found a nest placed in a grassy spring-bank, and 'composed chiefly of old leave-stems and small roots, lined with fine black roots which resemble hair.' It contained four perfectly fresh eggs."

In Wisconsin the Canadian Warbler is a rather rare bird. I have seen it in many localities, but never found another nest. Mr. W. Brewster, in his paper "Notes on the Birds of Winchendon, Worcester County, Massachusetts" (Auk, Vol.V, 1889, p. 392), says that it is everywhere abundant in the spruce swamps. A brood of young, barely able to fly, were met with June 25, 1887, and the next day Mr. Purdie found another nest with eggs. "The nest was in the face of a low, Sphagnum-covered mound about eighteen inches above its base. In the soft mound behind the outer covering of Sphagnum the birds had excavated a cavity about the size of one's fist. In the bottom of this cavity was the nest, a loosely formed, but nevertheless neat structure, composed outwardly of dry leaves, and lined with pine needles, black rootlets, and a little horse hair. The bird entered by a small round hole, the bottom of which was about on a level with the top of the nest. All the nests (a dozen or more) of this species which I have examined were built like the one just described, although the height above ground has varied, one which I took at Lake Umbagog in 1879, being higher than my head in a patch of moss that covered the face of a perpendicular cliff. I have yet to see a nest placed on the ground and open at the top, as most of the book descriptions indicate." 
The eggs, numbering from four to five, are white, speckled and spotted, chiefly around the larger end, with lilac, reddish, and dark brown.

This and many other small birds are frequently victimized by the Cowbird. Mr. John Burroughs, in his excellent little book "Wake Robin," gives the following account:

"In a little opening, quite free from brush and trees, I step down to bathe my hands in the brook, when a small, light slate-colored bird flutters out of the bank, not three feet from my head, as I stoop down, and, as if severely lamed or injured, flutters through the grass and into the nearest bush. As I do not follow, but remain near the nest, she chips sharply, which brings the male, and I see it is the Speckled Canada Warbler. I find no authority in the books for this bird to build upon the ground, yet here is the nest, made chiefly of dry grass, set in a slight excavation in the bank, not two feet from the water, and looking a little perilous to anything but ducklings or sandpipers. There are two young birds and one little speckled egg, just pipped. But how is this? What mystery is here? One nestling is much larger than the other, monopolizes most of the nest, and lifts its open mouth far above that of its companion, though obviously both are of the same age, not more than a day old. Ah! I see; the old trick of the Cow Bunting, with a stinging human significance. Taking the interloper by the nape of the neck, I deliberately drop it into the water, but not without a pang, as I see its naked form, convulsed with chills, float down stream. Cruel? So is nature cruel. I take one life to save two. In less than two days this pot-bellied intruder would have caused the death of the two rightful occupants of the nest; so I step in and turn things into their proper channel again.

"It is a singular freak of nature, this instinct which prompts one bird to lay its eggs in the nests of others, and thus shirk the responsibility of rearing its own young. The Cow Buntings always resort to this cunning trick; and when one reflects upon their numbers it is evident that these little tragedies are quite frequent. In Europe the parallel case is that of the Cuckoo, and occasionally our own Cuckoo imposes upon a Robin or a Thrush in the same manner. The Cow Bunting seems to have no conscience about the matter, and, so far as I have observed, invariably selects the nest of a bird smaller than itself. Its egg is usually the first to hatch; its young overreaches all the rest when food is brought; it grows with great rapidity, spreads and fills the nest, and the starved and crowded occupants soon perish, when the parent bird removes their dead bodies, giving its whole energy and care to the foster-child. The Warblers and smaller Flycatchers are generally the sufferers, though I sometimes see the Slate-colored Snowbird unconsciously duped in like manner; and the other day, in a tall tree in the woods, I discovered the Black-throated Green-backed Warbler devoting itself to this dusky, overgrown foundling. An old farmer to whom I pointed out the fact, was much surprised that such things should happen in his woods without his knowledge. These birds may be seen prowling through all parts of the woods at this season, watching for an opportunity to steal their egg into some nest. One day while sitting on a log I saw one moving by short flights through the trees and gradually nearing the ground. Its movements were hurried and stealthy. About fifty yards from me it disappeared behind some low brush and had evidently alighted upon the ground.

"After waiting a few moments I cautiously walked in the direction. When about 
half way I accidentally made a slight noise, when the bird flew up, and seeing me hurried off out of the woods. Arrived at the place, I found a simple nest of dry grass and leaves partially concealed under a prostrate branch. I took it to be the nest of a Sparrow. There were three eggs in the nest and one lying about a foot below it as if it had been rolled out, as of course it had. It suggested the thought that perhaps when the Cowbird finds the full complement of eggs in a nest, it throws out one and deposits its own instead. I revisited the nest a few days afterward and found an egg again cast out, but none had been put in its place. The nest had been abandoned by its owner and the eggs were stale.

"In all cases where I have found this egg, I have observed both male and female of the Cowbird lingering near, the former uttering his peculiar liquid, glassy note from the tops of the trees. In July the young, which have been reared in the same neighborhood, and which are now of a dull fawn color, begin to collect in small flocks, which grow to be quite large in autumn. The Speckled Canada is a very superior Warbler, having a lively, animated strain, reminding you of certain parts of the Canary's, though quite broken and incomplete; the bird, the while hopping amid the branches with increased liveliness, and indulging in fine sibilant chirps, too happy to keep silent. His manners are quite marked. He has a habit of courtesying when he discovers you, which is very pretty. In form he is an elegant bird, somewhat slender, his back of a bluish lead-color becoming nearly black on his crown: the under-part of his body, from his throat down, is of a light, delicate yellow, with a belt of black dots across his breast. He has a fine eye, surrounded by a light yellow ring.

"The parent birds are much disturbed by my presence, and keep up a loud emphatic chirping, which attracts the attention of their sympathetic neighbors, and one after another they come to see what has happened. The Chestnut-sided and the Blackburnian come in company. The Black and Yellow Warbler pauses a moment and hastens away; the Maryland Yellow-throat peeps shyly from the lower bushes and utters his fip! fip! in sympathy; the Wood Pewee comes straight to the tree overhead, and the Red-eyed Vireo lingers and lingers, eying me with a curious, innocent look, evidently much puzzled. But all disappear again, one by one, apparently without a word of condolence or encouragement to the distressed pair. I have often noticed among birds this show of sympathy, - if indeed it be sympathy, and not merely curiosity, or desire to be forewarned of the approach of a common danger.-An hour afterward I approach the place, find all still, and the mother bird upon the nest. As I draw near she seems to sit closer, her eyes growing large with an inexpressibly wild, beautiful look. She keeps her place till I am within two paces of her, when she flutters away as at first. In the brief interval the remaining egg has hatched, and the two little nestlings lift their heads without being jostled or overreached by any strange bedfellow. A week afterward and they were flown away, - so brief is the infancy of birds. And the wonder is that they escape, even for this short time, the skunks and minks and muskrats that abound here, and that have a decided partiality for such tidbits."

The Canadian Warbler finds a congenial winter home in Central and northern South America. 
NAMES: Canadian WArbler, Speckled Canada Warblext(Burroughs), Canada Flycatcher, Canadian Flycatching Warbler, Necklaced Warbler. - Gürtelsänger (German).

SCIENTIFIC NAMES: Muscicapa canadensis Linn. (1766). Myiodioctes canadensis Aud. (1839). SYL VANIA CANADENSIS RIDGw. (1885). Muscicapa bonapartii Aud. (1831). Myiodioctes bonapartii Aud. (1839).

DESCRIPTION: "Upper parts, bluish-ash; a ring around the eye, with a line running to the nostrils, and the whole under-part (except the tail-coverts, which are white), bright yellow. Centre of the feathers in the anterior half of the crown, the cheeks, continuous with a line on the side of the neck to the breast, and a series of spots across the forepart of the breast, black. Tail-feathers, unspotted. Female, similar, with the black of the head and breast less distinet. In the young, obsolete.

"Length, 5.34 inches; wing, 2.67; tail, 2.50 inches." (Ridgway.)

\section{WILSON'S WARBLER.}

\section{Sylvania pusilla NutTaLt.}

Plate XIII. Fig. 4.

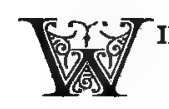

IISON's WARBLER is during the migrations a more or less common bird throughout the country. In the last days of April it reaches south-eastern Texas from its winter-quarters, which are usually the mountainous regions of Mexico and Central America. Where the trees are adorned with many species of epiphytal orchids, this small Warbler finds a congenial winter home. Many of these wonderful beauties are in full flower early in spring, especially Odontoglossum citrosmum, whose pendulous spikes, a yard long, adorned with innumerable white and lilac flowers, perfume the air with their delightful fragrance. The stoutest branches of the oaks are literally loaded with these orchids. Lrlia anceps, L. albida, L. acuminata, and many other species of the wonderful orchid family are in full flower and fragrance in winter, when many of our beautiful Warblers hunt among them for their insect prey.

In south-western Missouri it appears in the first week of May, and in central Wisconsin we may observe many of them about May 20.

Its breeding range must be looked for in the Arctic regions, near the Yukon in Alaska, etc., in Labrador, in Maine, in the mountains of New Hampshire and Vermont, and in the Rocky Mountains. Prof. J. A. Allen gives the following interesting account of this bird, as it appears in Colorado:

"The Black-capped Warbler is a common inhabitant of the subalpine and alpine districts in the Colorado Mountains, breeding from about 8,000 feet up to timberline. In the dwarfed willows and other low shrubs that grow for some distance above the limit of trees, we found it by far the most numerous of all the insectivorous birds. It was here more plentiful even than at lower points, and may hence be regarded as an eminently alpine species. Although evidently breeding, we failed to discover its nest. It manifests great anxiety when its chosen haunts are invaded, and during 
our excursions at the above described locality, we were almost constantly scolded by one or more pairs of these birds. Later in the season we met with this species at Cheyenne, and near Colorado City and Denver, and also found it common in the vicinity of Ogden, Utah, in September."

The late Mr. H. D. Minot found a nest of Wilson's Warbler at Seven Lakes, Pike's Peak, twelve miles from Manitou, about 11,000 feet in altitude and near the timberline. He writes as follows :

".... I devoted the morning of June 22nd to finding the nest and eggs of Wilson's Black-cap, which I confidently expected would be in a bush. Being attracted by the songs of the birds to a bushy swamp, where they were numerous, I ransacked it thoroughly, and finally started a female from a bush. I dropped upon my knees without much faith, and was soon rewarded for my humility. The nest was found at the edge of the swamp, on the ground, under a low, spreading branch of a dwarf willow, and beneath an almost natural archway of dry grasses, opening toward the South. It was composed outwardly of shreds loosely set in a hollow, and inwardly of fine grass-stalks, with a few hairs. It measured 2.50 inches across inside, by half as much in depth. The eggs were five in number, about $0.60 \times .0 .50$ in size, and dull whitish in color, thickly freckled with dark rusty brown and some slight lilac markings, and with some blotches at the larger end,-in three cases on the crown, and in two about it. The swamp was too extensive to beat over thoroughly, and I did not succeed in finding another nest, nor in putting up another female. The males which I saw, perhaps a dozen in all, kept much together, as if they were a colonial troop, fluttering through the shrubbery, fly-catching very little, touching the ground occasionally, and often having their playful quarrels. Their faces and cheeks were of the richest golden yellow, much of the bill being of the same color; and their song was different from that of the Eastern bird, as I recall it. They were, I take it, of the Western variety (Sylvania pusilla pileolata)."

The true species is distributed from the Atlantic west to and including the Rocky Mountains, north to the Hudson's Bay territory and Alaska. The variety, called the PIleolated Warbler, Sylvania pusilla pileolata RIDGWay, inhabits western North America, from the Great Basin to the Pacific, breeding north to Alaska. Mr. Nuttall found a nest of this variety in Oregon, where it arrived early in May. He calls it a "little cheerful songster, the very counterpart of our brilliant and cheerful Yellow-bird." According to his opinion the song sounds like 'tsh-'tsh-'tsh-tshea. "Their call is brief and not so loud. It appeared familiar and unsuspicious, kept in bushes busily collecting its insect food, and only varied its employment by an occasional and earnest warble. By the 12th of May some were already feeding their full-fledged young. Yet on the 16th of the same month he found a nest containing four eggs. This was in a branch of a small service bush, laid very adroitly, as to concealment, upon a mass of Usnea. It was built chiefly of hypnum mosses, with a thick lining of dry, wiry, slender grasses. The female, when approached, slipped off the nest, and ran along the ground like a mouse. The eggs were very similar to those of the Yellow Warbler, with spots of a pale olive-brown, confluent at the larger end." (B. B. R., I, p. 318.) 
NAMES: Wnson's WARBLER, Wilson's Black-cap, Black-capped Yellow Warbler, Green Black-capped Flycatching Warbler.

SCIENTIFIC NAMES: Muscicapa pusilla Wils. (1811). Wilsonia pusilla Bonap. (1838). SVLVANIA PUSILLA NutT. (1840). Myiodioctes pusillus Sclat. (1858). Sylvia wilsonii Bonap. (1824). Myiodioctes wilsonii Aud. (1839).

DESCRIPTION: "Forehead, line over and around the eye, and under-parts generally, bright yellow. Upper parts, olive-green; a square patch on the crown, lustrous black. Sides of body and cheeks, tinged with olive. No white on the wings or tail. Female: Similar, the black of the crown, duller, or sometimes replaced by olive-green.

"Length, 4.75 inches; wing, 2.25; tail, 2.30 inches." (Ridgway.)

The variety, S. pusilla pileolata, is brighter colored.

\section{AMERICAN REDSTART.}

\section{Setophaga ruticilla SwaInson.}

Plate XIV. Fig. 5.

(a)

UR COUNTRY is blessed with a great number of exceedingly beautiful birds. No other land, outside of the Tropics, can boast of so large a variety of brilliant songsters. Our large forests, broad prairies, verdant meadows, and shrub-covered swamps exhibit in the spring and summer months an exuberance of beautiful flowers, but are also pleasantly enlivened by numerous birds of gorgeous colors. Their singing, resounding in the deep solitudes as well as in the neighborhood of human abodes, compares favorably with the bird-songs of other countries. If the observer rambles through the tangled masses of blooming rhododendrons, azaleas, kalmias, andromedas, and other beautiful shrubs belonging to the mountainous parts and moist regions of the Eastern and South Atlantic States, he encounters everywhere the richly colored forms of diverse Wood Warblers. When he rests on an old moss-covered fallen tree in the woods of the Northern States amid ferns, wintergreen, partridge-berry, club moss, bunch-berry ${ }^{1}$, trailing arbutus, terrestrial orchids, wood lilies ${ }^{2}$, and other beautiful plants, he hears the indescribable song of the Veery, or in the deep forest retreats the enchanting strain of the Hermit Thrush and the charming lay of the Ovenbird. In the Gulf region the Mockingbird, the Cardinal, the Nonpareil, and the Blue Grosbeak enliven from early morn till late at night the gardens, abounding in camellias, Indian azaleas, Cape jasmine ${ }^{3}$, pittosporum, myrtles, oleanders, crape myrtles, palms, a profusion of magnificent tea and Noisette roses, orange trees, many climbers, and a great variety of other tropical and semi-tropical plants; while in the less gorgeous and yet very attractive parks and gardens of the North resound the chants of the Robin, Catbird, Brown Thrasher, Bluebird, Baltimore Oriole, and the melodies of a great number of other songsters. The northern meadows and prairies, where the Canada,

1 Cornus Canadensis. 2 Trillium. 3 Gardenia florida. 
meadow, and Philadelphia lilies ${ }^{1}$ proudly hold up their radiant large flowers, are ringing with the cheerful strains of the Bobolink and the Meadow Lark. Wandering observingly through the woods at the time when the wild grape-vine ${ }^{2}$ fills the woodland with penetrating mignonette-like fragrance, we may often perceive a lovely little bird fluttering and hopping among the branches. It is the AMERICAN ReDstart. Like a true Flycatcher it is continually sallying forth in the air to catch small winged insects "with a sharp click of the bill, or chasing them hotly along the limbs of trees, when its gleaming colors are fully displayed, and flash in contrast with the green foliage." It is one of the most active and adroit Flycatchers, flying repeatedly with great rapidity from the tops of tall trees down to the ground in graceful zigzag lines. The glossy black of the head and breast, the white color of the under-parts, but more especially the glowing orange-red tint of the tail, wings, and sides of the body contrasts sharply with the fresh green of the leaves and the pink and white blossoms of the apple, plum, and cherry trees, which this bird frequently visits during the spring migration. In the Eastern, Middle, and Northern States the Redstart is a common summer resident. Its gorgeous colors show that it belongs to a semi-tropical group of Warblers, which are very abundant in Mexico and Central America. Its winter home extends over the West Indies, southern Mexico and Central America, as far south as northern South America. In summer it breeds north to Fort Simpson, west regularly to the Great Basin and casually to the Pacific Coast. In south-western Missouri it is a common summer resident, choosing for its home the deep shady woods, where only a sparse growth of underwood occurs. In south-eastern Texas it is very abundant, when the large flowering magnolias are in full bloom, about April 15 to 25. In Wisconsin it is quite common about May 9 , at a time when the plum trees are snowy with blossoms. It then even visits the gardens and parks of Milwaukee and other cities. Its movements in spring are quite regular, and at the height of the season the Redstart is too abundant to be overlooked.*

The departure for its winter-quarters commences in south-western Missouri about Sept. 15 ; by the last of that month all have left.

The Redstart is one of our most beautifully colored birds, and in a certain degree we may call it a familiar bird, which is unusual among Warblers. Its beauty, the large numbers in which it appears in spring, its rapid movements make it more conspicuous to the eye of the indifferent than any other Warbler except the Summer Yellowbird. It is a bird that deserves to be known by every lover of nature. Dr. Elliott Coues, in his unrivaled work, "Birds of the Colorado Valley," gives the following classical sketch of this bird:

"The Redstart shines among the birds that throng the woods in spring, when his transparent beauty flashes like a lambent tongue of flame at play amidst the tender pale green foliage of the trees. The brilliant little meteor glances here and there in seeming sport, with most exuberant vivacity, as if delighted to display in every action

1 Lilium Canadense, L. superbum, and L. philadelphia, 2 Vitis cordifolia.

* At St. Louis the following record on the Redstart's arrival was made by Mr. Otto Widmann:

"April 17, first old males; April 26, bulk of old males; April 30, first females; Mray 7 , height of transient old males; May 9, height of transient females: May 11, first one-year-old male; May 16, young males more conspicuous than old males. 
of his tiny body the full effect of color-contrast, shifting every moment into novel combinations with the cool shade of the background, himself the foremost figure of an animated picture. But with all this grace and elegance, this revelry and waywardness, when color plays the pleasing part of a continual surprise, the Redstart has an eye to business, and incessantly pursues the gauzy creatures that furnish food to him and all his kind. You may know him even in his early incompleted dress, and never fail to recognize his less conspicuous mate, by several characteristic traits. In their unceasing forays on the insect world, they have a fashion of skipping rapidly along the larger horizontal boughs of trees, with lowered head and drooping wings, and with incessant sidewise flirting of the fan-shaped tail, that best displays its pretty parti-coloration, the attitude and action being exactly those you have observed in the poultry-yard, when the sultan of the harem pursues a reluctant fugitive. These headstrong raids along the limbs are changed at intervals, when still more buoyant and more dexterous action absorbs the ceaseless stream of the Redstart's energy; without a moment's pause, the birds shoot out, to this side or to that, and capture insects on the wing in the most spirited manner; they dart in zigzag, generally downward, while the repeated clicking of their mandibles, as turn after turn is executed at seeming random, yet with admirable precision, tells with what success these dashing guerillas wage their warfare. Such raids are made right through the ranks of the airy little insects that swarm in the sunbeams, and at every descent into their midst not one, but many, of the midges meet their fate; the Flycatcher regains his foothold with marvelous celerity, and races as before along the $\operatorname{limb}$, with many a twitter of delight, till he is lost to view."

The song of the Redstart is not at all characteristic, reminding the observer of the notes of the Yellow-throated, Chestnut-sided, Yellow, and other Warblers. It is quaint and not very musical, though hearty and frequently uttered. According to Nuttall, who had a very fine ear for bird-melodies, many of the Redstart's notes cannot be recalled by any human sounds, as they are mere trills of harmony. "Their song on their first arrival is however nearly uniform, and greatly resembles the 'tsh, 'tsh tshee, tshè, tshe, tshe tshea or 'tsh 'tsh 'tsh 'tshitshee of the Summer Yellowbird (Dendroica aestiva), uttered in a piercing and rather slender tone; now and then also agreeably varied with a somewhat plaintive flowing 'tshé 'tshé 'tsché, or a more agreeable 'tshit, 'tshit a'tshee, given almost in the tones of the common Yellowbird (Spinus tristis). I have likewise heard individuals warble out a variety of sweet, and tender, trilling, rather loud and shrill notes, so superior to the ordinary lay of incubation, that the performer would scarcely be supposed the same bird." Audubon gives a good account of the Redstart's song. I quote the whole paragraph, which gives another pleasing glimpse of the bird. "It keeps in perpetual motion," he says, "hunting along the branches sidewise, jumping to either side in search of insects and larvæ, opening its beautiful tail at every movement which it makes, then closing it, and flirting it from side to side, just allowing the transparent beauty of the feathers to be seen for a moment. The wings are observed gently drooping during these motions, and its pleasing notes, which resemble the sounds of teetee-whee, teetee-whee, are then emitted. Should it observe an insect on the wing, it immediately flies in pursuit of it, either mounts into the air in its wake, or comes towards the ground spirally and in many zigzags. The insect secured, the lovely 
Redstart reascends, perches, and sings a different note, equally clear, and which may be expressed by the syllables wizz, wizz, wizz. While following insects on the wing, it keeps its bill constantly open, snapping as if it procured several of them on the same excursion. It is frequently observed balancing itself in the air, opposite the extremity of a bunch of leaves, and darting into the midst of them after the insects there concealed."

In south-western Missouri we may look for the nest about May 20, and in Wisconsin about June 5. It usually breeds in mixed groves, in the gloomy forest, and in bottom woods. In a certain piece of damp woodland in northern Illinois, traversed by the Des Plaines River, I found about five to six nests in an hour's walk. Oaks, elms, lindens, hickories, and black walnut trees, ashes, and, on the edge, many white-thorns, were the prevailing trees. Rose-breasted Grosbeaks, Towhees, Wood Thrtishes, Blue Jays, and Red-eyed Vireos were very common, and on the woodland border many other birds occurred in great numbers. The nests, either saddled on a branch or placed in the upright forks of a small tree, are about eight to ten feet above the ground, but often much higher. They are very beautiful, cup-shaped, compact, and usually under a roof of dense leaves, which protect them from heavy rains and the fierce rays of the sun. The structure is mainly built of silvery asclepias fibres, bits of leaves, spider's webs, and is lined with fine bark-strips and frequently with hair. In Wisconsin the nests were 'often built of fine hempen and milk-weed (asclepias) fibres, the wooly bark of the white cedar, pine needles, all held.together by spider's webs. The lining consisted of horse-hair, pine needles, and fine grasses. In Missouri the nests are much coarser and looser, consisting almost entirely of grape-vine bark, fine grasses, and bits of old leaves. They are lined with fine strips of bark and grasses. "A rather curious nest, taken at Racine, Wisconsin, by Dr. P. R. Hoy, and now preserved in the National Museum, is attached entirely to one side of an upright fork, and setting away from the support altogether, excepting a small part of its circumference, which reaches down into the crotch. Another remarkable nest, taken in Massachusetts by Mr. George O. Welch, and described by Dr. Brewer, is a reconstruction of one begun by a pair of Summer Warblers, and either abandoned by the originators, or from which they had been driven away. The Redstarts built upon this basis, constructing a nest of their own. The base was composed of the downy covering of the under-side of fern-leaves, with a few herbaceous stems and leaves; within this was built an entirely distinct nest, composed of long slender strips of bark, pine needles, and grass-stems. In a third nest, found by the same writer in Hingham, Mass., the more ustual bark-strips were replaced by hempen fibres, thistle down, bits of newspaper, and other matters. This nest was in a tree standing in an open space near a dwelling-house; another was in a swampy thicket, five feet from the ground; one of the northern nests Dr. Brewer notices was built in low willow bushes." The eggs, usually four in number, are white, sometimes greenish or grayish-white, speckled and spotted with cinnamon-brown and lilac, chiefly in wreathlike manner round the larger end. Like many other Warblers' eggs, they are subject to much variation in regard to size and coloring. The young which are able to leave the nest about twelve days after hatching, are fed with fine insects, such as mosquitoes, gnats, and very small moths. The food of the Redstart consists at all times almost 
exclusively of flying insects, but sometimes it captures them from the leaves and bark with great activity. While flying after insects, it frequently sings and always closes and opens its tail in fan-like manner.

In winter it seems to be a common bird in the woods of Honduras and Guatemala. Where the beautiful and fragrant cow's horn orchid ${ }^{1}$, barkerias, brassavolas, lælias, oncidiums, cattleyas, epidendrums, chysis, and other orchids are partly flowering, partly resting, but always imparting to the landscape an indescribable charm, these sprightly birds are hunting among them for insects.

NAMES: AMERICAN REDSTART, Redstart Warbler, Redstart Flycatcher.

SCIENTIFIC NAMES: Motacilla ruticilla Linn. (1758). Sylvania ruticilla Nutt. (1832). SETOPHAGA RUTICILLA SwAINS. (1827).

DESCRIPTION: "Male, in full plumage: Glossy bltte-black; belly and breast, white; sides of breast, lining of wings, bases of nearly all the wing-quills and tail-feathers, flame-color; this rich orange making it conspicuous spot on the wings, and forming a transverse outline with the black on the tail; bill and feet, black. Female: Olive-gray where the male is black, and clear yellow where the male is orange. - Young males at first resemble the female, and later, in the progress to mature coloration, show every graduation in color between the two sexes, being often irregularly patched with black feathers.

"Length, 5.00 to 5.50 inches; wing and tail, 2.25 to 2.50 inches." (Stearns and Coules" "New England Bird Life." Vol. I, p. 175.)

\section{PAINTED REDSTART.}

Setophaga picta Swanson.

The PAINTed ReDSTaRT is one of our most brilliant and distinct birds, its color being a deep glossy bluish-black, relieved by a white patch on the wings and a fine carmine-red on the breast and belly. This Warbler is common throughout the year in the highlands of Mexico, and is found in summer in considerable numbers in southern New Mexico and Arizona, where it seems to frequent the oak belt of the mountains. Mr. Walter E. Bryant, a well-known and conscientious California ornithologist, was the first naturalist who described the nest of the Painted Redstart. He writes: "For my knowledge of the nidification of this species, and for the nest and eggs in my collection, I am indebted to Mr. Herbert Brown, who became familiar with the birds while in Arizona. From Mr. Brown's observations it appears that they differ somewhat in their habits from Setophaga ruticilla, as they seldom or never catch insects on the wing, but pick them from the leaves, and branches of the trees; one specimen was seen feeding her young with what appeared to be moths and long-legged flies. The nesting-site was on a hill-side in a slight depression in the ground. A nest was found in a hole in a road bank, in the Santa Rita Mountains, by Mr. Brown, June 6, 1880. It was loosely constructed of dry grasses and fine shreds of vegetable bark, and lined with white horsehairs; it measured 4.00 inches in diameter by 1.75 inches in height, and the cavity 2.00 inches in diameter by 1.75 inches in depth. Another nest found by Mr. Brown was built in a depression beneath a small bush, on the lower side of a mountain trail.* According to Mr. Stephens the Painted Redstart is frequently met with after March 21

1 Schomburgkia tibicinis.

* Bull. Nutt. Club. Vol. VI, 1886. 
in the Chiricahua Mountains, Arizona, at an elevation of fully 7,000 feet. They appear most numerously among pines. In the Santa Rita Mountains, where it was rather common in May, Mr. Stephens had the good fortune to find a third nest of this bird, under a projecting stone, in a bank near a small stream. The nest was composed of bark, coarse fibres from weed-stalks, and fine, bleached grasses, the latter, with a few hairs, forming a simple lining. The eggs are described by $\mathrm{Mr}$. Brewster as clear dead white, delicately spotted with light reddish-brown, the markings being sparsely distributed over the general surface of the egg, and handsomely wreathed about the larger end.

Mr. W. E. D. Scott found this bird common in the higher regions of the, oak belt and throughout the pine region in the neighborhood of Las Sierras de Santa Catalina, Pima County, Arizona.

DESCRIPTION: "Head, neck, chest, sides, and upper parts, glossy blue-black; the wing with a large white patch, covering greater and middle coverts and edges of tertials; no chestnut or rufous on top of head; breast and belly, rich carmine-red; lower eyelid and under tail-coverts, pure white.

"Length about 5.00 to 5.50 inches; wing, 2.70 to 2.82 ; tail, 2.35 to 2.78 inches." (R. Ridgway.)

RED-Bellied Redstart, Setophaga miniata Swains. This bird is an inhabitant of the highlands of Mexico, north to southern Texas. There is nothing known about its breeding habits in our territory.

\title{
RED FACED WARBLER.
}

\section{Cardellina rubrifrons ScLater.}

Plate XXXII. Fig. 2.

\begin{abstract}
$\mathrm{N}$ THE mountain regions of Central America and Mexico north to southern Arizona 6 this beautiful little Warbler seems to be a more or less frequent summer sojourner. It is one of Mr. J. P. Giraud's "Sixteen Species," alleged to have been procured in Texas. Only recently its occurrence in the United States has been confirmed, when the bird was rediscovered by Mr. Henshaw in southern Arizona. He found these Warblers at two points about a hundred miles apart, - on Mount Graham. and near Camp Apache. They proved to be common birds on Mount Graham, where flocks of ten or fifteen were not unusual among the pines and spruces. They frequented these trees almost exclusively, only rarely being seen on the bushes that fringed the streams. This was in the first days of August, 1874. The habits of the RED-FACED WARBLER "are a rather strange compound, now resembling those of Warblers, again recalling the Redstarts, but more often perhaps bringing to mind the less graceful motions of the familiar Titmice. Their favorite haunting places appeared to be the extremities of the limbs of the spruces, over the branches of which they passed with quick motion, and a peculiar and constant sidewise jerk of the tail. When thus engaged, especially when high overhead, they might
\end{abstract}


easily be passed by, as a busy group of Titmice intent only on satisfying their hunger. They appear to obtain most of their food from the branches, seizing the insects when at rest; but they are abundantly able to take their prey on the wing, and accomplish this much after the style of the Redstarts. Their disposition seems to prompt them to sociability with other species, and occasionally I found them accompanying the Audubon's Warblers, and imitating them in their short flights from tree to tree, occasionally paying flying visits to the fallen logs and even to the ground. Save in being rather louder and harsher, their chirps resemble the notes of the Yellow-rump Warblers." (Henshaw.)

Mr. W. W. Price found a nest of this beautiful Warbler in the Huachuca Mountains, on May 31, 1888. This was at an altitude of about 6,500 feet. The nest was placed on sloping ground in a slight hollow and contained four fresh eggs. A few sprays of columbine hid the nest so completely that, had not the bird been frightened directly off from it, Mr. Price should not have found it. The structure was a very poor attempt at nest-building, and made of such loose material that it crumbled to fragments on being removed. "The chief substance was fine fibrous weed-stalks, while the lining consisted of fine grass, rootlets, plant fibres, and a few hairs. Skeleton leaves and bits of fine bark were scattered sparingly throughout the nest. Leaves and other rubbish had drifted with the wind or had been scratched up all around, to a level with the rim, so that one could hardly see where the nest proper left off. Inside the nest was about 2.50 inches wide by 1.50 inches in depth; outside it was about 5.00 inches wide by 3.00 inches in depth. The ground on which the nest was placed was so damp, that the bottom part of it was badly decayed." The "ground-color of the eggs is a delicate creamy-white, and they are spotted with small blotches of cinnamon-rufous and a few dots of heliotrope-purple and pale lavender. These form a wreath around the larger end. They resemble the eggs of Virginia's and Lucy's Warbler to a certain extent." (Chas. E. Bendire.)

NAMES: RED-FACED WARBLER.

SCIENTIFIC NAMES: Muscicapa rubrifrons Giraud (1841). CARDELLINA RUBRIFRONS ScLAT. (1855). DESCRIPTION: “Sexes, alike. Forehead, lores, cheeks, chin, throat, and sides of neck, rich rermilion-red, sometimes inclining to carmine; crown and ear-coverts, deep black; occiput, whitish; upper parts, uniform ash-gray; the rump, white, and middle wing-coverts indistinctly tipped with same; lower parts (except throat), whitish.

"Length about 5.00 to 5.50 inches; wing, 2.53 to 2.80 ; tail, 2.32 to 2.60 inches. (Ridgway.)

Three other beautiful Warblers, also figured and described in Giraud's "Sixteen Species," have not yet been met with in our territory. These are the RED WARBLER, Ergaticus ruber Sclat. \& Salv.; Brasher's Warblę, Basileuterus culcivorus Bonap.; and Bell's Warbler, Basileutetus belli Sclat. 


\section{VIREOS, OR GREENLETS.}

Vireonidæe.

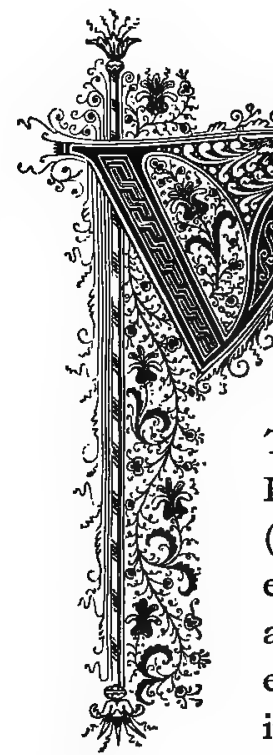

9) YriReus, or GREENLETs, though closely allied to our exquisitely colored Wood Warblers, are very characteristic birds. They are not attired in vivid colors, and the sexes can not be distinguished with any certainty. The color of the back and the head is usually gray or olive-green, while the under-parts are white, yellow, or olivaceous. The bill is like that of a Shrike in miniature, and for this reason Dr. A. E. Brehm, in his celebrated work, "Thierleben," called them Leaf Shrikes (Laubwürg̉er). They are small birds and their food consists almost exclusively of insects, which they collect from the leaves, the blossoms, and the bark of forest and orchard trees and shrubs. All the Vireos are exceedingly beneficial, as they destroy an immense number of noxious insects. It is deeply to be regretted that these and all our insectivorous birds are not cared for and protected in such a way as they should be. Our State laws for the protection of birds ought to be strictly enforced. Parents, teachers, all good citizens, and the press can do much valuable work in this direction. Birds beautify the landscape. They imbue our woodlands, meadows, fields, and gardens with poetry and song. They are valuable property not only from an æsthetical and ethical standpoint, but also in regard to their valuable work in destroying injurious insects. They make our life happier and more poetical. It is a great outrage, if our boys are allowed to rove about shooting birds, disturbing their nests, and collecting their eggs. It should be a far greater pleasure to them to observe the birds and their ways closely, to plant dense shrubs for nesting-sites, and to build nesting-boxes for Bluebirds, Wrens, Titmice, Martins, and Great-crested Flycatchers. The aim of our rising generation should be, not to destroy, but conscientiously to preserve the beautiful and useful in nature. Parents and educationists should consider it their paramount duty to call the attention of their children and pupils to the beauties in nature, to make them acquainted with our native birds, and to create a sentiment that they must be protected. 
Formerly the Vireo family was divided into three different genera*, but now, according to the system adopted by the American Ornithologists' Union, all the species belong to the one genus Vireo. Dr. Elliott Coues gives in his excellent work, "Birds of the Colorado Valley" (p. 489), the following concise and characteristic description of the family :

"The specific characters in this group are for the most part very constant and tangible, though requiring in many cases nice discrimination, so curiously interrelated are these birds. They are an interesting and agreeable tribe of little birds, simply colored, in harmony with the foliage amidst which they live, and numerous enough, both in species and in individuals, to form a marked feature of our sylvan Ornis. Most of the Greenlets, including all the larger species, as the Red-eyed, the Blue-headed, the Yellow-throated, and the Warbling Vireos, inhabit high open woods, and the shade-trees of our parks, lawns, and public streets; while the smaller ones, like the White-eye of the East, and Bell's, and the Least Greenlet, live down in the shrubbery with the Chats, Thrashers, and Catbirds. Being mainly insectivorous, though they also feed on berries, they are migratory in our country, and appear with all the periodicity of the Warblers themselves; different Vireos nestle anywhere in the United States, and some of them are among our most numerous and conspicuous summer visitors; few go much, if any, beyond the United States, and only exceptionally reach high latitudes. They are very agile and industrious birds, indefatigable in the pursuit of insects, nervous and highly animated in bearing, voluble and versatile in song, each kind having its own musical accomplishments. Though insignificant in size, Greenlets are spirited birds - the plucky little Red-eye, for instance, will defend itself when wounded with all the courage of a Hawk; and some of the most touching scenes I have ever witnessed among the birds have been those when Greenlets sought to protect, encourage, and sympathize with a stricken mate. The Greenlets all build one style of nests, a rather slight and thin-walled, but neat and compact, pensile, cup-like structure, suspended from the fork of a twig; and the eggs are alike white, rather sparsely but sharply speckled with dark markings.

"Many species of Vireo, unknown to the United States, inhabit Mexico, the West Indies, and Central and South America as far at least as La Plata, some of them having a closely restricted geographical range."

Genus Vireo. Twelve species and six varieties.

* Vireosylvia, Lanivireo, and Vireo. 


\title{
RED-EYED VIREO.
}

\section{Vireo olivaceus BONAPARTE.}

\author{
Plate XV. Fig. 4.
}

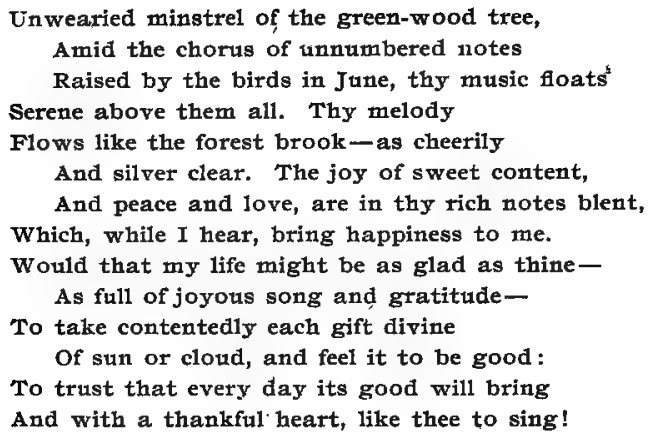

E. J. Loomis.

\begin{abstract}
T.N THE days of my youth the woodlands of Wisconsin appeared more imbued with 6 poetry and romance than at present. The primeval forests of white-pines, beeches, birches, and other trees, the extensive tamarack and white-cedar swamps were scarcely touched by the axe of the woodsman. Then in the early spring the new settlers went out into the woods to tap the maple trees. The sweet sap was boiled down into syrup or converted into the well-known but now rather scarce maple sugar. At present the grand maple forests are nearly exterminated; the once beautiful tall trees look sickly and sapless. What has become of the aromatic wintergreen, the trailing arbutus, and the rich deep green club moss or ground pine, the beautiful white reticulated leaf-rosettes of Goodyera repens, which used to cover the ground underneath the magnificent whitepines of my early forest haunts? Human hands have nearly exterminated these woodland beauties. The wintergreen is sought for its aromatic juice, the fragrant trailing arbutus during its blooming time is being torn from the ground, roots and all, and sent to the cities, and the club moss goes in the same direction by the cart-load for Christmas market. In former days there existed grand beech forests which at times were the roost of millions of Passenger Pigeons. Not every year did these birds arrive: in some successive years many were seen, in others their number was few. Often, after an absence of five or more years, they came again in cloud-like masses, even obscuring the sunlight. Not in thousands, but in untold millions did they come. It was a grand sight, when in the morning the great masses separated into swarms, flying away from their roosts in all directions, and returning at eve in the same unbroken swarms. During several seasons they hatched in the forest near my parental home. The nests, of which large numbers often were built in a single tree, were constructed of twigs and always contained each but a single egg. I never have seen two eggs in a nest. How changed seems all now! The romantic time seems to have passed away with the Indians, the
\end{abstract}




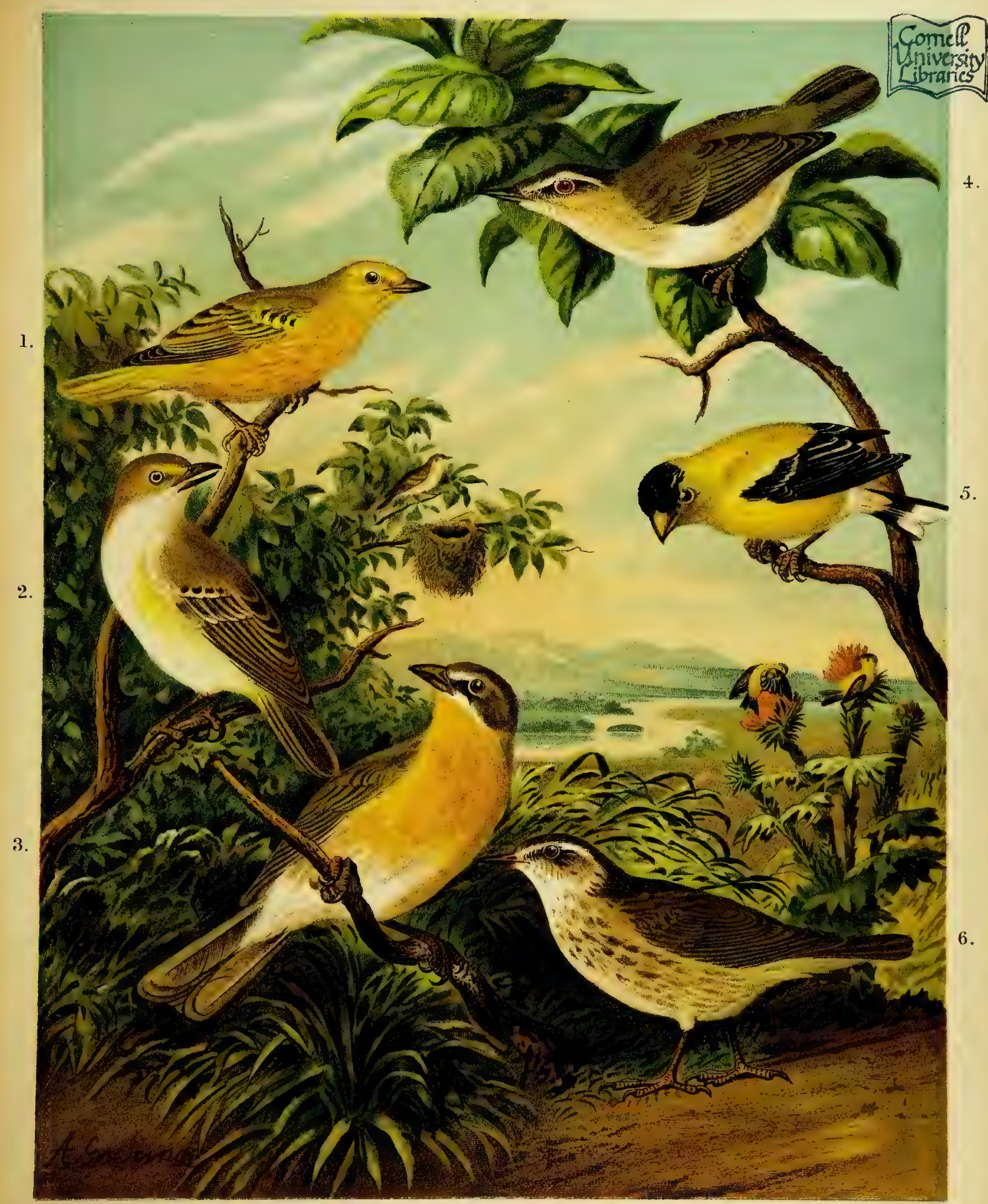

1. DENDROICA AESTIVA Brd.

2. VIREO NOVEBORACENSIS Bonap. -

3. ICTERIA VIRENS Brd.

4. VIREO OLIVACEUS Bonap.

5. SPINUS TRISTIS Stejn.

6. SEIURUS MOTACILLA Bonap.
- GARTENSÄNGER

- BUSCHVIREO

- SCHWÄTZER

- WALDVIREO

- GOLDSTIGLITZ

- WASSERSÄNGER
- Yellow Warbler

- White-eyed Vireo

- Yellow-breasted Chat.

- Red-eyed Vireo.

- American Goldfinch.

Louisiana Water-Thrush. 

forests of white-pines, the Passenger Pigeon, and the early settlers. The pioneer poet, General Conrad Krez, who made the forests of central Wisconsin his home over forty years ago, truly says in his elegiac lines:

\footnotetext{
"All, all about the the world has changed, and I recognize scarcely

Now the haunts where, when young, chasing, I followed the deer."
}

Even the people themselves have changed-changed in their aspect of life, their way of thinking, their aspirations. The sturdy old weather beaten settlers felt happier in the midst of the forest primeval in their simple log-cabins, on their own soil following the plow drawn by their slow ox-team, than the present generation, living in comparative ease. If to-day we enter the sparse remnants of the once so magnificent woods, we notice burned logs, masses of old branches, stumps, uprooted trees, and a peculiar quietness. The many Pileated Woodpeckers whose drumming on the trees once sounded through the woods, the Rose-breasted Grosbeak, the resplendent Scarlet Tanagers, the Ruffed Grouse, the beautiful Wood Ducks, are nearly exterminated, or they are so shy that they are rarely seen or heard. Only one old woodland songster of the days of yore gives vent to its voice to-day even as then. It is one of our common and popular poets of the woods, the RED-EYED VIREO.

This bird appears in large numbers from Texas to Manitoba, from Florida to Nova Scotia, and from the Atlantic west to the Rocky Mountains, being the most common woodland species of its family. It breeds wherever it is found in summer. Like the Warbling Vireo it lives for the most part in high, open woods, foraging for insects in the upper branches of the trees. In Wisconsin we find it common in the woods consisting of beeches, maples, iron-wood, hop trees, lindens, birches, cherry, hickory, butternut, and other trees. It is also found in the mixed woods, but rarely in the dark forests of white-pines and hemlocks. It is so familiar and fearless that it frequently breeds in the maples and elms near the farmer's house, in the parks of crowded cities, and in the trees of the streets in villages and towns. Though often not easily detected in the dense foliage of the tall trees, we may almost constantly hear its exceedingly pleasant and lively strain. In the narrow stretches of woodland, which border the water-courses of northern Illinois, in the Ozark region of south-western Missouri, and in the post-oak woods of Texas, I found this Vireo a common summer sojourner. Even in the rather dim woods of the coast region, consisting of magnificent magnolias, loblolly bays, water, laurel, pin, and live-oaks, gigantic sycamores, cherry laurels, hollies, pecan trees, sweet gums, and many other trees this bird was a common summer resident from early April to late in September. There almost all the trees are heavily draped with the gray Spanish moss, and the trumpet creeper, smilax, and different grape-vines climb to the very tops of the tall trees. From the holly and other thickets the songs of numerous Cardinal Redbirds are heard, and the lively strain of the Yellowthroated Warbler, the unrivaled notes of the Mockingbird fall on our ear, but through this woodland concert may always be heard the voluble lay of the Red-eyed Vireo. Indeed, this was the first bird that welcomed me by its familiar notes, when I first entered these woods. The impression made by this strain during a time, when the sweet blossoms of the magnolias filled the air with powerful fragrance, when all the birds far and near chanted their most joyful songs, while all the trees, shrubs, and 
herbs were garmented in beautiful fresh green or in flowers, was deep and enduring. The Red-eyed Vireo arrives in south-eastern Texas from its winter-quarters in the first days of April. About April 25 I observed them at Freistatt, Lawrence Co., Mo., and about May 20 in Sheboygan Co., Wis. According to the weather these dates may change somewhat. In the autumn they leave the Northern and Middle States in September. As late as October $15 \mathrm{I}$ have seen them in south-eastern Texas.

After their arrival they are very quiet and retired, but this changes when the trees don their garments of fresh green leaves, and when the air is mild and warm. They only seem to feel perfectly safe among the dense green foliage. In Texas the woods are always perfectly green when this Vireo arrives, but farther north, especially in Wisconsin, it usually makes its appearance several days before the leaf buds burst. From under the canopy of foliage the song is poured forth with such energy and persistence, that the bird rarely pauses a moment while capturing an insect. To my ear this song sounds exceedingly melodious. From early morn till the twilight of evening falls we may listen to it. Even at noon, when all other birds are resting, when rarely another sound interrupts the quietness of the woods, we may hear it sing as diligently as ever. Though a violent storm swing the tree-tops to and fro, though the rain pour down in torrents, this tireless songster can still be heard. Only during very cool and damp weather it becomes quiet and somewhat depressed, but the old happiness and song returns with the sunshine, and it sings among the wet and dripping foliage as lively as though nothing had happened. The sentiment expressed in this song is always that of cheerfulness. Dr. Elliott Coues says, that in the District of Columbia during the heat of the summer the Red-eye's energetic and voluble notes resound, no less than the querulous plaints of the Wood Pewees, throughout the woods. "The persistency of these musicians is really remarkable; they sing at all hours, even at the listless noon, which invites most birds to rest in the shade, and prolong their nervous notes to the very end of summer, long after the exaltation of other Warblers has passed away. If we watch a Red-eye, as we may easily do, in the nearest piece of wood, or in the shade-trees close by the house, we shall see him performing in a very nonchalant, almost mechanical way, as he goes about his business of fly-catching, sometimes stopping in the midst of a bar to snap at an insect, and resuming the note as soon as he has fairly cleared his throat. No one of the sylvan choir is more simple and unaffected than this modest performer, who seems to sing unconsciously or as if absorbed in reverie, while his daily work goes on."

Nuttall, who had a very fine ear for the sylvan voices, gives the following description of the Red-eye's song: "When our Vireo sings slow enough to be distinctly heard, the following sweetly warbled phrases, variously transposed and tuned, may often be caught by the attentive listener: 'tshoǒe peweĕ peeai mŭsik 'du' 'dŭ 'du, 'tshoŏve 'hĕre 'hĕre, hear hère, hear hère, 'k'ing 'ritshard, 'p'shĕgru 'tshevŭ, 'tsheevoo, 'tshŭvee peeaŭt 'péroi. The whole delivered almost without any sensible interval, with earnest animation, in a pathetic, tender, and pleasing strain, well calculated to produce calm and thoughtful reflection in the sensitive mind."

"The song of this Vireo," says Dr. T. M. Brewer, "is loud, musical, simple, and pleasing. It is uttered in short, emphatic bars, and at times has a very marked resemblance to the melodious chant of the Robin, though without its volume and 
power. This Vireo is one of the earliest of our spring musicians, as it is also one of the most constant and untiring in its song, continuing to sing long after most of the other vocalists have become silent, and even until it is about to leave us, at the close of September. The tender and pathetic utterances of this Vireo, uttered with so much apparent animation, to judge from their sound, are in striking contrast to the apparent indifference of unconsciousness of the little vocalist who, while thus delighting the ear of the listener, seems to be all the while chiefly bent on procuring its daily supply of food, which it pursues with unabated ardor."

The Red-eyed Vireo is a common bird of the old apple orchards and of the shadetrees surrounding the house of the farmer. Its sweet soliloquy is one of the most familiar and cheerful sounds near our rural homes. In the high elms and sugar maples near my parental home in Wisconsin a pair of these Vireos took up their abode every year. Like the Catbird, the Baltimore Oriole, and the Bluebird, this Vireo is one of my special favorites among the feathered choir living near our rural homes.

The food of this bird, which consists chiefly of worms and other small insects, is procured among the branches and the leaves of the trees. Its movements are rather slow and very peculiar, being somewhat like those of the Warblers. While moving slowly along the branches it peers to the right and left, explores the under-side of the leaves as well as the upper, looks into the crevices of the bark, and hops and flits a few feet farther, to examine another hunting ground. The song may always be heard while the bird procures its food among the branches. The insects captured are usually not in motion, but sometimes, when a beetle or a moth tries to escape, it will take it on the wing. In the fall when insects are scarce, this Vireo feeds, according to Mr. Nuttall, eagerly upon the berries of the cornel and the Viburnum dentatum. In Texas I have observed in the fall that they eat the aromatic berries of the Mexican mulberry ${ }^{1}$, the myrtle holly ${ }^{2}$, and the youpon ${ }^{3}$.

The pensile, cup-like nest of the Red-eye is a very beautiful and compact structure. It is always built in horizontal branches of trees, usually from six to twenty feet above the ground. In some cases it may even be higher, but I have never found it lower than six feet. The extremity of some horizontal twig of a sugar maple, beech, or other tree with slender straggling branches is always selected for a nesting-site. I have almost always found that the nests in the interior of the forest are usually lower than those built in single shade-trees near our dwellings. The pensile structure is always suspended from a forked horizontal $t w i g$. It is felted with the most miscellaneous materials. In the coniferous region of Wisconsin it is mainly composed of fine bark-strips, pine needles, hemp-like fibres, skeleton leaves, bits of paper, rotten wood, and wasp nests. The interior is lined with fine grasses and pine needles. When the female begins to deposit her eggs, the outside of the nest shows only little decoration. This is finally completed by the female, from materials carried by the male. She fastens, probably with saliva, bits of moss and wasp nests, curly bark of the paper birch, spider nests and webs to the outside. This serves not only as a beautiful decoration, but gives the structure strength and a more natural appearance. Nests in south-western Missouri were built similar, but were decorated on the outside with fine pieces of rotten wood and a few 
bits of old leaves. In Texas the outside of the nest was always covered beautifully with grayish-green Usnea lichens, and in some instances with Spanish moss. These very peculiar and exceedingly beautiful nests are very compact and durable, "hanging for many months after they have been deserted; and when the leaves have fallen, revealing the trees in their nakedness, these structures become conspicuous along the road-side, around the edges of clearings, and among the dogwood and Judas trees that form the undergrowth of our noble oak forests." (Coues.) The eggs, usually four in number, are pure white, sparsely sprinkled with small and sharp dark reddish-brown dots, chiefly about the larger end. The Red-eye's nest is frequently chosen by the Cowbird for the deposition of her parasitic eggs, and these foster-parents are singularly devoted to the alien offspring, whom they tenderly nurture, even to the neglect of their own young. Many broods of this Vireo are every year destroyed by this parasitic trait of the Cowbird. I have found frequently one, often two and even three Cowbird's eggs in one Vireo's nest. Dr. T. M. Brewer says that in one instance three eggs of a Cowbird were deposited in the nest of the Vireo before any of her own, and, without laying any, the female Vireo proceeded to sit upon and hatch the intruders. In another case, where two of the Vireos had been laid, two Cowbird's eggs were added. The Vireo stopped laying, and proceeded to incubate. In each instance the female Vireo seemed to forego her own natural aspirations, and at once conform to the new situation.

NAMES: RED-EYED VIREo, Red-eye, Red-eyed Greenlet, Red-eyed Flycatcher.-Waldvireo (German).

SCIENTIFIC NAMES: Muscicapa olivacea Linn. (1766). VIREO OLIVACEUS Bonap. (1826). V'ireosylvia olivacea Bonap. (1850).

DESCRIPTION: "Upper parts, olive-green. Top of head from bill to nape, ash-color. A white line from nostrils above and beyond the eye, bordered above by a dusky line forming the edge of the ashy cap, and below by a similar, perhaps paler, loral and post-ocular cheek-stripe. Beneath, including tibia, white, with perhaps a tinge of olivaceous ash across the breast; the sides of the neck, like the back; sides of body with a faint wash of olive. Axillars and crissum, faintly tinged with sulphur-yellow; lining of wings and its edge, the latter especially nearly white. Quills, blackish-brown, edged externally, except at ends of primaries, with olive; internally with white. Tail-feathers, lighter brown, edged externally like the back, internally with pale olivaceous white. Bill, dusky above, pale below; tarsi, plumbeous. Iris, red.

"Length, 6.33 inches; wing, 3.33 ; tail, 2.50 inches.

"Female, similar, but duller in plumage." (Ridgway.)

BLACK-Whiskered Vireo, Vireo altiloquus barbatulus Coues. This bird, abundant in the Bahamas and Cuba, is a common migrant, and breeds numerously on all of the mangrove keys of the west coast of Florida, as far north at least as the mouth of Anclote River, near Tarpon Springs. Mr. W. E. D. Scott says that the birds arrive there about May 10 to 15, and that the species seems to be confined almost exclusively to the mangrove keys, and is very difficult to obtain, even when seemingly plentiful, as they are wary and shy, and the cover in which they resort is dense and impenetrable.

The Yellow-Greer VIREJ, Vireo flavoviridis BAIRD, is a rather common summer resident in the valley of the lower Rio Grande in Texas, southward to Panama. 


\section{PHILADELPHIA VIREO.}

Vireo philadelphicus BAIRD.

2 URING the migration this Vireo frequently makes its appearance in northern Illinois and in Wisconsin, but from its close resemblance to the Warbling Vireo, it is doubtless often confounded with that species. In its breeding range it keeps usually in the tops of tall trees, singing almost incessantly. The song is so similar to the strain of the Red-eyed Vireo, that even celebrated ornithologists confounded the bird with that species. My experience with this bird is very limited, but happily $\mathrm{I}$ am able to complete this life sketch by quoting from an excellent authority. In the "Bulletin of the Nuttall Ornithological Club" (Vol. V, p. 1-7), Mr. Wm. Brewster, of Cambridge, Mass., not only a great ornithologist, but also a fine writer and a warm friend of the birds and the poetry in nature, gives the following description of the PHILADELPHIA VIREO:

"The Philadelphia Vireos usually arrive at Umbagog during the last week of May, or, if the season be a late one, in early June. They come with the last flight of - Warblers, when the forest trees are putting on a drapery of tender green, and the moosewood is white with snowy blossoms. They are most apt to be found singly at this season, though they not infrequently associate with the various species of Warblers. For some time after their first appearance they are severely silent, and, although by no means shy or suspicious, their habits are so retiring and unobtrusive, that their presence may be easily overlooked. Their motions are essentially like those of all the rest of the genus. A branch shakes, and you catch a glimpse of a pale lemon breast that matches well with the tint of the thin foliage. Then the whole bird appears, hopping slowly out along the limb, and deliberately peering on every side in that nearsighted way peculiar to the tribe. Occasionally its search among the unfolding leaves is rewarded by the discovery of some luckless measuring-worm, which is swallowed with the same indifference that marks all the bird's movements. You begin to feel that nothing can disturb the equanimity of the little philosopher, when it suddenly launches out into the sunshine, and, with an adroit turn, captures a flying insect invisible to human eyes. The next moment there is a dim impression of glancing wings among the trees, and it has vanished. There is little chance of finding it again, for its voice has as yet no place in the chorus that rises from the budding thickets around.

"But after the trees become dense with foliage, and the sense of early summer steals over the land, even the shy reserve of our recluse yields to the subtile influence, and he finds a tongue no less joyous than the rest. Indeed, after the breeding season has fairly begun, he is quite as indefatigable a singer as his Red-eyed cousin. I have heard his cheerful voice all day long when a gloomy storm brooded over the dripping woods, and during the hottest June days he is rarely silent for any length of time, even at nooritide. Nor does cold, blustering weather seem to affect his spirits. I remember shooting one in a tall yellow birch when a high north wind was bending the stoutest trees like so many saplings. The branch to which the little singer clung was lashed 
about by the blasts, which flouted the leaves and swung the whole tree-top through the air; yet he hardly paused a moment in his strain, though his voice was at times nearly drowned by the rushing wind.

"Contrary to what might be expected from the apparently close relationship of the two birds, the song of this species does not in the least resemble that of Vireo gilvus. It is, on the other hand, so nearly identical with that of the Red-eye that the most critical ear will, in many cases, find great difficulty in distinguishing between the two. The notes of $V$. philadelphicus are generally pitched a little higher in the scale, while many of the utterances are feebler, and the whole strain is a trifle more disconnected. But these differences are of a very subtile character, and, like most comparative ones, they are not to be depended upon unless the two species can be heard together. The Philadelphia Vireo has, however, one note which seems to be peculiarly its own, a very abrupt, double-syllabled utterance, with a rising inflection, which comes in with the general song at irregular but not infrequent intervals. I have also, on one or two occasions, heard the male, when in pursuit of his mate, utter a soft pseuo, similar to that sometimes used by Vireo olivaceus, and both sexes when excited or angry have a harsh, petulant note exactly like that of the Warbling Vireo.

"Although in the breeding season the species under consideration seems to be generally distributed throughout the wooded region about Umbagog, it occurs less commonly in the heavily timbered portions. As upon its first arrival, it chiefly affects the younger growths which have sprung up in the clearings and over old burnt lands. Its favorite haunts are the coppices of wild-cherry and gray birches by road-sides; rocky knolls tufted with black and yellow birches; the various small trees and tall shrubs that fringe the wood edges; and deserted farms, where cool groves of vigorous young paper birches and glaucous-foliaged poplars are grouped over the neglected acres, with intervals of sunny opening between. But wherever found, like most of the members of the Vireosylvia group, it makes its home in the tops and upper branches of the trees, rather than in the thickets beneath.

"The breeding season is probably longer deferred than with any other New England species, excepting, perhaps, $V$. solitarius. At least the males were not in full song before June 10, and even at that date they were not generally mated.

"My utmost efforts to discover the nest failed. Some old ones, which were hung in the usual manner near the extremity of birch or poplar limbs, may have originally belonged to this species, as several specimens of the birds were found in the grove, and no other Vireo seemed to be breeding near. The only one of these structures which I took pains to examine closely was somewhat smaller and deeper than the average nest of Vireo olivaceus, being rather more like that of Vireo noveboracensis.

"At the close of the breeding season, when the brakes are turning brown, and occasional maples along the lake shore begin to glow with the burning tints of autumn, the Philadelphia Vireos join those great congregations of mingled Warblers, Sparrows, Woodpeckers, Titmice, etc., which at this season go trooping through the Maine woods. The specimens taken at Upton, in 1874, were in flocks of this kind, and several of them were shot in low bushes, an apparent exception to the rule previously given. But mixed society among birds, as well as men, is a great leveller of individual traits, and it is. 
by no means uncommon on these occasions to find such tree-loving species as the Baybreasted, Cape May, Blackburnian, and Blue Yellow-backed Warblers, the Red-bellied Nuthatch, the Golden-crested Kinglet, and many others, consorting with Winter Wrens, Water Thrushes, and Canada Flycatchers in the thickets by wood paths, or along the banks of ponds or rivers; and I know of no more interesting sight, especially if it be a bright September morning, before the sun has risen above the trees. The dark foliage of the alders and viburnums is frosted with innumerable dew drops, which fall in sparkling showers where a Warbler hops or a Woodpecker taps on the slender stems. Yellow and gold and scarlet liveries flash among the glossy leaves, as the active little forms appear and disappear, while the constant rustling and low-toned conversational chirping from the depths of the thicket suggest all sorts of pleasing mysteries. It is a pretty picture, this gathering of the birds in the quiet depths of the forest, with the tall spires of sentinel-like firs and spruces keeping guard against the sky, and the incessant rasping of the wood-borers, - nature's time keepers, - counting the hours of the crumbling trunks around."

In Sheboygan Co., Wis., this Vireo doubtless breeds, but I was unable to find its nest. Probably the majority breed north of the United States. Near Duck Mountain, Manitoba, Mr. Ernest Thompson found a nest. of this bird, containing four eggs, on June 9,1884 . It was built in a forked twig of a willow, which was scant in foliage, as it grew in the shade of a poplar grove. It was about eight feet from the ground, pensile as is usual with all Vireos, and was formed of grass and birch bark. The eggs presented no obvious difference from those of the Red-eye.

NAMES: Philadelpiria Vireo, Brotherly-love Vireo, Philadelphia Greenlet.

SCIENTIFIC NAMES: Vireosylvia philadelphica Cass. (1851). VIREO PHILADELPHICUS BRD. (1858).

DESCRIPTION: "Above, dull olive-green, brightening on the rump, fading insensibly into ashy on the crown, which is not bordered with blackish; a dull white supraciliary line; below, palest possible yellowish, whitening on throat and belly, slightly olive-shaded on sides; sometimes a slight creamy or buff shade throughout the under-parts; no obvious wing-bars; no evident spurious first primary. The latter character distinguishes the species from Vireo gilvus, which it most resembles in color.

"About 5.00 inches long; wing, 2.70; tail, 2.25 inches." (Stearns \& Coues, "New England Bird Life," I, p. 197.) 


\title{
WARBLING VIREO.
}

\author{
Vireo gilvus BONAPARTE.
}

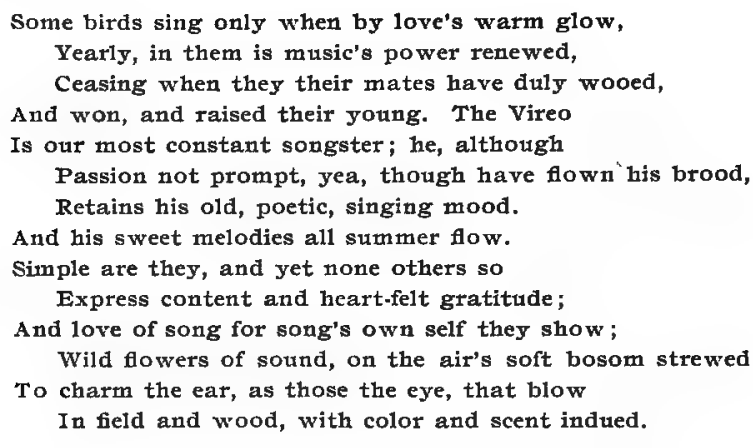

W. L. SYOEMAKER.

INCE the English Sparrow was imported and has multiplied to an indefinite (120) extent, few of our native birds build their nests in the thickets and ornamental trees of our large parks in the cities. Those imported anarchists of the feathery tribe occupy at once all the nesting-boxes placed in trees or attached to posts and buildings. Bluebirds, Wrens, and other hole breeders are always robbed of their nesting-places where the Sparrow has become abundant. Not only to those but to many of our small birds the Sparrow has become obnoxious by its quarrelsome disposition, audacious familiarity, and rude combativeness. Birds, accustomed to build their nests in the highest tree-tops, probably suffer the least from these intruders. Some observers explain the absence of various other birds, formerly common, by the absence of dense ornamental shrubbery; yet it is a fact that even in the rural districts and in cities where trees and shrubs are plenty, the native birds are represented by only a few species. Wandering through Lincoln and Humboldt Parks of Chicago during the breeding time, one is quickly convinced of the truth of this statement. The Sparrow prevails everywhere, but where is our beautiful Oriole, the sweet singing Catbird, the Swallow, the lovely Bluebird, the Chippy and Song Sparrow, the Cedarbird and Goldfinch, who generally like to be near human abodes. In the squares of New Orleans so rich in magnificent trees, beautiful shrubs, gorgeous crinums, and other semi-tropical plants, I have seen only the Sparrow. The streets and larger gardens in Milwaukee contain beautiful specimens of shade-trees. Nowhere have I seen such splendid tall; high-arched elms, nowhere such beautiful sugar maples, birches, mountain ashes, and box elders. Though their leaves come late in May, they afford throughout the summer months, which in this latitude are extremely warm, dense and refreshing shade; and when in autumn the deep green of the maples and other trees changes into bright and deep red, their appearance is enchantingly beautiful. And yet these trees are sought by birds only during their time of migration and in winter. Few only are seen during the breeding season. Apart from swarms of Sparrows I have seen only occasionally a Robin, a pair 
of House Wrens, a Summer Warbler, and now and then a Goldfinch. Though searching diligently I could not discover any other, until an enthusiastic lover of nature, a former school mate and now my assistant writer, Miss Hedwig Schlichting, called my attention to the WARBLING VIREo, which chanted its sweet soliloquy in one of the maples near her home. This was during the last days of May. The loud, incessant mellow warblings were poured forth, while the bird was searching among the dense foliage for insects. A few days later, when the majority had arrived from the South, the song resounded from all sides through the fresh, luxurious green in the streets of the finer parts of the city. Here its favorite trees are always the sugar maples and the tall, arching elms. Since my boyhood I have observed this familiar songster in the forest and ornamental trees of Wisconsin. Later I found it equally common in Illinois and Missouri. In New England and in all the Northern and Middle States it seems to be common everywhere, where large shade-trees are to be found. During the breeding season we may find this Vireo from the Atlantic to the Pacific Ocean, and from the mountainous regions of the Southern States, north to the fur countries. I have never observed it in the Gulf region in summer, although the magnificent evergreen magnolias and the wide spreading live oaks would afford excellent haunts for this bird. Only on a few occasions I have seen it during the spring migration in south-eastern Texas.

The tall trees in villages, towns, and even large cities, are the favorite haunts of the Warbling Vireo. In portions of the country, not cultivated, it is more or less common along the wooded margins of creeks and streams and on the edges of the woods. No other ornithologist has presented us with such a true and beautiful sketch of the Warbling Vireo's life and haunts as Dr. Elliott Coues. He writes as follows:

"Warbling Greenlets, whether of the Eastern or of the Western type, inhabit all the woodland of temperate North America. But in choosing their summer homes they usually show good taste enough to seek the luxuries of city life, displaying at the same time the force of character required to escape its dangers. Neither disposed to undue familiarity, nor given to over-confidence, these urbane birds move in a quiet circle of their own, in slight contact with less polished members of society, quite apart from the vulgarity of the street and market place, and always with the easy self-possession that marks the well-bred. We seldom see them, indeed, they are oftener a voice than a visible presence-just a ripple of melody threading its way through the mazes of verdure, now almost absorbed in the sighing of foliage, now flowing released on its grateful mission. Their's is a tender, gentle strain, with just a touch of sadness, borne on the same breath that wafts us the perfume of April's early blossoms; and these are all the sweeter for the instillation of such song. From the poplar that glances both silver and green as its tremulous verdure is stirred-from the grand old halls of the stately, splendid flowered liriodendron-from the canopied shade-weaving elm, and the redolent depths of magnolia - issues all summer long the same exquisite refrain, while the singers glide through their hermitage unseen. Who would know these spirituelle musicians better must be quick to catch a glimpse of a very small sober-colored bird whose tints are those of its leafy home, and whose course in the heart of the trees is as devious as the play of the sunbeam itself.

"The Warbling Vireo is no less agile a bird than his cousin the Red-eye, and 
equally tireless in the pursuit of his insect prey; both these birds sing as they go, with an unconscious air, as if in a reverie; but the easy and wonderfully skilful modulation of the former's flowing song contrasts to great advantage with the Red-eye's abrupt and somewhat jerky notes. Both are among the most persistent of our musicians; in the Middle States, for example, their notes are heard from the latter part of April until far into September, and at all hours of the day. But much as we may admire Gilvus in the agreeable sentiment which his song inspires, we owe him a higher and more respectful consideration for the good services he renders us in a very practical way. Inhabiting by choice our parks, lawns, and orchards, and even the shade-trees of our busiest streets, rather than the untried depths of the forest, these birds çollectively render efficient service by ridding us of unnumbered insects, whose presence is a pest, as well as a continual annoyance to sensitive persons. They take a foremost place among the useful birds for whose good services in this regard we have reason to be grateful, being much more beneficial than the European Sparrows, which we have imported for the same purpose, and against whose insolent aggressions these tender birds should be protected. The comparative abundance of these two species being duly considered, there can be but one opinion in the matter of their respective efficiency in destroying noxious insects; for the Vireos are particularly insectivorous birds, while Sparrows eat insects only at certain seasons, and then only through caprice; their natural food is seeds, and at present, in this country, they feed for the most part on street garbage."

The Warbling Vireo is in full song when it arrives from the South, in southwestern Missouri about April 28, in Wisconsin fully three weeks later. The very plain and modest colors account for its being frequently overlooked and confounded with other birds. It usually searches in the highest tops of tall shade-trees for insect food, especially under the leaves and branches, and always in that near-sighted way, peculiar to all Vireos. We can scarcely see it, as it moves along the branchès, but nevertheless we know that it is there, for the familiar, mellow song is incessantly uttered. From the tall elms and maples around our dwellings its music resounds from early morn till late in the afternoon, and from its arrival until long after the summer has gone. The song is not so loud and powerful as that of the Red-eyed Vireo. It is more prolonged, more liquid, sweeter, and exceedingly melodious. Once heard, it is ever remembered. Like its near congener, it also sings during the warmest part of the day, and even in July and August, when almost all other birds are silent.

Like all other Vireos, the Warbling Greenlet builds an elaborately woven and beautiful basket-like nest. It is usually suspended at a height from thirty to fifty feet, and is built in a horizontal.twig near the top of the tree, "secure from intrusion from their human neighbors, and protected by the near presence of man from all their more dreaded enemies." It is almost always protected from rain and sun by a canopy of leaves. In the far West, in Utah, Mr. Ridgway found nests, which were built in aspens only about four feet from the ground. Other nests, on the contrary, were built fifty to seventy and even hundred feet from the ground, "right under the canopy of foliage of such large trees as the elms, maples, and poplars, where they may sway in the breeze, but are secure against ordinary accidents of the weather, and remote from most enemies, 



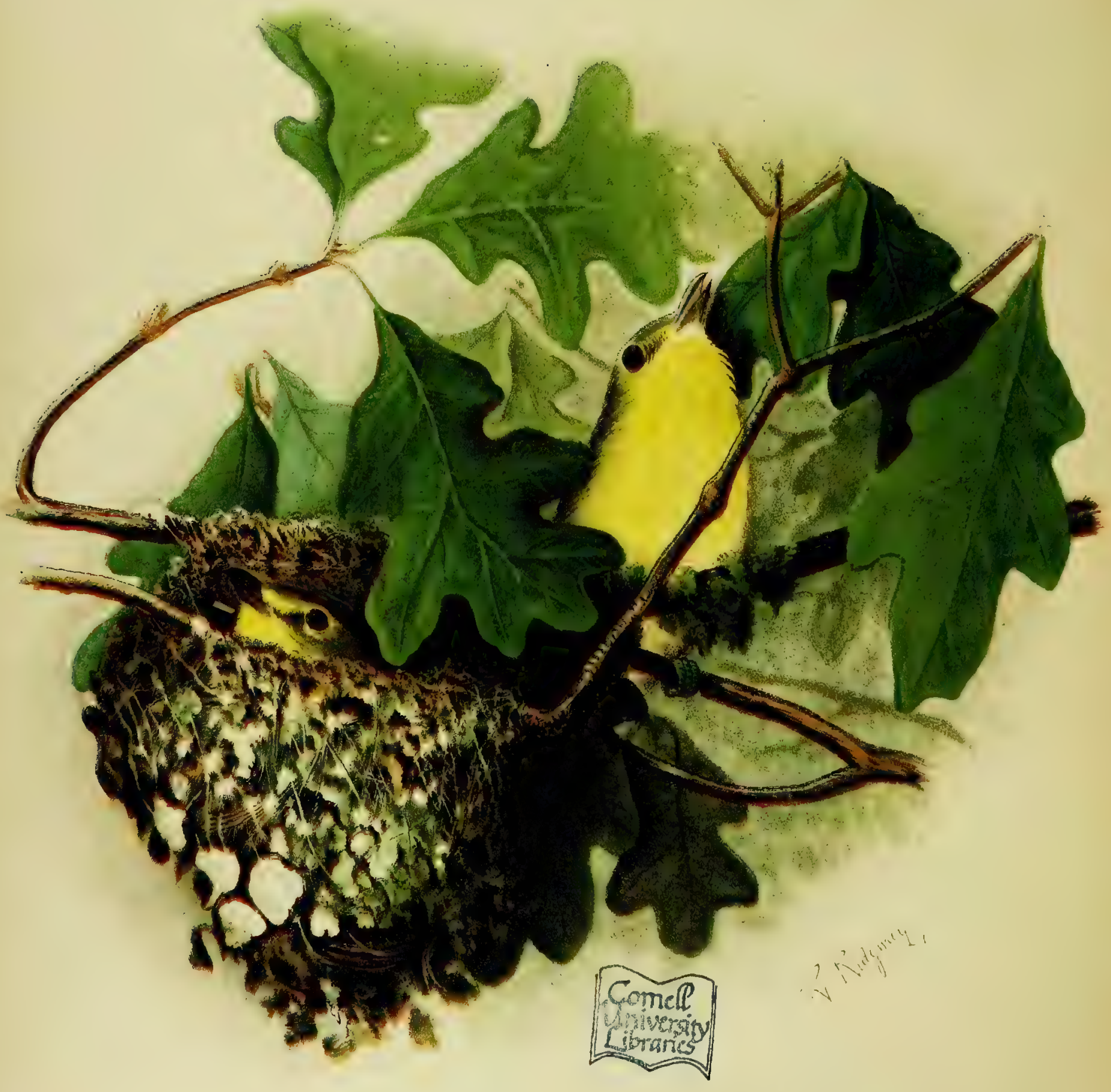

VIREO FLAVIFRONS VIEIIL. む GELBKEHLIGER VIREO. Yellow-throated Vireo. 
the inevitable Cowbird alone excepted." The structure is composed of fine bark-strips, flax-like fibres, leaves, bits of paper, and is lined with fine grasses and strips of bark. The exterior is very strong and durable, but it does not show such a variety of decorative matter as the Red-eye's nest. A few spider nests, now and then a piece of white birch bark, compose usually all the decoration the outside of the Warbling Vireo's nest shows. The eggs, three to four in number, are clear white; spotted and often blotched with dark and reddish-brown at the larger end. Sometimes there are a few fine spots scattered over the entire surface of the egg.

The Warbling Vireo leaves Wisconsin early in September and south-western Missouri about Sept. 20. It winters from southern Mexico southward.

NAMES: WaRbLING VIREo, Warbling Greenlet, Warbling Flycatcher.-Sängervireo (German).

SCIENTIFIC NAMES: Muscicapa gilva Vieill. (1807). VIREO GILVUS BonaP. (1824). Vireosylvia gilva Cass. (1851). Vireosylvia swainsonii Brd. (1866). Vireo gilvus var. swainsonii Coues (1874). Vireosylvia gilva swainsonii Ridgw. (1873). Muscicapa melodia Wils. (1812).

DESCRIPTION: “Scarcely distinguishable from Vireo philadelphicus in color and size. A very plainly colored bird, without wing-bars, or blackish stripe along side of crown, or decided contrast between color of back and of crown, which is bordered by a whitish supraciliary line; region inmediately before and behind eye, dusky. Under-parts, dull white, with a faint yellowish, sometimes a creamy or buffy tinge, shaded along sides with a delicate wash of the color of the back. Bill, dark horn-color above, pale below; feet, plumbeous.

"Length, 5.00 inches or a little more; wing, 2.80 ; tail, 2.25 inches." (Stearns \& Cotres, "N. E. B. L.," I, p. 200.)

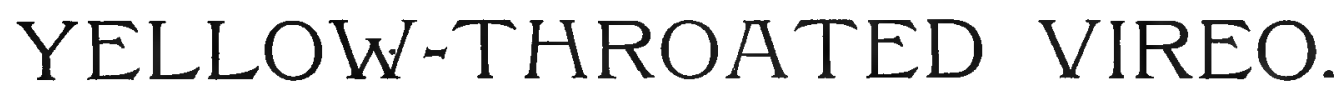

Vireo flavifrons VIEILLOT.

Plate XVI.

Pretty green worm, where are you? Dusky winged moth, how fare you, When wind and rain are in the tree? Cheeryo, cheerebly, chee, Shadow and sun one are to me. Mosquitoe and gnat, beware you, Saucy chipmunk, how dare you climb to my nest in the maple tree, And dig up the corn At noon and at morn? Cheeryo, cheerebly, chee.

ANoNyMous.

T.N THE early days of April, 1886, I had to spend, much against my inclination, some A time at RiverJunction or Chattahoochee, a little village near the Chattahoochee River, in northern Florida. Continued rains had swelled the rivers, inundated the lowlands, and damaged a number of rail-road bridges. The journey through northern and central Georgia, so rich in beautiful scenery, had been very interesting; so much the more disagreeable was the forced stay for an indefinite time in this place, surrounded by apparently interminable swamps. I was yearning to see the renowned Suwanee, the majestic St. Johns, to roam 
about in the far famed orange groves, and to investigate the hammock woods and palm groups of southern Florida. Meanwhile I could not remain inactive where I was. The air was extremely mild and delightful, filled with the fragrance of innumerable flowers. The trees were covered with fresh verdure, and a thousand-voiced chorus of Warblers passing northward to their summer home, resounded everywhere, and seemed to urge me to penetrate this to me unknown world; and I never regretted my stay at Chattahoochee. The forest is composed mostly of magnolias, sweet bays ${ }^{1}$, sweet gum trees, elms, oaks, and, on higher ground, of long-leaved pines. A dense growth of underwood, consisting of low, red flowering horse chestnut ${ }^{2}$, sparkleberry, holly, different species of haw ${ }^{3}$, styrax ${ }^{4}$, snow-drop ${ }^{6}$ and anise trees ${ }^{6}$, I found everywhere. Some places were filled with pink flowering azaleas ${ }^{7}$. In the gardens the last camelias were shedding their bloom, and the first buds of the sweet and strongly scented gardenias (Cape jasmine) were opening. The woods all around were swarming with northward bound birds, of which one particular species surprised me by being represented in unusually large numbers. It was the YELLOW-THROATED VIREo, a bird which I heretofore had always observed during the spring migration in very limited numbers. The males uttered their peculiar notes so loud and continually as to rivet my attention. Especially the characteristic geery, geery, with which the lay always begins, was heard everywhere. As a rule these Vireos are silent during their spring migration,' and I never heard them as I did in that place. This Vireo does apparently not breed in Florida, although it seems to be not uncommon in the upper districts of Georgia and in the mountains of South and North Carolina. It is distributed over the Eastern United States west to Kansas and Nebraska, north to Manitoba, south, in winter, through eastern Mexico to Costa Rica. Although it breeds throughout its United States range, it is very locally distributed. It is quite a common bird in Sheboygan County, Wis., where it breeds in apple and ornamental trees near dwellings, but I have seen only a few near Milwaukee and in northern Illinois. In south-western Missouri it is almost as abundant as the Red-eye. It there prefers the timbered lands near streams, where it hunts for insects among the foliage of the tree-tops, and I have never seen it in orchards and gardens. I have also observed it in south-eastern Texas, but not in the post oak region farther west. Col. N. S. Goss found it a rather abundant summer sojourner in eastern Kansas, where it inhabits the bottom woods; but as "they are not wild and timid, will no doubt soon become accustomed to the presence of man, and readily make their homes about our prairie dwellings, as soon as the trees and shrubbery form inviting haunts; at any rate, they are much more common here than in former years." (Goss.) Near St. Louis this Vireo is also frequently met with in the woods near creeks and streams. According to Mr. Robert Ridgway ("Ornithology of Illinois." Vol. I, p. 186), it is a common bird in the woodlands of southern Illinois. "In some respects the Yellow-throated Vireo," says Mr. Ridgway, "is the most remarkable of all the species of the family which occur within the United States. It is decidedly the finest songster of all those which reach the Northern States, has the loudest notes of admonition and reproof, and is the handsomest in plumage. So far as the

Magnolia glaucr. 2 Aescultas Pavia. \& Viburnum. 4 Styrax grandifolium. B Halesia tetraptera. B Illicium Florldanum. 7 Azalea nudifiora. 
writer's experience with it is concerned, he has found it only in the woods, and mostly in the luxurious forests of the bottom lands, where it may be regarded as the most abundant species of its family." In certain parts of New England it is a familiar summer resident. Dr. T. M. Brewer gives a highly interesting description of the bird as it appears in Massachusetts: "All the older ornithological writers, in speaking of the Yellowthroated Vireo, repeat each other in describing it as peculiarly attracted to the forest, seeking its solitudes and gleaning its food chiefly among its topmost branches. Such has not been my experience with this interesting and attractive little songster. I have found no one of this genus, not even the Warbling Vireo, so common in the vicinity of dwellings, or more familiar and fearless in its intercourse with man. All of its nests that I have ever met with have been built in gardens and orchards, and in close proximity to dwellings, and they have also been exclusively in comparatively low positions. In one of the most recent instances a pair of these birds built one of their beautiful moss-covered nests in a low branch of an apple tree that overhung the croquetground, within a few rods of my house. It was first noticed in consequence of its bold little builder flying in $\mathrm{my}$ face whenever I approached too near, even before its nest contained any eggs. The grounds were in frequent use, and the pair were at first a good deal disturbed by these constant intrusions, but they soon became reconciled to their company, and would not leave their position, even though the game was contested immediately under their nest, which was thus often brought within a foot of the heads of the players. Before this nest was quite finished, the female began her duties of incubation. Her assiduous mate was constantly engaged at first in completing the external ornamentation of the nest with lichens and mosses, and then with a renewal of his interrupted concerts of song. These duties he varied by frequent captures of insects, winged and creeping, most of which he duly carried to his mate. His song was varied, sweet, and touchingly beautiful. Less powerful than the notes of several others of its family, except those of the Warbling, I know of none more charming."

In Sheboygan County, Wisconsin, this Vireo usually arrives about May 15, simultaneously with the gorgeous Baltimore Oriole. Although originally a native of the beautiful forests of this region, it now seems more at home in the orchards and shadetrees near dwellings. It is now much more abundant than in the pioneer days, when almost all the land was covered with heavy timber. This beautiful and unsuspicious bird was one of my special favorites in the days of my boyhood. In front and on the sides of my early home stood a few large and spreading elms, a number of middle sized sugar maples, oaks, ashes, lindens, June-berry trees, and white-thorns, remnants of the once so magnificent forest. As cats, nest-robbing boys, and other bird enemies were strictly kept out of our premises, this grove and the near orchard were the very paradise for all our familiar songbirds. Bluebirds, Titmice, Wrens, and Martins selected their nesting-sites in the many nesting-boxes that I had provided for them. Chipping Birds and Song Sparrows found the shrubbery a very convenient home. Baltimore Orioles, Warbling Vireos, and Robins took up their abode in the elms, while Goldfinches, Red-eyed Vireos, Yellow Warblers, and Kingbirds showed a decided partiality for the maples, as Purple Finches did for the evergreens. Catbirds nested in the yellow honey-suckles, and Thrashers preferred white-thorns for the same purpose. 
Mourning Doves, Cedarbirds, Least Flycatchers, and especially the Yellow-throated Vireos selected the large and spreading apple trees for their nesting-sites. Of all the Vireos the Yellow-throated was the most familiar and beatiful. Its fine and peculiar song, commencing always with a very clear and mellow geery, geery, could be heard from the warmer days of May through June and the early part of July. Later, when the young became independent of parental care, all seemed to retreat to the woods. Often I watched them there in the latter part of July, in August, and early in September and heard snatches of their song. This song is one of the most beautiful and characteristic of our woods, orchards, and ornamental groves. It is exceedingty liquid, mellow and sweet, quite different from the loud strains of the Red-eye and the prolonged and somewhat tender song of the Warbling Vireo. The notes are clear, full of variety and charm, and are much admired by all who appreciate woodland melody of the sweetest type. If some enemy should happen to approach their nest, the birds utter notes full of anxiety and sadness. Their common call-note is a soft and mellow wee, wee.

The elegant nest I have often discovered at the extremity of some horizontal branch of an apple tree, usually not more than three to seven feet from the ground. The beautiful yellow breast always distinguishes the bird from other species. In the forest the structure is from ten to fifteen and even twenty-five feet from the ground. It is often conspictrously built in the extremity of a drooping branch. In the timbered lands near St. Louis and in south-western Missouri, where the bird always frequents the bottom woods near the banks of streams and creeks, it appears to be partial to oak groups, and the nest is usually placed in the horizontal branch of an oak. Our plate (XVI) gives a correct idea of .this Vireo's nest, exhibiting a copy of an exquisite water-color painting by Prof. R. Ridgway, the celebrated ornithologist of the Smithșonian Institution and National Musetum of Washington, D. C. Mr. Ridgway's bird portraits prove that he is not only an eminent artist, but also a friend of nature, a man of feeling and poetry. His bird portraits are far more natural and attractive than all others ever published. The picture of the Yellow-throated Vireo with its nest is perfection itself, and makes a description of the structure almost unnecessary. - The nest is very beautiful, strong, and durable. It is basket-like, composed chiefly of strips of fine bark, some flax-like fibres, mixed profusely with spider's webs, silky threads from insect cocoons, and skeletons of dry leaves. The outer surface is beautifully adorned with mosses and lichens, and sometimes with a few spider nests. The lining of the cavity consists of fine shreds of grape-vine and iron-wood bark, and sometimes of fine grasses. It requires about five to six days before the nest is finished. The birds work only in the early morning hours and sometimes also late in the afternoon. The mosses and lichens are fastened to the outside by the male while the female is breeding.

Mr. Nuttall describes a nest of this Vireo, found by him hanging in a forked $t w i g$ of an oak, near a dwelling. It was coated over with green lichens, attached very artfully by a slender string of cater-pillars' silk, the whole afterwards tied over by almost invisible threads of the same, so nicely done as to appear to be glued on. The whole fabric was thus made to resemble a natural knot of the tree, grown over with moss. Another nest found by Nuttall, was fixed on the depending branches of a 
wild cherry, and was fifty feet from the ground. So lofty a position is probably very unusual. Dr. Brewer says, he has never found a nest higher than ten feet from the ground.

The eggs vary from four to five in number. I have never found more than four in a set. The ground-color is white, often with a very perceptible roseate tint when fresh, in which respect they differ from all the eggs of other Vireos. They are more or less boldly marked with rosy and chestnut-brown spots, chiefly at the larger end.

The food of this Vireo conșists during the breeding time entirely of insects. Later in the season and in their winter-quarters, when insect-food gets scarce, various kinds of berries are also eaten. In its habits it resembles the other larger Vireos in almost every particular.

Early in September the majority leave Wisconsin for the South. Numbers of them winter in the dense hammock and palmetto woods of southern Florida, but the greater number pass further on to the West Indies. From the interior of our country they migrate to eastern Mexico, Central America, and even to Columbia.

NAMES: YelLow-Throated Vireo, Yellow-throated Greenlet. - Goldbrustvireo (German).

SCIENTIFIC NAMES: VIREO FLAVIFRONS VIEILl. (1807). Vireosylvia flavifrons Baird (1866). Lanivireo flavifions Lawr. (1866). Muscicapa sylvicola Wils. (1810).

DESCRIPTION: "A large, stout, highly colored species, with thicker bill than any of the foregoing. No evident spurious first quill; primaries apparently only nine, as in V. olivaceus and V. philadelphicus. Above, rich yellow-olive, shading to bluish-ash on the rump; below, bright yellow, the belly and vent abruptly white, the sides shaded anteriorly with olive, posteriorly with plumbeous. Extreme forehead, supraciliary line, and eye-ring, yellow like the throat. Lore, dusky; wings, dusky, with much white edging and two broad white cross-bars; tail, like wings, the feathers broadly edged with white. Bill and feet, dark plumbeous.

"Length, 5.75 to 6.00 inches; wing about 3.00 ; tail only 2.25 inches." (Stearns \& Coues, "N. E. B. L.," Vol. I, p. 201.)

\title{
BLUE $\sim$ HEADED VIREO.
}

\section{Vireo solitarius VIEILLOT}

\begin{abstract}
HIS FINE Vireo is not at all uncommon during the breeding season in Wisconsin and other Northern States and New England, although nowhere prominent in the composition of our ornis. It is more abundant in the Canadian fauna than in the Alleghanian. In Manitoba, north to the Mackenzie, it is rather common, also in the mountainous regions of New York, and some have been found breeding even in the Middle States. It occurs west to the Plains.

In the coniferous region of Wisconsin the Blue-headed, or Solitary Vireos are the first arrivals of the genus. They ustually appear about May 5 to 9 , if the weather permits, frequenting usually the woodland border, where the beautiful song may be heard from early morning till late in the afternoon. The basket-like hanging nest is from four to ten feet from the ground, and is always attached to a horizontal branch,
\end{abstract}


densely covered with foliage. It is more compactly built than other Vireos' nests; it has thicker walls, and the materials, consisting chiefly of asclepias and other flax-like fibres, are softer. All the nests I have found were only sparingly decorated with spider's nests on the outside. Mr. John Burroughs, whose excellent books on subjects of natural history ought to be in every family and school library, describes the love notes of these birds as being inexpressibly sweet and tender in both sexes. According to Dr. T. M. Brewer, the song of the male bears no resemblance to that of any other Vireo. It is a prolonged and very peculiar ditty, repeated at frequent intervals and always identical. It begins with a lively and pleasant warble, of a gradually ascending scale, which at a certain pitch suddenly breaks down into a falsetto note. The song then rises again in a single high note, and ceases. "For several summers," Dr. Brewer concludes, "the same bird has been heard, near my house in Hingham, in a wild pasture, on the edge of a wood, always singing the same singular refrain, during the month of June."

Of a nest found by Mr. Geo. O. Welch at Lynn, Mass., Dr. Brewer gives a more detailed description. It was "suspended from the branches of a young oak, about twelve feet from the ground. The external depth of this nest was only 2.50 inches, the diameter 3.25, and its cavity 1.75 inches deep, and 2.00 inches wide at the rim. It was constructed externally of strips of yellow and gray birch bark, intermingled with bits of wool and dry grasses. The external portion was quite loosely put together, but was lined, in a more compact manner, with dry leaves of the white pine, arranged in layers. Another nest, found at Hingham, was but two feet from the ground, on a branch of a hickory sapling. In its general structure it was the same, not differing in shape, being made to conform to its position, and being twice as long as it was broad. It contained four young, when found, about the 10th of June. One nest alone, built on a bush in Lynn, exhibits even an average degree of compactness in its external structure. This is largely composed of cocoons, which are woven together with a somewhat homogeneous and cloth-like substance. Within, decayed stems of grasses take the place of the usual pine needles. - In the summer of 1870 a pair built their nest in a dwarf pear tree, within a few rods of my house. They were at first very shy and would not permit themselves to be seen at their work, and suspended all labor when any one was occupied near their chosen tree. Soon after the construction of the nest two Cowbird's eggs were deposited, which I removed, although the female only laid two of her own before she began to sit upon them. By this time she became more familiar, and would not leave her nest unless I attempted to lay hands upon her. She made no complaints in the manner of the White-eyed, nor sought to attack like the Yellow-throated, but kept within a few feet, and watched me with eager eyes, until I left her. Unfortunately, her nest was pillaged by a Black-billed Cuckoo, and I was unable to observe her feed the young, as I had hoped to do."

The eggs, four, rarely five in number, have a white ground and are spotted pretty uniformly over the entire surface with dark and reddish-brown dots.

NAMES: BLUE-HEADED VIREo, Solitary Vireo, Solitary Greenlet. - Einsiedlervireo (German).

SCIENTIFIC NAMES: Muscicapa solitaria Wils. (1810). VIREO SOLITARIUS VIịIL. (1819). Lanjviręo solitarius Brd. (1858). 
DESCRIPTION: Upper parts, olive-green, of the same shade as in $V$. olivaceus, the crown and sides of the lead, bluish-ash in marked contrast, with a white line to and around but not behind the eye, and dusky lore. Below, pure white, the sides olive shaded, the under wing and tail-coverts quite yellowish. Wings and tail, dusky, most of the feathers edged with white, or with the color of the back, or both, and the wings with two white or yellowish cross-bars. Bill and feet, dark plumbeous. Fall specimens are commonly yellower than in spring.

Length about 5.50 inches; wing, 2.75 ; tail, 2.25 inches.

The Mountain Solitary Vireo, Vireo solitarius alticola Brewster, was discovered by the celebrated ornithologist, Prof. Wm. Brewster, of Harvard University, at Highlands, Macon County, North Carolina, May 29, 1885. It is larger than the true species, has a heavier bill, and different color of the upper parts. "In $V$. solitarius the crown and sides of the head are clear pure ash, in strong contrast with the olive-green of the back and rump; whereas in $V$. solitarius alticola the entire upper parts are nearly uniform blackish-plumbeous, with only a faint tinge of greenish on the back, which is essentially concolar with the crown."

"Throughout the elevated plateau occupying the south-eastern corner of Macon County, this new Vireo was one of the most abundant forest birds. It was found exclusively in open oak and chestnut woods, where its ringing voice, mingling with the rich music of the equally numerous Grosbeaks (Habia ludoviciana) and Scarlet Tanagers (Piranga erythromelas), was rarely still even at noontide. Its song was somewhat like that of $V$. solitarius, but to my ear much finer, many of the notes being louder and sweeter, and the whole performance more continuous and flowing. On the Black Mountains it was also a very common and conspicuous bird, ranging from about 4,200 feet to the lower edge of the balsams $(5,000 \mathrm{feet})$, and inhabiting woods similar to those just described." (Auk, III, 1886, p. 111, 112.) A nest sent to Mr. Brewster was found May 27, 1887, by Mr. J. S. Cairns, on Craggy Mt., Buncombe Co., North Carolina. It was in a chestnut, ten feet out from the main trunk and about twenty feet from the ground, and contained four perfectly fresh eggs. They were pure white, with a few fine spots, and rather numerous, minute dots of brown varying in tone from vandyke to seal-brown. The nest was suspended after the usual Vireo fashion. "In places the rim is nearly an inch in thickness. The exterior is beautifully diversified with white and brown sheep's wool, grayish lichens, small strips and fragments of decayed wood, and a few spider's cocoons, bound firmly to, or hanging loosely from, the frame-work proper, which is composed of coarse grass stalks and strips of bark, the latter partly a reddish colored inner bark, probably from the hemlock, but largely the pale golden, sheeny outer bark of the yellow birch ${ }^{1}$. The interior cavity is lined with fine bleached grasses and the reddish stems of some species of club moss."

Cassin's Vireo, Vireo solitarius Cassini Henshaw, another sub-species, inhabits the Western United States and is confined during the breeding season to the Pacific coast region. In Oregon, where it is a common bird, it frequents the coniferous woods, being found also in the alders and aspens. Nests were found in oaks and alders by Mr. A. W. Anthony. Dr. Merrill says, that these birds about Fort Klamath, Oregon, show a marked predilection for pines and firs, but are also found, though much less frequently, in aspen groves with Vireo gilvus. The nests and eggs resemble the latter, 
The Plumbeous Vireo, Vireo solitarius plumbeus Allen, a third sub-species, is found in the Rocky Mountain region. Dr. Elliott Coues says that it is by far the most common Vireo at Fort Whipple, Arizona. All these Vireos resemble closely the true species, and the Vera PAZ VIREo, Vireo propinquus RIDGw., of the Highlands of Guatemala, is also nearly allied to our Blue-headed Greenlet.

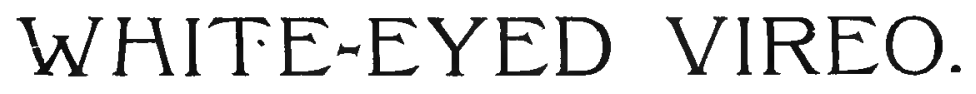

Vireo noveboracensis BONAPARTE.

Plate XV. Fig. 2.

Fis a lovely day in June. The air is filled with the delicious fragrance of wild 6 flowers, and from all sides the sweet music of numerous birds falls on our ear. Nothing is more enjoyed by the friend of nature at this time than to ramble through field and forest, to observe, to watch, to listen, to examine. We pass to-day the beautiful oak and beech forests, the mixed woods of pines and deciduous trees, to choose lower grounds, swampy places, along the edge of the forest. Ignoring the swarms of mosquitoes we penetrate the thickets, where dogwood, snowball ${ }^{1}$, willows, black, huckle, and gooseberry bushes crowd each other, overgrown and interlaced with smilax, grape-vines, virgin's bower, where clethras, azaleas, evergreen andromedas, and other beautiful shrubs lend a strange charm to these localities. In such places abound, in the North, Catbirds, Thrashers, Indigo Buntings, different Warblers, the common Grouse, and other birds. Farther south we find in swampy localities the Mockingbird, the brilliant Blue Grosbeaks, Cardinal Redbirds and Painted Buntings, Carolina Wrens, Chats, Water Thrushes, Kentucky and Hooded Warblers, and other small birds in great numbers.

In the Northern, Middle, and especially in the Southern States, we meet in such localities the very interesting and lively White-eyed VIreo, or "Politician," as Wilson called it. Where cool springs emerge from the hill-sides, where a rippling brook meanders through a dale, where thickets of shrubbery border marshy grounds, there this little bird is most frequently found. Dense forests, shady swamps in the woods, dry and mountainous localities it always avoids. Its favorite haunts are moist, shrub-covered woodland borders and patches of shrubbery among cultivated fields. In such places I found this bird from Wisconsin to southern Texas.

In the vicinity of Chicago I found the White-eyed Vireo in a few pairs only, especially near the Desplaines and Calumet Rivers, but it is more numerous farther south, in southern Illinois, Missouri, Tennessee, Pennsylvania, and.all the way down to Florida, Louisiana, and Texas. During the breeding season it is found also in southern New England. It "is strictly limited northward by the Alleghaniann fauna, and is more 
abundant in the Carolinian than elsewhere." In Wisconsin it is very rare. In the West it is occasionally found to the foot-hills of the Rocky Mountains. Its winter home extends from Florida and Texas southward.

I have nowhere found this bird in such large numbers as in south-eastern Texas, west to Austin. Near Houston it appeared not more numerous than Bell's Vireo, but along the West Yegua, in Lee County, it was more numerous than all the other Vireos together, in fact, it was one of the most abundant birds. Being very unevenly distributed, it is numerous in one locality, and scarcely or not at all to be found in another, to all appearance equally eligible. In its haunts this bird is easily found. Unlike almost all the Vireos, described in the preceding pages, this species prefers the low shrubbery and tangled thickets. In such places on the outer branches often hang the well concealed, purse-shaped nests two to four feet above the ground. The bird is easily detected by its peculiar call-note sounding like chickty-beaver, which is heard almost all day long and from all sides, when the pair is breeding. According to Mr. Robert Ridgway, who studied the habits of this bird in southern Illinois, "the White-eyed Vireo - popularly known tusually as the 'Little Green Hanging-bird,' or 'Chickty-beaver,' is an abundant species in suitable localities, which comprise hazel thickets, blackberry patches, bushy swamps, etc., where its presence is made known by its vociferous notes, which in loudness appear out of all proportion to the size of the little creature which produces them. These notes are remarkable for their oddity as well as for their strength. In Bermuda they are interpreted as ginger-beer,-quick, while in Illinois the writer has heard them translated by boys into chickty-beaver,-lim'ber, stick, with emphasis on the first syllable of each word."

The haunts of this Vireo are vociferously enlivened not only by this bird, but also by its many neighbors, all of whom live in these thickets in remarkable peace, showing even a kind of interest in each other. If a Catbird utters its mewing note, numbers of its feathered neighbors congregate at once, apparently asking for the cause. If a pair of White-eyed Vireos have their nest near by, they will surely attend such a meeting. "Like the Wrens and Titmice-like various birds, in fact, which live habitually in shrubbery, where they have to peer and pry about to see well-these Vireos show a good deal of curiosity and inquisitiveness when anything is going on that they do not quite understand; and if we take care not to frighten them into a flutter of excitement, they frequently come almost within arms' reach by slow and devious approaches, poising curiously on one twig after another, and soliloquizing the while in their quaint fashion. Their uneasiness, however, is chiefly exhibited during the breeding season, and all their vehemence is but the excess of their concern for their little families, which, as they seem to be aware, are peculiarly exposed to danger in their lowly homes; their ardor exhausts itself when the occasion is past, and what had been excessive solicitude gives way to the simple sprightliness and vivacity, which then appears as an agreeable trait. In the spring time they rival their relatives in brilliancy and versatility of song, which must be heard to be appreciated; it is a curious medley, delivered with great earnestness and almost endless variations, scarcely to be described in words, though several authors have made the attempt." (Dr. Elliott Coues.)

The borders of thickets more than their deeper mazes are the favorite dwelling 
places of this bird. Along the West Yegua Creek in Texas, in a distance of less than a mile, I found in 1882 more than forty nests, and I have no doubt that more could have been found for the seeking. The favorite nesting places were white-thorns, viburnum, and Mexican mulberry bushes growing on the edge of thickets and woodlands, or in the shade of taller trees, like elms, pecans, hackberry trees, etc. I also found several in the low hanging branches of elms and swamp oaks. These structures were the most beautiful Vireo nests I ever saw, quite different from nests of the same species in other localities. Their exposed surface was always beautifully decorated with the delicate soft greenish Usnea lichens and spider webs.

As I write this, there lay before me about a dozen nests from the West Yegua Creek, and about as many from northern and eastern regions. Not one is like the other except in shape. They are oblong, bag-like works of art, depending from a horizontal forked twig, and generally protected against rain and sunshine by overhanging leaves. A typical nest from Texas found by me May 12, 1882, I will describe more particularly. It was fastened to the uttermost end of a horizontal forked twig of a whitethorn about three feet from the ground. It was composed of Usnea lichens, fine ground moss, soft leaves, and fine grasses. The lining consisted of very soft and thin blades of grass. The exterior was heavily decorated with Usnea lichens, moss, broken leaves, and particles of bark, all firmly held together by spider webs and cater-pillar nests. Most of the Texan nests were fastened by the same material and in the same manner to the supporting twigs, the large quantity of spider nests and cater-pillar webs used in connection with Usnea lichens enable them to withstand months of wind and rain.

The nests from more northern regions somewhat resemble those found at the South, some being externally ornamented with particles of moss, others with bits of soft white birch bark, but they lack the bunches of greenish lichens which beautify the Texan nests in such a high degree.

The nests of the White-eye resemble in shape and size those of Bell's Vireo. The other larger species build shorter and wider nests. The average length of the nest is 4.50 inches, the width at the rim 2.25 inches and somewhat wider toward the middle. The interior is about 2.00 inches deep, the opening 1.75 inches wide. The nests are invariably built at the ends of horizontal forked twigs, usually three or four feet from the ground. At the time when the female begins to lay, the nest looks rugged and unfinished, and small branches of lichens hang down from it. The work is completed by the male, which labors assiduously to embellish and ornament the exterior. The fact, that the outside is often decorated with bits torn from newspapers, induced Alexander Wilson to apply to this bird the nickname "Politician."

The eggs, four to five in number, are clear white, sparsely speckled with reddishbrown and dark purple. Frequently the Cowbird lays her eggs into the nest of this Vireo; at times, indeed, two and even three of the eggs of this abominable parasite are found in one nest. The parent Vireos show great uneasiness when anyone approaches the nest, scolding all the while with very peculiar notes.

Near Washington, D. C., the White-eyed Vireo is a very common bird. Dr. Elliott Coues remarks: "In places where the White-eyes are numerous, as they are, for example, about Washington, these nests are among those we may most frequently brush 
against in threading our way through the thickets, and they are usually placed so low that one may look into them when standing on the ground. The tangled ravines along the course of Rock Creek, near the city just named, marking where numberless rivulets make into the main brook, are favorite resorts, where the nests will be found in a bunch of a sweet-brier, or on the wreathy stem of a blackberry bush, or, perhaps still oftener, at the very terminal fork of a slender, swaying branch of the sapling, whose lower limbs reach into some shady nook just over the bed of the rivulet-in any event, in a thicket, where the Catbirds, Thrashers, Chats, Cardinal Grosbeaks, Maryland Yellow-throats, and Carolina Wrens are all each other's neighbors. The White-eye's liking for low watery places is still further witnessed by its frequent, resort to the swamps that border the Potomac, in the same locality, where it nests about the very edges of the reedy tracts, and even in their midst, on the various little knolls that rise somewhat above water level. In August and September, when one goes shooting Reedbirds, Blackbirds, and Sora Rails, in the marshes that lie about Arlington, and along the course of the Eastern Branch, he is pretty sure to be scolded for his pains by one after another of these petulant little birds, which still linger in such places as $I$ have described, in company with buffy colored young Maryland Yellow-throats, and numberless reed-ragged Marsh Wrens."

If we approach the breeding haunts of this bird, it becomes extremely and vociferously irritated, and its chickty-beaver is heard louder than ever and with variations which denote the excitement. When in the central portion of our country on warm and sultry May and June days the feathered songsters fill the low thickets and the shrubbery on the woodland borders with their joyous lays and twitterings, the White-eyed Vireo is abundantly represented. When the Catbirds, Maryland Yellow-throats, Chats, Kentucky Warblers, Thrashers, and other tenants of such localities are silent, because the care for their nestlings leaves them no time for singing, this bird, while foraging, does not remit its peculiar notes. Only while returning with the bill full of food for the young ones, silence becomes a necessity for a few moments. Even the noon-day heat will not suppress those cheery notes. During the first few days after its arrival only the common call-note is heard, but later, when accustomed to its surroundings, the tones seem to change into a more perfect lay which, though not equalling in mellow loveliness that of the Red-eyed and Warbling Vireo, is still among the richest that are heard in the low thickets. The song is loud, varied, and melodious, and truly wonderful in the assiduity with which it continues to sing morn, noon, and eve from almost the time of its arrival till the days of its departure, when the leaves of its summer home assume red and golden hues, about the middle of September. Oft the notes are soft and plaintive, followed by loud and merry carols, so loud, indeed, that it seems impossible for so small a bird to be possessed of such force.

"This Vireo," says Dr. T. M. Brewer, "is one of the most conspicuous singers of this family. Its songs are more earnest and louder than those of any of our Eastern species, and exhibit the greatest variations, beginning in the earlier part of the season with a simple low. whistle, but changing in May into a very quaint and peculiar succession of irregular notes. Some of these are very softly and sweetly whistled, while others are uttered with a vehemence and shrillness that seem hardly possible in so small a bird." 
The song is seldom interrupted, except during the moments of swallowing a beetle or a moth, or carrying it to the female or young. On warm May and June days, when dark clouds suddenly shut out the sun, and the rain patters on the leafy roofs, under which other birds silently shelter themselves, the White-eyed Vireo cheerfully continues its song. Only when the rain lasts for hours in succession, this lively bird silently seeks shelter in the thickets, overgrown with smilax and other briers and wild vines. Dark threatening weather, storm, thunder and lightning will not interfere with its singing anymore than with that of the Red-eye, and after a protracted rain, while the trees are still dripping, the song is heard again.

Being a peculiar and very inquisitive bird, the White-eyed Vireo is easily recognized wherever it is found. If in the Eastern part of our country the observer passes in June through lowlands, where white swamp honey-suckles (clammy azaleas), pinxter flowers (purple azaleas), flame-colored azaleas, viburnum and dogwood bushes and other shrubs grow in profusion, he will soon notice this Vireo, which is at once attracted by any unusual object. He often approaches with utter fearlessness, very quietly to within a few steps, eying the intruder, turning its head, apparently listening, from one side to the other.

The food of this Vireo consists of all kinds of insects that live on the leaves, flowers, and bark of shrubs and small trees. Like "all its kindred, it feeds eagerly upon the young larvæ of the destructive canker-worm."

In south-eastern Texas it arrives from its winter home usually March 15. Several may pass the winter in sheltered localities on the bayous of southern Louisiana and south-eastern Texas, but the majority moves farther south. In the valley of the lower Rio Grande, in Bermuda and Florida it is a permanent resident. In the latter part of April I observed them in south-western Missouri, and in northern Illinois their arrival was made about May 15. They winter from the Gulf States southward to Guatemala.

A variety of this species, the KEY WEST VIREO, Vireo noveboracensis maynardi BREWSTER, inhabits the island of Key West, Fla.

NAMES: White-eyed Vureo, White-eyed Greenlet, Little Green Hanging-bird, "Chickty-beaver," "Politician" (Wilson), Hanging Flycatcher (Latham), Green Flycatcher (Pennant). - Buschvireo (German).

SCIENTIFIC NAMES: Muscicapa noveboracensis Gmel. (1788). VIREO NOVEBORACENSIS BoNAP. (1821). Muscicapa cantatrix Bartr. (1791). Vireo cantatrix Wils. (1810).

DESCRIPTION: Above, bright olive-green, usually tinged, more or less, with ashy on the hind-neck. Below, white, the sides of breast and belly, the axillars and crissum, bright sulphur-yellow; a bright sulphuryellow line from nostril to and around eye; lores, dusky; two conspicuous yellowish wing-bars; inner secondaries broadly edged with yellowish; bill and feet, dark plumbeous, Eyes, white.

Length, 4.50 to 5.00 inches; wing, 2.42 ; tail, 2.00 inches. 


\section{BLACK-CAPPED VIREO.}

Vireo atricapillus WoodHouse.

周HIS INTERESTING Vireo was discovered by Dr. G. W. Woodhouse May 26, 1851, near the source of the Rio San Pedro in south-western Texas. Very little additional information regarding it has been brought to light until the year 1879 , when Mr. Wm. Brewster, of Cambridge, Mass., presented an excellent account of the BLAcKCAPPED VIREo in the "Bulletin of the Nuttall Ornithological Club." In that year Mr. Edmund Ricksecker of Nazareth, Penn., informed Mr. Brewster that a number of nests had been discovered by Mr. W. H. Werner, of South Bethlehem, Penn., in May 1878, in Comal County, Texas. The last-named gentleman gave Mr. Brewster the following account of the nesting habits of these Vireos: "I first observed the Black-capped Vireo in the north-western part of Comal County, Texas, along the Guadelupe River, about twenty-three miles north-west of New Braunfels. They were not very plenty; I noticed during my rambles ten to twelve specimens in a radius of about ten miles, in the course of six weeks. The peculiar song of the male first attracted my attention, and as soon as I saw the bird I was sure that it belonged to the Vireo genus. They seemed to prefer mountainous districts; at least $I$ always found them in such localities. They frequented low brushwood, and built their nests from three to four feet above the ground. They were of a very lively disposition, restless, I should say, always flitting about from bush to bush, warbling and mimicking other birds like a Mockingbird in miniature. They seemed to be very much attached to their nests, and were very tame while sitting, so much so that at different times I walked up to the nest and touched it with my hand before the bird would leave it."

Mr. Brewster describes a nest, which Mr. Ricksecker sent him, in his usual accurate manner. "It is suspended in the fork of two very slender twigs, and is in every way after the usual type of Vireonine architecture. In a few points of detail, however, it differs slightly from any Vireo's nest that I have seen. Although, generally speaking, of the ordinary cup-shaped form, the walls are unusually thick and firmly felted, and the entrance being very much contracted, the bulging sides arch over to the mouth of the nest, giving to the whole a nearly spherical shape. This peculiarity may be of an individual nature, though it is conspicuously shown in the specimen represented by Mr. Werner's drawing (Bull. Nutt. Orn. Club. Vol. IV, p. 193, 194. Plate 1). The measurements of my nest are as follows: Greatest external diameter, 2.90 inches; external depth, 2.25; internal diameter at mouth, $1.30 \times 1.68$; internal depth, 1.40; greatest thickness of walls, .63 inch. Of the materials which compose it little really need be said, save that they are of the general kind and appearance made use of by most Vireos; but for the benefit of the critical in such matters, I will present the following analysis, premising that, as I have never been in Texas, I am not posted on the botany of that State, and consequently feel somewhat incompetent to identify 
the collections embodied in their domicile by the industrious little birds. The great bulk of the structure, however, is made up of fine strips of reddish bark, probably from some species of cedar, layers of small delicate, bleached leaves of a former year's growth, a few coarse grasses, one or two catkins, and several spiders' cocoons. These are firmly bound together, and the whole attached to the forked twigs above by fine shreds of vegetable fibre, caterpillars' or spiders' silk, and sheep's wool. The lining is of fine grasses and what appear to be the slender needles of some coniferous tree, the whole being arranged with that wonderful smoothness and care which belong to the highest order of nest-builders alone. .. The eggs are regularly ovoid in shape, and of a uniform pure, though rather dull, white, without spots or marking of any kind. In this last respect all the specimens obtained during the past season in Comal County, Texas, agree. In reply to my inquiries on this point, Mr. Werner assures me that the closest scrutiny on his part has failed to discover even the faintest dotting upon any of the specimens that he has examined, while Mr. Ricksecker writes that his sets are exactly similar in shape and color to those now in my possession, and that all he has seen are entirely immaculate."

The Black-capped Vireo has been found breeding also in Medina, Comanche, Cooke, and Tom Green Counties, in Texas, and I have observed it in the live oak and mesquit prairies of Lee and Lafayette Counties. The late Col. N. S. Goss found this bird breeding in Kansas. In his excellent work, "History of the Birds of Kansas," he gives the following description: "While collecting and observing birds in south-eastern Comanche County, Kansas, from May 7 to 18, inclusive, 1885, I captured three pairs of the Black-capped Vireo, and saw quite a number, all in the deep ravines in the gypsum hills, on the Red or Salt Fork of the Arkansas River. The birds were quite bold and noisy, but this may be the case only during mating and the early part of the breeding season. They are very pleasing singers, their song being not like the 'Who's-afraid,' jerky notes of the White-eyed Vireo, nor as loud as those of the Red-eyed, but a more warbling and varied song than that of any other of the family which I have heard. On the 11th I found a nest near the head of a deep cañon, suspended from the forks of the end of a horizontal branch of a small elm tree, about five feet from the ground. It was screened from sight above by the thick foliage of the tree and the larger surrounding trees, but beneath, for quite a distance, there was nothing to hide it from view. The material, however, of which it was made so closely resembled the gypsum that had crumbled from the rocks above, and thickly covered the ground, that I should have passed it by unnoticed had I not, on my near approach, been attracted to the spot by the scolding and the excited actions of the birds. On discovering the nest, I did not stop to examine it, but kept leisurely on my course till out of sight, then cautiously turned back, and, at a safe distance, had the pleasure of seeing both of the birds busily at work building their nest, then about two-thirds completed. The nest is hemispherical in shape, and composed of broken fragments of old, bleached leaves, with here and there an occasional spider's cocoon, interwoven together, and fastened to the twigs with fibrous strippings and silk-like threads from plants and the webs of spiders, and lined with fine stems from weeds and grasses. On the 18th, my last day in the vicinity, I went to the nest, conficlently expecting to find a full set of 
eggs, but, on account of the cold, wet weather, or for some other cause, the bird had not laid, and I had to content myself with the nest."

Mr. Goss found the birds very common near the south line of Kansas, especially in south-eastern Comanche County. They arrive there the last of April and leave in September. In the south-eastern part of Texas I have never observed this species.

NAMES: BLACK-CAPPED VirEO.

SCIENTIFIC NAMES: VIREO ATRICAPILLUS WOODHOUSE (1852).

DESCRIPTION: "Adult male: Top and sides of head, deep black, the lores and orbital ring pure white; lower parts, pure white, the sides and flanks olive-greenish, tinged with yellow; upper parts, olivegreen, the wings and tail black, with pale olive-yellow edgings. Adult female: Similar to male, but black of head usually duller, more slate-colored.

"Length, 4.40 to 4.75 inches; wing, 2.15 to 2.30 ; tail, 1.80 to 2.00 inches." (Ridgway.)

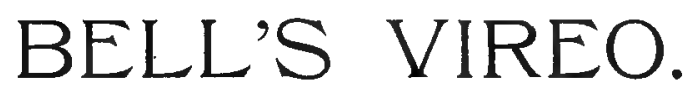

Vireo bellii AuduBon.

TN TEXAS I had the opportunity, not only of becoming acquainted with many species 6f of birds, never seen before in their haunts, but on my daily rambles in all directions I also came in contact with many disagreeable, annoying, and even dangerous animals. Sitting down on the ground or on an old log with the view of making close observations, one is at once troubled and bitten by ants and mosquitoes. In April fleas are exceedingly annoying, and wood-ticks are especially fond of penetrating through one's very clothes, boring themselves into the skin, to be removed only with difficulty. Redbugs (or "jiggers"), too small to be seen, work themselves also through the clothes and into the skin, "making one almost wild with intense itching." Partial relief may be obtained by the application of strong salt water or ammonia before going to bed, and before going out into the shrubbery in the morning, by rubbing the skin with a good quantity of kerosene. The removal of the loose bark of a tree brings to light numbers of scorpions ${ }^{1}$, and under stones and rotten wood every space seems to be filled with centipedes ${ }^{2}$. On the edge of woods and on prairies we notice many small, round cavities in the hard dark soil. From these holes glare eagerly the fiery green eyes of the tarantula $^{3}$. Woe to him who has the misfortune of being bitten by one of them. Harmless, though feared by many, are the horned toads or "horned frogs" 4 , and grass-green lizards ${ }^{5}$, which run with wonderful velocity up and down the tree trunks and along the fences. Another very swift lizard ${ }^{6}$, striped with yellowish on the back, lives on fences and among stones. - It is necessary to be carefully on the guard against the many snakes, although only few of them are poisonous. In the rural parts they often glide at night through open windows into the houses and make themselves quite at home

- 1 Buthus carolinensis. 2 Scolopendra castaneiceps. 3 Mygale Hentzii. + Phrynosoma cornutum. 5 Anolis principalis. G Ameiva sex-lineata. 
behind books and furniture, but particularly among bedding, blankets, and pillows in the bed rooms. Especially is this done by the very abundant chicken snake. Small specimens even entered my bird cages on the walls and swallowed the Canaries, Magpie Finches (Amadina cucullata GRAX), Zebra Finches (Amadina castanotis Gould), and Cut-throat Finches (Amadina fasciata Sw.), etc. Many a narrow escape I had from being bitten by the moccasin or copperhead ${ }^{1}$, when I was removing low brush with my hands, or was carelessly 1ying on the ground. On rising I frequently noticed one of these exceedingly poisonous animals in close proximity, the head lifted for an attack. These snakes are not easily noticed owing to their color, which is much like the old dead leaves or the ground. On logs lying in the water and on the borders of swamps and creeks, I often met the most dangerous of all our poisonous snakes, the water moccasin ${ }^{2}$. Quite plentiful, though less dangerous, are the often huge rattle-snakes, who, upon being approached, always give their peculiar warning with their rattle. All these venomous snakes move slowly and never climb bushes or trees.

The slender, long, and very speedy coach-whip snakes are the terror of all the small birds, as they desolate every nest within their reach, especially during the night time. On the 15th of April, 1881, I was roaming through the level prairies, dotted with insulated thickets, located south of Houston, partly with the intention of watching the northward bound birds, but chiefly to observe the Cardinal Grosbeaks and Mockingbirds at their work of nest-building. Frequently I had to crawl on hands and feet through the thickets, made almost impenetrable by masses of thorny trailing vines. I had just found in the centre of one of these thickets a Cardinal's nest, when I suddenly heard from the outer border shrill notes of anguish. Quite a number of different birds, evidently in close proximity to each other, joined in giving their alarm. Upon reaching the spot as quickly as I could, I readily discovered the cause of all this disturbance. A coach-whip snake, firmly coiled about a twig, held a still living female Cardinal in its terrible coils. It was a cruel scene in this apparently so peaceful and idyllic spot. The infortunate bird made a strong defence, but the firmly tightened coils of the furious animal soon ended the agony of its victim. The courageous male, assisted by other birds, were bravely attacking the snake, which, however, defended itself by quickly moving its head in all directions, hissing and darting its tongue in and out. The strangled bird was, however, not to remain unavenged. One stroke dealt by a stick on the back disabled the beast, another crushed its head. Among the birds attacking the enemy I noticed two particularly anxious little singers, which could hardly calm themselves even after the snake was lying dead on the ground. Soon I discovered the cause of their anxiety. Quite near the spot where the just described tragedy had been enacted, hung, partly hidden by leaves and twigs, a beautifully constructed, purse-shaped nest-a Vireo's nest. To which species it belonged, I had to ascertain by close examination. After I had killed the snake, most of the birds had left the spot. Almost perfect calm reigned again, and only the poor male Cardinal was bemoaning the loss of his mate in the most plaintive notes. Even the two Vireos had become silent after I had moved some little distance from their nest, the position of which I now closely examined by means of my fieldglass. The female bird at once resumed her place in the nest, while the male went out 
foraging for insects, continually singing while hunting among the branches and flower trusses of the shrubs.

The White-eyed Vireo had its nest in a neighboring thicket, hanging in the extremity of a Viburnum dentatum. The nest of the Vireo under consideration, although quite similar, was built mostly of plant fibres and Spanish moss, showing nothing of the beautiful decoration consisting of lichens and mosses, so peculiar to the nest of the former species. Although quite lively, these Vireos showed nothing of the White-eye's irritable and petulant temperament, and their notes were not so expressive and loud. This species proved to be BeLL's VIREo, or the "PrairIe GreEnLET," a tolerably common summer resident in all the prairie districts of Texas. In south-western Missouri it is abundant in all the prairie districts, dotted with thickets of dwarf oaks and masses of blackberry, snow-berry, and hazel bushes, and hedge-rows of osage oranges, and near St. Louis and in southern Illinois it seems to be equally common. In northern Illinois it also occurs as a rare summer resident. It is a bird of the Mississippi valley region, west to the base of the Rocky Mountains.

Mr. Ridgway gives a very correct description of the song: "... During a lull in the chorus we heard, from the depths of the thickets, a very curious gabbling or sputtering song, which was entirely new to us. We hastened to the thicket, and, entering it as far as possible, lay in wait for the strange songster to resume his vocal performance. In a few moments a little grayish bird carefully approached, flitting cautiously from twig to twig, now and then halting, and, after uttering the peculiar notes which had attracted our attention, would stretch out his neck and eye us with great curiosity and evident suspicion. After observing him carefully to our satisfaction at a distance of hardly a rod, we found that he was Bell's Greenlet. In its habits this species is the nearly counterpart of the White-eyed Vireo, inhabiting, like that species, dense thickets or brier patches. In Illinois it is confined to the prairie districts, and is almost everywhere a much less common bird than $V$. noveboracensis."

In lowa it is perhaps the most common species of the genus, frequenting, according to Mr. Lynds Jones, the brush fringing the woods or road-sides, where it attaches its nest to the hazel bush. The nest is a neat, purse-shaped structure, suspended from some horizontal branch of a small tree or shrub, three to four feet from the ground. It is built of flax-like fibres and bark-strips, lined with fine grasses and sometimes with down, rootlets, hair, and feathers. In south-eastern Texas the very strong black fibres of the Spanish moss, resembling horse hair, give the nest a very peculiar and substantial appearance. The eggs, usually four in number, are white, sparingly dotted with dark umber-brown around the larger end.

The bird is more retired and shy than its near congener, the White-eye. Its song is less distinct and not so frequently heard. "Their call and alarm notes are not quite so harsh, and their song is delivered in a less emphatic manner; an indescribable sputtering, that does not rank it high in the musical scale." (N. S. Goss.)

In their food and habits they are quite similar to the White-eye.

In south-western Missouri I noticed their arrival May 10, and in south-eastern Texas about April 20. They leave for their winter home in southern Mexico and Central America in September. 
NAMES: Bell's Vireo, Bell's Greenlet, Prairie Greenlet. - Prärie-Vireo (German).

SCIENTIFIC NAMES: VIREO BELLII Aud. (1844).

DESCRIPTION: “Top of head and hind-neck, dull brownish-gray, gradually changing to grayish olive-green on hack, scapulars, rump, and upper tail-coverts; a rather indistinct loral streak and interrupted orbital ring, dull white; cheeks and ear-coverts, light brownish-gray, fading gradually into dull white or buffy-white of throat; median lower parts, white, the breast usually faintly tinged with sulphuryellow; sides and flanks, sulphur-yellow, tinged with olive; under tail-coverts and under wing-coverts, clear pale sulphur-yellow.

"Length, 4.20 to 5.25 inches; - wing, 2.18; tail, 1.88 inches." (Ridgway's "Manual of North American Birds.")

LEAST VIREo, Vireo bellii pusillus RIDGw. "I well remember," says Dr. Elliott Coues, "when a copy of 'Audubon' first opened up to me, what seemed like a revelation - with what intensity I set myself to master the wonderful history-and the boyish despair I felt when I came to the Vireos! The very name was a mystery without a meaning, with a foreign sound, unlike Thrush, Warbler, or Sparrow, and there was a lot of these little myths, all alike greenish! I should have scouted the idea, had any one presented it, that there were any more Vireos in the world than Audubon knew; and that I should even discover a new one myself, would have seemed like a feverish dream."

Nevertheless our learned naturalist discovered one new species $-V$. vicinior-and a new form of Bell's Vireo, the LeAst VIreo, Vireo bellii pusillus RIDGw., both in Arizona. The last named variety occurs chiefly in the lower parts of the territory, and California from Sacramento to Cape St. Lucas. Near Sacramento Prof. R. Ridgway found it nesting. In its habits and almost in every particular it closely resembles the typical $V$. bellii.

Hutton's Vireo, Vireo huttoni Cass., is a resident of California and resembles closely our common White-eyed Greenlet. According to $\mathrm{Mr}$. Wm. Cooper, it breeds in the vicinity of Santa Cruz, though not in abundance. Retiring in habits, their nests and eggs are rarely found. April 7, 1874, he found a nest placed ten feet from the ground, suspended from a dead branch of a Negundo, containing three eggs.... March 30, 1875, he discovered another nest placed eight feet from the ground, suspended from a small twig of a Frangula. The nest-a neat, compact structure, composed of fine vegetable fibres, bits of paper, and grasses covered on the outside with green and gray mosses, lined with fine grasses-measures 3.25 inches in diameter outside, 1.75 inside; depth, 2.25 outside, 1.50 inside. The eggs are white, marked with fine dots of reddish-brown, most numerously at the larger end.

DESCRIPTION: "Above, decidedly olive, becoming more greenish posteriorly; beneath, decidedly tinged laterally with olive-yellow; wing-bands, narrow tinged with olive-yellow. "Length, 4.25 to 4.75 inches; wing, 2.43; tail, 2.06 inches." (Ridgway.)

A paler variety, STEPHEN's VIREo, Vireo huttoni stephensi Brewster, inhabits Mexico, western Texas, New Mexico, Arizona, and Lower California. A nest found by Lieut. Benson, June 21, 1887, near Fort Huachuca, Arizona, was described by Capt. Chas. E. Bendire." It was "attached to a fork of a small twig of some species of 
button wood, growing in a cañon of the Huachuca Mountains, and was well concealed. It is very peculiar looking, being outwardly exclusively composed of a yellowish-buff plant down, with similar colored grass-tops incorporated, giving the nest a uniform light color, not unlike a very fine cup-shaped sponge. It is lined with the extreme tops of grasses, also of a golden tint, and measures externally 2.75 inches in width by 2.50 inches in depth." The eggs are pure white, sparsely spotted about the larger end, with fine dots of dark umber-brown and brownish-red.

\section{GRAY VIREO, OR ARIZONA VIREO.}

Vireo vicinior Coues.

This species inhabits north-western Mexico, western Texas, New Mexico, Arizona, and southern California. Being of very rare occurrence, our knowledge regarding its habits is very limited. Mr. W. E. D. Scott found it in 1884 fairly common on the mesas and foothills of the San Pedro slope of the Santa Catalina Mountains, in Pinal County, Arizona, in an altitude of 2,800 to 4,000 feet during the breeding season. Its song he describes as clear and liquid in character; it is kept up so continually as to betray, under favorable circumstances, the presence of the male bird, which he believes monopolizes it, even a quarter of a mile away. It is composed of single whistling notes, generally delivered rather slowly, and seemingly with hesitation, and in an abstracted way, as if the performer was thinking the while of other affairs; and yet frequently this sort of abstraction seems cast aside, and the same series of notes are given with a precision and brilliancy that calls to mind a fine performance of the Scarlet Tanager, or even of a Robin. The bird is exceedingly active, rapidly searching the limbs of trees and bushes for food, constantly uttering its clear liquid song.

The nests are built in mesquit and other thorn bushes, from four to seven feet from the ground. They are like other Vireo nests, composed of coarse dry grasses and strips of bark, while the lining consists of fine, dry grasses. Eggs, white, spotted with reddish and umber-brown, chiefly at the larger end.

DESCRIPTION: "Colors as in Vireo bellii pusillus, but lores entirely grayish-white, and band across tips of greater wing-coverts less distinct (sometimes obsolete), the middle coverts never tipped with white. "Length about 5.60 to 5.75 inches; wing, 2.55 ; tail, 2.47 inches." (Ridgway.)

In Mexico and Central America occur a number of other very interesting species of Vireos, which Prof. R. Ridgway enumerates in his standard work, "Manual of North American Birds.'

The Vera Paz VIreo, V. propinquus RIDGW., is found in the highlands of Guatemala, at Coban and Vera Paz. Another, but smaller species, the LARge-billed VIREo, V. crassirostris Baird, and a variety, the Yellow Vireo, V. crassirostris flavescens RidGw., inhabit the Bahamas. $V$, ochraceus Salv, Ochrackous Vireo, is an inhabitant of southern Mexico, Honduras, and Guatemala, while Baird's Vireo, Y. bairdii RIDGw., occurs in the island of Cozumel, Yucatan. The PALE VIREO, V. pallens SALV., seems to be a common bird on the west coast of Nicaragua and Costa Rica. Another, the Yellow VrReo, V. hypochryseus ScLat., is a native of Mexico, from Oaxaca to Tres Marias. In Cuba we find the Cuban Vireo, V. gundlachi Lemb. Almost all these species are small and closely allied to our White-eyed and Bell's Vireo. 


\section{SHRIKES.}

Lanidæ.

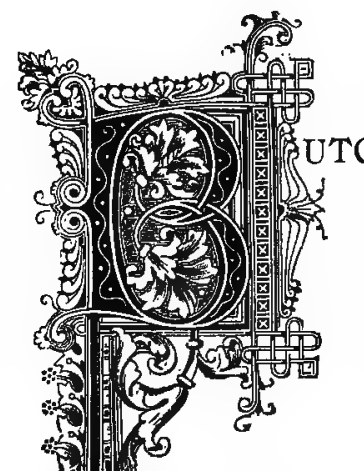

CHER BIRDS, or Shrikes are scattered throughout all zones, and are found in all parts of the globe. Where there is bush or tree, where field and meadow border on forests - be they composed of magnolias or maples, palms or birches, olives or pines; be they planted according to the rules of forestry by human hands, or be they the direct production of nature in the forest primeval, where in the strife for existence strong fresh growth emanates from the decay of past grandeur, mighty trees grow on the graves of mightier ones, which grew and fell before them that their successors may grow in their places-everywhere there are Shrikes, whose life is death to some weaker creature. The family of Shrikes, considered in all its subdivisions and genera, is a many colored race: Black and white, gray and brown, even green, yellow and red, from the darkest rust-red to the choicest hues of pink, nearly all colors are represented in the plumage of the race of Shrikes. In form these birds are as neat and dainty as they are strong and enduring. The beak is stout and hooked, "combining claw and tooth in one murderous instrument, is surely the weapon of a Hawk, or other rapacious bird! In one sense, we certainly have here a bird of prey; yet, if the portrait were finished at full length, we should find the feet as weak and harmless as those of a Thrush or Sparrow, instead of being furnished with the talons which confer such raptorial prowess upon the Falcon, the Eagle, and the Ow1. If, furthermore, we should examine the anatomy of the Shrikes, it would be merely to discover that the entire structure of the internal organs is modelled after a strictly Passerine type. Though the bone and muscle indicate unusual strength and vigor, the beak itself is the seal of the Shrike order-a mark as plain and unmistakable as that which stamps the tribes of Israel, wherever dispersed over the earth - the symbol of a spirit as bold and reckless as ever dwelt in the breast of any one of the Hawks called 'noble' in the olden time, when falconry beguiled the leisure hours of kings and royal mistresses." (Coues.) 
The Shrikes subsist entirely on animal food. Grain and berries to them are an abomination; but flesh, flesh is what they crave for, whether the tender warm-blooded flesh of a barely hatched young bird, the brain of larger birds, or the juicy inside of a full-sized beetle. In the preparation of their food most of the Shrikes are thoroughly cruel; they chase and catch more than they can eat, and force small living animals on sharp thorns, where they frequently remain to suffer for days before they die or are eaten by their captors. The Shrikes are partly migratory and partly they belong to certain latitudes, but they are all rovers.

Genus Lanius Linnfeus. Shrikes. Two species and two varieties.

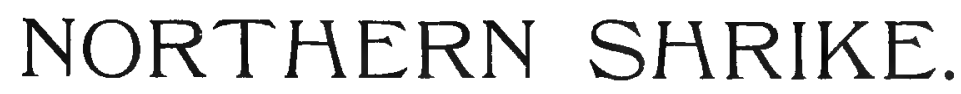

Lanius borealis VIEILLOT'

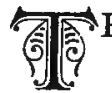
HIS "bold brigand" is very common in winter from the northern to the middle portions of the United States. Its summer home is the northern part of North America. It is said to breed also in Maine and in mountainous regions of other New England States. In Wisconsin and northern Illinois it arrives usually late in October or early in November, leaving again for its northern home early in March. It is usually seen in the tops of the osage orange hedges and on telegraph poles, scanning carefully the surroundings in every direction, watching for its prey, small birds and mice. It is of a cruel, reckless nature, very rapacious, catching almost every bird which it is able to overpower, and many more than it is able to eat. When the food supply becomes scarce, it frequently visits cities where it kills large numbers of European Sparrows. In Milwaukee they are frequently seen in gardens and even in crowded streets. Dr. T. M. Brewer gives an excellent description of the habits of this bird:

"Its bold audacity and perseverance are quite remarkable, and are often displayed, in the fall, in the manner in which it will enter an apartment through an open window and attack a Canary, even in the presence of members of the family. It rarely fails, if it gains access to the cage, to destroy its inmate before the latter can be rescued by the intervention of those present, and only by great promptness in sheltering the cage. In one instance the writer was sitting at a closed window, reading, with a Canary hanging above him. Suddenly there was a severe blow struck at the pane of glass near the cage, and the frightened Canary uttered cries of alarm, and fell to the bottum of its cage. The cause was soon explained. A Shrike had dashed upon the bird, unconscious of the intervening glass, and was stretched upon the snow under the window, stunned by the blow. He revived when taken up, and lived several days, was sullen, but tame, and utterly devoid of fear. He refused raw meat, but eagerly tore in pieces anci devoured small birds when given to him. His tameness and indifference to our presence may have been occasioned by stupor arising from h:s injury. In another case, a Shrike made a 
similar attack, but escaped unharmed, and though he remained about the house several days, was too wary to allow himself to be decoyed within gunshot."

In the winter of 1879 my friend, Consul-General Emil Dreier, of Chicago, caught three of these Shrikes in a trap cage. As he had no suitable cage to keep them separate, he confined them all three to one large cage. In a very short time one of them was killed, his body torn to pieces and impaled on a sharp piece of wire. The next morning the other one was killed also by his companion. They, and also Sparrows which afterwards were put in its cage, were killed by sharp blows on the head. In its nesting habits it resembles closely the Loggerhead Shrike.

NAMES: NorTherN Shrike, Butcher-bird, Great American Shrike, Great Butcher Shrike.-Raubwürger (German).

SCIENTIFIC NAMES: Lanius excubitor Forst. (1771). LANIL'S BOREALIS VieILLot (1807). Collario borealis Brd. (1858).

DESCRIPTION: "Adults: Clear bluish-ash, bleaching on the scapulars and upper tail-coverts, the under-parts pure white, always more or less vermiculated with fine wavy cross-lines of dusky. A black bar along side of head, not meeting its fellow across forehead, enclosing the white under eyelid, and bordered above by hoary white, which reaches across the forehead. Wings, black, many or most of the quills tipped with white, and a large white spot at base of primaries. Tail, black, the outer feathers mostly white, the next three or four tipped with white in decreasing extent. Bill and feet, plumbeousblack.

"Length about 10.00 inches; wing, 5.50; tail rather more." (S. \& C., N. L. B. L., I. p. 207.)

\section{LOGGERHEAD SHRIKE.}

\section{Lanius ludovicianus LINNÉ.}

Plate XVII. Fig. 4 .

䀏

HE Loggermead SHRIKe is distributed over the more southern portions of the

Eastern United States, north irregularly to Ohio and some of the New England States, regularly to Virginia and southern Illinois. According to Mr. Otto Widmann, this is the prevailing Shrike at St. Louis, Mo. In the Carolinas and Georgia it is also commonly met with, and in many of the orange groves of Florida it is a frequent summer sojourner, many even remaining through the winter months. The WHITERUMPED Shrike, Lanius ludovicianus excubitorides CouEs, inhabits the "central region of North America, north to the Saskatchewan, south over table-lands of Mexico, west to Lower California, Arizona, Nevada, etc., east across great plains, and sporadically through basin of the great lakes to northern New York." (Ridgway.) A third form of the Loggerhead, the CALIFornia SHRIKE, Lanitis ludovicianus gambeli RIDGW., occurs in California, especially in the coast district.

The Shrike which we find in Wisconsin and northern Illinois, is the White-rump. In Wisconsin it frequently nests in apple and pear trees, in white-thorns and wild crab trees, while in northern Illinois it preferably selects for its nesting-site the osage orange 


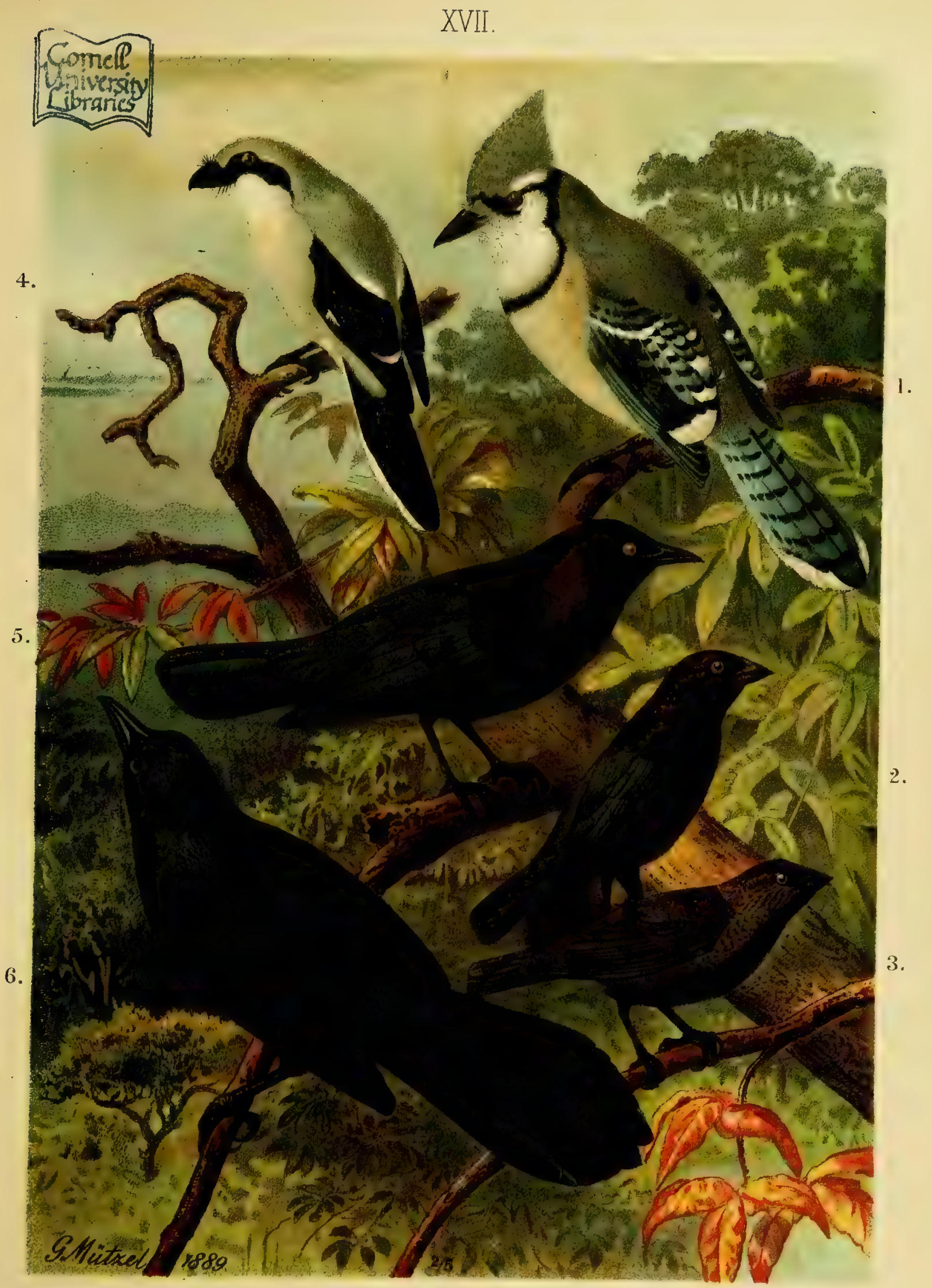

1. CYANOCITTA CRISTATA Strickl.

2. MOLOTHRUS ATER Gray. ô

$3 ., ", "$,

4. LANIUS LUDOVICLANUS Linn.

5. SCOLECOPHAGUS CYANOCEPHALUS Cab.

6. QUISCALUS QUISCULA AENUS Stejn.
- BLAUHEHER.

- KUHVOGEL $\delta$

- "

- DORNDREHER.

- BLAUKOPFSTÄRLING.

- BRONZESTÄRLING.
- Blue Jay.

- Cowbird (Male)

- " (Female).

- Loggerhead Shrike.

- Loggerhead Shrike.

- Bronzed Grackle. 

hedge-rows. In south-western Missouri as well as in Texas I have observed this Butcher-bird. Near Houston I found several nests, and in Fayette, Bastrop, and Lee County I also met with the bird during the breeding season, although much less frequently than in Wisconsin and Illinois. Everywhere they prefer for nesting places hedge-rows and gardens. It is partial to those open districts where plenty of thorny trees are growing. Where the orange is cultivated, where the honey-locust with its terribly armed trunks are growing, where miles of hedge-rows of the osage orange mark the boundrary lines and road-sides in the prairie districts of Illinois, where white-thorns and wild crab trees grow on the woodlands' edge, there we may look for these marauders. These thorny trees "seem indispensable to its presence for the reason that the slender, sharppointed thorns are required for impaling its prey, and the matted impenetrable covert for the concealment or protection of its nest." (Ridgway.)

Where these birds feel safe they seek the company of man, nesting frequently near dwellings. They are such innocent looking creatures that most people are not aware, what bold brigands they are, and in how short a time they destroy the idyllic life of our familiar garden songsters. When the Shrikes have young they will rid even a large orchard and garden of its feathered inhabitants. They kill almost every bird from a Catbird down to a Wren, murdering many more than they will eat. In my fine orchard and garden in south-western Missouri a pair of these innocent looking marauders built their nest in a very thorny honey-locust near my house. A large number of different birds were breeding in the ornamental trees and shrubs near the dwelling and in the orchard, and their beautiful songs resounded from early morn till late at evening on all sides. In a very short time this happy and idyllic life was disturbed and the locality desolate. Many of the old birds were found impaled on sharp thorns of the honeylocusts, while their offspring were carried to the young Shrikes. Although the Butcherbirds destroy many grasshoppers and mice, I do not think they should be tolerated among other birds, especially in gardens. In many of the orange groves of Florida no birds are found except a pair of Shrikes, and this holds true of many northern gardens. As the three forms of this Shrike agree in every respect, and as all are alike "savage and blood-thirsty," I shall not describe them separately. Dr. Elliott Coues, in "Birds of the Colorado Valley" (p. $547 \mathrm{ff}$.), gives the following classical sketch of the Butcher-bird:

"Matching the bravest of the brave among birds of prey in deeds of daring, and no less relentless than reckless, the Shrike compels that sort of deference, not unmixed with indignation, we are accustomed to accord to creatures of seeming insignificance, whose exploits demand much strength, great spirit, and insatiate love of carnage. We cannot be indifferent to the marauder who takes his own wherever he finds it-a feudal baron who holds his own with undisputed sway-an ogre whose victims are so many more than he can eat, that he actually keeps a private grayeyard for the balance.

"Lest such a picture may seem to be exaggerated, let me make good my statements. The Shrike's food consists of such birds, quadrupeds, and reptiles as he can capture and overpower, together with insects, chiefly of the larger kinds, and especially grasshoppers. These he pursues, attacks, and destroys quite as a Hawk does; and he has the very curious habit of impaling their bodies upon thorns.

"Numberless illustrations of the spirit the Shrike displays might be given. Though 
smaller in stature than the least of our Hawks, he habitually destroys birds and other animals as large as those upon which some Hawks subsist, and quite as capable of resisting attack. Appropriating to himself sufficient territory, where no other bird may safely intrude, he becomes the terror of the neighborhood; and woe to the unlucky Finch or Warbler that ventures to trespass on these hunting grounds! like a veritable sentinel on guard, the Shrike stands in wait upon his chosen post, ready to pounce with unerring aim upon the first little bird that may dare to rustle in the nearest bush. His impetuosity and temerity are well displayed in the onslaught he sometimes makes upon cage birds hanging at our windows; and he has even been known to enter an apartment, bolting through the open sash with perfect recklessness. Dr. Brewer narrates the case of a Shrike who dashed at a Canary without perceiving that the window was closed. He struck the glass with all the momentum of his impetuous flight, and fell to the ground, stunned by the force of the blow. He revived, however, and was kept in confinement for some time, during which be continued sullen and fearless, and greedily devoured small birds which were offered him for food, though refusing to eat raw meat of other kinds. Notwithstanding the protection that a cage affords, Canaries are not seldom killed by the Shrike unless speedily relieved from his attack. Sometimes they are so terror-stricken that they fall fainting to the bottom of the cage; but they oftener flutter and dash themselves against the wires, till seized by the bird of prey, who scalps them, breaks in their skull, or takes their heads off. The small birds that the Shrike destroys in a state of nature are either captured at a single dash, or caught in open chase, and killed with a blow of the beak. They are then devoured upon the spot, or carried to the 'cemetery' and stuck upon a thorn, as I shall presently describe with more particularity.

"As if conscious of his prowess, the Shrike shows little fear in the presence of man. Under some circumstances, indeed, I have found a Shrike so wild that my endeavors to get a shot were unavailing, but the very opposite is oftenest the case. You may enter the thicket the Shrike has chosen as his hunting ground, and the bird will regard you with contempt, returning your regard with a gaze as steady and unflinching as if he were the better man of the two and knew it. At such a time, you will have a good opportunity to observe the easy nonchalant air with which he asserts himself. For all that the Shrike is such a gallant marauder, it must not be inferred that he is always on the war-path, intent on prodigies of valor. The doughtiest knights lay aside their armor at times, and the Shrike is fond of his ease in the intervals of his piratical enterprises. At such times, you may observe him lounging about with his hands in his pockets, so to speak, and nothing on his mind, when, as you approach, he will turn his head toward you with languid curiosity, just for a moment, and then dismiss you from further consideration. Sometimes you will see him ready for business, scanning the neighborhood closely from his watch-tower on the topmost $t$ wig of some bush or sapling, where he stands stiffly, bolt upright, like a soldier on dress parade, ready to move at a moment's warning. He makes a rather imposing picture just then in his uniform of French gray with black and white facings, which fits him 'like a dream': the next instant-whish! he is gone, and the piteous cry of the Sparrow in yonder bush tells the rest of the story. 
"A good deal of the Shrike's business, however, is neither brilliant nor romantic. The green sward below his perch harbors a great many field mice of different kinds, according to the lay of the land, and he has nothing to do but drop quietly down upon these little innocents. At certain seasons of the year, moreover, the fields swarm with grasshoppers, of which the Shrike is very fond, as he is also of spiders, beetles, caterpillars, and, in fact, almost any insect. In July and August I have frequently seen Shrikes skipping about in old weedy fields, apparently amusing themselves; but I generally found, on watching them closely, that they were hunting for the 'hoppers, some of which they devoured then and there, after beating off their long hind legs, while others were carried to some tree near by and duly impaled....

“The Shrike is a veritable 'Butcher-bird,' in as far as that title may be given to a bird who kills what he does not eat, and his operations in this line have been made the subject of repeated observations, so that we are in possession of all the facts in the case. The birds, mice, and insects are sometimes impaled alive, and left to perish miserably; sometimes their dead bodies are similarly stuck upon the sharp twigs. The shambles of the pitiless butcher may be found in some thorny tree or bush, which in the course of time presents a curious spectacle, with the numerous creatures sticking here and there. Quite a museum of anatomy is sometimes thus brought together in one place, but as the Shrike is not particular about making a collection of curiosities, we may recognize his work in single specimens scattered anywhere about fields and shrubbery.....

"There are two very different birds of this country which the Shrike resembles in the relative proportions of the wings and tail, as well as in the general conformation of the body. These are the Mockingbird and the Sharp-shinned Hawk, Accipiter velox. Now if we picture to ourselves a bird whose attitudes, movements, and especially whose mode of flight, may partake, on occasion, of those of either of the birds just named, we shall have no wrong idea of the varied actions of which the Shrike is capable. The close general resemblance of the Shrike to a Mockingbird is really remarkable. The two are of about the same size, shape, and color-in fact, it is not the easiest thing to tell them apart at a little distance, especially when they are flying. The similarity has long since been duly noted and commented upon; in fact, Swainson went so far as to make it the basis of a strong argument in favor of his fanciful quinarian theory of affinity. The mode of flight, then, of the Shrike, under ordinary circumstances, is necessarily much the same as that of a Mockingbird, being light, wayward, and even undulatory, when the bird is simply moving. about at his ease, or foraging for the humbler kinds of prey that contribute to his support. Yet even under these conditions there is a certain dash about it, giving hint of the spirit he can infuse into his actions when he calls his powers to their full display. Then, in the manner of the Hawk, his flight is strengthened, firmly sustained for long distances, and on occasion quickened at a prodigious rate; the climax of this exploiting being reached when he plunges headlong after his prey, hurtling like a very Hawk. He is said at times to hover in the air, just over his intended victim, as if taking aim before he stoops to his quarry; but this can hardly be a characteristic habit, or it would not have escaped my attention. I do not remember to have ever witnessed it, though it need 
not be doubted that the action is sometimes performed. When not on the wing, we may observe in the Shrike's habitual attitudes the same blending of Mockingbird and Hawk; or rather, the transition from one to the other, when his air of indifference and rather 'slouchy' appearance give way to the martial bearing which indicates that his attention is riveted upon intended conquest.

"So versatile and animated a spirit as that which the Shrike possesses necessarily seeks expression. There is no reticence about this bird, whose harsh outcries we may in turn interpret to mean anger and exultation - the challenge and the conquest-while the course of his passionate life runs on in almost incessant warfare. These notes mean much the same as the stridulation of the Kingbird, in whose temper there is much of kinship with the Shrike, both being impatient and aggressive birds. But notwithstanding the magnitude of his exploits, the Shrike is not a very lofty character after all; he picks many a needless quarrel with his fretful fellows, and all the petulance of a wilful, badly governed disposition may be traced in some of the harshest of the cries that greet our ear. It is easy to say, and quite safe to make the assertion, that nothing more unmusical than the Shrike's notes is often heard; and it is usual to compare the voice of this bird to the creaking of a sign-board, or the grating of any other rusty hinge. But I suspect, though I am not a competent witness in this case, that those are right who ascribe to the Shrike some powers of song, limited though they be. Technically speaking, the Shrike is as truly Oscine as the Mockingbird itself; and no à priori reason appears why his notes should not at times be modulated with a tuneful quality. Sev ral authors have in fact asserted such to be the case, protesting fairly against any sweeping denunciation in this particular."

The Shrikes build their nests preferably in thorny hedges of the osage orange, in honey-locusts, and, in the South, also in orange trees and mesquit bushes. The nest is a loose, bulky, but very warm structure, being composed of plant-stems, thorny twigs, grasses, paper, wool, feathers, rootlets, mosses, etc. The lining consists of feathers which usually conceal the eggs from view.

The eggs, five to six in number, are almost identical with those of the Northern Shrike. They are dull white or greenish-gray, spotted and marked with obscure light brown and purple.

NAMES: Loggerhead Shrike, Loggerhead, Butcher-bird, Common Butcher-birrl, Louisiana Shrike, Carolina Shrike, Southern Shrike.

SCIENTIFIC NAMES: LANIUS LUDOVICIANUS LiNN. (1766). Collyrio ludoricianus Brd. (1858). Lanius carolinensis Wils. (1811).

DESCRIPTION: "Adult: Above, ash-gray, usually somewhat paler-occasionally white-on the upper tailcoverts, the tips of the larger and outermost scapulars distinctly white. Wings and tail, black; secondaries, tipped with white, and primaries with a white patch at the base; ends of tail-feathers, except middle pair, white, the outer rectrices sometimes almost wholly white. Lores, orbits, and auriculars, deep black. Lower parts, entirely white, the sides sometimes tinged with grayish. Bill and feet, black at all scasons; iris, brown. ....

"Total length, about 9.00 inches; wing, about 3.75 to 4.10 ; tail, about 4.00 inches." (Ridgway, "Ornithology of Illinois," Vol. I, p. 194.)

The variety, L. Iudovicianus excubitorides Cours, is paler, the upper tail-coverts usually more or less distinctly whitish, the scapulars more extensively white, the sides usully faintly, if at all, tinged with gray; wings, tail, and tarsus averaging longer and bill smaller. 


\section{WAXWINGS.}

Ampelidx.

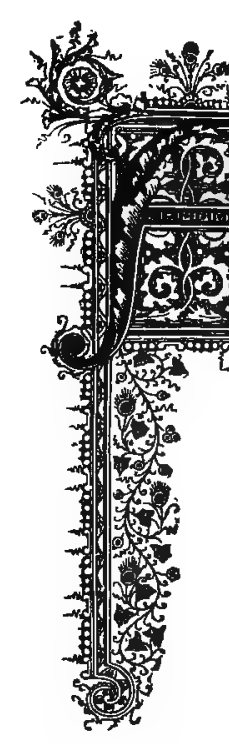

S DR. ELLIOTT COUES observes in his ornithological works, "this appears to be an arbitrary and unnatural association of a few genera that agree in some particulars, but are widely different in others. Hardly any writers are agreed upon the composition of the group, or the disposition to be made of it in the series. It has been made to cover the Myiadestinæ, Ptilogonydinæ, Dulinæ, and Ampelinx; but the first named I have already removed to the Turdid, the third may be a Vireonine, and the other two do not seem to be specially related. Under these circumstances, I do not attempt to define the group."

The Waxwings, which are also known as Chatterers, belong to the genus Ampelis, consisting of three species: the Common Waxwing, or Chatterer (in German, "Seidenschwanz"-Silk-tail), A. gatrulus, which inhabits the northern parts of the Northern Hemisphere; the Cenarbird, A. cedrorum, of North America; and the JAPAnese Chatterer, A. phoenicoptera, in which the tail is tipped with red instead of yellow. The first named is celebrated for its nomadic disposition, whence the name "Bohemian Waxwing"; the Cedarbird has also much of this nomadic trait, being found here and there in winter, in the Northern States as well as among the tropical trees covered with epiphytal plants, especially orchids, bromeliads, anthuriums, and ferns of Central America. The general traits and habits of the Bohemian Waxwing and the Cedarbird are much the same, and very strongly are they pronounced. "They are insectivorous and frugivorous, gregarious and irregularly migratory, and remarkable silent birds to be called 'Chatterers,' having only a weak and wheezy voice." Both species have "sealing-wax" tips on the wings.

Genus Ampelis. Two species. 


\title{
BOHEMIAN WAXWING.
}

\author{
Ampelis garrulus LinNé.
}

(10)

UR WAXWINGS, the BohEmian as well as the Carolinean, belong in many respects to our most interesting and peculiar birds. Both species show a roving character and a certain mystery, in their life, both are similar in color and very beautiful. The Cedarbird is a common summer sojourner in many parts of the United States, and consequently we are more familiar with its life history than with that of the Bohemian Waxwing, which only in special winters enters our territory in immense numbers. Although a true cosmopolitan, breeding in the Arctic regions of America, Europe, and Asia, it seems to be nowhere common, and in America only a few nests have been discovered. Its nest has been found by Mr. Kennicott on the Yukon, and by Mr. McFarlane in the Anderson River region. The nest which the first named naturalist found July 4, on the Yukon, was situated about eighteen feet from the ground and contained one egg. It was built on the side branch of a small spruce that was growing at the outer edge of a clump of thick spruces, on low ground. The structure was built of small dry spruce twigs, and the lining consisted of fine grass, moose hair, and a thick layer of feathers.

A set of four eggs in Capt. B. F. Goss' excellent collection of eggs of North American birds, now exhibited in the Public Museum of Milwaukee, Wis., was collected in Labrador June 18, 1885. The ground-color of these eggs is bluish, like those of the Cedarbird, but the eggs are more heavily spotted, all over the surface, with lilac and dark brown. In other respects they closely resemble those of the Cedarbird, but are larger.

Although the Waxwings are very gregarious, moving mostly in immense numbers, they are not so abundant in their breeding haunts, where they are distributed over an immense territory. They usually migrate southward when the berry crop of their northern home has failed to give a good yield. I have seen them only once during my youth in Wisconsin, and then again in the winter of 1875 to 1876 , and 1878 to 1879 in northern Illinois. While residing in the Ozark region of Missouri, my friend Miss Hedwig Schlichting informed me in the winter of 1886 to 1887, that the Bohemian Waxwings were very common in Milwaukee, usually frequenting the mountain ash trees early in the morning just after day break. The trees stood very near the window of her room, and she could watch the birds at leisure. Cedarbirds were also among the flocks, and somewhat later in the day Evening Grosbeaks and American Pine Grosbeaks visited the same spot. The birds frequented these trees until all the berries were consumed. The lady remarks also that the Waxwings, and the above named Grosbeaks, usually appear in large numbers when the mountain ash trees in the gardens and the juniper bushes near the shore of Lake Michigan are loaded with berries. Whenever she noticed these birds there was always an abundant crop of these berries.

The Bohemian Waxwings do not move far to the South. They have been observed south to Philadelphia, Ohio, Nebraska, Colorado, and even Arizona. Since they inhabit 
unpopulated northern regions, they are upon their first appearance without any fear, and for that reason are killed in large numbers. Very truly Brehm remarks in this connection: "It occurs that in some winters they come in great numbers, and remain for weeks and months in a locality where otherwise they were seldom seen. This would probably happen oftener, were it not that every peasant considers it his prerogative to let out his hunting propensities upon these harmless creatures. Their beauty is something which these ill-bred, coarse people seem unable to understand or appreciate, and they can think of nothing better than destruction."

NAMES: Bohemian Waxwing, Bohemian Chatterer, Northern Chatterer or Waxwing, European Chatterer or Waxwing, Black-throated Waxwing; Waxen Chatterer. - Seidenschwanz (German).

SCIENTIFIC NAMES: AMPELIS GARRULUS LiNN. (1766). Bombycilla garrula Vieill. (1823).

DESCRIPTION: "Under tail-coverts, chestnut; front and sides of the head tinged with a richer, more orange-brown shade; primary wing-coverts tipped with white; each quill with a sharp white (or yellowish) stripe at end of the outer web; chin, velvety black in a large, well defined area; narrow line across forehead, along sides of head, through eyes, meeting its fellow on occiput behind the crest, also velvety black; no white on under eyelid nor across forehead; no yellowish on belly; bill and feet, black.

"Length, 7.75 inches; wing, 4.50 ; tail, 2.50 inches." (S. \& C., “N. E. B. L." I, p. 191.)

\section{CEDARBIRD.}

Ampelis cedrorum Gray.

Plate V. Fig. 1.

[0:

ATURE OFFERS to people of thought and sentiment innumerable pleasures and ever new charms. To them, all that is beautiful and enchanting in nature has an irresistible attraction. The true lover of nature often seeks to attach to his own immediate surroundings any of his special favorites. In the city this can, of course, be done only on a small scale, but in the country it is quite easily accomplished if the party in question occupies an aesthetic standpoint. He will surround his home with flowers, shrubbery, and trees of various kinds, and, in so doing, take into consideration not only the fragrant and beautiful blossoms but fully as much the shape, density, and hues of the foliage, the graceful forms of the shrubs, trees, and climbers. The arrangement must be natural, not formal. Trees and shrubs planted in a group appear more impressive than if planted in a straight line. Ornamental trees and shrubs, flowers and foliage plants belong in front of and on the sides of the dwelling; the orchard and vegetable garden should find a place in the rear of it. Gardens in our Northern and Western States cannot be so arranged as to appear charming and enjoyable all the year, while in the South Atlantic and Gulf States, and in California they are always attractive, owing to the tropical and semi-tropical plants which especially imbue to those regions their charming beauty. Where, as in the Eastern States and southern New England, the grand hybrid rhododendrons and azaleas grow, where andromedas and 
kalmias can be introduced into the gardens, hardly anything more beautiful can be imagined. The large and dense beds of broad-leaved evergreen rhododendrons, every bush covered in May and June with gorgeous flower trusses, the fragrant and bright hued azaleas (mostly hybrids of Azalea pontica and our American species), the white bells of the andromedas, the beautiful rosy fringed flower cups of the kalmias vie in beauty with camellias, Indian azaleas, gardenias (Cape jasmines), and magnolias of the South Atlantic and Gulf States. When the bloom has quite passed away, other plants emerge from among the rhododendron bushes. The golden-banded lily ${ }^{1}$, the meadow lily ${ }^{2}$, the Canada ${ }^{3}$, Japan ${ }^{4}$, tiger ${ }^{5}$, Humboldt $^{6}$, and Washington lily ${ }^{7}$, lobelias and other plants lift their heads above these shrubs, exhibiting flowers of wonderful beauty and fragrance. In such parts of our country, where the climate is more severe, the mock orange, upright and twining honey-suckles, weigelias, spiræas, snowball bushes, the wild crab trees, white-thorns, groups of evergreens and other trees would create, in addition to a good orchard, an almost ideal home, especially when the birds, whose chief mission seems to be the enlivening of the scenes of nature, make their appearance in goodly numbers. In such gardens or in parks of dense shrubbery, shade and ornamental trees, supplied with numerous nesting-boxes, the Bluebirds, Wrens, Titmice, Martins, Great-crested Flycatchers will make themselves at home. If we stroll around in such a place in early June, we will notice that most of the feathered favorites are busy hatching or feeding their young. All nature seems to have put on holiday clothes, and cheery life reigns all around. Plant life is then also at its best, in its fullest glory. We hear the flute-like notes of the Robin, the caressing warble of the Bluebird, the sweet melodies of one of our best songsters, the Catbird, the lays of the Song Sparrow and Chipping-bird, the songs of the Thrasher, the Vireo, the Summer Yellow-bird, the Goldfinch, etc. They all are, thanks to the protection they receive from the owner, very confiding. Yet one of our handsomest and most peculiar feathered dwellers of the garden is still missing. That rover must be tarrying in far away places, mayhap in the South among palmettos and magnolias, or among the trees covered with orchids, bromeliads, and other epyphital plants of Mexico and Central America. Perhaps it forms one of a swarm roving about in a neighboring county or State. At last these birds appear. In noiseless, rapid flight they arrive, alighting suddenly, as if by military command, in the topmost part of some high tree. From that elevated position they all look about, stretching their necks and raising the tufts of their heads. This late arrival is the Cedarbird, known also by the names of Carolina Waxwing, Small Waxwing, Little Waxwing, Cedar Waxwing, Cherry and Spider-Bird. It belongs to the latest bird arrivals in our northern gardens, though many of them winter in the North.

Our Cedar Waxwing is a dignified and beautiful bird. The highly elegant coloring of the soft plumage reminds one of both the North and the tropics. The ground-color is a mixture of ash-gray, wine-red, and chestnut-brown, from their light tints increasing to even a deep black, these hues in their gradual shadings and variations producing a mild effect, finely contrasting with the rich yellow of the edge of the tail and the

1 Lillum auratum, 2 L. superbum, a I. Canadense, 4 L. speciosum. G L. tigrinum. B L. Humboldti. T L, Washingtonianum. 
bright scarlet of the "sealing-wax"-like tips of the wings; so that, as regards plumage, it may vie with any bird of the tropics. The development of the inner wing-quills is very peculiar, ending into small hard, horny appendages similar to sealing-wax of beautiful scarlet color. If I may judge the wild birds from my observations of those that are caged, it would seem that these little appendages disappear in July or August, to reappear when the bird is moulting. This process is analogous to that of some other birds who in spring loose a small edge of the outer border of their plumage, so that the usual color changes into a richer looking wedding dress.

The flight of our Cedarbird is exceedingly graceful, quick, and soft. Even among dense twigs it never moves without dexterity, though somewhat slow owing to its comparatively short legs, yet gracefully and with lively and active expression. With all birds the moods and excitements of feeling are expressed in the face, as every experienced observer well knows; but those whose head the Creator has ornamented with a crest, possess in this ornament an exceedingly fit organ for the expression of their feelings. Any one may convince himself of the fact by watching the Cedarbirds. When in the spring the male courts the female, he seems to speak so perstuasively by his bows, the peculiar puffing up of certain feathery parts of his face, and the quick alternate lifting and lowering of the crest of his head, that the female soon responsively denotes the state of her feelings in somewhat similar mimical manner. During this time the female also singsa pleasant medley of soft lisping, trilling, chirping, and whistling notes. The male sings somewhat louder and, if well, all the year, though most continually and energetically in the spring. The mates are much attached to each other and very tenderly demonstrative. They not only place their head and beak affectionately into each other's plumage, but they generally sit, fly, and hop about in close companionship. If for a few moments by chance they are separated, a gentle, tremulous whistling call quickly unites them again. They rest and sleep perched closely side by side, and eat together in most peaceful concord and without a shadow of envy. Even after nesting time the mates keep together, at least they do so in captivity. During their stay with us in swarms in winter, when resting after their meals, they separate into pairs also. When just caught and placed in a cage $-I$ always caught them in winter-this bird seems quickly resigned to the change. Instead of raging and hurting its beak and plumage by flying against the cage-bars, it looks about first somewhat surprised, then apparently from curiosity, flies down to the feed pot, if there are berries in it, then takes a bath, and after that places itself in cool composure on the perch to rest and put its plumage in the best possible order. This as well as many other qualities recommend it for a cage bird. Among these qualities are its beauty and the care it takes of its fine plumage, its amiable disposition even to other birds in the same cage, and its easy keeping. But the following conditions must be complied with: Its cage must be as roomy as possible for free flight and motion. It must not be caged alone, but in pairs or even in small flocks of from four to ten, and for cleanliness' sake the floor of the cage must be thickly. covered with sand, and in places where necessary with short cut moss. The food consists of grated raw carrots (as a substitute for berries), small pieces of boiled carrots and potatoes, dried fruit cut small, fresh berries of all kinds, dried berries soaked in warm water, and such food as is given to insect eaters. A mixture of grated carrots and mockingbird-food is also a 
very good substitute for its natural diet. Fresh water for drinking and bathing must be given frequently. At least every other day the cage must be cleaned and fresh sand given. Thus kept, these birds will last many years, if protected a gainst strong draught and sun shine in summer. Whoever cannot grant these and other cage birds a comfortm. able existence in this manner, should not keep them in captivity.

We have already seen that the Cedarbirds cannot be depended upon for regular periodicity of movement. I have seen them late in April in the hammock woods of southern Florida, and in south-eastern Texas I observed in the latter part of May large flocks in magnolias and live oaks and even among the shade trees of Houston. From Florida to Canada, from Texas to Manitoba and beyond, and from the Atlantic to the Pacific, at any time of the year, one may hear some very peculiar wheezing and lisping sounds, and, on "looking about him, may see a dozen or a hundred little birds, flying in easy, rather undulating course, to alight in a compact body on the nearest tree, where they remain silent and motionless for a few moments, drawn up to their full heights, displaying their long top-knots; then they begin to move about and feed, unless some alarm sends them off to another tree. When the cedar ripens its glaucousblue berries, these same birds are sure to be found there, gorging themselves until they are choke-ful." (Coues.) In the cities and towns of the Northern States they are always abundant when the mountain ash is covered with berries. Miss Hedwig Schlichting says that she always observed these birds in Sheboygan County and in Milwaukee, Wis., throughout the winter, when the mountain ashes in the preceding fall yielded large crops of berries. In Milwaukee they usually visit the trees just after day-break; in places where they are protected they may be noticed at any time of the day. In California they feed on the berries of the beautiful evergreen pepper tree $^{1}$; in other regions they eat juniper berries and in the South wax-myrtle, sparkle, gum, and other berries, and even the aromatic fruit-like seeds of the magnolias are consumed. In many districts they are called Cherry-birds, from their fondness for cherries, and in Wisconsin they are also known as Spider-birds, because they are always in pursuit of spiders and other small insects. As they usually enter the orchards during the cherry time in considerable troops, the horticulturists kill great numbers of these silky-feathered fruiterers. I must say with regret that in many sections of our country these beautiful birds become noticeably reduced. The farmer and fruit-grower "should always remember that at certain seasons these indolent, easy going gormandizers display more agility and address in bug-catching than might be expected from them, destroying vast numbers of noxious insects. Let the irate gardener remember this when he goes for his gun; and let us all hope that people will learn in the course of time, that the indiscriminate slaughter of birds, even of such noted thieves as Crows and Blackbirds, necessarily turns a well-poised balance in favor of insect pests and by so much against the true interests of agriculture." (Coues.) I have frequently observed them destroying insects, especially beetles, bugs, moths, and caterpillars, in immense numbers, and Prof. Robert Ridgway says that "during the spring of 1881, when the willow trees in a swamp near Wheatland, Indiana, were infested with myriads of the larvæ of a small beetle (Pilagiodera lapponica), immense numbers of Cedarbirds were present feeding exclusively 
on these insects. They are said also to be very fond of the destructive canker worm. In short there can be no doubt that, although to a certain extent inimical to the grower of small fruits, they partially if not fully pay for what they take, in ridding the premises of insects which would otherwise injure if not destroy the trees."

According to Dr. T. M. Brewer, the horticulturist does not appreciate to the full the immense services the Cedarbird renders to him each spring in the destruction of injurious insects. "A flock of these birds will, in a short space of time, devour an immense number of larvæ of the destructive canker worms (Phalonæ) that infest the apples and elms in Massachusetts, and, if permitted, would soon greatly reduce their numbers. But these prejudices cannot be softened by their good deeds, and the Cherrybird is still hunted and destroyed."

Our elegant Cedar Waxwings are very late breeders, and when other birds are already feeding their full grown young, or are almost through with a second brood, we may see them lounging about in flocks. They scarcely begin nest-building before the season is half over, and sometimes they postpone their domestic affairs until the beginning of September. They are very capricious in their movements, being one day here and the other quite a distance away. Their presence or absence seems to bear no relation to season or weather, the question of food supply being probably the controlling influence in their wanderings. When the mating time arrives the flocks separate into pairs and each pair soon occupies its old nesting-quarters, preferably orchards, gardens, ornamental plantations, and the borders of woods. By the end of June and in July we may find some nests, but the majority of the Cedarbirds breed in August. The nest, mostly a bulky but very warm and handsome structure five to eight feet from the ground, is built of bark-strips, roots, fine grasses and weed stems, pieces of paper, birch bark, rags, twine, and wool, and is lined with fine grasses, bark-strips, and hair. A typical Wisconsin nest of the Cedarbird which was placed in the lower horizontal branch of an oak near my parental home, was built externally of fine grape-vine bark, a few rootlets, and grass stems all intermixed with wool. The lining consisted of fine rootlets and strips of bark. The cavity is large and deep for the bird. It usually takes from thirteen to fourteen days till the eggs are hatched. The birds are exceedingly careful and silent near their nest, not even uttering their faint lisping note when their domain is approached. It is a beautiful sight when the female sits on her nest, while the observer stands near by. With raised top-knot and a wild look she turns her head to the intruder. Then she glides softly away from the nest and soon disappears. Nests of these birds from the Arctic regions are more carefully and compactly built and lined with warmer materials. They are constructed largely of fine dark colored lichens that cover the forest trees of those regions.

The eggs, ustually five in number, have a bluish slate or stone-color tinged with olive. They are marked with blotches of purple and dark brown, almost black.

The Cedarbird winters from the Northern States south to Guatemala, and breeds from Florida to the Arctic regions.

NAMES: CedarbrRd, Carolina Waxwing, Cedar Waxwing, Little Waxwing, Carolina Chatterer, Cherrybird, Spider-bird. - Cedervogel (German). 
SCIENTIFIC NAMES: Bombycilla cedrotum Vieill. (1807). AMPELIS CEDRORUM GrAY (1849). Ampelis americana Wils. (1808). Bombycilla americana Licht. (1830). Bombycilla carolinensis Briss. (1860). Ampelis carolinensis Gosse (1847).

DESCRIPTION: "Plumage peculiarly soft and smooth; head conspicuously crested. Body-color shading insensibly from clear ash on the rump and upper tail-coverts through olivaceous-cinnamon to rich purplish-cinnamon on the foreparts and head, and through yellowish on the belly to white on the under tail-coverts. Forehead, lore, chin, and eye-stripe, velvety-black; a sharp mandibular line, one also bordering the black lore, with the under eyelid, white. Wing-quills slate-gray, dusky at the ends and pale on the inner webs, without white or yellow markings, but the inner ones with hard horny appendages, like red sealing-wax. Tail tipped with yellow, occasionally also having the waxy appendages. Bill plumbeous-black, sometimes pale at base below; feet, blackish.

Length, 6.00 to 7.00 inches; wing, 3.50 to 3.75 ; tail, 2.25 inches." (S. \& C., "N. E. B. L.," I, p. 192.)

\section{SWALLOWS.}

The Swallows, heralds of the Spring Have come to us again,

And my heart feaps to hear once more

Their merry, twittering strain. See, see,

With what abounding glee They soar,

And now sweep down to earth,

Making the wakened echoes ring

With music and with mirth.

The melodies that, in my heart, Slumbered the winter long,

Wake, like the echoes, when $I$ hear

The gushing of their song.

Her wings

- My fancy spreads, and sings ;

The cheer

of these glad birds doth share,

As swift they glide, and skim, and dart Along the liquid air.

My fancy makes no eagle-flight; Near the green earth she keeps

Nor higher than the Swallows go,

on light-some pinion sweeps. Her art

Is but a thankful heart And so

She pours her grateful words

For God's gifts, life, and love, and light, And sings as sing the birds.

W. L. SHOEMAKEK, 


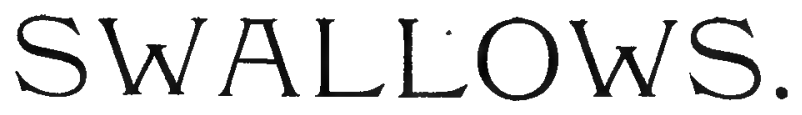

Hirundinidæe.

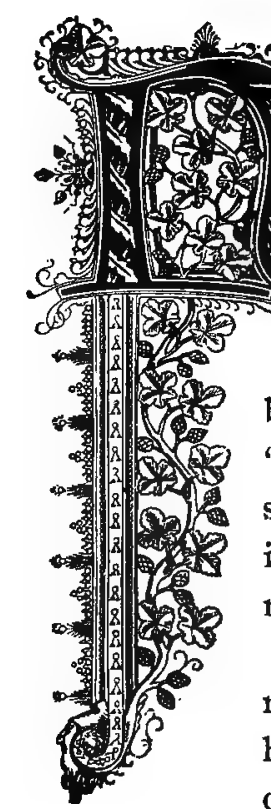

ONE OF our birds are greater favorites with man, none are more familiar, happy, and innocent than the SwalLows. In the country, and even in villages and small towns, they frequently breed under his roof and in boxes especially supplied for them. With sorrow and sadness he sees them depart in the late summer, and with joy and hope he cheers their arrival in the spring, when the days become mild and balmy and the leaf and flower buds are opening. In his "Birds of the Colorado Valley" (p. 364-405), Dr. Elliott Coues gives such an excellent family sketch of these birds, that I would deem this work incomplete, should I neglect to quote at least a part of it. Regarding the migration of Swallows he says :

"Being insectivorous birds that take their prey on the wing, Swallows necessarily migrate through the cold and temperate zones of the northern hemisphere. Their recession from the North is urged as well by the delicacy of their organization and their susceptibility to cold as by the periodical failure of the sources of their food supply. The prowess of their pinion is equal to the emergency of the longest journeys - no birds whatsoever fly better or farther than some of the Swallows do; and their movements are pre-eminent in the qualities of ease, of speed, and of regularity. These facts are matters of common knowledge; the comings of Swallows have passed into proverb, and their leave takings been rehearsed in folk lore among the signs of the waning times. Swallows have long been held for weather prophets; and with reason enough in the quick response of their organization to the influence of atmospheric changes. Swallows have figured in augury; their appearance has been noted among auspicia; and truly their flight is barometric, for they soar on clear warm days, and skim the surface of the ground in heavy falling weather, perhaps neither always nor entirely in the wake of winged insects on which they prey. These mercurial birds are also thermometric; they are gauges of temperature, if less precise than the column of the fluid metal itself. It takes but a few warm days, 
even in our midwinters, to send Swallows trooping northward from the orange and the cypress of the South; and the uncertain days, when capricious young spring pours delicious balm on the wounds of winter, are sure to lure some Swallows on beyond their usual bounds, like skirmishers thrown out before the oncome of the host of occupation.

"There is concert, too, in the campaigns of the Swallows; they act as if by consultation, and carry out agreement under leadership. One may witness, in the autumn more particularly, before the Swallows leave us, that they gather in noisy thousands, still uncertain of their future movements, eager for the council to determine their line of march. Great throngs fly aimlessly about, with incessant twittering, or string along the lines of telegraph, the eaves of houses, or the combs of cliffs. In all their talk and argument, their restlessness and great concern, we see how weighty is the subject that occupies their minds; we may fancy all the levity and impulse of the younger heads, their lack of sober judgment, the incessant flippancy with which they urge their novel schemes, and we may well believe their departure is delayed by wiser tongues of those taught by experience to make haste slowly. Days pass, sometimes, in animated debate, till delay becomes dangerous. The gathering dissolves, the sinews are strung, no breath is wasted now - the coming storm may work its will now, the Swallows have escaped its wrath, and are gone to a winter's revelry in the land where winter's hand is weakened till its touch is scarcely felt.

"All this, and more that might be written, is no news. Reckless of space, these animated time-slaying wings, these mercurial embodiments of buoyancy, have long been favored objects of the ornithologist's speculation. Conspictous, notorious, familiar as they are among all feather-bearers, in the extension of their flights, in the multitudes of individuals that twice a year fly past our very face and eyes in going to and from the winter-quarters we have learned as well as we have their summer sojourn in our midst - with all these attributes, I say, Swallows are prodigies, phenomenal and problematical still. Their flights have been closely watched and studied, furnishing large basis for our general inductions respecting the whole subject of the migrations of birds. Swallows are taken as the typical migrants, whose dates of arrival and departure are fixed points in the ornithologist's calendar, and known factors in the great equation of bird's movements. In short, no birds are better known in all that pertains to their regular and normal migrations.

"Thus, the competent observer in each locality in the United States knows exactly when to expect the Swallows, and can predicate their arrival within a few days-the probable error being due to advance or retardation of the season. This local observer knows as well how long the birds will stay. Then, those of us who make a business of the matter, and supplement our individual observations with the recorded experiences of all the rest, in all other countries, trace the movements of the birds into warmer parts of America; we map the distribution of each species, and account for every day in the lives of Swallows during the period of their absence from our midst. We know just where they go and what they do. We know, for instance, that countless thousands of White-bellied Swallows disport all winter long in Florida, as bright and active then and there as during their summer sojourn in New England. We know that myriads 
of Swallows are then at play in the air in Mexico, in the West Indies, and in Central America, just the same as at any other season of the year."

In speaking of the architecture of the Swallows, Dr. Cones writes:

"Next after the migration, the nidification of Swallows is the best known point in their natural history. The nesting and the eggs of all the North American species haye become perfectly well known, such is the abundance of the birds, such their familiarity with man. Their buildings illustrate two striking propositions:

"1. The versatility of architectural genius within the limits of a small and perfectly natural group of birds.

"2. The influence of man in modifying the architectural customs of birds.

"Every one of the North American species nests in a way peculiar to itself, even those which are most alike being distinguished by some circumstance, either of the nest itself, or of the freight it bears; and all the species, with a single probable exception, have stuccessively yielded to the modifying influences of the gradual settlement of the country by man. The Violet-green Swallow has held out the longest, and it is only very recently, in fact, that we have learned of its acceptance of the new order of things. The time when the Barn Swallow forsook its primitive custom of building has passed out of mind; the modification is so profound, that this bird now very rarely nests elsewhere than in artificial resorts which man presents to its choice. In some cases, the change is complete in settled portions of the country, while elsewhere the same species retains its primitive habits. Thus the Cliff or Eave Swallow now nests habitually on buildings in the Eastern United States, though it still glues its curious mud fabrics to the faces of cliffs in the West; and the Purple Martin nests indifferently in boxes set up for its use, and in holes in trees. In the case of the Cliff Swallow, another curious result of the settlement of the country is seen in the gradual extension of the range of the species. Formerly restricted to regions abounding in natural nesting-sites, it has spread into populous districts, where the eaves of buildings afford a convenient substitute for the original breeding places. The Rough-winged Swallow originally nested, and generally still nests, like the Bank Swallow, in holes dug by itself in the ground; but it now often avails itself of the nooks afforded by bridges, piers, and other contrivances of man. I should not be surprised if this bird were an immigrant, in to some parts at least of North America, of comparatively recent naturalization among us, attracted at length by conveniences for nesting. The Bank Swallow, the most cosmopolitan species of the whole family, seems to retain its wonted ways most sturdily of any -a fact perhaps explained by the highly exceptional character of its nidification.

"To all this there is no parallel among our birds. Various species, indeed, now regularly accept the artificial nesting-places man provides, whether by design or otherwise. Such is notably the case with several kinds of Wrens, with at least one kind of Owl, with the Bluebird, the Pewit Flycatcher, and especially the House Sparrow. Various other birds occasionally avail themselves of like privileges, still retaining in the main their original habits. But in no other case than that of Swallows is the modification of habit so profound, or so nearly without exception throughout an entire family. Next after the Swallows, the Wrens appear to yield the most readily, and all of our species will probably become modified in due time after the fashion of the House 
Wren. But the geographical distribution of no other birds than Swallows has been thus far affected by increased facilities for nesting.

"As architects, our Swallows are separable into several categories, according to the order of the structures they build. It will be remembered that they are weak-billed, feeble-footed birds, without the instruments required for the weaving of intricate fabrics, or the elaboration of ornate and highly finished dwelling places. So varied is their workmanship, so curious are some specimens of their art, that we can hardly refer their structures to any single plan; yet, in general, we may discern in their nesting the tendency, usually seen in weak-footed birds, to retire into holes, into which are brought, and artlessly arranged, the materials that are to receive the eggs. At least, such seems to be the primitive custom; and it is still the wont of the Purple Martin and of the Violet-green and Rough-winged and Bank Swallows. A modification of this is witnessed in the Barn Swallow, which builds by preference in corners, in any angle between converging plane surfaces. The most remarkable extreme is that the Cliff Swallow furnishes, where we can trace the most elaborate retort-shaped mud receptacles, back through less perfected purse-like structures, to the early idea of the bird, which was simply the walling-up of chinks and crannies on the face of cliffs, or the formation of a cup-like projection. In the material employed, we likewise see the progressive steps by which, from the mere deposit of soft material in a natural hollow, the Swallows began to project their fabrics out beyond the base of support; securing the required coherence of the materials, not by weaving, which to them was impracticable, but by plastering with mud. Thus we gradually reach those wonderful structures which the Cliff Swallow builds entirely of mud, with only a little hay or a few feathers for a lining.- The case of the Bank Swallows (Clivicola and Stelgidopteryx) is peculiar. It is the rule with weakbilled and small-footed hole inhabiters that they accept natural cavities ready made to their purposes. Yet some of the feeblest of the Swallow tribe dig their own holes in the ground, exactly as the Kingfisher excavates its gallery, or the Woodpeckers chisel out their nesting-places in trees. The fact, then, that Swallows are naturally hole breeders, taking possession of such cavities as come to hand, serves to explain their readiness to accept the convenient artificial nesting-sites that man provides. Even the Cliff Swallow, when nesting on buildings, seleets a site under eaves, and thus in a quasi cavity. The fact that the Bank Swallow habitually excavates a hole for itself, instead of accepting a ready made retreat, renders intelligible the fact that it still maintains its primitive ways, instead of yielding, like the others, to modifying surroundings. But the Roughwinged Swallow, which normally breeds quite like the Bank Swallow, is already yielding to the times, and in the East now generally nests in or about buildings, such as bridges and piers; and we may confidently anticipate the time when the Bank Swallow shall go and do likewise.

"The nesting of our Swallows now presents the following categories of method:

"1. Holes in the ground, dug by the bird itself, slightly furnished with soft material: Clivicola riparia, Stelgidopteryx serripennis.

"2. Holes in trees or rocks not made by the birds, fairly furnished with soft material: Progne subis, Tachycineta bicolor, Tachycineta thalassina.

"3. Holes, or their equivalents, not made by the birds, but secured through human 
agency, and more or less fully furnished with soft material, according to the shallowness or depth of the retreat. (Formerly, no species; now, all the species excepting Cotyle riparia.)

"4. Holes constructed by the birds, of mud, plastered to surfaces, whether artificial or natural, and loosely furnished with soft material. This is seen in perfection in the nesting of Petrochelidon lunifrons, and is imperfectly illustrated by the nidification of Chelidon erythrogaster. It has every appearance of an acquired trick, by which these hole breeders carry out their original instincts on a greatly improved_plan.... .

"Connected both with the migration and nidification of Swallows are some remarkable facts relating to the return of the same pair of birds to the same nest year after year. In the nature of the case, this is difficult to determine with certainty; but observations which have not seldom been made on birds that were marked by some recognizable peculiarity have established the fact beyond question. Far from being singular, however, it accords with many observations made upon birds of other families. How marvelous, how admirable, how complex and subtile, must be the mental faculties of such humble creatures, who can find their homes again with unerring precision, after journeying for thousands of miles!...."

On the general habits and traits of Swallows our author writes as follows:

"... The most graceful flyers among the Swallows are the lashing-tailed species of Chelidon proper, like the Barn Swallow, which glides, soars, and sweeps with extraordinary facility, and instantaneously arrests or diverts its flight at a touch of the guiding helm. The motion of the Swallow skimming the ground, and 'quartering' in zigzag after its prey, has been aptly compared to the coursing of the greyhound. No one who has attentively observed the flight of Swallows can have failed to notice their peculiar 'towering,' when they rise abruptly with few vigorous strokes, and seem to hang suspended for a moment, before falling with great velocity through the beautiful curve of the cycloid - with half gathered wings, and at such little loss of impetus by friction that they avail themselves of this peculiar line to rise nearly to their former level without muscular effort. Sometimes their course is as straight as an arrow's, and only less swift-sometimes they hover and flutter at seeming random, and not the least marvelous of their. feats is the spirited dash they make, with unerring aim, to enter the narrow window or belfry, and settle, as light as a feather, with joyous twittering, on the nest.

"The feeding of Swallows is almost an inference from the structure of the bill, wings, and feet. These delicate birds have very weak bills, but very capacious mouths, and seem not very dainty in their choice of food. They would soon be starved if forced to gather food on foot-on the wing, no one of the smaller flying insects is safe from that gaping bill, split to the very eyes, propelled with enormous velocity into their ranks, and capable of following after, to close on the most agile and devious bug. Swallows feed on the wing, and this prime point in the economy of these indefatigable insect hunters is signalized in the very names the birds have acquired in various languages. Not only the mode of flight, but its direction, whether high or low, and the entire migrations of the birds, turn upon the prime point of food supply; and upon this hinges, secondarily, the recognized relation between the movements of Swallows 
and the weather and seasons. The numbers of insects that Swallows destroy in the aggregate is simply incalculable-in fact, beyond the reach of our usual notions of numeration - and the holocaust includes a large proportion of annoying or injurious kinds. The loquacity of the birds, and the unseemly hours they keep, babbling to an unaired world, together with the litter they make about the premises, sometimes brings them into disfavor, or even causes them to be summarily dispossessed. The tempting targets they offer when in flight, taxing the skill of the most expert marksman, is another cause of their wanton and cruel destruction. But the most determined and calculating utilitarian should be brought to see the impolicy of killing Swallows, and the sportsman be besought to consider its inhumanity. Needless taking of any life is a crime against nature-we may well pause at this, even if no spark of sentiment should kindle indignation at the thought of cutting short such useful, bright, and joyous life. Things both useful and beautiful are not so common that we can afford to sacrifice them in vain. The rowdy boys and all the crew of tramps and potters of the gun who shoot Swallows for sport may be seriously admonished that these birds are worth more to society than their idle, vicious selves.

"The song of Swallows strikes a single key-note-the theme runs through the entire fugue-the itus, "iv species, at any rate- and I presume the exotics are much the same in this respect-the Swallow's voice is unmistakable. The tone is rather thin and sharp, and the pitch is high; the method of delivery is quick, nervous, and even jerky - it is mere twittering, indeed, as always called, rather than any higher art of singing. But the pieces are given with such volubility, vigor, and verve-they are so earnest, artless, and spontaneous, animated with such a bright and joyous spirit, that we forget to criticise, and even own the Swallow has a sympathetic voice. The simple notes are susceptible of much modulation, and capable of intoning the varied passions that these sanguine birds experience momentarily; while the different species, moreover, have each their own tone and inflections, easily discriminated by the accustomed ear. If I may add, that our Swallow medley touches a very secret chord of home associations, there is no wonder that it often moves us when more ambitious music fails to please.

"Among the leading traits of the Swallow tribe, no one can fail to recognize their sociability. 'Troops of Swallows' is a familiar phrase. The birds are not gregarious, in one sense,- not like Blackbirds for example, or Bobolinks in the autumn, flying in compact flocks, as if animated by a common impulse,-for no two Swallows bend their flight alike. But in places where, for any reason, the attraction is common, Swallows swarm. In foraging for insects on their 'happy hunting ground,' thousands eddy and whirl inextricably confused in flying currents, each one the vortex of a tiny maelstrom. In the consultation over a projected journey, thousands seek each others' countenance, perching in long lines upon the ridge-pole, the telegraph, the picket-fence. On warm dry days, the Swallows flock to the pools by the wayside, enclosing the grateful water with a pretty frame, or dallying over the surface with the yellow butterflies. But in nothing is the strength of social instincts more apparent-in nothing is the amiability of these cheery, genial birds displayed to more advantage-than in their nesting. Every rafter of the barn may possess its pair in peace, and every box beneath 
the eaves its contented, orderly inmates. The stretch of river-bank, the loamy crest of the quarry, may be honey-combed with burrows, and never a sign of strife in the settlement. Nay, more: among the Swallows, perhaps alone of our birds, do we find that rare climax of sociability which the actual clustering of nests betokens; and a colony of Cliff Swallows shows that a high degree of communism is not incompatible with perfect decency and decorum. Such free, impatient, and impulsive birds as Swallows, one might fear, could not sustain too close relations without at least occasional breaches of the peace; but the harmony remains unbroken. This surely speaks well for the disposition of the birds, arguing many a good quality beyond mere amiability; it indicates forbearance, self-respect, fidelity in all relations, and regard for another's rights; it reasserts that liberty does not mean license, and that freedom is to will to do right.

"Some who may be less interested in Swallows than I admit myself to be, or lack a sentiment I am willing to betray, may think the picture overdrawn, and ask for the other side of a shield that seems to me golden. If by this is meant, what are the bad qualities of Swallows? I must admit my incompetency to reply. These birds are said by some to be irascible and pugnacious. But quarrelsome they certainly are not, and their quickness of temper is resolvable into the admirable spirit they display in defence of their home and family. They are said to show special animosity against cats-quite an antipathy, in fact. Who wouldn't, under the circumstances? Which one of us, being a Swallow, could be expected to be fond of cats? These timid and delicate birds sometimes make Puss retire discomfited, such are the spirit and the vigor of their onset against this prowling enemy. Their courage is nowadays often called into action in defence of their homes against those wretched interlopers, the European Sparrows. There is a dead-lock here, and the feud is both bitter and relentless, in natural consequence of the Sparrows' total depravity. The Purple Martins, as I know, defend themselves against spoliation of their homes with success, and I hear that even the much weaker White-bellied Swallows, whose action in protecting themselves against outrage I have had no opportunity of studying, have proven no less valiant. I wish that the same could be said of some other birds which the Sparrows attack, harass, and turn out of doors; and to the Swallows in particular,- to every pair of these lovable birds that may nestle with us, $-I$ wish success in resisting invasion, peace, plenty, and every joy that can fill their gentle breasts."

The Swallows which inhabit our country are divided into the following genera:

1, Progne Bole. Two species.

2, Petrochelidon Cabanis. One species.

3, Chelidon Forster. One species.

4, Tachycineta Cabanis. Two species.

5, Clivicola Forster. One species.

6, Stelgidopteryx BaIrD. One species. 


\title{
PURPLE MARTIN.
}

Progne subis BAIRD.

\author{
PI,ATE XVJII. FIgURE 2 and 3.
}

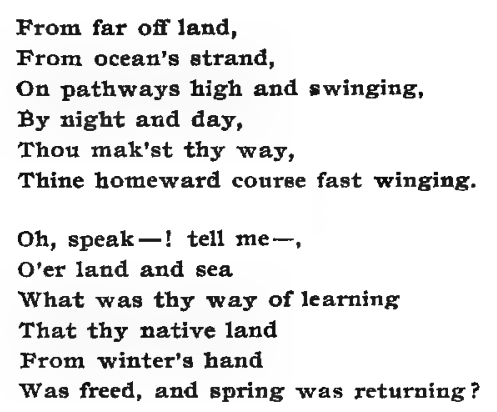

\author{
Thy sweet song wells - \\ And this it tells: \\ "I know not whence the feeling- \\ But-on! away! \\ Nor rest-nor stay! \\ The voice of spring seems pealing. \\ Thus, without rest, \\ With joyous zest, \\ On pathways high and swinging \\ I seek my way \\ Without delay- \\ My spring-clad course fast winging!"
}

From the German of Jutius Sturm, by HrLma Silliw.

㬄 PRIL in the Gulf region is the real spring month, the most beautiful of all the I year. Then the air is most balmy and invigorating filled with the fragrance of innumerable flowers, then the birds sound their gayest and loudest carols. In order to admire nature in all her freshness and glory, we rise as early as four o'clock in the morning and step out into the fresh, soft air, impregnated with the richest perfumes. In the garden and along the piazza blossom the queens of the realm of flowers, the precious tea and Noisette roses, which in the North can be grown only with great care under glass. The powerfully fragrant sweet olives ${ }^{1}$, banana shrubs ${ }^{2}$, gardenias (Cape jasmine), and orange trees, the oleander, myrtle, ardisia, the last still ornamented with lustrous red berries, and many other shrubs are in full bloom. The night jasmine fills the air with its delicious odor. We cannot yet distinguish the different objects about us, for darkness still hovers over all nature. Only a barely perceptible streak in the far East intimates that day-break is approaching. Mockingbirds, the most enchanting songsters among the feathered tribe, are heard in every direction. Singing they fly up into the air and descend without interrupting their loud and indescribably sweet song. Here and there a Cardinal Redbird or a Carolina Wren, apparently yet half asleep, sound a few notes. When day breaks in the East, signs of life are perceptible in the Martin-house of our garden. At first we hear the pleasing melodious notes uttered quite softly and at intervals, but with the increasing light they increase in frequency and loudness. While thus twittering, the males project their purplish-black heads into the fresh morning air. After a short while one after another emerges, smoothing the plumage and twittering cheerily. Then, with loud music out they dart into their real element, the air. A fresh, gay, and cheery liveliness the twelve pairs, breeding in our Martin-house, impart to the garden, the yard, and the landscape around. The Bluebirds, the Tufted Titmice, and the Carolina and Bewick's Wrens appear from out of their nesting-boxes, but they 


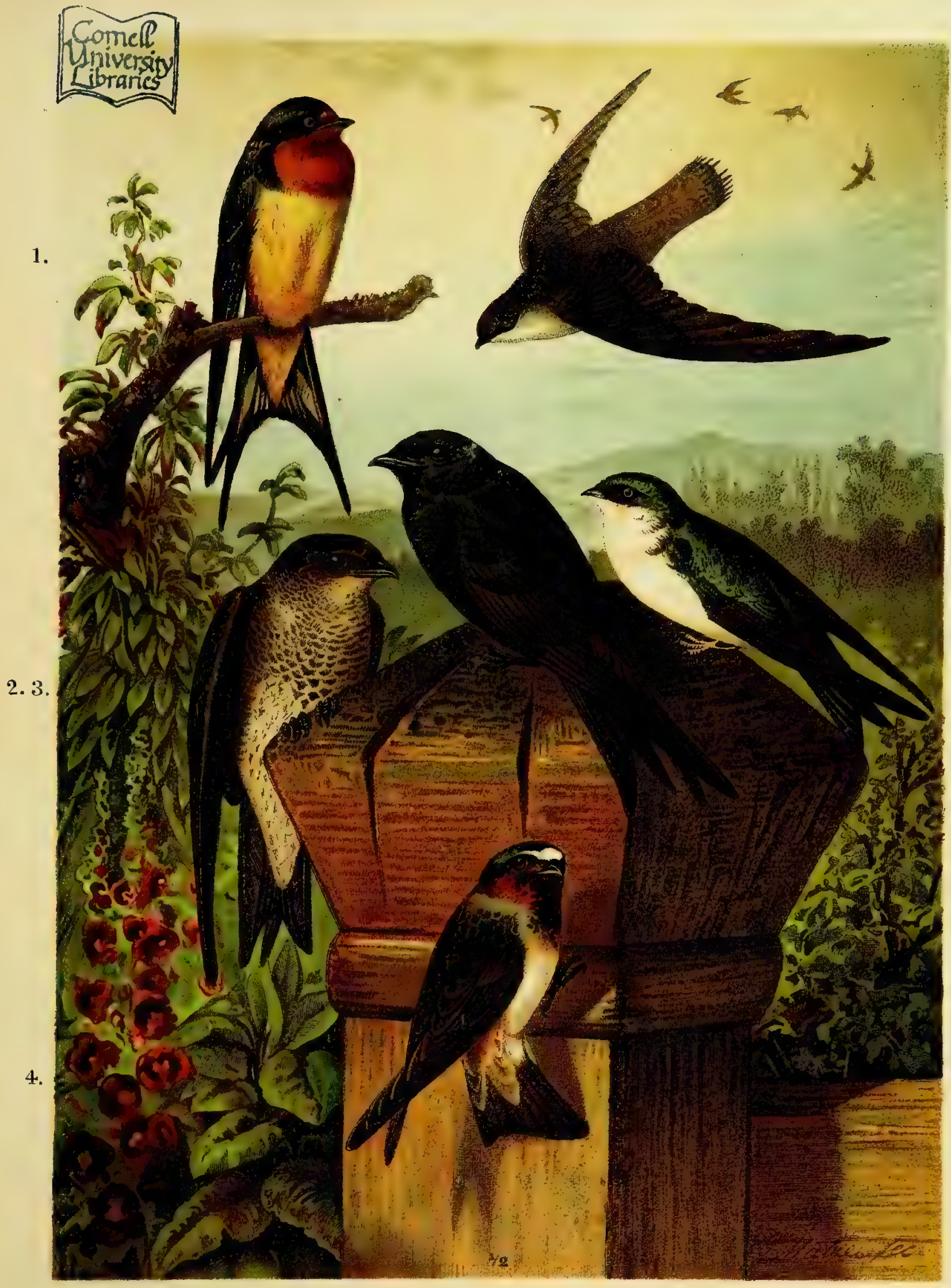

5.

6.

1. CHELIDON ERYTHROGASTER Stejn. - SCHEUNENSCHWALBE. - Barn Swallow.

2.3. PROGNE SUBIS BId. \& \&

4. PETHOCHELIDON LUNIFRONS Brd

5. CHAETURA PELAGICA Steph.

6. TACHYCINETA BICOLOR Cab.
- MARTINSCHWALBE.

- TRAUF SCHWALBE.

- SCHORNSTEINSEGLER . -

- BAUMSCHWALBE.
- Purple Martin (2 female,3 male)

- Cliff Swallow.

Chimney Swift.

- Tree Swallow. 

fly away for some distance before they begin to greet the new day with their loud chants. All these and many other garden birds add much to the pleasures of country life, but none of them in the familiar and attractive manner of the cozy Purple Martin, which always likes to breed in colonies of two to twenty and more pairs. How wonderfully glitters their blue-black plumage in the finest purple and violet hues, how charmingly graceful is their flight, how cozy and exhilerating their melodious, loud, and twittering song, and what a peaceful and gay life do they impart to garden and yard by all this, and by their incessant flying to and fro! City people and late risers have no conception of the lovely idyll that developes itself before our eyes in the earliest morning hours. How contented and happy man could be, how delightfully in sympathy with nature's own attractions, if he more frequently would lift his eyes from the simply realistic to the ideal, to what is beautiful and refining!

Our Martin-house, which has twelve comfortable rooms (each $10 \times 10$ inches wide and 10 inches in height), stands on a strong post about eighteen feet high. The beautiful star creeper ${ }^{1}$, evergreen fragrant honey-suckles, the climbing Solanum jasminoides, and the Mexican mountain rose-vine ${ }^{2}$ are trailing over the trellis and along the post. Around this group of beautiful vines are planted young thrifty palms, but particularly gorgeously flowering amaryllis ${ }^{8}$, crinums, and spider lilies ${ }^{4}$. The three last named plantforms, really tropical productions of the amaryllis family, occupy in the South the places filled in the North by the lilies, which, with the exception of several species ( $L$. longifforum, L. longiflorum Harrisii, L. Brownii, L. speciosum), do not thrive very far south. The spider lily and many of the crinums excel chiefly by their fragrance, the noble amaryllids by richness of their hues and fine form. We see these blossoms before us, just now varying from the most glowing red to a very delicate light pearly and creamy-white. Many of them show an intense vermilion, which is relieved by a yellowish or greenishwhite star in the throat of the flower. Most beautiful are the bright red kinds, which seem to be covered with countless sparks of gold whenever the direct rays of the sun rest on them. But still more beautiful and glittering is the plumage of our Purple Martins, which are now flying in and out in the full sunny brightness of the morning.

None of our Swallows are so generally known nor such favorites as is the Martin. Everywhere, from the Atlantic to the Pacific coast, and from Florida and Texas to high northern latitudes, this bird is known. Wherever, throughout this immense territory, man settles down, it becomes his companion, whether it be near the log-cabin, crudely built in the primeval forest, or near the simple sod-dwellings of the settler on the wide treeless prairie of the far West. It is abundantly present in villages and even in cities, and is everywhere a welcomed favorite, whose coming is yearningly expected, joyfully greeted, and whose departure causes a pang of melancholy. None of our Swallows have attached themselves as intimately to the human family as these. All the other species are more pretentious in their claims, and will breed only where the conditions are particularly favorable. The Martin is as well satisfied with the simple hollow gourd attached to a pole near a negro hut, as with the most ornamental and best arranged Martin-house in the beautiful gardens and parks of rich planters and opulent merchants. Where no nesting-boxes are provided, our Martin will not bréed,

1 Rhychospermum jasminoides. 2 Antigonon leptopus. I Hippeastrum. 4 Hymenocallis Carihza. 
and it hardly ever accepts nesting-boxes attached to trees, preferring locations where the chance is given to dart in and out uninterrupted by any obstacle.

In the northern part of our country a few Martins appear late in April. The first arrivals are old males, who come to investigate the old nesting-places and hunting grounds, and then disappear again for a few days. These are evidently the scouts, who doubtless fly back to rejoin the main army, which makes its appearance a number of days later. In Texas and northern Florida they arrive late in February; in southwestern Missouri I observed the reconnoitering males about the middle of April, while the main body did not arrive until the 26th of that month. They at once announce their return by their loud melodious twittering song and take possession of their old nesting-boxes. Very frequently a colony of European Sparrows has forestalled them, which often occasions bitterly contested feuds. If the invading proletarians are numerous, then our brave Martin is vanquished and must seek another home. But frequently these Swallows are victorious, and, the foreign intruder, after leaving some of its plumage on the battle-field, departs loudly scolding. Then the Martins, announcing their victory in loud jubilating sounds, rise high into the air, almost invisible to the human eye, and after a few moments return, gayly twittering, to their nesting-box. Although they care little, whether on high or low ground, they prefer to domesticate themselves wherever water is near. Brooks, ponds, rivers, and lakes are their favorite hunting grounds. For hours in their flight they will almost skim the surface of the water, catching insects, drinking, and even taking a bath. In great numbers they also fly over treeless marshes and bushless lowlands, where in the warm season swarms of mosquitoes and other small insects abound. At the North the returned Martins not infrequently have a hungry time late in April and early in May, when the season is exceedingly changeable and backward, and flying insects are still scarce. But by the middle of May gentler zephyrs blow; the bursting buds open rapidly. By the end of that month all is in bloom, and the richest fresh green foliage expands rapidly. Grass and weeds shoot up thriftily, and with these the immense and varied army of insects celebrates its resurrection. The "bill of fare" for all the small birds is now richly varied and plentiful. Cheerily twitters and jubilates the feathered choir, but above all others, and louder and cheerier than all, our beautiful lustrous Purple Martin. Now is the time for nestbuilding. Bits of straw, hay, old leaves, plant stems, feathers, rags, twine, and sometimes mud, are carried into the nesting-box promiscuously and piled up rather loosely. The cavity is more carefully lined with feathers from the poultry yard, bits of cotton, and the like. Fearlessly these beautiful birds come to the very house door to pick up material for their nest. The eggs, usually four to five, rarely six in number, are pure white, never spotted.

Formerly, before our country was settled by the European race, when vast regions were covered by primeval forests, the Martin's resort for nesting and shelter was to hollow trees and crevices in rocks. "The introduction of civilized life, and with it of safer and more convenient places, better adapted to their wants, has wrought an entire change in its habits. It is now very rarely known to resort to a hollow tree, though it will do so where better provision is not to be had. Comfortable and convenient boxes, of various devices, in our cities and large towns, attract them to build in small 
communities around the dwellings of man, where their social, familiar, and confiding disposition make them general favorites. There they find abundance of insect food, and repay their benefactors by the destruction of numerous injurious and noxious kinds, and there, too, they are also comparatively safe from their own enemies. These conveniences vary from the elegant Martin-houses that adorn private grounds in our Eastern cities, to the ruder gourds and calabashes which are said to be frequently placed near the humbler cabins of the southern negroes. In Washington the columns of the public buildings, and the eaves and sheltered portions of the piazzas, afford a convenient protection to large numbers around the Patent Office and the Post Office buildings" (Brewer). In Wisconsin I had, in the days of my boyhood, each season colonies of Martins in my Martin-houses, and later I attracted them to my garden in Texas and Missouri by placing boxes and miniature houses on high posts among ornamental shrubbery and vines. In Houston, Texas, they breed in large numbers under the roofs over the side-walks, even in the business part of the city. I have frequently observed them in Texas, Louisiana, and Florida nesting in gourds in close proximity to the primitive negro cabins. The small garden of my friend, Mr. H. Baumgærtner, situated in a densely populated part of Milwaukee, harbors not only a pair of Bluebirds, House Wrens, Hairbirds, and Robins, but a few pairs of Martins breed also in the boxes provided for them. In order to protect these beautiful native birds from the attacks of the ever present House Sparrows, Mr. Baumgærtner kills from four to five hundred of these feathered anarchists annually. A pair of Tree Swallows also breed in the neighborhood. The last named species is said to drive away the more familiar, beautiful and interesting Purple Martins, though I am unable to speak from my own experience. In the vicinity of Boston, where the Martin was once very common, its places are now taken by the Tree Swallows, who occupy almost exclusively the Martin-houses, very rarely breeding at present in hollow trees.

In a very interesting article ("On some of the Causes affecting the Decrease of Birds." Bull. Nutt. Club, VI, p. 193), Mr. H. W. Henshaw writes on the extermination of the Martins, near Boston, as follows: "Of the local effects of a storm, however, the best example I know of is the case of the extermination of the Purple Martins in Cambridge and near vicinity years ago during a cold storm which caught the birds a day or two after their arrival from the South. This instance is of peculiar interest, inasmuch as the Martins, although affected only within a small area and remaining abundant outside of it, have never reoccupied the lost ground; whether from a failure to increase sufficiently to colonize it, or from inability to make headway against the Tree Swallows and Wrens, usurpers of their ancestral seats, is uncertain."

In the North the Martins raise only one brood, while in the Gulf region two broods are raised annually.

On the feeding of the young, Mr. Otto Widmann says: "As a rule, the older the birds in the nest, the oftener they are fed, and from the size of the insects which the parents bring, the age of the young may be judged. The youngest birds are fed at longer intervals with crushed insects, mostly small beetles, from the craw. About a fortnight old, they are fed from the bill with soft insects of the size of large flies; but insects with stings, such as bees and wasps, are never brought. When four weeks old, 
large dragon-flies, grasshoppers, and butterflies make the principal food. The young Martins do not leave their box until they are six weeks old."

The most dangerous enemy of our beautiful Martin in the neighborhood of man is the European Sparrow, which occupies the nesting-boxes and Martin-houses before our Swallow makes its appearance in spring. In this connection I quote from an article written by my friend, Mr. Otto Widmann, of St. Louis :

"Immediately on arriving in early spring the Martin seeks a box-his old box of last year, if possible. A few days afterwards his mate joins him, and the pair regard the chosen box as their home long before they begin nest-building. During this time, in the full enjoyment of their honey-moon, the pair used to leave home together when going out in search of food. Of late they have begun to take turns, one staying at home to keep the Sparrows out. This is an important strategical progress, because it is comparatively easy to keep the Sparrow out of a box, but it is impossible for a Martin to dislodge him after he has built a nest.

"Besides being much more intelligent and courageous than the birds with which it comes in conflict, the House Sparrow has several really good qualities which are worthy of imitation by our native birds. Its diligence is marvelous. After removing their nest in the evening, one is surprised to see the heap of material which this single pair has carried in within a few hours the following morning; and this is done day after day with wonderful perseverance.

"But the most prominent trait of its character, and the one which explains in a great measure the immense multiplication of the species, is the unsurpassed attachment of the parent Sparrows for their offspring. A Sparrow never deserts its brood. If one of the parents is killed, the other will do all the work alone. If a young one happens to fall down from the lofty nest, it is not lost; the parents feed it, shelter, and defend it. If a young Sparrow is taken from the nest and placed in a cage, the mother feeds it for days and weeks, even if she has to enter a room to get to it. Many young Martins tumble out of their nests, and are invariably lost. The parents make much noise about it, and try to make the young fly up, but finding that they can not do it, they let them perish, and even if placed where they could easily get to them, they do not feed them. In times of drought many young Martins starve to death, being sometimes entirely deserted by the parents.

"While from the four to six eggs which the Martins lays, on an average only two young are successfully reared, the Sparrow succeeds in bringing up all the young hatched, which are four or five.

"The Sparrows have traits of character which may set a good example to some of our birds, and I hope they will follow it. If they do so, the danger of being displaced by the foreigner will be greatly diminished. (March 10, 1888.)

"As a great lover of birds, I am naturally inclined to be mild in censuring their misdeeds, and although I have been living in war with the House Sparrow since its appearance, I still hoped sometimes that our native birds would learn to repulse the intruder, and that its presence might yet be tolerated to a certain degree. It was in such a spirit of reconciliation that I wrote last March, but the experience of this spring has demonstrated more clearly than ever that leniency toward the House Sparrow 
would be a crime. A careful watch has revealed the fact beyond doubt that the House Sparrow destroys the eggs of the Martin by eating them without leaving even a trace behind. Six nests were thus destroyed, with from four to six eggs in each. The Martins had defended their nests successfully until the cool period about the middle of May, when the scarcity of winged insects caused them to go far from home and to stay away long. This absence from their nests enabled the Sparrows to enter the boxes and to eat the eggs.

"In one case the Sparrow was hindered from proceeding farther than drilling holes ( $1 / 4$ by $3 / 8$ inch), through which he probably intended to empty the contents of the eggs and then finish by eating the shells. In the other cases the eggs disappeared without leaving any traces. Only in one case did the Sparrows begin to build in the box; in all other cases the nests were left undisturbed.

"The Martins watch their treasures well enough during the morning hours, but in the afternoon, especially in cool or dry weather, they like to go off for a hunt and to stay away for severd hours. This is the time when the sparrows sneak into the boxes, and it requires constant vigilance on our part to keep them off and to save the eggs (eighty-five contained in the boxes to-day).

"As long as eight years ago, seeing that the House Sparrow became irrepressible, I tried to compromise with him by putting up separate boxes for his special use, giving him to understand that he would be tolerated there, but nowhere else. This plan seemed to work well, but for a short time only, and I soon found that the only way to deal with them was to destroy. their nests and young ones.

"Last spring, being much warmer than this year, was favorable for the Martins; they could stay about home nearly all the time, and it really seemed as if they had learned to be more effective in the defense and repulse. But this cool spring showed me that the Martin is too much dependent on the weather to be a successful defender of its home, and the verdict is, therefore, that the House sparrow will no longer be tolerated on my grounds, and that it will be destroyed without mercy, by any means, and at every time of the year, not merely in spring as heretofore." (Saint Louis, Mo., June 2, 1888.)

In the South many broods are destroyed by the very abundant tree climbing snakes, which enter the breeding-boxes during the night. On its wings the Martin is a bold and courageous bird, "prompt to meet and repel danger," especially when Hawks, Crows, and other winged enemies enter its domain. It never hesitates to attack and drive them away from its neighborhood, often in company with Kingbirds. . Like the! last named species, it, therefore, is a valuable protection to the barn yard, as no Hawk dares to come near its domain. .Its food consists of all kinds of flying insects, and in destroying them it again does good service to the gardener, farmer, and fruit-grower. In cold and rainy weather I have often observed Martins sweeping and touching the branches of apple trees to dislodge insects. As it only captures its prey in the air, a number of cold and rainy days are very detrimental to the welfare of our birds, and often many perish by cold and hunger during the changeable days of May.

The Martin's flight is exceedingly swift and beautiful, and its twittering song is very loud and mellow, and, to my ear, very sweet and charming. 
In regard to the roosting and departure of the Martin no other ornithologist has made so close and painstaking observations as Mr. Otto Widmann. In an article in "Forest and Stream" (1884, p. 183, 184), he writes as follows:

"It is generally known that the Martins spend the night in their boxes only during the breeding season. At all other times they sleep in the open air. By taking possession of a box in early spring the Martin shows its intention to become pater familias. All old males take boxes on arriving, as soon as they can find any to suit them. Young males, although several weeks behind in arriving, do not show so much eagerness to own their own box, and even young pairs prefer camping out until nestbuilding has begun. Bachelors sleep in the open air all summer, but visit the colony of their brothers and sisters regularly in the morning and evening, meddling sometimes with their domestic affairs, playing tricks, and doing real mischief by annoying the young ones. During the breeding season both parents sleep in their box until the young ones have left the box. The first few nights the young Martins are often brought home by their parents. The weather has much to do with it; rainy, windy weather brings home most of them, but as a rule the best parents, those which feed them most regularly and diligently, bring them home safest and longest, even to a whole fortnight. This home-bringing is attended by much noise-making, and great excitement prevails until the young are safely lodged. The parents do not enter the boxes, but one of them watches the entrance until quite dark, when it hurries off in the direction of the common roost.

"Where is the roost? This is not so easily found out. When Audubon saw a high old tree covered with Martins after sunset and again the next morning before sunrise, he thought he would make no mistake by imagining that the Martins sleep on those dead trees all night. But they do not. Those trees are only the meeting place for the Martins of a certain district, from whence they start for the distant roost in the willow thicket, which they do not enter until it is quite dark, and which they leave with the first dawn, from ten to fifteen minutes before the Swift leaves its chimney.

"The young join the parents as soon as they are able to fly the distance, or, as here, to cross the Mississippi. From that moment the boxes are never entered again, but their roofs are used for social gathering in the morning hours during the next few weeks. The regularity of these visits does not last long; pauses occur; in dry, hot weather the visits are short, in cool spells they are cut off entirely, but a sultry, rainy term brings them back again to spend a few hours in animated chattering around the old home. In the evening they only pass without stopping, but they visit often their old hunting grounds in the neighborhood. During the day they are seldom seen after the first of August. After this date they appear late in the evening, but their number increases rapidly. They collect on tree-tops, church steeples, and other points of prominence and loftiness, around which they swarm like bees for about half an hour, when the air for a mile around is filled with Martins, which now form a whirling body of many thousand, rolling up and down at first above the bluff, then above the Mississippi, going and returning in wicle circles, but all this time drawing surreptitiously toward the willows on the other side of the river. It has now become dusk and the descent cannot be seen from this shore, but the moment can be known by a sudden 
outcry of alarmed crows and blackbirds which had retired into the same willows long before.

"Such vast numbers of Martins cannot be sent forth from one city nor from a few counties. The Martins of half of the States of Missouri and Illinois must flock together to form such an army. But it is not yet migration; it is only the prelude to it. Such common roosts are the starting points for those thousands, and are the resting stations for many more thousands which pass through in the last week of August and in September.

"Our birds became peculiarly excited and mysteriously restless after Aug. 12. After an interval of several weeks, the old birds began at this day to visit their boxes again, hung around them for half hours, not with merry carols as in early summer, but for the purpose of giving a last look at the scenes of former happiness.

"A.ug. 20 and 21 were stormy, followed by a north wind period with several cool nights. The tactics of the great army were now changed. Migration began. After the 24th, the gatherings on this side of the river ceased, our St. Louis Martins had left, and to the St. Louis man the Martins had become very scarce. Not to the initiated, and if you come along with me across the Mississippi, I will show you more Martins than one can otherwise see in a life-time.

"It is Aug. 25, 6 P. M. Only a few Martins are seen on this side of the river going east. We take a skiff and follow them. After ten minutes' rowing, we approach the opposite shore. What is that? Hundreds and hundreds of birds sailing low, above the water, hundreds of silvery splashes flashing up from the now dark waters of the great river. What a strange sight! The Martins are taking their bath. Now we are on the sand-bar of the Illinois side, opposite the southern part of St. Louis, just north of Arsenal Island. It is a large tract of fine river sand, newly formed, almost quite dry and free from vegetation, except a strip along the willow thickets which border it on the east. It is 6:30. Since we have arrived, the air all around us has filled up with martins, pouring in from all directions, high up and low above the water, all going toward the one place-the outer rim of the sand-bar, where on a few acres of sand ten thousand Martins are sitting already in solemn silence, probably in secret session. Ten thousand Martins sitting close together on a few acres of sand-bar is a sight not often met with, and we must look at them very sharply. They are not very shy, many alight a few yards from us, and we can watch every movement. The only movement we can see is a picking motion as if taking up a grain of sand, but this is only play work, because we see them also pick at straw protruding from the sand. They did not come to eat sand, their only purpose is to meet here and decide if to go on with their journey southward or to take a rest in the neighboring roost. It is now 6:45 and getting dusk. The smoke of the city, driven by a north-east wind, has enveloped the western horizon and all will be dark in a few minutes. Do they sleep on that sand? They have been sitting here now for half an hour. Look here, four birds coming toward the willows, they are scouts! Is this not a strange call, a call never heard around their breeding boxes? They are now all four above us, circling over the willows and returning to the sand. Presently the ranks of the Martins thin ont, and in less than a minute all have left the sand, flying ont on the river, down toward the island, rising 
above the willows, and in a few minutes all is quiet, dark. The Martins have gone to rest, and we will not disturb them. It would be difficult work to penetrate these willow thickets at night.

"The willows are about twenty feet high, and stand very close together. The ground is swampy in some places and it is covered all over with debris left by last year's inundation. We shall try to see them leave the willows to-morrow morning.

"It is $5 \mathrm{~A}$. M., the stars have disappeared, with the exception of a few bright ones. We are on the bluffs opposite the sand-bar. The first break of day stands in the .eastern horizon, but night still reigns west of us. This is the moment when the Martin leaves its roost. They are already coming over the river; a few voices only, then more and more, and now the whole air is filled with the short calls of Progne. They seem to be all around us, below and above, but we may strain our eyes in all directions, not a single bird can be discovered; it is too dark and the birds are to high above us. A few minutes later the bulk has passed, but it is getting lighter and we are able to see a few loiterers, mere dots passing the zenith, following the others in a northwesterly or 'westerly direction. A few minutes more, the last will be gone and no Martin will be seen at this place before $5 \mathrm{P}$. M.

"After migration has thus begun, it will be good for us to visit the scene of rendezvous every day. The Martins begin to arrive at $5 \mathrm{P}$. M.; they arrive mostly low above the water, comparatively few are coming at some height. As soon as a few hundred are together, they begin to sit down on the sand. In the beginning they are pretty restless, changing their places every few minutes, sometimes flying up in a cloud to settle down at or near the same spot again. If we are watching them now from a place south of the bar, we notice that not all settle down again. After swinging a few circles, part of the flock detaches itself from the rest, and, heading south, soon disappears in that direction. Although the number remains about the same for two weeks, we soon find that a change has been going on from the beginning. As early as Sept. 1 we become aware that we have almost entirely to do with birds of the year. The old birds, the old males, at least, have mostly left.

"The most imposing sight may be had by disturbing the army at the moment when all have settled on the sand. The whole mass goes up in a body, turning right and left, forms two mighty streams which unite above the water in a great whirlpool, rushes up and down, sweeping along the river to a distant point, then coming back again like a huge cloud, which moves hither and thither until the neutral tint of night allows the safe retreat. On Sept. 7 and 8 the number of Martins present was still as large, or larger, than ever. After the sultry, stormy weather of Sept. 9 and 10 a cold north-west wind reduced the temperature to $66^{\circ}$ on the 11 th, and on this evening the Martins assembled on the sand-bar for the last time. The number was much smaller than usual, and when the cloud rose from the bank at 6 P. M. comparatively few returned. On the 12 th no Martin was sitting on the bar, but about a hundred flocked together low above the water near the bar and disappeared soon, moving slowly in a southerly direction. The same took place on all the following days. Small flocks began to collect at 5:30 and disappeared after staying about the neighborhood until a little after 6 P. M. The last were seen on the 18th, but only a few, and none to-day (19th)." 
It is the duty of all friends of nature, of all who love our beautiful native birds, to do their utmost to protect the Martins and other birds of song and beauty. By its familiarity, cheerfulness, and graceful flight, its beauty and song the Martin adds greatly to the charms of rural life. No country place where sentiment and refined taste dominates, ought to be without its Martins.s. Convenient nesting-boxes and Martinhouses should be provided for these birds, and the Sparrows and other enemies should be kept continually in check by killing them and destroying their nests.

The Martin inhabits the whole of temperate America, from the Atlantic to the Pacific, and from Mexico and Florida north to the Saskatchewan.

NAMes: Purple Martin, Martin, Purple Swallow, Black Martin, Black Swallow, Great American Martin, Blackbird Swallow.-Martin and Martinschwalbe (German).

SCIENTIFIC NAMES: Hirundo subis Linn. (1758). PROGNE SUBIS BAIRN (1865). Hirundo purpurea Linn. (1766). Progne purpurea Boie (1826).

DESCRIPTION: "Male, adult: lustrous blue-black. Female and young: duller steel-blue; below, more or less extensively white with dark gray streaks. Bill and feet, black; the former very stout and much cturved for a bird of this family; nostrils, circular and prominent.

"Length, 7.00 inches or more; extent; 16.00 ; wing, nearly 6.00 ; tail, 3.50 inches, simply forked." (S. \& C., "N. E. B. L.," Vol. I, p. 189.)

The Cuban Martin, Progne cryptoleuca Bairn, inhabits Cuba and suuthern Florida.

\title{
Cliff Swallow; Eave Swallow.
}

\section{Petrochelidon lunifrons BAIRD.}

Plate XVIII. FIG. 4.

\begin{abstract}
Fin the Swallows homeward fly"-these words of a pcpular song came into my mind, when late in August I noticed large numbers of Swallows soaring through the air over the prairies of south-western Missouri. Quietly and restlessly they fly at this time over corn-fields, over pastures, and woodlands. They gather now. In a few days they will be ready to migrate to countries where majestic palms and other tropical trees, covered with gigantic climbers, border the Magdalena, the Orinoco, and the Amazon, or to regions where orchids, fuchsias, gloxinias, and other plants of our green-houses grow in the cool shade of the mountain-sides, where many species of Hummingbirds, vieing in color with the splendor of diamonds and other precious stones, dart and buzz from flower to flower. But our Swallows do not fly "homeward." On the contrary, they depart in a melancholy mood to their winter-quarters in a foreign land. Their home is where they spend the summer, where they twitter their love-songs, and raise their young. Among the thousands of Swallows which are thus preparing for their journey, we notice numerous CLIFF Swallows, popularly known as Eave, or Mud Swallows.
\end{abstract}


The Cliff Swallow, a very sociable, though somewhat noisy bird, is one of our most abundant and familiar species. Although distributed over an immense territory, from the Atlantic to the Pacific, and from high northern latitudes to Panama, it is in summer of rather sporadic occurrence, being found in one section in exceedingly large numbers, and not at all in another. The breeding range extends from Texas to the Yukon in Alaska, and to Nova Scotia. Formerly these birds only were found nesting on projecting cliffs, but the settlement of the country conduced to their general dispersion; and they now make their appearance where they were unknown before. In all the settled parts of our country they have everywhere changed from Cliff to Eave Swallows. In this connection it may be remarked that the form of their nests has also changed. If clustered on perpendicular cliffs, the mud structures are bottle-nosed or retort-shaped, while under the eaves of barns and other buildings they form globular nests with an entrance hole on the side. In some cases even open nests, like those of the Barn Swallow, have been found.

In my native State, Wisconsin, I found the Eave Swallow in greater numbers than in any other State in which I resided. Under the north eave of our barn in Sheboygan County each season from thirty-five to fifty nests could be counted. The birds were exceedingly fearless; they did not mind our curiosity and the uproar and noise beneath their nests. Usually on the 9 th or 10 th of May, if the weather would permit, our Eave Swallows made their arrival from the South, and were greeted with exhilerating sounds by the children. They at once enlivened the barn yard by their peculiar loud and creaking notes and their incessant flying to and fro. By the end of May they always began building new nests, or repairing those formerly occupied. This work was performed with much twittering and great industry, they often completing their task with wonderful celerity. I have always noticed that they do not like to build on very smooth surfaces, but prefer such eaves where there is a narrow space between the roof and the boards. In such a space the nests have a better hold. When our old barn was torn down and a new modern structure erected in its place, the Eave Swallows were much surprised when returning in spring. They soared around in great excitement, and evidently did not know what to do. There was no crevice between the roof and the boards, and the latter were smooth and painted. A few pairs commenced building, but the mud pebbles evidently found no hold, and they gave up their task in great disappointment. Many or all visited the different barns in the neighborhood, but could apparently not come to a conclusion where to construct their nests. To encourage these birds to return to our barn, I placed narrow strips of boards under the eave, and they at once took advantage and began to build their mud homes. They are not treated everywhere so kindly as they deserve. Many people have the absurd idea that the nests contain bed bugs, and destroy them wherever they can. Hundreds and thousands of nests are thus destroyed by farmers and others, who are ignorant of the great services of these industrious and innocent birds. Others dislike their noisy chatter in the early morning hours, and consequently dislike the birds too. Although the song is a rather unmusical twitter and almost incessantly uttered, it is to the real lover of bird life far from being unpleasant. The Eave Swallows show, unlike other members of the family, a noted pertinacity and stick to their first choice. "Considering how sedulously most birds 
strive to hide their nests and screen themselves during incubation, it becomes a matter of curious speculation why these Swallows should ever build beneath our eaves in the most conspicuous manner, and literally fly in the face of danger." Their confidence in man is, as we have already seen, too often betrayed. With what pertinacity these birds cling to their chosen homes, though subjected to every annoyance, and repeatedly ejected from the premises by the destruction of their nests, the following examples cited from Dr. Elliott Coues' "Birds of the Colorado Valley," will show :

"I have two notable cases in mind. At Fort Pembina, Dakota, a colony insisted on building beneath the low portico of the soldiers' barracks, almost within arm's reach. Being noisy and untidy, they were voted a nuisance, to be abated, but it was 'no use; - they stuck, and so did their nests. In the adjoining British province of Manitoba, at one of the trading-posts I visited, it was the same thing over again; their nests were repeatedly demolished, on account of the racket and clutter they made, till the irate lord of the manor found it cheaper in the end to let the birds alone, and take his chances of the morning nap. I think such obstinacy is due to the bird's reluctance to give up the much needed shelter which the eaves provide against the weather-indeed, this may have had something to do with the change of habit in the beginning. The Cliff Swallow's nest is built entirely of mud, which, when sun-baked into 'adobe,' is secure enough in dry weather, but liable to be loosened or washed away during a storm. In fact, this accident is of continual occurrence, just as it is in the cases of the Chimney Swifts. The bird's instinct-whatever that may mean; I despise the word as a label of our ignorance and conceit-say rather, their reason, teaches them to come in out of the rain. This may also have something to do with the clustering of nests, commonly observed when the birds build on the faces of cliffs, for obviously such a mass would withstand the weather better than a single edifice.

"It is pleasant to watch the establishment and progress of a colony of these bircls. Suddenly they appear-quite animated and enthusiastic, but undecided as yet; an impromptu debating society on the fly, with a good deal of sawing the air to accomplish, before final resolutions are passed. The plot thickens; some Swallows are seen clinging to the slightest inequalities beneath the eaves, others are couriers to and from the nearest mud-puddle; others again alight like feathers by the water's side, and all are in a twitter of excitement. Watching closely these curious sons and daughters of Israel at their ingenious trade of making bricks, we may chance to see a circle of them gathered around the margin of the pool, insecurely balanced on their tiny feet, tilting their tails and ducking their heads to pick up little 'gobs' of mud. These are rolled round in their mouths till tempered, and made like a quid into globular form, with a curious working of their jaws; then off go the birds, and stick the pellet against the wall, as carefully as ever a sailor, about to spin a yarn, deposited his chew on the mantel-piece. The birds work indefatigably; they are busy as bees, and a steady stream flows back and forth for several hours a day, with intervals for rest and refreshment, when the Swallows swarm about promiscuously a-flycatching. In an incredibly short time, the basement of the nest is laid, and the whole form becomes clearly outlined; the mud dries quickly, and there is a standing place. This is soon occupied by one of the pair, probably the female, who now stays at home to welcome her mate with 
redoubled cries of joy and ecstatic quivering of the wings, as he brings fresh pellets, which the pair in closest consultation dispose to their entire satisfaction. In three or four days, perhaps, the deed is done; the house is built, and nothing remains but to furnish it. The poultry yard is visited, and laid under contribution of feathers; hay, leaves, rags, paper, string-Swallows are not very particular-may be added; and then the female does the rest of the 'furnishing' by her own particular self. Not impossibly, just at this period, a man comes with a pole, and demolishes the whole affair; or the enfant terrible of the premises appears, and removes the eggs to enrich his sanded tray of like treasures; or a tom-cat reaches for his supper. But more probably matters are so propitious that in due season the nest decants a full brood of Swallows - and I wish that nothing more harmful ever came out of the bottle."

In speaking of the occurrence of the Eave Swallow, Dr. Coues remarks:

"It may be remembered in this connection that a happy conjunction of circumstances is required to satisfy these birds. Not only are cliffs or their substitutes necessary, but these must be situated where clayey mud, possessing some degree of adhesiveness and plasticity, can be procured. The indication is met at large in the West, along unnumbered streams, where the birds most do congregate; and their very general dispersion in the West, as compared with their rather sporadic distribution in the East, is thus readily explained. The great veins of the West-the Missouri, the Columbia, and the Colorado, - and most of their venous tributaries, returning the humors from the clouds to their home in the sea, are supplied in profusion with animated congregations of the Swallows, often vastly more extensive than those gatherings of the feathered Sons of Temperance beneath our eaves, where the sign of the order, - a bottle, neck downward, - is set for our edification."

When the nests of a large colony are invaded by a strange object, these Swallows manifest great uneasiness, collecting in a swarm over the head of the intruder, flying and wheeling around, uttering loud notes of anguish, and even flying near his head, as if to attack him.

The eggs, four to five in number, are white, marked with dots and blotches of reddish-brown. In some cases they are so much like those of the Barn Swallow, that they are not distinguishable.

NAMES: Cliff Swallow, Eave Swallow, Crescent Swallow, Mud Swallow, Republican (Audubon), White-fronted Swallow, Rocky Mountain Swallow.-Traufschwalbe (German).

SCIENTIFIC NAMES: Hirundo lunifrons Say (1823). Cecropis lunifrons Boie (1828). PETROCHELIDON LUNIFRONS BAIRD (1865). Hirundo republicana Aud. (1824).

DESCRIPTION: "Above, glossy steel-blue; a blue-black spot on the throat; rump, rufous; a white or brownish-white crescent on the forehead; throat and sides of head deep chestnut, the rest of the under-parts dull rusty-gray, or grayish-brown, becoming paler on the belly; much of the under-parts with dusky sharp lines on the individual feathers. Wings and tail, blackish, with little gloss, and unmarked. Bill, black; feet, dark. Sexes, alike. ...

"Length, 5.00 to 5.50 inches; extent, 12.00 to 12.50 ; wing, $\$ 25$ to 4.50 ; tuil, 2.25 inches (nearly square)." (S. \& C. "N. E. B. L. Vol. I, p. 184.) 


\section{BARN SWALLOW.}

Chelidon erythrogaster STEJNEGER.

I'LATE XVIII. FIG. 1.

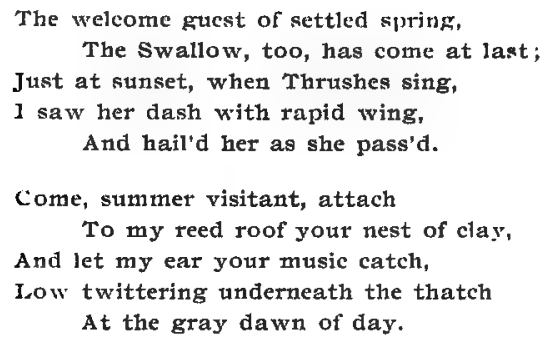

Charlotte SMith.

O ONE of all our North American birds is more widely diffused, more generally 6 abundant, wherever found, "or better known, than the graceful and familiar BaRn Swallow. And no one is more universally or more deservedly a favorite. Found throughout North America, from Florida to Greenland and from ocean to ocean, and breeding nearly throughout the same wide extent, its distribution is universal. Venturing with a confiding trust into our crowded cities, and building their elaborate nests in the porches of dwellings, as well as entering in greater numbers the barns and farm buildings of the agriculturists and placing themselves under the protection of man, they rarely fail to win for themselves the interest and good will they so well deserve. Innucent and blameless in their lives, there is no evil blended with the many benefits they confer on man. They are his ever constant benefactors and friends, and are never known, even indirectly, to do him any injury. For their daily food, and for that of their offspring, they destroy the insects that annoy his cattle, injure his fruit trees, sting his fruit, or molest his person. Social, affectionate, and kind in their intercourse with each other; faithful and devoted in the discharge of their conjugal and parental duties; exemplary, watchful, and tender alike to their own family and to all their race; sympathizing and benevolent when their fellows are in any trouble, - these lovely and beautiful birds are bright examples to all, in their blameless and useful lives." With these introductory words Dr. T. M. Brewer begins the life history of our beautiful Barn Swallow in the "History of North American Birds." * The only Swallow to compare with it in beauty, song, flight, and familiarity, is our Purple Martin. The Barn Swallow is the especial favorite of the immigrated Germans, because it resembles and reminds them so much of the favorite House Swallow (Chelidon urbica) of their native land. There is, indeed, a close relationship between the two, and they resemble each other in all essential points. Our Barn Swallows' prominent qualities are: unreserved confidence in man, gentle and cheerful disposition, peacefulness and sociability, their indescribably graceful way of flying, their sweet, cozy, melodious twittering song. All these qualities 
secure to them the affection of all friends of nature, and the sympathy of even the most indifferent people. It is not surprising, therefore, that they are favorites everywhere in the country, and that people everywhere encourage them to remain and become domesticated.

Although distributed over an immense territory, the Barn Swallow does not occur everywhere with equal regularity and frequency. In the East it is more numerous than in California and Oregon. In the North we find it a much more frequent and familiar summer resident than in many parts of the South. In Wisconsin it is an exceedingly abundant bird, and three to six, and even ten pairs, may be found breeding peacefully in close proximity to each other in one barn. During my residence in Oak Park, I11., I frequently observed these birds in the neighborhood. In south-western Missouri they breed usually in the gables of churches, houses, barns, and other buildings; in some parts of Texas I found them also well represented, while in the eastern and southeastern parts of that State they were exceedingly scarce. They spend their winters in the West Indies, Central and South America. The same birds that raised their young under the roofs of our barns, may be seen in winter flying around magnificent palms and other tropical trees, or over streams, where the Victoria regia and Victoria Randi is at home.

Before the settlement of our country by the Europeans, our Barn Swallow made the projecting cliffs and rocks, little holes and crevasses in the perpendicular faces of banks near streams and like localities their breeding places. "In the case of this Swallow," says Dr. Coues, "whose name is a 'household word' alike with the learned and the ignorant of ornithology, it is unnecessary to rehearse the items which have formed staples of biography since Wilson wrote truly that the light of heaven itself, the sky, the trees, or any common objects of nature, are not better known than the Swallows. We welcome their first appearance with delight, as the faithful harbingers of flowery spring and ruddy summer; and when, after a long, frost-bound, and boisterous winter, we hear it announced, that 'the Swallows are come,' what a train of charming ideas are associated with the simple tidings! But almost all the written history of the bird has the savor of home; we think of Swallows and the city street, the farm yard, the bursting barn, the new-mown hay, the flocks and herds, and all the changes of the seasons that come to us when comfortably housed-forgetting, perhaps, the trackless waste of the West, where Swallows are still as wild and primitive as any birds, bounden by no human ties, and no associates of civilization. Let us see the Swallow as he was before there were houses in this country-as he still remains in some parts of the world: we shall find him living in caverns, like the primitive cave-dwellers of our race; in holes in the ground like the foxes of Scripture; in hollow trees, like the hamadryads of mythology - so lowly is the habitation of this winged messenger of the changeful seasons. And yet, no sooner does the sound of the woodsman's axe in the clearing foretell the new day, than the twitter of the Swallow responds like an echo, and the glad bird hastens to fold his wings beneath the sheltering roof."

Prof. Robert Ridgway found the Barn Swallow most abundant about Pyramid Lake, Nevada, where it nested among the tufa-domes, each nest being attached to the ceiling of a cave among the rocks, and each cave having generally but a single pair, 
He also found nests in caverns of the limestone cliffs on the eastern side of the Ruby Mountains. These "tufa-domes," as described by Mr. Ridgway, are rocks of remarkable form and structure, usually having rounded or domed tops, being thickly incrusted with calcareous tufa, and honey-combed beneath with winding passages and deep grottoes, in which various birds nest, such as the Burion (House Finch), Say's Pewee, and the Barn Swallow. But even in the vast regions of the West these Swallows will soon change their wild life, for those parts are being gradually populated with sturdy settlers. The same is the case on the almost boundless prairies. Barely is the log-cabin in the primeval forest, or the simple shanty on the grassy prairie under roof, when these birds are clinging to and peeping about among the rafters, eaves, and gables to find a suitable place for their nest. Thus the Barn Swallows, in company with Bluebirds, Wrens, Phœbes, and Robins, are almost the only feathered guests who share the summer solitude of early pioneer life. By their cheery ways and gay twitter they make life in and about the crude log-cabin less lonely. As soon as the ornamental trees and shrubs, and the fruit trees of the orchard are growing larger and denser, other birds like the Song Sparrow, the Cedarbird, the Chippingbird, the Thrasher, the Catbird, and other songters join the society of man.

Our Barn Swallows show a considerable pertinacity in the choice of their breeding places. Not every farm will suit them, and towns and villages are at present generally avoided, as they do not like to be disturbed by that abominable tramp, the European Sparrow. They prefer barns with openings in the gable, which permit free and uninterrupted darting in and out, and choose rough rafters to which they can easily and safely fasten their nests. They also avoid the stately, modern barns ornamented with little towers or steeples, which, instead of small openings in the gables, are provided with windows. This Swallow prefers, at least in Wisconsin, always barns, and it is thus appropriately named "Barn Swallow." As a rule, one to three pairs breed in one barn, but in especially favorable places eight to ten pairs will breed peacefully together. Although preferring for nesting quiet spots, where interruptions are unlikely, it is in no way timid and often mixes its twittering pleasant song with the laughing and noise of children at play. In the days of my boyhood I frequently assisted these birds by nailing small boards across the peaks of the rafters. Through the openings thus made I pushed another small board about three inches wide, so that it projected on each side of the rafters about six inches. Upon these boards, generally on both sides of the rafters, they built their nests. To smooth rafters their nests will not adhere safely, but to rough, knotty objects they cling very firmly. Old pairs return from year to year to their old nests. I have known the same pair using the same nest for five successive years. In such cases the nest undergoes each year a thorough cleaning and repairing, especially the lining, which is removed and replaced by fresh material.

The nests are always built of distinct layers of mud or clay, about ten to twelve in number, and, according to Dr. T. M. Brewer, "each separated by a strata of fine dry grasses. These layers are each made up of small pellets of mud, that have been worked over by the birds and placed one by one in juxtaposition, until each layer is complete. These mud walls are an inch in thickness. When they are completed, they are warmly stuffed with fine soft grasses and lined with downy feathers. When built 
against the side of a house, a strong foundation of mud is first constructed, upon which the nest is erected. In this case the nest is much more elongate in shape and more strongly made. A striking peculiarity of these nests is frequently an extra platform, built against, but distinct from the nest itself, designed as a roosting-place for the parents, used by one during incubation at night or when not engaged in procuring food, and by both when the young are large enough to occupy the whole nest." The eggs, four to six in number, have a clear white ground-color, and are marked, chiefly at the larger end, with reddish and purplish-brown spots.

The song of the Barn Swallow is exceedingly fascinating, melodious, and sprightly, especially when on the wing. It consists of a succession of twittering notes, which are uttered loudly, and with great rapidity and animation. The bird also sings when alighted either on the roof or the nest, but then the notes are more slowly delivered. The call-note is a very soft and affectionate witt, witt. When surrounded by danger the bird utters a harsh trrrr trrrr.

None of our Swallows has such a graceful flight as the Barn Swallow. "The wonderful activity of this bird," says Dr. Brewer, "its rapidity and powers of flight are too striking a peculiarity of this species not to be mentioned. During their stay with us, from May to September, from morn to night they seem to be ever in motion, especially so before incubation, or after their young have flown. The rapidity of their tortuous evolutions, their intricate, involved, and repeated zigzag flights, are altogether indescribable, and must be witnessed to be appreciated. Wilson estimated that these birds fly at the rate of a mile a minute, but any one who has witnessed the ease and celerity with which they seem to delight in overtaking, passing, and repassing a train of cars moving at the rate of thirty miles an hour, must realize that this estimate is far from doing full justice to their real speed."

On the ground they move about very gracefully. Near my house in Missouri there was a bare place covered with fine particles of lime and plaster. To this spot a number of Barn Swallows each day made a visit of about ten minutes. They walked along slowly but not without grace, frequently picking up particles of lime and plaster, which they swallowed. This was just before they deposited their eggs. When the young were hatched, they made also frequent visits, and evidently carried numerous lime fragments to their offspring. This calcareous matter is necessary for the formation of the shells of the eggs and the bones of the young, but I was not aware that such a large quantity was required.

All the Swallows are never and in no way, not even indirectly, injurious to man. On the contrary, their good services are inestimable. The number of small insects they need for their own consumption, and that of their nestlings is almost incredible. During a number of cool, dark, and rainy days, when insects hide in the ground, among the leaves and blossoms, and in the crevices of the bark, the Swallows suffer greatly. Then they often fly around the outer branches of trees to start insects from their hiding places among the leaves. In the spring of 1892 the month of May was exceedingly cold and the rain came down in torrents, often for five to six successive days. All the Swallows suffered from cold and want of food, and almost half of the colonies of Purple Martins in Sheboygan County, and other localities in Wisconsin, died, and large numbers of Barn Swallows fell victims to the inclemency of the season. 
These innocent birds are very amiable and attentive to each other, and even to other birds they are very forbearing. A pair of Phœbes frequently nests in the same barn, and all agree well together. Among the enemies of our Barn Swallows the worst of all are the European Sparrows, which, frequently, take possession of the nests of the former, prior to their return from winter-quarters. Under such circumstances they have to build new nests, or they are obliged to seek other quarters.

NAMES: BarN Swal,Low, House Swallow, American Barn Swallow.-Scheunenschwalle (German).

SCIENTIFIC NAMES: Hirundo erythrogaster Bodd. (1783). Hirundo erythrogaster var. horreorum Cones (1874). Hirundo horreorum Barton (1799). Hirunlo americana Wilson (1812). CHELIDON ERYTHROGASTER STEJN. (1882).

DESCRIPTION: "Above, glossy steel-blue; forehead and under-parts chestnut of variable shade, generally deepest on the throat; an incomplete stecl-blue necklace. Tail, when fully developed, deeply forficatc, with linear lateral feathers, like the back in color, with sevcral white spots. Bill and fcet black. Sexes, similar.

"Length, very variab"e, according to the development of the tail, usially 6.00 to 7.00 inches; extent, 12.50 to 13.50 ; wing, 4.50 to 5.00 ; tail, 3.00 to 5.00 inches." (S. \& C., "N. E. B. L." I, p. 181.)

\section{TREE SW ALLOW.}

\section{Tachycineta bicolor CaBanis.}

I'H.ATE XVIII. Fir. 6.

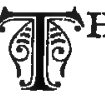

He Tree Swallow, also known as the White-bellied Swallow, River or

Wood Swallow, has, like most of the members of its family, a very extended distribution. It is found throughout North America, from Central America and the West Indies to the Arctic regions, and from ocean to ocean, breeding from latitude $38^{\circ}$ northward. It is a resident throughout the year in the Platean of Mexico, and is found in winter as far south as northern South America. Many winter in southern California and in the Gulf region, and thousands enjoy the serenity of the Florida winters. From their winter homes the Tree Swallows spread northward in March and April, appearing in south-western Missouri usually by the 10th of April, and in eastern Wisconsin in the first days of May. I have seen them in summer occasionally near the borders of woods in south-eastern Texas, but am not certain that they breed there. In winter, even in January, they. were tempted by the exceedingly warm weather which usually preceeds a furious "norther," to appear in large numbers at Houston, but they disappeared again after the cold had set in.

The bird is one of the hardiest of our Swallows, suffering less than the Barn Swallow and the Purple Martin from the protracted rainy and cold weather of April and May. It is a very beautiful bird, of a lustrous steel-green above, and of the purest white beneath, both colors contrasting finely with each other.

This species is comparatively quiet, and the few guttural notes which it utters 
during the love season, are not musical. It is of a more quarrelsome disposition than our other species, and although very gregarious, rarely more than one pair are found breeding in a Martin-house.

In Wisconsin these Swallows breed in large numbers in the old hollow trees in mill-ponds, full of Woodpeckers' holes, and in cavities of trees in low woods and swamps. They are confirmed hole-breeders, rather jealous of the ancient customs of their family, and slow to yield to the allurements of civilization, though the most beautiful and tempting boxes be presented to their choice. "When it will, it will, and when it won't, the Purple Martins must be depended on to fill the neat little houses that we build to entice the Swallows. In eastern Massachusetts the change of habit is confirmed, and they now breed there exclusively in Martin-boxes and, according to Dr. T. M: Brewer, rarely if ever, nesting in hollow trees, - a fact perhaps attributable to the scarcity of these opportunities along the sea-coast, where this bird is principally found. Any sheltered and accessible box, however rough it may be, will answer its purpose, whether the more elaborate Martin-house, or a mere candle-box with an open end. The same pair will return year after year to the same premises, and they soon become on familiar terms with the members of a family they frequently meet, so much so as to watch, when they have received materials for their nests, for a further supply, and will fly close to the person from whom they receive them. A pair which had thus, year after year, received supplies of feathers for their nests, from the younger members of the family in whose yard their nest was built, would almost take them from the hands of their providers. This pair sat so close as to permit themselves to be taken from their nest, and when released would at once fly back to their brood." They build a loose, soft, and warm nest which consists of old leaves, grass, and rootlets, and it is lined with down and feathers, with which the eggs are frequently covered. An addition of soft and warm materials is often made during incubation. When the birds begin to build in the old boxes, they always throw out the old materials and carry in fresh.

The eggs, four to six in number, are pure white and never spotted. The pair is devotedly attached to each other and to their young, and bewail any accidents to them or any threatened peril.

In Wisconsin as well as in northern Illinois I have observed only here and there a single pair breeding in nesting boxes provided for Martins. The great majority are still nesting in the woods, and their real hunting grounds are over the forest trees, where they soar and fly, sail and skim with much grace and great rapidity. Even those Tree Swallows which breed in the nesting boxes near dwellings, fly and hunt for insects in the air over the woodlands. I have never seen these Swallows during the breeding time in the almost limitless prairies of Illinois and other States. In the far West this Swallow is also a very abundant summer resident. Mr. Ridgway found them more numerous in certain portions of Nevada than they have usually been supposed to be anywhere in the West. Mr. Ridgway writes:

"This species and the Purple Martin were the only Swallows which were confined strictly to wooded districts or to settlements, their distribution being much the same, except that, in the case of wooded localities, the former was most abundant in the river valleys, while the latter occurred oftenest on the mountains. Among the cotton- 
woods of the Lower Truckee, near Pyramid Lake, in May, the White-bellied Swallow abounded more than elsewhere, and every knot-hole or other cavity among the trees seemed to have been taken possession of by a pair. They were then engaged in building their nests, and throughout the day would come to the door-yard of the Reservationhouse to pick up the feathers, or bits of rag or paper, scattered about the ground, after hurriedly seizing which they would fly with the article selected in a direct line to their nests. As they sat on the ground, they were beautiful little birds, and though they squatted somewhat awkwardly, on account of the smallness of their feet, they raised their heads so proudly, and glanced so sharply, yet timidly, about them, that they seemed graceful in their motions; while each movement caused the sunlight to glance from their burnished backs of lustrous steel-blue, with which the snowy white of their breasts contrasted so strikingly. Although the object picked up was most often a feather, it occasionally happened that one would take hold of a string, or a long shred of cloth, perhaps a yard or more in length, in which case, so conspicuous an object was certain to be seized upon by others, as the bearer labored to carry it to his nest, thus becoming the subject of quite a struggle, and much twittering.

"The White-bellied Swallow was by no means confined to the wooded river valleys, however, but it was equally abundant among the aspen woods, high up in the Wahsatch Mountains, at an altitude of 8,000 or 9,000 feet; it was also common in the Sacramento valley, but a few feet above sea-level, among the oak trees of the plain. Neither is it invariably arboreal, for it seems to have become, in certain localities, more 'civilized,' like its cousin, the Purple Martin, and to have taken advantage of the abode of man in localities where there are no trees to accommodate them. Such was conspicuously the case at Carson City, where they were quite numerous, and built their nests under the eaves, behind the weather-boarding, or about the porches of dwellings or other buildings, and were quite familiar."

The Tree Swallow differs in one respect from all other members of its family, departing from the insectivorous customs so far as to feed at times principally on the berries of the wax-myrtle (Myrica cerifera), the cirier of the French Creoles of Louisiana. Wilson saw hundreds of White-bellies on the sandy beach of Great Egg Harbor. They completely covered the myrtle bushes of the low islands thereabouts; a man told him he had seen a hundred and two killed at a shot. Audubon speaks of this Swallow as roosting by night in the wax-myrtles. During the winter, he says, many were sheltered in the holes about the houses, but the greater number resorted to the lakes, to spend the night among the myrtles. "About sunset," he continues, "they began to flock together, calling to each other for that purpose, and in a short time presented the appearance of clouds moving towards the lakes, or the mouth of the Mississippi, as the weather and wind suited. Their aërial evolutions before they alight, are truly beautiful. They appear at first as if reconnoitering the place; when, suddenly throwing themselves into a vortex of apparent confusion, they descend spirally with astonishing quickness, and very much resemble a trombe or water-spout. When within a few feet of the ciriers, they disperse in all directions, and settle in a few moments. Their twitterings, and the motion of their wings, are, however, heard during the whole night.... The hunters who resort to these places destroy great numbers of them, by knocking them down 
with light paddles, used in propelling their canoes." In another place, Audubon prints a note from Bachman, who states that on the 16th of October, 1833, in company with Dr. Wilson and Mr. J. W. Audubon, he "saw such an immense quantity of this species of birds that the air was positively darkened. As far as the eye could reach, there were Swallows crowded thickly together, and winging their way southward; there must have been many millions!"

Mr. Maynard found the crops and stomachs filled with the aromatic wax-myrtle berries. These berries, which are known in the East also as bay-berries, are about the size of black pepper, and are coated with a waxy substance, of which the bay-berry tallow is made. This was formerly used for manufacturing candles. This substance seems to be highly nutritious, as the birds become very fat from feeding upon it.

The great mass of White-bellied Swallows depart early in September. In the first week of that month $I$ have seen thousands of them in south-western Missouri, and only a few days later I observed them in still larger numbers on Galveston Bay in southeastern Texas.

NAMES: Tree Swallow, White-bellied Swallow, River Swallow, Wood Swallow, Green-blue Swallow, Black-and-white Swallow. - Waldschwalbe (German).

SCIENTIFIC NAMES: Hirundo bicolor Vieill. (1807). Herse bicolor Bonap. (1850). TACHYCINETA BICOLOR Cab. (1850). Hirundo viridis Wils. (1802). Iridoprocne bicolor Coues.

DESCRIPTION: "Adult male: Above, rich burnished steel-blue (varying much in shade), the larger wingfeathers and tail blackish, faintly glossed with dull greenish; loles, deep black; entire lower parts pure white. Adult female: Usually duller above than ma!e, but often indistinguishable.

"Length, 5.00 to 6.25 inches; wing about 4.50 to 4.80 ; tuil, 2.30 to 2.50 inches acutely emarginate." (R. Ridgway, "Manual of North American Bircls," p. 461.)

\section{VIOLET-GREEN SWALLOW.}

\section{Tachycineta thalassina CABANIS.}

氛国 HIS BEAUTIFUL Swallow is confined to the western part of our country, north to the border of the United States, which may be considered its limit of distribution in this direction. "The Great Plains seem to present an impassable barrier to the eastward dispersion of even so excellent a flyer as this; but it does come a little beyond even the foot-hills of the Rockies. Thus, on the 26 th of June, 1874, being then on the Upper Missouri, above the mouth of the Yellowstone, near the Quaking Ash River, I observed a few individuals. ...

"In general terms, as far as the United States is concerned, the Violet-green inhabits wooded regions from the Rocky Mountains to the Pacific, spreading over all our territory during March; it is liable to be found breeding wherever suitable trees occur, but, like other Swallows, is more or less locally distributed. During September it retires southward, probably none wintering amongst us. It is resident in Mexico, 
as Mr. Sumichrast informs us, at almost all elevations, and is very common. Mr. Salvin witnessed its abundance in Guatemala during a portion of the year." (Coues.) "When in New Mexico, in 1864," Dr. Elliott Coues continues, "I found the Violetgreen' Swallows to be very common in the Raton Mountains. This was in June, and I have no doubt that the birds were then nesting, though I had no chance of observing them closely. I noticed their close resemblance to White-bellied Swallows in general appearance, and particularly in mode of flight; and I observed, then as subsequently, the curiously misleading circumstance that the birds appeared to have white rumps. In fact, as is well known, the rump is like the rest of the upper parts in color, but the fluffy white feathers of the flanks lie over the part during flight; sometimes meeting over the root of the tail, thus causing the appearance observed. This appearance of tricoloration-violet, green, and white-is striking. The following year, at Fort Whipple, in Arizona, I made quite a study of these birds, whose exquisite beauty could hardly fail to touch even the most insensible observer. They nestled in considerable numbers in the pine woods about the fort, usually preferring the edges of the timber, and constructed their nests of hay and feathers in the natural cavities of trees, or in old Woodpeckerholes. Sometimes isolated pairs occupied the deciduous trees in the vicinity, as the cotton-woods along the creek and the oaks of the open hill-sides; but most of the birds gathered in little colonies in clumps of pine trees. The birds reached this elevated locality the second or third week in March, and remained until late in September. I considered them the commonest of their tribe, quite characteristic, in fact, of the Arizona pine-belt.

"In Utah, Arizona, and New Mexico, agrees Mr. Henshaw, this Swallow inhabits the higher regions, abundantly in all suitable localities, preferring the open spaces or edges of the pineries and groves of oaks, where it breeds in old Woodpecker-holes. In southern Colorado he found it in large colonies at the great altitude of 10,000 feet, early in June, when these ambitious little beauties were preparing to nest on high pinestubs. In the same Territory Allen met with them at corresponding altitudes, generally nesting in the wonted Woodpecker-holes, but sometimes also in holes in rocks, in company with White-throated Swifts. Ridgway has given us our best accounts of this rock-building, which I have myself never witnessed. The birds, he says, were abundant during May at Pyramid Lake, Nevada, where they were observed to enter the fissures of the calcareous tufa cliffs, where they doubtless had nests. In July he saw them again in the limestone cañons of the Ruby Mountains, associated with Cliff Swallows and the Swifts just mentioned. Here their nests were in horizontal fissures of the rock, and mostly inaccessible. Two, however, were in places admitting the hand; and these were found to be masses of sticks and straws, lined with feathers. One of these contained five eggs; the other, three broken eggs and the dead parent. The writer continues with a pertinent remark on the general subject:- Although other observers, whose statements we do not in the least doubt, have described the habits of this bird as arboreal, like those of the White-bellied Swallow ( $T$. bicolor) and the Purple Martin, we never found it so in any locality during our trip, it being everywhere a strictly saxicoline species, and an associate of Micropus melanoleucus, Petrochelidon Iunifrons, and Hirundo erythrogaster rather than of the species named, and to be found only where precipitous rocks, affording suitable fissures, occurred.' 
"This is enough to settle the question we asked each other for some years, Where does the Violet-green breed? We have here simply a hole-breeder, indifferent whether the cavity it occupies be tree or rock; and we need not be surprised to learn any day that it has been found nestling in a bank of earth, in a natural excavation, or even in a Kingfisher's or Bank or Rough-winged Swallow's hole. One thing, however: it has never learned the plasterer's trade, at which the Cliff and Barn Swallows are such clever artisans; and yet it has been stated by me, in the 'Birds of the North-west,' p. 88, on the authority of Mr. T. M. Trippe, to have been found 'nesting under the eaves of houses, like the Cliff Swallow,' the fact being adduced to show 'that, like most others of its tribe, this bird had at length paid its compliments to human civilization. The details of the circumstance had not been communicated to me in 1874; but Mr. Trippe yesterday (March 17,1878 ) visited my study, and we had some conversation on the subject. He described the nests, in which Violet-green Swallows certainly had their eggs, as bulky structures of mud, and like those of Cliff Swallows. Being perfectly familiar with the birds, he could not have been mistaken in identifying the species; and he agreed with me that the birds must have occupied in these instances the deserted nests of other Swallows. This brings up Nuttall's early testimony to the same effect, and makes it seem much more probable - if it may not indeed be regarded as confirmatory - though he or Townsend certainly got hold of the wrong egg, a drawing of which subsequently came into Dr. Brewer's possession through Audubon. We should expect the Violet-greens, on yielding to civilization, to come to terms in the same way the Martins and Whitebellies have, by occupying boxes set up for their use, or else to enter knot-holes or the crevices behind weather-boards, as the Wrens; but that their habits will be modified in some way, and at no distant day, there is no reasonable doubt. With which understanding, I leave the wilful and capricious little creatures to enjoy their hermitages, whether of tree or rock, as long as they please."

The eggs are pure white, without spots.

NAMES: Violet-Green Swallow, Mountain Swallow.-Gebirgsschwalbe (German).

SCIENTIFIC NAMES: Hirundo thalassina Swains. (1827). TACHYCINETA THALASSINA CaB. (1850). DESCRIPTION: Adult male: Top of head, hind-neck, back, and scapulars, rich green, either the head and neck or dorsal region, or both, usually overlaid by a more or less distinct wash of bronze or purple; rump and upper tail-coverts rich bluish-green or bluish, usually mixed with rich plum-purple; a white patch on each side of the rump, these in life often brought close together so as apparently to form a continuous white band; entire lower parts, including ear-coverts and line over posterior hall (or more) of eye, pure white, but the feathers immediately beneath surface grayish.

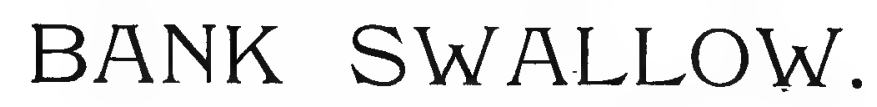

Clivicola riparia STEJNEGER.

(궁

F THIS cosmopolite, little remains to be said by any one at the present day. One of our best writers wittily complains that the poets have stolen our best thoughts; and I might lament, that some of my best bird-biographies have been plagiarized in the most shocking manner by ornithologists who died before I was 
born..." With these characteristic words in his "Birds of the Colorado Valley," our ingenious naturalist, Dr. Elliott Coues, introduces the Bank Swallow, or Sand Martin, to his readers.

The Bank Swallow is one of the most abundant and familiar birds of Europe, Asia, and North America. Our own Sand Martins winter in Central and South America, while those inhabiting Europe choose their winter-quarters in Africa, and those occurring in northern Asia spend their winters in India. In our country they breed from Texas northward to Alaska, and from the Atlantic to the Pacific. They are rather locally distributed, being abundant only where they can find high, rather sandy banks near water. Wherever the banks are clayey or rocky, these weak-billed birds are not able to excavate nesting holes. I have found a few pairs breeding in some parts of Texas, especially on the banks of Galveston Bay, on the Buffalo and White Oak Bayous. In certain parts of my native State Wisconsin, particularly in Sheboygan County, they are exceedingly abundant. The sandy banks of the Sheboygan and Pigeon Rivers, and Lake Michigan are full of nesting holes, presenting in June the appearance of immense honey-combs alive with bees. Mr. Otto Widmann and myself found them breeding in an embankment of a railroad in southern Illinois near East St. Louis, the other bank being occupied by several pairs of Rough-winged Swallows.

The Bank Swallow is an early spring visitant wherever found, appearing in Wisconsin, if the weather permits, late in April or early in May. Even in high Arctic latitudes it has been known to arrive early in May, often in such inclement weather that it was obliged to take refuge in holes. Mr. Dall met with this species in immense numbers in Alaska in favorable situations. He counted on the face of a sand-bluff over seven hundred nest-holes, made by these Swallows, and all apparently occupied.

All our Swallows are known to breed near human abodes, but the Bank Swallow is entirely independent of man. It never breeds in boxes and Martin-houses, and never enters barns or other buildings. The nests of the Bank Swallows are always placed in excavations constructed by themselves, usually in the sandy banks of river and lake banks, and on the sea-shore and similar favorable situations. These excavations are usually near the surface of the ground, and always in such soil which permits to be readily penetrated. Sandy soil, soft enough to be worked, is always preferred. It is astonishing how far these weak-billed and weak-footed birds penetrate the ground. The depth of the cavities varies from twelve or fourteen inches to four feet, though two feet is the usual distance. In favorable positions the river banks are studded with neat little round holes. According to Mr. Winfrid A. Stearns, "they display much tact in selecting the most suitable soil to work in, neither too hard to be penetrated with ease, nor too soft as to cave in, or be unsafe from the falling of loosened pebbles. Any one may be satisfied of this by examining a bank where different strata are exposed, and noting how the Swallows confine themselves to such belts of soil as suit them best. At the farther end of the passage-way the nest is placed-a slight affair of dried grasses lined with feathers." The eggs are from four to six in number and of a pure white color.

The flight of the Bank Swallow is very rapid, but unsteady and flickering, showing little of the extreme gracefulness of the Barn Swallow's and the Purple Martin's 
soaring through the air. In searching for their food, which consists mainly of small insects, these birds skim low over meadows and the surface of the water, "dropping upon the latter, as they fly to drink or bathe."

The'Bank Swallow is a remarkably silent bird. Its song is of little value, consisting only of a number of low twittering notes.

NAMES: Bank Swallow, Sand Martin, Sand Swallow,-Uferschwalbe (German).

SCIENTIFIC NAMES: Hiründo riparia Linn. (1758). Cotyle riparia Boie (1826). Hirundo riparia var. americana Max. von Wied (1858). CLIVICOLA RIPARIA STEJN. (1882).

DESCRIPTION: "Lustreless mouse-brown above, white below, with a brown necklace; wings and tail, dusky, unmarked. A small tuft of feathers at the lower end of the tarsus. Sexes, alike.

"Small: length scarcely 5.00 inches; extent, 10.50; wing, 4.00; tail, 2.00 inches." (S. \& C., "N. E. B. L." I, p. 186).

\section{ROUGH WINGED SWALLOW.}

\section{Stelgidopteryx serripennis BAIRD.}

5.

URING MY residence at Houston, Texas, in the years of 1879 to 1881 , I found the Rough-winged Swallow the most abundant of the family. The experienced observer can readily distinguish this bird from other Swallows by its comparatively slow and low flight, its peculiar quietness, and its gray color. Though distributed over an immense territory, from the Atlantic to the Pacific, and from Mexico to the British Provinces, it was not known to Wilson and other naturalists of the same period. Audubon discovered it near Bayou Sara, in his native State Louisiana, October 20, 1819 , but at that time he did not, "perhaps, recognize it as distinct from the Sand Martin; for he did not describe it for many years afterward, and then did so from a pair procured in South Carolina.... He knew nothing of the birds' habits, and surmised that its most habitual residence might prove to be far westward, perhaps the valley of the Columbia River, which was a famous ultima Thule in ornithology of the Audubonian period." (Coues.) In the East it occurs as far north as southern New England, and in the West it was found north to Vancouver. In Wisconsin and northern Illinois I have never observed the Rough-winged Swallow. In southern Illinois and Missouri it is rather common, and in Texas $I$ have met with it in many places.

In July and August hundreds of these Swallows fly over the streets in Houston, Texas, circling around cattle and around the houses, and catching mosquitoes and flies. In that city and in Galveston many pairs breed in crevices and crannies in the brickwalls of large store-houses and public buildings, under bridges, and in the banks of the bayous and rivers. In other localities they occasionally breed in clefts of rocks, in knotholes of trees, and in deserted Kingfishers' holes. Although in Texas and Missouri I put up quite a number of convenient nesting-boxes, which were fastened to poles, buildings, and trees, none of them ever was occupied by a pair of Rough-winged Swallows, neither have I observed them nesting behind weather-boards of buildings. When 
rambling about with $\mathrm{Mr}$. Otto Widmann near East St. Louis, we found a colony of Bank Swallows breeding on one side of a railroad embankment, while about six or eight pairs of Rough-winged Swallows nested on the other side. The entrance holes to the nests of the last named species were not so nicely finished, not so symmetrical as those of their near relatives. These holes were roughly circular, and not crowded together, but scattered at irregular intervals along the embankment. The cavity which is also built in a rather slovenly way, is not very deep. The nest is usually placed about a foot from the entrance and is constructed of grasses, and in the vicinity of dwellings feathers of domestic fowl enter largely into the composition. The eggs, four to six in number, are pure white, closely resembling those of the Bank Swallow.

In conclusion I quote the following account from Dr. T. M. Brewer's writings:

"This species was first found breeding in Carlisle, Penn., by Professor Baird, in the summer of 1843. The following year I visited the locality early in June, and had an opportunity to study its habits during the breeding season. We found the bird rather common, and examined a number of their nests. None that we met with were in places excavated by the birds, although previously several had been found that had apparently been excavated in banks in the same manner with the Bank Swallow. All the nests (seven in number) that we then met with, were in situations excellently adapted to their need, and all were directly over running water. Some were constructed in crevices between the stones in the walls and arches of bridges. In several instances the nests were but little above the surface of the stream. In one, the first laying had been flooded, and the eggs chilled. The birds had constructed another nest above the first one, in which were six fresh eggs, as many as in the other. One nest had been built between the stones of the wall that formed one of the sides of the flume of a mill. Two feet above it was a frequented footh-path, and, at the same distance below, the water of the mill-stream. Another nest was between the boards of a small building in which revolved a water-wheel. The entrance to it was through a knot-hole in the outer partition, and the nest rested on a small rafter between the outer and the inner boardings. The nests were similar in their construction to those of the Bank Swallow, composed of dry grasses, straws, and. leaves, and lined with a few feathers; but a much greater amount of material was made use of, owing, perhaps, to the exposed positions in which they were built."

NAMES: Rough-winged Swallow, Rough-wing.-Grauschwalbe (German).

SCIENTIFIC NAMES: Hirundo serripennis Aud. (1838). Cotyle serripennis Boie (1844). STELGIDOPTERYX SERRIPENNIS Baird (1865).

DESCRIPTION: "Resembling the Bank Swallow in general aspeet; no tuft of feathers on tarsus; outer wel of first primary rough and serrated, the vane being converted into a series of stiff recurved hooks. Above, brownish-gray; below, paler, whitening on the belly.

"A little larger than the Bank Swallow." (S. " C., N. E. B. L. I, p. 187.)

The Bahama Honey Creeper, Certhiola bahamensis Reich., enters our territory from the Bahamas on the Keys of the south-eastern coast of Florida. 



\section{LIST OF PLATES.}

PLATE I. G. MUETZEL.

No. 1. Robin. Merula migratoria Swains...

"2. Hermit Thrush. Turdus aonalaschkæ pallasi Ridgw...................................... 22

“ 3. Varied Thrush. Hesperocichla nævia Ridgw.

“4. Veery, Wilson's Thrush. Turdus fuscescens Steph.

“ 5. Wood Thrush. Turdus mustelinus Gmel...

“ 6. Olive-backed Thrush. Turdus ustulatus swainsonii Ridgw...

PLATE II. A. GOERING.

Mockingbird. Mimus polyglottus Boie.

PLATE III. R. RIDGWAY.

Catbird. Galeoscoptes carolinensis $\mathrm{Cab}$.

PLATE IV. A. GOERING.

No. 1. Phairtopepla. Phainopepla nitens Sclat... 88

“2. Cactús Wren. Campylorhynchus brunneicapillus Gray.

“ 3. Sage Thrasher. Oroscoptes montanus

" 4. Crissal Thrasher. Harporhynchus crissalis Baird.

PLATE V. A. GOERING.

No. 1. Cedarbird. Ampelis cedrorum Gray. 323

"2. Tufted Titmouse. Parus bicolor Linn...... 106

" 3. Phoebe. Sayornis phoebe Stejn. Vol. II.

“4. Brown Thrasher. Harporhynchus rufus Cab............................................. 59

“5. Bluebird. Sialia sialis Haldem. Male...... 75

"6. " " " " " Female... 75

"7. Song Sparrow. Melospiza fasciata Scott. . Vol. II.

PLATE VI. R. RIDGWAY.

Blue-gray Gnatcatcher and nest. Polioptila carulea Sclat. 92

PLATE VII. R. RIDGWAY.

Golden-crowned Kinglet. Regulus satrapa Licht. Male and female..
PLATE VIII. R. RIDGWAY.

Page

Bush Tit and nest. Psaltriparus minimus Bonap. Male and female.

PLATE IX. R. RIDGWAY.

Cañon Wren. Catherpes mexicanus conspersus Ridgw 139

PLATE X. R. RIDGWAY.

Prothonotary Warbler. Protonotaria citrea Brd, 170

PLATE XI. G. MUETZEL.

No. 1. Parula Warbler and nest. Compsothlypis americana Cab.................................... 198

“ 2. Blue-winged Warbler on flower-truss of Kalmia latifolia. Helmintophila pinus Ridgw .

“ 3. Black and White Warbler. Mniotilta varia Vieill.

“ 4. Golden-winged Warbler. Helmintophila chrysoptera Ridgw.............................. 184

“ 5. Worm-eating Warbler. Helmitherus vermivorus Bonap.

\section{PLATE XII. A. GOERING.}

No. 1. Blackburnian Warbler. Dendroica blackburnia Baird.

، 2. Magnolia Warbler. Dendroica maculosa Brd..................................................... 208

“ 3. Black-poll Warbler. Dendroica striata Brd. 217

“ 4. Bay-breasted Warbler. Dendroica castanea Brd................................................. 215

" 5. Chestnut-sided Warbler. Dendroica pensylvanica Brd...................................... 213

. 6. Black-throated Green Warbler. Dendroica virens Baird.

PLATE XIII. G. MUETZEL.

No. 1. Yellow-throated Warbler. Dendroica dominica Baird........................................ 222

“ 2. Prairie Warbler. Dendroica discolor Brd. 236

“ 3. Palm Warbler. Dendroica palmarum Brd. 233

“4. Wilson's Warbler. Sylvania pusilla Nuțt. 273

“ 5. Myrtle Warbler. Dendroica coronata Gray 204

“6. Cerulean Warbler. Dendroica carulea Brd. 212 
No. 7. Mourning Warbler. Geothlypis philadelphia Brd..

8. Canadian Warbler. Sylvania canadensis Ridgw.

\section{PLATE XIV. G. MUETZEL.}

No. 1. Maryland Yellow-throat. Geothlypis trichas Cab............................................ 254

“ 2. Black-throated Blue Warbler. Dendroica cærulescens Baird................................. 201

“ 3. Kentucky Warbler. Geothlypis formosa Ridgw 248

“4. Hooded Warbler. Sylvania mitrata Nutt. 261

" 5. American Redstart. Setophaga ruticilla Swains.............................................. 275

“ 6. Oven-bird. Seiurus aurocapillus Swains.... 238

PLATE XV. A. GOERING.

No. 1. Yellow Warbler. Dendroica æestiva Brd.... 198

“2. White-eyed Vireo. Vireo noveboracensis Bonap............................................. 362

“ 3. Yellow-breasted Chat. Icteria virens Brd. 258

“4. Red-eyed Vireo. Vireo olivaceus Bonap.... 284

“ 5. American Goldfinch. Spinus tristis Stejn. Vol. II.

“ 6. Louisiana Water Thrush. Seiurus motacilla Bonap.
PLATE XVI. R. RIDGWAY.

Yellow-throated Vireo and nest. Vireo flavifrons Vieill. Male and female.

PLATE XVII. G. MUETZEL.

No. 1. Blue Jay. Cyanocitta cristata Strickl. Vol. II.

“ 2. Cowbird. Molothrus ater Gray. Male. Vol. II.

" 3. Cowbird. Molothrus ater Gray. Female. Vol. II.

“ 4. Loggerhead Shrike. Lanius ludovicianus Linn....................................................... 31

. 5. Brewer's Blackbird. Scolecophagus cyanocephalus Cab. Vol. II.

6. Bronzed Grackle. Quiscalus quiscula Stejn. Vol. II.

\section{PLATE XVIII. G. MUETZEL.}

No. 1. Barn Swallow. Chelidon erythrogaster Stejn...

“ 2. Purple Martin. Progne subis Brd. Male... 336

" 3. " " " " " Female 336

“4. Cliff Swallow. Petrochelidon lunifrons Brd. 345

“ 5. Chimney Swift. Chrtura pelagica Steph. Vol...II.

"6. Tree Swallow. Tachycineta bicolor Cab. 353 


\section{INDEX.}

Page Page

242

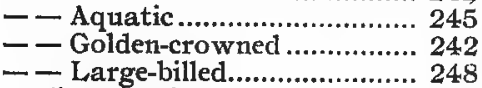

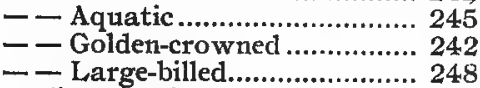

Acclimatisation of Exotic Birds, page XLviII.

Act for the Protection of Birds; page XLV.

Alaskadrossel

Alice-Drossel.

Alice's Thrush...

$\begin{array}{lll}\text { Alice-Drossel.............................. } & 15 \\ \text { Alice's Thrush.................... } & 14 \\ \text { Aldrich, Charles. Merciless War } & \end{array}$ upon our Birds, page $x x \times v i r$.

Allen, J. A. Origin of Instinct of Migration of Birds, page xxv.

- The present WholesaleDestruction of Bird-life in the United States, page $\mathrm{xxx}$.

American Barn Swallow......... 353

American Bluebird..................... 82

American Creeper ..................... 133

American Dipper....................... 72

American Golden-crested Kinglet

103

American Ouzel.............................. 74

American Pipit......................... 161

American Redstart, Plate 14, Fig. 5..

American Robin, Plate 1, Fig. 128

American Song Thrush........... 9

Ampelidae .................................. 3

Ampelis cedrorum, Plate 5 Fig. 1............................. 323 Ampelis garrulus ........................ 322

Amsel, Wasser-..................... 74

Anonymus. Poem. The Robin 28 - - Poem. The Yellow-

throated Vireo ..................... 295

Anthus cervinus........................... 162

Anthus pensylvanicus................. 161

Anthus pratensis ....................... 162

Anthus spragueii ........................ 162

Aquatic Accentor...................... 245

Arizona Gnatcatcher................ 97

Arizona Vireo ............................ 313

Arctic Bluebird ......................... . 84

Ashy Titmouse ........................ 112

Audubon's Hermit Thrush....... 27

Audubon's Warbler................. 207

Auriparus flaviceps, Plate 32 ,

Fig. 4............................... 122

Autumn Beauty. Poem.......... 204

Azure Warbler................... 213

\section{B.}

Bachman's Warbler............... 192

Bahama Honey Creeper............ 361

Baird's Wren.
Bank Swallow.

Barri Swallow, Plate 18, Fig.. 1 349

Baumläufer ..

Basileuterus belli..................... 281

Basileuterus culcivorus.............. 281

Bay-breast ............................ 217

Bay-breasted Warbler, Plate 12, Fig. 4 ........................ 215

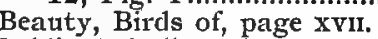

Belding's Yellow-throat........... 257

Bell's Greenlet............................ 312

Bell's Warbler.............................. 281

Bell's Vireo .............................. 309

Bendire's Thrasher.................... 65

Bessy Kickup............................ 245

Bewick's Wren......................... 148

Bicknell's Gray-cheeked Thrush 15

Birds, Daily Life of, page xix.

Bird Enemies, page $\mathrm{xxx}$.

Birds, Exotic, Acclimatisation of, page XLVilI.

Bird Legislation, page xuv.

Bird-life, Wholesale Destruction of, page $\mathrm{xxx}$.

Birds of Beaty, page xvir.

Birds of Song, page xIr.

Birds, Plea of the, page $v$.

- Protection of, page xull.

Black and White Creeper......... 169

Black and White Swallow....... 356

Black and White Warbler, Plate 11, Fig. 3................ 168

Black and Yellow Warbler...... 212

Black-bird Swallow............. 345

Blackburnian Warbler, Plate 12, Fig. 1

Black-cap

- - Wilson's ............................. 275

Black-capped Chickadee.............. 115

Black-capped Titmouse............ 115

Black-capped Yellow Warbler.. 275

Black-cheeked Yellow-throat.... 257

Black-crested Titmouse............ 108

Black-eared Bush Tit................ 122

Black-headed Gnatcatcher....... 97

Black-headed Warbler............. 268

Black-masked Ground Warbler 257

Black Flycatcher ...................... 91

Black Martin.............................. 345

Black-poll................................. 218

Black-poll Warbler, Plate 12,

Black Ptilogonys......................... 91

Black Swallow ........................ 345

Black-tailed Gnatcatcher.......... 97

Black-throated Blue Warbler, Plate 14, Fig. 2.............. 201

Black-throated Gray Warbler.. 225

Black-throated Green Warbler, Plate 12, Fig. 6
Black-capped Vireo.................. 307 Fig. 3.............................. 217
Black-throated Ground War-

bler.................................... 253

Black-throated Waxwing......... 323

Black-whiskered Vireo............... 288

Blauflügeliger Buschsänger...... 184

Blauvogel.................................. 82

- - Californischer.................... 83

-7 Gebirgs-............................. 84

Bleigraue Buschmeise................. 122

Blue-backed Redbreast Warbler 82

Bluebird, Plate 5, Fig. 5 and $6 \quad \mathbf{7 5}$

- - American........................... 82

- - Aretic ............................... 84

- California, Plate 20, Fig.1 83

- Common............................ 82

- - Eastern ............................. 82

- - R ^cky Mountain................ 84

- - Mexican .......................... 83

- - Mountain, Plate 20, Fig. 283

- - Western.

- - Western'............................. 83

Blue Golden-winged Warbler... 187

Blue-gray Flycatcher................ 96

Blue-gray Gnatcatcher, Plate 692

Blue-headed Vireo.................... 299

Blue Redbreast....................... 82

Blue Robin............................... 82

Blue Warbler.........................82, 213

Blue Yellow-backed Warbler.... 195

Blue-winged Swamp Warbler.. 184

Blue-winged Warbler................ 184

Blue-winged Yellow Warbler,

Plate 11, Fig. 2 ................ 183

Bohemian Chatterer.................. 323

Bohemian Waxwing............... 322

Boxes, Nesting, page XLIX and L.

Brasher's Warbler................... 281

Braundrossel............................ 64

Brewster, Wm. On Bird Migration, page Xxir.

Brewster's Warbler.................. 192

Bridled Titmouse......................... 113

Brier Wren.................................. 257

Brown-capped Chickadee......... 118

Brown Creeper .......................... 130

Brown-headed Creeper Wren... 136

Brown-headed Nuthatch........... 128

Brown Thrasher, Plate5, Fig.4 59

Brown Thrush........................ 64

Brotherly-love Vireo................... 291

Budytes flavus leucostriatus.... 161

Buntdrossel............................ 36

Burroughs, John, Bird Enemies, page XLI.

Butcher-bird ................... 316, 320

- - Common ........................... 320

Buschmeise................................. 121

- Bleigraue............................ 122

Bush Tit, Plate 8................... 119

- - Black-eared ........................ 122

- - Lead-colored ......................... 121

Bush Vireo.................................. 306 


\section{Page \\ C.}

Cactus Wren, Plate 4, Fig. 2.. 135

Cactuszaunkönig ...................... 136

Campylorhynchus affinis.......... 136

Cathpylorhynchus brunneicapillus, Plate 4, Fig. 2 ............ 135

Caniada Nuthatch.................... 128

Carlada-Spechtmeise ................... 128

Catiadian Warbler................... 203

Catton Wren, Plate 9............... 139

Capie May Warbler .................... 196

Calaveras Warbler ................... 190

California Black-capped Gnatcatcher

Calífornia Bluebird, Plate 20, Fig. 1............................... Catifornia Brown Thrush......... 66

California Cáctus Wren............ 136

Callfornia Chickadee .................. 118

California Nuthatch ................... 130

California Shrike ....................... 316

California Thrasher.................. 66

Californian Titmouse................. 112

Callfornischer Blauvogel ............ 83

Callfornischer Hüttensänger.... 83

Cariada Flycatcher................... 273

Canadian Flycatching Warbler 273

Canadian Warbler, Plate 13 Fig. 8............................ 269 Cardellina rubrifrons, Plate 32, Fig. 2 .......................... 280

Carolina Chatterer................... 327

Catolina Chickadee .................... 116

Carolina-Meise.......................... 118

Carolina Nuthatch ................... 127

Carolina Shrike ......................... 320

Carolina Titmouse..................... 118

Carolina Waxwing................. 327

Carolina Wren, Plate 26, Fig.6 141

Cassin's Vireo............................. 301

Catbird, Plate 3..................... 52

- - Merle.................................. 58

Cat Flycatcher ........................... 58

Catherpes mexicanus................ 140

Catherpes mexicanus consper-

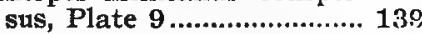

Cedarbird, Plate 5, Fig. 1....... 323

Cedar Warbler........................... 228

Cedar Waxwing .......................... 327

Cedervogel ............................... 327

Cetulean Warbler, Plate 13,

Fig. 6............................. 212

Certhia familiaris americana... 130

Cetthiola bahamensis............... 361

Certhia familiaris mexicana..... 133

Chamæa fasciata...................... 105

Chamæa fasciata henshawi.... 105

Chat .................................... 26.

C-Long-tailed .......................... 262

- Yellow-breasted, Plate 15.

Fig. 3............................... 258

Chatterer, Bohemian................ 323

- Carolina.............................. 327

- - European ............................ 323

- - Northern ............................. 323

- Waxen................................. 323

Chelidon erythrogaster, Plate 18, Fig. 1 ........................ 349

Cherry-bird ............................. 327

Chestnut-backed Chickadee...... 118

Chestnut-crowned Titmouse.... 121

Chestnut-sided Warbler, Plate 12, Fig, 5......................... 213

Chickadee, Plate 21, Fig. 2..... 114

- Black-capped..................... 115

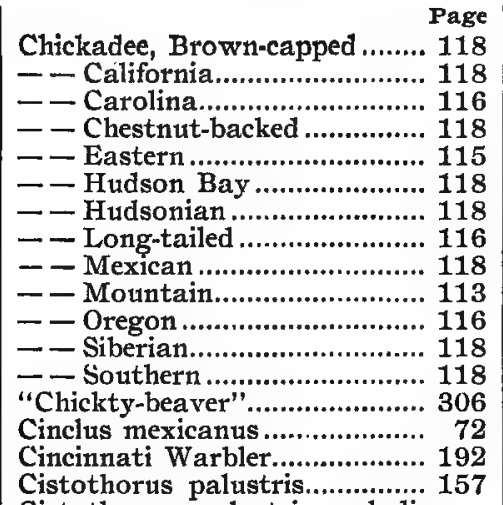

Cistothorus palustris paludicola ............. 159

Cistothorus stellaris................. 159

Clarino...................................... 88

Cliff Swallow, Plate 18, Fig. 4345

Clivicola riparia ....................... 358

Columbia Robin ......................... 36

Common Bluebird ....................... 82

Common Butcher-bird............. 320

Compsothlypis americana, Plate 11, Fig. 1 ................ 193

Compsothlypis nigrilora.......... 195

Connecticut Warbler .................2250

Cottage Warbler ......................... 82

Creeper, American .................... 133

- - Bahama Honey ................ 361

- - Black and White................ 169

Creeper, Brown ........................ 130

- Mexican ............................ 133

Creeping Warbler.......................... 169

Crescent Swallow,.................... 348

Crested Shining-black Whitewinged Flysnapper............. 91

Crested Titmouse ...................... 108

Crissal Thrasher, Plate 4, Fig.4 68

Cuban Martin .......................... 345

Curve-billed Thrasher................. 65

Curve-billed Thrush.................. 66

\section{D.}

Daily Life of our Birds, page XIX.

Dedication, page III.

Dendroica aestiva, Plate 15 Fig. 1.............................. 198

Dendroica aestiva morcomi..... 201

Dendroica auduboni .................. 207

Dendroica blackburniae, Plate 12, Fig. 1 ..........................

Dendroica caerulea, Plate 13, Fig. 6............................... 212 Dendroica caerulescens, Plate 14, Fig. 2 ....................... 201

Dendroica castanea, Plate 12, Fig. 4.............................. 215

Dendroica chrysoparia............. 225

Dendroica coronata, Plate 13, Fig. 5.............................. 204

Dendroica discolor, Plate 13, Fig. 2........................... 236 Dendroica dominica, Plate 13, Fig. 1................................. 222

Dendroica dominica albilora.... 224

Dendroica graciae..................... 224

Dendroica kirtlandi ................. 231

Dendroica maculosa, Plate 12, Fig. 2.
Page

Dendroica nigrescens ................ 225

Dendroica occidentalis............. 231

Dendroica olivacea ................ 197

Dendroica palmarum, Plate 13, Fig. 3..............................

Dendroica palmarum hypochrysea............................. 235

Dendroica pensylvanica, Plate 12 , Fig. 5...................... 213

Dendroica striata, Plate 12, Fig. 3.............................. 217

Dendroica tigrina...................... 196

Dendroica townsendi............... 230

Dendroica vigorsii.................... 232

Dendroica virens, Plate 12 , Fig. 6............................... 228

Dipper, American...................... 72

Drossel, Alice-......................... 15

- Braun-............................. 64

- Einsiedler-............................ 26

- - Fuchs-................................ 14

- - Grauwangen-..................... 15

- Katzen-............................. 58

- Oliven-...................................... 22

- - Rötel-

- - Sänger-............................. 22

- Salbei-................................. 40

- - Spott........... 51

- Wald-............................ 9

- Wander-................................ $\mathbf{3 4}$

Dwarf Hermit Thrush............... 27

E.

Eastern Bluebird

Eastern Chickadee...

Eave Swallow, Plate 18, Fig. 4.345

Einfarbige Haubenmeise........... 112

Einsiedlerdrossel .................... $\quad 26$

Einsiedlervireo ........................... 300

Enemies, Bird, page $\mathrm{xxx}$.

Erdmeise ..................................... 106

Ergaticus ruber ....................... 281

European Chatterer................... 323

Exotic Birds, Acclimatisation of, page XLvul.

\section{F.}

Felsenzaunkönig ..................... 138

Ferrugineus Mockingbird.......... 64

Ferrugineus Thrush.................., 64

Fiery-crowned Wren................. 103

Flechtensänger............................ 195

Florida Wren............................... 146

Flycatcher, Black...................... 91

- Blue-gray .............................. 96

- Canada ............................... 273

- - Cat...................................... 58

- - Green.......................................... 306

- Hanging................................. 306

- - Little Blue-gray................... 96

- - Red-eyed............................... 288

- - Redstart................................ 279

- - Shining-crested................... 91

- - Warbling ............................. 295

Flysnapper, Crested Shining

White-winged............ 91

Fox-colored Mockbird................ 64

French Mockingbird................... 64

Fresh Water Marsh Wren....... 160

Frisch. Poem. The Veery ...... 10

Fuchsclrossel.......................... 14 

Plate 3..............................
Gallagher, Wm. D. Poem.

G. Page Autumn Beauty.................. 204

Gambel's Titmouse...

"Garden and Forest.". The Utility of what makes Life interesting, page $\mathrm{xxv}$.

Gartensänger........................... 201

Gebirgs-Blanvogel...................... 84

Gebirgs-Hiittensänger................. 84

Gebirgsschwalbe ........................ 358

Geothlypis agilis...................... 250

Geothlypis beldingi.................... 257

Geothlypis formosa, Plate 14,

Fig. 3.............................. 248

Geothlypis macgillivrayi..........253

Geothlypis philadelphia, Plate 13, Fig. 7 ....................... Geothlypis trichas, Plate 14,
Fig. 1..............................

251

Geothlypis trichas occidentalis 257

Gnatcatcher, Arizona............... 97

- - Black-headed........................ 97

- - Black-tailed...................... 97

- Blue-gray, Plate 6........... 92

- California Black-capped... 97

- - Plumbeous .......................... 96

Gnatcatchers................................. 92

Goldbrustvireo............................ 299

Golden-crowned Accentor........ 242

Golden-crowned Kinglet,Plate 7100

Golden-crowned Thrush.......... 24.2

Golden-crowned Wagtail.......... 24,2

Golden Robin........................... 36

Golden Swamp Warbler............. 177

Golden Warbler.................177, 201

Golden-cheeked Warbler........... 225

Golden-crested Kinglet.............. 1 (n.

Golden-winged Swamp Warbler 187

Golden-winged Warbler, Plate 11, Fig. 4........................ 184

Goldfitigelsänger.......................... 187

Goldhähnchen, Rubin-.............. 100

Goldmeise.................................. 125

Goldsänger ..................................... 177

Grace's Warbler.......................... 224

Grauschwalbe ............................ 361

Grauwangendrossel .................. 15

Gray-cheeked Thrush................ 14

Gray Titmouse ........................ 112

Gray-tufted Titmouse................ 112

Gray Vireo............................. 313

Great American. Martin ........... 345

Great American Shrike.............. 316

Great Butcher Shrike............... 316

Great Carolina Wren............... 14.7

Green Black-capped Flycatching Warbler..........................275

Green-blue Swallow.................. 356

Green Flycatcher ....................... 306

Greenlet, Bell's........................ 312

- $\rightarrow$ Philadelphia....................... 291

- - Prairie................................... 312

- - Red-eyed.............................. 288

- - Solitary............................... 300

- Warbling............................. 295

— - White-eyed ........................ 306

- - Yellow-throated................. 299

Greenlets.................................. 282

Grinnell's Water Thrush......... 245

Ground Tit.............................. 106

Ground Warbler......................... 257

Ground Wren............................ 106

Gürtelsänger............................. 273
H.

Hammock Wren.

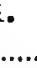

Page

147

Hanging Flycatcher................... 306

Harporhynchus bendirei.......... 65

Harporhynchus cinereus......... . 65

Harporhynchus crissalis, Plate

4, Fig. 4

Harporhynchus curvirostris...... 65

Harporhynchus curvirostris palmeri.

Harporhynchus lecontei.............

Harporhynchus longirostris.....

Harporhynchus redivivus.........

Harporhynchus rufus, Plate 5, Fig. 4 ...

Hatubenmeise.

Helmintophila bachmani........... 192

Helmintophila celata............... 191

Helmintophila celata lutescens 191

Helmintophila chrysoptera, Plate 11, Fig. 4.............. 184

Helmintophila cincinnatiensis.. 192

Helmintophila lawrencei .......... 192

Helmintophila leucobronchialis 192

Helmintophila luciae............... 188

Helmintophila peregrina.......... 191

Helmintophila pinus, Plate 11 ,

Fig. 2

Helmintophila ruficapilla........... 189

Helmintophila ruficapilla gutturalis

190

Helmintophila virginiae ............ 188

Helinaia swainsonii.................. 178

Helmitherus vermivorus, Plate 11, Fig. 5....................... 182

Hemlock Warbler...................... 221

Henry's Thrasher.................... 71

Hermit Thrush, Plate 5, Fig. 222

Hermit Warbler....................... 231

Hesperocichla naevia, Plate 1 , Fig. 3.............................. 34

Hirundinidae............................... 329

Hooded Flycatching Warbler.. 268

Hooded Warbler, Plate 14, Fig. $4 \ldots \ldots \ldots \ldots \ldots \ldots \ldots \ldots \ldots \ldots . . . . . . . . . . . .263$

House Swallow ........................... 353

House Wren............................. 151

- Southern ............................ 150

Hudson Bay Chickadee............. 118

Hudsonian Chickadee............... 118

Hudsonian Wagtail................... 162

Hummock Wren ........................ 147

Hïttensänger......................... 82

- - Californischer.................... 83

- - Gebirgs-............................... 84

Hutton's Vireo ........................ 312

\section{I.}

Icteria virens, Plate 15, Fig. 3258 Icteria virens longicauda......... 262 Introduction, page $\mathrm{xI}$.

\section{K.}

Katzendrossel

Kentucky Yellow-throat............ 250 Kentucky Warbler, Plate 14,

Fig. 3.................................2 248

Key West Vireo.......................... 306

Kinglet, American Goldencrested................................ 103

- - Golden-crowned, Plate 7.. 100

- - Golden-crested................... 103

- - Ruby-crowned.
Kage

Kirtland's Warbler................... 231

Klarinettvogel ......................... 88

Klettersänger.......................... 169

Krez, Conrad. Poem: Bluebird 75

L.

Land Kickup......................... 242

Lanidae................................... 314

Lanius borealis......................... 315

Lanius ludovicianus, Plate 17,

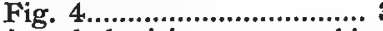

Lanius ludovicianus excubitorides................................ 316 Lanius ludovicianus gambeli... $\mathbf{3 1 6}$ Large-billed Accentor................ 24.8 Large-billed Water Thrush...... 248 Lark, Louisiana........................ 162 Lawrence's Warbler................. 192 Lead-colored Bush Tit............... 121 Leaden Titmouse........................ 122 Least Tit ......................... 121 Least Titmouse .......................... 121 Least Vireo................................. 312 Leconte's Thrasher................... 67 Legislation, Bird, page XLV.

Little Blue-gray Flycatcher...... 96 Little Green Hanging-bird ........ 306

Little Thrush............................. 22 Little Waxwing.............................. $\mathbf{3 2 7}$

Loggerhead............................. 320

Loggerhead Shrike, Plate 17,

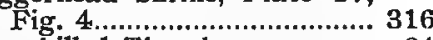
Long-billed Thrasher................... 64

Long-billed Marsh Wren.......... 157

Longfellow, $H$. W. Plea of the Birds, page $v$.

Long-tailed Chat..................... 262

Long-tailed Chickadee................ 116

Long-tailed Wren ...................... 150

Loomis, E. J. Sonnet: Redeyed Vireo.........................28 281

Louisiana Lark............................ 162

Louisiana Shrike...................... 320

Louisiana Water Thrush, Plate 15, Fig. 6 ......................... 245

Louisiana Wren...................... 147

l.ucy's Warbler............................ 188

Lutescent Warbler....................... 191

\section{Ii.}

Macgillivray's Ground Warbler 254

Macgillivray's Warbler........... 253

Magnolia Warbler, Plate 12, Fig. 2................................. 208

Martin ..................................... 345

- - Black............................... 345

- Cuban ................................. 345

- Great American.................. 345

- Purple, Plate 18, Fig. 2

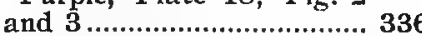

- - Sand................................ 360

Martinschwalbe......................... 345

Marsh Wren .............................. 159

Maryland Yellow-throat, Plate 14, Fig. 1 ......................... 254

Matzatlan Robin........................ 34

Mead, Theodore L. Garden of, page XLIII.

Meadow Pipit ........................... 162

Meadow Wren......................... 160

Meise, Busch-.............................. 121

- Bleigraue Busch-................ 122

- - Canada-Specht-.................. 128 


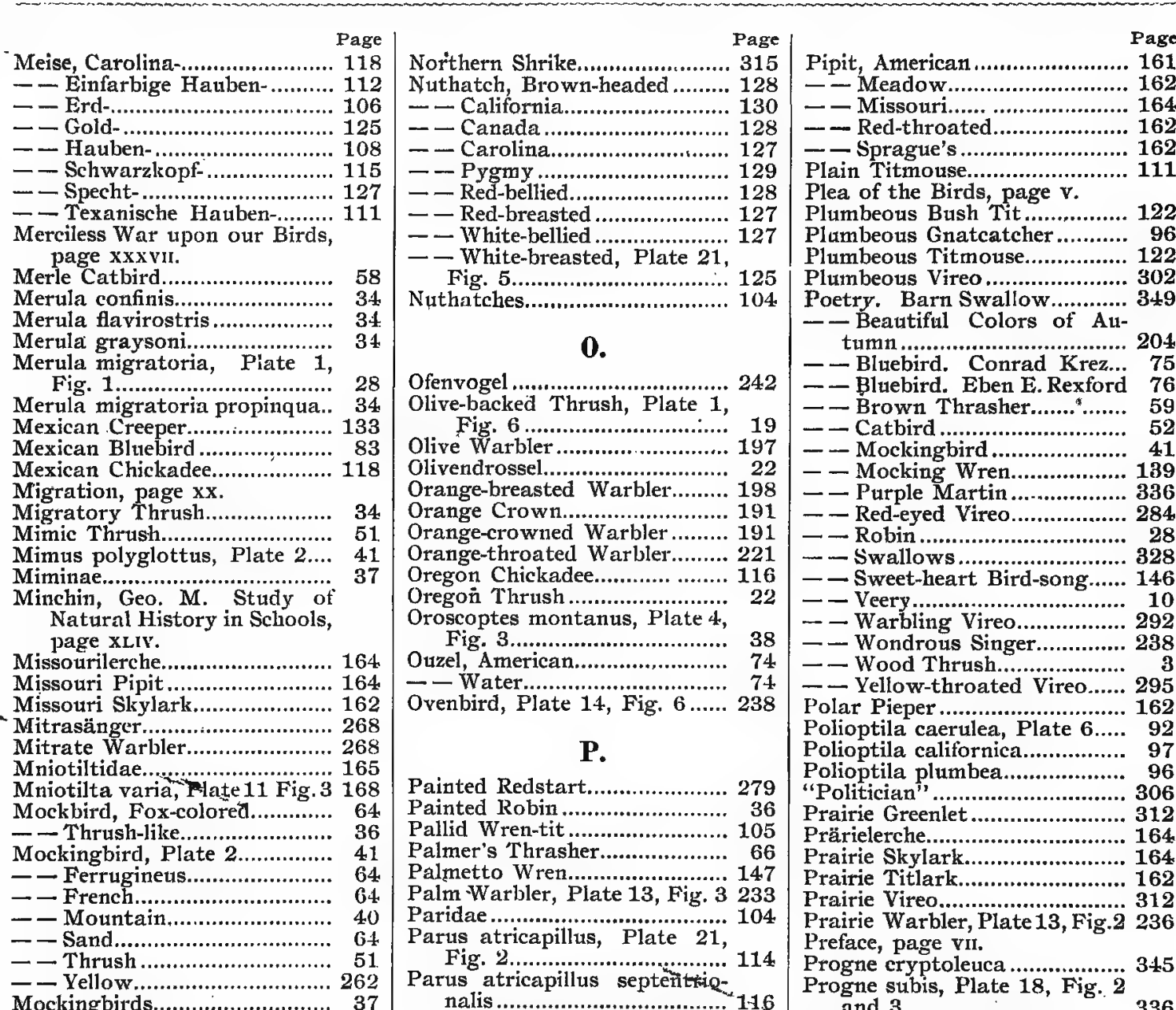

Mockingbirds......... 37

Mocking Wren......................... 1477
Moossänger......................... 195

Mountain Bluebird, Plate 20, Fig. 2............................ 83

Mountain Chickadee................. 113

Mountain Mockingbird............. 40

Mountain Solitary Vireo......... 301

Mountain Swallow .................. 358

Mourning Warbler, Plate 13,

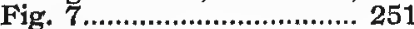

Motacilla alba......................... 161

Motacilla ocularis..................... 161

Motacillidae............................. 161

Mückenfänger............................. 96

Mud Swallow........................348

Myadestes townsendi, Plate 20 ,

Fig. 4.

Myrtle Bird.................................. 207

Myrtle Warbler, Plate13,Fig.5 204

\section{N.}

Nashville Swamp Warbler...... 191.

Nashville Warbler...................... 189

Nashville Worm-eater.................. 191

Necklace Warbler....................... 273

Nesting Boxes, page XLIX and L.

New York Aquatic Thrush ..... 245

"Nightingale".......................... 14

- - Wood .

Northern Chatterer................... 323

\section{Northern Shrike. \\ Nuthatch, Brown-headed \\ Red-bellied \\ White-breasted, Plate 21 \\ Fig. 5 \\ o.}

Parus atricapillus occidenta! is 116 Parus atricristatus.................. 108 Parus bicolor, Plate 5, Fig. 2. 106

Parus bicolor texensis............. 108

Parus carolinensis ..................... 116

Parus cinctus obtectus............... 118

Parus gambeli .......................... 113

Parus hudsonicus ....................... 118

Parus inornatus......................... 111

Parus inornatus cineraceus..... 112

Parus inornatus griseus........... 112

Parus meridionalis .................... 118

Parus rufescens........................... 118

I'arus rufescens neglectus......... 118

Partus wollweberi ...................... 113

Parti-colored Warbler............... 237

Parkman's W ren ....................... 153

"Pasture Warbler"................... 237

Parula Warbler, Plate 11, Fig.1 193

Pensile Warbler ...................... 224

Petrochelidon lunifrons, Plate 18, Fig. 4 ............................. 345

Phainopepla........................... 88

Phainopepla nitens, Plate 4 , Fig. 1.

Philadelphis Greenlet.............. 88

Philadelphia Vireo...................... 289

Pieper........................................ 162

Pine-creeping Warbler............... 233

Pine Swamp Warbler................. 203

Pine Warbler ........................... 232
Page

162

62

11

122

02

204

75

59

52

41

36

(2)

28

46

192

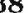

95

62

92

96

06

312

162

(36 345 336

Protection of Birds, page XL...

Protection of Birds, An Act for the, page $x L v$.

Prothonotary Warbler, Plate 10 170

Protonotaria citrea, Plate 10.170

Psaltriparus melanotis............. 122

Psaltriparus minimus, Plate 8119

Psaltriparus plumberis .............. 121

Ptilogonys, Black...................... 91

- Townsend's.......................... 88

Purple Martin, Plate 18, Fig.

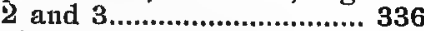

Purple Swallow.......................... 345

Purpose and Objects of the proposed Act on Bird Protection, page XLVIr.

Pygmy Nuthatch...................... 129

Q.

Quebec Warbler

\section{R.}

Raubwürger............................ 316

Red-backed Warbler ................... 237

Red-bellied Nuthatch .................. 128

Red-bellied Redstart..................... 280

Redbreast, Blue ........................... 82 
Ped Page

Nuthatch............ 127

Red-breasted Thrush ................ 34

Red-eye..................................... 288

Red-eyed Flycatcher................... 288

Red-eyed Greenlet ....................... 288

Red-eyed Vireo, Plate 15, Fig. +284

Red-faced Warbler, Plate 32 ,

Fig. 2........................... 280

Red-poll...

235

Red-póll Warbler

Redstart, American, Plate 1\%, Fig. 5 ...

Redstart Flycatcher................. 275

Redstart, Painted..................... 279

$-\frac{1}{}-$ Red-bellied............................ 280

Redstart Warbler.................... 279

Red-throated Pipit.................. 162

Red-vented Thrasher............... 71

Reddish-brown Titlark............ 162

Red Warbler......................... 281

Regulus calendtula..................... 98

Regulus cuvieri....................... 103

Regulus obscurus................... 103

Regulus satrapa, Plate 7 ........ 100

Regulus satrapa olivacea........ 103

"Republican". ......................... 348

Rexford, Eben E. Poem: The Bluebird.

Ridgway, R. Songbirds in Europe and America, page XIV.

River Pink

River Swallow............................ 356

Robin .................................. 34

- American, Plate 1, Fig. 128

\begin{tabular}{l} 
- Blue................................. 82 \\
\hline- Columbia.
\end{tabular}

- Golden................................ 36

- Matzatlan........................... 34

- - Painted .............................. 36

- Redbreast........................ 34.

- - Spotted ................................ 36

— - St. Lucas......................... 34

- Swamp.....................22, 26

- - Tres Marias..................... 34

- - Varied ................................. $\quad 36$

- Western............................. 34

- Rock Wood .................................. 98

Rocky Mountain Bluebird...... 84,

Rocky Mountain Swallow...... 348

Rocky Mountain Warbler........ 189

Rocky Mountain Wren............ 138

Rohrzaunkönig ....................... 160

Röteldrossel ............................ 14

Rough-wing ............................ 361

Rough-winged Swallow ........... 360

Rubin-Goldhähnchen............... 100

Ruby-crown ........................... 100

Ruby-crowned Kinglet .............. 98

Ruby-crowned Wren................ 100

Rufous-tailed Thrush............... 26

Russet-backed Thrush ............ 22

\section{S.}

Sängerdrossel....................... 22

Sängerschlüpfer..................... 150

Sängervireo........................... 295

Sage Thrasher, Plate 4, Fig. 338

St. Lucas Cactus Wren............ 136

St. Lucas Robin ................... 34

St. Lucas Thrasher................. 65

Salbeidrossel .......................... 40

Salpinctes obsoletus .............. 137

Salt Water Marsh Wren.......... 159
Page

Sand Martin............................ 360

Sand Mockingbird..................... 64 .

Sand Swallow .......................... 360

Sargent, C. S. The Utility of what makes Life interesting, page $\mathrm{xxy}$.

Satrap..................................... 103

Scheunenschwalbe...................... 353

Schools, Study of Natural History in, page $x$ LIV.

Schwarzlkopfmeise.................... 115

Schwätzer ................................. 262

Seidenschwanz...................... 323

Seiurus aurocapillus, Plate 14 , Fig. 6 .

Seiurus motacilla, Plate 15 Fig. 6.............................. 245

Seiurus noveboracensis............ 242

Seiurus noveboracensis notabilis ..................................... 245

Selby's Waxbler.......................... 268

Sennett's Warbler..................... 195

Setophaga miniata.................... 280

Setophaga picta ........................ 279

Setophaga ruticilla, Plate 14 Fig. 5............................ 275

Shining-crested Flycatcher........ 91

Shoemaker, W. L. Poem: Mocking Wren.................... 139

- - Poem : Swallows............. 328

- - Poem: Sweet-heart Bircl-

song ................................ 146

- - Poem: Wood Thrush....... 3

-.-Sonnet: Catbird............... 52

- - Sonnet: Warbling Vireo.. 292

Short-billed Marsh Wren ......... 159

Shrike, California ...................... 316

- - Carolina ........................... $\mathbf{3 2 0}$

- - Great Ameriean ................. 316

- - Great Butcher.................... 316

- Loggerhead, Plate 17, Fig. 4............................... 316

- - Louisiana........................ 320

- - Northern .......................... 315

- - Southern ........................... 320

- - White-rumped .................... 316

Shrikes .................................... 314

Sialia arctica, Plate 20, Fig. 283

Sialia mexicana, Plate 20, Fig.1 83

Sialia sialis, Plate 5, Fig.5 and 675

Siberian Chickadee................... 118

Siberian Yellow Wagtail........... 161

Siller, Frank. Poem, page XLIr.

Siller, Hilda. Poem: Purple Martin .............................. 33

Sitta canadensis ..................... 127

Sitta carolinensis, Plate 21, Fig. 5...

Sitta pusilla

Sitta pygmaea........................... 129

Skylark, Missouri................... 162

- - Prairie.............................. 164

- - Sprague's ....................... 164

Smith, Charlotte. Poem: Barn Swallow

349

Solitaire

- Townsend's, Plate 20 ,

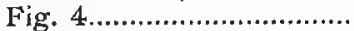

Solitary Greenlet......................... 300

Solitary Tlirush...................... 26

Solitary Vireo........................... 300

Song; Birds of, page xII.

Song Birds in Europe and America, page xil.
Page

Song Wren............................... 150

Sonnet: Catbird..................... 52

- - Red-eyed Vireo.................. 284

- - Warbling Viréo.................. 292

Southern Chickadee.................... 118

Southern House Wren.............. 150

Southern Shrike....................... 320

Speckled Canada Warbler......... 273

Spechtmeise............................. 127

Spider-bird ............................ 327

Spotted Robin .......................... 36

Spotted Thrush ....................... 36

Spottdrossel.............................. 51

Sprague's Pipit.......................... 162

Sprague's Skylark ................... 164.

Stephen's Vireo......................... 312

Stelgidopteryx serripennis......... $\mathbf{3 6 0}$

Sturm, Julius. Purple Martin 336

Summer Warbler.................. 201

Summer Yellow Bird.................. 201

Sumpfzaunkönig........................ 159

Swainson's Swamp Warbler... 181

Swäinson's Thrush................. 22

Swainson's Warbler..................... 178

Swallow, American Barn......... 353

- - Bank ............................. 358

- - Barn, Plate 18, Fig. 1.... 349

- - Black................................. 345

- - Black-bird ........................ 345

- Black and White................ 356

- - Cliff, Plate 18, Fig. 4 ..... 345

- - Crescent .......................... 348

- - Eve, Plate 18, Fig. 4....... 34.5

- - Green-blue ........................... 356

- - House................................ 353

- Mountain............................ 358

- Mud ................................. 348

- Pu1rple......................... 345

- - Rocky Mountain ............... 348

- - Rough-winged.................... 360

- - Sand 360

- - Tree, Plate 18, Fig. 6...... 353

- - Violet-green ........................ 356

- - White-bellied ...................... 356

- - White-fronted....................... 348

- Wood ................................ 356

Swallows .................................. 329

Swamp Robin..................22, 26

Swinhoe's Wagtail..................... 161

Sycamore Warbler.................... 224

Sylvania canadensis, Plate 13 ,

Fig. 8........................... 269

Sylvania mitrata, Plate 14,

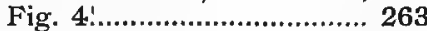

Sylvania pusilla, Plate 13, Fig.4 273

Sylviidae ................................ 92

\section{T.}

Tachycineta bicolor, Plate 18 ,

Fig. 6............................. 353

Tachycineta thalassina ............... 356

Tawny Thrush ......................... 14

Tennessee Swamp Warbler ...... 192

Tennessee Warbler.................... 191

Texan Tufted Titmouse ........... 108

Texanische Haubenmeise.......... 111

Texas Thrasher......................... 65

Texas Titmouse........................ 111

Texas Warbler.......................... 228

Thrasher..................................... 64

- - Bendire's ............................ 65

- Brown, Plate 5, Fig. 4.... 59

- California.......................... 66

- Crissal, Plate 4, Fig. 4.... 68

- Curre-billed........................ 65 


\begin{tabular}{|c|c|c|c|}
\hline \multicolumn{2}{|c|}{ Fas } & \multicolumn{2}{|r|}{ Page } \\
\hline Thrasher, Leconte's................. & 67 & Townsend's Flycatching & \\
\hline - - Long-billed. & 64 & Thrush. & 88 \\
\hline - Palmer's..... & 66 & Townsend's Ptilogonys & 88 \\
\hline - Red-vented ......... & 71 & Townsend's Solitaire, Plate 20, & \\
\hline - Sage, Plate 4, Fig. 3....... & 38 & 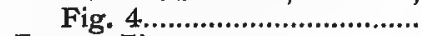 & 84 \\
\hline int Lucas......................... & 65 & Toupet Titmouse.. & 108 \\
\hline 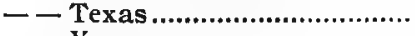 & 65 & Townsend's Warbler......... & 230 \\
\hline 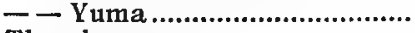 & 68 & 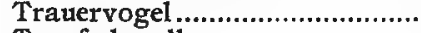 & 91 \\
\hline 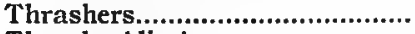 & 37 & Traufschwalbe.... & 348 \\
\hline llice's..... & $1+\frac{14}{9}$ & Treat, Mrs. Mary. & \\
\hline & & Helpers, page & \\
\hline .. & 27 & e Swallow Pl & 35 \\
\hline knell's Gray-cheeked.... & 15 & Robin..................... & 34 \\
\hline ....... & 64 & Troglo & \\
\hline rnia Brown ....... & 66 & Trog & 151 \\
\hline 0 & 66 & $\operatorname{Tr}$ & 153 \\
\hline ermi & 27 & $\operatorname{Tr}$ & 15 \\
\hline us. & 64 & cificus. & 15 \\
\hline ............... & 242 & late 5, Fig. 2 & \\
\hline ….............. & 14 & $\mathrm{Tr}$ & 15 \\
\hline - - Hermit, Plate 1, Fig. 2... & 22 & idae. & 1 \\
\hline like Mockbird.................. & 36 & $T_{2}$ & 1 \\
\hline Thrush, Little.... & 22 & nelli.. & 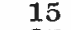 \\
\hline 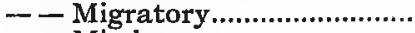 & 34 & $T_{i}$ & 27 \\
\hline-- & 51 & Turdus aonalaschkae Auduboni & 27 \\
\hline - Mocking............................. & 51 & $\begin{array}{l}\text { Turdus aonalaschkae pallasi, } \\
\text { Plate } 1 \text { Fig. }\end{array}$ & \\
\hline 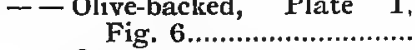 & 19 & Turdus fuscescens, Plate 1 , & \\
\hline- - Oregon..... & 22 & 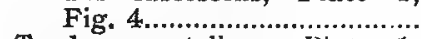 & 10 \\
\hline - - Rutous-tailed. & 26 & Turdus mustelinus, Plate 1 , & \\
\hline Russet-backed. & 22 & & 3 \\
\hline Solitary ........................... & 26 & Turdus ustulatus & 22. \\
\hline Tawny... & 14 & Turdus ustulatus Swainsoni, & \\
\hline Red-breasted & 34 & Plate 1, Fig. 6 & 19 \\
\hline 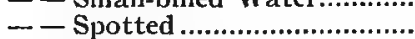 & & & \\
\hline incon's & 22 & & \\
\hline & & & \\
\hline
\end{tabular}

Page

- Hutton's ............................ 312

- - Key West............................ 306

- - Least.................................. 312

- - Mountain Solitary............. 301

- - Plumbeous ... 302

- - Red-eyed, Plate 15, Fig. 4284

- - Stephen's............................. 312

- - Solitary............................... 300

- - Warbling...................... 292

- - White-eyed, Plate 15, Fig.2 302

- - Yellow-green ...................... 288

- - Yellow-throated, Plate 16295

Vireonidae................................ 282

Vireos............................................. 282

Virginia's Warbler................... 188

\section{W.}

Wagtail.................................. 24,

- Golden-crowned .................. 242

- - Hudsonian ........................... 162

- - Sibirian Yellow.................. 161

- - Swinhoe's......................... 161

- - Water...........................245, 248

Wagtail Warbler.................... 24:2

Wagtail, White....................... 161

Wagtails ................................... 161

Walddrossel ................................ 9

Waldschwalbe......................... 356

Wald vireo .................................... 288

Wanderdrossel ............................. 34

War, Merciless, upon our Birds, page $x \times \times v^{\prime} I$.

Warbler, Audubon's ................ 207

- - Azure.................................. 213

- Bachman's ......................... 192

- Bay-breasted, Plate 1\%, Fig. 4........................... 215

Utility of Birds, page $x \times y$.

- - Western Hermit.................. 24

- Wilson's, Plate 1, Fig. 4.. 10

- Wood, Plate 1, Fig. 5..... 3

Thrushes

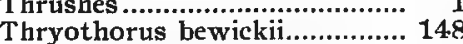

Thryothorus bewickii bairdii... 150

Thryothorus bewickii spilurus. 150

Thryothorus ludovicianus,

Plate 26, Fig. 6................ 141

Thryothorus ludovicianus niamensis

Titlark ...................................... 162

- - Prairie................................... 16. 16\%

$\longrightarrow \rightarrow$ Reddish-brown...................... 162

Titmouse, Ashy ........................ 112

- Black-capped...................... 115

- - Black-crested......................... 108

- - Bridled ................................. 113

- - Californian......................... 112

- Carolina............................... 118

- - Chestnut-crowned............... 121

- - Crested ............................. 108

- Gambel's ............................ 112

- - Gray...................................... 112

- - Gray-tufted ........................ 112

- - Leaden ................................ 122

- Least.................................... 121

- Plain ................................ 111

- Plumbeous ....................... 122

- Texan Tufted...................... 108

- - Toupet 108

- - Tufted, Plate 5, Fig. 2.... 106

- - White-browed ..................... 113

- - Wollweber's ............................ 113

Tits ....................................... 104

Tolmie's Ground Warbler ........ 254

\section{V.}

Varied Robin

Varied Thrish Plate 1, Fig. 36

Veery, Plate 1, Fig. 4,............. 10

Verdin, Plate 32, Fig. 4 .......... 122

- - Yellow-headed.................... 125

"Vigor's Vireo"............................ 233

Vigor's Wren ............................ 150

Violet-green Swallow ............... 356

Vireo altiloquus barbatulus..... 288

Vireo atricapillus....................... 307

Vireo bellii ................................ 309

Vireo bellii pusillus..................... 312

Vireo, Black-whiskered............... 288

Vireo flavoviridis..................... 288

Vireo flavifrons, Plate $16 \ldots \ldots . . .295$

Vireo gilvus ............................... 292

Vireo huttoni............................ 312

Vireo huttoni stephensi............ 312

Vireo noveboracensis, Plate 15, Fig. 2

Vireo noveboracensis maynardi 306

Vireo olivaceus, Plate 15, Fig.4 284

Vireo philadelphia ................... 289

Vireo solitarius........................... 299

Vireo solitarius alticola............. 301

Vireo solitarius cassini.............. 301

Vireo solitarius plumbeus........ 302

Vireo vicinior............................. 313

Vireo, Arizona .......................... 313

- - Bell's .................................. 309

- Black-capped.......................... 307

- - Blue-headed.......................... 299

- - Brotherly-love........................ 291

- Cassin's............................ 301
- - Bell's ................................ 281 11, Fig. 3................... 168

- Black and Yellow............. 212

- Blackburnian, Plate 12 , Fig. 1........................ 218

- Black-capped Yellow ......... 275

- - Black-headed...................... 268

- - Black-masked........................ 257

- - Black-poll, Plate 12, Fig.3 217

- Black-throated Blue, Plate 14, Fig. 2 ................... 201

- - Black-throated Gray ........ 225

- - Black-throated Green,

- Black-throated Ground..... 253

- - Brasher's........................... 281

— - Brewster's............................... 192

- - Blue............................82, 213

- $\rightarrow$ Blue-backed Redbreast..... 82

- - Blue Golden-winged........... 187

- - Blue-winged .

- - Blue-winged Swamp......... 184

- - Blue-winged Yellow, Plate 11, Fig. 2.................... 183

- Blue Yellow-backed ........... 195

- Calaveras........................... 190

- Canadian, Plate 13, Fig. 8269

- - " ..................... 203

- Canadian Flycatching....... 273

- Cape May........................... 196

- - Cedar................................ 228

- - Cerulean, Plate 13, Fig. 6212

- Chestnut-sided, Plate 12,

Fig. 5......

213

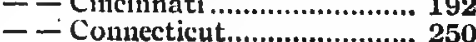
Plate 12, Fig. 6.......... 228

- - Cincinnati. 


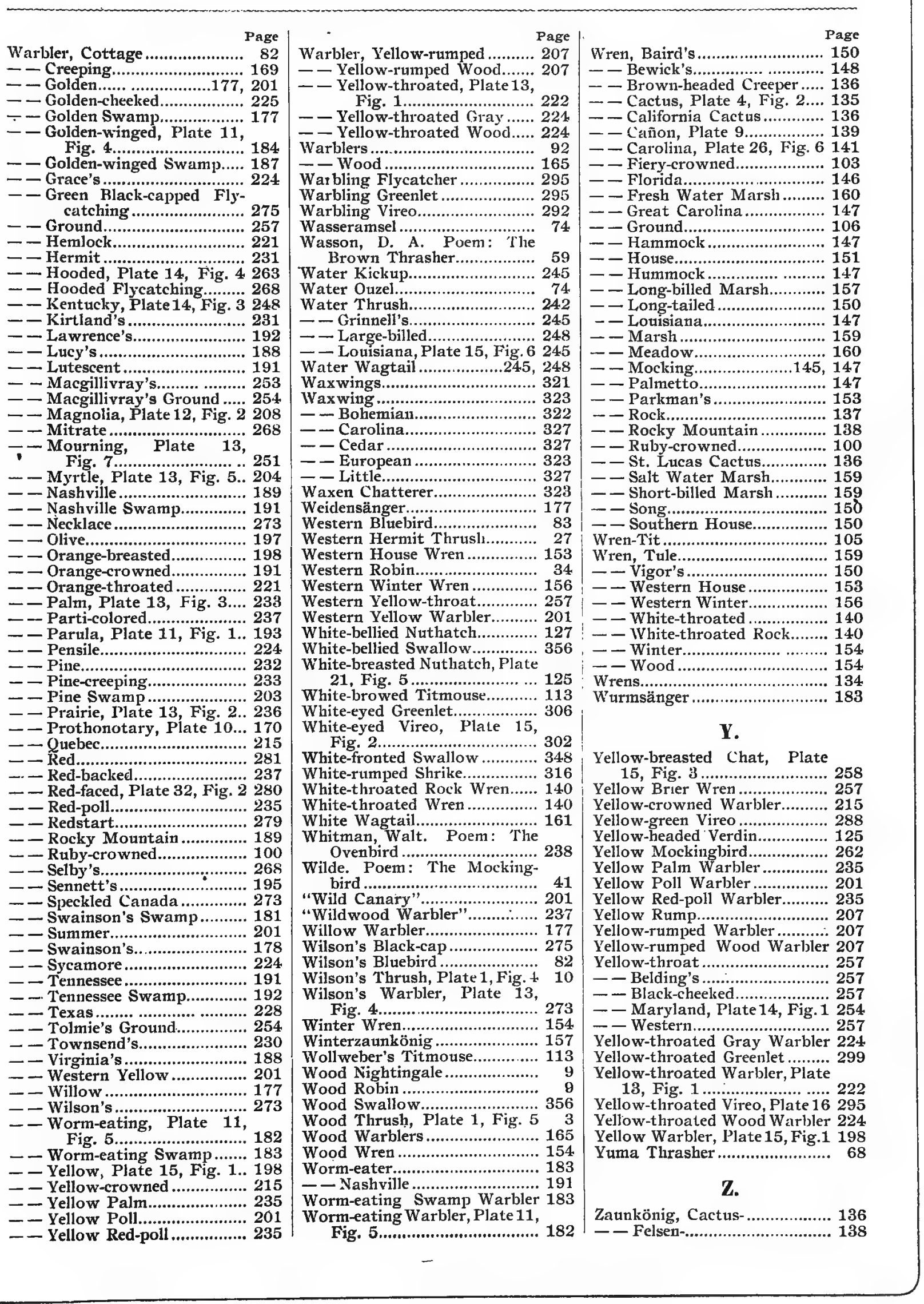






